\title{
Geburtshilfe und Frauenheilkunde
}

\section{„Ausführer und Vollstrecker des Gesetzeswillens“ -}

die Deutsche Gesellschaft für Gynäkologie im Nationalsozialismus

\section{Bet: Milflicalsbeitiay}
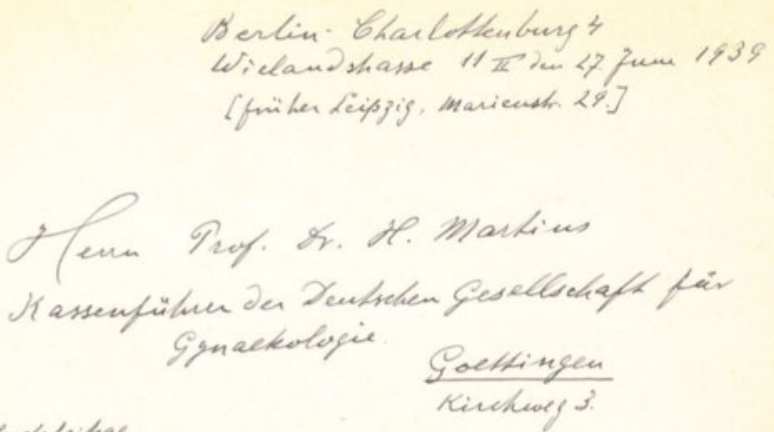

Seh gechiter then Opofessor

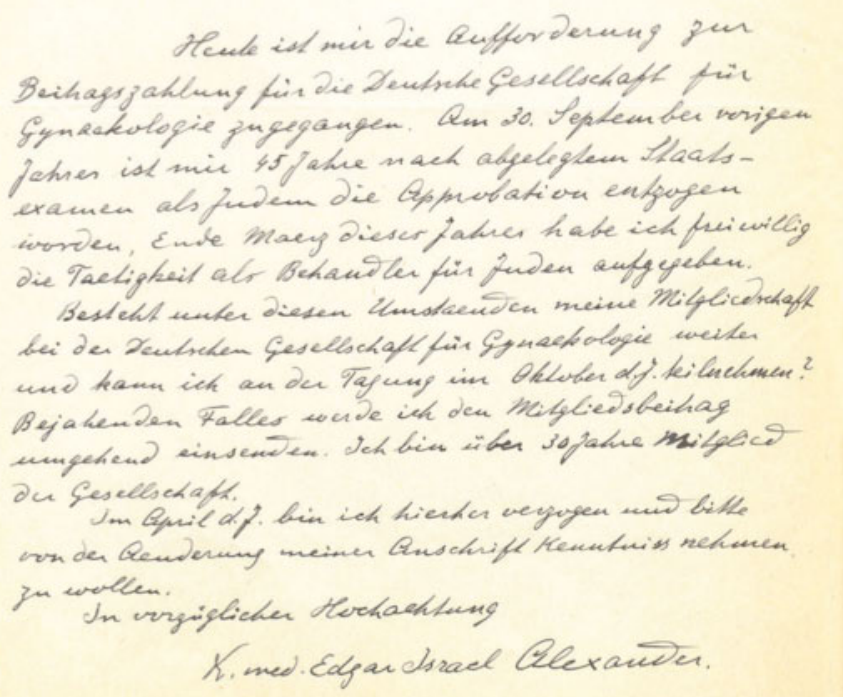

\section{Supplement}

Fritz Dross, Wolfgang Frobenius,

Andreas Thum und Alexander Bastian, unter Mitarbeit von Ulrike Thoms

Herausgegeben von:

Thomas Dimpfl, Diethelm Wallwiener und Fritz Dross - im Auftrag der DGGG

www.thieme-connect.de/products 


\section{EDITORIAL BOARD}

\section{Geburtshilfe und Frauenheilkunde}

\section{Executive Editors/Leitende Herausgeber}

Matthias W. Beckmann, Erlangen

Diethelm Wallwiener, Tübingen

Diethelm Wallwiener, Tübingen - Präsident DGGG

Uwe Lang, Graz - OEGGG

\section{Co-Editors/Co-Herausgeber}

Christian R. Löhberg, Nürnberg

Heiko B. G. Franz, Braunschweig (Aktuell referiert)

Michael Friedrich, Krefeld (Aktuell referiert)

Burkhard Schauf, Bamberg (Aktuell diskutiert)

Christian Bayer, Erlangen (Assistenz)

Paul Gaß, Erlangen (Assistenz)

\section{Begründet von}

Carl Kaufmann

Ludwig Seitz

\section{Weitergeführt von}

Josef Zander

Kurt Holzmann

Meinert Breckwoldt

Werner Rath

Manfred Kaufmann

\section{Vereinigt mit:}

Zentralblatt für Gynäkologie

(J. A. Barth in Georg Thieme Verlag KG)

Wissenschaftliches und offizielles Leitlinien-Organ der Deutschen Gesellschaft für Gynäkologie und Geburtshilfe e. V. (DGGG) und der

Österreichischen Gesellschaft für Gynäkologie und Geburtshilfe (OEGGG)

Offizielles Leitlinien-Organ der Schweizerischen Gesellschaft für Gynäkologie und Geburtshilfe - gynécologie suisse (SGGG)

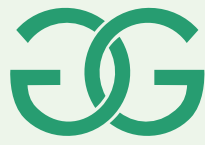

\section{DGGG-Ausgabe}

\section{Herausgeber}

Diethelm Wallwiener, Tübingen

Birgit Seelbach-Göbel, Regensburg

Thomas Dimpfl, Kassel

Frank Louwen, Frankfurt a. M.

Gerlinde Debus, Dachau

Sara Y. Brucker, Tübingen

Harald Abele, Tübingen

Ute Germer, Regensburg

Ekkehard Schleußner, Jena

Ludwig Kiesel, Münster

Ariane Germeyer, Heidelberg

Christl Reisenauer, Tübingen

Stefan Rimbach, Hausham

Andree Faridi, Berlin

Tanja N. Fehm, Düsseldorf

Sarah Schott, Heidelberg

Johannes Lermann, Erlangen

\section{Georg Thieme Verlag KG}

Rüdigerstraße 14

D-70469 Stuttgart

Postfach 301120

D-70451 Stuttgart 


\section{EDITORIAL BOARD SUPPLEMENT}

\section{„Ausführer und Vollstrecker des Gesetzeswillens“ - \\ die Deutsche Gesellschaft für Gynäkologie im Nationalsozialismus}

\section{Autoren}

Fritz Dross, Wolfgang Frobenius, Andreas Thum und Alexander Bastian, unter Mitarbeit von Ulrike Thoms

\section{Herausgeber}

Thomas Dimpfl, Diethelm Wallwiener

und Fritz Dross - im Auftrag der DGGG

\section{Bibliografie}

DOI http://dx.doi.org/10.1055/s-0042-110591

Geburtsh Frauenheilk 2016; 76: S1-S158

(c) Georg Thieme Verlag KG Stuttgart · New York · ISSN 0016-5751

\section{Anschrift von Herausgebern und Autoren}

Prof. Dr. med. Thomas Dimpfl

Frauenklinik

Klinikum Kassel GmbH

Mönchebergstraße 41-43

34125 Kassel

Prof. Dr. med. Diethelm Wallwiener

Department für Frauengesundheit

Universitäts-Frauenklinik Tübingen

Calwerstraße 7

72076 Tübingen

PD Dr. phil. Fritz Dross

Friedrich-Alexander-Universität Erlangen-Nürnberg Institut für Geschichte und Ethik der Medizin

Glückstraße 10

91054 Erlangen

PD Dr. med. Wolfgang Frobenius

Friedrich-Alexander-Universität Erlangen-Nürnberg Institut für Geschichte und Ethik der Medizin

Glückstraße 10

91054 Erlangen

Andreas Thum

Friedrich-Alexander-Universität Erlangen-Nürnberg Institut für Geschichte und Ethik der Medizin

Glückstraße 10

91054 Erlangen

Dr. Alexander Bastian

Otto-von-Guericke-Universität Magdeburg

Medizinische Fakultät,

Fachbereich Geschichte, Ethik und Theorie der Medizin

Leipzigerstraße 44

39120 Magdeburg

Dr. Ulrike Thoms

Max-Planck-Institut für Wissenschaftsgeschichte

Boltzmannstraße 22

14195 Berlin 


\section{GebFra Supplement}

S1 Vorwort

S2 Einleitung

S8 Vorstand und Geschäftsführung 1929-1949

S36 Die Kongresse der DGG und das „Gesetz zur Verhütung erbkranken Nachwuchses“ (GzVeN)

S52 Die Kongressarbeit jenseits des GzVeN (1933-1941)

S59 Die Mitglieder der DGG

S95 Keine Stunde Null: Die DGG nach Diktatur und Krieg

S104 Statuten der Deutschen Gesellschaft für Gynäkologie

S107 Mitglieder des Vorstands 1931-1949

S109 Kurzbiografien

S141 Quellen und Literatur

S156 Namenverzeichnis

S158 Abbildungsverzeichnis

A3 Impressum

\section{Hel Geburtshilfe und Hif Frauenheilkunde}

\section{„Ausführer und Vollstrecker des Gesetzeswillens“ -}

die Deutsche Gesellschaft für Gynäkologie im Nationalsozialismus

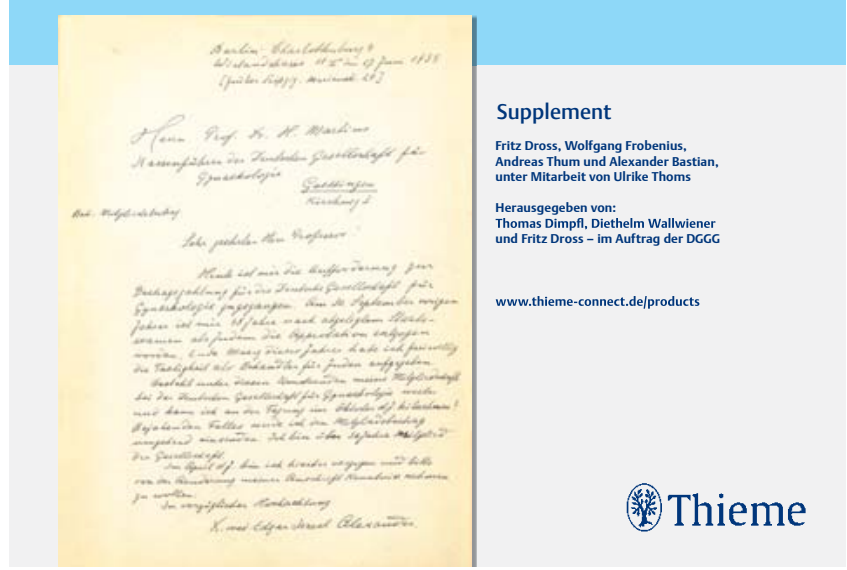

\section{Hinweise zur Titelseite}

Titelzitat: Ludwig Seitz auf dem DGG-Kongress 1933 in Berlin. Abbildung: Brief des DGG-Mitglieds Edgar Alexander vom 19. Juni 1939 an den Kassenwart der Gesellschaft, Heinrich Martius. Alexander wurde am 20. Juli 1942 nach Theresienstadt deportiert und starb dort knapp ein halbes Jahr später an einer „Gehirnblutung“ (Quelle: Bayerische Staatsbibliothek München). 


\section{Vorwort}

Die Deutsche Gesellschaft für Gynäkologie und Geburtshilfe (DGGG) initiierte im November 2012 ein Forschungsprojekt zur Geschichte der Gesellschaft im Nationalsozialismus. Sie knüpft damit an vergleichbare Anstrengungen benachbarter Fachgesellschaften an, aus denen in den vergangenen Jahren zahlreiche einschlägige Publikationen erwachsen sind. Kaum ein Kongress der größeren Fachgesellschaften verzichtet inzwischen auf ein Panel, das spezifisch medizinhistorischen Fragen gewidmet ist. Die Bedeutung der nationalsozialistischen Vergangenheit nimmt dabei eine bedeutende Stellung ein. Dies hat die Bundesärztekammer mit der Verleihung ihres Preises zur Rolle der Ärzteschaft in der Zeit des Nationalsozialismus für das Jahr 2013 unter anderem an eine Arbeit zur Geschichte der Urologie und der urologischen Fachgesellschaft besonders anerkannt.

Innerhalb unseres Faches war das Forschungsprojekt der Bayerischen Gesellschaft für Geburtshilfe und Frauenheilkunde (BGGF) ein wichtiger Anstoß. Das erste zusammenhängende medizinhistorische Projekt wurde von der BGGF anlässlich ihres 100-jährigen Bestehens in dem Buch „Herausforderungen“ im Jahr 2012 im Georg Thieme Verlag publiziert. Dem Georg Thieme Verlag und insbesondere dem redaktionellen Projektmanagement unter der Leitung von Frau Dr. Silvia Jung danken wir, dass er auch die hier vorgelegten Arbeiten ebenso gründlich wie wohlwollend betreut hat.

Nach der Freigabe der nötigen Mittel durch den Vorstand hat im Jahr 2013 eine unabhängige Arbeitsgruppe aus dem Medizinhistoriker Herrn PD Dr. Fritz Dross, der Berliner Wissenschaftshistorikerin Dr. Ulrike Thoms, dem Erlanger Gynäkologen PD Dr. Wolfgang Frobenius sowie dem Erlanger Historiker Andreas Thum ihre Arbeit aufgenommen. Der Vorstand dankt allen beteiligten Forscherinnen und Forschern für ihre Arbeit und freut sich, hiermit das Ergebnis dieser Arbeiten vorlegen zu können.

Die Geschichte der DGG im Nationalsozialismus ist die Geschichte einer medizinischen Fachgesellschaft in einem Unrechtsstaat. Insofern sind die folgenden Ausführungen keine angenehme, aber eine notwendige Lektüre. Für die Frauenheilkunde und die DGGG ist zum einen auf massenhaft durchgeführte, eugenisch begründete Abtreibungen und Zwangssterilisationen hinzuweisen, die uns inzwischen in Grundzügen bekannt sind. Daneben, und bislang innerhalb der DGGG weit weniger thematisiert, sind die Folgen für viele Mitglieder zu nennen: systematische Ausgrenzung, Enteignung und Amtsenthebung, Entzug von Promotion und Habilitation, Verlust der beruflichen Grundlage sowie psychische und physische Gewalt bis zur Folter, Deportation und Ermordung. Besonders betroffen waren Ärzte und Ärztinnen jüdischer Herkunft. Die DGGG will sich ihrer Verantwortung stellen und bislang Verdrängtes aufarbeiten. Sie darf nicht vergessen, was in ihrem Namen und auch durch ihre Repräsentanten getan wurde, und sei es auch nur durch duldendes Unterlassen.

Es ist aber nicht so, als ob noch gar nichts getan worden wäre. Hermann Hepp hat vor über 20 Jahren die „späte Entschuldigung“ bei den Opfern der Zwangssterilisierungen zum zentralen Thema des 50. Kongresses der DGGG 1994 gemacht. In diesem Zusammenhang sind auch die Arbeiten von Manfred Stauber und Günter Kindermann zu erwähnen, die am Ende des 20. Jahrhunderts zu den ersten Frauenärzten gehörten, die sich mit der NS-Vergangenheit unseres Faches auseinandersetzten. Manfred Stauber wurde für seine Verdienste um Aufklärung, Aussöhnung und Entschädigung mit der Ehrenmitgliedschaft der Bayerischen Gesellschaft ausgezeichnet.

In diese Tradition stellt sich der Vorstand der DGGG mit seiner Initiative zu den hier vorgelegten Forschungen. Die Zwangssterilisierungen sind für zahlreiche - wenn auch nicht für alle - universitären und nicht-universitären Frauenkliniken inzwischen historisch gut erforscht. Auch zur Geschichte der rassistischen Verdrängung und Vertreibung vieler Kolleginnen und Kollegen liegen zahlreiche Studien vor. Es geht also inzwischen darum, genauer zu erkennen, wie die gynäkologische Fachgesellschaft mit der nationalsozialistischen Gesundheits-, Wissenschafts- und Gesellschaftspolitik in der Breite verwoben war.

Möge das vorliegende Werk dazu dienen, die Geschichte der DGGG besser zu verstehen, sie zu ergänzen und in einen größeren medizinhistorischen Zusammenhang zu stellen. Nur so ist es möglich, den Opfern auch posthum die Ehre zurückzugeben und ihre Nachfahren um Vergebung zu bitten.

Bei diesem Projekt handelt es sich nicht um ein weiteres Bußritual, sondern es geht vielmehr um den Versuch, einfühlsames Verständnis für die Opfer zu entwickeln und insbesondere darum, mehr Licht ins Dunkel zu bringen.

Prof. Dr. med. Thomas Dimpfl

Präsident der DGGG 2012-2014

Prof. Dr. med. Diethelm Wallwiener

Präsident der DGGG 2014-2016 
„Unsicherheit, Zukunftspessimismus und innerer Hader sind überwunden; Klarheit, Zielsicherheit, der Zusammenschluß aller nationalen Kräfte und ein unerschütterlicher, fanatischer Glaube an Deutschlands Zukunft sind zum breiten Fundament aller aufbauenden Arbeit geworden."

Walter Stoeckel, Eröffnungsansprache zur 23. Tagung der DGG, Oktober 1933

„Das Schicksal hat unser Vaterland schwer geschlagen. Aber auch die Deutsche Gesellschaft für Gynäkologie ist schwer geschlagen worden."

Rudolf Theodor von Jaschke, Eröffnungsansprache zur 27. Tagung der DGG, April 1949

Zwischen diesen beiden Zitaten aus den Eröffnungsreden der Vorsitzenden zur 23. und zur 27. Tagung der Deutschen Gesellschaft für Gynäkologie (DGG) im Oktober 1933 in Berlin und im April 1949 in Karlsruhe liegen nicht ganz 16 Jahre, die eine tiefe Zäsur nicht nur in der Geschichte der DGG, sondern in der deutschen, der europäischen und der Weltgeschichte markieren. Die vorliegende Arbeit stellt den Versuch dar, zu klären, wie der im Namen der DGG durch deren Vorsitzenden Walter Stoeckel beschworene „fanatische Glaube an Deutschlands Zukunft" offenbar weniger zur „aufbauenden Arbeit“ als vielmehr zu einer Entwicklung beigetragen hat, die auf der ersten Konferenz der DGG nach der nationalsozialistischen Diktatur im Jahr 1949 als von anonymen Mächten ausgeführter „Schicksalsschlag“ wahrgenommen wurde.

Annähernd 70 Jahre später geht es nunmehr darum, die durch Jaschke vorgenommene Deutung des Schicksalsschlages zu wenden, der „unser Vaterland“ ebenso wie die DGG „schwer geschlagen“ habe; es geht um eine Geschichte der DGG während des Nationalsozialismus, um eine fachärztliche wissenschaftliche Ge- sellschaft, die nicht nur einem „Schicksal“ ausgesetzt war, die nolens volens ein Teil dieser Geschichte war, die ihren Teil zu dieser Geschichte beigetragen hat.

Eine solche Perspektive kann nach gut einem halben Jahrhundert Geschichtsschreibung zum Nationalsozialismus gewiss keine besondere Originalität mehr für sich in Anspruch nehmen - unverzichtbar bleibt sie doch. Sie fügt sich ein in eine - wenngleich unvollständige -, so doch bereits stattliche Reihe von Geschichten medizinischer Fachgesellschaften im Nationalsozialismus. ${ }^{1}$ Gleichwohl ist eine Untersuchung wie die hier vorgelegte ohne massive Unterstützung nicht zu bewerkstelligen. Unser Dank gilt daher vorab dem Vorstand der Deutschen Gesellschaft für Gynäkologie und Geburtshilfe (DGGG) und insbesondere deren heutigem Past-Präsidenten Thomas Dimpfl als dem Initiator, Auftraggeber und beharrlichen Förderer dieser Forschungen.

Doch worin genau besteht, was ist der Gegenstand einer Geschichte der Deutschen Gesellschaft für Gynäkologie, die ihren Namen erst 1974 um die Geburtshilfe ergänzt hat? ${ }^{2}$ Welche Rolle spielt die DGG für die Entwicklungen im geburtshilflich-gynäkologischen Fach, und was ist der Unterschied zwischen einer Geschichte der Gynäkologie und derjenigen der nationalen gynäkologischen Fachgesellschaft? Besaß sie in Bezug auf das „Dritte Reich“ nennenswerte politische Bedeutung angesichts der monströsen Menschheitsverbrechen, die im Zuge der Shoa und des Zweiten Weltkriegs verübt wurden?

Diese Fragen bildeten den Hintergrund einer internen Debatte, die bereits vor knapp 20 Jahren in der DGGG ausgetragen wurde. Eine von Hans Ludwig im Auftrag des Vorstands besorgte Edition der präsidialen Eröffnungsansprachen auf den Tagungen der DGG seit dem Gründungskongress 1886 bis ins Jahr $1998^{3}$ warf die Frage auf, ob die Kürzung politisch einschlägiger Passagen der von Walter Stoeckel 1933 gehaltenen Eröffnungsrede als Versuch verstanden werden könne, „die damaligen Wortführer [...] von ihrer politischen Mitverantwortung für das Geschehen in

\footnotetext{
1 Zuletzt und mit einem umfassenden Überblick zu den parallel unternommenen Anstrengungen anderer Fachgesellschaften: Schmuhl: Neurologen (2016); als eine Umschau laufender einschlägiger Arbeiten fand im Oktober 2013 eine Tagung zur historischen Erforschung medizinischer Fachgesellschaften im Nationalsozialismus in Aachen statt, deren Beiträge ebenfalls soeben publiziert wurden: Krischel/Schmidt/Groß (Hrsg.): Fachgesellschaften (2016).

2 Ludwig (Hrsg.): Reden (1999), S. 299. Der von August Mayer bereits 1935 geäußerte Vorschlag, den Namen der Gesellschaft um die Geburtshilfe zu ergänzen, scheiterte am Einspruch von Walter Stoeckel (UAT 150/33,41: Gegenstände der letzten Vorstandssitzung und eigene Beobachtungen).

3 Ludwig (Hrsg.): Reden (1998).
} 
diesen Jahren reinzuwaschen“. ${ }^{4}$ Der Vorstand der DGGG unter dem Vorsitz von Günther Kindermann hat schließlich die - kostspielige - Entscheidung getroffen, das durch die Gesellschaft finanzierte Werk nicht weiter auszuliefern und nach Möglichkeit ausgelieferte Exemplare einzuziehen. Im Folgejahr sollte eine ergänzte zweite Auflage mit den ungekürzten Originalreden präsentiert werden. ${ }^{5}$

Der aufgeheizte Ton der Debatte gegen Ende der 1990er-Jahre, der mit den Kontroversen um die Arbeiten von Manfred Stauber zur Analyse der Zwangssterilisationen im Nationalsozialismus an der I. Münchner Universitätsfrauenklinik (UFK) unüberhörbar geworden war, ${ }^{6}$ ist inzwischen seinerseits Gegenstand der Wissenschaftsgeschichte. Zumindest hintergründig stand mit der politisch-moralischen auch die wissenschaftliche Integrität der Lehrergeneration der Ordinarien der 1990er-Jahre zur Debatte ausgetragen wurde sie erneut nicht zum kleinsten Teil als Generationenkonflikt, in dem die Schülerinnen und Schüler die Verstrickung der Lehrer ihrer Lehrer in den Nationalsozialismus auszuleuchten suchten. Dies ist kein Spezifikum der Gynäkologie, und auch keines der Medizin. ${ }^{7}$

\section{Gynäkologie und Nationalsozialismus als Ressourcen füreinander \\ $\nabla$}

Die Aufregung der späten 1990er-Jahre steht aber gleichzeitig auch für einen erheblichen Wandel, der besonders die Wissenschafts-, und damit nicht zuletzt die Medizin- einschließlich der Gynäkologiegeschichte betrifft. Die 1948 etablierte Max-PlanckGesellschaft setzte 1997 eine Historikerkommission ein und beauftragte diese mit der Erforschung ihrer Vorgängerorganisation im Nationalsozialismus. Im Jahr 2000 erschien der erste Band der bis 2007 auf 17 Bände angewachsenen Reihe „Geschichte der Kaiser-Wilhelm-Gesellschaft im Nationalsozialismus“. ${ }^{8}$ Ebenfalls um die Jahrtausendwende stellte der Wiener Wissenschaftshistoriker Mitchell Ash methodische Überlegungen zusammen, anhand derer die oben formulierten Fragen aus neuer Perspektive beantwortet werden können; das seitdem ausgebaute Paradigma versteht „Wissenschaft und Politik als Ressourcen füreinander“. ${ }^{9}$

Wissenschaft - so die zugrunde liegende und bereits ältere Überzeugung - kann insofern nicht „unpolitisch“ sein, als sie innerhalb von mehr oder weniger „politisch“ gesteuerten und verfass- ten Gesellschaften stattfindet. Dies gilt in besonderem Maße für in Universitäten, Akademien und wissenschaftlichen Vereinigungen organisierte und verfasste Wissenschaft. Außerhalb eines auf die eine oder andere Weise gesellschaftlich-politisch beeinflussten Rahmens findet Wissenschaft kaum statt. Der Wissenschaftsbetrieb ist also erstens von Entwicklungen in Politik und Gesellschaft hochgradig abhängig, und es ist von Interesse, in welcher Form sich der Wissenschaftsbetrieb und seine Protagonisten dazu bekennen. Spätestens im Laufe des 20. Jahrhunderts wurde zweitens die Politik ihrerseits von der Wissenschaft abhängig. Besonders auffällig geschah dies in der Rolle einer Legitimationsinstanz. ${ }^{10}$ Dies kann als „Verwissenschaftlichung des Sozialen“ (Lutz Raphael) und konkret als „Verwissenschaftlichung der Politik“ (Mitchell Ash) verstanden werden. Daraus ergibt sich drittens eine „Beziehungsgeschichte von Politik und Wissenschaft“, innerhalb derer schließlich die Grenzen zwischen „Wissenschaft“ und „Politik“ im Einzelnen nicht mehr nachvollziehbar sind. Diese Beziehung kann als Austausch von Ressourcen thematisiert werden, wenn darunter „kognitiv-konzeptionelle, apparativinstitutionelle, finanzielle oder auch rhetorische“ Unterstützung verstanden wird. So lässt sich darstellen, „wie die Allianzen, die Wissenschaftler mit externen Unterstützungsinstanzen eingehen, zur Entscheidung wissenschaftlicher Kontroversen beitragen, deren Ergebnisse dann im Nachhinein der Außenwelt beziehungsweise der Welt des Faktischen zugeschrieben werden, so als hätte sich alles von selber ereignet" ${ }^{11}$

Diese Grundüberlegungen spielen für das im Folgenden Dargelegte eine herausragende Rolle. Die DGG - wie andere fachärztliche Gesellschaften auch - erhält eine historisch untersuchbare Kontur, wenn sie als zentraler Umschlagplatz eines dermaßen gefassten Ressourcentausches verstanden wird. ${ }^{12}$ Sie gewinnt Mitgliederbeiträge, fachliche Erfahrung, wissenschaftliche Expertise und Autorität, indem sie möglichst viele Fachvertreter vereinigt und insbesondere als führend anerkannte Persönlichkeiten zu ihren Vorstandsmitgliedern macht. Letztere profitieren auf diesem Wege durch die Bestätigung, dass sie zurecht als bedeutende Vertreter des Faches gelten können; Erstere erhalten eine durchsetzungsfähige standespolitische Vertretung sowie eine Plattform für den wissenschaftlichen, standespolitischen und persönlichen Austausch. Die auf diesem Wege gewonnene Autorität der Gesellschaft lässt sich sodann ummünzen in die Rolle des legitimen Anwalts einschlägiger wissenschafts- und standespolitischer Interessen gegenüber der Gesellschaft und

\footnotetext{
4 Das geht hervor aus den der zweiten Auflage hinzugefügten Vorbemerkungen des Herausgebers zu den Reden, die in der Zeit zwischen 1933 und 1945 bei der Eröffnung der Kongresse gehalten worden sind: „Die Eröffnungsansprachen der Präsidenten, die im ,Dritten Reich“ der Deutschen Gesellschaft für Gynäkologie vorstanden, enthalten Passagen mit eindeutig politischem Inhalt. Diese Passagen haben mit dem ärztlichen Fach nichts oder nur wenig zu tun. Sie deshalb wegzulassen, wie es dem streng fachlich orientierten Konzept des Herausgebers zunächst gemäßer zu sein schien, wurde von einigen jedoch so verstanden, als werde beabsichtigt, die damaligen Wortführer - und nicht nur sie - von ihrer politischen Mitverantwortung für das Geschehen in diesen Jahren reinzuwaschen. Deshalb wurde in Übereinstimmung mit dem gegenwärtig verantwortlichen Vorstand der Gesellschaft beschlossen, die in diesem Kapitel abgedruckten Eröffnungsreden in vollem Wortlaut wiederzugeben, also nichts auszulassen, selbst wenn wir heute den Jargon dieser Zeit kaum mehr meinen ertragen zu können.“: Ludwig (Hrsg.): Reden (1999), S. 148.

5 Ludwig (Hrsg.): Reden (1999).

6 Vgl. für die Gynäkologie im Rückblick: Stauber: Vergangenheitsbewältigung (2012).

7 Auch die Geschichtswissenschaft hat sich erst auf dem Historikertag 1998 in Frankfurt am Main in nicht weniger aufgeheizter Stimmung mit ihrer Geschichte im Nationalsozialismus und speziell derjenigen ihrer wichtigsten Vertreter in der jungen Bundesrepublik öffentlich auseinandergesetzt; vgl. Schulze/ Oexle (Hrsg.): Historiker (1999).

8 Kaufmann: Kaiser-Wilhelm-Gesellschaft (2000).

9 Ash: Wissenschaft (2001); Ash: Wissenschaft(en) (2007); Ash: Beziehungsgeschichte (2010); Ash: Universität (2015).

${ }^{10} \mathrm{Vgl}$. Schmuhl: Neurologen (2016), S. 12: „Eine Politik, die sich überzeugend auf eine wissenschaftliche Grundlage berufen kann, erscheint als wertneutral und überparteilich, unbedingt sinnvoll, ja notwendig und ohne Alternative, mit hoher Wahrscheinlichkeit zielführend und erfolgversprechend. Als Quelle einer derart starken Legitimation löst die Wissenschaft in säkularisierten Gesellschaften in gewisser Weise die Religion ab."

11 Ash: Wissenschaft (2010), S. 16.

12 Schmuhl spricht von „hybriden Strukturen im Grenzbereich von Wissenschaft und Politik“; Schmuhl: Neurologen (2016), S. 13.
} 
der „Politik“. Von den politischen Instanzen akzeptierte und politisch erfolgreiche Vorstandsmitglieder wiederum erhöhen ihr Renommee und die Attraktivität der Fachgesellschaft gegenüber ihren Mitgliedern.

Dies gilt in ganz besonderer Weise für das Verhältnis von Medizin und Nationalsozialismus. ${ }^{13}$ Mit Hans-Walter Schmuhl kann der Nationalsozialismus als „biopolitische Entwicklungsdiktatur“14 gefasst werden, „die darauf abzielte, die Kontrolle über Geburt und Tod, Sexualität und Fortpflanzung, Körper und Keimbahn, Variabilität und Evolution an sich zu bringen, den Genpool der Bevölkerung von allen unerwünschten ,Beimischungen‘ zu ,reinigen' und auf diese Weise einen homogenen ,Volkskörper' zu schaffen “. ${ }^{15}$ Eugenik und Rassenhygiene waren gerade keine beliebigen Bestandteile einer abstrusen rassistischen Ideologie, sondern die auch von großen Teilen der universitären Medizin akzeptierte wissenschaftliche Grundlage derselben. Erbgesundheits- und Rassenpolitik wurden zum Kern eines gesellschaftspolitischen Mammutvorhabens, für das die Medizin von der Formulierung der wissenschaftlichen Konzepte über die Beratung der legislativen Einführung bis zur praktischen Durchführung unentbehrlich war. Mehr noch: In der historischen Rückschau zeige sich, so Volker Roelcke, dass die „Grenzüberschreitungen in der Medizin zwischen 1933 und 1945 [...] nicht spezifisch für die Zeit des Nationalsozialismus, sondern lediglich eine extreme Manifestation von Potentialen, die in der modernen Medizin generell, oder noch breiter in modernen Gesellschaften mit ihrer Orientierung an wissenschaftlicher Autorität und instrumentelltechnisch plausibilisierten Machbarkeitsvorstellungen angelegt sind“. ${ }^{16}$

Dies hat weitreichende Folgen für die Geschichte der Gynäkologie und ihrer Fachgesellschaft. Wenn der nationalsozialistische Staat behauptete, „sich wieder auf den Sinn unseres Lebens, auf den Zweck unseres Staatswesens, den Kampf um Fortbestand und Leben der Familie, der Art und Rasse besonnen " zu haben, ${ }^{17}$ dann wurde die professionelle Beschäftigung mit den Vorgängen um Zeugung, Fruchtbarkeit und Geburt zur staatstragenden Aufgabe. Die nationalsozialistische Diktatur war folglich ganz erheblich auf die Zustimmung und Unterstützung der deutschen Geburtshelfer und Gynäkologen angewiesen und die maßgebliche Agentur zur Formulierung dieser Unterstützung war die DGG. Die Geschwindigkeit, in der Prozesse wie Nazifizierung und „Gleichschaltung“ abliefen, ist nur erklärbar auf der Grundlage einer weitreichenden Übereinstimmung maßgeblicher Vertreter der deutschen Medizin mit den Zielen der sich selbst als revolutionär verstehenden Regierung der „nationalen Erhebung“. Hinsichtlich der DGG ist zu analysieren, wie die Gesellschaft, ihr Vorstand und allen voran der seinerzeitige Vorsitzende Walter Stoeckel diese Entwicklung rezipiert, wenn nicht antizipiert haben, wie den neuen Machthabern in Staat und Partei die Mitarbeit der DGG in dem Prozess der Umgestaltung der deutschen Gesell- schaft angeboten wurde und welche Vorteile die Vorsitzenden und die Gesellschaft ihrerseits daraus erwarben oder wenigstens davon erhofften.

Als konkrete Ausformulierung und praktische Tatbestände einer durch Gynäkologen vollzogenen eugenisch-rassenhygienisch begründeten Politik müssen die Zwangssterilisierungen nach dem „Gesetz zur Verhütung erbkranken Nachwuchses“ (GzVeN) gelten. Historische Untersuchungen zur nationalsozialistischen Medizin fokussierten vom Nürnberger Ärzteprozess bis in die 1980er-Jahre die verbrecherischen Humanexperimente in Konzentrationslagern und den Krankenmord. Erst mit der 1986 publizierten Untersuchung von Gisela Bock begann die eingehendere historische Erforschung der Zwangssterilisationen. ${ }^{18}$ Innerhalb des frauenheilkundlichen Fachs war die Zeit zwischen 1933 und 1945 in historischen Betrachtungen bis dahin weitgehend einvernehmlich ausgeblendet worden. Dies änderte sich erst in den 1990er-Jahren mit den Arbeiten von Manfred Stauber ${ }^{19}$ und Rolf Winau. ${ }^{20}$

Das am 14.Juli 1933 verabschiedete GzVeN, das am 1.Januar 1934 in Kraft trat, war das erste „Gesundheitsgesetz“ des nationalsozialistischen Staates. Es betraf die deutsche Gynäkologie und mit ihr die DGG in mehrfacher Hinsicht. So waren die gutachtliche Expertise sowie die wissenschaftliche Autorität der DGG und ihrer maßgeblichen Protagonisten gefragt. Mit Albert Döderlein und Heinrich Eymer haben führende Mitglieder der Gesellschaft den quasi-amtlichen Gesetzeskommentar in den beiden Auflagen von 1934 und 1936 um die Darstellung der operativen Sterilisationstechnik bereichert und damit zur wissenschaftlichen Legitimation beigetragen. ${ }^{21}$ Auf den großen DGGTagungen der Jahre 1933 und 1935 stand das Gesetz und die Optimierung seiner Durchführung im Mittelpunkt der wissenschaftlichen Beratungen. Schließlich waren die Universitätsfrauenkliniken Schrittmacher der Sterilisationspraxis. Von derzeit geschätzten insgesamt 350-400000 Sterilisationen wurde etwa die Hälfte an Frauen und durch dazu gesondert bevollmächtigte Gynäkologen vorgenommen; der Höhepunkt mit wiederum etwa der Hälfte der im gesamten Zeitraum durchgeführten Eingriffe lag in den Jahren 1934-1936. Bei in diesen Vorkriegsjahren des vermeintlich „normalen“ Betriebs etwa 15000 jährlich an Frauen durchgeführten Sterilisationseingriffen ist schon der Zahl nach keine Zurückhaltung der deutschen Gynäkologie in der Breite zu unterstellen. Es ist daher von Interesse, wie die DGG durch hervorragende Vertreter wie Ludwig Seitz und August Mayer ein Sterilisationsgesetz erst forderte, dann die Einführung des „Gesetzes zur Verhütung erbkranken Nachwuchses“ durch das neue Regime unterstützte und schließlich die sich daraus ergebenden Eingriffe auch in großer Zahl zuverlässig durchführte im Sinne des Ressourcentausches handelt es sich gleichsam um einen Ressourcenumlauf.

\footnotetext{
13 Zusammenfassend und mit der neueren Literatur: Eckart: Medizin (2012); Jütte/Eckart/Schmuhl/Süß: Medizin (2011).

14 Schmuhl: Entwicklungsdiktatur (2009).

15 Schmuhl: Neurologen (2016), S. 12.

16 Roelcke: Medizin (2012), S. 38 f., 47.

17 Aus dem Vorwort zur ersten Auflage der kommentierten Ausgabe des „Gesetzes zur Verhütung erbkranken Nachwuchses“ in Gütt/Rüdin/Ruttke (Hrsg.): Gesetz (1936), S. 5.

18 Bock: Zwangssterilisation (1986); Neuauflage 2010. Forschungsüberblick in Schmuhl: Zwangssterilisation (2011).

19 Stauber: Gynäkologie (1994). Details zu Stauber und seinen Aktivitäten in Stauber: Vergangenheitsbewältigung (2012).

20 Winau: Gynäkologie (1994).

21 Döderlein: Eingriffe (1934); Eymer: Eingriffe (1936).
} 
In einer solchen Perspektive ist die Gesellschaft tatsächlich mehr als die Summe der einschlägigen Äußerungen, Anstrengungen und Verdienste ihrer Vorstände oder ihrer Mitglieder. Die vorliegende Studie versteht sich dementsprechend als eine Beziehungsgeschichte zwischen der DGG und dem nationalsozialistischen Staat sowie der deutschen Gesellschaft in der Diktatur. Diese Beziehung wird hinsichtlich der Gesellschaft in 3 zentralen Strängen verfolgt: Zum einen gilt die Aufmerksamkeit dem Vorstand, speziell den Vorsitzenden - weibliche Vorstandsmitglieder hat die DGG in dem infrage stehenden Zeitraum nicht gehabt und ihren Aktivitäten in Ausübung dieses Amtes. Zum anderen werden die großen Tagungen sowie ihre Vorbereitung und Durchführung besonders betrachtet. Schließlich steht der Umgang der Gesellschaft mit ihrer wichtigsten Ressource, nämlich ihren Mitgliedern, im Fokus.

\section{Zur Quellensituation}

Eine umfängliche Geschichte der Deutschen Gesellschaft für Gynäkologie während des Nationalsozialismus (und darüber hinaus) lässt sich heute umstandslos allerdings nicht mehr schreiben: ein Archiv der Gesellschaft existiert nicht (mehr); Mitgliederlisten, Protokolle von Vorstandssitzungen, daneben Kassenrevisionen, um nur besonders wichtige Bestandteile zu nennen, sind weitestgehend verloren. Immerhin konnte ein kleiner Teil über Umwege ermittelt werden: In dem in der Münchner Staatsbibliothek (BSB) archivierten Nachlass von Josef Zander (19182007), 1978/79 Präsident der DGGG, fanden sich einige Aktenordner mit Korrespondenz der Geschäftsführung der DGG aus der hier infrage stehenden Zeit. Von besonderem Wert ist daneben der umfangreich überlieferte Nachlass des langjährigen Direktors der Tübinger UFK und DGG-Vorsitzenden August Mayer (1876-1968) im Universitätsarchiv der Eberhard-Karls-Universität in Tübingen (UAT). Der von Thorsten Doneith bereits hinsichtlich Mayers Biographie und Funktion als Tübinger Klinikdirektor ausgewertete Bestand ${ }^{22}$ bietet mit der Vorstandskorrespondenz einen ungewöhnlich detaillierten Einblick in Mayers einschlägige Tätigkeit - insbesondere in die Vorbereitung der Tagung 1935 in München. Daneben erlauben die Bestände des Bundesarchivs Berlin (BArch) zur Organisation des Gesundheitswesens und speziell zur Reichsarbeitsgemeinschaft „Mutter und Kind“ Aufschlüsse über die Beteiligung der DGG.

Unter den gedruckten Materialien sind die im „Archiv für Gynäkologie“" publizierten Kongressbände zu den in der Vorkriegszeit 2-jährlich veranstalteten großen Tagungen der DGG von besonderem Interesse. Sie ermöglichen nicht nur eine Gesamtschau der jeweiligen Schwerpunkte, sondern bringen auch bemerkenswerte Diskussionsbeiträge und sind in der hier gewählten Perspektive insbesondere durch die programmatischen Eröffnungsansprachen, die Protokolle der Mitgliederversammlungen, die Satzungen und Satzungsänderungen sowie die leider nicht komplett vorhandenen Mitgliederlisten wertvoll.

Besonders schwierig ist und bleibt eine genauere Qualifikation der Mitgliedschaft. Tatsächlich erscheinen die allermeisten Mitglieder lediglich als Namen in den Listen, soweit sie gedruckt wurden. Die überlieferten Korrespondenzen bilden fast ausschließlich die Ansichten des Vorstands ab, die wissenschaftlichen Beiträge spiegeln fachliche Diskurse und Positionen wider, sagen aber wenig über die Rolle und das Selbstverständnis des Referenten als Mitglied der Gesellschaft. Ergänzungen ergeben sich aus den Gynäkologen- sowie den Reichsmedizinalkalendern (GK/RMK). Unverzichtbare Hinweise lieferte die Auswertung des Reichsarztregisters durch Rebecca Schwoch. ${ }^{23}$

Auf der Grundlage der Überlieferungssituation sowie der gewählten Perspektive steht im Zentrum der Darstellung der Organismus der fachärztlich-gynäkologischen Gesellschaft als Vermittler zwischen den Zielen der nationalsozialistischen Gesundheitsund Rassenpolitik, den darin involvierten staatlichen Behörden und Parteieinrichtungen und der verfassten Ärzteschaft, wie sie seitens der DGG insbesondere durch deren Tagungen und deren Publikationen greifbar wird. Schwerpunkte liegen dabei zum einen auf dem Vorgang der Anpassung der Gesellschaft an die neuen Machtverhältnisse und den frühzeitig akzentuiert geäußerten gesundheits-, standes- und rassepolitischen Maßgaben, sodann auf dem Agieren der Vorstände als Kommunikationskanäle der Reichsleitung innerhalb der Ärzteschaft wie auch umgekehrt als Vertreter fachärztlich-gynäkologischer Interessen in den einschlägigen Reichsarbeitskreisen. Deutlich wird dies im konkreten Beispiel an der Organisation und Durchführung der großen Tagungen. Hinsichtlich der Mitglieder gilt den aus rassischen Motiven verdrängten und vertriebenen Mitgliedern der DGG besonderes Augenmerk.

\section{Zur Gliederung der Arbeit \\ $\nabla$}

Diesem Konzept folgt die Gliederung dieser Arbeit. Im ersten Hauptkapitel stehen der Vorstand und die Geschäftsführung der DGG im Zentrum. Grundlage des Organismus sind die Satzungen und Geschäftsordnungen der Gesellschaft und ihre Entwicklung während des Nationalsozialismus, denen das einleitende Kapitel gewidmet ist. Es folgt eine Skizze der Vorstandsämter und der Aufgabenverteilung innerhalb des Vorstands, bevor ausführlicher und mit weitergehenden biografischen Informationen auf die Vorstandsmitglieder und speziell selbstverständlich auf die Vorsitzenden der DGG und ihre Amtsführung eingegangen wird. Besondere Beachtung findet der Vorgang der Nazifizierung und "Gleichschaltung“ in einem eigenen Abschnitt. Im Anschluss daran wird die Vorstandsarbeit der DGG im Nationalsozialismus jenseits der Kongresse an einigen Beispielen beleuchtet. Dies betrifft zum einen die Mitwirkung der DGG in der im Schnittfeld zwischen Wissenschafts-, Gesundheits- und Sozialpolitik beim Reichsinnenministerium eingerichteten Reichsarbeitsgemeinschaft für Mutter und Kind. Zum anderen werden die Aktivitäten des Vorstands in der umstrittenen Frage des Primats der durch ärztliche Geburtshelfer geleiteten Klinik- oder der überwiegend von Hebammen betreuten Hausgeburt dargestellt. Hinzu kommen Aufträge der Reichsregierung wie die Überprüfung von Vorwürfen gegen den Grazer Klinikdirektor Karl Ehrhardt.

Das zweite Hauptkapitel behandelt die Kongresse mit Schwerpunkt auf den Themen, die für die Gesellschaft im Nationalsozia-

\footnotetext{
22 Doneith: Mayer (2007).

${ }^{23}$ Schwoch (Hrsg.): Kassenärzte (2009); Schwoch/Hahn: Aufgaben (2008).
} 
lismus von besonderem Interesse waren. Die Vorbereitung dieser Kongresse nahm den größeren Teil des den Amtsgeschäften gewidmeten Arbeitsaufwands der Vorsitzenden in Anspruch, die gleichzeitig als Kongresspräsidenten firmierten. Die Tagungen waren - und sind - zudem die Plattform, auf der sich die Gesellschaft als starke Gemeinschaft inszeniert. Sie standen unter nationaler und internationaler Beobachtung, präsentierten in den Referaten und deren Publikation den wissenschaftlichen Stand der Dinge und boten die Möglichkeit, diesen auch außerhalb des akademischen Lebens in die Praxis der niedergelassenen Kolleginnen und Kollegen zu kommunizieren. Im Verlauf der 5 in den Jahren 1931, 1933, 1935, 1937 und 1941 veranstalteten Kongresse lassen sich anhand der Kongressbände auch die bevorzugten wissenschaftlichen Gegenstände, vor allem die auf diesem Weg veröffentlichte Position zu Fragen der Eugenik im Allgemeinen sowie den Zwangsterilisationen im Besonderen hervorragend nachvollziehen.

Das dritte Hauptkapitel beschäftigt sich mit dem eigentlichen Kapital der Gesellschaft, ihren Mitgliedern. Es fällt auf, dass auch neuere Arbeiten zur Geschichte medizinischer Fachgesellschaften die Entwicklung von Zahl und Zusammensetzung der Mitgliedschaft eher am Rande vermerken. Dies ist wohl nicht allein der Fokussierung auf Lebenswege ausgesuchter Persönlichkeiten und fachgeschichtliche Entwicklungen geschuldet, sondern auch den methodischen Problemen, die sich bei dem Versuch einer Annäherung an das ständig fluktuierende und außerordentlich heterogene Gebilde der Mitgliederschaft ergeben. Auch an dieser Stelle wird zunächst kurz die in der Satzung gegebene Grundlage der Mitgliedschaft dargestellt, um dann aber näher auf die Entwicklung und Zusammensetzung der Mitgliedschaft bis 1937 einzugehen (für die spätere Zeit bis zum Kriegsende liegen keine verwertbaren Mitgliedslisten vor). Anschließend steht die Frage im Mittelpunkt, in welchem Umfang Mitglieder das wichtigste Angebot der Gesellschaft wahrnahmen und die Kongresse der DGG besuchten.

An einigen Beispielen werden dann nationalsozialistische Gynäkologenkarrieren beleuchtet. Im Mittelpunkt stehen Frauenärzte, die sich innerhalb der DGG nicht durch die Übernahme von Vorstandspositionen hervorgetan haben, sondern deren berufliche Wege dem Nationalsozialismus besondere Förderung verdanken - sei es durch ihre Mitgliedschaft in der Nationalsozialistischen Deutschen Arbeiterpartei (NSDAP) oder die Verfolgung besonders unterstützter Forschungsgegenstände. Zwei Gruppen der Mitgliedschaft erfahren anschließend eine nähere Betrachtung, nämlich die - im Zusammenhang mit dem Fach Frauenheilkunde interessanten - weiblichen Frauenärzte als Mitglieder der DGG, sowie die für die Außendarstellung der Gesellschaft als eminent wichtig erachteten „Ausländer“, die - obwohl mehrheitlich deutschsprachig - keine Bürger des Deutschen Reiches waren.

Besondere Aufmerksamkeit gilt abschließend einem Aspekt, der seit der im Jahr 2000 publizierten grundlegenden Arbeit von Eduard Seidler ${ }^{24}$ auch auf der Ebene der medizinischen Fächer und ihrer Fachgesellschaften stets gründlichere Bearbeitung erfährt: die Verdrängung und Entrechtung eines erheblichen Teils der Mitgliedschaft, der unter politisch-weltanschaulichen, vor allem aber rassistischen Maßstäben als nicht mehr tragbar erachtet wurde. Anhand der wichtigsten Schritte der staatlichen Judenverfolgung - vom „Gesetz zur Wiederherstellung des Berufsbeamtentums“ am 7. April 1933 über die antisemitische Publizistik, den Entzug der Bestallung, die Novemberpogrome im Jahr 1938 bis zur Deportation und dem massenhaften Mord in den Vernichtungslagern - wird am Beispiel von DGG-Mitgliedern der Prozess von der Ausgrenzung bis zum Massenmord erläutert.

Das abschließende vierte Kapitel des Bandes gibt erste Hinweise zur Re-Etablierung der DGG nach der Diktatur. Die ersten Nachkriegstagungen 1949 in Karlsruhe und 1951 in Bad Pyrmont standen noch unter dem Schock des Zusammenbruchs nach Diktatur und Krieg. Neben der Mitgliederentwicklung der Nachkriegszeit ist insbesondere der Umgang mit der nationalsozialistischen Vergangenheit der eigenen Gesellschaft und des eigenen Fachs von Interesse. Es handelt sich dabei vorerst um Bruchstücke, auf die eine - noch zu erarbeitende - Geschichte der frauenärztlichen Gesellschaften in den beiden deutschen Staaten hoffentlich wird aufbauen können. ${ }^{25}$

\section{Die Autorinnen und Autoren}

Die vorliegende Arbeit ist das Werk einer Gruppe, die bereits längere Zeit eng zusammenarbeitet. Auf Initiative von Christoph Anthuber, des seinerzeitigen Vorsitzenden der Bayerischen Gesellschaft für Geburtshilfe und Frauenheilkunde (BGGF), und mit finanzieller Unterstützung der BGGF waren im Jahr 2009 Arbeiten für eine Festschrift zum 100-jährigen Bestehen der bayerischen Regionalgesellschaft begonnen worden, die 2012 zum Jubiläum mit der Publikation der Festschrift abgeschlossen werden konnten. ${ }^{26}$ Vor diesem Hintergrund beschloss der Vorstand der DGGG auf Initiative von Thomas Dimpfl im Jahr 2013, eine Arbeitsgruppe unter der Leitung von Fritz Dross (Erlangen) mit einem Forschungsprojekt zur Geschichte der nationalen Fachgesellschaft während des Nationalsozialismus zu beauftragen. Dieser Arbeitsgruppe haben vom Beginn bis zum Abschluss der Arbeiten Wolfgang Frobenius und Andreas Thum (beide Erlangen) angehört, die bereits an den Forschungen zur BGGF maßgeblich beteiligt waren. Neu hinzugewonnen wurde die Wissenschaftshistorikerin Ulrike Thoms (Berlin), deren intimer Kenntnis und präziser Recherche der Berliner Archivbestände sowohl in der Breite als auch in der Tiefe diese Arbeit unverzichtbare Dokumente und wesentliche konzeptionelle Impulse verdankt. Als studentische Hilfskraft hat Claudia Beck (Magdeburg) wichtige Hintergrundarbeit geleistet, die schließlich zur Vorstellung der Forschungen auf dem 60. Kongress der DGGG im Oktober 2014 in München sowie zu einer kleineren Publikation geführt haben. ${ }^{27}$ Für die Abschlussphase stieß Alexander Bastian (Magdeburg/Berlin) zu der Gruppe, der soeben sein geschichtswissenschaftliches Habilitationsprojekt „Körperpolitik, Bio-Macht und der Wert menschlichen Lebens. Nationalsozialistische Zwangssterilisation auf dem Gebiet des heutigen Bundeslandes Sachsen-Anhalt" abschließt. Insbesondere mit Bild- und Literaturrecherchen hat Kerstin Wagner (Erlangen) zum Gelingen dieses

\footnotetext{
24 Seidler: Kinderärzte (2000); erweiterte Neuauflage 2007.

${ }^{25}$ Vgl. Halling/Moll/Fangerau: Urologie (2015).

${ }^{26}$ Anthuber/Beckmann/Dietl/Dross/Frobenius (Hrsg.): Herausforderungen (2012); im Kurzüberblick: Frobenius/Kinzelbach/Anthuber/Dross: Societies (2014)

${ }^{27}$ Frobenius/Thoms/Dross: Spurensuche (2014).
} 
Bandes beigetragen. Für redaktionelle und Lektoratsarbeiten hat sich die Gruppe auf die Unterstützung von Annemarie Kinzelbach (München) verlassen können, die ebenfalls bereits als Autorin der ersten Arbeitsgruppe zur Geschichte der BGGF angehört hatte.

Abschließend gilt es, Dank zu sagen: allen voran der Deutschen Gesellschaft für Gynäkologie und Geburtshilfe, ihrem Vorstand sowie insbesondere dem Initiator, Förderer und herzlichen Begleiter dieser Arbeiten, Thomas Dimpfl. Über den Abschluss des bayerischen Projekts hinaus hat Christoph Anthuber unsere Arbeit ebenso interessiert wie wohlwollend gefördert. Für ermutigende Hintergrundgespräche danken wir Günther Kindermann, Manfred Stauber und Volker Lehmann. Gerne sind wir der Einladung zur Diskussion von Matthis Krischel im Oktober 2014 nach Aachen gefolgt, ${ }^{28}$ um von der Tagung „Medizinische Fachgesellschaften im Nationalsozialismus - Bestandsaufnahme und
Perspektiven“29 viele wertvolle Anregungen mitzunehmen. Anregende Diskussionspartner und interessierte Begleiter der Arbeiten waren darüber hinaus Eva Brinkschulte in Magdeburg, Karl-Heinz Leven, Philipp Rauh und Renate Wittern-Sterzel in Erlangen. Ohne die geduldige Arbeit der zahlreichen besuchten Archive und Bibliotheken kann historische Forschung nicht gedeihen - namentlich erwähnt seien an dieser Stelle lediglich Klaus von Fleischbein-Brinkschulte vom Berliner Institut für Geschichte der Medizin und Ethik in der Medizin für die Recherche von Porträts und deren unkomplizierte Bereitstellung. Für Hinweise auf in Privatnachlässen befindliche Porträts danken wir Matthias David und Andreas Ebert (Berlin), Maike Rotzoll (Heidelberg) und Michael Görig, Jutta Hübner (Hamburg) und Rudolf de Wall (Pinneberg) sowie Sari Siegel (Washington) und Joe Bradley (GB). Angelika Kretschmer und ihr Team der Erlanger Institutsbibliothek des Instituts für Geschichte und Ethik der Medizin bildeten nicht zum ersten Mal unser bibliothekarisches Rückgrat.

${ }^{28}$ Frobenius/Kinzelbach/Dross: Gynäkologen (2016).

${ }^{29}$ Krischel/Schmidt/Groß (Hrsg.): Fachgesellschaften (2016). 


\section{Vorstand und Geschäftsführung 1929-1949}

\section{Satzung und Geschäftsordnungen bis 1933 \\ $\nabla$}

Die Statuten der DGG gehen auf einen Entwurf von 1877 zurück, der nach der Gründung der Gesellschaft 1885 in Straßburg und ihrem ersten Kongress 1886 in München ${ }^{30}$ nahezu unverändert übernommen wurde. Geregelt waren darin vor allem der Zweck der Gesellschaft ( $§ 1$ ), die Voraussetzungen für die Mitgliedschaft ( $\S \S 3$ und 8), die Wahl, die Zusammensetzung und Amtszeit des Vorstandes sowie seine Rechte und Pflichten ( $(5)$, ferner die Modalitäten der Veröffentlichung der Kongressberichte $(\S 9)$. $\S 10$ schließlich legte die Voraussetzungen für eine Veränderung der Statuten fest (Beratung im Vorstand, Zweidrittelmehrheit in der Mitgliederversammlung).

Die Geschäftsordnung fixierte in einigen wenigen Paragrafen vor allem den Einfluss des Vorsitzenden auf die Gestaltung des Kongressprogramms. Bis zu den Verhandlungen 1929 in Leipzig war dahingehend nur davon die Rede, dass der Vorsitzende „nach eigenem Ermessen“ für die Vorträge und Demonstrationen einen „Numerus clausus" einführen und die Reihenfolge festlegen konnte. ${ }^{31}$ Dies wurde dann - mit Wirkung für den Kongress 1931 - auf Vorschlag von Hugo Sellheim grundlegend geändert. Der Vorsitzende erhielt nunmehr zusätzlich das Recht auf Festlegung der Tagungsschwerpunkte („am meisten interessierende Themata“); ihre Behandlung sollte durch ausgewählte Referenten mit anschließenden Diskussionsbeiträgen aus dem Plenum erfolgen. ${ }^{32}$ Ab 1929 legte die Geschäftsordnung auch fest, dass die Öffentlichkeitsarbeit exklusive Angelegenheit des Vorstands war. ${ }^{33}$

Modifikationen der Satzung, ${ }^{34}$ die sich aus Vorschlägen des Vorstands, aber auch aus Wünschen der Mitglieder ergaben, betrafen bis 1933 vor allem den Vereinszweck, die Bedingungen für die Mitgliedschaft und die Zusammensetzung des Vorstands damals noch „Ausschuss“ genannt. So modifizierte die Mitgliederversammlung den Vereinszweck, , , [...] die Gynäkologen durch persönlichen Verkehr in regelmäßig wiederkehrenden Versammlungen näher zusammenzuführen und gemeinsame Arbeiten zu fördern“, dahingehend, dass der Passus „in regelmäßig wieder- kehrenden Versammlungen“ offenbar als zu limitierend gestrichen wurde. Stattdessen sollte künftig der persönliche Verkehr „den Austausch der Ideen [...] erleichtern“, ohne dass dies auf die Tagungen beschränkt war. Auf die Voraussetzungen für die Mitgliedschaft wird im entsprechenden Kapitel näher eingegangen. ${ }^{35}$

Der Vorstand, zu dem ursprünglich ein 1. und ein 2. Vorsitzender, ein 1. (ständiger) und ein 2. Schriftführer sowie der „Kassenführer" und 2 Beisitzer aus der Mitgliedschaft zählten, wurde bereits 1909 in Straßburg um 2 zusätzliche Beisitzer erweitert, wobei 2 der nunmehr insgesamt 4 Beisitzer „den Universitätskreisen nicht angehören“ sollten. Die Vorsitzenden, die Schriftführer und der Kassenführer bildeten wie schon bisher das „Bureau des Kongresses“, waren also für die Organisation zuständig. Der gesamte Vorstand einschließlich der Beisitzer regelte den Statuten zufolge die Angelegenheiten der Gesellschaft für 2 Jahre, wobei die Amtsführung eines neu gewählten Vorstands nach einem Beschluss von 1927 erst dann begann, wenn die Verhandlungen des vorausgegangenen Kongresses im Druck erschienen waren. Im Detail sah die Satzung folgende Aufgaben für den Gesamtvorstand vor: Beratung etwaiger Änderungen der Statuten und der Geschäftsordnung, Entscheidung über die Aufnahme neuer Mitglieder sowie die „Verwahrung der Archive und der Gelder der Gesellschaft“. Im Zusammenhang mit der Verpflichtung zur Veröffentlichung der Verhandlungen wurde das „Archiv für Gynäkologie" 1931 in den Stauten erstmals nicht mehr explizit als das Publikationsorgan der Wahl genannt.

Als bis dahin am weitesten reichende Änderung in den Gepflogenheiten der Gesellschaft, die sich allerdings nicht in einer Änderung der Statuten niederschlug, brachte der Frankfurter Kongress von 1931 die Entkoppelung von Präsidentenamt und Kongressort: Während bis dahin mit der Wahl des Kongressortes quasi automatisch auch der dort residierende Ordinarius bzw. Klinikchef zum 1. Vorsitzenden bestimmt wurde, sollten nun beide auf Vorschlag des Vorstands in der Mitgliederversammlung unabhängig voneinander gewählt werden. Dieser neue Modus

\footnotetext{
30 Zu Gründungsgeschichte der DGG vgl. Ludwig: Gründung (1986).

${ }^{31}$ Geschäftsordnung (1927), XIII.

32 Geschäftsordnung (1929), XIII.

33 Geschäftsordnung (1929), XIII.

34 Die aktuell gültigen Satzungen sowie die Modifikationen und deren Zeitpunkt wurden jeweils mit den Kongressberichten im „Archiv für Gynäkologie“ veröffentlicht.

35 Siehe hierzu S. $59 f$.
} 
war bereits im Mai 1930 durch eine Urabstimmung unter den Mitgliedern per Postkarte mit großer Mehrheit festgelegt worden. ${ }^{36}$ Ebenfalls nicht explizit in den Statuten findet sich die Tradition, dass der Präsident von der Mitgliederversammlung „seines“ Kongresses für die darauffolgenden 2 Jahre zum 2. Vorsitzenden gewählt wurde. Einer weiteren ungeschriebenen Vereinbarung folgte die Praxis, die Wahl des 2.Schriftführers dem Präsidenten zu überlassen. ${ }^{37}$

\section{Vorstandsämter und Aufgabenverteilung}

Die Vorsitzenden bzw. Präsidenten der DGG waren also nach der Geschäftsordnung mit weitreichenden Kompetenzen für die Gestaltung der Kongresse ausgestattet. Sie konnten damit für die Mitglieder, die übrige Ärzteschaft und auch die Öffentlichkeit das jeweils aktuelle Bild des Faches in 2-jährigem Turnus individuell prägen. Der Umgang der Präsidenten mit ihren Vollmachten folgte daneben ebenso Traditionen und Erwartungen wie dem bereits beschriebenen Prozedere bei der Wahl des 2. Vorsitzenden und des 2 . Schriftführers. Walter Stoeckel charakterisierte diese Traditionen und Erwartungen in seinen Memoiren wie folgt: „[Der Präsident] sollte mit dem Vorstand arbeiten, Vorstandssitzungen einberufen, alles durchberaten lassen und die Vorstandsbeschlüße [sic] dann ausführen.“38 Bei der Vorbereitung „seines“ Kongresses hat er dies alles freilich weitgehend ignoriert.

Wegen der großen Innen- und Außenwirkung lag es im Interesse der Gesellschaft, herausragende Persönlichkeiten in das Amt des Vorsitzenden zu bringen. Stoeckel bezeichnete es als „höchste Ehre“, zum Präsidenten eines Fachkongresses gewählt zu werden“. ${ }^{39}$ Andere haben sich in ähnlicher Weise geäußert. Dennoch konnten bei den Wahlen nicht nur fach-, sondern auch allgemeinpolitische Erwägungen eine Rolle spielen. Wie sich zeigen wird, kam in der Ausübung des Präsidentenamtes auch ein sehr unterschiedliches Amtsverständnis zum Tragen. Autokratischen Persönlichkeiten spielte dabei im Nationalsozialismus die Forderung nach umfassender Einführung des Führerprinzips in die Hände.

\section{Wer soll Präsident werden?}

Einen speziellen Modus der Kandidatenauswahl gab es im Untersuchungszeitraum offenbar nicht. Gewisse Einblicke in das Prozedere gewähren die Unterlagen von August Mayer über den Kongress im Oktober 1935. Danach wurde bereits bei der ersten vorbereitenden Sitzung im Februar des Jahres über mögliche Kandidaten diskutiert. Anwesend waren aus dem Kreis der Vor- standsmitglieder neben Mayer nur die beiden Schriftführer Eduard Martin (Elberfeld) und Moritz Tausch (Tübingen) sowie der Beisitzer Hans Albrecht (München). Mayer sprach sich schon damals für den Berliner Ordinarius Georg August Wagner aus, Martin äußerte Bedenken („katholisch, [...] seitens der Regierung nicht geschätzt“); weitere Namen in der Diskussion waren der Erlanger Hermann Wintz (,internationale Bedeutung“; Wiedergutmachung für Unrecht in der „Münchner Berufungsangelegenheit“), Robert Schröder aus Kiel (Begrenzung des Einflusses von Stoeckel) sowie Rudolf Theodor von Jaschke aus Gießen. ${ }^{40}$

Diese Debatte setzte sich im Mai 1935 in noch kleinerem Kreise fort. Beteiligt waren nun nur Mayer, Martin und diesmal Ludwig Seitz - zu diesem Zeitpunkt Ex-Präsident ohne aktuelle Funktion. Nach offenbar ausführlicher Diskussion fixierte Mayer den diesmal abwesenden Albrecht an erster Stelle auf einer Liste der „Präsidentenanwärter“, es folgten Wagner, Jaschke und Wintz. Mit Albrecht, so hieß es, könne auch einmal ein Nicht-Ordinarius Präsident werden, seine Wahl würde ihn als Arzt und Wissenschaftler anerkennen. Außerdem würde er dadurch „eine Entschädigung haben für die Nichtberufung nach Innsbruck, die ihm [Carl] Menge verdorben haben soll, und für die mühevolle Kongressvorbereitung“. Seitz und Martin hatten sich in erster Linie für Wintz ausgesprochen, Seitz glaubte aber, „dass dieser nicht durchgeht“. Im Zusammenhang mit Jaschke waren Bedenken geäußert worden, weil ihn das „Braune Haus“ in München schon für das dortige Ordinariat abgelehnt hatte. Auch der mögliche Widerstand des Regimes gegen Wagner wurde wieder aufs Tapet gebracht. Schließlich kam man überein, der Vorsitzende solle sich „durch private Beziehungen erkundigen, wer von den 4en der Regierung genehm ist“. ${ }^{41}$

Die „privaten Beziehungen“ Mayers hießen offenbar Stoeckel. Aus den Unterlagen geht hervor, dass Mayer mit ihm zumindest ein diesbezügliches Gespräch geführt hat. In einem späteren Schreiben an Mayer bekräftigte Stoeckel seine damals offenbar geäußerte Ansicht, er habe „garnichts dagegen, dass Wagner auf dem Berliner Kongress Präsident wird“. Gleichzeitig sprach er sich für eine Wahl Albrechts für den übernächsten Kongress aus, von dem er annahm, er würde wieder in München stattfinden. ${ }^{42}$ So wurde Wagner bei einer Vorstandssitzung am 22. Oktober 1935 als offizieller Kandidat bestätigt, nachdem zuvor sein Plazet eingeholt worden war. ${ }^{43}$

Der 2. Vorsitzende, über dessen spezielles Tätigkeitsfeld in Satzung und Geschäftsordnung überhaupt nichts ausgesagt war,

\footnotetext{
${ }^{36}$ Geschäftssitzung [Verhandlungen 1931] (1931), LII.

37 Generalversammlung [Verhandlungen 1933] (1934), LIII.

38 Stoeckel: Leben (1954), S. 118. Autobiografisches von Stoeckel liegt in unterschiedlicher Form vor. Eine quellenkritische Analyse findet sich in Schagen: Stoeckel (2010), S. 203-207. Danach ist Stoeckel: Leben (1954) als von ihm selbst autorisiert zu betrachten. Dieses Werk wurde 1954 als Manuskript in geringer Auflage für den privaten Gebrauch gedruckt. Stoeckel hatte es ausweislich des Vorworts am 8. Mai 1953 abgeschlossen. Eine Veröffentlichung sollte entsprechend dem Wunsch des Autors frühestens nach seinem Tod erfolgen. Alle anderen Stoeckel-Biografien sind von den Herausgebern mehr oder weniger stark bearbeitet und gekürzt worden. Sie unterscheiden sich von dem „Original“ unter anderem dadurch, dass bestimmte Passagen fehlen, die das NS-Regime und seine Vertreter in günstigem Licht erscheinen lassen. In der vorliegenden Arbeit wird neben dem von Stoeckel autorisierten Werk die von Dr. Hans Borgelt 1966 herausgegebenen Fassung verwendet, die neben den angesprochenen Kürzungen offenbar auch durch Autobiografisches aus anderen Quellen (Briefen, Reden etc.) ergänzt ist: Stoeckel Erinnerungen (1966). Schagen sieht keinen Grund, die Ausgabe von Borgelt hinsichtlich der Authentizität des Inhalts in Zweifel zu ziehen.

39 Stoeckel: Leben (1954), S. 117.

40 UAT 150/33,41: Sitzungsprotokoll (25.02.1935), S. 6: „Die Richtung Menge/Eymer soll unter allen Umständen umgangen werden.“ Zur Berufung Eymers vgl. Frobenius: Wiederbesetzung (2012), S. 166.

41 UAT 150/33,41: Besprechungsprotokoll (25.05.1935).

42 UAT 150/33,41: Stoeckel an Wagner (04.09.1935)

43 UAT 150/33,41: Protokoll Vorstandssitzung (22.10.1935: Brief an G.A. Wagner [01.10.1935]).
} 
konnte in der DGG vor allem wegen des erwähnten Wahlmodus eine besondere Rolle spielen: Er besaß als Ex-Präsident Kongresserfahrung und war so seinem Nachfolger bei Bedarf ein wertvoller Berater. Dieses Modell stellte bei dem 2-jährigen Wechsel im Amt des Präsidenten ein Element der Kontinuität dar. Dies gilt speziell für die Ämter des 1.Schriftführers sowie des Kassenwarts. Beide Ämter wurden in der Gesellschaft üblicherweise für viele Jahre, wenn nicht Jahrzehnte, ausgeübt. Im hier relevanten Zeitraum gab es in beiden Ämtern nur jeweils einen Wechsel.

Die wichtigste Aufgabe des 1. Schriftführers war die Herausgabe der Kongressberichte, die er zusammen mit dem jeweiligen Präsidenten verantwortete. Darüber hinaus war er in die Kongressvorbereitung involviert. Allerdings griffen die Präsidenten für die Kongressvorbereitung auch aus Gründen der Praktikabilität gerne auf einen ihrer Oberärzte zurück. Deshalb bürgerte sich die Gewohnheit ein, dem Präsidenten die Wahl des 2. Schriftführers zu überlassen. Gelegentlich übernahmen auch Beisitzer Teile der Kongressvorbereitung - vor allem dann, wenn der Präsident nicht am Kongressort tätig war und deshalb nicht auf die Ressourcen einer großen Klinik zurückgreifen konnte.

Der 1.Schriftführer und der Kassenwart waren in die meisten Mitgliederangelegenheiten involviert. Vor allem die Aktualisierung der Mitgliederlisten vor den Kongressen verursachte lebhafte Korrespondenz.

\section{Die Akteure des engeren Vorstands 1931-1949}

Die Persönlichkeiten, deren Arbeit im engeren Vorstand die DGG vom Ende der Weimarer Republik bis in die Zeit nach dem Zweiten Weltkrieg geprägt hat, weisen gemeinsame Züge auf. Mit Ausnahme von Hans Fuchs, dem 1937 gewählten Präsidenten, und Eduard Martin, dem 1.Schriftführer zwischen 1920 und 1936, waren alle langjährige Direktoren von Universitätsfrauenkliniken. Die entscheidende Prägung der Vorstandsmitglieder erfolgte im bürgerlichen Milieu des Kaiserreichs, durch den Ersten Weltkrieg sowie die darauffolgenden politischen Wirren und nur noch teilweise in der Weimarer Republik. Die Vorsitzenden waren national-konservativ, standen eugenischen Maßnahmen aufgeschlossen gegenüber und lehnten Abtreibungen sowie Kontrazeption strikt ab, soweit dies nicht medizinisch begründet war.

Die folgenden biografischen Skizzen sollen einen etwas genaueren Eindruck davon vermitteln, um welche Persönlichkeiten es sich bei den Vorstandsmitgliedern handelte. Ein Schwerpunkt der Betrachtung liegt dabei auf der Rolle, die sie im Zusammenhang mit der Machtübernahme der Nationalsozialisten einnahmen und während der Diktatur ausfüllten. Gemeinsamkeiten sind auch hier, dass Anpassung, wenn nicht zumindest anfänglich begeisterte Zustimmung, die Regel war und sich bei niemandem - vielleicht mit Ausnahme von Heinrich Martius - grundsätzliche Bedenken gegen die nun implementierten Zwangssterilisationen erkennen lassen. Im Engagement dafür zeigten sich allerdings durchaus Unterschiede, worauf im Detail noch zurückzukommen sein wird. Das GzVeN wurde an allen Hochschulkliniken umge- setzt, wenn auch in unterschiedlichem Ausmaß. ${ }^{44}$ Hinsichtlich rassisch motivierter Abtreibungen an Zwangsarbeiterinnen gibt es - soweit DGG-Vorsitzende betroffen sind - kaum erhaltene Daten, spärliche liegen für die Tübinger Klinik von Mayer vor. ${ }^{45}$

Die im Rahmen dieser Untersuchung aufgefundene Korrespondenz der Vorstandsmitglieder untereinander zeigt respektvollen bis freundschaftlichen, durch die Behandlung von Sachfragen dominierten Umgang. Gelegentlich findet sich ein persönlicher Satz, ganz persönlich gehaltene Schreiben zählen zu den Raritäten. Eine kritische Auseinandersetzung mit der NS-Politik spielt nur insofern eine Rolle, als mit Fortschreiten des Krieges zuweilen Zweifel an einem siegreichen Ausgang spürbar werden. Lediglich anlässlich der Auseinandersetzung um die Hausgeburt und in der einschlägigen Denkschrift dazu um die Jahreswende 1939/40 wagte die DGG einen Konflikt mit dem Reichsgesundheitsführer Leonardo Conti.

Informationen zu Details der Amtsführung der Vorstandsmitglieder sind - soweit sie sich nicht aus gedruckten Quellen ergeben wegen des Mangels an Archivalien eher selten. Auch hier gibt es jedoch Ausnahmen: Der Nachlass von August Mayer ermöglicht einen detaillierten Einblick in die Vorbereitungen des DGG-Kongresses 1935 und belegt, dass im Gegensatz zu den von Stoeckel 2 Jahre zuvor coram publico geäußerten Erwartungen massive Einflussnahme von Seiten des Regimes auch in Bezug auf die Gestaltung des wissenschaftlichen Teils der Veranstaltung stattgefunden hat. Ebenso finden sich in den im Nachlass von Josef Zander aufgefundenen Akten der Gesellschaft vereinzelt Hinweise auf den Stil der Amtsführung - so etwa die Tatsache, dass Wagner am 2.Juli 1937 relativ kurzfristig eine Vorstandssitzung in sein Ferienhaus in Garmisch einberief. ${ }^{46}$

\section{Die Vorsitzenden}

Ludwig Seitz: Promotor eugenischer Abtreibungen

Ludwig Seitz, 1931 in Frankfurt am Main Präsident der letzten Tagung der DGG vor der Machtübernahme der Nationalsozialisten, gehört zu den bedeutenden deutschen Frauenärzten des 20. Jahrhunderts ( A Abb. 1). In der Auswahl der Themen und Referenten sowie in den kontroversen Diskussionen des von ihm organisierten Kongresses spiegelte sich die ganze Vielschichtigkeit der sozial-, gesundheits- und bevölkerungspolitischen Debatte der Weimarer Republik wider. Die Veranstaltung stand damit in krassem Gegensatz zu dem 2 Jahre später durchgeführten "Gleichschaltungskongress“ von Walter Stoeckel. Gleichwohl konnte Seitz offensichtlich nicht der Versuchung widerstehen, dem großen Referat des ihm wohl doch etwas zu liberalen Ludwig Fraenkel über „Sterilisierung und Konzeptionsverhütung“ in einem Korreferat die weitgehend konträren Ansichten eines aufstrebenden völkischen Rassenhygienikers gegenüberzustellen. ${ }^{47}$

Ludwig Seitz sind für das beeindruckende wissenschaftliche Lebenswerk, das er als Assistent und Oberarzt an der I. UFK in München begonnen sowie als Ordinarius in Erlangen (1910-1921) und Frankfurt am Main (1921-1938) fortgesetzt hat, zahlreiche Ehrungen zuteilgeworden. Wie viele seiner Zeitgenossen war er allerdings auch ein Anhänger radikaler eugenischer Maßnah-

\footnotetext{
44 Überblick bei Schmuhl: Zwangssterilisation (2011).

45 Vgl. Doneith: Mayer (2008), S. 95-100.

46 BSB München, Nachlässe, Ana 691: Wagner an Martius (02.07.1937).

47 Siehe hierzu S. 37 f. Details zu biografischen Daten und Quellen in der Kurzbiografie im Anhang.
} 

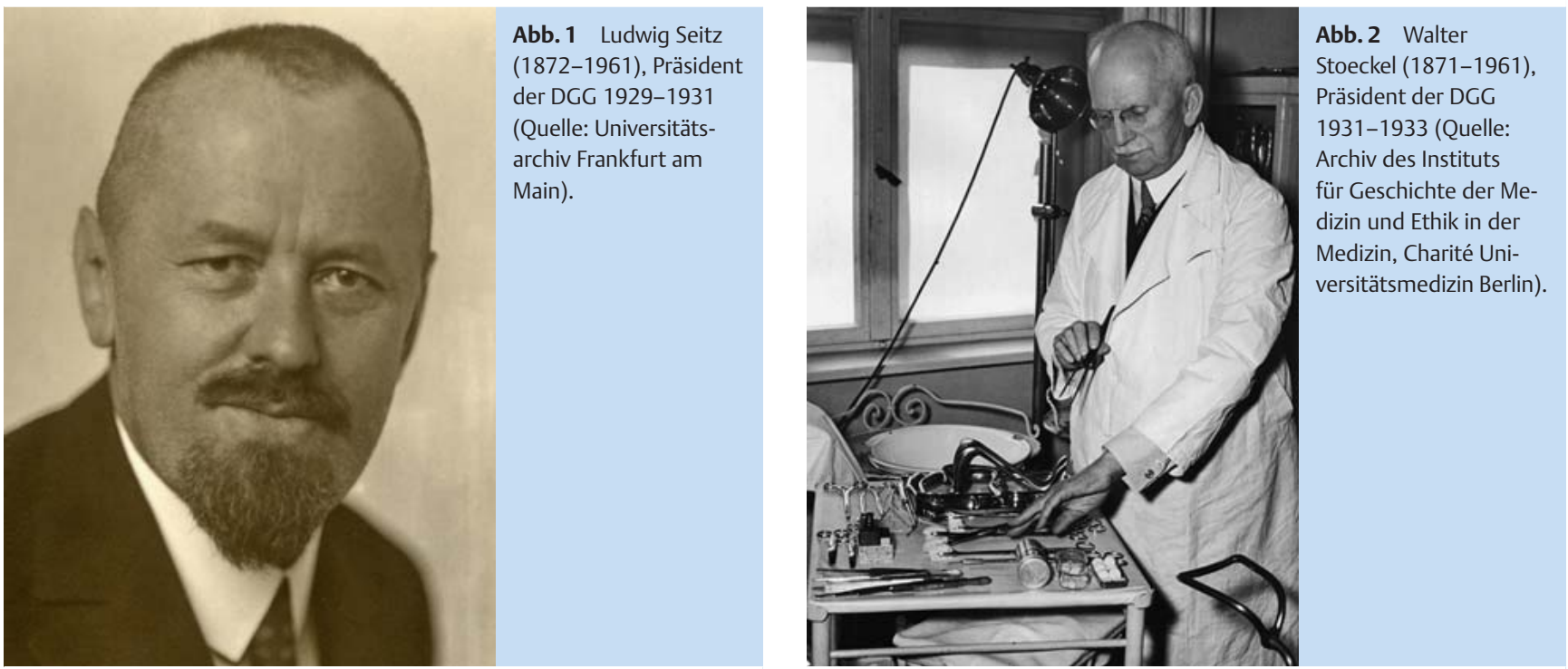

men. Dies ließ ihn, obschon nie Parteimitglied, nicht nur zu einem Helfershelfer, sondern sogar Förderer der verbrecherischen NS-Rassenpolitik werden: Er setzte sich massiv für die Legalisierung eugenischer Schwangerschaftsabbrüche ein.

Trotz dieses Engagements im Sinne des NS-Staates erschien Seitz den braunen Machthabern offenbar nicht so systemkonform, dass für ihn - wie etwa für Walter Stoeckel - eine Ausnahme von der Zwangsentpflichtung für Hochschullehrer an der Altersgrenze gemacht wurde. Er musste deshalb 1938 mit 66 Jahren die Emeritierung akzeptieren, blieb aber weiter publizistisch tätig. Die Leitung der UFK Frankfurt am Main übernahm sein Oberarzt Heinrich Guthmann, der 1937 in die NSDAP eingetreten war, als „Werkzeug des Gauleiters“ galt und zwischen 1940 und 1944 das Amt des Gaudozentenführers ausübte. ${ }^{48}$

Das wissenschaftliche Gesamtwerk von Seitz bereicherte fast alle Teilgebiete des Faches. Ein Schwerpunkt lag bei der damals aufstrebenden gynäkologischen Endokrinologie, zu der er 1913 auf dem DGG-Kongress in Halle ein großes, vielbeachtetes Referat erstattete, das später auch als Monografie erschien. ${ }^{49}$ Als Direktor der Erlanger Klinik erarbeitete Seitz ab 1914 zusammen mit seinem Schüler und Nachfolger im Amt, Hermann Wintz, wichtige technische und methodische Grundlagen der Strahlentherapie. Dazu gehörte auch eine spezielle Methode zur Behandlung von Gebärmutterhalskrebs, die in Analogie zu der berühmten Operation des Wiener Gynäkologen Ernst Wertheim die Mitbehandlung der Lymphabflussgebiete des erkrankten Organs vorsah (,Röntgen-Wertheim“). ${ }^{50}$

Als Seitz nach Frankfurt wechselte, hatte sich das Röntgeninstitut der Frauenklinik Erlangen internationalen Ruf als Forschungs- und Behandlungszentrum erworben. Diese radiologische Aufbauarbeit setzte Seitz in Frankfurt zusammen mit seinem noch in Erlangen speziell ausgebildeten Schüler Guthmann erfolgreich fort. Er realisierte dort gegen viele Widerstände einen adäquaten Ausbau der Strahlenabteilung und steigerte die Zahl der einschlägigen Behandlungen innerhalb von 12 Jahren fast um den Faktor 7 von 1090 auf $6300 .^{51}$

\section{Walter Stoeckel: „Praeceptor Gynaecologiae“}

Walter Stoeckel ${ }^{52}$ muss als die herausragende Persönlichkeit der deutschen Frauenheilkunde in der ersten Hälfte des 20. Jahrhunderts bezeichnet werden ( $\bullet$ Abb. 2). Seine jahrzehntelang nahezu unangefochtene Dominanz in den wichtigsten wissenschaftlichen Fachgesellschaften, seine stete Präsenz als Herausgeber von Fachzeitschriften und Autor erfolgreicher Lehr- bzw. Handbücher sowie seine Stellung als Leiter der bedeutendsten UFK des Landes und gesuchter Arzt der Prominenten wurde von keinem seiner Fachgenossen übertroffen. Das glanzvolle Bild, das viele seiner Kollegen, nicht zuletzt aber auch er selbst, ${ }^{53}$ von seinem Wirken gezeichnet haben, erfährt erst neuerdings eine kritischere Betrachtung. Hinterfragt werden vor allem Stoeckels Aktivitäten während des „Dritten Reiches“ im Kontext von NSUnrecht und -Verbrechen. ${ }^{54}$

Die Leistungen Stoeckels, der die traditionsreiche I. UFK Berlin von 1926 an rund 25 Jahre lang ohne Unterbrechung bis zu seiner Emeritierung am 1. August 1950 im Alter von fast 80 Jahren geleitet hat, sind in Geburtstagsartikeln, Nachrufen und medizinhistorischen Beiträgen vielfach beschrieben worden. ${ }^{55}$ In Letzteren ist man sich weitgehend einig darin, dass es vor allem die enorme, über Jahrzehnte währende Präsenz Stoeckels auf allen genannten Gebieten war, die ihn unter den Fachkollegen in der ers-

\footnotetext{
48 Vgl. Klee: Personenlexikon (2003), S. 211.

49 Seitz: Sekretion (1913).

50 Frobenius: Röntgenstrahlen (2003), S. 420-424.

51 Kleinert: Radium-Jubel (1988), S. 85.

52 Details zu biografischen Daten und Quellen in der Kurzbiografie im Anhang.

$53 \mathrm{Vgl}$. Anm. 38 (Autobiografisches von Stoeckel).

54 Schagen: Stoeckel (2010), S. 200-218; Doetz: Alltag (2011), S. 168-176; Czarnowski: Volkswachstum (2008), S. 133-150.

55 Vgl. Anm. 16.
} 


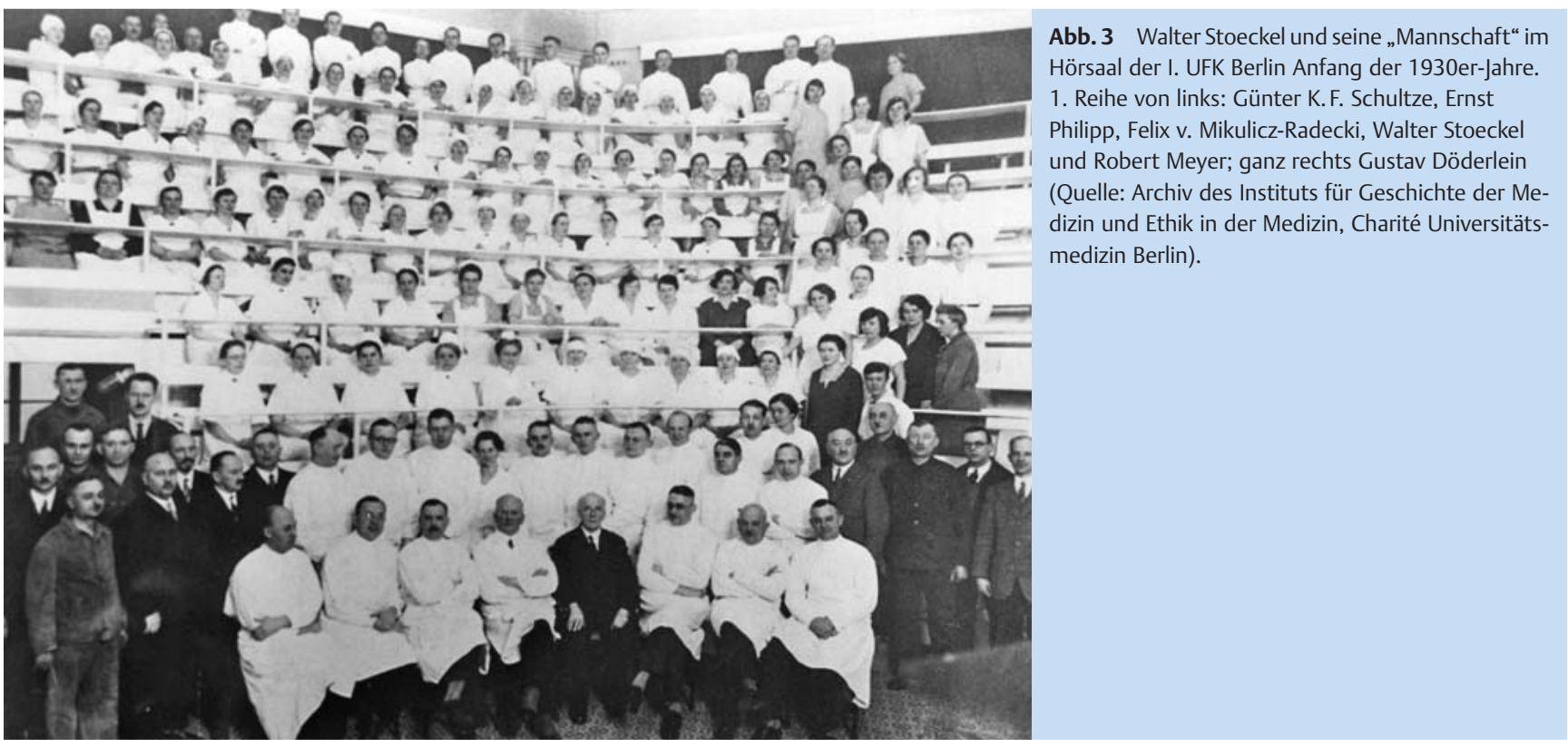

ten Hälfte des 20. Jahrhunderts zu einer Persönlichkeit von singulärer Dominanz werden ließ. Hinzu kamen seine Fähigkeiten als Operateur, die Sicherheit seines Auftretens, seine rhetorische und didaktische Begabung sowie seine Nähe zu den Mächtigen - vor allem im Nationalsozialismus, obwohl er nie der Partei angehörte. Wissenschaftliches Neuland hat er nicht betreten, wohl aber vieles institutionalisiert (wie die gynäkologische Urologie) und perfektioniert (wie bestimmte operative Techniken, z.B. die von Friedrich Schauta entwickelte radikale vaginale Hysterektomie).

Stoeckel hat sich selbst ${ }^{56}$, wie viele seiner Laudatoren und Biografen, als „unpolitisch“ dargestellt. Auch die DDR-Staatssicherheit konstatierte in einem auf „Ausführliche[n] Ermittlungen“ beruhenden Bericht aus dem August 1953: „[Walter Stoeckel] hat sich um politische Dinge wenig gekümmert. Heute steht er auf dem Boden der DDR und ist Nationalpreisträger I. Klasse 1952. Er hat einen guten Leumund. “57

Die Assistenten und Schüler Stoeckels Eine das Fach ein halbes Jahrhundert prägende Gestalt wie Walter Stoeckel lässt sich schließlich an ihren Schülern trefflich charakterisieren. Im Gegensatz zu seinem Counterpart Georg August Wagner in der Frauenklinik der Charité stand Stoeckel durch oder wegen seiner ärztlichen Mitarbeiterinnen und Mitarbeiter offenbar kaum im Fadenkreuz der Nationalsozialisten. Nach 3 frühzeitigen Entlassungen auf der Basis des „Gesetzes zur Wiederherstellung des Berufsbeamtentums“ konnte nur noch der „Nichtarier“ Robert Meyer, um dessen Verbleib Stoeckel sicher nicht nur aus altruistischen Motiven sehr bemüht war, als Stein des Anstoßes gelten.
Doetz zufolge lag bei den Assistentinnen und Assistenten die Quote der NSDAP-Mitglieder deutlich über dem entsprechenden Reichsdurchschnitt. Alle 6 Oberärzte zwischen 1933 und 1945 gehörten der Partei an. ${ }^{58}$

Ein nicht geringer Teil der Schüler Stoeckels hat sich inzwischen über bloße Parteimitgliedschaft und die Mitwirkung an Zwangssterilisationen hinaus als im Nationalsozialismus belastet erwiesen. Dies betrifft zum einen besonderes Engagement für die Ziele der NSDAP durch Mitarbeit in speziellen Gremien, zum anderen aber auch die Durchführung von bzw. die Mitwirkung an schon damals illegaler Forschung auf Kosten der Patientinnen im Rahmen von Maßnahmen zur NS-Eugenik. Percival Treite, einer der Berliner Assistenten, auf den Stoeckel besonders große Stücke hielt und für den er sich mehrfach einsetzte, wurde wegen seiner Tätigkeit als SS-Arzt im Frauen-KZ Ravensbrück nach dem Krieg von einem englischen Militärgericht zum Tod verurteilt. ${ }^{59}$

In der besonderen Gunst des Meisters standen außerdem Felix von Mikulicz-Radecki und Günter K.F. Schultze, die Stoeckel zusammen mit Ernst Philipp als „meine Ordinarien-Schüler“ bezeichnete $($ Abb. 3). Mikulicz-Radecki, Ordinarius in Königsberg, nutzte die Möglichkeiten der NS-Sterilisationsgesetzgebung für auch seinerzeit illegale Forschung an Sterilisandinnen auf der Basis nicht indizierter Hormonbehandlungen, Kürettagen und Röntgenuntersuchungen; 60 der SS-Brigadeführer Günter K.F. Schultze, zuletzt Ordinarius in Greifswald, dürfte seinen Probandinnen für Kontrastmitteluntersuchungen nach der eugenischen Sterilisierung ebenfalls kaum erklärt haben, dass diese nicht un-

\footnotetext{
56 Stoeckel: Leben (1954), S. 186.

57 BStU, MfS HA VIII IR FI (Stoeckel).

58 Doetz: Alltag (2011), S. 184-186. Die Vergleichszahlen für das Reich hat Doetz der Untersuchung von Kater: Doctors (1989), S. 252 entnommen. Bei den Oberärzten, von denen zunächst immer zeitgleich 2 in der Klinik tätig waren, handelte es sich um Günther Frommolt, Ernst Philipp, Günter K. F. Schultze, Paul Caffier und Günter Schäfer. 1941 wurde Helmut (Hellmuth) Kraatz zum dritten Oberarzt ernannt.

59 Details zu biografischen Daten und Quellen in der Kurzbiografie im Anhang.

60 Czarnowski: Beherrschung (2014), S. 234-237.
} 
gefährlichen und schmerzhaften Untersuchungen vom Gesetz nicht vorgesehen waren. ${ }^{61}$ Günther Frommolt, der Stoeckel bei der „Gleichschaltung“ der DGG unterstützte, war später an der Universität Halle Vertrauensmann der NSDAP sowie Mitglied des rassepolitischen Amtes und des Erbobergerichtes Naumburg. ${ }^{62}$ Und der Stoeckel-Oberarzt sowie spätere Chef der Brandenburgischen Landesfrauenklinik Benno Ottow darf wohl als der engagierteste Vollstrecker des Sterilisationsgesetzes unter den deutschen Gynäkologen bezeichnet werden. Nicht zuletzt ist das SS-Mitglied Hans Baatz zu erwähnen, der die Klinik von G.A. Wagner 1936 wegen Denunziationen verlassen musste, von Stoeckel aber offenbar in Gnaden aufgenommen wurde und später unter anderem in der NS-Dozentenschaft Karriere machte. ${ }^{63}$

Stoeckel und die Nationalsozialisten Über sein Verhältnis zum Nationalsozialismus und zum gesellschaftlichen Umgang mit den Mächtigen des „Dritten Reichs“ ( Abb.4) hat sich Stoeckel in seiner Anfang der 1950er-Jahre abgeschlossenen Autobiografie - womöglich aus einer gewissen Eitelkeit heraus erstaunlich offen und unbefangen geäußert. Das entsprechende Kapitel beginnt mit einer Distanzierung: „Ich bin immer ein unpolitischer Mensch gewesen und habe mich absichtlich und bewußt von der Politik ferngehalten...". Stoeckel begründet dies zum einen mit seiner persönlichen Entwicklung, in deren Verlauf er zwar Interesse für die „parlamentarischen Verhandlungen und insbesondere für die Reden der führenden Parteimänner“ entwickelt, sich aber nie für eine bestimmte politische Partei habe begeistern können. Zum anderen habe sich mit seiner Tätigkeit als Hochschullehrer in ihm ein Satz gefestigt, der „fast akademisches Gesetz“ sei: „Wissenschaft hat mit Politik nichts zu tun und soll sich von ihr fernhalten." Zudem breche die ärztliche Ethik zusammen, „wenn das ärztliche Fühlen und Handeln durch politische Antipathien beeinflußt und geschädigt werden kann“. 64

Es folgt die Beschreibung von Begegnungen mit Adolf Hitler, Joseph Goebbels und anderen hohen Repräsentanten des Regimes, die zumindest initial wohl deshalb zustande kamen, weil die Frau des Reichspropagandaministers, Magda Goebbels, langjährig Patientin Stoeckels war und ihre Kinder in dessen Klinik zur Welt brachte. Zu diesen Begegnungen kam es Stoeckel zufolge ab November 1932 im engsten Kreise - „[...] ich fand ihn [Hitler] neben dem Bett der Kranken [Frau Goebbels] sitzend...“-, aber auch im Rahmen kleinerer Gesellschaften - „[...] darunter war Himmler, der [...] wie ein friedlicher Volksschullehrer aussah“ - oder bei glanzvollen gesellschaftlichen Ereignissen der NS-Prominenz „Es war ,Alles‘ da, von der Universität aber außer Sauerbruch und uns [dem Ehepaar Stoeckel] niemand“. ${ }^{65}$

Die Begegnungen im kleinsten Kreis, so Stoeckel weiter, hätten dazu geführt, dass er „zunächst Herrn Hitler, und dann den Führer" menschlich besser kennen gelernt habe als manche Größe

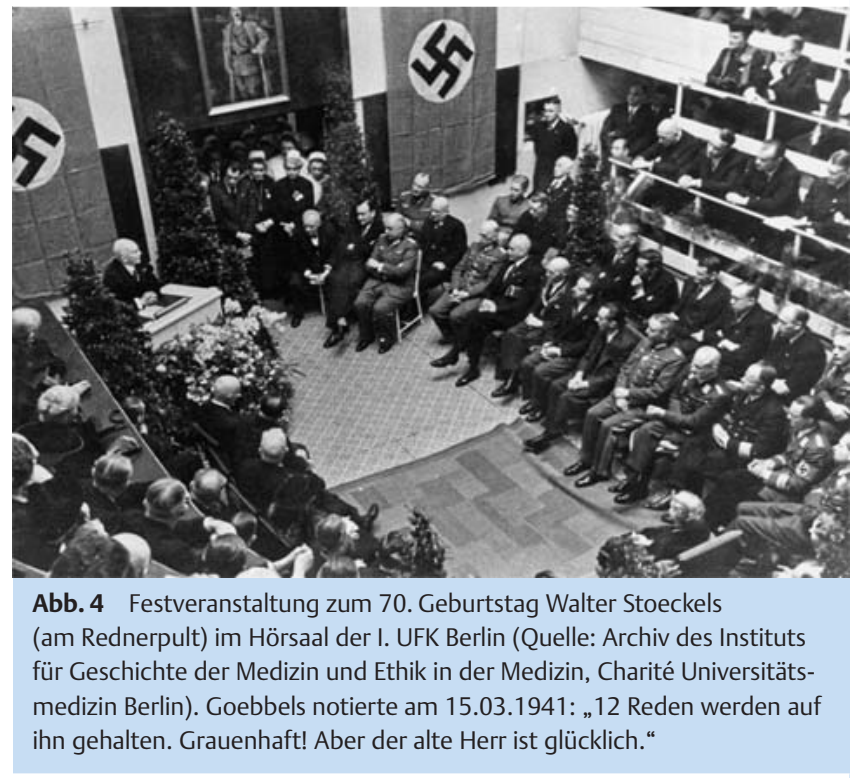

der Partei. Stoeckel machte dabei aus seiner zumindest anfänglichen Bewunderung keinen Hehl: „Bei jenem ersten Bekanntwerden hatte ich den sehr starken Eindruck bekommen, daß ich einen [sic] bedeutenden, edlen Menschen von größtem Format und einer überragenden, begeisternden Persönlichkeit gegenübergestanden hatte.“ Und an anderer Stelle: „Ich bin heute noch der Überzeugung, daß er damals ein von Idealen getragener Mann war, und daß der Verbrecher, als welcher er endete, erst im Lauf der Jahre durch seine Erfolge und durch die Menschen, die ihn verherrlichten und verhimmelten, allmählich heranwuchs." ${ }^{66} \mathrm{Im}$ Widerspruch dazu steht allerdings das zuvor geäußerte Eingeständnis Stoeckels, es sei „retrospektiv betrachtet“ ein großer Fehler gewesen, dass er vor seiner ersten Begegnung mit Hitler nichts über ihn gelesen habe. ${ }^{67}$ In der Biografie von 1966 schließlich bezeichnet Stoeckel seine positive Einschätzung Hitlers als „die schlimmste Fehldiagnose, die ich mir je geleistet habe“ . 68

Die Auseinandersetzung Stoeckels mit dem Nationalsozialismus folgt im Hinblick auf die Judenverfolgung und die Konzentrationslager dem in der Nachkriegszeit üblichen Narrativ. Besonders interessant im Zusammenhang mit der Geschichte der DGG erscheint, dass für Stoeckel auch im Rückblick der „aktive Antisemitismus“ erst „mit der Ansteckung der Synagogen und mit der Zerstörung der Judenläden“69 begann - also mit der Reichspogromnacht 1938, 5 Jahre nach dem Kongress, auf dem er als Vorsitzender der Gesellschaft die Verdrängung der jüdischen DGG-Mitglieder mit martialischem Vokabular im Namen der neuen Staatsführung gerechtfertigt hatte.

Diese Sicht der Dinge fügt sich nahtlos ein in die Aufzählung von mehreren positiv zu bilanzierenden Aspekten, die wohl Stoeckels

61 Vgl. Schultze: Röntgendiagnostik (1939), S. 194-200. Basisdaten zur Person in den Kurzbiografien im Anhang, ferner S. 66.

62 Eberle: Martin-Luther-Universität (2002), S. 87,119 f. Basisdaten zur Person in den Kurzbiografien im Anhang, ferner S. 26.

63 Zu Ottow und Baatz Kurzbiografien im Anhang mit Basisdaten zur Person. Ferner zu Baatz bei G. A. Wagner siehe S. 16.

64 Stoeckel: Leben (1954), S. 186. Den Nationalsozialismus positiv darstellende Passagen sucht man in den von Herausgebern bearbeiteten, späteren „Erinnerungen“ Stoeckels vergeblich; vgl. Stoeckel: Erinnerungen (1966).

65 Stoeckel: Leben (1954), S. 189; in den Tagebüchern von Joseph Goebbels wird Stoeckel von 1931 bis 1944 über 30 -mal erwähnt.

66 Ebd., S. 187.

67 Ebd., S. 186.

68 Stoeckel: Erinnerungen (1966), S. 360.

69 Stoeckel: Leben (1954), S. 191. 


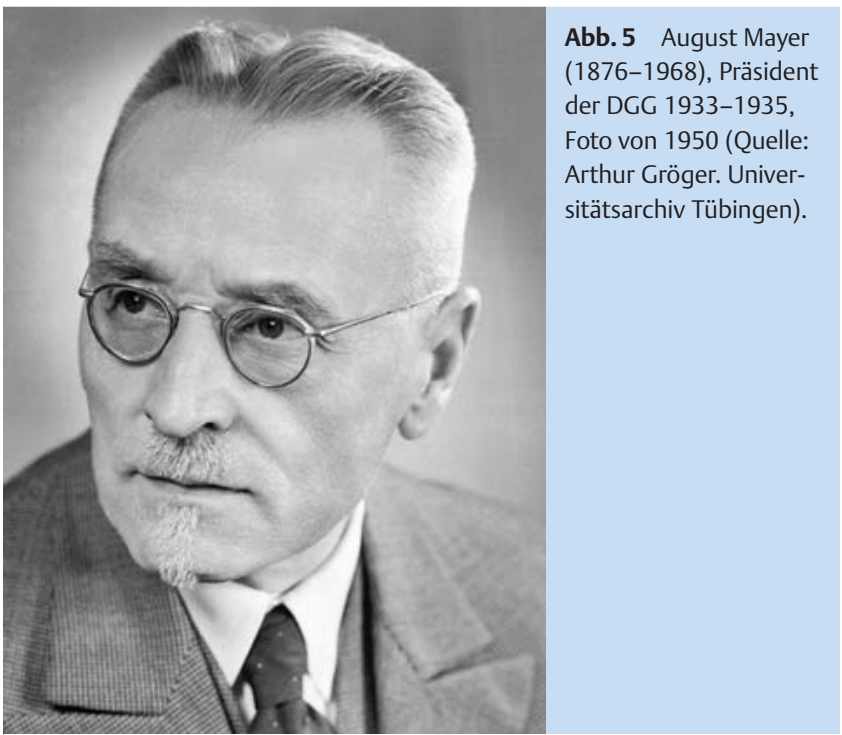

anfängliche Begeisterung rechtfertigen sollten. „Was mir am meisten imponierte“, schrieb Stoeckel und kennzeichnete damit sein antidemokratisches Staatsverständnis, „,war die rasche Beseitigung der Landeshoheiten und der politischen Parteien, einschließlich des Zentrums, dieses größten Feindes unserer nationalen Politik“. Daneben äußerte er Bewunderung dafür, mit welcher Furchtlosigkeit der Vertrag von Versailles zerbrochen worden sei, „ohne daß eine fremde Macht wagte, dem Einhalt zu gebieten“. Zwar bestehe kein Zweifel, dass dabei „Verlogenheit und bestellte Arbeit“ eine wichtige Rolle gespielt hätten. „Aber“, so fragte Stoeckel, „wann wäre das in der Politik anders gewesen? Ein ganz sauberes Geschäft war sie nie und wird sie nie werden“ ${ }^{70}$

Im Zusammenhang mit Kritik am Finanzgebaren des NS-Staates („Wo das Geld blieb [...], erfuhr niemand“) wird allerdings deutlich, dass der Zweck für Stoeckel durchaus die Mittel heiligen konnte: „Daß die Winterhilfe zum Bau des Westwalls verwendet wurde, hat Hitler später selbst mitgeteilt. Über solche zunächst getarnte Verwendung wird bei dem Ernst der Situation kein Verständiger ein Wort verlieren. Derartige Verschleierungen sind oft Kriegsgebot und Vorkriegsnotwendigkeit.“ Das Verhältnis des neuen Staates zu den Frauen war nach Stoeckel „nicht weit von Mißachtung entfernt [...], wenn auch sehr mit Recht die Gebärpflicht stark gefordert wurde“" ${ }^{71}$

Stoeckels Ehrungen in beiden Systemen Nachkriegsdeutschlands Nach dem Ende des Zweiten Weltkriegs und der Aufteilung Berlins unter den Siegermächten fand sich Stoeckel mit seiner Klinik, die fast völlig zerstört worden war, im sowjetischen Einflussbereich wieder. Seinen biografischen Aufzeichnungen ist zu entnehmen, dass er seine klinische Arbeit mit dem verbliebenen Personal, nunmehr bereits 74-jährig, über die Besetzung und Kapitulation hinaus nahezu ohne Unterbrechung fortsetzte.
Schon vor Wiedereröffnung der Universität im Januar 1946, zu der er in seinen Funktionen bestätigt wurde, hatte Stoeckel auch damit begonnen, „Bunkerseminare“ abzuhalten. Erst zum 1. September 1950 erfolgte seine Emeritierung. Stoeckels hohes Ansehen hatte in beiden deutschen Nachkriegsstaaten Bestand. $\mathrm{Zu}$ den vielen Ehrungen und Auszeichnungen kamen in den Nachkriegsjahren weitere, unter anderem von hochrangigsten Vertretern der beiden neuen politischen Systeme. ${ }^{72}$

Mit dem Anspruch Stoeckels, ein ganz der Wissenschaft verpflichteter, unpolitischer Mensch gewesen zu sein, hat sich schon Udo Schagen intensiv auseinandergesetzt. Er kommt dabei zu dem Ergebnis, dass Stoeckels ganzes Leben ihn als Wissenschaftler und Klinikdirektor ausweise, dem „politisches Denken und Handeln in der Realität zur zweiten Natur geworden war“. Dies sei belegt durch sein Handeln in vielfältigen Zusammenhängen, gegenüber Landes- und Reichsregierung, in den wissenschaftlichen Gesellschaften, durch sein gesundheitspolitisches Denken und seine entsprechenden, immer wieder auch öffentlichen Stellungnahmen. ${ }^{73}$

\section{August Mayer: der Verlegenheitspräsident}

August Mayer, Präsident der Tagung der DGG im Jahr 1935 und Direktor der UFK Tübingen von 1917 bis 1949, war ein Verlegenheitskandidat für den Vorsitz der Gesellschaft ( Abb. 5): Vor seiner Wahl auf dem Berliner Kongress 1933 teilte Walter Stoeckel der Mitgliederversammlung mit, eigentlich habe der Vorstand den Freiburger Ordinarius Otto Pankow nominieren wollen. Pankow sei jedoch schwer erkrankt, weshalb nun der „ebenfalls in Vorschlag gebrachte“ Mayer zur Wahl gestellt werde. ${ }^{74}$ Mayer selbst hat später immer wieder darauf hingewiesen, dass er das Amt nur auf heftiges Drängen von Stoeckel und Franqué übernommen habe - „aus Pflichtgefühl und nicht zur Mehrung meines persönlichen Ansehens oder zum persönlichen Erfolg““. ${ }^{75}$

Mayer gehört zu den gynäkologischen Ordinarien, deren Belastung durch ihr Verhalten im Nationalsozialismus erst Jahrzehnte nach dem Ende des Zweiten Weltkriegs für eine breitere Öffentlichkeit deutlich wurde. Zuvor hatten prominente Fürsprecherinnen wie die von Mayer behandelte Olga-Maria Gräfin von Stauffenberg dafür gesorgt, dass der Säuberungsausschuss der Universität Tübingen sowie die Spruchkammer ihn für entlastet erklärten und er seine Ämter als Ordinarius und Klinikdirektor in der Nachkriegszeit bis zu seiner Emeritierung behalten konnte. ${ }^{76}$

Mayer lässt sich als tief im Katholizismus verankerte, patriarchalische und streng konservative Persönlichkeit mit ausgeprägt monarchistisch-deutschnationaler Weltanschauung beschreiben. Insofern war er, will man Walter Jens in seiner Beschreibung der „Tübinger Gelehrtenrepublik“ folgen, ein typischer Vertreter seiner zeitgenössischen Kollegenschaft, ohne allerdings deren dort in der Weimarer Zeit sehr verbreiteten radikalen Antisemitismus zu teilen. ${ }^{77}$ Darüber hinaus fühlte sich Mayer, stark be-

\footnotetext{
70 Stoeckel: Leben (1954), S. 190.

71 Ebd., S. 191.

72 Stoeckel: Erinnerungen (1966), S. $600 \mathrm{f}$.

73 Schagen: Stoeckel (2010), S. 215.

74 Generalversammlung [Verhandlungen 1933] (1934), S. LII.

75 Vgl. z. B. UAT 150/33,41: Mayer an Menge (13.04.1935).

76 Zu Mayer existiert eine ausführliche Biografie: Doneith: Mayer (2008). Dieser Biografie wird hier gefolgt, falls Quellen nicht besonders gekennzeichnet sind.

77 Jens: Universität (1993), S. 324-333.
} 
einflusst von den sozialdarwinistischen Ansichten seines Lehrers Alfred Hegar, ${ }^{78}$ der Eugenik besonders verpflichtet. Dazu äußerte er sich in vielen Artikeln, Büchern und Vorträgen vor Fach-, aber auch vor Laienpublikum. Er wandte sich kategorisch gegen Abtreibungen, propagierte mit heute kaum nachvollziehbaren Formulierungen ein vaterländisch-patriarchalisches Frauen- sowie Mutterbild und zeigte sich schon Anfang der 1930er-Jahre in der damals geführten Diskussion als glühender Anhänger der eugenischen Sterilisation - im Zweifel auch gegen den Willen der Betroffenen.

Viele dieser über Jahre entwickelten Vorstellungen und Ideale konnte Mayer im Programm der Nationalsozialisten wiederfinden. Nach 1933 sah er deshalb gute Chancen, sie endlich zu verwirklichen. In diesen Bemühungen machte er sich jedoch mehr und mehr zum Werkzeug der braunen Machthaber. Dies wird auch bei der Organisation und Durchführung des von ihm präsidierten Kongresses der DGG 1935 in München deutlich, für dessen Erfolg er viele Kompromisse schloss. ${ }^{79}$ In Konfliktsituationen mit den Nationalsozialisten pflegte er gerne darauf hinzuweisen, dass er „als erster deutscher Gynäkologe“ für eugenische Sterilisierungen eingetreten sei. ${ }^{80}$

Insgesamt genoss Mayer als Klinikchef und Arzt nicht nur im Kollegenkreis, sondern auch bei den Hebammen und in der Bevölkerung einen hervorragenden Ruf. Seine wissenschaftlichen Leistungen werden nicht allzu hoch eingeschätzt, obwohl er sehr viel publiziert hat. Bemerkenswert erscheint im Rückblick allerdings sein Engagement für die Untersuchung psychosomatischer Einflüsse auf die Frauengesundheit.

\section{Georg August Wagner: im Fadenkreuz von NS-Aktivisten} Georg August Wagner, 1935 zum 1. Vorsitzenden der DGG gewählt und 1937 Präsident der dritten Tagung der Gesellschaft im Nationalsozialismus, zählt zu den bedeutendsten gynäkologischen Operateuren in der ersten Hälfte des 20.Jahrhunderts ( Abb. 6). Als Schüler von Ernst Wertheim hat er auch nach seiner Berufung an die Frauenklinik der Berliner Charité 1928 die chirurgische Technik seines österreichischen Lehrers gepflegt, ausgebaut und weitergegeben. Während der gesamten Amtszeit musste er sich gegen den dominanten Walter Stoeckel in der I. Berliner UFK behaupten - keine einfache Aufgabe, vor allem, wenn man das offenbar vergleichsweise eher zurückhaltende Naturell Wagners, seine Position als „ehemaliger Auslandsdeutscher"81 und seine wiederholten Schwierigkeiten mit Vertretern des NS-Regimes berücksichtigt. Neben dem Schriftführer Eduard Martin ist er wohl das DGG-Vorstandsmitglied gewesen, das von Denunziationen am meisten betroffen war.

Dass Wagner die Ziele der NS-Eugenik befürwortete, ist seinen Publikationen zu entnehmen. Er sprach aber auch von den Risiken der Operation. Als besonders versierter Operateur fühlte er sich dazu berufen, zur optimalen chirurgischen Umsetzung des „Gesetzes zur Verhütung erbkranken Nachwuchses“ (GzVeN)

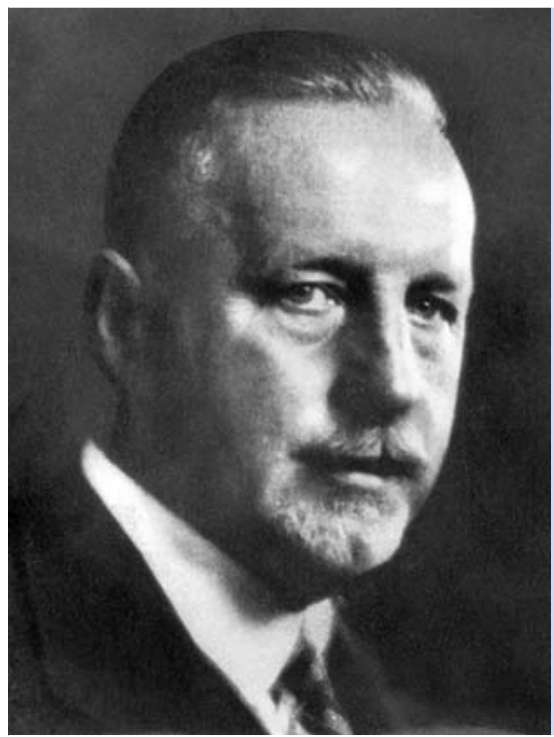

Abb. 6 Georg August Wagner (1873-1947), Präsident der DGG 1935-1937 (Quelle: Archiv des Instituts für Geschichte der Medizin und Ethik in der Medizin, Charité Universitätsmedizin Berlin).

Stellung zu nehmen und verschiedene Techniken auch im Film zu demonstrieren. ${ }^{82} \mathrm{Zu}$ den bei ihrer Umsetzung angewandten Zwangsmaßnahmen äußerte er sich wie viele seiner Kollegen höchstens indirekt. Die Röntgenkastration lehnte er ab. ${ }^{83}$ Über die Zahl der an der Charité durchgeführten Zwangssterilisationen und eugenischen Abtreibungen ist nichts Genaues bekannt.

$\mathrm{Zu}$ Wagner existieren mehrere biografische Skizzen und Nachrufe. ${ }^{84}$ Vor seiner Berufung nach Berlin hatte er (ab 1917) den Lehrstuhl an der Deutschen Universität Prag inne, den er trotz der zunehmend schwierigen politischen Situation der deutschen Hochschule nach Gründung der Tschechoslowakischen Republik im Jahr 1918 und des Angebotes der Wertheim-Nachfolge in Wien (1920) bis 1928 behielt. Der Wechsel zu Wagner im Direktorat der Frauenklinik der Charité vollzog sich offenbar gut geplant und reibungslos: Erich Bracht, der die Klinik nach dem Tod von Karl Franz kommissarisch geleitet hatte, trat die Chefarztstelle der gynäkologisch-geburtshilflichen Abteilung am Krankenhaus Berlin-Wilmersdorf an; Bernhard Zondek, bereits seit 1919 an der Charité tätig und damals durch die endokrinologischen Arbeiten mit seinem Konassistenten Selmar Aschheim gerade auf dem Weg zu Weltruhm, wurde auf Wunsch Wagners zum Oberarzt ernannt. Den Wagner'schen „Stil“ etablieren sollte Paul Klein, ein habilitierter Assistent der Prager Klinik, den der künftige Klinikchef zu diesem Zweck vorausgeschickt hatte. ${ }^{85}$

Zondek, Aschheim und Klein waren jüdischer Herkunft. Zum Zeitpunkt der Machtübernahme hatten Zondek und Klein die Klinik allerdings bereits verlassen: Klein war - wie vorher verabredet - nach 3 Semestern in Berlin nach Prag zurückgekehrt, Zondek hatte die Chefarztposition an der geburtshilflich-gynäkologischen Abteilung des Städtischen Krankenhauses in BerlinSpandau übernommen. Der in der Charité verbliebene Aschheim

\footnotetext{
78 Seidler: Fakultät (1993), S. 218-221; ferner zu Hegar, einem der bedeutendsten deutschen Frauenärzte: Ludwig: Hegar (2004).

79 Siehe hierzu S. 44-48.

80 UAT 335/73, Brief Mayer an das Innenministerium in Berlin (13.09.1934).

81 Wagner: Eröffnungs-Ansprache [Verhandlungen 1937] (1938), S. 1.

82 Vgl. hierzu die Demonstration auf dem Kongress von 1935: Arch Gyn 161 (1936), S. 461 f.

83 Wagner: Technik (1934), S. 90.

84 Ebert/David: Wagner (2014); Ulrich/Ebert: Wagner (1994); vgl. auch die Kurzbiografie im Anhang.

85 GStAPK Berlin, I.HA, Rep. 76A, Kultusministerium, Va, Sekt. 2, Tit. IV, Nr. 46, Bd. 26, Bl. 8.
} 
schien zunächst durch den „Frontkämpferparagraphen“ geschützt; 1935 wurde jedoch auch er seines Amtes enthoben und verlor die Lehrerlaubnis. Daran konnte eine Intervention von G.A. Wagner nichts ändern, in der er die Verdienste Aschheims schilderte und ihn als für die Charité nahezu unersetzlich bezeichnete. Letztlich blieb Aschheim 1936 nur die Emigration. Zondek hatte Deutschland bereits 1933 verlassen. ${ }^{86}$

Denunziationen und Intrigen Wagners Schwierigkeiten mit Sympathisanten bzw. Vertretern des NS-Regimes waren vermutlich vor allem das Produkt seiner in vielerlei Hinsicht vergleichsweise liberalen Grundeinstellung, die sich unter anderem aus Erfahrungen seiner Prager Zeit ergab, und der Bemühungen junger Ärzte, aus den geänderten politischen Machtverhältnissen für sich Kapital zu schlagen. So warf Ende 1932 der abgelehnte Stellenbewerber Heinrich Günther in einer Eingabe an das Innenministerium Wagner vor, in seiner Klinik bevorzugt Ausländer zu beschäftigen. Damit würden „Reichsdeutsche“ benachteiligt und die Patientinnen müssten Behandlungen durch „Fremdrassige“ ertragen. Wagner war deshalb bis zum März 1933 wiederholt genötigt, sich in ausführlichen Stellungnahmen zu rechtfertigen. Schließlich stellte das Kultusministerium fest, Wagner habe „formell“ korrekt gehandelt. Dennoch verschaffte das Ministerium Günther - offenbar mit sanftem Druck - eine Ersatzstelle an der Universität Bonn bei dem Internisten Max Bürger, um „dies in Wahrheit geschehene Unrecht wieder gutzumachen“. 87

Fast zur gleichen Zeit - im April 1933 - attackierte der damalige Staatskommissar und spätere Reichsärzteführer Leonardo Conti den Klinikchef. Er übermittelte dem Kultusministerium eine Denunziation von Wagners tschechischer Ehefrau durch einen Parteigenossen: Die „glühende Deutschenhasserin“ habe „vor einiger Zeit“ ihr Dienstmädchen als „deutsche Schlampe“ und „deutsches Schwein“ beschimpft. Von Wagner selbst, so hieß es weiter, sei ja bekannt, dass er sich „neuerdings dauernd wegen der von ihm angestellten jüdischen Assistenzärzte verantworten muss““ ${ }^{88}$ Conti erklärte in seinem Begleitschreiben, ihm sei Wagners „,öllig minderwertige politische Einstellung und auch seine menschliche Minderwertigkeit [...] seit langem bekannt“. Der gleichzeitig dringend geäußerte Wunsch, „gerade in diesem Falle, obgleich es sich um einen Nichtjuden handelt“, eine Entlassung Wagners nach dem NS-Berufsbeamtengesetz zu prüfen, hatte aber offenbar keine Konsequenzen. ${ }^{89}$

1936 sahen sich Wagner und sein damaliger Oberarzt Carl Kaufmann heftigen Angriffen durch Hans Baatz ausgesetzt. Baatz, ${ }^{90}$ seit 1933 Mitglied der SS, war von Wagner 1932 als außerplanmäßiger Assistent in der Frauenklinik der Charité angestellt worden. Im Juni 1936 lehnten Wagner und Kaufmann eine von Baatz vorgelegte Habilitationsarbeit zur Krebsforschung qualitativer
Mängel wegen ab. Wagner äußerte sich dabei in einer Weise, die das SS-Mitglied besonders getroffen haben dürfte. Er sprach von „Hochstapeleien in einer Arbeit“ die seiner Ansicht nach „des nordischen Menschen unwürdig“ seien. Baatz drohte seinem Chef Wagner daraufhin, dass er „eine Untersuchung der Angelegenheit bei seiner Schutzstaffel veranlassen und bis nach München" gehen würde. ${ }^{91}$

Baatz ventilierte dann Vorwürfe gegen Kaufmann wegen angeblichen „geistigen Diebstahls“. Tatsächlich war eine entsprechende Anzeige beim Ministerium eingegangen, ein Verfahren wurde dort allerdings nie eröffnet, da „der Vorwurf einer bewussten Verletzung fremden geistigen Eigentums nicht erhoben werden“ könne. ${ }^{92}$ Im Januar 1937 kam das Reichserziehungsministerium nach einer Untersuchung zu dem Ergebnis, dass die Vorwürfe von Baatz unbegründet seien und sich vielmehr Baatz in der Affäre einer groben Pflichtverletzung schuldig gemacht habe, die seinen Verbleib in der Klinik unmöglich mache. Baatz war zu diesem Zeitpunkt nach Beurlaubung bereits gekündigt worden.

Der weiteren Karriere von Baatz, der 1937 auch der NSDAP beitrat, tat dies jedoch keinen Abbruch. Er wechselte in die I. UFK zu Walter Stoeckel und widmete sich weiter der Krebsforschung, die auch mit Drittmitteln gefördert wurde. ${ }^{93}$ Daraus erwuchs seine Habilitationsschrift über „Beziehungen zwischen dem Krebswachstum und dem inkretorischen Milieu“94 - also dem Thema nach die von Wagner abgelehnte Arbeit. Angenommen wurde die Arbeit am 7. Januar 1938 in Bonn, dort als Sonderabdruck aus der „Monatsschrift für Geburtshülfe und Gynäkologie“ publiziert. Es fällt ins Auge, dass die Wünsche beider bei Wagner in Ungnade gefallener Kandidaten - des nicht als Assistent eingestellten Heinrich Günther und des verhinderten Habilitanden Baatz - in Bonn befriedigt wurden, ohne dass der Zusammenhang an dieser Stelle abschließend geklärt werden kann.

Das Verhältnis Stoeckel - Wagner Das Verhältnis zwischen Wagner und Stoeckel ist mehrfach beschrieben worden - zunächst vor allem unter dem Aspekt der Beziehungen zwischen der Wiener und der Berliner operativen Gynäkologie, ${ }^{95}$ dann eher vergleichend mit Blick auf die unterschiedliche wissenschaftliche Leistung der Kliniken der beiden Protagonisten. ${ }^{96}$ Herangezogen wurden dazu neben fachbezogenen wissenschaftlichen Publikationen und Nachrufen auch Informationen aus dem sehr umfänglichen autobiografischen Nachlass von Stoeckel. Wagner, von dem nur eine 13-seitige, maschinengeschriebene autobiografische Skizze aus dem Jahr 1943 existiert, hat sich dazu nicht geäußert. ${ }^{97}$

\footnotetext{
${ }^{86} \mathrm{Hinz} /$ Ebert/Goetze: Exodus (1994). Zum „Frontkämpferparagraphen“ siehe S. 79 f. der vorliegenden Arbeit.

87 BArch Berlin, R 4901, Nr. 1347; Forsbach: Bonn (2006), S. 153.

88 GStAPK Berlin, I. HA, Rep. 76A, Kultusministerium, Va, Sekt. 2, Tit. IV, Nr. 46, Bd. 29, Bl. 568.

89 Ebd., Bl. 567.

90 Vgl. Grüttner: Lexikon (2004), S. 16 f.; Dietrich: Nachruf (1996).

91 BArch Berlin, R 4901/1347 Acta betr. Die Frauenklinik der Charité, Bd. V: Januar 1930 bis Dezember 1936.

92 BArch Berlin, R 4901/1348 Acta betr. die Frauenklinik der Charité, Bd. VI: Januar 1937 bis November 1942.

93 Moser: Forschungsgemeinschaft (2011), S. 171. In einem Nachruf heißt es, Baatz habe bei Stoeckel das „Institut für experimentelle Krebsforschung“ geleitet; vgl. Dietrich: Nachruf (1996).

94 Baatz: Beziehungen (1938); vgl. Jahresverzeichnis der deutschen Hochschulschriften 1938, S. 93.

95 Richter: Beziehungen (1986).

96 Ulrich/Ebert: Wagner (1994), S. 198.

97 Die Verfasser danken Prof. Dr. Matthias David, Berlin, für die Überlassung einer Kopie.
} 
Ein kritischer Punkt in der Beziehung waren zunächst die Umstände der Berufung Wagners, bei der Stoeckel in einem Vorschlag für die Fakultät nach eigenen Angaben „in Deutschland tätige Professoren vor ihn [Wagner] gestellt" hatte. Wagner wusste das, denn Stoeckel hatte ihn darüber informiert, gleichzeitig aber betont, er sei nun mit der Wahl der Fakultät einverstanden und hoffe auf gute Zusammenarbeit. ${ }^{98}$ Hinzu kam, dass Wagner in den folgenden Jahren mit ansehen musste, wie die Stoeckel'sche Klinik aufwendig renoviert wurde, während der ihm zugesagte Klinikneubau ausblieb. An Letzterem änderten auch neuere Versprechungen nichts, die anlässlich von Bleibeverhandlungen 1931 gegeben wurden, als Wagner einen Ruf nach Wien auf den ehemaligen Schauta-Lehrstuhl erhalten hatte.

Stoeckel, der sich damals als Dekan für den Verbleib Wagners einsetzte, will von seiner Seite aus alles getan haben, um ein gutes Verhältnis zu Wagner herzustellen. Der Ton, den er dazu in seiner Autobiografie anschlägt, spricht allerdings Bände:

„Ich vermied peinlichst alles, was ihn in den Hintergrund hätte drängen können, suchte bei jeder Gelegenheit zu zeigen, dass unsere Kliniken gleichwertig seien, ihm zu Ehrungen, zum gemeinsamen Berliner Kongress, zur schnellen Publikation seiner und seiner Schüler Arbeiten zu verhelfen, - ich gab ihm meinen Assistenten Gustav Döderlein, als er einen Oberarzt brauchte. Aber es war und blieb doch so, dass er sich gynäkologisch immer als Nummer zwei fühlte und das konnte und wollte er nicht schlucken.“99

Richter resümiert in seiner Analyse, bei Wagner fänden sich keine Hinweise auf ein ähnliches Konkurrenzdenken. Es sei anzunehmen, dass er es neben Stoeckel nicht immer leicht gehabt habe. „Wollte man die damaligen Beziehungen zwischen den beiden Schulen auf eine Kurzformel bringen, könnte man sie als eine kühle, doch fachlich uneingeschränkte gegenseitige Hochachtung charakterisieren."100 Ulrich und Ebert meinen, Stoeckel habe sich mit der Berufung Wagners abgefunden, obwohl er nicht dafür gewesen sei. Insgesamt habe er sich Wagner gegenüber „wohl doch recht kollegial“ verhalten: „Man war durchaus andere Töne von ihm gewohnt." Hinsichtlich der wissenschaftlichen Leistung habe die Stoeckel'sche Klinik auf gynäkopathologischem Gebiet, die Wagner'sche dagegen auf endokrinologischem Gebiet dominiert. ${ }^{101}$

Ungeklärt bleibt einstweilen die Frage, ob und welche aktive Rolle Stoeckel beim Wechsel des von Wagner geschassten Baatz gespielt hat - klar ist dagegen, dass weder Wagner noch Kaufmann dessen Wechsel an Stoeckels Klinik als vertrauensbildende Maßnahme auffassen konnten. Die Frage nach den treibenden Kräften kann auch im Zusammenhang mit den Aktivitäten gestellt werden, die Wagner nach Erreichen der Altersgrenze und seiner Entpflichtung 1938 möglichst rasch endgültig aus seinem Amt ent- fernen und dabei auch Kaufmann loswerden wollten. Während Wagner selbst, die Fakultät und zunächst auch die NSDAP (,in politischer Hinsicht keine Bedenken“) ${ }^{102}$ einer Verlängerung seiner Tätigkeit im Sinne einer Vertretung positiv gegenüberstanden, trat bei Letzterer im Juni 1939 plötzlich ein Sinneswandel ein: Die Reichsdozentenführung, so hieß es, habe schon wiederholt zum Ausdruck gebracht, dass eine derartige Maßnahme grundsätzlich nur als Anerkennung für besondere Verdienste infrage komme. Sie sei „weder bei Wagner noch bei Kaufmann notwendig bzw. erwünscht“. ${ }^{103} \mathrm{Zu}$ diesem Zeitpunkt war - wie erwähnt - Hans Baatz als Sonderbeauftragter des Reichsdozentenführers tätig.

Als im Sommer 1944 unter den Dekanen der medizinischen Fakultäten nochmals die Ablösung der überalterten Hochschullehrer diskutiert wurde, erklärte sich Wagner prinzipiell zum Rücktritt bereit - allerdings mit folgender Einschränkung: „Keinesfalls möchte ich, dass ich etwa als Einziger unserer Fakultät abtrete. Ich erwarte, dass gegebenenfalls die anderen überalterten Kollegen in gleicher Weise wie ich ihre Stelle freimachen." ${ }^{104}$ Es darf angenommen werden, dass diese Bemerkung vor allem in Richtung Stoeckel zielte, der knapp 2 Jahre älter war, sich mit dem Regime besser arrangiert hatte und auf Wunsch des „Führers“ verlängert worden war. ${ }^{105}$

Alle Bemühungen, Wagner und Kaufmann aus ihren Ämtern zu entfernen, waren jedoch - sicherlich auch kriegsbedingt - bis zum Ende des NS-Regimes erfolglos: Wagner blieb Klinikchef. Allerdings wurde er - nunmehr über 70 Jahre alt und von Knie- und Beinbeschwerden geplagt - zunehmend von Kaufmann vertreten. Nach Kriegsende übertrug man Kaufmann vertretungsweise die Klinikleitung, bis er 1946 einen Ruf nach Marburg annahm. Wagner wurde zu seinem 70. Geburtstag am 23. September 1943 die Goethe-Medaille des „Führers“ verliehen. Er starb am 15. August 1947 in Garmisch-Partenkirchen, wohin er sich gegen Ende des Krieges zurückgezogen hatte. In der unmittelbaren Nachkriegszeit war er kurzzeitig noch als kommissarischer Leiter der I. UFK München im Gespräch gewesen, als deren Direktor Heinrich Eymer von den Amerikanern vom Dienst suspendiert worden war. ${ }^{106}$

Ungeachtet der Differenzen mit NSDAP-Gliederungen wie der Reichsdozentenführung war Wagner für das Regime aber auch in offiziellen Missionen tätig. ${ }^{107}$

\section{Hans Fuchs: ein politischer Präsident?}

Hans Fuchs, bei seiner Wahl zum Vorsitzenden der DGG 1937 ordentlicher Professor an der Akademie für praktische Medizin in Danzig, wurde nicht zuletzt aus politischen Gründen zum Präsidenten ( Abb. 7): „Wir wollten mit seiner Wahl ihn ehren und zugleich ein Treuebekenntnis zu dem damals von Polen schi-

\footnotetext{
98 Stoeckel: Leben (1954), S. 115.

99 Ebd., S. 115.

100 Richter: Beziehungen (1986), S. 293.

101 Ulrich/Ebert: Wagner (1994), S. 198.

102 BArch Berlin, BDC, DS A 0072, 1410; Brief der NSDAP, Stellvertreter des Führers, Stab, München, an den Wissenschaftsminister (15.04. 1939).

103 BArch Berlin, BDC, DS A 0072, Bl. 1416; Brief der Reichsdozentenführung an das Reichserziehungsministerium, Prof. Bach (26.06. 1939).

104 Ebd., Bl. 1476 [Dekan der Med. Fak. zitiert Wagner in einem Schreiben an das Wissenschaftsministerium vom 08.08. 1944].

105 BArch Berlin, BDC, DS B 0042; Goebbels: Tagebücher I, 3/II, S. 42 (15.03.1936).

106 Frobenius: Wiederbesetzung (2012), S. 165.

107 Siehe hierzu S. 34f.
} 


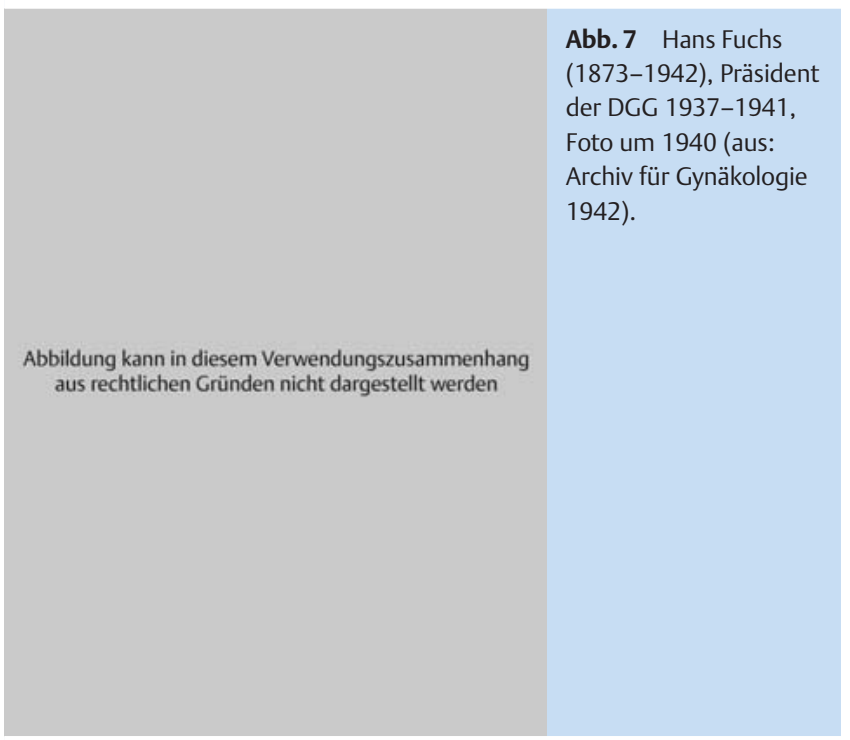

kanierten und bedrohten Danzig ablegen“, schrieb Walter Stoeckel in einem Nachruf. ${ }^{108}$ Ähnlich äußerte sich auch G.A. Wagner, der seinen damaligen Vorschlag von Fuchs für den Vorsitz damit begründete, dass jener nicht nur ein hervorragender Vertreter des Faches, sondern auch „Kämpfer um Deutschtum und deutsche Geistesarbeit auf feindbedrängtem Posten“ sei. ${ }^{109}$ Allerdings war schon damals „aus technischen Gründen“ nicht Danzig, sondern Berlin als Kongressort gewählt worden - letztlich sollte es dann Wien werden, und zwar auch nicht 1939, sondern erst $1941 . .^{110}$

Insgesamt ist über den „politischen“ Hans Fuchs allerdings wenig bekannt. Akten zu seiner Person und seiner Amtsführung zwischen 1930 und 1939 als Direktor der Staatlichen Frauenklinik Danzig bzw. als Professor der Medizinischen Akademie ließen sich nicht nachweisen. ${ }^{111}$ Die Spuren seiner Tätigkeit als Direktor der Gaufrauenklinik Posen von 1939 bis zu seinem Tod 1942 sind bisher rudimentär. ${ }^{112}$ Sicher ist allerdings, dass Fuchs das „Gesetz zur Verhütung erbkranken Nachwuchses“ befürwortete, eine eigene Methode zu seiner chirurgischen Umsetzung entwickelte und dass unter seiner Leitung zumindest an der Staatlichen Frauenklinik Danzig Zwangssterilisationen durchgeführt wurden. ${ }^{113}$ Einer seiner Schüler, Boris Belonoschkin, benutzte - sicherlich mit Wissen seines Lehrers - Organe von Leichen hingerichteter Männer für reproduktionsmedizinische Untersuchungen. ${ }^{114}$
Wie sich zeigen wird, muss Fuchs zu den schwachen Präsidenten der DGG gezählt werden. So versäumte er es offensichtlich, dafür zu sorgen, dass die Gesellschaft in der seit der Machtübernahme schwelenden Auseinandersetzung mit Funktionären des Regimes um die Haus- bzw. Klinikgeburtshilfe belastbares Zahlenmaterial zur Unterstützung ihrer Argumentation in die Hand bekam: Die nach seiner Wahl 1937 auf dem Kongress beschlossene Einsetzung eines Ausschusses für entsprechende Untersuchungen blieb offenbar folgenlos - ein Umstand, der sich später bei der Eskalation der Auseinandersetzungen sehr negativ bemerkbar machte. Auch während der Zuspitzung der Situation 1939/40 mussten andere initiativ werden. ${ }^{115}$ Mögliche Gründe liegen in der besonderen Situation von Fuchs, dessen Amtszeit eigentlich schon 1939 hätte enden sollen.

Hans Fuchs gehört zu den Ende des 19. und Anfang des 20. Jahrhunderts nicht seltenen Gynäkologen, die jenseits der Universitäten erfolgreich Privatkliniken etablierten, dort Forschung betrieben, deren Ergebnisse in angesehenen Fachzeitschriften publizierten und auf dieser Basis in fortgeschrittenem Lebensalter noch akademische Karrieren beginnen konnten. 1873 in Berlin als Sohn eines Musikprofessors geboren, wuchs er in Danzig auf und besuchte dort auch das Gymnasium. Nach dem Medizinstudium in Breslau, Freiburg im Breisgau und Berlin wurde Fuchs 1896 in Würzburg promoviert und im Folgejahr auch approbiert. Seine Fachausbildung absolvierte er ab 1898 in der UFK Kiel bei Richard Werth. 1903 verließ er die Klinik, um sich in Danzig als Frauenarzt niederzulassen - er hatte eine Tochter seines akademischen Lehrers geheiratet und wollte sich nicht dem Vorwurf des Nepotismus aussetzen. ${ }^{116}$

Im Zuge seiner Niederlassung gründete Fuchs die erwähnte Privatklinik, die sich in den folgenden fast 3 Dekaden sehr erfolgreich entwickelte und ihn - wie Stoeckel in seinem Nachruf schrieb - zum „führenden Gynäkologen Westpreußens bis weit in das damalige Polen hinein werden ließ“. ${ }^{117}$ Ein Blick in das Publikationsverzeichnis von Fuchs zeigt, dass in dieser Zeit mehr als die Hälfte seiner fast 100 Arbeiten entstanden ist. ${ }^{118}$ Gleichzeitig engagierte er sich berufspolitisch und in wissenschaftlichen Fachgesellschaften: Er war lange Jahre Vorsitzender des Ärztlichen Vereins in Danzig sowie Mitbegründer und Vorsitzender der Nordostdeutschen Gesellschaft für Gynäkologie. ${ }^{119}$

Nachdem 1929 der langjährige Leiter der Hebammenlehranstalt Danzig, Rudolf Köstlin, in den Ruhestand getreten war, wurde Fuchs 1930 zu ihrem Direktor berufen. Er baute sie zu einer zeitgemäßen Frauenklinik aus. 1931 zum Professor ernannt, setzte

\footnotetext{
108 Stoeckel: Fuchs [Nachruf] (1942) S. 1907. Danzig war mit dem Vertrag von Versailles vom Deutschen Reich abgetrennt und 1920 unter internationaler Kontrolle zu einem eigenen Staat geworden (Freie Stadt Danzig). 1939 kam die Stadt mit dem Überfall auf Polen wieder zum Deutschen Reich.

109 Wagner: Fuchs [Nachruf] (1942) S. 355.

110 Mitgliederversammlung [Verhandlungen 1937] (1938), S. 19.

111 Die Findbücher des Staatsarchivs Danzig weisen keine Unterlagen zur Staatlichen Frauenklinik aus. Die Überlieferung dazu ist offensichtlich verloren gegangen. Ebenso wenig existiert ein Personalakt zu Fuchs in den Akten der Medizinischen Akademie Danzig. Der vorhandene Bestand bezieht sich vor allem auf die Jahre 1941-1944.

112 Die Findmittel im Staatsarchiv Posen geben nur im Bestand 301 (Gauselbstverwaltung Posen) unter der Signatur 2159 einen Hinweis auf Prof. Hans Fuchs. Der entsprechende Akt enthält hier zitierte Korrespondenz zu den UK-Stellungen der Assistenten von Fuchs.

113 Fuchs: Tubensterilisierung (1935).

114 Belonoschkin: Biologie (1942). Zur Biografie und wissenschaftlichen Bedeutung von Belonoschkin siehe Mildenberger: Tintenfische (2005-2007).

115 Siehe hierzu S. 32-34.

116 Lebensdaten zu Fuchs stammen außer aus den zitierten Nachrufen aus GK 1928 und 1939 sowie GW 1956, S. 152.

117 Stoeckel: Fuchs [Nachruf] (1942), S. 1906.

118 GK 1939, S. 121-123.

119 Wagner: Fuchs [Nachruf] (1942), S. 355
} 
sich Fuchs vehement für die Gründung einer Medizinischen Akademie in Danzig ein, die 1935 auch tatsächlich realisiert wurde. Fuchs wurde dort zum Ordinarius für Frauenheilkunde berufen. Als Praesidens electus der DGG für den ursprünglich 1939 geplanten Kongress wurde seine Amtszeit an der Akademie über die Altersgrenze hinaus verlängert, die er 1938 erreicht hatte.

Vergebliches Hoffen auf ein Ordinariat an der „Reichsuniversität Posen“ Nach der Besetzung Polens 1939 übertrug man Fuchs jedoch die Leitung der durch Fliegerbomben erheblich zerstörten Gaufrauenklinik und Hebammenlehranstalt im rund 300 Kilometer entfernten Posen. „Ohne Häuslichkeit, ohne ausreichende Zahl von Ärzten und Pflegepersonal begann er, während seine Söhne als Soldaten draußen waren, die unter den Polen verkommene Klinik wieder aufzubauen“, schrieb Wagner in seinem Nachruf. ${ }^{120}$ Eine attraktive Perspektive lag für Fuchs offenbar darin, dass die Klinik der Medizinischen Fakultät der damals im Aufbau befindlichen „Reichsuniversität Posen“ angegliedert werden sollte, die die Nationalsozialisten zu einer Vorzeigeinstitution formen wollten. Der Stellenplan der Klinik mit 380 Betten, rund 1800 Geburten und 705 großen gynäkologischen Operationen sah 1941 neben dem Chef, seinem Vertreter und einem zweiten Oberarzt 8-10 Assistenten vor, war jedoch kriegsbedingt nicht voll besetzt. ${ }^{121}$ Für Fuchs sollte sich die Hoffnung auf ein Ordinariat an der Universität jedoch nicht erfüllen. Kurz vor seinem Tod am 28. Oktober 1942 wurde er wegen seines Alters nur zum Honorarprofessor ernannt. Im Übrigen kam es im Nationalsozialismus an der „Reichsuniversität Posen“ wegen des Kriegsverlaufes offenbar nie zur Aufnahme eines regulären klinischen Lehrbetriebes für die Frauenheilkunde. ${ }^{122}$

In den Jahren von 1939 bis zu seinem Tod war Fuchs offenbar ständig unterwegs. Seine Familie war in Danzig geblieben, in Posen arbeitete er als Klinikchef und wegen organisatorischer Fragen im Zusammenhang mit dem mehrfach verschobenen DGGKongress pendelte er nach Berlin und Wien. Davon zeugen Reiseabrechnungen für die DGG, aber auch Vertretungen in Posen, für die der erwähnte Schüler von Fuchs, Boris Belonoschkin, als sein erster Oberarzt zuständig war. ${ }^{123}$ Belonoschkin hatte 1934 in Danzig als Assistent bei Fuchs eine geburtshilflich-gynäkologische Ausbildung begonnen und ihn dann nach Posen begleitet.

Fuchs hatte sich schon in den 1920er-Jahren mit reproduktionsmedizinischen Fragen befasst. So publizierte er 1926 über durch Verschluss der Eileiter bedingte Sterilitätsprobleme und deren Behandlung. ${ }^{124}$ Schon 1931 erschien eine Arbeit, in der über Röntgenkontrastmittel-Untersuchungen zur Effektivitätskontrolle verschiedener Sterilisationsverfahren berichtet wurde. Darin heißt es prophetisch:
„Die Frage der tubaren Sterilisation ist heute besonders aktuell geworden. Fraenkel hat die Zahl der alljährlich in Deutschland vorgenommenen Tubosterilisationen approximativ auf 50.000 bis 100.000 angenommen. Ein sehr vorsichtiger Ansatz, der bald überschritten werden dürfte. Denn auch für den Arzt von gewissenhafter Berufsausübung fällt der soziale Faktor als Zusatzindikation zur medizinischen immer schwerer ins Gewicht.“ 125

Von einer eugenischen Indikation ist hier allerdings noch nicht die Rede, schon gar nicht von Zwangsmaßnahmen. Der Begriff der sozialen Indikation wurde mit größter Wahrscheinlichkeit in dem Sinn gebraucht, wie ihn Ludwig Fraenkel im Mai des Jahres auf dem DGG-Kongress in Frankfurt am Main interpretiert hatte: als zwar bedauerliche, aber immer noch bessere Alternative zur Abtreibung aus wirtschaftlicher Not. ${ }^{126}$

Die eingangs erwähnten Untersuchungen von Belonoschkin an Organen hingerichteter Männer sollten - in Analogie zu Forschungen des Anatomen Hermann Stieve an Männern und Frauen - einen Beitrag zum Einfluss von Haft und psychischer Belastung auf die Physiologie der Reproduktion liefern. ${ }^{127}$ In der einschlägigen Publikation, die im Band 174 des „Archivs für Gynäkologie“ unmittelbar nach einem Nachruf auf Fuchs erschien und von Belonoschkin dem Andenken des „verehrten Lehrers, Prof. Dr. Hans Fuchs, ehrfurchtsvoll gewidmet“ war, berichtet er über die Qualität der Spermien aus den Hoden und Nebenhoden von 14 ursprünglich gesunden Männern im Alter zwischen 21 und 44 Jahren. ${ }^{128}$ Der Zeitraum zwischen der Hinrichtung und der Untersuchung lag den Angaben im Abschnitt „Material und Methoden“ zufolge zwischen 50 Minuten und 5 Stunden. Zu den Limitationen seiner Studie erklärt Belonoschkin:

„Die Eigenart des Materials bringt es mit sich, daß in einigen Punkten auf Vollständigkeit verzichtet werden muß und die Zahl der Versuche nur beschränkt sein kann." ${ }^{129}$

Aus der Arbeit geht nicht hervor, woher die Organe der Hingerichteten stammten, wo und wann sie untersucht wurden und wie sie in das Labor von Belonoschkin gelangten. Es heißt nur, die Untersuchungen hätten sich über einige Jahre hingezogen. Angesichts der Situation an der „Reichsuniversität Posen“ kann aber mit einiger Wahrscheinlichkeit davon ausgegangen werden, dass Belonoschkin eine Kooperation mit dem dortigen Ordinarius für Anatomie, Hermann Voss, eingegangen war. Voss erlangte in den 1980er-Jahren - nach dem Zweiten Weltkrieg in der DDR als Ordinarius in Halle sowie Jena tätig und hoch geehrt - traurige Berühmtheit für seine menschenverachtende Einstellung gegenüber den Polen und den zynischen Umgang mit den Leichen der

120 Wagner: Fuchs [Nachruf] (1942), S. 352.

121 Staatsarchiv Posen, Bestand 301 (Gauselbstverwaltung) Sig. 2159: Korrespondenz von Fuchs bezügl. UK-Stellung von Assistenten (19.01.1942).

122 Vgl. Majewski: Posen (2012).

123 Staatsarchiv Posen 301, 2159: Korrespondenz von Fuchs wegen UK-Stellung seiner Assistenten (19.01.1942).

124 Fuchs: Pertubationen (1926).

125 Fuchs/Lork: Röntgenkontrollen (1931), S. 211.

126 Fraenkel: Sterilisierung [Verhandlungen 1931] (1931), S. 88

127 Hermann Stieve, als „Anatom der Gynäkologen“ apostrophiert und Anfang der 1950er-Jahre zum Ehrenmitglied der DGG ernannt, genoss weit über seinen Tod hinaus größtes Ansehen als Wissenschaftler. Seine Rolle im „Dritten Reich“ ist Gegenstand kritischer Untersuchungen; vgl. Hildebrandt: Anatomy (2016); ferner: Schagen: Forschung (2005).

128 Belonoschkin: Biologie (1942).

129 Belonoschkin: Biologie (1942), S. 357. 


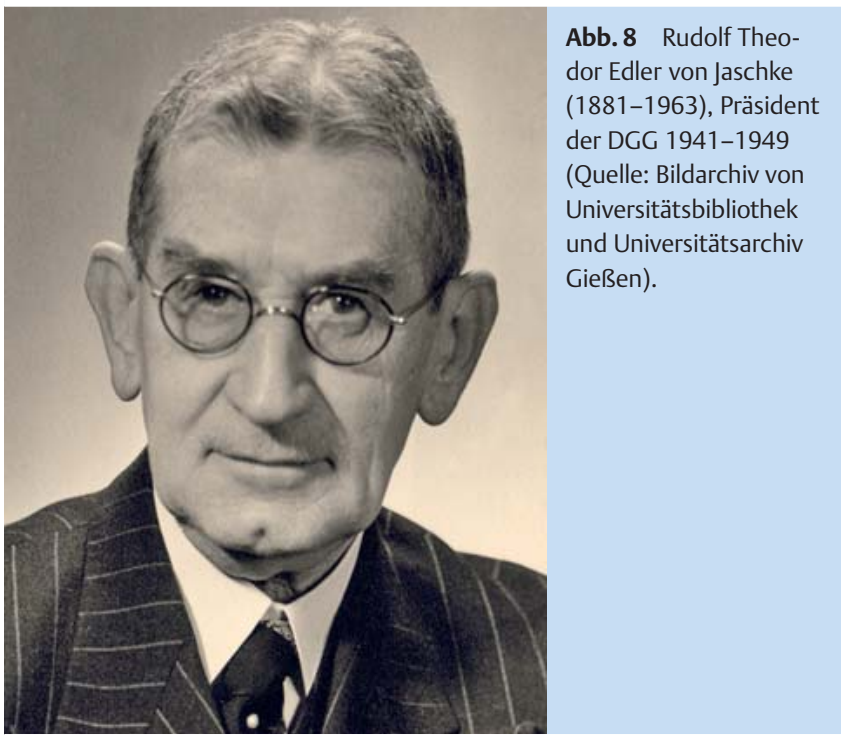

vielen Hingerichteten, die in sein Posener Institut gebracht wurden. ${ }^{130}$

\section{Rudolf Theodor von Jaschke: Präsident des Übergangs}

Rudolf Theodor Edler von Jaschke wurde für die DGG zum Präsidenten des Übergangs ( Abb. 8): 1937 erstmals in den erweiterten Vorstand berufen, wählte ihn die Mitgliederversammlung auf ihrem Kriegskongress 1941 im annektierten Wien zum neuen Präsidenten. Die damals für 1943 in München geplante 27. Tagung der DGG sollte allerdings erst im April 1949 in Karlsruhe stattfinden - 4 Jahre nach dem Untergang des „Dritten Reiches“ und im Jahr der Gründung der beiden neuen deutschen Staaten. ${ }^{131}$

Jaschke, der die UFK Gießen trotz ehrenvoller Rufe nach Wien und Düsseldorf von 1918 an fast 30 Jahre geleitet hat, genoss unter seinen Fachkollegen einen hervorragenden Ruf. „Für einen Forscher, Kliniker und Lehrer vom Range des Herrn v. Jaschke, für einen Mann, der der Gesellschaft Jahrzehnte hindurch die wertvollsten Dienste mit Referaten großen Formats geleistet hat, bedarf es keiner besonderen Begründung“, erklärte Hans Fuchs, als er der Mitgliederversammlung Jaschke für das Präsidentenamt vorschlug. ${ }^{132}$ Jaschke galt als geschickter und schneller Operateur, zu seinen wissenschaftlichen Schwerpunkten zählten neben der gynäkologischen Onkologie, der komplizierten Schwangerschaft und den internistisch-gynäkologischen Grenzgebieten auch die besondere Sorge um die Neugeborenen. ${ }^{133}$ Besonders bemerkenswert erscheint, dass sich in der langen Liste seiner Publikationen auch Arbeiten für chirurgische Fachzeitschriften finden. ${ }^{134}$

Rudolf Theodor Edler von Jaschke war von österreichischem Adel. Er wurde am 17. August 1881 in Pettau in der Steiermark geboren. Sein Vater diente der Donaumonarchie als Offizier - ein Berufsweg, den auch der Sohn ursprünglich hatte einschlagen wollen. Er entschied sich dann jedoch für ein Medizinstudium, das ihn ab 1899 nach Berlin, Wien, Freiburg im Breisgau sowie nach Innsbruck führte. Das Staatsexamen legte er 1905 in Innsbruck ab und war damit nach österreichischer Gepflogenheit auch promoviert. Bis 1907 arbeitete er dann als Assistent in der Anatomie (Innsbruck), in der Chirurgie (Linz) sowie in den Medizinischen Universitätskliniken von Wien und München. Seine gynäkologisch-geburtshilfliche Ausbildung erwarb er zunächst als Assistent von Alfons von Rosthorn in Heidelberg und Wien (1907-1910). Nach dessen unerwartetem Tod ging Jaschke auf der Suche nach einer Möglichkeit zur Habilitation zunächst nach Greifswald, dann nach Düsseldorf zu Erich Opitz und wechselte mit ihm 1912 nach Gießen. Dort habilitierte er sich, leitete die Klinik während der kriegsbedingten Abwesenheit von Opitz, wurde 1916 zum außerordentlichen Professor ernannt und folgte schließlich 1918 seinem nach Freiburg im Breisgau berufenen Lehrer Opitz im Alter von erst 36 Jahren im Gießener Ordinariat nach.

Wie fast alle seine zeitgenössischen Fachkollegen war Jaschke national-konservativ geprägt. Schon im Ersten Weltkrieg beschäftigte ihn die aus den „Menschenverlusten des Völkerkrieges“ und dem Geburtenrückgang resultierende demografische Entwicklung in Deutschland. Dabei beklagte er, dass die Bestrebungen zur Lösung des Problems bisher in den Kreisen der Geburtshelfer „merkwürdig wenig Widerhall“ gefunden hätten und unterstützte eine Forderung des Königsberger Ordinarius Georg Winter nach einer breiten allgemeinen Beratung „im Schoße unserer Deutschen Gesellschaft für Gynäkologie“ - freilich vergeblich, wie sich zeigen sollte. Jaschke sah es damals als vordringlich an, die in Deutschland vergleichsweise hohe Säuglingssterblichkeit zu senken und mütterliche Todesfälle im Zusammenhang mit Schwangerschaft und Geburt durch erhöhte präventive Maßnahmen zu reduzieren. „[...] jede Mutter, welche vor Beendigung ihres Gebärgeschäftes ausscheidet, bringt einen neuen Verlust von 2-3 Menschenleben“, erklärte er. ${ }^{135}$ Ähnlich argumentierte er auch im „Kampf gegen die Fruchtabtreibung“, durch deren Komplikationen vielfach „ganz junge Mädchen [...] für die Fortpflanzung vollständig verloren“ gingen. Jaschke setzte sich dafür ein, nur noch die „Abtreiber“ zu bestrafen. Er hoffte, die Frauen würden eher geneigt sein, Namen zu nennen, wenn sie selbst keine Strafe fürchten müssten. ${ }^{136}$

Lebhafte Unterstützung der SS Nach 1933 gehörte Jaschke zu den Mitgliedern der Medizinischen Fakultät Gießen, die noch vor der Aufnahmesperre der NSDAP beitraten. Sigrid Oehler-Klein schreibt in ihrer ausführlichen Darstellung der Fakultätsgeschichte, das Engagement Jaschkes für die Ziele der Partei sei allgemein bekannt gewesen. Außerdem war er ein eifriger Förderer der SS. Sie zitiert dazu ein Schreiben des SS-Obersturmführers Gerd Unbehaun, der damals Assistent an der Frauenklinik war. Darin heißt es:

\footnotetext{
130 Aly/Chroust/Heilmann: Biedermann (1987), S. 65.

131 Siehe hierzu S. 95-98.

132 Mitgliederversammlung [Verhandlungen 1941] (1942), S. 10.

133 Lang: Jaschke (1989). Dieser Darstellung wird im Hinblick auf die berufliche Karriere gefolgt.

134 GK 1939, S. 214-217.

135 Jaschke: Beitrag (1917), S. 67.

136 Jaschke: Kampf (1924), S. 850 f.
} 
„[...] die Unterstützung des Prof. v. Jaschke besteht seit Jahren vor allem in reichlichen Geldzuwendungen und Zur Verfügung Stellung seiner Wagen, es wurde sogar ein nagelneuer Wandererwagen des Prof. v. Jaschke von SS-Kameraden restlos zum Teufel gefahren, ohne dass seine lebhafte Unterstützung in finanzieller Hinsicht Einbusse erlitten hätte.“137

In der DGG gab es 1944 Befürchtungen, dass Jaschke sein Präsidentenamt nicht mehr werde ausüben können, weil er an einem Stimmbandkarzinom erkrankt war. Auch Jaschke selbst hatte deshalb ursprünglich angeregt, ihn von dem Amt zu entbinden. ${ }^{138}$ Dies hätte zu erheblichen Schwierigkeiten geführt, weil der damalige 2. Vorsitzende Hans Fuchs ja schon 1942 verstorben war. Nach einer Operation erholte sich Jaschke aber so gut, dass er auch seine Dienstaufgaben im Zusammenhang mit der Evakuierung der zerstörten Klinik in das Kloster Arnsburg wahrnehmen konnte. ${ }^{139}$

Nach Kriegsende wurde Jaschke am 15. Mai von den Militärbehörden zunächst aus allen seinen Ämtern entlassen. Wie andernorts kam es jedoch - bedingt durch die Notwendigkeit einer ausreichenden medizinischen Versorgung - zu seiner raschen, allerdings immer wieder zeitlich befristeten, Wiederverwendung als Arzt während der laufenden Entnazifizierung. Angesichts der Unsicherheit der Situation nahm Jaschke 1947 ein Angebot zur Leitung der Städtischen Frauenklinik Offenbach an. Diese Funktion übte er bis 1949 aus, anschließend war er bis zu seinem völligen Rückzug aus der praktischen Medizin 1954 noch privatärztlich tätig. Unter erheblichen Bemühungen und mit großer Unterstützung des unbelasteten Gießener Anatomen Ferdinand Wagenseil gelang es ihm, 1950 seinen Titel als ordentlicher Professor wiederzuerlangen und sich pensionieren zu lassen. Die Emeritierung erreichte er erst 1952, dann allerdings rückwirkend bis 1950. ${ }^{140}$ Die Medizinische Fakultät der Universität Gießen verlieh Jaschke 1960 die Ehrendoktorwürde. ${ }^{141}$

\section{Die Schriftführer, Kassenwarte und Beisitzer}

Eduard Martin: Opfer kollegialer Intrigen

Eduard Balduin Karl Victor Martin, 1. (ständiger) Schriftführer der DGG von 1920 bis 1936, entstammte in dritter Generation der berühmten gleichnamigen Berliner Gelehrtenfamilie: Sein Großvater Eduard Arnold war der erste Vorsitzende der Berliner Gynäkologischen Gesellschaft, sein Vater Eduard August Martin erwarb sich nach Habilitation und Ausscheiden aus der Universität in einer von ihm gegründeten Privatklinik internationales Ansehen als gynäkologischer Operateur, ehe er 1899 einen Ruf nach Prag ablehnte und stattdessen als Ordinarius nach Greifs- wald ging. ${ }^{142}$ In der Greifswalder Klinik begann 1905 auch die gynäkologisch-geburtshilfliche Ausbildung von Eduard Martin, die ihn ab Dezember 1906 zurück in seine Geburtsstadt Berlin führte, wo er bei Ernst Bumm zuerst an der Charité und dann an der I. UFK schließlich zur Habilitation und in Oberarztfunktion gelangte. 1912 ließ sich Eduard Martin als Frauenarzt in Berlin nieder, war aber weiterhin als Dozent tätig. Von 1914 bis 1918 leistete er Kriegsdienst und konnte schließlich 1919 - unterstützt durch die Fürsprache prominenter Persönlichkeiten - den Posten des Direktors der Hebammenlehranstalt in Elberfeld übernehmen. ${ }^{143}$

1920 wählte die DGG Martin zu ihrem 1. Schriftführer. Er war Rotarier und gehörte der Freimaurerloge „Zur Bruderkette“ in Barmen an. 1933 trat Martin in die NSDAP ein, wurde jedoch nach einem Jahr wegen seiner Mitgliedschaft in der Loge wieder ausgeschlossen. Martin verließ deshalb die Loge; die Beiträge für die NSDAP bezahlte er trotz seines Ausschlusses weiter. Als von Seiten der Partei 1937 auch die Mitgliedschaft bei den Rotariern mit der NSDAP-Mitgliedschaft für unvereinbar erklärt wurde, trat er auch aus diesem Club aus. ${ }^{144}$

Martin hat die Elberfelder Anstalt, die ab 1924 auf sein Betreiben hin auch als Frauenklinik firmierte, unter schwierigen Bedingungen geleitet. Wirtschaftliche Probleme, Konkurrenz in der Nachbarschaft, aber auch zeitweise amtlich verordnete Perspektivlosigkeit spielten dabei eine Rolle. Die Geburten- und Operationszahlen im zweiten und letzten Drittel der 1920er-Jahre stiegen trotzdem stetig an. ${ }^{145}$ Im Mai 1931 wurde sein Vertrag um weitere 12 Jahre verlängert. Dennoch beantragte Martin schon am 16. Juni 1936 im Alter von erst 57 Jahren „aus persönlichen Gründen" die sofortige Versetzung in den Ruhestand. ${ }^{146}$ Gleichzeitig legte er sein Amt als Schriftführer der DGG nieder, das er mehr als anderthalb Jahrzehnte ausgeübt hatte. ${ }^{147}$

Eine verhängnisvolle Affäre Die Hintergründe dieses zumindest für die DGG unerwarteten Schrittes sind vielschichtig und nicht klar zu durchschauen. Nach Aktenlage wurde Martin offenbar das Opfer einer Intrige, bei der sich missgünstige bzw. von Martin in der Vergangenheit düpierte niedergelassene Kollegen und Untergebene eher geringfügige Reibereien des Klinikchefs mit Funktionären der NSDAP zunutze machten. ${ }^{148}$ Darüber hinaus hatte sich Martin wahrscheinlich unter anderem durch eine angeblich allgemein bekannte Affäre mit seiner langjährigen OPSchwester angreifbar gemacht, die seine erste Frau 1932 in einem Zivilprozess als Trennungsrund angab und die eine partielle gesellschaftliche Isolation Martins zur Folge hatte. ${ }^{149}$

\footnotetext{
137 BArch Berlin, ehem. BDC, Duken, 12.1.89 RS, Bl. 8; zit. n. Oehler-Klein: Gründung (2007), S. 483, Fußnote 57.

138 BSB Ana 691, Durchschlag eines Briefes an Naujoks v. 30.08.1944 (vermutlich von Martius); Jaschke: Eröffnung-Ansprache [Verhandlungen 1949] (1950), S.1.

139 Kirschbaum/Herold: Baugeschichte (1989), S. 289 f.

140 Oehler-Klein: Gründung (2007), S. 482.

141 Lang: Jaschke (1989), S. 234.

142 Zur Familie Martin siehe Ebert/David: Eduard Arnold Martin (1944) sowie Ebert/David: August Eduard Martin (1994).

${ }_{143}$ ALVR, 25626, Bl. 6: Eigenhändiger Lebenslauf von Martin aus Anlass seiner Bewerbung.

144 ALVR 25617, 214: Gaurechtsamt Düsseldorf der NSDAP in einem Gutachten zu Martin (17.02.1938).

145 Blassing: Hebammenlehranstalt (2010).

146 ALVR, 25617, Bl. 172: Schreiben Martins an den Landeshauptmann der Rheinprovinz (16.06.1936).

147 BSB München, Ana 691: Martin an Martius (31.06.1936).

148 Dazu umfangreiches Aktenmaterial: ALVR 25619; 25622; 25625.

149 ALVR 25617, Bl. 99. Für das Verfahren „Martin gegen Martin“ fordert das Landgericht Wuppertal die Personalakte von Martin an und bittet um „amtliche Auskunft darüber, ob die dem Professor Dr. Martin vorgeworfenen Beziehungen zu der Schwester [...] Gegenstand eines amtlichen Verfahrens gewesen sind“ (20.06.1932). Zur Scheidung kam es damals noch nicht, das Paar trennte sich aber.
} 
Jedenfalls führte die Gestapo 1935 auf Veranlassung der Kassenärztlichen Vereinigung Ermittlungen gegen Martin durch, in deren Verlauf vor allem von früheren Assistenten und Oberärzten schwere Vorwürfe auch fachlicher Natur erhoben wurden: Kunstfehler bei Operationen und Entbindungen, vorsätzliche Tötung eines Frühgeborenen und Schwangerschaftsabbrüche aus pseudomedizinischer Indikation. Darüber hinaus habe er Aktivitäten seiner Assistenten für die NS-Bewegung behindert, auch im Verlauf antinationalsozialistische Gesinnung gezeigt und sich insgesamt als „Volksschädling ersten Ranges“ erwiesen. ${ }^{150}$ Diese Vorwürfe hat Martin in einer umfangreichen Erklärung zurückgewiesen. ${ }^{151}$

Es erscheint bezeichnend, dass es dem Anwalt von Martin trotz dieser gravierenden Vorwürfe gelang, die Einleitung eines förmlichen Dienststrafverfahrens gegen Martin zu verhindern. Die Gegenleistung bestand in dem Antrag auf Versetzung in den Ruhestand. ${ }^{152}$ Auch zu einem Strafverfahren kam es nicht. Martin hat dann aus privater Praxis heraus durch vielerlei Aktivitäten versucht, seine Rehabilitierung zu erreichen. Tatsächlich bescheinigte ihm das Gaurechtsamt der NSDAP 1938, er habe die Beschuldigungen gegen ihn „mit Erfolg“ zu entkräften versucht. Hinsichtlich seiner politischen Zuverlässigkeit bestünden „heute keine Bedenken mehr“. Allerdings hieß es, wenn auch ohne Begründung, er komme „als Leiter einer Anstalt künftig nicht mehr in Frage“. 153

Örtliche Kliniken verweigerten sich Die Ausübung der privaten Praxis wurde Martin dadurch erschwert, dass alle örtlichen Klinken ihm eine Benutzung ihrer Einrichtungen für absehbar schwierige Entbindungen oder Operationen seiner Patientinnen verweigerten. Dennoch verließ er die Gegend um Wuppertal erst 1952, nach Aufgabe seiner Berufstätigkeit, um in München Wohnsitz zu nehmen. In den Jahren zuvor muss sich Martins finanzielle Situation trotz seiner vollen Ruhestandsbezüge dramatisch verschlechtert haben, denn am 20. April 1953 wurde ihm wegen 4000 Mark Bankschulden das Ruhegehalt gepfändet.

Vermutlich nicht zuletzt wegen finanzieller Schwierigkeiten hatte Martin knapp 2 Jahre zuvor einen Antrag auf Wiedergutmachung für erlittenes NS-Unrecht gestellt, der allerdings abgelehnt wurde. ${ }^{154}$ Zur Begründung führte er neben dem erzwungenen Amtsverzicht auch Gesundheitsschäden an: „[...] bin ich nach Otosklerose hochgradig schwerhörig und auf dem linken Auge praktisch blind. Auf dem rechten Auge ist das stereoskopische Sehen so stark behindert, dass ich bei Dunkelheit [...] geführt werden muss. Beide Behinderungen sind nach den fachärztlichen Gutachten auf die nationalsozialistischen Einwirkungen zurückzuführen.“155
Die geschilderte Hilfsbedürftigkeit Martins war eigenen Angaben zufolge auch der Grund für die späte Scheidung des damals 69Jährigen und die unmittelbar darauf folgende Wiederverheiratung mit der 33 Jahre jüngeren Margarete Rehm im Mai 1949. ${ }^{156}$ Dass es sich dabei um eine „Versorgungsehe“ handelte, kann auch aus einem Schreiben Martins geschlossen werden, in dem er 1952 das Sozialministerium von Nordrhein-Westfalen im Fall seines Todes bat, das Gesuch seiner Frau um Witwenpension „wohlwollend“ zu berücksichtigen.

Hans Christian Naujoks:

eher Überzeugungstäter als Mitläufer

Hans Christian Naujoks, als 1. Schriftführer der DGG von 1936 bis 1956 Nachfolger des zurückgetretenen Eduard Martin und dann bis 1958 Präsident der Gesellschaft, ist das einzige hier behandelte Mitglied des engeren Vorstands, das erst in der Diktatur in eine Chefposition gelangte. Irene Franken und Daniel Schäfer, die sich intensiv mit dem ehemaligen Kölner, Marburger und Frankfurter Ordinarius auseinandergesetzt haben, halten ihn für einen Profiteur des Regimes. Seine große Professionalität als Arzt, Forscher und Hochschullehrer wird dabei nicht in Zweifel gezogen. Hinsichtlich seiner sehr aktiven Beteiligung an der Umsetzung der eugenischen Ziele des Nationalsozialismus ordnen sie ihn eher als „Überzeugungstäter“ denn als Mitläufer ein. ${ }^{157}$

Hans Naujoks wurde am 2. September 1892 im ostpreußischen Jessen (Kreis Insterburg) als Sohn eines Landwirts geboren. Ab 1911 studierte er zunächst Mathematik und Naturwissenschaften in Königsberg, wandte sich dann jedoch der Medizin zu. Zwischen August 1914 und Januar 1919 leistete er freiwilligen Militärdienst, konnte aber dennoch bereits im Oktober 1919 in Rostock das medizinische Staatsexamen ablegen. Nach einer Tätigkeit im Pathologischen und Mikrobiologischen Institut der Königsberger Universität begann Naujoks 1920 seine gynäkologisch-geburtshilflich Ausbildung zunächst am Städtischen Krankenhaus Königsberg; 1921 wechselte er an die UFK zu Georg Winter, der ihn 1925 habilitierte. Anschließend ging Naujoks zu Erwin Kehrer an die UFK Marburg (1926). Dort erhielt er 1934 den Ruf nach Köln in sein erstes Ordinariat (@ Abb. 9).

Bereits zu Beginn seiner Assistentenzeit bei Winter in Königsberg hatte Naujoks begonnen, sich intensiv mit Fragen der gynäkologischen Radiologie zu befassen. Ein großes Thema für ihn wurde dabei die Frage der „temporären Sterilisierung“ der Frau durch Bestrahlung der Ovarien, bei der allerdings nicht die zeitweilige Ausschaltung der reproduktiven, sondern der endokrinen Funktion der Ovarien zur Behandlung symptomatischer Myome im Vordergrund stand. ${ }^{158}$ Verknüpft damit war die Frage der Strahlenschädigung bei Kindern exponierter Frauen. ${ }^{159}$ Daneben hat Naujoks in Königsberg recht unterschiedliche geburtshilfliche Probleme bearbeitet.

150 ALVR 25618, Bl. 1-3; 25619, Bl. 8-13, 35, 36.

151 ALVR 25625, Bl. 23-34: Abschrift eines Protokolls der Düsseldorfer Verwaltung vom 06.04. 1936, das Martin unterschrieben hat.

152 ALVR, 25617, Bl. 174: Abschrift einer Aktennotiz der Verwaltung der Rheinprovinz vom 16.06.1936 über ein Gespräch des Anwaltes von Martin mit dem Landeshauptmann.

153 ALVR, 25617, 214-222: Gutachten des NSDAP-Gaurechtsamtes Düsseldorf (17.02.1938).

154 ALVR 25617, Wiedergutmachungsbescheid des Landes Nordrhein-Westfalen (20.04.1953); ebenso LANW 110, Nr. 1087, Bl. 44-50.

155 ALVR 25617: Martin an den Sozialminister von NRW (25.04.1952).

156 ALVR, 25617, Bl. 272.

157 Franken: „Nationalsozialist“ (2008); Franken/Schäfer: Handeln (2011).

158 Naujoks: Problem (1925).

159 Naujoks: Fruchtschädigung (1925). 


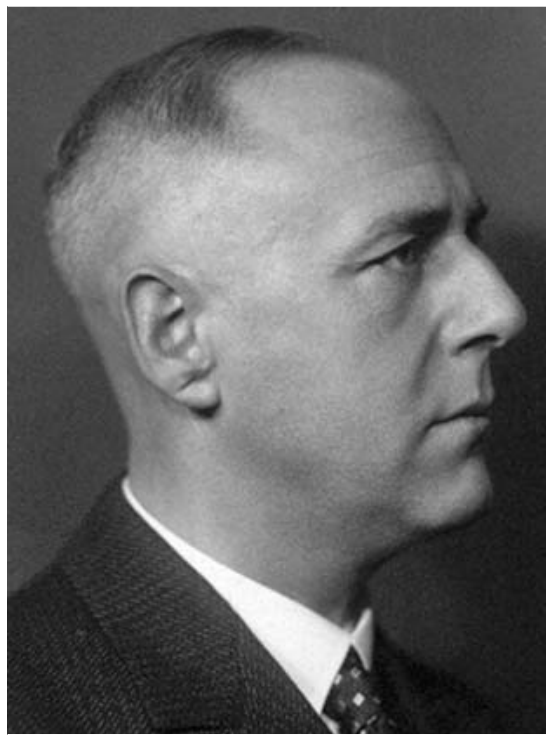

Abb. 9 Hans C. Naujoks (1892-1959), 1. Schriftführer der DGG 1936-1956, Präsident der DGG 1956-1958 (Quelle: Historisches Archiv der Universität zu Köln).

Herold des NS-Frauenbildes In den ersten Jahren seiner Kölner Zeit widmete sich Naujoks vor allem dem Umbau und der Erweiterung der Klinik. Durch diese Bemühungen, aber auch durch die Anhebung der medizinischen Standards sowie die Erfolge der durch Naujoks ausgebauten onkologischen Strahlentherapie verbesserte sich der durch eine längere Vakanz beeinträchtigte Ruf der Klinik zunehmend und die Belegungszahlen stiegen ebenso wie die Geburtenzahlen. „1938 leitete Naujoks [...] eine der modernsten und größten Frauenkliniken Deutschlands“, heißt es dazu bei Irene Franken. ${ }^{160}$

Als Herold des NS-Frauenbildes und dessen Verteidigung gegen die in der Weimarer Republik - vor allem im Rahmen der Sexualreformbewegung - erwachten Bestrebungen zur Emanzipation der Frau präsentierte sich Naujoks vor allem in seiner Kölner Antrittsvorlesung. Bei diesem Anlass behauptete er sogar, nie habe eine Weltanschauung die Frauen höher geachtet als der Nationalsozialismus: „Er weist der Frau wieder den ihr von Natur zukommenden Ehrenplatz der Erziehung und Hüterin und Bewahrerin des Volkes zu. Die Mutter, die mütterliche Frau ist das Frauenideal des neuen Deutschland geworden. “161 Unter anderem diese Vorlesung war offenbar im Kollegenkreis besonders zur Kenntnis genommen worden: Naujoks Vorgänger im Amt des Schriftführers, Eduard Martin, meinte im November 1945 in einem Brief an Heinrich Martius: „Von Naujoks [...] fehlt mir jede Nachricht. Ich glaube nicht, dass er sich halten kann. Er ist zu sehr für die Deutsche Frau im nationalsozialistischen Sinne eingetreten.“162

Im Zweiten Weltkrieg musste Naujoks erleben, dass die von ihm ausgebaute Kölner Klinik weitgehend in Trümmer gelegt wurde. Noch zum 1. April 1945 folgte er einem Ruf zurück nach Marburg und übernahm den dortigen Lehrstuhl, wurde allerdings schon am 28. September durch die US-Militärbehörden seines Amtes enthoben. Nach Vertretungen, einer Episode in privater Praxis und für ihn erfolgreicher Entnazifizierung im Spruchkammerverfahren übernahm er schließlich 1947 Ordinariat und Direktorat an der UFK Frankfurt. Beides hatte er bis zu seinem Tod am

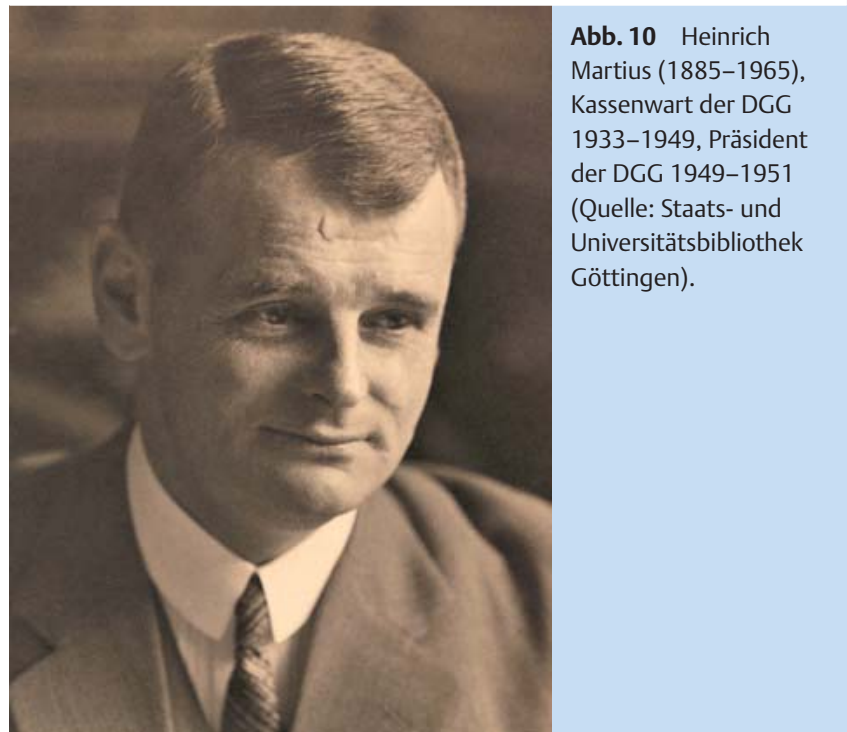

29. September 1959 inne, im Jahr zuvor leitete er noch den DGG-Kongress in Frankfurt am Main.

Heinrich Martius: moralische Instanz mit Widersprüchen Heinrich Fedor Emil Martius, von 1926 bis 1954 über seine Emeritierung hinaus Direktor der UFK Göttingen, hat sich in den 1930er- bis 1950er-Jahren für die DGG ganz besonders engagiert: Ab 1933 unterstützte er teils unter schwierigen Bedingungen als Kassenwart 5 Präsidenten in ihrer Amtsführung; 1949 gegen Ende seiner erfolgreichen akademischen Laufbahn selbst an die Spitze der Gesellschaft gewählt, richtete er im April 1951 ihren zweiten Kongress nach dem Zusammenbruch des „Dritten Reiches“ aus. Neben der großen Reputation, die er sich als Arzt, Hochschullehrer und Wissenschaftler erworben hatte, galt er vielen auch als moralische Instanz - wohl nicht zuletzt deshalb, weil er sich mit seiner Familie im Nationalsozialismus immer wieder wegen „nicht arischer“ Abstammung bedroht fühlen musste und deshalb jeder Nähe zum Regime als unverdächtig galt. Dennoch - oder vielleicht gerade deswegen - finden sich in seiner Biografie auch Widersprüchlichkeiten.

Heinrich Martius kam am 2.Januar 1885 in Berlin zur Welt (ه Abb. 10). Seine Mutter Martha (1861-1946) war nach der NS-Terminologie „Dreivierteljüdin“, er selbst damit „Nichtarier“ bzw. „Mischling zweiten Grades“. Da sein Vater Friedrich 1899 zum Ordinarius für Innere Medizin in Rostock berufen wurde, wuchs er in der Ostseestadt auf und legte dort das Abitur ab. Zum Medizinstudium ging Martius zunächst nach Freiburg und Leipzig, das Staatsexamen (1909) und die Promotion (1910) sahen ihn wieder in Rostock.

Nach seiner Zeit als Medizinalpraktikant absolvierte Martius zunächst eine 2-jährige chirurgische Ausbildung. 1913 wurde er dann Assistent an der Bonner UFK bei Otto von Franqué. Militärdienst im Ersten Weltkrieg, aus dem er nach vielen Fronteinsätzen mit dem Eisernen Kreuz I. Klasse dekoriert zurückkehrte, unterbrach jedoch die Fachausbildung. Dennoch konnte sich Mar-

\footnotetext{
160 Franken: „Nationalsozialist“ (2008), S. 118.

161 Naujoks: Wandlung (1935), S. 18.

162 BSB München, Nachlässe, Ana 691: Martin an Martius (18.11.1945).
} 


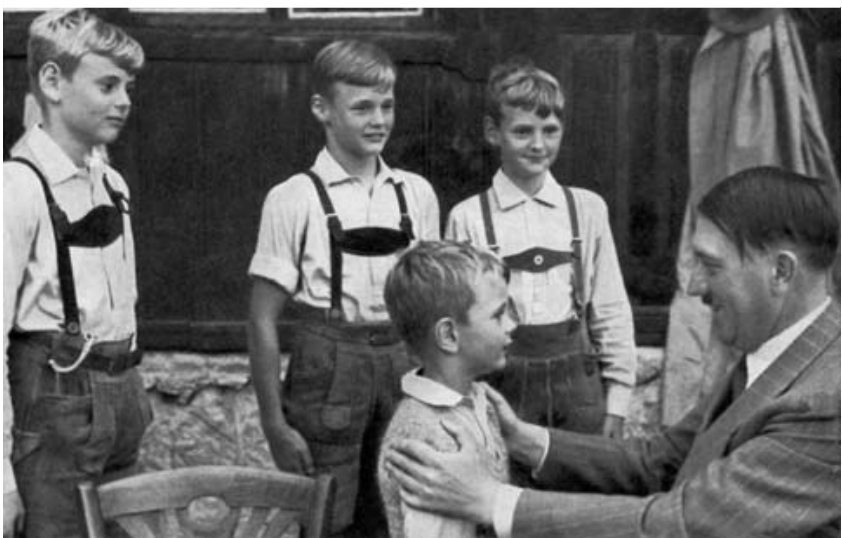

Abb. 11 Das „Hitlerbild“, eine zufällig zustandegekommene Aufnahme seiner vier Söhne mit dem „Führer“, bereitete Heinrich Martius in den 1930er-Jahren erhebliche Sorgen: Vielfach als Exempel für die ideale "deutsche Familie“ in unterschiedlichstem Kontext veröffentlicht, gab das Foto nach Bekanntwerden der „jüdischen Versippung“ des Vaters Anlass zu zahlreichen Attacken aus der NSDAP (Quelle: Yad Vashem Photo Archive, Jerusalem)

tius schon 1919 in Bonn habilitieren, 1922 wurde er dort zum Professor ernannt. Vier Jahre später nahm er den Ruf nach Göttingen an - an die Universität, an der er trotz mehrerer Rufe an größere Hochschulkliniken geblieben ist. Zumindest einmal ist dies allerdings nicht seine Entscheidung gewesen: Den Ruf an die ETH nach Zürich 1934 wollte Martius annehmen - doch damals lehnte der Stadtrat, der die entsprechende Entscheidung der Universität formal zu bestätigen hatte, die Berufung eines Deutschen aus politischen Gründen ab. ${ }^{163}$

Die herausragenden Leistungen von Martius als Arzt und Hochschullehrer, vor allem aber auch als Autor begehrter Fachbücher, sind ausführlich beschrieben worden. ${ }^{164}$ Mit seinen über 300 wissenschaftlichen Publikationen deckte Martius nahezu das gesamte Spektrum des Faches ab. Strahlentherapeutische Themen beschäftigten ihn ebenso wie die operative Gynäkologie und die Geburtshilfe. Informierte Laien waren ihm wichtig, deshalb zählte er auch zu den ersten Hochschulmedizinern, die sich mit populären Schriften direkt an Frauen wandten. ${ }^{165}$

Als die Nationalsozialisten 1933 mit dem „Gesetz zur Wiederherstellung des Berufsbeamtentums“ mit der Verdrängung „nichtarischer" und politisch missliebiger Personen begannen, war Martius zunächst durch den „Frontkämpferparagraphen“ geschützt. Objektiv vorhandene und subjektiv empfundene persönliche Bedrohung im weiteren Verlauf mögen unterschiedlich gewesen sein. Die etwas komplizierte Sachlage dazu wurde andern- orts beschrieben. ${ }^{166}$ Gesichert ist jedoch, dass Martius in den Unterlagen der Universität Göttingen bis 1945 als „Mischling zweiten Grades“ geführt wurde und der einzige „Nichtarier“ war, der während der gesamten NS-Herrschaft Mitglied der Medizinischen Fakultät geblieben ist. ${ }^{167}$

Auch in der Öffentlichkeit der Stadt Göttingen und bei örtlichen NS-Parteiorganisationen galt Martius als ,jüdisch versippt“. Gravierender Verfolgung durch die Nationalsozialisten war er deshalb aber nicht ausgesetzt. Allerdings gab es für die Familie wiederholt Anlass zu Befürchtungen, stärker in den Fokus brauner Rassisten zu rücken. Zu nennen sind die Vorgänge um das „Hitlerbild“ 1935 ( Abb.11), eine Denunziation wegen eines Einkaufs in einem jüdischen Geschäft 1938, Ermittlungen gegen Martius zu Abstammung und politischer Einstellung 1939 und schließlich 1942 beim Reichssippenamt eine offenbar unüberlegte Aktion von Heinrich Martius selbst, mit der er vermutlich allen Unsicherheiten ein Ende bereiten wollte. Letztere scheint nur deshalb folgenlos geblieben zu sein, weil ein Mitarbeiter des Amtes Martius aus nicht geklärten Motiven heraus warnte und zur Rücknahme seiner Eingabe veranlasste. ${ }^{168}$

Im Kollegenkreis der DGG spielte das „Abstammungsproblem“ von Martius ebenfalls eine gewisse Rolle. Es war offenbar akzeptiert, dass er sich gegenüber NS-Funktionsträgern möglichst wenig exponierte. 1937 lehnte er es ab, in der Auseinandersetzung mit den Nationalsozialisten um die Haus- bzw. Klinikgeburt für die DGG offiziell Stellung zu beziehen. Wagner hatte sich damals bei der Kongressvorbereitung in seiner Eigenschaft als Präsident an Martius gewandt: „Sie hatten mehrmals geäussert, dass die Gesellschaft sich mit den ewigen Meckereien gegen die Anstaltsgeburten [...] in einer Resolution befassen solle. Würden Sie so freundlich sein, mir bald den Entwurf einer solchen Resolution zukommen zu lassen?“ Martius antwortete: „Wäre es nicht vielleicht besser, A. Mayer um die Erfüllung dieser Aufgabe zu bitten?"169

Zu den Widersprüchlichkeiten in der Biografie von Martius gehört, dass er offensichtlich einerseits ein Gegner des NS-Sterilisationsgesetzes war, andererseits in seiner Klinik aber zumindest in der Hochphase der Sterilisationen für dessen reibungslose Umsetzung sorgte: Nach seinem Oberarzt Werner Bickenbach war er mit 146 einschlägigen Eingriffen der aktivste Operateur. Für seine ablehnende Haltung gegenüber dem GzVeN sprechen Erinnerungen des katholischen Sozialgynäkologen Albert Niedermeyer ${ }^{170}$ sowie ein mehrfach zitierter Brief, der wohl an den Minister für Wissenschaft und Volkserziehung gerichtet war und in dem Martius um Entbindung von diesen Eingriffen bat, „da er den Widerspruch, Leben zu geben und Fruchtbarkeit zu nehmen, nicht mehr mit sich vereinbaren konnte“. ${ }^{171}$

\footnotetext{
163 Martius: Deutschland (2002/2003), S. 110. Der Autor zitiert hier aus der Personalakte: UB Göttingen, PA Martius, XVI - A. a.21, Bd. II, Bl. 79.

164 Vgl. z.B. Ebert/David: Martius (2015); Ludwig: Forscher (2006); Hagene: Gynäkologe (2006) mit vielen weiteren Literaturangaben.

165 Hagene: Gynäkologe (2006) S. $24 \mathrm{f}$.

166 Martius: Deutschland (2002/2003), insbes. S. 106-108

167 Beushausen/Dahms/Koch/Massing/Obermann: Fakultät (1998), S. 192

168 Martius: Deutschland (2002/2003), S. 267-278.

169 BSB München, Nachlässe, Ana 691: Briefwechsel Wagner (07.10.1937) und Martius (08.10.1937).

170 Siehe hierzu S. 43.

171 Koch: Zwangssterilisation (1994), S. 59,65; Franken: „Nationalsozialist“ (2008), S. 134. Eine Quelle für den Brief ist bei Franken nicht angegeben. Koch nennt einen Sohn von Heinrich Martius, Gerhard Martius, als Quelle, der sich wiederum auf eine Äußerung des Vaters bezieht. Bei Götz-Alexander Martius, einem zweiten Sohn von Heinrich, von dem die Frage der Zwangssterilisationen in seiner Familiengeschichte nur sehr kursorisch abgehandelt wird, fehlt ein derartiger Hinweis; vgl. Martius: Deutschland (2002/203), S. 22, 249-251.
} 


\section{Zur Rolle der Beisitzer}

Mit den Beisitzern versuchte die Gesellschaft, ihre Vorstandsarbeit auf eine breitere Basis zu stellen. Es ging dabei darum, den unterschiedlichen Gruppen in der Gesellschaft eine Stimme zu verleihen und dies durch die Wahl auch unter den Mitgliedern kund zu tun. So sollten beispielsweise mit der ersten Erweiterung des Vorstands 1931 auch „extrauniversitäre Kreise“ einbezogen werden. Im Laufe des Untersuchungszeitraums zwischen 1931 und 1949 stieg - soweit sich dies ermitteln ließ - die Zahl der Beisitzer von zuerst 4 auf bis zu 11 an. Daneben war die Aufnahme in den Vorstand der DGG auch ein wichtiges Zeichen nach außen: So achtete der Vorstand darauf, den internationalen Anspruch der Gesellschaft durch die Aufnahme ausländischer Mitglieder als - für die praktische Vorstandsarbeit letztlich unbedeutende - Beisitzer zu dokumentieren. Die Erhöhung der Zahl der Beisitzer wurde nicht zuletzt damit begründet. Voraussetzung war allerdings, dass es sich um politisch und speziell gesundheitspolitisch mit dem Nationalsozialismus übereinstimmende Gynäkologen handelte. ${ }^{172}$

Eine besondere Rolle spielt die 1937 erfolgte Aufnahme von Ernst Bach als Vorstandsbeisitzer, mit der der DGG-Vorstand Nähe zur NSDAP sowie zum Wissenschaftsministerium dokumentierte. Ernst Bach wurde bereits 1922 als Student Mitglied der NSDAP und war im Folgejahr am „Hitlerputsch“ beteiligt. Als „Alter Kämpfer“, später auch Träger des zum 1933 gefeierten 10. Jahrestag des Putschversuchs für die Teilnehmer gestifteten „Blutordens", konnte er sich auf besondere Verdienste aus der „Kampfzeit“ berufen, die auch besonders gewürdigt wurden. Bereits 1935 hatte sich Bach - seinerzeit kein DGG-Mitglied - als Leiter des Gauamts für Volksgesundheit in München an der Auswahl „geeigneter“ Referenten für die Sitzung zu den Zwangssterilisationen auf August Mayers Münchner Kongress beteiligt. 1936 wechselte er als medizinischer Referent in das Berliner Wissenschaftsministerium. Vermutlich ist Bach der Vorstandsposten angeboten worden, als er noch nicht einmal Mitglied war - bei seiner ersten Erwähnung auf den Mitgliedslisten der DGG 1937 firmiert er bereits als Beisitzer.

Die Beisitzer wurden auf Vorschlag des Vorsitzenden von der Mitgliederversammlung gewählt. Dies geschah den Versammlungsberichten zufolge per Akklamation für die gesamte Gruppe. So erklärte beispielsweise Hans Fuchs 1941 in Wien nach Verlesung der Vorschlagsliste: „Ich entnehme aus Ihrem Beifall, daß sämtliche Herren gewählt sind und darf wohl die Wahl auch seitens der Herren Beisitzer als angenommen betrachten.“" ${ }^{173}$ In der Satzung war die Funktion der Beisitzer nicht geregelt. Spezielle Aufgaben für sie ergaben sich von Fall zu Fall, unter besonderen Bedingungen konnten sie auch den Präsidenten bei der Kongressvorbereitung unterstützen - wie z.B. der Münchner Beisitzer Hans Albrecht den Tübinger Präsidenten August Mayer.

\section{Die „Gleichschaltung“ der DGG 1933}

\section{$\nabla$}

Allgemeine politische Rahmenbedingungen

Am 30. Januar 1933 wurde der NSDAP-Vorsitzende Adolf Hitler von Reichpräsident Paul von Hindenburg zum Reichskanzler ernannt. Formal eine weitere Koalitionsregierung, brach die nationalsozialistisch dominierte Reichsregierung der „nationalen Erhebung" gültige Verfassungsnormen annähernd nach Belieben. Zu den ersten Maßnahmen gehörten die „Reichstagsbrandverordnung“ vom 28. Februar 1933, mit der die verfassungsmäßigen Grundrechte der persönlichen Freiheit sowie der Meinungs-, Vereins- und Versammlungsfreiheit außer Kraft gesetzt wurden, ferner das „Ermächtigungsgesetz“ vom 23. März 1933, das der Reichsregierung Gesetzgebungskompetenz übertrug, dadurch das Parlament faktisch entmachtete und die Weimarer Verfassung außer Kraft setzte. Mit dem Ersten und Zweiten „Gesetz zur Gleichschaltung der Länder mit dem Reich“ vom 31. März und 7.April 1933 wurden die Länder der Weimarer Republik Reichskanzler Hitler verantwortlichen „Reichsstatthaltern“ unterstellt. Es folgten am 7. April des Jahres das „Gesetz zur Wiederherstellung des Berufsbeamtentums“, rechtliche Grundlage der Verdrängung „nicht arischer“ und politisch missliebiger Personen aus dem öffentlichen Dienst, sowie am 14. Juli 1933 das „Gesetz zur Verhütung erbkranken Nachwuchses“ (GzVeN), das Zwangssterilisationen als eine der zentralen Voraussetzungen der von den Nationalsozialisten angestrebten „Aufrassung“ des „Volkskörpers“" legalisierte.

„Gleichgeschaltet“ wurden öffentliche und staatliche Verwaltungen mit Parteidienststellen der NSDAP abschließend durch das „Gesetz zur Sicherung der Einheit von Partei und Staat" vom 1. Dezember 1933, das in $\S 1$ den „Sieg der nationalsozialistischen Revolution“ feststellte, die NSDAP zur „Trägerin des deutschen Staatsgedankens“ erklärte und sie „mit dem Staat unlöslich“ verband. Dies hatte weitreichende Auswirkungen auf das gesamte öffentliche Leben und betraf auch Verbände und Vereine wie die DGG.

Begleitet und unterstützt wurde diese Entwicklung von einem bis dahin beispiellosen Propagandafeldzug der NSDAP, der Entwicklung des Führerkultes um die Person Hitlers sowie von zunehmendem Straßenterror der SA mit Boykottaktionen gegen Andersdenkende und vor allem jüdische Mitbürger. Eines der frühen Opfer des Terrors war der in Regensburg geborene Münchner Frauenarzt Gustav Wiener, Mitglied der DGG und der Bayerischen Gesellschaft für Geburtshilfe und Frauenheilkunde (BGGF): Er wurde in der Nacht zum 29. März 1933 zusammen mit seiner Ehefrau in seiner zentral am Odeonsplatz gelegenen Münchner Wohnung von einer Horde SA-Schläger überfallen und so schwer misshandelt, dass er später an den Folgen verstarb. ${ }^{174}$

Vor diesem Hintergrund liefen in Berlin die Vorbereitungen für den 23. Kongress der DGG, dem Walter Stoeckel, der Direktor der dortigen I. UFK, präsidieren sollte. Stoeckel wurde damals auch in seiner mittelbaren und unmittelbaren beruflichen Umgebung mit den Auswirkungen der "nationalen Erhebung“ konfron-

\footnotetext{
172 Details zu den Auswirkungen der NS-Gesetzgebung auf die DGG-Mitglieder S. 79-82.

173 Mitgliederversammlung [Verhandlungen 1941] (1942), S. 10.

174 Dross: „Juden“ (2012), S. 98.
} 
tiert: Im April war allen jüdischen Ärzten die Zulassung zur Behandlung von Kassenpatienten entzogen worden, im Mai hatten fanatisierte Anhänger des Nationalsozialismus auf dem damaligen Opernplatz gegenüber der Humboldt-Universität eine öffentliche Bücherverbrennung inszeniert, bei der Joseph Goebbels in Anwesenheit des Rektors Eugen Fischer dazu aufforderte, den „geistigen Unflat“ den Flammen zu übergeben. ${ }^{175}$ Und in Stoeckels Klinik waren bereits die Volontärärztin Etelka Grotjahn sowie die Krankenschwestern Gertrud Kalmar und Elisabeth Wucke aufgrund des „Gesetzes zur Wiederherstellung des Berufsbeamtentums“ entlassen worden. Auch der wissenschaftlich am höchsten qualifizierte Mitarbeiter Stoeckels, der berühmte Gynäkopathologe Robert Meyer, war als „Nichtarier“ akut bedroht. ${ }^{176}$

\section{Diktat oder Verhandlungsergebnis?}

Schon in den ersten Monaten nach der Machtübernahme begann das NS-Regime, auch die „Gleichschaltung“ der wissenschaftlichen Fachgesellschaften in Angriff zu nehmen. Besonderes Interesse erfuhren dabei die Mediziner. Die neue rassistisch-biologistische Staatsauffassung und ihre Umsetzung benötigte einerseits die Bestätigung und Legitimation der einschlägigen Wissenschaften durch ihre Fachverbände, konnte und wollte aber andererseits keinerlei wissenschaftliche Debatte darüber aufkommen lassen. Die rasse- und bevölkerungspolitischen Maßnahmen waren gleichzeitig ohne breite Beteiligung der Ärzteschaft schlicht nicht vorstellbar. Treibende Kraft war Friedrich Bartels, der spätere stellvertretende Reichsärzteführer. 1933 noch Ministerialrat im Reichsinnenministerium, etablierte er eine „Reichszentrale für Gesundheitsführung“, unter deren Dach in zahlreichen Reichsarbeitsgemeinschaften (RAGs) wichtige Fachgesellschaften vereinigt und im Sinne des Regimes tätig werden sollten - darunter an hervorgehobener Stelle die RAG „Mutter und Kind“ mit der DGG als Mitglied. ${ }^{177}$ Ein wesentliches Ziel der Reichszentrale war die Bündelung der Maßnahmen zur „biologischen und funktionellen Ertüchtigung der Bevölkerung“. ${ }^{178}$ Dazu sollten unter anderem die Satzungen der an den RAGs beteiligten Fachgesellschaften so modifiziert werden, dass deren Kontrolle durch den NS-Staat gewährleistet war.

Bartels, schon damals Vertrauensmann des Reichsärzteführers Gerhard Wagner, hatte am 24.Juli 1933 zu einer Besprechung ins Innenministerium eingeladen. Auf dem Programm stand die „Eingliederung der wissenschaftlichen Gesellschaften in die Reichszentrale für Gesundheitsführung“. ${ }^{179}$ Für die DGG nahm Stoeckels Oberarzt Günther Frommolt teil, der zu diesem Zeitpunkt 2. Schriftführer der Gesellschaft war und seinen offenbar im Urlaub weilenden Chef vertrat. ${ }^{180}$ Im Verlauf der Sitzung stimmte Frommolt - wie Vertreter anderer Fachgesellschaften auch - den vorgeschlagenen weitreichenden Eingriffen in die Satzung der DGG zu, allerdings mit dem Vorbehalt des Einver- ständnisses von Stoeckel in seiner Eigenschaft als Präsident der Gesellschaft. Über Details der Eingriffe und den weiteren Verlauf informiert ein Briefwechsel Stoeckels mit Bartels, der im Bundesarchiv Berlin vorliegt. Eine Dokumentation von Seiten der DGG existiert nicht mehr bzw. ist nicht zugänglich. ${ }^{181}$

Das erste Schreiben Stoeckels an Bartels in dieser Angelegenheit stammt vom 2. August 1933. Ohne in irgendeiner Form auf Inhalte einzugehen, teilte er darin seine Zustimmung zu den zwischen Frommolt und der Behörde getroffenen Vereinbarungen mit. Gleichzeitig schlug Stoeckel sich für eine seiner Ansicht nach nötige „Verbindungsstelle“ zwischen der Reichszentrale und der DGG vor und bat um einen Termin für eine „kurze persönliche Besprechung“. ${ }^{182}$

Bartels antwortete eine Woche später darauf - allerdings ohne den gewünschten Termin zu nennen. Vielmehr hieß es ohne Umschweife:

„Ich bitte Sie, entsprechend der hier getroffenen Vereinbarung, mir die Aufnahme folgender Satzungszusätze in ihre Satzungen [...] mitzuteilen, damit ich Ihnen die Bestätigung des Reichsministeriums des Inneren möglichst umgehend zustellen kann.

1. Die Deutsche Gesellschaft für Gynäkologie untersteht der Führung durch das Reichsministerium des Inneren. Dem Reichsministerium des Inneren liegt die Bestätigung der Vorstandsmitglieder ob.

2. Das Reichsministerium des Inneren kann Vorstandsmitglieder jederzeit abberufen.

3. Das Reichsministerium des Inneren kann Beschlüsse aussetzen oder aufheben.

4. Die Deutsche Gesellschaft für Gynäkologie gehört über den Reichsausschuss für Mutter und Kind der Reichszentrale für Gesundheitsführung an.

5. Satzungsänderungen unterliegen der Zustimmung des Reichsministeriums des Inneren.

Ich danke Ihnen für die von uns gewünschte Mitarbeit an den Aufgaben des Staates, bei der gerade Ihre Gesellschaft, um für das deutsche Volk und die deutsche Frau segensreich wirken zu können, nicht entbehrt werden kann." ${ }^{183}$

Knapp einen Monat später, am 15. September 1933, teilte Stoeckel Bartels wiederum schriftlich mit, dass der Vorstand der DGG „die notwendig gewordenen Statutenänderungen“ beschlossen habe. Sie müssten nun nur noch von der Mitgliederversammlung auf der Oktobertagung angenommen werden. Von zwischenzeitlichen Verhandlungen über die Inhalte bzw. die Vorschläge des Ministeriums dazu ist nicht die Rede. Stoeckel ergänzte lediglich, dass der Vorstand der Mitgliederversammlung außerdem vorschlagen wolle, ihn für 4 Jahre zum Vertreter der DGG gegenüber

\footnotetext{
175 Heiber: Universität (1992), S. 89.

176 Doetz: Alltag (2011), S. 177. Zu Robert Meyer und seinem Schicksal Ebert: Recht (2010), S. 219-237.

177 Zur Rolle der DGG in der RAG „Mutter und Kind“ siehe S. 29-31.

178 BArch Berlin, R 1501/126476 Reichzentrale für Gesundheitsführung beim Reichsinnenministerium, Bl. 3: Schreiben von Bartels an den Innenminister (ohne Datum).

179 BArch Berlin, R 1501, 126476, Bl. 8-9.

180 Stoeckel: Leben (1954), S. 118: „Ich verlebte meine Ferien als Kurgast in Mergentheim und später in Nussbach [...] das kongreßliche Vorposten-Geplänkel überließ ich meinem Oberarzt Frommolt $[\ldots]^{*}$

181 Einsicht in den Nachlass Stoeckels, in dem sich wie in den Nachlässen der Ex-Präsidenten August Mayer und Josef Zander möglicherweise noch einschlägige Dokumente befinden, war leider nicht zu erhalten.

182 BArch Berlin, R 1501, 126481, Bl. 37.

183 Ebd., Bl. 38.
} 
dem Innenministerium und anderen Behörden zu wählen. Er hoffe, dass „damit die Angelegenheit geregelt“ sei. ${ }^{184}$ Bartels hatte dem beigefügten Entwurf der neuen Satzung gegenüber keine Einwendungen und bat nur noch um Bestätigung der Annahme durch die Mitgliederversammlung. ${ }^{185}$

Nach Aktenlage vollzog sich der erste Akt der „Gleichschaltung“ der DGG also offenbar rasch und unspektakulär innerhalb von knapp 3 Monaten. An keiner Stelle wird deutlich, dass es zu den vom Regime gewünschten Eingriffen in die Satzung der DGG Diskussionen oder gar Widerstand gab. In den autobiografischen Quellen Stoeckels und seinen Äußerungen in der Eröffnungsrede zum Kongress 1933 stellt sich der Vorgang allerdings etwas anders dar - vor allem wohl deshalb, weil hier „Gleichschaltung“ und Kongressvorbereitung in der Darstellung nicht klar getrennt werden. Allerdings dürfte das eine (Zustimmung zur „Gleichschaltung“) die Voraussetzung für das andere (Durchführung des Kongresses) gewesen sein.

Auch bei Einbeziehung der autobiografischen Quellen Stoeckels und seiner Äußerungen zum Thema in der Eröffnungsrede zum Kongress 1933 bleibt unklar, ob es bei den Gesprächen im Reichsinnenministerium über die vom Regime verlangten Satzungsänderungen überhaupt Verhandlungen im Sinn des Wortes gab oder ob entsprechende Forderungen der Regierung weitgehend widerspruchslos akzeptiert wurden. Für Letzteres spricht, dass vergleichbar formulierte Eingriffe in die Autonomie entweder schon zuvor oder aber in etwa gleichzeitig von mindestens 2 anderen Fachgesellschaften akzeptiert worden waren: der Deutschen Gesellschaft für Innere Medizin und der Deutschen Gesellschaft für Kinderheilkunde. ${ }^{186}$ Weitere sollten folgen.

Der aktenkundige Dialog mit Ministerialrat Bartels wird nur in der Eröffnungsrede Stoeckels vom Oktober 1933 explizit erwähnt. Er konstatiert dazu lediglich: „Die Verhandlungen mit dem Ministerium sind zunächst von Professor Frommolt, dann von mir selbst geführt worden; ich habe die Mitarbeit der Gesellschaft zugesagt und die gestellten Bedingungen angenommen."187 Von einer Vorstandssitzung, in der darüber diskutiert und ein Beschluss dazu gefasst worden wäre, ist vor den Mitgliedern nicht die Rede. Auch sonst findet sich in den zugänglichen Unterlagen kein Hinweis darauf.

In der Autobiografie von 1954 schreibt Stoeckel ohne Hinweis auf ein konkretes Ereignis: „[...] wir mußten uns auch umstellen und auf die an uns von der Regierung herangetragenen Wünsche eingehen.“ Deren Forderungen habe er „mit nicht geringen innerlichen Bedenken“ zugestimmt. Er sei aber davon überzeugt gewesen, „daß bei den bestehenden Machtverhältnissen die Gesellschaft nur auf diese Weise in die neue Zeit hineingeführt und ihr Bestand für die Zukunft gesichert werden konnte“. Die Verhandlungspartner hätten immer wieder und sehr nachdrücklich versichert, dass von einem Eingreifen der Regierung in die „Ver- handlungen oder Geschäfte unserer Gesellschaft gar keine Rede sein könne“. Stoeckels Berater und Konvorstand Otto von Franqué war in dieser Hinsicht offensichtlich weniger zuversichtlich: „[Er...] sprach von Rücktritt und Auflösung, war völlig pessimistisch, und es gelang mir nur schwer und allmählich und nicht völlig, ihn etwas zuversichtlicher zu machen“, schrieb Stoeckel. ${ }^{188}$

Deutlich anders dagegen die Darstellung in den bearbeiteten „Erinnerungen“ aus dem Jahr 1966. Hier wird die Kongressplanung in den Vordergrund gerückt, in deren Rahmen offenbar mit dem damaligen Staatskommissar im Innenministerium und späteren Reichsärzteführer Leonardo Conti verhandelt werden musste. „Als Hauptschwierigkeit zeichnete sich allmählich ein gewichtiges Problem ab: die Judenfrage“, heißt es da. Die Verhandlungen mit der Regierung seien aber durch den „freiwilligen“ Rücktritt zweier sehr angesehener jüdischer Vorstandsmitglieder erleichtert worden: des damaligen Direktors der Brandenburgischen Landesfrauenklinik, Sigfrid Hammerschlag, und des Direktors der UFK Breslau, Ludwig Fraenkel. Im Ergebnis sei man mit Conti dahingehend einig geworden, dass das Mitgliederverzeichnis wissenschaftlicher Gesellschaften nicht ,judenrein“ zu sein brauche. Es bestünden auch keine Bedenken gegen die Einreise und Vorträge ausländischer Juden in wissenschaftlichen Sitzungen. Inländische Juden sollten allerdings nicht sprechen „und sich in ihrem eigenen Interesse zurückhalten“.

An dieser Stelle folgt nun unvermittelt eine Verknüpfung mit den Satzungsgesprächen:

„Die wissenschaftliche Arbeit der Gesellschaft und ihr Wahlprinzip sollte uneingeschränkt bestehen bleiben, ein in Berlin wohnendes Vorstandsmitglied Verbindungsmann zur Regierung werden. Nur einer Forderung mussten wir uns beugen: Die Regierung behielt sich das Recht vor, Vorstandsmitglieder abzuberufen und Beschlüsse der Gesellschaft auszusetzen oder aufzuheben.“189

Diese Konstruktion sollte im Nachhinein wohl suggerieren, dass hart verhandelt wurde, und so der sofortige Ausschluss der jüdischen Mitglieder der Gesellschaft ebenso habe verhindert werden können wie die Nichtzulassung der Einreise ausländischer Juden oder ein Sprechverbot für sie. „Im ersten Jahr des nationalsozialistischen Regimes war es noch möglich, auf dem Verhandlungswege Zugeständnisse zu erreichen“, heißt es dazu in Stoeckels „Erinnerungen“. 190

\section{Der Kongress folgt seinem Präsidenten}

Den autobiografischen Äußerungen Stoeckels von 1954 ist zu entnehmen, dass er zumindest in den Anfängen des „Dritten Reiches" von der Person Hitlers fasziniert war und sich mit wesentlichen Zielen des Nationalsozialismus identifizieren konnte. ${ }^{191}$ Zudem sah er in einer engen Zusammenarbeit mit dem Regime nicht unerhebliche Chancen für die DGG und sicherlich auch für sich selbst, zu mehr Macht und Einfluss zu gelangen. Nicht zu-

\footnotetext{
184 BArch Berlin, R 1501, 126481, Bl. 39.

185 BArch Berlin, R 1501, 126481, Bl. 44.

186 Siehe hierzu Schmuhl: Neurologen (2016), S. 80, Fußnote 263.

187 Stoeckel: Eröffnungs-Ansprache [Verhandlungen 1933] (1934), XLII.

188 Stoeckel: Leben (1954), S. 118.

189 Stoeckel: Erinnerungen (1966), S. 391.

190 Stoeckel: Erinnerungen (1966), S. 390 f.

191 Siehe S. $13 \mathrm{f}$.
} 
letzt lag ihm das Gelingen „seines“ Kongresses sehr am Herzen, den er gegen vielerlei andere Widerstände und auch gegen Bedenkenträger aus den eigenen Reihen durchsetzen musste. Letztere hielten die politische Situation für noch zu instabil - eine Einschätzung, die in jenen Tagen andere Fachgesellschaften veranlasste, Tagungen abzusagen oder zu verschieben. ${ }^{192}$

Unter diesen Voraussetzungen bereitete Stoeckel jene Rede vor, mit der er am 11. Oktober 1933 in Berlin vor die Teilnehmer der 23. Tagung der DGG treten wollte. Nachdem die Bedingungen des Regimes für die künftige Satzung der Gesellschaft im Vorfeld de facto bereits akzeptiert waren, kam es jetzt darauf an, die Mitglieder zu einer möglichst einhelligen Zustimmung zu bewegen. Darüber hinaus sollten auch die übrigen Versammlungsteilnehmer - vor allem die vergleichsweise wenigen Ausländer - einen positiven Eindruck mit nach Hause nehmen. Hierfür war die Behandlung des zweiten kritischen Punktes besonders bedeutungsvoll: die „Judenfrage“. Stoeckel schrieb später: „Meine Rede mußte $[\ldots]$ auch politisch, sozusagen ,gesellschafts-politisch` sein." 193

Dieser Prämisse ist Stoeckel dann auch gefolgt. Mit einem Rückblick in völkischer Rhetorik auf die politischen Ereignisse, von denen die Versammlungen der DGG seit dem Ende des Ersten Weltkriegs begleitet waren, beschrieb er vor den Teilnehmern die „dritte Revolution“194, deren Folgen den aktuellen Kongress prägen sollten: Sie sei

„erst wenige Monate vor unserer diesjährigen Zusammenkunft [...] mit der elementaren Wucht einer gewaltigen Naturkraft über Deutschland dahingebraust [...]. Unsicherheit, Verwirrtheit, Zukunftspessimismus und innerer Hader sind überwunden; Klarheit, Zielsicherheit, der Zusammenschluß aller nationalen Kräfte und ein unerschütterlicher, fanatischer Glaube an Deutschlands Zukunft sind zum breiten Fundament aller aufbauenden Arbeit geworden. [...] Weich war die Zeit im Niedergang unseres Volkes - hart ist sie im Aufstieg geworden und stahlhart wird auch die Führung im neu gestalteten Staat bleiben müssen." ${ }^{195}$

Damit stellte Stoeckel den Bezug zum Schicksal der „Juden“ her, deren Verdrängung und Verfolgung in vollem Gange war. Alle verstanden, was gemeint war, als Stoeckel feststellte, dass „diese unerbittliche Härte [...] schicksalhaft über Einzelschicksale hinweg“" gehe. ${ }^{196}$

Seine Ausführungen zur „Gleichschaltung“ der Gesellschaft begann Stoeckel mit dem Hinweis darauf, dass er eine Mitteilung zu machen habe, „die für unsere Gesellschaft von einschneidender Bedeutung ist“. Anschließend teilte er mit, dass er folgende Bedingungen angenommen habe:

„1. Der Vorstand unserer Gesellschaft bedarf der Bestätigung durch das Reichsministerium des Inneren und kann von ihm abberufen werden.
2. Die Satzungen unserer Gesellschaft bedürfen ebenso wie etwaige Satzungsänderungen der Zustimmung des Reichsministeriums des Inneren.

3. Beschlüsse des Vorstandes und der Mitgliederversammlung können, auch wenn sie sachlich richtig sind, vom Reichsministerium des Inneren ausgesetzt oder aufgehoben werden.“197

Diese Sätze, so fuhr Stoeckel mögliche Kritik antizipierend fort, wirkten in ihrer „Buchstabennacktheit, ohne jede Bekleidung mit erläuternden Zusätzen hart, hemmend - als Eingriff, als Aufsicht". Es könne der Eindruck entstehen, mit der völlig unabhängigen, zwangfreien wissenschaftlichen und klinischen Arbeit sei es nun vorbei. Er sei aber fest davon überzeugt, dass derartige Befürchtungen „völlig abwegig und unbegründet“ seien. Im Übrigen lasse sich Wissenschaft nicht beschließen, und wissenschaftliche Streitpunkte könnten „nicht durch Mehrheitsfeststellungen und behördliche Einwirkung“, sondern immer nur durch weitere Prüfung entschieden werden. So würden die verlangten Satzungsänderungen die Gesellschaft auf ihrem „primären, dem wissenschaftlichen Arbeitsfeld“ letztlich nicht berührten.

In Gegensatz dazu stellte Stoeckel die Aktivitäten der DGG in anderen Bereichen, wie etwa der Sozial-, Gesundheits-, Rechts- und Wissenschaftspolitik. Hier habe die „Beschlussfreudigkeit“ nach dem Weltkrieg zugenommen, weil die Gesellschaft in den „Wirbelwinden des politischen und sozialen Lebens“ nicht als $\mathrm{Zu}$ schauer habe abseitsstehen wollen. Stoeckel zählt dann eine Reihe von Initiativen auf, etwa zur Studienreform, zum Schwangerschaftsabbruch und zu einer deutschen Kaiserschnittstatistik. Er erinnert ferner an Aktionen gegen die Errichtung von Krebskrankenhäusern und strahlentherapeutischen Zentralinstituten sowie gegen die Herabwürdigung der Eheberatungsstellen zu „getarnten Zentralen der Schwangerschaftsverhütung“. Die Aufzählung schließt mit der rhetorischen Frage: „Und wie war der Erfolg - was ist dabei herausgekommen? Gar nichts! " ${ }^{198}$ Nun aber sei erstmals umgekehrt eine Regierung an die DGG herangetreten und habe ihre Mitarbeit gesucht. Kein Gesetz - dies sei der kürzlich ausgesprochene, persönliche Wille des Reichskanzlers -, das die Gesundheit des Volkes betreffe, solle erlassen werden, ohne vorher „der eingehenden, zuständigen ärztlichen Kritik“ unterworfen worden zu sein.

In seinen weiteren Worten stellte Stoeckel die Zusammenarbeit mit der Regierung gleichwohl als Kontinuität der sozialgynäkologischen Aktivitäten früherer Präsidenten dar und betonte die Verpflichtung wissenschaftlicher Gesellschaften, über den „umschrieben Kreis ihrer Arbeitsinteressen“ hinaus das Volkswohl zu fördern:

„Wir können, skeptisch und formal denkend, über ein paar Paragraphenknüppel, die am Wege liegen, stolpern und uns versagen. Ich aber meine, wir müssen uns in idealistischer Gesinnung und

\footnotetext{
192 Siehe hierzu Stoeckel: Leben (1954), S. 118.

193 Stoeckel: Leben (1954), S. 119.

194 Als die beiden ersten Revolutionen bezeichnet Stoeckel die Novemberrevolution von 1918 und den Kapp-Putsch von 1920.

195 Stoeckel: Eröffnungs-Ansprache [Verhandlungen 1933] (1934), XL-XLI.

196 Ebd., XLI-XLII

197 Ebd., XLII-XLIII.

198 Ebd., XLV.
} 
aus der klaren Erkenntnis unserer Gegenwartsverpflichtung heraus zu dieser Mitarbeit bereit erklären." 199

Stoeckel schloss seine Rede mit einer pathetisch formulierten Reminiszenz an den Handschlag Hindenburgs und Hitlers am 30. Januar 1933, an die Verpflichtung, die sich daraus für die DGG ergebe und mit der Verlesung von 2 Huldigungstelegrammen an die beiden Politiker. ${ }^{200}$

In den autobiografischen Schriften Stoeckels findet sich zum Inhalt seiner Rede nichts Konkretes, er hat sie im Gegensatz zu anderen Reden später auch nicht noch einmal veröffentlicht. ${ }^{201}$ In dem Manuskript von 1954 ist nur die Originalquelle angegeben. Dagegen wird die Reaktion der Versammlung auf seinen Auftritt genau beschrieben:

„Als ich mit dem Vorstand erschien und das Rednerpult betrat, war die Spannung im Saal fühlbar groß. [...] [Die Rede] wurde mit gespanntester Aufmerksamkeit entgegengenommen und löste starken Beifall aus. Das ganze Plenum ging geschlossen mit. Ich fühlte bei jedem Satz, den ich sprach, wie die Zustimmung zu dem von mir entwickelten Programm wuchs. Als ich am Schluss das Einverständnis zur Absendung zweier Huldigungstelegramme an Hindenburg und Hitler erbat, klang begeisterter Beifall auf." ${ }^{202}$

\section{Vorstandsarbeit jenseits der Kongresse \\ $\nabla$}

Im Folgenden sollen Gegenstände der Vorstandsarbeit dargestellt werden, die nicht in unmittelbarem Zusammenhang mit den später abzuhandelnden Kongressen und deren Vorbereitung standen. Von besonderem Interesse sind dabei die Zusammenarbeit der DGG mit der Reichsarbeitsgemeinschaft „Mutter und Kind" sowie die Kontroverse der Gesellschaft mit Repräsentanten des Regimes über Hausgeburtshilfe, Hebammenbefugnisse und Schwangerenvorsorge. In dieser Auseinandersetzung, die vor allem mit dem Reichsgesundheitsführer Leonardo Conti ausgetragen wurde, dessen Mutter Nanna Conti die Reichshebammenführerin war, prallten absolut konträre Interessen aufeinander. Sie bot damit erhebliches Konfliktpotenzial mit dem NS-Staat.

\section{Die DGG und die RAG „Mutter und Kind“}

Walter Stoeckel, der sich schon zu Beginn der „Gleichschaltungsgespräche“ gegenüber dem Innenministerium als Verbindungsmann der DGG zur RAG „Mutter und Kind“ ins Gespräch gebracht hatte, wurde beim Kongress der Gesellschaft im Oktober 1933 erwartungsgemäß für 4 Jahre in das angestrebte Amt gewählt. Anschließend bezeichnete er es als besondere Ehre, der Gesellschaft auf diesem Posten dienen zu dürfen und versicherte, er werde die Rechte der Mitglieder ,jederzeit mit Festigkeit und Nachdruck vertreten“. Gleichzeitig äußerte er die Erwartung, „daß diejenigen Herren, die ich um Hilfe bitte, sie mir jederzeit mit Freude und mit der Einsetzung ihrer gesamten Arbeitskraft leisten werden“. 203

Im Rückblick erscheint es nicht ganz klar, weshalb Stoeckel sich nach seiner Präsidentschaft und dem aus seiner Sicht erfolgreichen Vollzug der „Gleichschaltung“ noch in diese Funktion wählen ließ. Mögliche Gründe dafür sind, dass er so seine Zugehörigkeit zum DGG-Vorstand für die ebenfalls von ihm vorgeschlagene 4-jährige Amtsperiode fortschreiben und damit gleichzeitig seine Netzwerke innerhalb der Gesellschaft und nach außen zu den Reichsbehörden ausbauen wollte. Andererseits zeigte er schon zu Beginn seiner Kontakte zu dem neuen Gremium der Reichsbehörden kein übergroßes Interesse an persönlicher Präsenz: Beim ersten Gespräch zur Eingliederung der Fachgesellschaften ließ er sich als Urlauber von Frommolt vertreten, bei der später stattfindenden Gründungsveranstaltung der den RAGs übergeordneten „Reichszentrale für Gesundheitsführung“ von einem weiteren seiner Oberärzte, Ernst Philipp. Auch insgesamt, so scheint es, hat Stoeckel sich - wenn überhaupt - nur im Hintergrund als Organisator der ohnehin relativ spärlichen Auftritte von DGG-Vertretern bei Veranstaltungen der RAG oder der übergeordneten Reichszentrale betätigt. Und auf der DGG-Tagung von 1937 zog er sich und die Gesellschaft dann noch weiter zurück: „[...] unser jetziger Vorstand hat einen so breiten Kontakt mit der Regierung, daß es eines Verbindungsmannes nicht mehr bedarf“, erklärte Stoeckel, als eine Neuwahl in diese Position anstand, die dann auch ersatzlos gestrichen wurde. ${ }^{204}$

Dies alles spricht nicht dafür, dass der RAG von Seiten der DGG große Bedeutung beigemessen wurde. Man glaubte offenbar, sich weiterhin im Wesentlichen auf die Beschäftigung mit den eigenen wissenschaftlichen Tagungen beschränken zu können und nur von Fall zu Fall mit einem Vortrag bei der RAG auftreten zu müssen. In den Unterlagen von August Mayer zur Vorbereitung des DGG-Kongresses 1935 wird - soweit erkennbar - die RAG nur ein einziges Mal erwähnt: bei der ersten Sitzung des Organisationsteams in Stuttgart im Februar 1935. Damals hatte man für einen oder zwei Kongressnachmittage populärwissenschaftliche öffentliche Veranstaltungen erwogen. „Die DGG schaltet sich von sich aus damit in die Reichsfachschaft für Mutter und Kind ein“, heißt es in einer entsprechenden Protokollnotiz. ${ }^{205}$ Das ganze Projekt wurde dann wohl zugunsten der Planung eines öffentlichen Vortrages von Mayer ad acta gelegt. Jedenfalls sind anschließend keine Aktivitäten für die RAG mehr nachweisbar.

Dies erstaunt etwas, denn der Reichszentrale und den insgesamt 10 ihr zuarbeitenden RAGs ${ }^{206}$ waren weitreichende Aufgaben zugedacht: Sie sollten den Erfolg der Gesundheitsführung und -für-

\footnotetext{
199 Stoeckel: Eröffnungs-Ansprache [Verhandlungen 1933] (1934), XLV.

200 Ebd., XLVII. Die Depesche an Hitler lautet: „Dem Mann, der Deutschland gerettet, neu gestaltet und zusammengeschmiedet - der Standesdünkel und Klassenhochmut verächtlich gemacht - der die Hände aller ehrlicher Arbeiter ineinander gefügt hat - dem edlen Menschen und dem großen Staatsmann, unserem Volkskanzler Adolf Hitler huldigen die deutschen Gynäkologen in begeisterter Verehrung und geloben, an der Gesundung und an der Gesunderhaltung des deutschen Volkes mit aller Kraft mitarbeiten zu wollen.“

201 Vgl. hierzu: Stoeckel: Ansprachen (1952).

202 Stoeckel: Leben (1954), S. 119.

203 Mitgliederversammlung [Verhandlungen 1933] (1934), LIV.

204 Mitgliederversammlung [Verhandlungen 1937] (1938), S. 17.

205 UAT 150/33,41: Besprechung (23.02.1935).

206 Dazu zählten u.a. RAGs für Krankenhauswesen, Krebsbekämpfung, Volksernährung sowie die RAG der Berufe im ärztlichen und sozialen Dienst, der auch die Reichsfachschaft Deutscher Hebammen unter der Leitung von Nanna Conti angegliedert war; UA HUB, Sammlung Rott, Kasten 150.
} 
sorge kontrollieren, aber auch „durch eigene wissenschaftliche sozialbiologische Arbeit die Unterlagen und die Richtung für die praktische Arbeit geben“. ${ }^{207}$ Möglicherweise hat sich die DGG durch ihre Zurückhaltung in der RAG „Mutter und Kind“ unter anderem um Einfluss auf die Entwicklungen in der Geburtshilfe gebracht, deren Korrektur 1939/40 im Zusammenhang mit dem Eklat um die Denkschrift der Gesellschaft des Kraftaktes bedurfte, von dem anschließend die Rede sein wird.

Die Zurückhaltung der DGG in der RAG „Mutter und Kind“ führte bereits frühzeitig zu einer Dominanz der Kinderheilkunde, die sicherlich dem als stellvertretenden Vorsitzenden agierenden Sozialpädiater Fritz Rott zuzuschreiben war. Diese Dominanz zeigte sich sowohl in der praktischen Arbeit der RAG als auch in deren Publikationen und Veranstaltungen. Darüber hinaus blieb die DGG auch bei Themen, die ihr Interessengebiet direkt betrafen, weitgehend unberücksichtigt, weil sie bei einschlägigen Arbeitssitzungen offenbar nicht oder nicht ausreichend präsent war. Prominente Mitglieder der Gesellschaft äußerten sich zwar bei den beiden großen Tagungen der RAG 1935 und 1937, blieben aber auf dem zunehmend kontrovers betrachteten Gebiet der Haus- bzw. Klinikgeburtshilfe entweder unverbindlich oder überließen das Thema dem späteren Reichsgesundheitsführer Conti.

Bereits bei der Gründungsveranstaltung der Reichszentrale für Gesundheitsführung am 20. November 1933 wurde über erste Aktivitäten der RAG „Mutter und Kind“ berichtet. Danach lagen unter anderem Entwürfe für eine reichseinheitliche Regelung zur Ausbildung von Kinderpflegerinnen und Kinderschwestern vor. Ferner hatte man gemeinsam mit der „Reichsfachschaft deutscher Hebammen“ und dem Reichsgesundheitsamt den Entwurf einer gesetzlichen Regelung für das Hebammenwesen erarbeitet. Weitere Maßnahmen betrafen Richtlinien für die Gesundheitsführung der Hitlerjugend und die Basis für ein Mütterhilfswerk. Außerdem waren - vor allem im Rahmen der „Deutschen Vereinigung für Säuglings- und Kleinkinderschutz“ - konstitutionsbiologische und gesundheitsstatistische Arbeiten aufgenommen worden. Eine sozialbiologische Erhebung über die Gesundheitsverhältnisse der weiblichen Landbevölkerung hatte die RAG bereits abgeschlossen und publiziert. ${ }^{208}$ Fünf Monate später, im Februar 1934, stellte die „Reichszentrale für Gesundheitsführung“ dann ein ausformuliertes Arbeitsprogramm für die RAG „Mutter und Kind“ vor, in dem sich das Fach Frauenheilkunde und Geburtshilfe nur an wenigen Stellen wiederfinden konnte etwa in einer Untersuchung über „Konstitution und Mutterschaft". 209

Die erste eigene Veranstaltung der RAG „Mutter und Kind“, die am 21. November 1933 stattfand - einen Tag nach der offiziellen Gründung der Reichszentrale und rund einen Monat nach dem
„Gleichschaltungskongress“ der DGG -, enthielt keinen einzigen Tagesordnungspunkt, der für die Gynäkologie oder Geburtshilfe einschlägig gewesen wäre. Anschließend war die RAG rund 2 Jahre lang nicht öffentlich tätig. Erst am 26. April 1935 veranstaltete sie wieder eine Tagung. Zu diesem Zeitpunkt war ein Erlass des Reichsinnenministeriums bereits rund 6 Monate alt, in dem die Hausentbindung als der nationalsozialistischen Weltanschauung entsprechend propagiert wurde. Zur Begründung hieß es unter anderem, die der Bevorzugung der klinischen Entbindung „stillschweigend zugrundeliegende Überzeugung“, dass damit eine Senkung der Müttersterblichkeit auf ein möglichst geringes Maß möglich sei, stimme „mit den heutigen ärztlichen Erfahrungen jedoch nicht überein“. 210

In seiner Eröffnungsansprache zu dieser ersten größeren Tagung der RAG „Mutter und Kind“ machte Leonardo Conti als Vertreter der Reichsbehörden den Teilnehmerinnen und Teilnehmern unmissverständlich klar, welche Intentionen der Veranstaltung zugrunde lagen: Die RAG, so sagte er, habe sie „zusammengerufen, um Ihnen in zwei Vorträgen dasjenige zu geben, was wir gerne an Richtlinien in Ihre Arbeitsgebiete hereintragen möchten“.211 Anschließend sprach Georg August Wagner, der rund ein halbes Jahr später zum DGG-Präsidenten gewählt werden sollte, über die „Grundlagen der Mutterschaftsfürsorge“. Im Zusammenhang mit der Entbindung erklärte er zunächst, er wolle „auf den neulich wieder aufgenommenen Streit, ob die Hausgeburt oder die Anstaltsgeburt mehr Vorteile oder Gefahren bietet,“ an dieser Stelle nicht weiter eingehen, konnte es sich dann aber doch nicht verkneifen, das häufig gegen die Anstaltsgeburt ins Feld geführte erhöhte Infektionsrisiko anzusprechen. Er zitierte dabei unter anderem Nanna Conti, die behauptete, in New York habe sich gezeigt, dass die Zahl der Infektionen im Wochenbett nach Klinikentbindungen im Vergleich zu Hausentbindungen um 50\% höher liege. „Nach unseren eigenen Erfahrungen müssen wir sagen, daß da wohl etwas nicht stimmen kann“, kommentierte Wagner. Eine direkte Konfrontation vermied er allerdings, indem er den Streit gewissermaßen als gegenstandslos erklärte: „Die möglichste Ausnutzung der Vorteile der Hausgeburt ist uns allen durch den Erlass des Innenministeriums zur Pflicht gemacht worden." 212 Zweiter Referent nach Wagner war der Berliner Pädiater Georg Bessau, ein führender Kinderarzt der NS-Zeit, der später verbrecherische Impfversuchen an behinderten Kindern vornahm. Er sprach über „Die Grundlagen der Kinderfürsorge“. 213

Die zweite und wahrscheinlich letzte große Tagung der RAG ${ }^{214}$ fand erst im Mai 1937 statt, wiederum einige Montage vor dem Kongress der DGG. Diesmal wurden 2 der insgesamt 7 Vorträge von hochrangigen DGG-Mitgliedern gehalten: Ludwig Seitz, Präsident von 1929 bis 1931, sprach über „Die Betreuung der kranken Schwangeren“;215 Rudolf Theodor von Jaschke, damals Ordi-

\footnotetext{
207 Rott: Reichszentrale (1933), S. 7, zit. n. Schabel: Hygiene (1995), S. 151.

208 UA HUB, Sammlung Rott, Kasten 150.

${ }^{209}$ Details in der Niederschrift der Sitzung der Reichszentrale für Gesundheitsführung vom 22.02. 1934, vormittags 10 Uhr, im Reichsministerium des Innern; BArch Berlin, R 1501/12 647, 162-179.

210 Runderlass des Preußischen Ministeriums des Inneren (06.09.1934).

211 Conti: Eröffnungsansprache (1935).

212 Wagner: Grundlagen (1935), S. $11 \mathrm{f}$.

213 Zu Bessau: Beddies/Schmiedebach: „Euthanasie“-Opfer (2004), S. 177-189.

214 Ob eine ursprünglich für den 17. Oktober 1939 geplanten Tagung der RAG „Mutter und Kind“ noch stattfand, ist unklar. Überliefert ist nur die Einladung in das Berliner Langenbeck-Virchow-Haus. Mit hoher Wahrscheinlichkeit fiel die Tagung ebenso wie der DGG-Kongress 1939 dem Kriegsbeginn zum Opfer.

215 Seitz: Betreuung (1937).
} 
narius in Gießen und Präsident der DGG in spe, über die „Betreuung des gesunden und kranken Neugeborenen in der geburtshilflichen Klinik“. ${ }^{216}$ Das brisanteste Thema hatte sich freilich Leonardo Conti persönlich vorbehalten: „Geburtshilfe und Hebammenwesen in Deutschland“.

In der Eröffnungsrede zu der Veranstaltung, bei der wie auf den DGG-Tagungen auch eine Aussprache zu den einzelnen Referaten vorgesehenen war, forderte Conti ausdrücklich zur Diskussion auf ( Abb. 12). „Arbeitstagungen wie diese haben nur Zweck, wenn in ihnen frei die Meinung gesagt wird, wenn gerade die schwierigsten und akuten Probleme angepackt und zur Erörterung gestellt werden“, erklärte er. ${ }^{217}$ In seinem Referat nahm er dann ausführlich zum Für und Wider von Haus- und Anstaltsentbindung Stellung, wobei seine Ausführungen von den seit Jahren bekannten Argumenten dominiert wurden, die einerseits von der NS-Ideologie, andererseits aber auch durch berufspolitische Interessen des Hebammenstandes geprägt waren. Die Klinikgeburt desavouierte er dabei unter anderem mit dem Satz: „Das Dogma der grundsätzlichen Überlegenheit der Anstaltsentbindung beherrscht besonders die gebildeten Kreise, gerade diese bevorzugen die Anstaltsentbindung." Zugute kam ihm bei seiner Argumentation, dass er unwidersprochen auf gravierende Mängel bei der statistischen Erfassung und Auswertung relevanter geburtshilflicher Daten verweisen konnte. Auch das immer wieder benutzte Argument von schlecht geführten und deshalb gefährlichen Entbindungs- oder Mütterheimen ließ sich nur schwer entkräften. ${ }^{218}$

In der Diskussion zu Contis Vortrag meldete sich neben einigen Amtsärzten von Seiten der DGG als Wissenschaftler und Klinikchef nur der Heidelberger Ordinarius Hans Runge zu Wort. Runge, aktiver Nationalsozialist und an der Medizinischen Fakultät seiner Universität auch Wegbereiter der Neuen Deutschen Heilkunde, äußerte sich diplomatisch. Zunächst, so begann er, hätten die Ausführungen Contis die Sorge entstehen lassen, „daß eine Klärung der von ihm behandelten Fragen nicht ohne streitige Auseinandersetzung möglich sein würde“. Nun könne er aber mit Erleichterung feststellen, dass die Schlusssätze Contis in den wichtigsten Punkten auch die Zustimmung der meisten Leiter öffentlicher geburtshilflicher Anstalten finden würden. Runge setzte sich in seinem Beitrag ausdrücklich für die von Conti geforderte Besserstellung der Hebammen ein und schloss mit der Feststellung, „die erstklassige, im Bau und Betrieb nach besten hygienischen Grundsätzen eingerichtete geburtshilfliche Anstalt“ bleibe unentbehrlich für die Hebamme und den in der häuslichen Geburtshilfe tätigen praktischen Arzt. Durch die gleichmäßige Förderung dieser 3 Faktoren würden die besten Ergebnisse für die Volksgesundheit erzielt. ${ }^{219}$

Die nicht gerade ausgeprägte Präsenz der DGG in der RAG schlug sich auch in der Aktivität für deren - allerdings schon nach einem

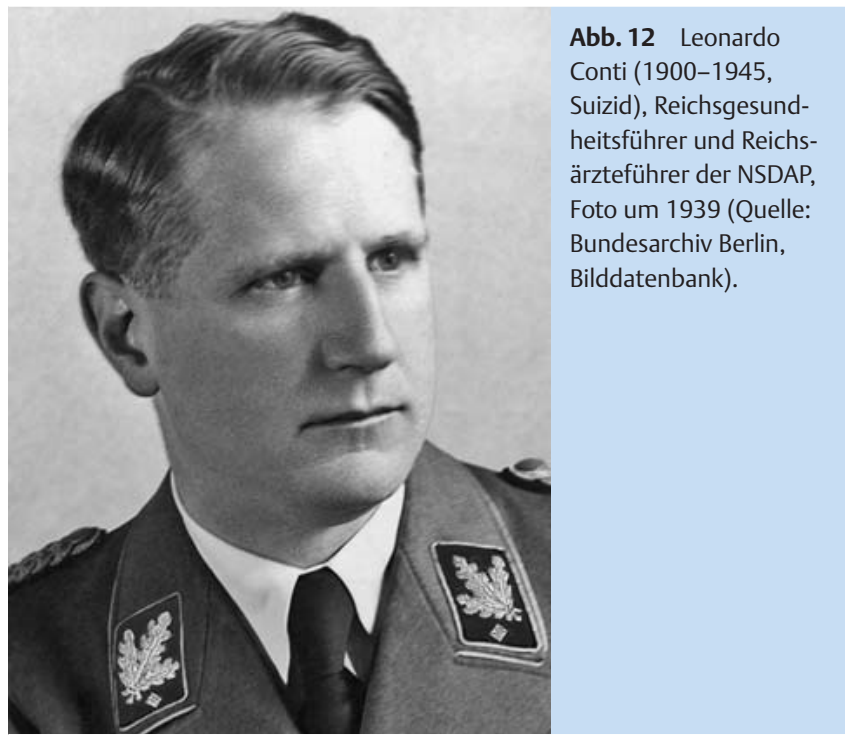

Jahr eingestellte - „Zeitschrift der Gesundheitsführung für Mutterschaft, Kindheit, Jugend“ nieder. ${ }^{220}$ Höchstens 6 der insgesamt 59 Beiträge waren der Gynäkologie und Geburtshilfe zuzuordnen, insgesamt überwogen Themen, die im weitesten Sinne zur Kinderheilkunde und Gesundheitsfürsorge gehörten. Unter den frauenheilkundlichen Arbeiten befand sich ein Beitrag des Leipziger Ordinarius und ehemaligen DGG-Präsidenten Hugo Sellheim über „Die konstitutionelle Ertüchtigung der weiblichen Jugend“. ${ }^{221}$ Zwei weitere Arbeiten stammten von Mitarbeitern der Stoeckel'schen Klinik: Günter K.F. Schultze, DGG-Mitglied und damals Oberarzt, schrieb über „Die Bekämpfung der weiblichen Unfruchtbarkeit“, 222 Günther Schäfer, Assistent und noch nicht habilitiert, über „Die Begrenzung des Fortpflanzungserfolgs der Vierzigjährigen“.223

Ähnliches gilt für das „Archiv für soziale Hygiene und Demographie“, dem von Bartels und Rott herausgegebenen „Offiziellen Organ der Reichszentrale für Gesundheitsführung beim Reichsministerium des Innern“. Dort dominierten Beiträge zu den gesundheitspolitischen Kernthemen des Nationalsozialismus, insbesondere zur Erbgesundheitspflege und Rassenhygiene. Zu den DGG-Mitgliedern, die sich in dieser Zeitschrift zu Wort meldeten, gehörte der spätere Präsident G.A. Wagner, der über „Die Funktionen und die Funktionsstörungen des Ovarium und ihre Bedeutung für die Volksgesundheit“" referierte, ${ }^{224}$ Heinz Küstner, damals Oberarzt bei Sellheim in Leipzig, und Elisabeth Krüger griffen mit einem Beitrag zur „Frauenarbeit in der Textilindustrie“ ein sozialgynäkologisches Thema auf. ${ }^{225}$

\footnotetext{
216 Jaschke: Betreuung (1937).

217 Conti: [Begrüßungsansprache] (1937), S. 5.

218 Conti: Geburtshilfe (1937), S. 7,14.

219 Runge: [Diskussionsbeitrag] (1937), S. 24. Basisdaten zur Person in den Kurzbiografien im Anhang.

220 Zeitschrift der Gesundheitsführung (1934 ff.).

221 Sellheim: Ertüchtigung (1934).

222 Schultze: Bekämpfung (1934)

223 Schäfer: Begrenzung (1934).

224 Wagner: Funktionen (1933/34).

225 Krüger/Küstner: Frauenarbeit (1933/34).
} 
Die DGG und die Kontroverse um die Geburtshilfe

Mit 2 Brandbriefen an den Präsidenten begannen Ende November 1939 hektische Aktivitäten der DGG, die am Rande eines Eklats mit Reichsgesundheitsführer Conti standen. Es ist dies der einzige heftige Konflikt mit einem maßgeblichen Vertreter des Regimes. Anlass war eine mit Kriegsbeginn eingetretene Eskalation in der seit Jahren schwelenden Auseinandersetzung mit der Reichsgesundheits- und Reichshebammenführung um Klinikgeburt und Hebammenbefugnisse: Zum einen verlangte das Reichsinnenministerium mit Hinweis auf die „Zu erwartende Steigerung des Bettenbedarfs“ in einem Erlass die Rückführung „der im Laufe der letzten Jahre auf Kosten der Hausentbindungen stark gestiegenen Zahl der Anstaltsentbindungen auf das unbedingt notwendige Maß“.226 Zum anderen sollten Hebammen „bis auf weiteres“ berechtigt werden, „zur Abwendung einer ernsten Lebens-oder Gesundheitsgefahr“ zuvor Ärzten vorbehaltene medikamentöse Maßnahmen anzuwenden und auch Dammschnitte durchzuführen. ${ }^{227}$

Autoren der Brandbriefe vom 21. und 30. November 1939 waren der damalige 2. Schriftführer der DGG, Gustav Döderlein aus Berlin, und der 1937 als Beisitzer in den erweiterten Vorstand gewählte Friedrich Karl Lönne aus Düsseldorf. In beiden Schreiben wurde Fuchs zu unverzüglichem Handeln aufgefordert: Während Döderlein sich noch darauf beschränkte, „baldmöglichst“ eine Vorstandssitzung zu beantragen, nannte Lönne 3 alternative Termine schon für die zweite Dezemberwoche. Ferner regte er an, zu der Sitzung auch „Geheimrat Stoeckel“ hinzuzuziehen, „der ja nur aus formellen Gründen dem Vorstand [...] nicht angehört, ebenso Herrn von Stuckrad“. Der Letztgenannte war damals Vorsitzender der Berliner Gesellschaft für Geburtshilfe und Gynäkologie.228

Auch unter Bezug auf die vorangegangenen Bemühungen des Reichsgesundheitsführers Leonardo Conti und seiner Mutter, der Reichshebammenführerin Nanna Conti, „Anstaltsentbindungen“ zugunsten der Hausgeburt zu diskreditieren, sahen Döderlein und Lönne nun eine Schmerzschwelle überschritten. Letzterer schrieb, er mache sich „als deutscher Arzt und Geburtshelfer [...] zum Sprecher von ungezählten Ärzten und Frauenärzten“, wenn er gegen die „Herabwürdigung der großen Leistungen unserer geburtshilflichen Abteilungen [...] die schärfste Verwahrung“ einlege. Döderlein sprach von einem „unerhörten Vorwurf gegen die geburtshilflichen Anstalten“. Beide warnten ferner vor der Befugniserweiterung für Hebammen und übten scharfe Kritik an der Tatsache, dass die DGG vor so wichtigen Entscheidungen nicht gehört worden sei.

Auf Seiten der Gesellschaft war der Konflikt - wie erwähnt - von G.A. Wagner erstmals 1935 in einem Vortrag bei der RAG
„Mutter und Kind“ vorsichtig angesprochen worden. Im Vorfeld seines Kongresses 1937 hatte Wagner dann vergeblich versucht, Martius zur Formulierung einer Resolution gegen die Aktivitäten der Contis zu veranlassen.229 Schließlich thematisierte Wagner das Problem dann selbst in seiner Eröffnungsrede - immer noch mit verbindlichen Tönen. Er veranlasste aber als eine seiner letzten Amtshandlungen per Mitgliederbeschluss die Einsetzung eines Ausschusses, der valide Daten zur Leistungsfähigkeit von Haus- und Klinikgeburtshilfe erfassen sollte, um überzeugend argumentieren zu können. Wagners Nachfolger Fuchs hätte für die Umsetzung dieses Beschlusses sorgen müssen. Lönne konnte sich deshalb in seinem Brief an Fuchs einen Seitenhieb auf dessen Amtsführung nicht verkneifen: „Es ist der Augenblick gekommen, sehr verehrter Herr Präsident, in dem ich Sie bitten muß, das Arbeitsergebnis dieses Ausschusses bekannt zu geben." ${ }^{230}$

Tatsächlich fand dann schon am 9. Dezember 1939 die geforderte außerordentliche Vorstandssitzung in Berlin statt. Während unklar bleibt, wer im Einzelnen teilgenommen hat, sind die wichtigsten Ergebnisse durch Korrespondenz von Vorstandsmitgliedern dokumentiert: Döderlein und Kurt-Otto von Stuckrad erhielten den Auftrag, im Namen der Gesellschaft eine Denkschrift zu den strittigen Fragen zu erarbeiten; ${ }^{231}$ Gustav Haselhorst, Direktor der UFK Rostock, und Werner Bickenbach, damals Oberarzt bei Martius in Göttingen, sollten die seit 1937 überfällige Datensammlung zu den Ergebnissen der klinischen Geburtshilfe möglichst rasch realisieren. ${ }^{232}$ Haselhorst, der dem Regime politisch sicherlich nicht fern stand, wurde offenbar mit der Koordination beauftragt.

Unter dem Druck der Ereignisse wurde die Denkschrift innerhalb kürzester Zeit verfasst ( $\triangle$ Abb. 13). Ein Exemplar dieser 16 Druckseiten umfassenden Stellungnahme der DGG „zu den vom Reichsgesundheitsführer und von der Reichshebammenschaft aufgeworfenen Fragen “ befindet sich noch bei den Gesellschaftsakten im Nachlass Zander. ${ }^{233}$ Genannt werden in diesem Zusammenhang auf der Titelseite 3 Punkte: Hausgeburt oder Anstaltsentbindung/Befugniserweiterung für Hebammen/Vorsichtsuntersuchung bei Schwangeren.

Unterzeichnet ist das Dokument „Im Auftrag des Vorstandes der Deutschen Gesellschaft für Gynäkologie“ von H. Fuchs, W. Stoeckel, G. A. Wagner, G. Döderlein, Fr. Lönne und K.v. Stuckrad, also von den beiden aktuellen Vorsitzenden (Fuchs, Wagner), dem 2.Schriftführer (Döderlein) sowie einem Beisitzer (Lönne) und einem Mitglied ohne besondere Funktion (Stuckrad). Mit Martius (Kassenwart) und Naujoks (1. Schriftführer) fehlen somit 2 Mitglieder des engeren Vorstandes. Als mögliche Erklärung bietet sich bei Martius an, dass er - wie bei anderen Gelegenheiten - ge-

\footnotetext{
226 Runderlass des Reichsministeriums des Inneren (06.09.1939); IV d 4992/39/3715

227 DÄ 69 (1939), S. $684 \mathrm{f}$.

228 BSB München, Nachlässe, Ana 691, Schwarzer Ordner: Döderlein an Fuchs (21.11.1939) sowie Lönne an Fuchs (30.11.1939). Stuckrad war von Stoeckel 1938 in typischer Manier ins Amt des Vorsitzenden befördert worden: „Ich habe [...] ernannt ..... Zu Stuckrad und Lönne vgl. Kurzbiografien. In dem Schwarzen Ordner befinden sich die aus den übrigen Unterlagen der DGG im Nachlass Zander aussortierten Schriftstücke zum Themenkomplex „Die DGG und die Kontroverse um die Geburtshilfe“. Sie dienten offensichtlich als Quellen für die Publikation Zander/Goetz: Hausgeburt (1986) und waren deshalb in den vorhandenen DGG-Akten zunächst unauffindbar. Die Verfasser danken Frau Dr. Nino Nodia aus dem Nachlassreferat der Abt. für Handschriften und Alte Drucke der Bayerischen Staatsbibliothek München für ihre Unterstützung bei der Suche.

229 Siehe hierzu S. 24.

230 BSB München, Nachlässe, Ana 691, Schwarzer Ordner: Lönne an Fuchs (30.11.1939).

231 Ebd.: Döderlein an Martius (ohne Datum)

232 Ebd.: Martius an Döderlein (20.01.1940). Zu Haselhorst und Bickenbach: Kurzbiografien.

233 Ebd.
} 
genüber dem Regime nicht exponiert werden sollte. Naujoks war zum Zeitpunkt der Zuspitzung der Situation offenbar für die Gesellschaft nicht greifbar: man hatte ihn zum Militärdienst eingezogen. ${ }^{234}$

Inhaltlich zählt die Denkschrift einleitend alle Erlasse, Anordnungen und Veröffentlichungen des Jahres 1939 auf, gegen die von Seiten der DGG „schwere Bedenken“ geltend gemacht werden. Die Behandlung der darin angesprochenen Fragen sei „in der vorliegenden Form und Tendenz [...] auf das Tiefste zu bedauern“, heißt es. Dies habe nicht nur bei den deutschen Ärzten, sondern „besonders bei den deutschen Frauen größte Erregung und Widerspruch hervorgerufen“. Bei den Mitgliedern der DGG sei darüber hinaus vielfach der Eindruck entstanden, die Maßnahmen hätten „lediglich in dem Existenzkampf der deutschen Hebammenschaft ihre tiefere Ursache“. ${ }^{235}$

In der Frage Hausgeburt versus Klinikentbindung werden die von Seiten der Gesundheitsführung und der Hebammenschaft geäußerten Vorwürfe hinsichtlich erhöhter Komplikationsraten in der Klinik auf das schärfste zurückgewiesen und als „diffamierend“ sowie dem Ansehen der deutschen Wissenschaft im Ausland abträglich bezeichnet. Es sei „höchst unlogisch“, normale Geburten aus Angst vor schlecht arbeitenden Kliniken zu Hause stattfinden zu lassen, dann aber eben diesen schlechten Kliniken die komplizierten und schweren Fälle zuzuweisen. Ferner sei es unbestreitbar, dass in der häuslichen Geburtshilfe oft Komplikationen entstünden, denen die Hebamme allein nicht gewachsen sei. Gerade in Kriegszeiten erwachse durch die größeren Schwierigkeiten bei der Erreichbarkeit ärztlicher Hilfe daraus ein zusätzliches Risiko für Mutter und Kind. Die Frage des Entbindungsortes könne, soweit keine zwingenden Gründe für die Klinikentbindung vorlägen, nur von der deutschen Frau selbst beantwortet werden. Im Übrigen ließen „zahlreiche namhafte Führer und viele Männer der Partei“ ihre Frauen in Kliniken entbinden. Wehrmacht, Polizei und Reichsführung der SS hätten für die Familienangehörigen ihrer Gliederungen eigene geburtshilfliche Einrichtungen geschaffen. ${ }^{236}$

Zur Befugniserweiterung der Hebammen heißt es in der Denkschrift, die Hebammen würden dadurch mit einer Verantwortung belastet, die sie nicht tragen könnten. Sie müsse daher in der veröffentlichten Form entschieden abgelehnt werden. Die Autoren beziehen sich dabei auf den vorgesehenen Einsatz von Chinin zur Wehenförderung nach länger zurückliegendem Blasensprung oder die Gabe von Hypophysen-Hinterlappenpräparaten in der Plazentarperiode. Im ersteren Fall sei es selbst für Ärzte gelegentlich schwierig, einen Blasensprung überhaupt zu diagnostizieren, im zweiten Fall könnten die Präparate durch Blutdruckerhöhung bei Frauen mit unerkannter Schwangerschaftstoxikose auch nach der Geburt noch das Leben der Mutter gefährden. $^{237}$

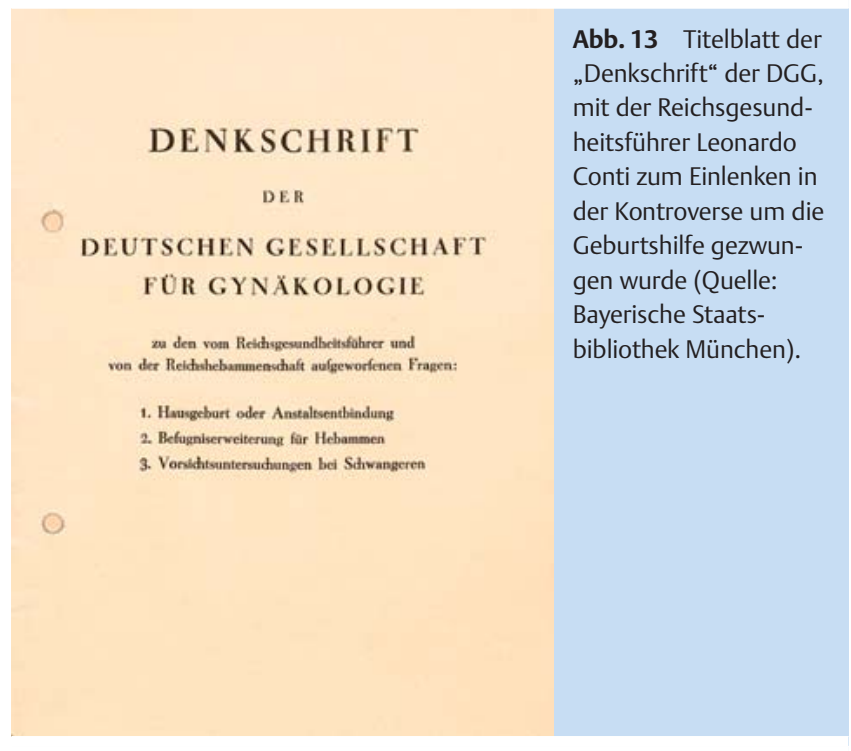

$\mathrm{Zu}$ den 3 Vorsichtsuntersuchungen bei Schwangeren, zu denen die Reichshebammenführerin Nanna Conti alle Hebammen verpflichtet habe, erklärt die DGG, sie halte diese Untersuchungen nicht nur für „völlig wertlos“, sondern sogar für einen „ausgesprochenen Schaden“. Zur Begründung heißt es, damit werde eine Maßnahme vorgetäuscht, „die in ihrer oberflächlichen Unzulänglichkeit die Frauen in falscher Sicherheit wiegt und vom rechtzeitigen Arztbesuch abhält“. Hebammen seien aufgrund ihrer Ausbildung gar nicht in der Lage, die wünschenswerten Maßnahmen durchzuführen. Genannt werden in diesem Zusammenhang unter anderem die Blutentnahme zur Luesdiagnostik, die gründliche körperliche Untersuchung zur Entdeckung von eventuell bestehenden Allgemeinerkrankungen, die Basismaßnahmen zur Diagnostik einer sich entwickelnden Schwangerschaftstoxikose sowie die Krebsfrüherkennung. ${ }^{238}$

Abschließend stellen die Autoren der Denkschrift 4 Forderungen auf, die sie diplomatisch als „Schlüsse“ aus den „Vorstehend begründeten Erkenntnissen“ bezeichnen. Darin heißt es, durch Gesetz oder Verordnung dürften keine Maßnahmen getroffen werden, die für Mutter und Kind anstelle eine Vorteils eher einen Schaden verursachten. Bereits verfügte Maßnahmen müssten durch noch zu erlassende Durchführungsbestimmungen „weitgehend ergänzt" werden. Die Öffentlichkeit sei durch sachgemäße Aufklärung in der Tagespresse darüber zu unterrichten, „daß einer Entbindung in gut geleiteten und eingerichteten Entbindungsanstalten keine Gefahren anhaften, und daß es gebärenden Frauen keineswegs verwehrt ist und auch nicht verübelt wird, in einer solchen Entbindungsanstalt niederzukommen“. 239

Um den Jahreswechsel 1939/40 entwickelte sich nach dem sehr kurzfristig realisierten Druck der Denkschrift unter den beteilig-

\footnotetext{
234 BSB München, Nachlässe, Ana 691, Schwarzer Ordner: Naujoks an Martius (29.02.1940).

235 Ebd.: Denkschrift, S. 2.

236 Ebd.: Denkschrift, S. 3-9.

237 Ebd.: Denkschrift, S. 9-11.

238 Ebd.: Denkschrift, S. 11-13.

239 Ebd.: Denkschrift, S. 13-16.
} 
ten DGG-Mitgliedern hektische Aktivität, die durch entsprechende Korrespondenz noch gut nachvollziehbar ist. Es ging dabei zunächst darum, wie, an wen und von wem die Schrift verschickt werden sollte. Dabei kristallisierte sich heraus, dass bei Martius zwar die Adressen für den Versand geschrieben, die Texte aber von Döderlein verschickt werden sollten. Als Empfänger der 3000 Exemplare waren neben den DGG-Mitgliedern auch die Mitglieder der Regionalgesellschaften vorgesehen. Dem Reichsgesundheitsführer und dem Innenminister wollte man die Denkschrift vor dem Versand bei einem persönlichen Termin überreichen.

Den erwünschten Termin bei Conti, den Stoeckel vereinbart hatte, ${ }^{240}$ erhielt die DGG-Delegation für den 22. Januar 1940. Er begann mit einem Eklat, den Döderlein in einem Brief an den erneut nicht persönlich involvierten Präsidenten Fuchs sehr plastisch beschrieben hat. Dazu beigetragen hatte wohl die Tatsache, dass Conti die Denkschrift durch eine Indiskretion von Stuckrad bereits vorab erhalten hatte und der Meinung war, der Text sei schon veröffentlicht - eine Überzeugung, von der er im Laufe der dreistündigen Konfrontation nur schwer abzubringen war.

In dem Brief an Fuchs heißt es weiter:

„[Conti] ist wütend über die Denkschrift und hat getobt. Auch wir haben ebenso getobt [...] Bei der erregten Kampfesstimmung [...] und bei der Schärfe der Sprache, die auf beiden Seiten, besonders von Stoeckel, unverblümt geführt wurde, war eine sachliche Diskussion nicht möglich. Es bestätigte sich leider nur, daß Herr C. ganz einseitig die Interessen der Hebammen vertritt und von den höheren Gesichtspunkten der Geburtshilfe weder etwas versteht noch offenbar sich belehren lassen will. Der Unterton in seinen Ausführungen ging aber schließlich [...] dahin, daß ihm bei der ganzen Sache nicht wohl in seiner Haut ist [...] Unsere Schrift hat also doch gewirkt und die ganze Sorge von Herrn C. ist, der Inhalt könnte demnächst in der ausländischen Emigrantenpresse erscheinen."

Dem Brief zufolge zeigte sich Conti deshalb dann doch bereit, für die Einstellung der Propaganda der Hebammen in den Medien zu sorgen. Als Stoeckel und Stuckrad nach Ende der offiziellen Sitzung angeboten hätten, die Verbreitung der Denkschrift zu stoppen, scheine Conti ein Stein vom Herzen gefallen zu sein und er habe angeboten, „gerne ,kameradschaftlich“ und sachlich über die von uns gewünschten Fragen weiter zu verhandeln“. 241

Die Denkschrift blieb also unversandt, bereits an die Regionalgesellschaften zur Verteilung verschickte Exemplare wurden von Döderlein zurückbeordert. Anfang März 1940 berichtete Döderlein Martius über den weiteren Gang der Dinge. Die Angelegenheit, so heißt es in einem Brief, entwickle sich nun doch besser als gedacht. Conti habe Stoeckel mitgeteilt, dass er einsehe, Fehler gemacht zu haben, und um eine kurzfristige Aussprache mit ihm gebeten. „Mir scheint, daß doch eine höhere Instanz Herrn C. zurückgepfiffen hat", schrieb Döderlein. ${ }^{242}$ Und am 16. Juli 1940 konnte Döderlein Martius schließlich „Vollzug“ melden, indem er ihm Contis neue „Leitsätze für die Ordnung der Geburtshilfe“ übersandte, die er als „Waffenstillstandsbedingungen zwischen uns und dem Reichsgesundheitsführer" bezeichnete. ${ }^{243}$ Martius konstatierte in seiner Antwort, damit sei im Großen und Ganzen alles Notwendige erreicht. „Die Hauptsache bei der ganzen Angelegenheit ist wohl, daß man gesehen hat, daß man sich nicht alles gefallen läßt. Die Deutsche Gesellschaft wird den wackeren Kämpfern in Berlin sehr dankbar sein.“244

Stoeckel hat die Ereignisse in seiner Autobiografie von 1954 in der für ihn typischen Weise kommentiert. In einem Kapitel mit der Überschrift „Mein Kampf mit Conti“ schreibt er unter anderem, er habe sich im Stillen darüber amüsiert, „daß beim ersten Fall, bei dem Konflikte und unangenehme Auseinandersetzungen zwischen der Gesellschaft und der neuen Regierung durchzukämpfen waren, der Vorstand sich nicht stark genug fühlte, sondern ,meine Autorität', wie immer wieder betont wurde, benötigte“. Das Einlenken Contis führt Stoeckel wie Döderlein auf eine „höhere Instanz“ zurück: Der Umschwung sei gekommen, nachdem er den Minister Goebbels informiert und dieser „eine Fortissimo-Unterredung“ mit Conti gehabt habe. ${ }^{245}$ Allerdings sei anschließend noch ein halbes Jahr Kampf um Wörter erforderlich gewesen, bis der Reichsgesundheitsführer „die von mir aufgesetzten 24 ,Thesen““ anerkannte und ihre Veröffentlichung zuließ.

\section{Weitere fachpolitische Aktivitäten von Vorstandsmitgliedern}

Jenseits der Kongresse war der Vorstand noch in manch anderer Hinsicht aktiv, nicht selten in offizieller Mission für das Regime. So trat Wagner ungeachtet seiner Differenzen mit NSDAP-Gliederungen wie der Reichsdozentenführung beim Internationalen Kongress für Geburtshilfe und Gynäkologie in Amsterdam im Mai 1938 als Leiter der deutschen Delegation auf. ${ }^{246}$ Anfang 1942 entsandte ihn das Berliner Reichswissenschaftsministerium zusammen mit den Ordinarien Carl Joseph Gauß, Würzburg, und Ernst Philipp, Kiel, als Chef einer Untersuchungskommission nach Graz, um Vorwürfen gegen Karl Ehrhardt nachzugehen, der 1939 aus Frankfurt auf den dortigen Lehrstuhl berufen worden war. Assistenten der Grazer Klink hatten Ehrhardts Fähigkeiten als Diagnostiker, Operateur und Klinikleiter in Zweifel gezogen; es ging zudem um die Klärung von 7 Todesfällen.

„[Die] Untersuchungen gingen mit massiver Unterstützung der Fakultät positiv für Ehrhardt aus, während die Assistenten gemaßregelt wurden“, stellt Gabriele Czarnowski fest, die sich intensiv mit diesen Vorgängen befasst hat. Nach einer fast vollständigen Auswechslung des wissenschaftlichen Personals sei es in der Klinik später vor allem an schwangeren Ostarbeiterinnen zu Medizinverbrechen in einem Ausmaß gekommen, „wie es bisher

\footnotetext{
240 BSB München, Nachlässe, Ana 691, Schwarzer Ordner: Döderlein an Martius (11.01.1940).

241 Ebd.: Döderlein an Fuchs (23.01.1940).

242 Ebd.: Döderlein an Martius (02.03.1940).

243 Ebd.: Döderlein an Martius (16.07.1940).

244 Ebd.: Martius an Döderlein (ohne Datum). Die Leitsätze erschienen u.a. im DÄ 70 (1940), S. 310 f. und im Zbl Gyn 64 (1940), 2, S. $1346-1348$.

245 Stoeckel: Leben (1954), S. 136; Goebbels: Tagebücher I, 7, S. 323 f. (25.02.1940): „Conti hat ein paar blödsinnige Erlasse herausgegeben.“

246 BArch Berlin, R 4901, Nr. 2827.
} 
noch für keine andere Universitätsfrauenklinik im ,großdeutschen Reich“ bekannt geworden ist“. So „übte“ Ehrhardt Schritte der radikalen vaginalen Chirurgie für onkologische Operationen an den Ostarbeiterinnen. Vor Zwangsabtreibungen wurden intraamniale Kontrastmitteluntersuchungen an den Feten vorgenommen, auch die häufig durch Sectio parva möglichst in der stehen- den Fruchtblase abgetriebenen Feten nutzte Ehrhardt noch für seine Experimente. ${ }^{247}$ Womöglich hatte Gustav Döderlein den Ausgang der Untersuchungen gegen Ehrhardt unter der Leitung von Wagner im Sinn, als er 1947 über Wagner in einem Nachruf schrieb, er sei „weich, manchmal zu weich gegen andere“ gewesen. ${ }^{248}$

247 Czarnowski: „Anschluss“ (2012), S. 144. Zu Ehrhardt siehe auch S. 65.

248 Döderlein: Wagner [Nachruf] (1947), S. 1045 


\section{Die Kongresse der DGG und das „Gesetz zur Verhütung erbkranken Nachwuchses" (GzVeN)}

\section{Zur Funktion der Tagungen \\ $\nabla$}

Wie eingangs kurz erwähnt, waren die Kongresse der DGG das zentrale Element der Gesellschaftstätigkeit, das sich aus $\S 1$ der Satzung ergab und auch so gelebt wurde. Die Kongresse stellten Foren des wissenschaftlichen Austausches auf nationaler und internationaler Ebene dar. Darüber hinaus sollten aktuelle Entwicklungen und Standortbestimmungen auch in den extrauniversitären Raum und in die Praxen der niedergelassenen Ärzte kommuniziert werden. Wesentlichen Anteil daran, die Tagungsinhalte für die Wissenschaftsgemeinde und die Mitglieder öffentlich zu machen, hatten die Kongressberichte, die damals als „Verhandlungsbände“ im „Archiv für Gynäkologie“ erschienen und allen Mitgliedern kostenlos zugestellt wurden. In geraffter Form veröffentlichte man Tagungsberichte auch in anderen Fachzeitschriften - z. B. in dem von Walter Stoeckel verantworteten „Zentralblatt für Gynäkologie“, das wöchentlich erschien und wegen dieser raschen Folge auch bevorzugt für Kongressankündigungen eingesetzt wurde.

Außerdem versuchte die DGG in der Weimarer Republik zunehmend durch Resolutionen, die während ihrer Kongresse gefasst wurden, Einfluss auf gesellschaftliche und politische Entwicklungen im Gesundheitsbereich zu nehmen. Auf entsprechende Beispiele hat Stoeckel in seiner oben zitierten Rede hingewiesen. Zusätzlich gab es im national-konservativ geprägten Vorstand Bemühungen, durch die Wahl der Tagungsorte politische Akzente zu setzen. Ein Beispiel dafür war 1925 die Entscheidung für Bonn als kommenden Kongressort; die Stadt war damals infolge des Ersten Weltkriegs noch von den Franzosen besetzt. Auch Breslau wurde unter solchen Gesichtspunkten ins Gespräch gebracht. ${ }^{249}$

Für die nationalsozialistische Diktatur stellten Kongresse medizinischer Fachgesellschaften mit ihren Publikationen wichtige Instrumente dar, ideologisch motivierte Ziele wissenschaftlich zu legitimieren. Dies galt in besonderem Maße für die Frauenheilkunde, deren Mitwirkung an der Umsetzung der bevölkerungspolitischen Intentionen des Regimes unverzichtbar war. Nicht umsonst gehörte die DGG zu den ersten Fachgesellschaften, die 1933 unter dem Dach der „Reichszentrale für Gesundheitsführung" gleichgeschaltet wurden.
Wenn nun im Folgenden die Behandlung der NS-Eugenik, und hier im Besonderen die Zwangsmaßnahmen, auf den Kongressen der DGG näher betrachtet werden soll, muss zunächst ein kurzer Blick auf die Geschichte der Eugenik und die Verhältnisse am Vorabend der Diktatur geworfen werden. Dazu gehört auch der Kongress von 1931 in Frankfurt, auf dem sich die Mitglieder zum letzten Mal unter demokratischen Verhältnissen austauschen konnten. Bezeichnenderweise spielte bereits 1931 in Frankfurt das Thema „Sterilisierung und Konzeptionsverhütung“ eine erhebliche Rolle.

\section{Eugenik - keine nationalsozialistische Erfindung $\nabla$}

Das GzVeN war keine genuin nationalsozialistische Erfindung, sondern beruhte auf evolutionstheoretischen, rassenbiologischen und vererbungswissenschaftlichen Vorstellungen und Erkenntnissen des ausgehenden 19. Jahrhunderts als inhärenten Bestandteilen eines überformenden Biologismus. ${ }^{250}$ Auf der Grundlage von rassenbiologischen Gesellschaftsdeutungen, zeitgenössischen Erkenntnissen der Vererbungslehre sowie in Übertragung der von Charles Darwin entwickelten Evolutionstheorie auf die menschliche Gesellschaft in Form des sogenannten Sozialdarwinismus vertrat die 1883 von Francis Galton begründete Eugenik den Standpunkt, dass das natürliche Selektionsprinzip durch sozialpolitische Fürsorgemaßnahmen sowie medizinische Versorgung außer Kraft gesetzt und deshalb eine gesellschaftliche Degeneration zu befürchten sei. ${ }^{251}$ Um dieser Entwicklung entgegenzutreten, müssten entsprechend dem „individuellen Erbwert" zielgerichtete pro- und antinatalistische Regulierungsmaßnahmen ergriffen werden. Zum Spektrum von eugenischen Ausschlussverfahren gehörten Eheverbote, die Sterilisation oder die Asylierung.

Die Verbindung von Vererbungs- und Rassenlehre führte im Jahr 1905 zur Gründung der „Gesellschaft für Rassenhygiene“. Im Gegensatz zur internationalen Entwicklung fristete die Rassenhygiene in Deutschland bis zum Ende des Ersten Weltkrieges allerdings ein Schattendasein. ${ }^{252}$ Erst die Niederlage mit Millionen von toten und kriegsversehrten Soldaten sowie die umfangreichen soziapolitischen Maßnahmen in der Weimarer Republik be-

\footnotetext{
249 Vgl. Stoeckel: Leben (1954), S. 161.

250 Vgl. Wecker/Braunschweig/Imboden/Küchenhoff/Ritter (Hrsg.): Eugenik (2009).

251 Vgl. Weingart/Kroll/Bayertz: Rasse (2003); Schmuhl: Rassenhygiene (1992).

252 Vgl. v.a. Kühl: Internationale (2014).
} 
scherten diesem Paradigma seit den 1920er-Jahren zunehmende Akzeptanz. Gleichzeitig konnte sich die Rassenhygiene in Anlehnung an die Psychiatrie als eigenständige Wissenschaft etablieren. ${ }^{253}$

Diese Entwicklung, die durch wirtschaftliche und soziale Krisen in der Weimarer Republik flankiert wurde, führte zu fortwährenden Diskussionen über den Einsatz staatlicher Regulierungsmaßnahmen für das Fortpflanzungsverhalten. In der Politik mündete dies im Februar 1926 in die Empfehlung des preußischen Ministers für Volkswohlfahrt, „Eheberatungsstellen“ einzurichten, in denen sich Heiratswillige vor der Hochzeit über ihre gesundheitliche Ehetauglichkeit und etwaige „erbliche Belastungen“ beraten lassen sollten. Einen vorläufigen Höhepunkt der Diskussionen über staatliche Regulierungsmaßnahmen bildete der preußische Entwurf eines Sterilisationsgesetzes im Jahr 1932, der die freiwillige Unfruchtbarmachung „Erbkranker“ vorsah. ${ }^{254} \mathrm{Zu}$ diesem Zeitpunkt wurde dies parteiübergreifend unterstützt. ${ }^{255}$

Jenseits der politischen Debatten, in denen auch das Gespenst einer Selbstauflösung des „Volkskörpers“ durch den schon seit der Jahrhundertwende andauernden Geburtenrückgang beschworen und deshalb Kontrazeption ohne medizinische Indikation von konservativen Kräften verteufelt wurde, sahen sich Ärztinnen und Ärzte in der Weimarer Republik nicht zuletzt angesichts der für die Massen schlechten wirtschaftlichen Lage mit dem Massenphänomen Abtreibung konfrontiert. Konservative Gynäkologen wie August Mayer sprachen in diesem Zusammenhang von einer „Abtreibungsseuche“, die es zu bekämpfen gelte. Das DGG-Mitglied Hans Lehfeldt, das seit 1929 in der Berliner Beratungsstelle für Sexualreform tätig war, berichtete über Erfahrungen in seiner Kassenpraxis: „[Es] kamen Frauen aller Schichten, Arbeiterinnen, wohlhabende Frauen, Studentinnen. Alle baten mich um einen Schwangerschaftsabbruch. Alle waren verzweifelt [...]“.256 Die parallel dazu geführte Kampagne gegen den Abtreibungsparagrafen 218 erreichte Mitte April 1931 mit einer Kundgebung in Berlin ihren Höhepunkt, die 15000 Teilnehmerinnen und Teilnehmer zählte. Das war wenige Wochen vor dem Frankfurter Kongress der DGG, auf dem „Sterilisierung und Konzeptionsverhütung“257 nach einem großen Referat des Breslauer Ordinarius Ludwig Fraenkel ausgiebig und sehr kontrovers diskutiert werden sollten.

\section{Der Kongress 1931: „Liberale“ versus „Konservative“ $\nabla$}

Der von Ludwig Seitz gestaltete Kongress unterschied sich in vielerlei Hinsicht von den vorangegangenen, aber auch von den folgenden Veranstaltungen ( $\bullet$ Abb. 14). Auf Anregung des vorherigen Präsidenten Hugo Sellheim hatte der Vorstand bereits im

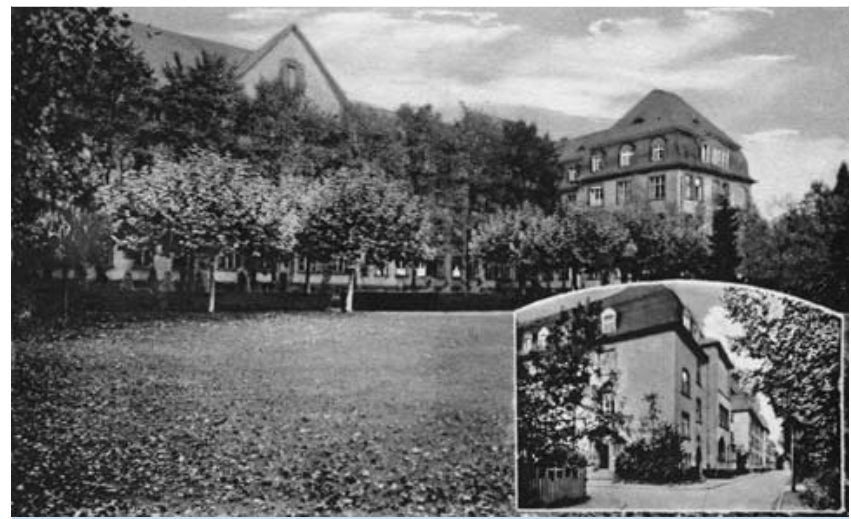

Abb. 14 Die UFK in Frankfurt am Main, Ort der DGG-Tagung 1931 (Quelle: Institut für Stadtgeschichte Frankfurt am Main).

Januar 1930 die Mitglieder aufgefordert, Vorschläge für Schwerpunktthemen einzureichen. Im Ergebnis entstand ein Programm, das - wie Seitz es in der Eröffnungssitzung formulierte - zum ersten Mal Themen auf die Tagesordnung brachte, „in denen der wissenschaftliche Kern von einer sozialen Schale umgeben ist". Dass diese „soziale Schale“ für lebhafte Diskussionen sorgen würde, war absehbar. Seitz ermahnte denn auch die Mitglieder gleich zu Beginn, „Weltanschauungsfragen, die jeder für sich entscheiden muß, möglichst wenig zu besprechen und [...] jegliche Erörterung über den $§ 218$ grundsätzlich zu unterlassen“. ${ }^{258}$

Zu den Themen mit „sozialer Schale“ gehörte neben dem Referat von Fraenkel vor allem der Beitrag von Max Hirsch zur Mutterschaftsfürsorge, in dem der Sozialgynäkologe weit über das Medizinische hinausgehenden Handlungsbedarf „,von den Reifejahren bis zum Ende der Fortpflanzungsfähigkeit“ sah. ${ }^{259}$ Größte wissenschaftliche Aktualität zeigten die Referate von Bernhard Zondek $^{260}$ und Selmar Aschheim ${ }^{261}$ über die endokrine Funktion des Hypophysenvorderlappens, die durch einen Beitrag des Schweizers Hans Guggisberg zum Hypophysenhinterlappen ergänzt wurden. ${ }^{262}$ An dieser Stelle soll nur auf das Referat von Fraenkel und die damit zusammenhängenden Beiträge eingegangen werden.

Wie schon Seitz bat auch Fraenkel zu Beginn seiner Ausführungen darum, nicht über das Pro und Kontra von Verhütung, sondern „über den Wert der einzelnen Prohibitiva“ zu diskutieren. Ungeachtet dessen hatte er allerdings zuvor schon seine persönliche Meinung kundgetan: „In früheren Jahren meiner Tätigkeit habe ich die Beteiligung an verhütenden Maßnahmen, außer bei medizinischer Indikation, abgelehnt - heute täte ich es nicht. Den meisten Ärzten ohne religiöse oder politische Bindung wird

\footnotetext{
253 Vgl. Peter: Einbruch (2004); Schmuhl: Grenzüberschreitungen (2005).

254 Vgl. Müller: Sterilisation (1985); Saretzki: Reichsgesundheitsrat (2000); Benzenhöfer: Genese (2006).

255 Vgl. Schwartz: Eugenik. (1995).

256 Zit. n. Dienel: Frauenbewegung, (1993), S. 148.

257 Fraenkel: Sterilisierung [Verhandlungen 1931] (1931).

258 Seitz: Eröffnung [Verhandlungen 1931] (1931), LVIII.

259 Hirsch: Mutterschaftsfürsorge [Verhandlungen 1931] (1931); Basisdaten zur Person in den Kurzbiografien im Anhang.

260 Zondek: Hypophysenvorderlappen [Verhandlungen 1931] (1931); Basisdaten zur Person in den Kurzbiografien im Anhang.

261 Aschheim: Vorderlappen [Verhandlungen 1931] (1931); Basisdaten zur Person in den Kurzbiografien im Anhang.

262 Guggisberg: Hinterlappen [Verhandlungen 1931] (1931); Basisdaten zur Person in den Kurzbiografien im Anhang.
} 
es ähnlich ergehen." ${ }^{263}$ Inhaltlich stellte Fraenkel alle bekannten und medizinisch relevanten Formen von Kontrazeption dar und bewertete sie. Es müsse mit der „völlig veralteten Vorstellung“ aufgeräumt werden, dass der Arzt „a limine jede Unterhaltung auf diesem Gebiete ablehnen soll“, erklärte er. Ausführliche Beratung der Patientinnen und gründliche Ausbildung der Studierenden in diesen Fragen sei vielmehr Pflicht. Wenn es seine Weltanschauung verlange, könne der Arzt von der Anwendung kontrazeptiver Maßnahmen ja abraten. ${ }^{264}$

Im Zusammenhang mit der Sterilisation sprach sich Fraenkel entschieden gegen den Einsatz ionisierender Strahlen aus. Er begründete dies mit ihrem kastrierenden Effekt. Nach einer knappen Erörterung und Bewertung der operativen Methoden setzte er sich mit den Begründungen für derartige Eingriffe auseinander. Eine soziale Indikation sei im Allgemeinen nicht gegeben, sagte er. „Zur Beseitigung sozialer Nöte gibt es andere Auswege als eine Bauchschnittoperation und eine Verstümmelung." Ausnahmen seien höchstens denkbar, wenn der Eingriff im Rahmen einer ohnehin erforderlichen Laparotomie durchgeführt werden könne. ${ }^{265}$ Für die medizinische Indikation verlangte er neben dem Einverständnis der Betroffenen die Zustimmung von 2 voneinander unabhängigen Ärzten, zumal wenn eine nicht-gynäkologische Erkrankung begründend sei. ${ }^{266}$

Besonders kritisch setzte sich Fraenkel mit der eugenischen Indikation auseinander. Probleme sah er vor allem darin, dass die wissenschaftlichen Grundlagen dafür „nicht genügend fundiert“ seien und das Strafgesetzbuch keinerlei Absicherung für den Operateur biete. Den Bemühungen verschiedener Gesellschaften für Eugenik und Rassenhygiene, Letzteres zu ändern, räumte er wenig Chancen ein: „Aus anderen als aus medizinischen Gründen, d. h. für das betreffende Individuum selbst heilsamen Gründen darf einem noch so berechtigt erscheinenden Verlangen nach Sterilisierung nicht ohne weiteres stattgegeben werden."267 Größte Vorsicht sei bei der Behandlung „Schwachsinniger“ geboten. „Der Geistesschwache hat ein ganz besonderes Anrecht auf Rechtsschutz“, erklärte Fraenkel. Er kam zu dem Schluss, dass in diesen Fällen die Zustimmung (oder wenigstens nicht die Ablehnung) der Betroffenen und des Vormundes bzw. des Vormundschaftsgerichtes sowie das Konsilium zweier Ärzte erforderlich sei, von denen wenigstens einer Psychiater sein müsse. ${ }^{268}$

Vor der Diskussion folgten dem Referat Fraenkels 20 Vorträge, in denen das Thema meist unter dem Aspekt eigener Untersuchungen der jeweiligen Referenten nochmals beleuchtet wurde. Ein Auftritt mag Fraenkel dabei überrascht haben: der des erst 30 Jahre alten Lothar Loeffler. Der Redner war weder DGG-Mitglied noch Frauenarzt, sondern Assistent am Anthropologischen Institut der Universität Kiel bei Otto Aichel, dem Mitherausgeber der Zeitschrift „Volk und Rasse“. Loeffler, der ab 1933 im Rahmen einer steilen Karriere rasch in den Kreis der führenden Rassenbiologen und -hygieniker des Nationalsozialismus aufsteigen sollte, griff Fraenkels kritische Stellungnahme zur eugenischen Indikation ebenso an wie den Appell an die DGG-Mitglieder, zur Verbreitung von Kenntnissen in der Kontrazeption beizutragen. ${ }^{269}$ Sein Auftritt legt die Vermutung nahe, dass der Vorstand nach der Vorablektüre von Fraenkels liberalem Referat der Meinung war, hier sei eine stringenter am Ausleseprinzip orientierte Ergänzung angebracht. Der Vorstand muss dann auch eine entsprechende Einladung an Loeffler ausgesprochen haben, wie dies nach der Satzung für Vorträge von Nichtmitgliedern erforderlich war.

Auch von Seiten seiner Kollegen bekam Fraenkel in der teilweise offenbar sehr erregten Debatte neben viel Zustimmung heftigen Gegenwind zu spüren. Es waren vor allem die Ordinarien Carl Joseph Gauß, Otto von Franqué, August Mayer und Walter Stoeckel, die Fraenkels Empfehlungen zum Umgang mit der Kontrazeption aus weltanschaulichen Gründen kritisierten. Der Angegriffene reagierte mit einem scharfen Schlusswort, in dem er bedauerte, „aus der Arena wissenschaftlicher Diskussion herabsteigen zu müssen in das Gewirr der Tagesmeinungen, die meines Erachtens auf einen Gynäkologenkongress nicht gehören“. Besonders heftig ging er Stoeckel an, der in der Diskussion auf eine eigene Stellungnahme „als klinischer Lehrer“ zur Konzeptionsverhütung im „Zentralblatt“ verwiesen hatte. Dort empfahl er in 32 „Paragraphen“ zum Thema, „gegen die verlogene Not stahlhart“ zu bleiben. ${ }^{270}$ „Weniger Verbote und mehr Verständnis den Schülern beibringen, das scheint mir richtig“, erklärte Fraenkel dazu. ${ }^{271}$ Stoeckel beschrieb den Frankfurter Kongress übrigens später als jenen mit dem aus seiner Sicht „tiefsten Niveau“. „Die Referate und die Diskussion über den Paragraphen 218 (Abtreibung) wirkten stark deprimierend“, heißt es dazu in seinen Memoiren. ${ }^{272}$

Der Kongress verabschiedete nach der Debatte eine Entschließung zur Einrichtung von Ehe- und Sexualberatungsstellen, die einen Kompromiss mit einem entsprechenden Vorschlag Fraenkels darstellte. Darin hieß es, die Einrichtung derartiger Institutionen werde anerkannt. Sie dürften jedoch nur von Ärzten geleitet werden, „die sich ihrer Verantwortung für die Zukunft des Deutschen Volkes bewußt sind“. Ganz besonders werde Verwahrung dagegen eingelegt, „daß solche Beratungsstellen zu Einrichtungen herabgewürdigt werden, die nur der Verbreitung antikonzeptioneller Mittel dienen sollen“. 273

\footnotetext{
263 Fraenkel: Sterilisierung [Verhandlungen 1931] (1931), S. 87.

264 Ebd., S. 130.

265 Ebd., S. 111.

266 Ebd., S. 108.

267 Ebd., S. 110.

268 Ebd., S. 111.

269 Grüttner: Lexikon (2004), S. 111; Klee: Personenlexikon (2003), S. 376.

270 Stoeckel: [Diskussionsbeitrag, Verhandlungen 1931] (1931), S. 378.

271 Fraenkel: Sterilisierung [Verhandlungen 1931] (1931), S. 383.

272 Stoeckel: Leben (1954), S. 117.

273 Fraenkel: [Schlusswort, Verhandlungen 1931] (1931), S. 383.
} 


\section{Der Kongress 1933: Die Implementierung des Zwangs $\nabla$}

\section{Das „Gesetz zur Verhütung erbkranken Nachwuchses“ (GzVeN)}

Als sich die DGG-Mitglieder im Oktober 1933 in Berlin wiedertrafen, hatte sich das politische Umfeld komplett verändert. Von den neuen Machthabern waren die Sexualberatungsstellen als Einrichtungen mit „kulturbolschewistischen Bestrebungen“ durch Erlass vom 17. Mai 1933 verboten worden. ${ }^{274}$ Bald darauf, am 14. Juli 1933, hatte die Reichsregierung das GzVeN beschlossen. ${ }^{275}$ Es definierte in Anlehnung an den erwähnten preußischen Entwurf 5 psychiatrisch-neurologische Krankheitsbilder, 3 somatische Behinderungen und eine Suchterkrankung als „Erbkrankheiten“. Dabei handelte es sich um „angeborenen Schwachsinn“, Schizophrenie, manisch-depressives Irresein, Epilepsie, Veitstanz (Huntington'sche Chorea), Blindheit und Taubheit, schwere körperliche Missbildungen sowie schweren Alkoholismus. ${ }^{276}$

Der Vererbungsgang der gesetzlich definierten „Erbkrankheiten“ war zu diesem Zeitpunkt keineswegs geklärt, sondern beruhte im Wesentlichen auf seriellen Untersuchungsreihen, wonach die Nachkommen „erbkranker“ Eltern „nach den Erfahrungen der ärztlichen Wissenschaft mit großer Wahrscheinlichkeit [...] an schweren körperlichen oder geistigen Erbschäden leiden werden“.277 Insbesondere der medizinische Nachweis von „Schwachsinn“ gestaltete sich schwierig, sodass das Gesetz nicht von „erblichem“, sondern von „angeborenem Schwachsinn“ sprach, um die Sterilisation all derjenigen Frauen und Männer zu ermöglichen, für die exogene Erkrankungsursachen, wie etwa Unfälle, ausgeschlossen werden konnten.

Vor allem unter dem Oberbegriff „moralischer Schwachsinn“ wurden Frauen und Männer unfruchtbar gemacht, die aus sozial prekären Familien stammten, über geringe intellektuelle Fähigkeiten verfügten, keinen hinreichenden Schulabschluss besaßen, keiner geregelten Arbeit nachgingen, kleinere Straftaten begangen hatten oder in ihrem Sozialverhalten schlicht „auffällig“ oder unangepasst waren. ${ }^{278}$ Diese Kriterien spiegeln allerdings keinen spezifisch nationalsozialistischen Beurteilungskatalog wider. Vielmehr handelt es sich um divergente Bewertungsmaßstäbe, die sich am nationalsozialistischen „Volkskörper“ als Leitbild, an ökonomischer Leistungsfähigkeit, an einem bürgerlichen Tugendkanon oder an habituellen Auffassungen der begutachtenden Ärzte orientierten. Betroffene Frauen und Männer begutachtete man auch anhand von geschlechtsspezifischen Kriterien. Dabei wurde vor allem das Sexualverhalten von Frauen überprüft. Abweichungen von überkommenen gesellschaftlichen Vorstellungen sanktionierte man. Hierzu gehörten frühzeitiger Geschlechtsverkehr oder Promiskuität ebenso wie die Geburt un- ehelicher Kinder oder die Vernachlässigung der Kindererziehung oder des familiären Haushalts. Entsprechend der Begutachtungspraxis anhand von intellektuellen und beruflichen Leistungen, familiärer Situation oder Sozialverhalten entstammte ein erheblicher Teil der zwangssterilisierten Frauen und Männer den unteren sozialen Schichten. ${ }^{279}$

Der entscheidende Unterschied des GzVeN zum preußischen Gesetzentwurf bestand darin, dass die Sterilisation mithilfe von Polizeimaßnahmen auch zwangsweise durchgesetzt werden konnte: „Hat das Gericht die Unfruchtbarmachung endgültig beschlossen, so ist sie auch gegen den Willen des Unfruchtbarzumachenden auszuführen [...]. Soweit andere Maßnahmen nicht ausreichen, ist die Anwendung unmittelbaren Zwangs zulässig.“" 280 Diese Möglichkeit der Durchsetzung verlieh dem Sterilisationsgesetz unter den diktatorischen Bedingungen des „Dritten Reiches" eine besondere Schlagkraft und ordnete individuelle Interessen der staatlich betriebenen erb- und rassenbiologischen Politik zur „Aufartung“ der „Volkgemeinschaft" unter. Damit verbunden war ein grundsätzlicher Wandel in der Auffassung von Krankheitsvorsorge: Sie sollte nun auch dadurch betrieben werden, dass man potentielle Überträgerinnen und Überträger an der Fortpflanzung hinderte. Die Einbindung der Justiz knüpfte die Durchführung an ein formalisiertes Rechtsverfahren, sollte dem Gesetz Legitimität verleihen und vor allem befürchteten Vorwürfen einer willkürlichen Sterilisationspraxis vorbeugen.

Verfahrenstechnisch sind eine Erfassungs- und Ermittlungsphase sowie eine gerichtliche Entscheidungsphase zu unterscheiden, an der eine Vielzahl von staatlichen Behörden sowie ärztlichen Berufsgruppen beteiligt war. Zur Erfassung „erbkrankverdächtiger" Frauen und Männer durch Sterilisationsanzeigen waren alle approbierten Ärzte oder „sonstige Personen, die sich mit der Heilbehandlung, Untersuchung oder Beratung von Kranken befassen“, gesetzlich verpflichtet. ${ }^{281}$ „Erbkranke“ Frauen und Männer konnten auch selbständig die Sterilisation beantragen. Der Sterilisationsantrag war formalisiert und umfasste ein ärztliches Gutachten mit Informationen über Familienangehörige, die persönliche Vorgeschichte sowie den körperlichen und psychischen Befund. „Angeborener Schwachsinn“ wurde anhand eines zusätzlichen Intelligenzprüfungsbogens diagnostiziert. ${ }^{282}$

Die von antragsberechtigten Ärzten erstellten Sterilisationsanträge wurden vor im Frühjahr 1934 speziell eingerichteten Erbgesundheitsgerichten verhandelt. Personell bestanden sie aus 3 Personen: einem vorsitzenden Amtsrichter sowie je einem beamteten und einem nichtbeamteten Arzt, „der mit der Erbgesundheitslehre besonders vertraut sein sollte“.283 Die nichtbeamteten Ärzte wurden anhand fachlicher und insbesondere politischer Gesichtspunkte ausgewählt. Entsprechend der Zuord-

\footnotetext{
274 Siehe hierzu Soden: Sexualberatungsstellen (1988), S. 146-163.

275 Die Bekanntgabe erfolgte erst am 26. Juli, um die Konkordatsverhandlungen mit der katholischen Kirche nicht zu gefährden. In Kraft trat das Gesetz am 1. Januar 1934. Vgl. Bock: Zwangssterilisation (2010), S. $88 \mathrm{f}$.

276 GzVeN, S. 529.

277 Gütt/Rüdin/Ruttke: Gesetz (1934), S. 56.

278 Vgl. Braß: Zwangssterilisation (2004), S. 108,335; Kaminsky: Zwangssterilisation (1995), S. 293 f.; Ayaß: „Asoziale“ (1995), S. $105-113$.

279 Vgl. Bock: Zwangssterilisation (2010), S. 365-429; Köbsell: Eingriffe (1987); Maria-Hix: Zwangssterilisierungen (1994), S. $232-245$.

${ }^{280}$ GzVeN, S. 530.

281 GzVeN, S. 1021.

282 GzVeN, S. $1023-1036$

283 GzVeN, S. 530.
} 

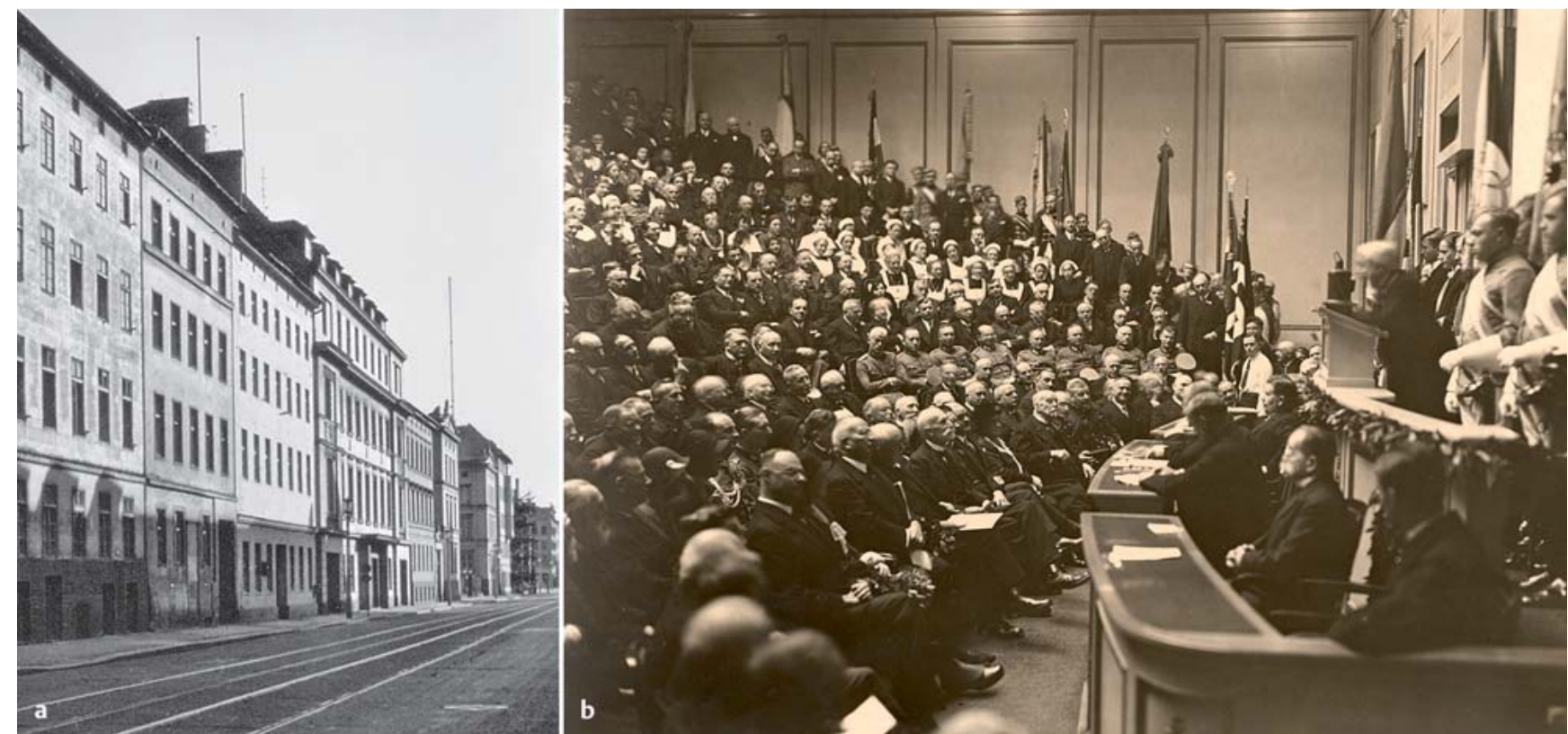

Abb. 15a und b a Das Langenbeck-Virchow-Haus in der Luisenstraße, Berlin, Ort der DGG-Tagungen 1933 und 1937.

b Vortragssaal des Langenbeck-Virchow-Hauses, vermutlich während eines Chirurgenkongresses 1933 oder 1934. Hier fand 1933 der „Gleichschaltungskongress“ der DGG unter der Leitung von Walter Stoeckel statt (Quelle für a und b: Archiv des Instituts für Geschichte der Medizin und Ethik in der Medizin, Charité Universitätsmedizin Berlin).

nung zur freiwilligen Gerichtsbarkeit verfügten die Erbgesundheitsgerichte über erhebliche Handlungsspielräume. ${ }^{284}$ So konnten sie eigenständig Ermittlungen führen sowie in nichtöffentlichen Sitzungen und in Abwesenheit der Betroffenen nach Aktenlage entscheiden.

Die Betroffenen besaßen das Recht, binnen einer zunächst 4-, später 2-wöchigen Frist Widerspruch einzulegen. ${ }^{285}$ Dann wurde vor einem Erbgesundheitsobergericht erneut verhandelt. Bei Bestätigung des Sterilisationsbeschlusses musste die Unfruchtbarmachung innerhalb einer zweiwöchigen Frist durchgeführt werden. ${ }^{286}$ Als Altersuntergrenze bestimmte das Gesetz die Vollendung des 10. Lebensjahres. ${ }^{287} \mathrm{Zu}$ den Eingriffen wurden öffentliche Krankenhäuser, psychiatrische Einrichtungen, aber auch gynäkologische Privatkliniken „ermächtigt“. Voraussetzung war die Möglichkeit zur stationären Versorgung und die Fachkompetenz der operierenden Ärzte. ${ }^{288}$ Methodisch kamen ursprünglich nur chirurgische Eingriffe an den Ei- oder Samenleitern infrage. Das GzVeN wurde jedoch im Laufe der Jahre immer wieder modifiziert, teils auch mit geheimen Durchführungsverordnungen. ${ }^{289}$
Ideale Plattform zur wissenschaftlichen Legitimierung Es ist oben bereits deutlich geworden, dass für die Vorbereitungen des Kongresses der Gesellschaft im Oktober 1933 nur lückenhaftes Quellenmaterial vorliegt ( Abb. 15a und b). Berücksichtigt man jedoch die geschilderte Ausgangslage, so erscheinen ideale Bedingungen für einen Ressourcentausch gegeben: Stoeckel hatte - entgegen den Warnungen vieler Kollegen - den dringenden Wunsch, „seinen“ Kongress auch unter den damals aktuellen politischen Verhältnissen planmäßig durchzuziehen. Er war, so schrieb er in seinen Memoiren, „überzeugt, daß bei den bestehenden Machtverhältnissen die Gesellschaft nur auf diese Weise in die neue Zeit hineingeführt und ihr Bestand für die Zukunft gesichert werden konnte“.290 Die Nationalsozialisten ihrerseits mussten größtes Interesse daran haben, die DGG für die Implementierung des GzVeN zu gewinnen. Ein Kongress der Gesellschaft zwischen der Veröffentlichung des Gesetzes und seinem Inkrafttreten bot zudem eine ideale Plattform für die wissenschaftliche Legitimation der damit verbundenen Maßnahmen auch gegenüber der Öffentlichkeit.

Dieser Ressourcentausch lässt sich zumindest im Ergebnis tatsächlich nachvollziehen. Das von Stoeckel präsentierte Programm zum Thema „Eingriffe aus eugenischer Indikation“ dürfte hinsichtlich der eingeladenen Referenten bei den Nationalsozia-

\footnotetext{
284 Vgl. u.a. Bock: Zwangssterilisation (2010) S. 195 f.; Einhaus: Zwangssterilisation (2006), S. 31-39.

285 Vgl. Gütt/Rudin/Ruttke: Gesetz (1934), S. 156.

286 Ebd., S. 162.

287 VO GzVeN, S. 1021.

288 Vgl. Gütt/Rudin/Ruttke: Gesetz (1934), S. 159

289 Eine von Hans Reiter, Präsident des Reichsgesundheitsamtes, und Bernhard Möllers, Oberregierungsrat im Reichsgesundheitsamt, herausgegebene Sammlung aus dem Jahr 1940 zählt 80 „gültige Gesetze, Verordnungen, Durchführungsbestimmungen, Rundschreiben, Merkblätter usw.“ für das GzVeN auf. Vgl. Möllers/Reiter (Hrsg.): Rassenpflege (1940).

290 Vgl. Stoeckel: Leben (1954), S. 118 f.
} 
listen keine Wünsche offengelassen haben: Es handelte sich um ausgesprochene Exponenten des Regimes. Der Berliner Strafrechtler Eduard Kohlrausch sollte später „zur Elite der Jurisprudenz im totalitären Staat" gehören, ${ }^{291}$ der Münchner Psychiatrie-Ordinarius Oswald Bumke blieb in der NS-Zeit unangefochten ein führender Vertreter seines Faches ${ }^{292}$ und der Anthropologe Eugen Fischer gilt als einflussreichster Rassenforscher im „Dritten Reich“. Von Seiten der DGG selbst war Ludwig Seitz aufgeboten, bekanntlich nicht nur engagierter Verfechter der Zwangssterilisationen, sondern auch der Abtreibungen aus eugenischer Indikation. Stoeckel seinerseits wurden bei der Planung und Durchführung „seines Kongresses“ offenbar keine größeren Steine in den Weg gelegt; der glatte Verlauf der Veranstaltung brachte ihm viel Lob aus dem In- und Ausland ein und stärkte seine Position sowohl unter den Fachkollegen als auch bei den Vertretern des Regimes.

Dieser Erfolg dürfte auch deshalb nicht ganz unwichtig gewesen sein, weil Stoeckel bei der Vorbereitung getreu seiner Devise von der Notwendigkeit „diktatorischen“ Organisierens offenbar alle für den vorhergehenden Kongress eingeführten Neuerungen wie eine Mitgliederbefragung zu den Themen ignoriert hatte, ohne darüber ein Wort zu verlieren. Es gibt im Vorfeld und auch bei der Veranstaltung selbst keine Hinweise auf eine breiter angelegte Erörterung zu den Kongressthemen oder gar zur Referentenauswahl. Dass er sich damit zwar nicht direkt über die Statuten hinwegsetzte, aber doch die Gepflogenheiten der Gesellschaft weitgehend ignorierte, war ihm klar: „[Der Präsident] sollte mit dem Vorstand arbeiten, Vorstandssitzungen einberufen, alles durchberaten lassen und die Vorstandsbeschlüße [sic] dann ausführen. Ich habe das alles nicht getan, worüber die ausländischen Vorstandsmitglieder wahrscheinlich etwas ungehalten gewesen sind“, schrieb er in seiner Autobiografie. ${ }^{293}$

Auch zu Beginn der Sitzung beschränkte sich Stoeckel darauf „ein besonders erlauchtes Referentengremium zu begrüßen“, ohne auf die doch bemerkenswerte Tatsache näher einzugehen, dass hier 4 Experten das Wort ergreifen sollten, von denen nur einer Mitglied der Gesellschaft und Gynäkologe war. Stattdessen hielt er es für erforderlich, auf offenbar bereits im Vorfeld laut gewordene Kritik zu reagieren, wonach eine Debatte über das bereits veröffentlichte Gesetz nicht mehr sinnvoll sei: „Ich teile diese Meinung nicht“, erklärte er. Aktuell würden die Durchführungsbestimmungen eingehend beraten und die Regierung lege größten Wert auf die hier geäußerten Ansichten. Alle, die zu diesem Thema sprechen wollten, sollten sich „durch keinerlei Hemmungen irgendwie beeinflussen“ lassen. ${ }^{294}$

\section{Ausführer und Vollstrecker des Gesetzeswillens}

Der Jurist Kohlrausch bemühte sich in seinem Beitrag, ethische Bedenken gegen das GzVeN zu entkräften. Dazu unterschied er zwischen „ärztlichem“ und „weltanschaulichem“ Gewissen. Es sei klar, dass eine Zwangssterilisation nicht vorgenommen wer- den müsse, wenn ihr gravierende medizinische Bedenken entgegenstünden. „[Der Arzt] könnte sich trotz positiver Entscheidung des Dreierauschusses geradezu strafbar machen, wenn er hier gegen seine Überzeugung operierte und der Eingriff ungünstig ausginge“, sagte Kohlrausch. Was das weltanschauliche Gewissen angehe, so seien hier in der Tat ernste Gewissenskonflikte denkbar, „mit denen die Standesethik bisher nicht belastet war“. Er gehe aber davon aus, dass die oberste Landesbehörde bei der Bestimmung der Krankenanstalten und Ärzte für die Durchführung der Sterilisationen „auch überlegen wird, wem sie die Ausführung zumuten darf; negativ gesagt: daß sie die Ausführung keinem Arzt ,überlassen` wird, der grundsätzliche Bedenken äußert“. Kohlrausch räumte ein, dieser Gedanke hätte im Gesetz zum Ausdruck gebracht werden können. Er halte es aber für eine Selbstverständlichkeit, dass dem auch so Rechnung getragen werde. $^{295}$

In seinen weiteren Ausführungen bedauerte Kohlrausch, dass die eugenische Schwangerschaftsunterbrechung nach wie vor nicht geregelt sei. Dies habe eine Unstimmigkeit in die Rechtslage gebracht, denn die „Gefährdung des Volkswohls“ stehe dabei ebenso zur Debatte wie bei der Sterilisation. Hinsichtlich der möglichen Ausgestaltung eines derartigen Gesetzes, das ja namentlich von Seitz „unermüdlich gefordert“ worden sei, erklärte Kohlrausch, er halte auch dabei eine Einwilligung der Betroffenen nicht für erforderlich. Bei der medizinischen Indikation sei es Sache der Mutter, ob sie ihr Leben aufs Spiel setzen wolle. „Es darf aber nach heutiger Anschauung nicht in ihr Belieben gestellt sein, ob sie das Volksganze mit schwer erbkranken Kindern belasten will.“296

Der Psychiater Oswald Bumke erläuterte in seinem Referat die psychiatrisch-neurologischen Indikationen zur Zwangssterilisation einschließlich des schweren Alkoholismus. Dabei räumte er ein, dass die im GzVeN geforderte „große Wahrscheinlichkeit“ (mindestens 51\%) der Übertragung schwerer körperlicher und geistiger Erbschäden bei den unmittelbaren Nachkommen „beinahe niemals gegeben“ sein würde. Das Gesetz beziehe sich aber auf die gesamte Nachkommenschaft eines Menschen, erklärte er. „Sobald man [...] fragt, ob sich unter den so verstandenen Nachkommen [...] schwere geistige Erbschäden mit großer Wahrscheinlichkeit finden werden, so muß diese Frage bei vielen Krankheiten mit Ja beantwortet werden.“297

Besonders bemerkenswert erscheint, wie Bumke die Defizite der wissenschaftlichen Erkenntnis für die Indikationen „angeborener Schwachsinn“ und Schizophrenie relativierte: „[...] bei dieser Störung [Schwachsinn] - ähnlich wie bei der Schizophrenie brauchten wir uns den Kopf nicht so furchtbar darüber zu zerbrechen, wie der Erbgang ist und ob ein schwachsinniger Mensch seinen Zustand überhaupt ererbt hat und vererben kann. Schwachsinnige können ihre Kinder schließlich doch nicht erziehen, und jedenfalls ist es nicht wünschenswert, daß Kinder von

\footnotetext{
291 Karitzky: Kohlrausch (2002), S. 105.

292 Mit der Begutachtung des Hitler-Attentäters Georg Elser beauftragt; Mitarbeit am Indikationskatalog Schwangerschaftsunterbrechungen.

293 Stoeckel: Leben (1954), S. 118.

294 Stoeckel: [Einführung, Verhandlungen 1933] (1934), S. 103.

295 Kohlrausch: [Eingriffe, Verhandlungen 1933] (1934), S. $106 \mathrm{f}$.

296 Ebd., S. 109.

297 Bumke: [Eingriffe, Verhandlungen 1933] (1934), S. 112. Diese Interpretation findet sich auch im Kommentar von Gütt, Rüdin und Ruttke (1934), S. 87. Hier heißt es an der entsprechenden Stelle allerdings im ersten Satz: „7. Unter Nachkommen sind in erster Linie die leiblichen Kinder gemeint.“ Die Einschränkung folgt erst später.
} 
schwachsinnigen Eltern erzogen werden." Auch im Zusammenhang mit „häufig psychisch schwer veränderten“ Epileptikern sah er die seiner Ansicht nach fehlende Eignung, „eine Ehe einzugehen und Kinder zu erzeugen“, als eine Sterilisation rechtfertigend an, obwohl über den Erbgang „bisher nichts Zuverlässiges“ bekannt sei. ${ }^{298}$

Auch von Bumke wurden im Gesetz noch nicht vorgesehene Maßnahmen erörtert. Dabei sprach er sich klar gegen Schwangerschaftsabbrüche aus eugenischer Indikation bei psychischneurologischen Erkrankungen aus und setzte sich für die Zwangssterilisation von „Rückfallverbrechern“ ein. Bei den häufigen Geisteskrankheiten liege, wenn nur ein Elternteil erkrankt oder schwer belastet sei, die Wahrscheinlichkeit für das einzelne Kind, auch krank zu werden, immer bei weniger als $50 \%$. Selbst bei der seltenen Chorea Huntington, die sich „offenbar einfach dominant vererbt“, könne nur die Hälfte der Kinder als gefährdet angesehen werden. „Das ist gewiß genug, um die Sterilisierung dieser Kranken zu verlangen, aber es reicht nach meiner Überzeugung nicht aus, um eine schon bestehende Schwangerschaft zu unterbrechen“, erklärte er. Den „Rückfallverbrechern“ sprach er wie den Schizophrenen und den Schwachsinnigen die Fähigkeit ab, Kinder zu „brauchbaren Staatsbürgern“ zu erziehen. ${ }^{299}$

Der Erbforscher Eugen Fischer versuchte die häufig geäußerten Bedenken zu entkräften, durch den im GzVeN zum Ausdruck kommenden Paradigmenwechsel vom salus aegroti zur salus publica werde das Vertrauensverhältnis zwischen Arzt und Patient zerstört. Dazu wies er darauf hin, dass die letzte Verantwortung für die geplanten Zwangssterilisationen bei den Erbforschern und bei den Erbgesundheitsgerichten liege, nicht bei den behandelnden Ärzten. ${ }^{300}$ Diese Sicht der Dinge wurde gerne übernommen - beispielsweise von Seitz, der im folgenden Referat erklärte: „Heute sind wir, Gott sei es gedankt, der persönlichen Verantwortung ganz enthoben. Die Prüfung und Verantwortung liegt völlig beim Erbgesundheitsgericht. Wir Frauenärzte sind nunmehr die Ausführer und Vollstrecker des Gesetzeswillens.“301

Fischer präsentierte ferner einen ausführlichen Überblick zur Erbforschung und äußerte sich - wie die Vorredner - zur eugenischen Abtreibung, für die er nur eine Indikation sah, wenn es für das Kind eine „100\%ige Krankeitserwartung [sic]“ gebe. „Hier halte ich Notlage (echte, wie im Krieg) des Volkes für gegeben“, sagte er. Der Eingriff in das Gebot, nicht zu töten, sei allerdings so schwerwiegend, dass er an die Entscheidung eines Erbgesundheitsgerichtes gebunden werden müsse. ${ }^{302}$ Fischer lehnte vor den DGG-Mitgliedern auch Abtreibungen aus rassenhygienischen Gründen ab. Seiner Ansicht nach sei zwar die „Herabsetzung der kulturellen Leistungsfähigkeit unseres Volkes durch Aufnahme von Blut minderwertiger Rassen“ sicher. Aber zu dessen Verhinderung genügten Gesetze. Dies gelte auch für die unerwünschte Mischung mit Juden. „[...] [D]aß der Einzelfall von arisch-semitischer Kreuzung nicht minderwertig zu sein braucht und es sehr häufig tatsächlich nicht ist, bedarf keines Wortes; daß auch diese [...] völkisch unerwünscht sind, leuchtet ein“, sagte er. ${ }^{303}$

Die Benutzung von Kontrazeptiva wollte Fischer auf wenige Ausnahmen begrenzt sehen. Der Arzt, so sagte er, habe „mit allen Mitteln gegen die volksmordenden Präventivmittel zu kämpfen und für die Hebung der Fortpflanzung bei gesunden Ehegatten einzutreten“. Als eugenisch wünschenswert nannte er die Zahl von 4 Kindern. ${ }^{304}$

Ludwig Seitz schloss sich der Meinung Stoeckels an, wonach die Gesellschaft auf die zu erwartenden Ausführungsbestimmungen für das GzVeN Einfluss nehmen sollte. Dies sei für die richtige Handhabung des Gesetzes von größter Wichtigkeit und von den „maßgebenden Kreisen“ auch erwünscht. Das GzVeN bedeute nicht nur in eugenischer Beziehung einen Wendepunkt, sondern sei auch für das Fachgebiet von überragender Bedeutung. Seitz sagte:

„Mancher von uns mag, wenn er bei der Geburt eines mißgestalteten oder geistig minderwertigen Kindes vielleicht im Schweiße seines Angesichtes Beistand geleistet hat, sich nachher die Frage vorgelegt haben, ob es für Kind und Mitwelt nicht besser gewesen wäre, wenn er sich dieser Mühe nicht unterzogen hätte. Auch ist es sicherlich öfters vorgekommen, daß bewußt oder unbewußt bei unseren medizinischen Indikationsstellungen zur Schwangerschaftsunterbrechung eugenische Gesichtspunkte mit eine Rolle gespielt haben.“305

In seinen weiteren Ausführungen äußerte sich Seitz unter anderem zum Risiko des Eingriffs für Frauen und zum „Verhalten bei bereits eingetretener Schwangerschaft einer Erbkranken“. Er räumte ein, dass die Sterilisationen unabhängig vom operativen Zugangsweg nicht ohne weiteres als völlig harmlos hingestellt werden könnten. Wegen fehlender Daten sei es auch nicht möglich, ein zuverlässiges Urteil über das Risiko abzugeben. Dennoch kam er zu dem Schluss, die „Gefahrenquote“ sei „ganz verschwindend klein“ und berechtige die Betroffenen nicht zur Verweigerung des Eingriffs. Im Zusammenhang mit Abtreibungen verwies Seitz auf seine Initiative, Sterilisation und Schwangerschaftsunterbrechung aus eugenischer Indikation in einem Gesetz zu „koppeln“. Da die Reichsregierung anders entschieden habe, müsse nun überlegt werden, wie mit dieser Situation umzugehen sei. Als eine Lösung des Problems deutete er dabei die Möglichkeit an, die medizinische Indikation unter Einbeziehung eines Sachverständigen durch die Erbgesundheitsgerichte künftig weiter fassen zu lassen. Beide Eingriffe könnten dann in der Regel gleichzeitig durchgeführt werden. ${ }^{306}$

\section{Niedermeyers Bekenntnis}

Unter den 9 Diskussionsrednern, die nach den Ausführungen der Referenten das Wort ergriffen, äußerte nur der Frauenarzt, Jurist und Theologe Albert Niedermeyer grundsätzliche Kritik an dem

\footnotetext{
298 Bumke: [Eingriffe, Verhandlungen 1933] (1934), S. 115.

299 Ebd., S. 117.

300 Fischer: [Eingriffe, Verhandlungen, 1933] (1934), S. 126

301 Seitz: [Eingriffe, Verhandlungen 1933] (1934), S. 133.

302 Fischer: [Eingriffe, Verhandlungen 1933] (1934), S. 126.

303 Ebd., S. 126.

304 Ebd.

305 Seitz: [Eingriffe, Verhandlungen 1933] (1934), S. 132.

306 Ebd., S. 138.
} 
neuen Gesetz. In dieser Kritik bezog sich Niedermeyer vor allem auf die katholische Glaubenslehre und dabei speziell auf die knapp 3 Jahre zuvor veröffentliche Enzyklika „Casti connubii“ von Papst Pius XI., der ein Verbot von Kontrazeption und Sterilisation aus eugenischen Gründen zu entnehmen ist. Es werde, so sagte Niedermeyer, der Sinn des gesamten Geschlechtslebens entleert, „sobald durch einen menschlichen Eingriff irgendwelcher Art die Folgen der geschlechtlichen Vereinigung vereitelt werden." Das sei der Generalnenner, auf den alles andere zurückzuzuführen sei, „ganz gleich, ob es sich um Fruchttötung handelt oder um Sterilisierung oder Geburtenverhütung unter Verkehrung der Natur des Geschlechtsaktes“.307

In seiner Stellungnahme, die in der gedruckten Fassung den Umfang eines kleineren Referates hatte, ging Niedermeyer auch auf die biologistische Maxime des NS-Staates ein, wonach die geplanten Eingriffe in individuelle Rechte im Interesse des „Volkskörpers“ bzw. des „Volksganzen“ gerechtfertigt seien. Die christliche Weltanschauung, so sagte er, habe von jeher betont, dass Gemeinnutz (bonum publicum) vor Eigennutz (bonum privatum) gehe. Aber auch das bonum publicum sei nur dann richtig orientiert, wenn es sich an dem höchsten und letzten Lebenswert, dem summum bonum ausrichte. Wirkungsvolle Eugenik könne auch ohne die genannten Eingriffe und Maßnahmen betrieben werden. Den Weg dahin weise die Enzyklika „Quadrogesimo anno“, in der die Normen für soziale Gerechtigkeit entwickelt würden. $^{308}$

Zuvor hatte Niedermeyer auch Zweifel an der wissenschaftlichen Begründung für die Indikationen zur Sterilisation geäußert. Es sei bemerkenswert, dass manche Autoren die Zuverlässigkeit der Erbprognose unterschiedlich beurteilten - je nachdem, welcher Eingriff damit begründet werden solle: eine freiwillige oder eine Zwangssterilisation oder aber eine Fruchttötung. Es könne jedoch für alle infrage kommenden Eingriffe die tatsächliche Grundlage nur so beurteilt werden: „Entweder vermögen wir eine Erbprognose mit genügender Sicherheit zu stellen oder wir vermögen es nicht. Das ist die wissenschaftliche Voraussetzung für sämtliche ausmerzenden Maßnahmen.“309

Niedermeyer hat seinen Auftritt bei Stoeckels Kongress in seiner Autobiografie beschrieben. Danach verließ er den Katheder

„unter eisigem Schweigen der Versammlung. Nicht eine einzige Hand rührte sich zum Beifall. In der vordersten Reihe saßen in braunen und schwarzen Uniformen die ärztlichen Mitglieder der Reichsführung - und heute muß es mir fast unglaublich erscheinen, daß man mich damals nicht direkt aus dem Hörsaal [...] verhaftet hat. [...] Als ich den Saal verließ, entstand um mich herum geradezu ein luftleerer Raum, so wich man mir aus. Aber im Gedränge der Garderobe fühlte ich plötzlich einen verstohlenen Händedruck. Es war Prof. Martius, der mir zuflüsterte: ,Lassen Sie sich wenigstens danken, daß Sie der einzige waren, der hier den Mut hatte, für die Wahrheit einzutreten. Leider sind wir beamteten Professoren jetzt nicht frei und dürfen nicht reden; ich möchte Ihnen aber sagen, daß Ihnen mehr Teilnehmer zustimmen, als Sie ahnen.' So verdanke ich Prof. Martius, dem charaktervollen protestantischen Arzt und Gelehrten, den einzigen tröstlichen Lichtblick dieser Tagung.“310

Aus der Autobiografie geht auch hervor, dass Stoeckel den Auftritt Niedermeyers offenbar „nach besten Kräften“ verhindern wollte. Obwohl er seinen Vortrag bereits monatelang vorher als Referat angemeldet habe, sei er nur als Diskussionsbemerkung mit einer Redezeit von 10 Minuten zugelassen worden, schrieb Niedermeyer. Stoeckel habe dann die Diskussionsbemerkungen so platziert, „daß die meinige immer mehr in den Hintergrund gedrängt wurde“. Schließlich habe er ihm mit Hinweis auf die fortgeschrittene Zeit nur noch 3 Minuten Redezeit zubilligen wollen. Nur seine, Niedermeyers, persönliche Bitte an das Auditorium habe es ihm ermöglicht, seine Ausführungen zu Ende zu führen.

Der Text Niedermeyers wurde dann - offenbar unverändert - auf fast 7 Seiten in den Verhandlungsberichten abgedruckt. In den Schlussworten der Referenten ging nur Eugen Fischer auf die Äußerungen von Niedermeyer ein. Zur Kritik an der Validität der Erbprognose nahm er dabei nicht Stellung, sondern erklärte lediglich, er lehne es mit aller Entschiedenheit ab, dass ihm und den zahllosen auf seinem Standpunkt stehenden gewissenhaften Ärzten unterstellt werde, ethische Forderungen weniger zu berücksichtigen „als irgendjemand anders“. 311

\section{Der Kongress 1935: eine „Erfolgskontrolle“ $\nabla$}

\section{Die Weiterentwicklung der Gesetzgebung}

Bis zum DGG-Kongress 1935 und darüber hinaus wurde die Implementierung des GzVeN von umfangreichem medizinischem und juristischem Schrifttum begleitet, das die gesetzlichen Rahmenbedingungen, die vererbungswissenschaftlichen Grundlagen, den diagnostischen Nachweis der einzelnen „Erbkrankheiten" sowie die möglichen Variationen des chirurgischen Eingriffs diskutierte und darlegte. ${ }^{312}$ Außerordentliche Bedeutung entwickelte dabei die von Arthur Gütt, Ernst Rüdin und Falk Ruttke ausführlich kommentierte, inoffizielle Publikation des Gesetzes. ${ }^{313}$ Sie sollte den beteiligten Ärzten und Richtern als Handreichung dienen, nahm für die Fachwelt letztlich den Charakter eines wissenschaftlichen Standardwerks an und übte damit erheblichen Einfluss auf die praktische Durchführung des Gesetzes aus. Der entsprechende Band erschien erstmals 1934. Zwei Jahre später wurde er im Hinblick auf die bis dahin erfolgte Erweiterung der eugenischen Gesetzgebung der Nationalsozialisten neu aufgelegt. In beiden Auflagen bedienten sich die Verfasser bzw. Herausgeber angesehener DGG-Mitglieder als Mitautoren: 1934 schrieb der gerade emeritierte Münchner Ordinarius Albert Döderlein das Kapitel über „Die Eingriffe zur Unfruchtbarmachung

\footnotetext{
307 Niedermeyer: [Diskussionsbeitrag, Verhandlungen 1933] (1934), S. 146.

308 Ebd., S. 148.

309 Ebd., S. 144.

310 Niedermeyer: Wahn (1956), S. 279 f.

311 Fischer: [Schlusswort, Verhandlungen 1933] (1934), S. 161.

312 Vgl. Leuthold: Veröffentlichungen (1975).

313 Vgl. Gütt/Rüdin/Ruttke: Gesetz (1934).
} 
der Frau“, 1936 übernahm sein Nachfolger im Amt, Heinrich Eymer, diese Aufgabe. ${ }^{314}$

Eine der angesprochenen Ausweitungen der gesetzlichen Grundlagen erfolgte am 26. Juni 1935 mit der Zulassung der eugenischen Schwangerschaftsunterbrechungen. Diese Novellierung des GzVeN sollte die bis dahin rechtswidrige Praxis von Abtreibungen im Sterilisationsverfahren legalisieren. Sie war in hohem Maße auf den Einfluss der NSDAP zurückzuführen. Es hatten sich aber auch einflussreiche DGG-Mitglieder wie Ludwig Seitz und Hans Naujoks sehr intensiv dafür eingesetzt. Eduard Martin hatte deshalb für den Kongress 1935 eine Resolution der DGG zum Thema vorgeschlagen - eine Initiative, die sich dann erübrigte. ${ }^{315}$ Für die NSDAP stellte die Novelle allerdings nur einen politischen Teilerfolg dar, da die Schwangerschaftsunterbrechungen an die Einwilligung der betroffenen Frauen geknüpft wurden. ${ }^{316}$ Aufgrund dessen spielten sie eher eine untergeordnete Rolle. ${ }^{317}$

Daneben wurden 1935 weitere erb- und rassenpflegerische Maßnahmen beschlossen, die in mittelbarer und unmittelbarer Beziehung zur nationalsozialistischen Zwangssterilisation standen. ${ }^{318}$ So erschien am 18. Oktober 1935 das „Gesetz zum Schutze der Erbgesundheit des deutschen Volkes“, das ein Eheverbot vorsah, „wenn einer der Verlobten an einer Erbkrankheit im Sinne des Gesetzes zur Verhütung erbkranken Nachwuchses leidet“ ${ }^{319}$ Ebenfalls 1935 wurde mit der „erbbiologischen Bestandsaufnahme“ begonnen, die eine entsprechende Kartierung der gesamten deutschen Bevölkerung zum Ziel hatte. Damit sollte die effektive Durchführung pro- und antinatalistischer Maßnahmen gewährleistet werden. ${ }^{320}$ Eine wichtige medizinisch-bürokratische Voraussetzung dafür bildeten die staatlichen Gesundheitsämter, die aufgrund des „Gesetzes zur Vereinheitlichung des Gesundheitswesens“ vom 3. April 1934 gegründet worden waren und als Schaltzentralen der nationalsozialistischen Erb- und Rassenpflege fungieren sollten. ${ }^{321}$

Auf dem von August Mayer organisierten und geleiteten Kongress 1935 in München spielte erneut die Bevölkerungspolitik im weitesten Sinn eine wichtige Rolle, nun zum dritten Mal in Folge. ${ }^{322}$ Neben der eugenischen Sterilisierung, die diesmal unter dem Aspekt der „bisherigen Erfahrungen“ mit dem GzVeN erörtert werden sollte, standen auch Beiträge auf der Tagesordnung, die sich mit Problemen des Pronatalismus beschäftigten. Mayer, der die vorangegangene „Gleichschaltung“ in seiner Eröffnungsrede ganz im Sinne Stoeckels dahingehend interpretierte, dass die Gesellschaft nun „eine Art Fachberater der Regierung“ geworden sei, fasste die Intention des Programms wie folgt zusammen:
„Angesichts unserer besonderen Stellung zur Regierung schien es richtig, [...] auf die Bedürfnisse der Staatsführung Rücksicht zu nehmen, wie es in den Referatthemen ,Sterilität‘ und ,eugenische Sterilisierung zum Ausdruck kommt. Auch an wichtigen Fragen der Gegenwartsmedizin wollten wir nicht vorübergehen und berücksichtigten deswegen auch die natürlichen Heilschätze von Klima und Boden.“323

Für das Sterilisierungsthema hatte Mayer auf das von Stoeckel inaugurierte und schon 1933 bewährte Konzept zurückgegriffen, wonach in den Hauptreferaten neben einem besonders geeigneten Fachvertreter auch ein Jurist und ein Erbwissenschaftler zu Wort kommen sollten. Es handelte sich dabei um den deutsch-baltischen Frauenarzt Benno Ottow, den Stuttgarter Oberlandesgerichtsrat Hans Göz sowie den erwähnten Mitautor des GzVeN-Kommentars, Ernst Rüdin. Ottow, ein Stoeckel-Schüler und seit 1933 Direktor der Brandenburgischen Landesfrauenklinik Berlin-Neukölln, gehörte nach dem Urteil von Fachkollegen zu den Frauenärzten mit der größten klinischen Erfahrung bei Zwangssterilisationen. Er war außerdem ärztlicher Beisitzer des Erbgesundheitsgerichtes Berlin und NSDAP-Mitglied bereits seit $1932 .{ }^{324}$

\section{Kongressplanung in der Diktatur}

Im Gegensatz zu den anderen hier behandelten Kongressen der DGG, über deren Organisation wegen fehlender Archivalien kaum etwas bekannt ist, existiert für die Veranstaltung von 1935 im Nachlass von August Mayer umfangreiches Material, das sich aus offizieller und privater Korrespondenz, Sitzungsprotokollen sowie persönlichen Aufzeichnungen in Form von Resümees und „To-do-Listen“ zusammensetzt. ${ }^{325}$ Dies ermöglicht einen genaueren Blick auf die Bedingungen, die sich aus der „Gleichschaltung“, der NS-Biopolitik sowie den in der Diktatur herrschenden polykratischen Strukturen für die Gesellschaft ergaben. Ferner lässt die Korrespondenz Rückschlüsse auf die Amtsführung des Präsidenten zu. Dass das wissenschaftliche Programm, wie von Stoeckel bei der „Gleichschaltung“ versichert, durch Eingriffe der Partei- und Staatsführung unbeeinflusst bleiben würde, ist dabei nicht feststellbar - ganz im Gegenteil.

Die Schwierigkeiten, mit denen Mayer unter diesen Auspizien bei der Programmgestaltung für den Kongress 1935 kämpfen musste, waren organisatorischer und inhaltlicher Natur ( Abb. 16). Die der Machtübernahme folgenden gesellschaftlichen Umwälzungen hatten die Möglichkeiten zu wissenschaftlicher Tätigkeit zumindest zeitweise nicht unerheblich eingeschränkt. ${ }^{326}$ Dies zeigte sich unter anderem darin, dass Sitzungen von mindestens

\footnotetext{
314 Döderlein: Eingriffe (1934), S. 224-226. Eymer: Eingriffe (1936).

315 UAT 150/33,41: Protokoll (23.02.1935).

316 Vgl. RGBl. Jg. 1935 I, Nr. 65, S. 773.

317 Vgl. Vossen: Gesundheitsämter (2001), S. 311-314.

318 Weiterhin wurde am 15.09.1935 auch das „Gesetz zum Schutze des deutschen Blutes und der deutschen Ehre“, das sogenannte Blutschutzgesetz, erlassen.

319 RGBl. Jg. 1935 I, Nr. 114, S. 1246. Weiterführend insbesondere Czarnowski: Paar (1991).

320 Vgl. grundlegend Roth: Bestandsaufnahme (1984).

321 Grundlegend Labisch/Tennstedt: Weg (1985); Vossen: Gesundheitsämter (2001).

322 Bei dieser Veranstaltung gedachte die DGG auch ihrer damals 50 Jahre zurückliegenden Gründungsversammlung in Straßburg.

323 Mayer: Eröffnungs-Ansprache [Verhandlungen 1935] (1936), S. 6. Mit den „wichtigen Fragen der Gegenwartsmedizin“ ist die Neue Deutsche Heilkunde des Nationalsozialismus gemeint.

324 Basisdaten zu Ottow in den Kurzbiografien im Anhang.

325 UAT 150/31 (295), Korrespondenz zur Tagung 1934; 150/33,41 Korrespondenz zur Tagung 1935; vgl. Doneith: Mayer (2007), S.94-97.

326 Zu nennen sind hier vor allem spezielle Dienstverpflichtungen in NS-Organisationen. Klinikchefs konnten erheblichen Ärger bekommen, wenn sie ihre Assistenten nicht dafür freistellten (z. B. Eduard Martin, siehe S. 22). Die Dienste beanspruchten aber auch die Freizeit. Hinzu kam die Einführung der allgemeinen Wehrpflicht.
} 
2 regionalen gynäkologischen Fachgesellschaften ersatzlos gestrichen wurden. ${ }^{327}$ Stoeckel schrieb dazu 1936:

„Die vergangenen Jahre waren politische Sturmjahre, in denen es um Größeres ging als um Facharbeit, [...] und es blieb für viele von uns nicht so viel Zeit wie früher, um die Wissenschaft in Wort und Schrift zu pflegen. Jetzt sind wir durch diese Zeit hindurch $[\ldots]$...328

Mayer seinerseits erlebte deshalb, dass seine Ende 1934/Anfang 1935 veröffentlichten Bitten um Vorschläge für Kongressthemen nahezu völlig ins Leere liefen. In Briefen an Stoeckel, mit dem er in allen Fragen der Kongressvorbereitung eng zusammenarbeitete, führte er beredt Klage darüber, dass auch seine Assistenten „neben ihren wichtigen nationalen Aufgaben“ nur noch „knapp Zeit zur klinischen Arbeit, aber nicht zur Wissenschaft“ hätten. ${ }^{329}$

So heftig der Kongresspräsident diese Situation auch kritisierte sie gab ihm doch die Möglichkeit, die wissenschaftlichen Schwerpunkte weitgehend selbst zu setzen. Dabei konnte er mit den Themen „Behandlung der Sterilität“ und „eugenische Sterilisierung“ schon länger intensiv gepflegten, speziellen eigenen Interessen Rechnung tragen. Gleichzeitig erschien es aber auch möglich, damit wichtige Anliegen der pro- und antinatalistischen Politik der Nationalsozialisten zu bedienen, die Mayer aus seinen deutsch-nationalen und religiös-ethischen Vorstellungen heraus in vielerlei Hinsicht teilte, ohne ein klassischer Parteigänger zu sein. Sein Engagement gegen Abtreibung und „sittliche Verwahrlosung“ war aus zahlreichen Publikationen allgemein bekannt, ebenso sein Kampf gegen den Geburtenrückgang und für die klassische Mutterrolle.

Beide Themenkomplexe - Sterilität und Sterilisierung - hatte Mayer bereits im November 1934 unter anderem bei einem Besuch im „Braunen Haus“ in München frühzeitig mit Vertretern der Parteiführung bzw. der Reichsregierung abgesprochen. ${ }^{330}$ Dennoch - das belegen die aufgefundenen Dokumente - gab es insbesondere im Zusammenhang mit der Sitzung zu Fragen, die mit dem GzVeN zusammenhingen, ein endlos anmutendes Hin und Her im Wirrwarr der Meinungen und Kompetenzen der NSMultifunktionäre und Behördenvertreter. Dabei ging es nicht nur um die Frage, welcher Referent zu welchem Thema sprechen sollte. Umstritten blieb bis rund einen Monat vor dem Kongress auch, ob in der Sterilisierungssitzung eine Diskussion zugelassen werden sollte, für welchen Tag man die Sitzung am besten einplante und ob man die ganze Sitzung nicht überhaupt streichen sollte. Selbst Mayer befürchtete zeitweise in einer Diskussion kritische Stimmen, die „die ganze doch überaus heilsame Sache schlecht machen könnten“. ${ }^{331}$ In dieser Debatte deutete sich sicherlich schon die „Krise“ der eugenischen Sterilisation an, von der noch die Rede sein wird. ${ }^{332}$

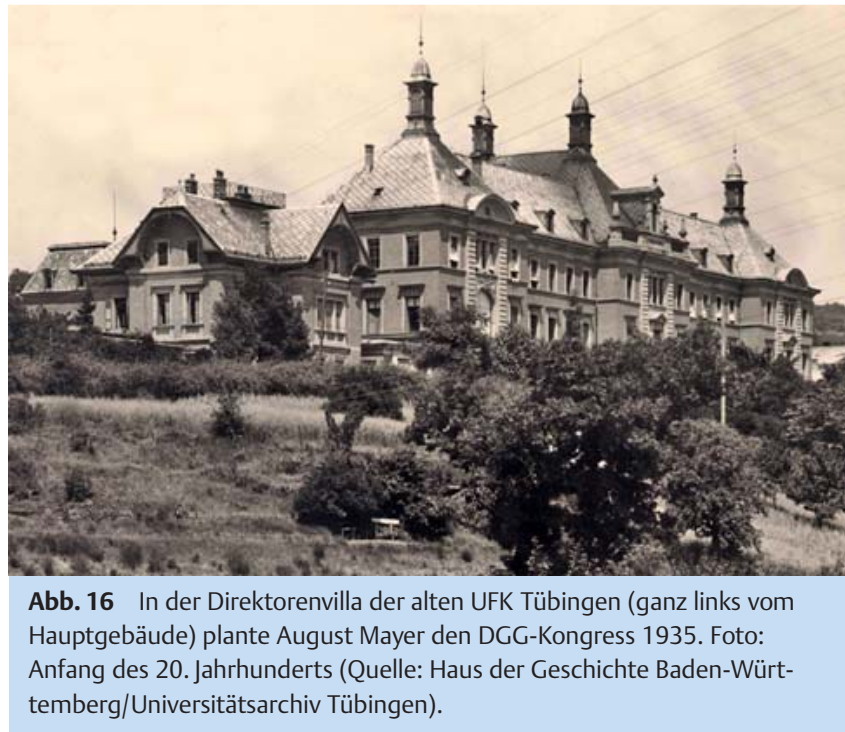

Blutordensträger, SS-Standartenführer, Multifunktionäre

Bei alldem hatte es Mayer ab Februar 1935 neben seinem kleinen Kongressteam mit folgenden Funktionsträgern des Systems zu tun: dem ehemaligen Oberarzt der I. UFK München, NS-Aktivisten und Blutordensträger Ernst Bach, unter anderem in seiner Eigenschaft als Gauamtsleiter für Volksgesundheit in München; dem Dermatologen, Geschäftsführer der Hochschulkommission der NSDAP und Beauftragten des Reichärzteführers für alle Fragen der Ernährung und der Neuen Deutschen Heilkunde, Franz Wirz; dem Chirurgen, NS-Aktivisten und Leiter der Abteilung Gesundheitswesen im bayerischen Innenministerium, Ministerialdirektor Walter Schultze (auch „Bubi“ Schultze oder „Bubischultze“ genannt); ${ }^{333}$ dem Präsidenten des Reichsgesundheitsamtes, Hygieniker und Bakteriologen, Hans Reiter; dem praktischen Arzt, Reichsärzteführer und Leiter des Hauptamtes für Volksgesundheit der NSDAP, Gerhard Wagner; dem Psychiater, Rassenhygieniker und Mitautor des GzVeN, Ernst Rüdin; dem Internisten, Vorsitzenden des Wissenschaftlichen Ausschusses der bioklimatischen Arbeitsgemeinschaft und späteren SS-Standartenführer, Alfred Schittenhelm, sowie dem ehemaligen DGG-Mitglied und NSDAP-Parteikarrieristen Arnulf Streck, der bei der Eröffnung des Kongresses in Vertretung des Reichsärzteführers befriedigt feststellte, es handle sich nun um die erste „judenfreie“ Tagung der Gesellschaft. ${ }^{334}$

Die Tagung 1935 war der erste Kongress der DGG, der nicht am Wirkungsort des Präsidenten stattfand. Der Tübinger Mayer hatte deshalb am 23. Februar 1935 zu einer vorbereitenden Sitzung in das Stuttgarter Bahnhofshotel eingeladen. Beteiligt waren nur der ständige Schriftführer Martin, Mayers Oberarzt und 2. Schriftführer Moritz Tausch sowie der Beisitzer Hans Albrecht, Direktor des Krankenhauses Rotes Kreuz in München. Auf der Sit-

\footnotetext{
327 z. B. BGGF 1933, Berliner Gesellschaft; Ebert/Weitzel (Hrsg.): Berliner Gesellschaft (1994), S. 181.

328 Stoeckel: Dank (1937), S. 100.

329 UAT 150/33,41: Mayer an Stoeckel (27.04.1935).

330 UAT 150/33,41: Rückblick Mayers auf den Kongress in einem Brief an Stoeckel (16.11.1935).

331 UAT 150/33,41: Mayer an G. A. Wagner (16.09.1935).

332 Siehe S. 50-51.

333 Der abwertende Spitzname von Schultze wurde auch von Mayer verwendet.

334 Streck: [Grußwort, Verhandlungen 1935] (1936), S. 11. Basisdaten zu Bach und Streck in den Kurzbiografien im Anhang.
} 


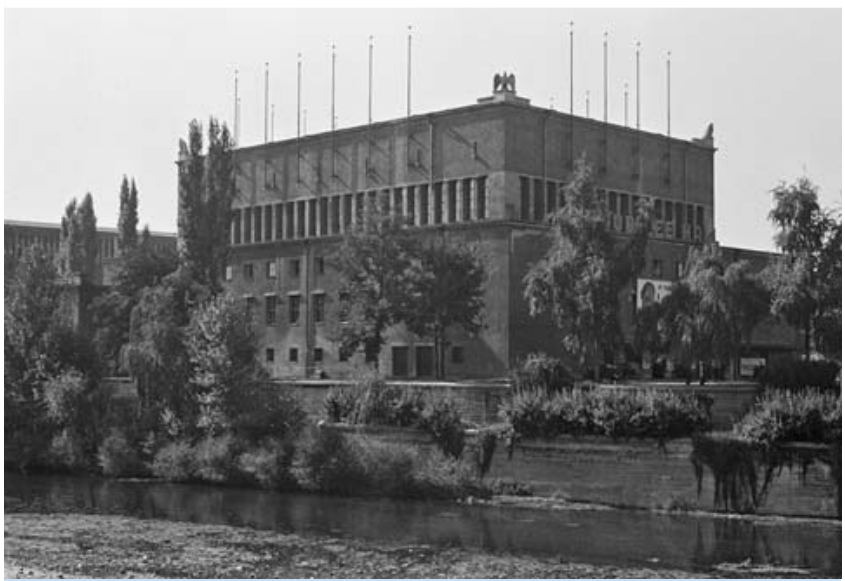

Abb. 17 Der 1935 eröffnete Kongressbau auf der Münchner Museumsinsel, Ort der DGG-Tagung 1935 (Quelle: Bildarchiv Foto Marburg).

zung wurde München als Tagungsort festgelegt - gegen den Willen Mayers, der Stuttgart präferiert hätte. Die Anwesenden entschieden sich ferner für das Deutsche Museum als Tagungslokal ( $\bigcirc$ Abb. 17), ein bewusster Affront gegen den Direktor der I. UFK München in der Maistraße, Heinrich Eymer, dessen Berufung 1934 unter Protegierung seines Lehrers Carl Menge und auf Druck der Nationalsozialisten erfolgt war. Albrecht ernannte man zum Vorsitzenden des lokalen Kongressausschusses. ${ }^{335}$

\section{Erster Eingriff der Partei: Knaus darf nicht eingeladen werden}

Erste Bekanntschaft mit Eingriffen der NSDAP in die Kongressplanung hatte Mayer bereits Ende 1934 bei seiner Besprechung im „Braunen Haus“ gemacht: Der von ihm im Zusammenhang mit dem Thema Sterilität vorgeschlagene Referent, der Prager Ordinarius Hermann Knaus, war abgelehnt worden, weil das Innenministerium ein von Knaus publiziertes Buch über natürliche Geburtenplanung als den Zielen des Regimes abträglich verboten hatte. ${ }^{336}$ Das Thema musste deshalb von Anfang an von Albrecht übernommen werden. Damit war die Sache aber noch keineswegs ausgestanden, wie sich zeigen wird.

Als besonders problematisch für das ohnehin auch vom Regime als heikel empfundene Sterilisierungsthema erwies sich, dass im März 1935 eine heftige Diskussion über die sogenannte "Gauß'sche Zahl“ ausgebrochen war. Damals hatte der Würzburger Ordinarius Carl Joseph Gauß, einer der Pioniere der gynäkologischen Radiologie und als überzeugter Nationalsozialist bekannt, in der „Münchener Medizinischen Wochenschrift“ ein Plädoyer für die Röntgensterilisation veröffentlicht und als Argument dafür unter anderem eine von ihm geschätzte Sterblichkeitsziffer der operativen Sterilisationen von ca. 5\% ins Feld geführt. ${ }^{337}$ Diese Zahl, so fürchteten die von der Publikation auf- geschreckten Parteifunktionäre und Repräsentanten der Reichsregierung, könne das GzVeN in der deutschen Öffentlichkeit diskreditieren und der Reputation der Machthaber im Ausland größten Schaden zufügen, zumal - so der Präsident des Reichsgesundheitsamtes, Hans Reiter, in einem als geheim deklarierten bösen Brief an Gauß - „im Ausland die unsinnigsten Übertreibungen in Bezug auf die Unfruchtbarmachungen umlaufen“. 338

Eine Wende in der Debatte um das Sterilisationsthema, die bei der Aufregung um die „Gauß'sche Zahl“ möglichst flach gehalten werden sollte, schien erst gekommen, als das „Zentralblatt für Gynäkologie“ im Juli 1935 eine Übersichtsarbeit publizierte, in der bei mehr als 6000 Sterilisationen eine Mortalität von 0,4\% ermittelt worden war. ${ }^{339}$ Mayer griff das sofort auf: „Ich bin jetzt der Meinung, dass wir [bei einer Behandlung des Themas] nicht nur auf die Diskussion nicht verzichten, sondern diese sogar anstreben sollen“, schrieb er an Ernst Bach. „Die in- und ausländischen Gegner des Gesetzes werden so lange mit der Mitteilung von Gauß manövrieren, bis man sie öffentlich des Irrtums überführt.“340 Der war damit allerdings wenig zu beeindrucken. Mit dem Hinweis auf den Beauftragten des Reichärzteführers schrieb er zurück: „Herr Wirz ist genau wie ich der Meinung, dass wohl der in dieser Arbeit aufgezeigte Erfolg sehr schön ist, dass aber nach wie vor, wenn eine Diskussion zu dieser Angelegenheit erlaubt ist, die Möglichkeit gehässiger Angriffe bleibt.“341

\section{„... damit ein Krach erst am Schluss des Kongresses kommt"}

So ging die Debatte hin und her. Die Frage, ob das Thema Sterilisation überhaupt behandelt werden sollte, und, wenn ja, mit oder ohne Diskussion, blieb offen. Daran änderte zunächst auch nichts, dass es Mayer im Verlauf gelang, den Präsidenten des Reichsgesundheitsamtes, Hans Reiter, von seiner Sicht der Dinge zu überzeugen. Vermutlich noch Mitte bzw. Ende August 1935, also nur knapp 2 Monate vor dem Kongress, hatte sich Mayer für ein Gespräch mit Stoeckel denkbare Alternativen und deren Konsequenzen auf einem Zettel notiert. Sie verdeutlichen den Grad der Verunsicherung, den die Verhältnisse verursacht hatten, und sollen hier in abgekürzter Form dargestellt werden:

„1. Absetzen. [...] Konsequenz: Das Ausland wird aber argwöhnisch, als ob man etwas zu verbergen hätte. [...].

2. Diskussion verbieten (überflüssig, verfrüht). Konsequenzen: a) Ausland wird wieder argwöhnisch; b) Auditorium will diskutieren und verlässt unter Umständen aus Protest das Lokal.

3. Alles lassen [wie geplant], vorher aber noch einmal Rücksprache mit dem [Reichsärzteführer] Wagner und Wirz unter Berufung auf Reiter.

4. Thema auf den letzten Tag verschieben, damit ein Krach erst am Schluss des Kongresses kommt. “342

\footnotetext{
335 UAT 150/33,41: Protokoll der Besprechung (23.02.1935).

336 Knaus: Fruchtbarkeit (1934). Basisdaten zur Person in den Kurzbiografien im Anhang.

337 Gauß: Anwendung (1935). Basisdaten zur Person in den Kurzbiografien im Anhang.

338 Zit. n. Wolf: Gauß (2008), S. 167.

339 Mikulicz-Radecki: Sammelstatistik (1935).

340 UAT 150/33, Mappe 2: 13.07.1935

341 UAT 150/33, Mappe 2: 07.08.1935

342 UAT 150/33,41: Notizzettel Mayers (ohne Datum); Vorbereitung für ein Gespräch mit Stoeckel, der in dieser Zeit im Schwarzwald Urlaub machte.
} 
Präsentiert und diskutiert wurde das Thema dann letztlich doch wie geplant. Es ist nicht ganz klar, was dafür den Ausschlag gab. Möglicherweise war es wieder Stoeckel, der den Weg bereitete. Am 9. Oktober 1935, knapp 2 Wochen vor Beginn der Tagung, erhielt Mayer einen Brief von ihm, in dem es unter anderem heißt:

„Ich habe neulich mit [dem Reichspropagandaminister Joseph] Goebbels ausführlich über die Diskussion zur eugenischen Sterilisierung gesprochen, und er hat mir gesagt, dass gegen eine solche Diskussion in unserem Kreis nicht das Geringste einzuwenden sei. Er legt nur entscheidenden Wert darauf, dass nichts in die Tagespresse kommt, und das können wir ja leicht machen.“343

Im Vorfeld waren allerdings einige Beiträge gestrichen worden, deren Autoren sich zur Röntgensterilisierung hatten äußern wollen. ${ }^{344}$ Die Erörterung dieses Aspektes erschien dem Regime zu diesem Zeitpunkt völlig indiskutabel. Gauß war durch seinen Artikel so in Ungnade gefallen, dass er sich auch nicht zu anderen Themen äußern durfte: Sowohl Schultze als auch Streck wandten sich in Brandbriefen an Mayer, als sie auf dem Programm eine Vortragsankündigung von Gauß mit dem Titel „Der Arzt im Dritten Reich“ entdeckten. Beide forderten Mayer auf, den Vortrag zu unterbinden und drohten mit „unliebsamen Auseinandersetzungen“ während des Kongresses. ${ }^{345}$ Mayer schrieb deshalb an Gauß, der antwortete, er sei ohnehin „durch mehrere Umstände“ an der Teilnahme verhindert. ${ }^{346}$

Auch der Krebsforscher Gustav Klein, Leiter des Biolaboratoriums Oppau der I.G. Farben AG Ludwigshafen, der auf besonderen Wunsch von Stoeckel zu einem Vortrag über Krebsdiagnostik eingeladen worden war, ${ }^{347}$ durfte sehr kurzfristig „unter keinen Umständen“ referieren. Eine entsprechende telegrafische Forderung von Reiter, begründet mit noch nicht abgeschlossenen „Nachprüfungen“, erreichte Mayer am 16.Oktober 1935. ${ }^{348}$ Auch hier musste Mayer - peinlich berührt - absagen ( Abb. 18).

\section{Abgesetzt: „Deutsche Mutter und deutscher Aufstieg“}

Den für ihn persönlich vermutlich bittersten Eingriff des Regimes in die Kongressplanung erlebte Mayer allerdings mit dem kurzfristigen Verbot seines großen Vortrages zum Thema „Deutsche Mutter und deutscher Aufstieg“, der sich an die Öffentlichkeit wenden sollte und für den in der ganzen Stadt plakatiert worden war. Dieser Vortrag war noch Ende Juli bei einer Besprechung mit den NS-Multifunktionären Wirz und Bach „überaus begrüßt“ worden. ${ }^{349}$ Auch Ministerialdirektor Schultze äußerte gegenüber Mayer Anfang September sein Einverständnis. Wenige Tage vor Kongressbeginn, so schrieb Mayer in einer persönlichen retrospektiven Betrachtung „seines“ Kongresses, habe ihm Bach dann telefonisch im Auftrag eben dieses Schultze ohne Angaben von Gründen mitgeteilt, „dass der Vortrag nicht stattfinden dürfe“ ( Abb. 19). Als er Schultze deshalb persönlich zur Rede stellen wollte, habe ihn Stoeckel dringend gebeten, „das nicht zu tun,

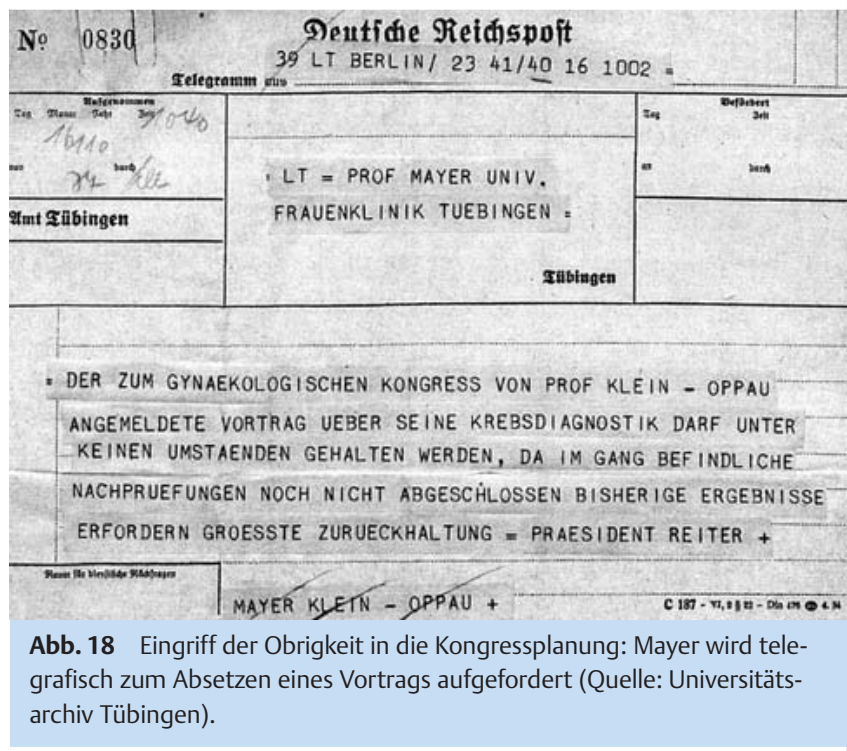

das gebe eine Pistolenforderung und der Präsident gehöre jetzt dem Kongress, und nicht seinen persönlichen Anliegen“.350

Mayer hat diesen Vortrag 1938 in erweiterter Form in der Reihe „Politische Biologie. Schriften für naturgesetzliche Politik und Wissenschaft" im völkischen Lehmanns Verlag München veröffentlicht ( $\triangle$ Abb. 20). Im Vorwort ging er auf seine ursprüngliche Absicht ein, mit diesem Vortrag beim Münchner Kongress als Präsident der DGG „eine Verbindung her[zu]stellen zwischen dem engen Rahmen des wissenschaftlichen Sitzungssaales und den breiten Volksmassen, die ja quasi der öffentliche Schauplatz für die praktische Bewährung des modernen Frauenarztes sind“. Der Vortrag, schrieb er, sei damals aus „äußeren Gründen“ unterblieben. ${ }^{351}$ Die Publikation - eingeleitet mit der Anrede „Deutsche Mütter, deutsche Männer!“ - beschäftigt sich mit dem gesamten Komplex der Bevölkerungspolitik und erscheint unter pathetischer Betonung der klassischen Mütterrolle weitestgehend aus der Sicht des Regimes geschrieben. Auffällig ist, dass an einschlägigen Stellen die strittigen Fragen zur Haus- bzw. Klinikgeburt ebenso vermieden werden wie der Hinweis auf Sterilisationen oder gar eugenische Abtreibungen im Zusammenhang mit der durchaus angesprochenen „Fortpflanzungspflege und Erbgesundheitspflege“.

\section{„Raus aus den Kartoffeln, rinn in die Kartoffeln“}

Eingriffe von NS-Funktionsträgern in die Kongressregie beschäftigten Mayer auch noch unmittelbar vor und während der Veranstaltung. Zu seinem größten Erstaunen kam man am Vorabend mit dem Hinweis auf ihn zu, der Reichsärzteführer Wagner sähe es gerne, wenn „Knaus durch Übertragung des Referates [zur periodischen Unfruchtbarkeit der Frau, das Albrecht übernommen

\footnotetext{
343 UAT 150/33,41: Stoeckel an Mayer (09.10.1935).

344 Es handelte sich um Ernst Puppel, den Direktor der Hessischen Hebammenlehranstalt und Frauenklinik Mainz, sowie um Friedrich Siegert, den Direktor der UFK Freiburg im Breisgau. Ottow wurde aufgefordert, aus seinem Referat Passagen über Röntgensterilisierung zu streichen.

345 UAT 150/33,41: Streck an Mayer (08.10.1935); Schultz an Mayer (15.10.1935).

346 UAT 150/33,41: Gauß an Mayer (16.10.1935).

347 UAT 150/33,41: Mayer an Reiter (17.10.1935).

348 UAT 150/33,41: Telegramm Reiter an Mayer (16.10.1935).

349 UAT 150/33,41: Protokoll einer Besprechung (26.07.1935).

350 UAT 150/33,41: Mayer: Offenbar persönliche Rückschau auf den „Gynäkologenkongress München“ (handschriftliches Datum: 1936).

351 Mayer: Mutter (1938), S. 4.
} 
87. Feldweg, Pforzheim: Erfahrungen mit Lokalanaesthesie in Geburtshilfe und Gynäkologie.

88. H u bert, Greifswald: Zur Frage der Abhängigkeit des postoperativen Verlaufes vom Menstruationscyclus.

89. Ch y d e nias, Helsingfors: Zur Behandlung der-akuten Peritonitis.

90. B u rg k h a r d t, Zwickau: Dünndarmfistel bei peritonitischem Ileus.

91. Kü st er, Breslau: Die Resektion des Plexus spermaticus be der Frau als schmerzstillendes Verfahren an der Hand von 100 Făllen.

92. St oecke1, Berlin: Vaginale Totalexstirpation des myomatösen Uterus durch Morcellement (evtl. Levatorplastik) (Film)

$$
20 \text { Uhr pünktlich }
$$

Öffentlicher Vortrag des Kongreßführers im Auditorium maximum der Universisät: „Die deutsche Mutter und der deutsche Aufstieg.

Samstag, den 26. Oktober

Demonstrationen $7.30-8.00 \mathrm{Uhr}$

93. Vog t, E., Zwickau: Seltene Mißbildungen der großen Gefäße. 94. L ö v s e t, Jörgen, Bergen: Ein neuer Uterusdilatator.

95. G a u B, Wūrzburg: Neue klinische Gebrauchsgegenstånde: a) Fahrbetten, b) Nachttisch, c) Bettwaschtisch, d) Vaginale Dauerspülung, e) Strahlenkranz, f) Sterilisator.

Referat: Bisherige Erfahrungen mit der eugenischen Sterilisierung.

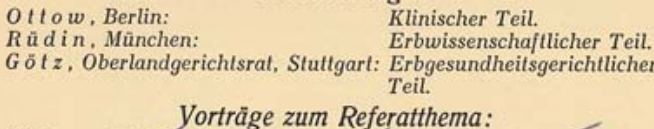

97. Re ch, München: Die eugenische Sterilisierung an der Mūnchener Universităts-Frauenklinik, unter besonderer Berückchener Universitáts-Frauenklinik, unter besonderer Ber

98. Thiessen, Freiburg i. Br.: Röntgenologische Nachuntersuchungen an operativ sterilisierten Frauen.

99. P u p p e 1, Mainz: Eugenische Sterilisation in der Graviđităt und im Puerperium.

Abb. 19 Selbst der „Kongressführer“ war den Machthabern als Referent nicht genehm: Mayers bereits im Programm angekündigter öffentlicher Vortrag musste aus politischen Gründen gestrichen werden, ebenso die Beiträge von Gauß und Puppel (Quelle: Universitätsarchiv Tübingen).

hatte] ausgezeichnet" würde. ${ }^{352}$ Mayer reagierte offenbar heftig. In seiner Kongressrückschau schreibt er dazu entnervt:

„Schärfste Auseinandersetzungen, glatte Ablehnung meinerseits, unmöglich Albrecht zu kränken, raus aus den Kartoffeln, rinn in die Kartoffel[n], das gibt es nicht, wenn [es] dem Herrn Reichsärzteführer nicht passt, soll er den Kongress selber leiten.“353

Mayer ließ sich dann aber doch zu einem Kompromiss überreden. Danach begrüßte er Knaus in der einschlägigen Sitzung besonders herzlich und ausführlich. Gleichzeitig bot er ihm eine verlängerte Diskussionsbemerkung nach Albrechts Vortrag an eine Möglichkeit, von der Knaus dann offensichtlich Gebrauch machte. Mit diesem Vorgehen hatte sich Mayer allerdings neuen Ärger eingehandelt: Bei der Begrüßung von Knaus sah er sich mit „spürbarem Missfallen“ aus dem Auditorium konfrontiert. Dort war offensichtlich noch nicht bekannt, „dass Knaus bei der NaziRegierung wieder zu Gnaden gekommen war“. Es erstaunt ange-

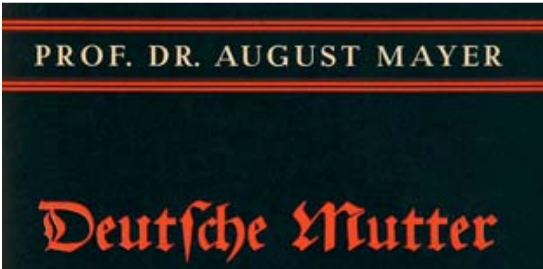

Abb. 20 Doch noch publiziert: Titelblatt der Veröffentlichung, in der Mayers 1935 abgesagter Vortrag Jahre später gedruckt wurde (Quelle: Universitäts-

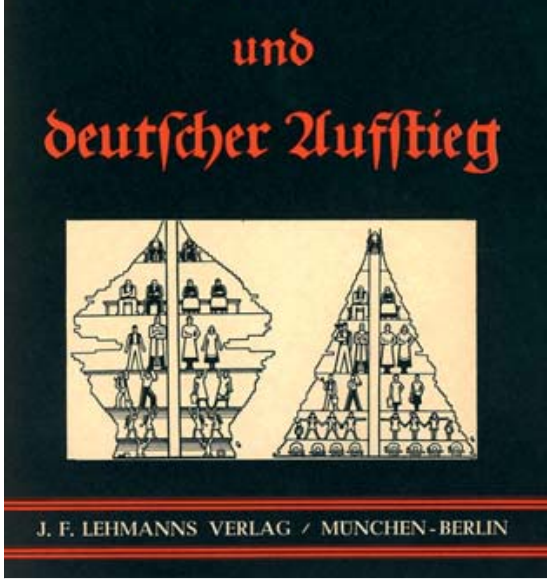
bibliothek Erlangen).

sichts der Gesamtsituation nur wenig, dass auch Mayer selbst während des Kongresses angeboten wurde, er könne seinen groß angekündigten öffentlichen Vortrag nun doch halten - was er jedoch ablehnte. ${ }^{354}$

\section{Bericht über rund 1800 Zwangssterilisationen}

In der Sitzung über die „gesetzlichen Sterilisationen“, die tatsächlich auf den letzten Tag des Kongresses verlegt worden war, berichteten Benno Ottow sowie 5 Korreferenten über insgesamt rund 1800 einschlägige Eingriffe. Allein in der Brandenburgischen Landesfrauenklinik Berlin-Neukölln, der Ottow vorstand, waren innerhalb von knapp 20 Monaten 750 Frauen unfruchtbar gemacht worden - eine Zahl, auf der, zusammen mit seiner etwa ebenso langen Mitarbeit am Erbgesundheitsgericht Berlin, Ottows weitgehend anerkannter „Expertenstatus“ beruhte. Dementsprechend zog sein Referat nicht nur eine Bilanz seiner klinischen Erfahrungen, sondern sollte ausweislich des Titels auch klinische „Richtlinien bei der gesetzlichen Unfruchtbarmachung erbkranker Frauen“ vorgeben. In Anbetracht der Tatsache, dass inzwischen zusätzlich eugenische Schwangerschaftsunterbrechungen erlaubt waren, bezog er sich auch darauf. 355

Die Gesamtbilanz, die Ottow zog, fiel ganz im Sinne des Regimes aus: „Das Gesetz“, so sagte er, „ruht auf den gesicherten Grundlagen naturwissenschaftlicher Erkenntnis [...], das allgemeine Verständnis für die Ethik und Notwendigkeit des Gesetzes wächst, seine gerichtliche Handhabung hat sich schnell und einheitlich durchgesetzt und seine praktische Durchführung hat Erfolge aufzuweisen, die der deutschen Medizin nicht unwürdig sind““. ${ }^{356}$ Die Morbidität der Eingriffe entspreche in etwa der ver-

\footnotetext{
352 Es ist nicht ganz klar, wer Mayer von diesem Wunsch in Kenntnis setzte: Conti oder Streck. Mayer selbst macht dazu unterschiedliche Angaben: UAT 150/ 33,41: Offenbar persönliche Rückschau auf den „Gynäkologenkongress München“ (handschriftliches Datum: 1936) und Brief an Albrecht (13.11.1935). Vermutlich war es Streck, der Conti ja auf dem Kongress vertreten hatte.

353 UAT 150/33,41: Offenbar persönliche Rückschau auf den „Gynäkologenkongress München“ (handschriftliches Datum: 1936).

354 Ebd.

355 Ottow: Erfahrungen [Verhandlungen 1935] (1936).

356 Ebd., S. 452.
} 
gleichbarer gynäkologischer Operationen, die Mortalitätsrate sei „überraschend gering“ - vor allem wenn man die Tatsache berücksichtige, dass die Operationen „an einem konstitutionell minderwertigen, weil erbkranken und daher widerstandslosen Organismus vorgenommen“ werden müssten. Ottow bezog sich dabei auf die erwähnte, wenige Wochen zuvor veröffentlichte Sammelstatistik mit der ungereinigten Sterblichkeitsziffer von $0,4 \%$. Gleichzeitig versäumte er es nicht, auf die dazu im Widerspruch stehenden, „ganz wesentlich zu hoch gegriffenen Angaben“ Einzelner in der Literatur hinzuweisen und dabei explizit Gauß zu erwähnen. ${ }^{357}$

Was die Technik des Eingriffs anging, sprach sich Ottow für eine möglichst radikale Form der Sterilisation aus und propagierte eine dahingehende Vereinheitlichung der Operationstechnik. Nur die komplette Entfernung der Eileiter gewährleiste höchste Sicherheit, sagte er, nicht zuletzt auch hinsichtlich denkbarer Refertilisationsversuche. Operativer Zugang der Wahl sei die Laparotomie, vaginale Sterilisationen sollten nur in besonders begründeten Ausnahmefällen durchgeführt werden. Bei Schwangerschaft einer Sterilisandin empfahl er einzeitiges Vorgehen: im ersten und zweiten Monat Dilatation und Kürettage, vom dritten bis zum sechsten Monat Sectio parva, jeweils mit anschließender abdominaler Sterilisation. Beim kleinen Kaiserschnitt müsse vermieden werden, „eine vielleicht noch lebende Frucht zutage zu fördern“. Möglichkeiten dazu seien die Kraniotomie vor der Entwicklung des Feten aus Fußlage oder das „Forttun der exprimierten uneröffneten Fruchtblase“.358

Für das Verfahren bei den Erbgesundheitsgerichten, so betonte Ottow, sollten Frauen zumindest grundlegend gynäkologisch voruntersucht sein. Es sei nicht sinnvoll, wenn erst bei der stationären Aufnahme bösartige Erkrankungen, vorbestehende Sterilität oder sogar mit Schwangerschaft unvereinbare genitale Fehlbildungen entdeckt würden. Diese Voruntersuchungen könnten aber in keinem Fall die spätere sorgfältige Prüfung der Operabilität ersetzen, zu der der Chirurg verpflichtet sei und von der die Durchführung des Eingriffs letztlich abhängig gemacht werden müsse - ohne Rücksicht auf das Diktum der Erbgesundheitsgerichte. Bei begründeten Zweifeln an der Fertilität sollte lieber auf die Sterilisation verzichtet werden. Ottow bezog sich dabei vor allem auf Frauen jenseits von 40 Jahren: „Wahllos und schematisch bis in das Klimakterium hinein zu sterilisieren“ könne ungerechtfertigten „ideellen Schaden“ in Form von „Förderung der Opposition gegen das Gesetz“ verursachen, erklärte er. ${ }^{359}$

In den Vorträgen und in der Diskussion wurde über weitere Serien eugenischer Sterilisationen berichtet. Zu Wort meldeten sich Oberärzte oder Direktoren von Universitätskliniken mit den Zahlen ihrer Eingriffe (I. UFK München 310, Freiburg 280, Kiel 255 und Heidelberg 353), aber auch der Inaugurator eines nach ihm benannten Sterilisationsverfahrens, Max Madlener (Kempten 82). In der ausführlichen und durchaus kontroversen Diskussion standen die Erfolgssicherheit und die Risiken der einzelnen Verfahren im Mittelpunkt. Die Auswirkungen des unmittelbaren Zwangs, unter dem viele der Eingriffe durchgeführt wurden, thematisierten die Teilnehmer allerdings nicht. ${ }^{360}$ Komplikationen darunter mindestens 2 Todesfälle - wurden, wie Seitz es formulierte, als „des großen Zweckes wegen wohl gerechtfertigt“ betrachtet. 361

Das Referat von Ottow stieß vor allem wegen seiner Empfehlung zur Vereinheitlichung der Operationstechnik auf erheblichen Widerspruch, zumal er sogar angeregt hatte, dies im Gesetz zu verankern. ${ }^{362}$ Eine besonders scharfe Attacke ritt dabei Carl Menge, bereits emeritierter Direktor der UFK Heidelberg und Vater der nach ihm benannten Sterilisation über einen Zugang in der Leiste: „Herr Ottow hat von der inguinalen Tubensterilisierung gesprochen wie der Blinde von der Farbe“, erklärte Menge. Seiner Kritik an der Methode fehle sowohl eigene Erfahrung im Umgang damit als auch das erforderliche Literaturstudium dazu. Dies sei ein Mangel, „der bei der Erstattung eines offiziellen Referates über das wichtige Sterilisierungsthema vor dem Forum der Deutschen Gesellschaft für Gynäkologie befremden muß““. ${ }^{363}$ Unterstützt wurde Menges Methode in der Diskussion vor allem von seinen Schülern, z.B. Heinrich Eymer, Walter Rech, Friedrich Schultze-Rhonhof und Adam Bauereisen.

\section{Das GzVeN - ein „medizinisches Gesetz“}

Das erbwissenschaftliche Referat, für das Ernst Rüdin als Redner vorgesehen war, musste wegen - wie es hieß - Krankheit entfallen. Es fand auch in gedruckter Form keinen Eingang in den Kongressband. ${ }^{364}$ So beschränkte sich der fachfremde Teil der Sektion auf einen Vortrag des Stuttgarter Oberlandesgerichtsrates Hans Göz, ${ }^{365}$ der einleitend Verständnis dafür zeigte, dass sich Ärzte in der ihnen zugewiesenen „neuen Rolle des Sterilisators [...] vorläufig nicht recht wohl und zuhause fühlen“. ${ }^{366}$ Dem müsse aber die Bedeutung des GzVeN gegenüber gestellt werden, das in der Welt bisher ohne Beispiel sei und zugleich „ein weithin leuchtendes Vertrauensvotum für die Kunst des deutschen Arztes und des Gynäkologen insonderheit bildet. Denn der hohe Stand Ihrer Wissenschaft und Operationskunst ist die technische Voraussetzung eines solchen Gesetzes“, erklärte Göz, ${ }^{367}$ der bereits im November 1932 gemeinsam mit Mayer bei einer erweiterten Kammersitzung der Württembergischen Ärztekammer in Stuttgart mit dem Thema „Eugenische Fragen und Maßnahmen insbesondere zur Vorbereitung eines Antrags an die Staatsregierung auf gesetzliche Regelung der Sterilisierung erblich Minderwertiger und schwer Erbkranker" aufgetreten war. ${ }^{368}$

\footnotetext{
357 Ottow: Erfahrungen [Verhandlungen 1935] (1936), S. 448.

358 Ebd., S. $442 \mathrm{f}$.

359 Ebd., S. 417.

${ }^{360}$ Vgl. hierzu etwa Czarnowski: Erkrankte (2007), S. 145-148.

361 Seitz: [Diskussionsbeitrag, Verhandlungen 1935] (1936), S. 474.

362 Ottow: Erfahrungen [Verhandlungen 1935] (1936), S. 431.

363 Menge: [Diskussionsbeitrag, Verhandlungen 1935] (1936), S. 471.

364 Arch Gyn 161 (1936), S. 452.

365 Es handelt sich um den Juristen Hans Göz, Sohn des bekannteren Juristen Karl von Göz. Mayer notiert den Namen in seinen Unterlagen fälschlich „Götz“.

366 Göz: Erfahrungen [Verhandlungen 1935] (1936), S. 453.

367 Göz: Erfahrungen [Verhandlungen 1935] (1936), S. 453

368 Doneith: Mayer (2007), S. 70. Vgl. Göz: Bemerkungen (1937).
} 
In Analogie zur Argumentation von Seitz, der sich durch die Erbgesundheitsgerichtsbarkeit der persönlichen Verantwortung enthoben sah, nur unter umgekehrten Vorzeichen, erläuterte Göz dann dem Auditorium, dass das GzVeN ein medizinisches Gesetz sei, d.h. ein Gesetz, „dessen Aufgaben trotz der Einkleidung in gerichtliche Verfahrensformen im wesentlichen von Ärzten zu lösen sind“. Am Anfang des Verfahrens stehe der Arzt, der den Antrag stelle und das grundlegende Gutachten erstatte. Die Entscheidung, ob eine Erbkrankheit einwandfrei festzustellen sei, werde von Ärzten getroffen, die die Mehrheit in den Erbgesundheitsgerichten bildeten. „Und am Ende steht wieder der Arzt, dem die letzte Entscheidung zukommt, ob der angeordnete Eingriff durchgeführt werden kann oder wegen Gefährdung des Lebens des Erbkranken oder aus einem wichtigen gesundheitlichen Grund unterbleiben muß.“369

In seinen weiteren Ausführungen bemühte sich Göz, die Ermessensspielräume deutlich zu machen, die das Gesetz seiner Ansicht nach zuließ. Jedes einzelne Verfahren sei ein von den Erbgesundheitsgerichten und seinen ärztlichen Beisitzern individuell zu lösendes Problem. Dazu führte er Beispiele an, so etwa einen an einer angeborenen Hüftgelenksluxation Leidenden, der gleichzeitig Träger eines hervorragenden geistigen Erbgutes sein könne. „Es wäre unverantwortlich, in einem solchen Fall die Unfruchtbarmachung anzuordnen“, sagte er. Ebenso könne in leichten Fällen manisch-depressiven Irreseins, die mit hervorragender Begabung verbunden seien, von der Anordnung der Unfruchtbarkeit abgesehenen werden. Dies gelte auch für „ledige Frauenspersonen [...], wenn den Umständen nach die Wahrscheinlichkeit einer Fortpflanzung im ledigen Stande eine entfernte ist“. Die Unterstellung von Geschlechtsverkehr stelle in diesen Fällen eine Verletzung des Rechtsgefühls dar und würde dem Ansehen des Gesetzes schaden. ${ }^{370}$

In seiner Eröffnungsansprache für den Kongress hatte August Mayer einleitend in der bereits zitierten Weise zum Themenkomplex „Eugenische Sterilisierung“ Stellung genommen. Den größten Teil seiner Ausführungen widmete er dann dem Anlass des damaligen 50-jährigen Gründungsjubiläums der DGG, indem er auf die Entwicklung der Gynäkologie als Spezialfach der Medizin einging. Gleichwohl schlug er abschließend wieder einen Bogen von einer der ersten Sitzungen 1889 zur Gegenwart des Jahres 1935: Schon der damalige Präsident, sein Lehrer Alfred Hegar, habe sich mit „ganz modern klingenden Dingen“ befasst:

„Schon er erwog den Gedanken, die Fortpflanzung von Minderwertigen zu unterdrücken. Ihm schien das besser, als Minderwertige ins Leben treten zu lassen, um sie dann ,auf Lebzeiten einzusperren oder ihnen den Kopf abzuschlagen'. Schon er hielt
[...] die Behandlung von manchen Kranken für wertlos, da man die Großeltern hätte behandeln sollen.“371

\section{Die „Krise“ der Zwangssterilisationen}

Die besondere Betonung der Notwendigkeit einer ausreichenden Basisuntersuchung von Sterilisandinnen schon vor dem Erbgesundheitsverfahren, die ausdrückliche Verpflichtung zu einer gründlichen präoperativen Untersuchung mit kritischer Beurteilung der Operabilität, für die sogar mehrere Tage stationärer Beobachtungszeit empfohlen wurden, sowie die Ermahnung, nicht „wahllos in das Klimakterium hinein zu sterilisieren“ - all die zitierten Ausführungen von Benno Ottow können als Zeichen einer Entwicklung gedeutet werden, die ab Mitte der 1930er-Jahre als „Krise“ der NS-Sterilisationspolitik in Erscheinung trat. ${ }^{372} \mathrm{Hinzu}$ kommt - ungeachtet der von Ottow gewissermaßen offiziell vorgetragenen gegenteiligen Einschätzung - die auf dem Berliner Kongress von anderer Seite immer wieder geäußerte Sorge um die öffentliche Akzeptanz des GzVeN. Auch der Vortrag des Juristen Göz war bemüht, Handlungsspielräume bei der Anwendung des Gesetzes zu betonen.

Noch im Mai 1936 wurde die Veröffentlichung einschlägiger Statistiken untersagt. ${ }^{373}$ Ferner legalisierte der Gesetzgeber die Strahlensterilisation von Frauen über 38 Jahren, bei denen ein chirurgischer Eingriff „mit Gefahr für Leben oder Gesundheit“ verbunden war. ${ }^{374}$ In der Kritik auch der Betroffenen und ihrer Angehörigen standen vorerst weniger das Gesetz als vielmehr die Diagnosen, der Verfahrensablauf und die Durchführung der Eingriffe, bei denen vor allem im Verlauf der Voruntersuchungen oft medizinische Standards verletzt wurden. ${ }^{375}$ Die Opfer, denen seit 1936 Verdienstausfall, Reisekosten sowie Krankengeld erstattet werden konnten, fühlten sich stigmatisiert, missachtet, in ihrer Integrität verletzt und ihrer Zukunftsperspektiven beraubt. ${ }^{376}$ Gisela Bock zitiert dazu ausführlich aus Prozessakten, die sie als „außergewöhnliche Dokumente des Widerstandes gegen Theorie und Praxis des nationalsozialistischen Rassismus“ bezeichnet. ${ }^{377}$

Vor allem der ungenügende diagnostische Nachweis von „angeborenem Schwachsinn“ wurde etwa von Martin Grunau, Vorsitzender des Erbgesundheitsobergerichts in Kiel und damit sicherlich kein Gegner des GzVeN, öffentlich kritisiert. ${ }^{378}$ Auf Intervention der NSDAP ordnete das Reichsinnenministerium am 22. August 1936 an, dass in einschlägigen Verfahren bei Beamten, Angestellten und Parteimitgliedern die „Lebensbewährung“ überprüft werden solle. ${ }^{379}$ Im Folgejahr wurde die allzu schematische Durchführung des notwendigen „Intelligenztests“ mittels eines statischen Prüfungsbogens zurückgestellt, um anhand offener Prüfungsfragen, die konkreter auf die Lebenssituation der Betroffenen angepasst werden konnten, ergänzt zu werden. ${ }^{380}$

\footnotetext{
369 Göz: Erfahrungen [Verhandlungen 1935] (1936), S. 453 f.

370 Ebd., S. 455 f.

371 Mayer: Eröffnungs-Ansprache [Verhandlungen 1935] (1936), S. 9.

372 Bock: Zwangssterilisation (2010), S. 336-346.

373 Ebd., S. 230.

374 RGBl. Jg. 1936 I, Nr. 16, S. 119 und 122.

375 Vgl. Krüger: Zwangssterilisationen (2007), S. 71-73.

376 Susanne Doetz: Widerspruch (2011).

377 Bock: Zwangssterilisation (2010), S. 278.

378 Grunau: Schwachsinn (1935).

379 Vgl. Bock: Zwangssterilisation (2010), S. 337.

380 Bock: Zwangssterilisation (2010), S. 316.
} 
Die massiven innen- und parteipolitischen Auseinandersetzungen über die Sterilisationspolitik vor allem seit Jahresende 1936 fanden vor dem Hintergrund des Machtkampfes zwischen NSDAP und Reichsinnenministerium statt. Reichsärzteführer Gerhard Wagner überprüfte seit 1935 Sterilisationsverfahren und übermittelte im Mai 1937 Hitler eine geheime Denkschrift, die eine „vernichtende“ Kritik an der bisherigen Sterilisationspolitik darstellte. Das Ziel der Denkschrift, die die vielfältigen praktischen Probleme schonungslos offenlegte, bestand jedoch nicht in einer Revision der nationalsozialistischen Sterilisationspraxis, sondern in der Steigerung des parteipolitischen Einflusses auf die Maßnahmen. ${ }^{381}$ In diesen Kontext gehört schließlich, weshalb schon bei der Vorplanung zu Mayers Kongress von den Beteiligten kommentarlos festgestellt wurde: „Wagner nicht zum Reden einladen.“" ${ }^{382}$ Auch die krankheitsbedingte Verhinderung Rüdins sowie die Tatsache, dass sein Referat nicht in den gedruckten Verhandlungsberichten erscheint, passt in diesen Zusammenhang.

Tatsächlich zeigt eine Betrachtung der Gesamtsituation im Reich, dass die Sterilisationszahlen von 1936 bis 1939 deutlich zurückgingen und für den genannten Zeitraum schließlich bei rund 100000 lagen. Dagegen hatte es zwischen 1934 und 1936 rund 200000 Sterilisationsbeschlüsse gegeben. Die enorme Zahl der Verfahren führte damals zu einer massiven Überlastung der Gesundheitsämter, Erbgesundheitsgerichte sowie der zur Unfruchtbarmachung zugelassenen Ärzte und Krankenhäuser. In Altona haben die Sterilisationen in den Jahren 1935 (32\%), 1936 (34\%) und 1937 (29\%) jeweils ein knappes Drittel aller dort durchgeführten Operationen ausgemacht. ${ }^{383}$ In den OPs der Universitätskliniken stellten Sterilisationen zeitweise ein Viertel aller Eingriffe dar. ${ }^{384}$ Das DGG-Vorstandsmitglied Heinrich Martius beantragte 1934 für die UFK Göttingen zusätzlich eine Assistenten- und 2 Volontärstellen, um die durch die eugenischen Sterilisationen bedingte „Mehrarbeit“ bewältigen zu können. ${ }^{385}$
Der Rückgang der Sterilisationszahlen, so Gisela Bock, „fiel jedoch zusammen mit einer Neubestimmung des ,Kreises der Erbkranken' und ,Minderwertigen' und mit neuen Maßnahmen zu ihrer ,Ausmerzung، und ,Ausrottung “'.386 Beides hatte - vor allem mit Fortschreiten des Krieges - erhebliche und zum großen Teil in ihrer Dimension noch unvollständig bekannte Auswirkungen auf „Fremdvölkische“ in den besetzten Gebieten, aber auch im Reich. Ein Beispiel für Letztere sind die Zwangsabtreibungen an „Ostarbeiterinnen“, die zwischen 1943 und 1945 auch an Universitätsfrauenkliniken durchgeführt wurden. Verantwortung dafür trugen - soweit bisher bekannt - unter anderem die DGG-Mitglieder Hermann Wintz (Erlangen), Heinrich Eymer (München) und August Mayer (Tübingen). ${ }^{387}$

Daneben stellten die Sterilisationen mancherorts - vor allem an primär strahlentherapeutisch orientierten Kliniken - auch eine willkommene Möglichkeit zur operativen Ausbildung des Nachwuchses dar. So beklagte sich das DGG-Vorstandsmitglied Theodor Heynemann in seiner Eigenschaft als Chef der UFK Hamburg 1936 bei der Unterrichtsbehörde über eine rückläufige Zahl der Sterilisationszuweisungen. Diese Zuweisungen seien für den akademischen Unterricht unerlässlich, erklärte er. ${ }^{388}$ Darüber hinaus wurden die Eingriffe von wissenschaftlich tätigen Ärzten häufig zu illegaler, grenzüberschreitender Forschung genutzt. ${ }^{389}$ Schließlich bildeten Sterilisationen für viele Kliniken auch eine willkommene Einnahmequelle.

Am 31. August 1939 erging eine Verordnung, wonach die Sterilisationen an "besonders große Fortpflanzungsgefahr" geknüpft werden sollten, um die personellen Ressourcen wegen des bevorstehenden Krieges zu schonen. ${ }^{390}$ Weitere Einschränkungen in der Folge ließen das GzVeN für die deutsche Bevölkerung im Verlauf des Krieges zusätzlich an Bedeutung verlieren. Auf den Kongressen der DGG spielten die Zwangssterilisationen dann auch keine Rolle mehr. Bleibt nachzutragen, dass nach einer Schätzung von Bock im Zusammenhang mit den Eingriffen unmittelbar oder mittelbar rund 5000 Frauen ihr Leben verloren und damit 90\% der Todesopfer dieser Gewaltmaßnahmen in ihren Reihen zu finden sind. 391

\footnotetext{
381 Bock: Zwangsterilisation (2010), S. 337-344; Vossen: Gesundheitsämter (2001), S. 301-305.

382 UAT 150/33,41: Notiz von einer Besprechung in Stuttgart (ohne Namen, mit Datum 17.08.1935).

383 Lehmann: Chronik (1995), S. 45.

384 Vgl. etwa Krüger: Zwangssterilisation (2007); Grimm: Zwangssterilisation (2003).

385 Koch: Zwangssterilisation (1994), S. 60.

386 Bock: Zwangssterilisation (2010), S. 287.

387 Vgl. u. a. Bock: Zwangssterilisation (2010), S. 429-449; Schwarze: Kinder (1997); Bayer: Zwangsarbeiterinnen (2008); Frobenius: Abtreibungen (2004).

388 Vgl. Pfäfflin/Rüb/Göpfert u. a.: Krankenversorgung. (1989), S. 60.

389 Diese Praxis war durchaus üblich, so etwa bei Mikulicz-Radecki oder Günter K.F. Schultze (Basisdaten in den Kurzbiografien im Anhang).

$390 \mathrm{Vgl}$. RGBl. Jg. 1939 I, Nr. 157, S. 1560 f. Demgegenüber wurden bestehende gesetzliche Grundlagen aufgeweicht, indem etwa in dringenden Fällen nun auch Ärzte den chirurgischen Eingriff vornehmen konnten, „die nicht ausdrücklich zur Ausführung von Unfruchtbarmachungen zugelassen sind, sofern sie die Gewähr für eine ordnungsgemäße Durchführung des Eingriffs bieten“.

391 Bock: Zwangssterilisation (2010), S. 375; vgl. Vossen: Gesundheitsämter (2001), S. 316-322. Demgegenüber schätzt etwa Horst W. Heitzer die Anzahl von 5000 Todesfällen als nicht realistisch ein. Heitzer: Zwangssterilisation (2005), S. 336.
} 


\section{Die Kongressarbeit jenseits des GzVeN (1933-1941)}

\section{Chemie der Sexualhormone blieb weitgehend außen vor \\ $\nabla$}

Das GzVeN und seine Umsetzung haben den Vorstand und die Mitglieder der DGG zweifellos sehr beschäftigt. Es wäre aber verfehlt anzunehmen, dass das Thema die Kongresse zwischen 1933 und 1941 vollständig beherrscht hätte. Zum einen spielte es nach Mayers Kongress 1935 bei den beiden folgenden Veranstaltungen überhaupt keine Rolle mehr. Zum anderen war es auf den vorangehenden Kongressen, 1933 und 1935, nur ein großer Tagungspunkt unter mehreren. Dies zeigt schon ein Vergleich des Raumes, den Referate und Diskussionen dazu in den einschlägigen Verhandlungsberichten einnehmen. ${ }^{392}$ Allerdings bleibt letztlich unübersehbar, dass zumindest in dem von jüdischen Forschern wesentlich beeinflussten Bereich der gynäkologischen Endokrinologie nach 1931 eine gewisse thematische Verarmung eintrat: So erfuhren die Kongressteilnehmer von den in den 1930er-Jahren umwälzenden Fortschritten in der Chemie der Sexualhormone relativ wenig und dies auch verspätet. ${ }^{393}$ Andererseits gelang es August Mayer und G. A. Wagner, für ihre Kongresse hoch angesehene Gastredner aus den USA zu gewinnen. Vor allem bei Wagner nahm - angesichts der wissenschaftlichen Orientierung seiner Klinik nicht überraschend - die Endokrinologie viel Raum ein.

Bei dem nun folgenden kurzen Blick auf die Kongressarbeit ,jenseits des GzVeN" lassen sich die Themen in diesem Rahmen natürlich nur sehr kursorisch und darüber hinaus unvollständig behandeln. ${ }^{394}$ Von größerem Interesse sind Sachgebiete, die in das gesundheitspolitische Konzept des NS-Regimes passten, dabei aber gleichzeitig als Desiderate der frauenheilkundlichen Forschung galten. $\mathrm{Zu}$ nennen sind die Physiologie und Pathologie der Fortpflanzung im weitesten Sinne sowie die Onkologie ${ }^{395}$ mit einem besonderen Schwerpunkt auf der Prävention und Früherkennung. Als Zugeständnis an die Bestrebungen des Nationalsozialismus in Sachen „Neue Deutsche Heilkunde“ fällt die Sektion „Klima- und Bäderbehandlung“ bei dem Kongress von Mayer auf, die hier aber nicht näher dargestellt werden soll. Auch
Wagner erwies dem - wie sich zeigen wird - bei der Referentenwahl zumindest in einem Punkt seine Reverenz. Abschließend zu erwähnen sind die wichtigsten Vorstands- und Mitgliederinitiativen, die auf den Kongressen in Form von Resolutionen behandelt wurden bzw. durch die Einsetzung von Ausschüssen auf den Weg gebracht werden sollten.

\section{1: Zondek und die Interaktion zwischen Ovar und Hypophyse $\nabla$}

Neben dem Referat Fraenkels und der kontroversen Diskussion darüber standen auf dem Frankfurter Kongress von 1931 die Beiträge von Selmar Aschheim und Bernhard Zondek zur Hypophysenfunktion als besondere Punkte auf der Tagesordnung. In einer Betrachtung von Hans H. Simmer zur Geschichte der Endokrinologie in den Verhandlungen der DGG heißt es dazu, es sei sicherlich das Verdienst von Seitz gewesen, dass die Frankfurter Tagung wie keine andere zuvor diesem Teilaspekt des Faches gewidmet wurde. Bernhard Zondek entwarf in seinem Referat ein Schema, das die Wechselwirkungen zwischen dem Hypophysenvorderlappen und dem Ovar erklären sollte, Selmar Aschheim beschäftigte sich unter anderem mit der Frage, ob ein im Schwangerenurin nachgewiesener, östrogen wirksamer Stoff aus der Hypophyse oder aus der Plazenta stamme. An der Diskussion, in der wie Simmer anmerkt - manche bedeutsame Mitteilung unbeachtet blieb, beteiligte sich als Gast auch der Schering-Chemiker Walter Hohlweg, der ein Jahr später die nervale Steuerung des Hypophysenvorderlappens durch das ZNS postulierte und 1937 an der Entwicklung des „Pillen-Östrogens“ Ethinylestradiol beteiligt war. ${ }^{396}$

Ein weiterer Schwerpunkt des Kongresses war das bereits kurz erwähnte große Referat von Max Hirsch zur Mutterschaftsfürsorge, die er als „das am meisten rückständige“ Teilgebiet der Gesundheitsfürsorge bezeichnete. Dementsprechend entwickelte er in seinem Beitrag, der fast 50 Seiten des Verhandlungsberichtes einnimmt, ein umfassendes Konzept zur Verbesserung der Si-

\footnotetext{
392 Verhandlungen 1933: 50 Seiten, dagegen u. a. 63 Seiten zu gynäkologischen Blutungen und 119 Seiten zum Zervixkarzinom; Verhandlungen 1935: 75 Seiten, dagegen u.a. 76 Seiten zu Leber und Schwangerschaft sowie 136 Seiten zur Sterilitätstherapie.

393 Siehe hierzu: Simmer: Endokrinologie (1986), S. 202-207.

394 Zusammenfassend im Auftrag der DGGG bereits erschienen: Beck (Hrsg.): Geschichte (1986); Ludwig/Jonat (Hrsg.): Programm (2008); Künzel/Oehmke: Präsidenten (1996) sowie Ludwig (Hrsg.): Reden (1999).

395 Vgl. Atzl/Helms: Krebsgesellschaft (2012); Moser: Forschungsgemeinschaft (2011).

396 Vgl. Simmer: Endokrinologie (1986), S. 204; Frobenius: „Rabbits“ (2011).
} 
tuation mit konkreten Forderungen an den Staat, aber auch an die eigene Fachgesellschaft. Ganz im Sinne des Zeitgeistes verlangte er dabei ein Verständnis für die Mutterschaftsfürsorge, das „nicht nur auf den Schutz von Mutter und Kind im Einzelfalle, sondern darüber hinaus auf die Sorge um die Fortpflanzungsleistung der Gesamtheit eingestellt" sei. ${ }^{397}$ In der Diskussion wurde ein Vorschlag von Hirsch begrüßt, an den Frauenkliniken besondere Sozialabteilungen einzurichten. Allerdings wollte man dies auf größere Städte begrenzt wissen. Zu der Forderung von Hirsch nach einer Reichsgeburtenstatistik erklärte Fritz Rott, der als Vertreter des Reichsauschusses für Bevölkerungsfragen anwesend war, das Reichsgesundheitsamt werde einen entsprechenden Fragebogen zur Begutachtung vorlegen. ${ }^{398}$

\section{3: Hinselmann präsentiert die Kolposkopie}

Ein großes Thema des „Gleichschaltungskongresses“ von 1933 war die „Frühdiagnose und elektive Therapie des Collumcarcinoms“. Mit der Sitzung strebte Stoeckel offenbar 2 Ziele an: Zum einen wollte er den unterschiedlichen Stellenwert von Operation bzw. Bestrahlung bei der Behandlung des Zervixkarzinoms herausarbeiten lassen und die DGG damit vor allem gegen einen therapeutischen „Alleinvertretungsanspruch“ der Radiologen abgrenzen. ${ }^{399}$ Zum anderen sollte Hans Hinselmann, der bereits seit 1930 an der Universität Hamburg regelmäßig eine Vorlesung zur „Kolposkopie und Frühdiagnose des Uteruscarcinoms“ anbot, Gelegenheit erhalten, seine seit den 1920er-Jahren entwickelte Methode vorzustellen. Sicherlich nicht zuletzt um die Bedeutung des Auftrittes von Hinselmann zu unterstreichen, hatte Stoeckel für die Diskussion Max Borst aus München eingeladen, den führenden Pathologen in der Onkologie. ${ }^{400}$

Hinselmanns Präsentation, mit der fast ein halbes Jahrhundert vor Einführung des Pap-Screenings in Deutschland für eine regelmäßige Krebsfrüherkennung an der Portio geworben wurde, stieß im Auditorium auf viel Zustimmung - auch bei Borst. Der Pathologe meinte allerdings, es sei noch eine längere Beobachtungszeit nötig, um entscheiden zu können, welche der von Hinselmann in 4 Gruppen eingeteilten Veränderungen des Epithels sich tatsächlich zu malignen Tumoren weiterentwickelten und welche reversibel seien. Zumindest retrospektiv besonders interessant erscheint hierzu die Bemerkung Hinselmanns, dies hänge womöglich davon ab, ob das bisher unbekannte Agens für die Epithelveränderungen ausgeschaltet werden könne. ${ }^{401}$

Hinsichtlich der von ihm in seiner Präsidentenrede beschworenen engen Zusammenarbeit zwischen der NS-Regierung und der DGG konnte Stoeckel in der Sitzung bereits von einer ersten DGG-Initiative berichten, die auf das Wohlwollen des Innen- ministeriums und des Präsidenten des Reichsgesundheitsamtes gestoßen sei. Es handelte sich um einen Gesetzentwurf, der die Einführung einer jährlichen Krebsfrüherkennungsuntersuchung für Frauen ab 30 Jahre vorsah. ${ }^{402}$ Initiator war der Düsseldorfer Chefarzt Friedrich Lönne, der den Bericht Stoeckels vor den DGG-Mitgliedern als „verheißungsvollen Auftakt zu weiterer erfolgreicher Zusammenarbeit“ wertete. In seiner Begründung stellte Lönne die Initiative - wie damals üblich - in erster Linie in den Zusammenhang mit einem Gewinn für „Familie, Volk und Staat“ ${ }^{403}$ In der Diskussion über den allgemein begrüßten Vorstoß meinte Heinrich Martius, welche Rolle die Hinselmann'sche Koloskopie dabei spielen werde, sei noch nicht zu übersehen. „Wir werden aber gut tun, uns den Enthusiasmus von Hinselmann zu eigen zu machen [...].“404

Schließlich muss noch die Sitzung zu den gynäkologischen Blutungen erwähnt werden, die Stoeckel als Auftakt der Präsentationen für den Kongress 1933 gewählt hatte. Referenten waren Robert Schröder sowie seine Schüler Hans Runge und Konrad Tietze. Schröder, dem die gynäkologische Endokrinologie die umfassende Korrelation des Endometriumzyklus mit den Vorgängen im Ovar verdankt und der die Ätiologie der Regelstörungen bei Follikelpersistenz geklärt hat, ${ }^{405}$ legte den Stand der Kenntnisse zur Pathogenese und Diagnose der gynäkologischen Blutungen dar. Runge sprach über die bestehenden therapeutischen Möglichkeiten und Tietze über periodische, nicht menstruelle Blutungen. ${ }^{406}$

\section{5: Sterilität als Kontrapunkt}

Beim Kongress von August Mayer 1935 in München bildete das Thema Sterilität gewissermaßen den Kontrapunkt zu den Zwangsterilisationen. Eingeleitet wurde die Sitzung zum Kongressauftakt durch das Referat „Periodische Fruchtbarkeit und Unfruchtbarkeit“, für das nach den geschilderten Auseinandersetzungen mit der NS-Polykratie Hans Albrecht eingesprungen war. Albrecht stützte sich in seinen Ausführungen ganz auf die Publikationen des ursprünglich ausgeladenen Knaus sowie des Japaners Kyūsaku Ogino, der in seinen Arbeiten zu ähnlichen Ergebnissen gekommen war. ${ }^{407}$ In der Diskussion, in der die Zuverlässigkeit der Methode wie schon bei früheren Veranstaltungen von einigen Teilnehmern angezweifelt wurde, konnte der überraschend doch noch zugelassene Knaus auf eine ganz neue US-Arbeit verweisen, die gerade im „Journal of the American Medical Association" (JAMA) erschienen war: Danach hatte man in einer Studie mit 114 Ehefrauen bei 4702 Kohabitationen während der „sterilen Zeit“ keine einzige Schwangerschaft beobachtet. ${ }^{408}$

\footnotetext{
397 Hirsch: Mutterschaftsfürsorge [Verhandlungen 1931] (1931), S. 36.

398 Rott: [Diskussionsbeitrag, Verhandlungen 1931] (1931), S. 401.

399 Stoeckel: [Diskussionsbeitrag, Verhandlungen 1933] (1934), S. 291-293.

$400 \mathrm{Zu}$ Borst siehe Barbaryka: Institut (2008) sowie Moser: Forschungsgemeinschaft (2011).

401 Hinselmann: [Schlusswort, Verhandlungen 1933] (1934), S. 305. Zu Hinselmann siehe S. 67 f. und die Kurzbiografie im Anhang.

402 Zur Vorgeschichte: Ebert/David: Winter (2016); zum Hintergrund: Atzl/Helms: Krebsgesellschaft (2012), S. 55-66.

403 Verhandlungen 1933, Arch Gyn 156 (1934), S. 281-283. Siehe hierzu auch die Kurzbiografie von Lönne im Anhang.

404 Martius: [Diskussionsbeitrag, Verhandlungen 1933] (1934), S. 292.

405 Vgl. Simmer: Endokrinologie (1987).

406 Schröder: Blutungen [Verhandlungen 1933] (1934); Runge: Blutungen [Verhandlungen 1933] (1934); Tietze: Blutungen [Verhandlungen 1933] (1934).

407 Albrecht: Fruchtbarkeit [Verhandlungen 1935] (1936).

408 Knaus: Fruchtbarkeit [Verhandlungen 1935] (1936), S. 122.
} 
Neben dem Tiermediziner Johannes Richter, der sich über Beobachtungen zur „biologischen Sterilität“ äußerte, hatte Mayer für die Sitzung auch einen seiner ehemaligen Tübinger Schüler eingeladen: den Deutsch-Amerikaner Gerhard Mönch aus New York, der zu den Begründern der Spermaanalyse zählt. Mönch sprach über die Mikropathologie des Samens und schilderte den wünschenswerten Ablauf einer andrologischen Untersuchung. Hinsichtlich der Therapie der andrologischen Sterilität konnte er wenig Hoffnung machen: die Ergebnisse seien im Allgemeinen „nicht zufriedenstellend“. ${ }^{409}$ Als relativ unbefriedigend bezeichnete auch Günter K.F. Schultze die aktuellen Aussichten der Behandlung von Frauen in sterilen Ehen. In einem Kollektiv von 800 Paaren, die sich über einen Zeitraum von 8 Jahren in der Ambulanz der Stoeckel'schen Klinik vorgestellt hatten und oft über lange Zeit intensiv behandelt worden waren, kam es nur zu rund 160 Schwangerschaften. Angesichts des enormen Aufwandes fragte Schultze dann, ob solche „Vom individuellen Standpunkt aus gewiss sehr hoch zu bewertende Erfolge vom Standpunkt des Volksganzen gesehen Bedeutung haben“. Dies sei nur dann der Fall, wenn der Ausbau der Sterilitätsbehandlung in der Breite gesichert werde. In diesem Fall sei ein „Gewinn“ von jährlich 20000 Geburten zu erhoffen. ${ }^{410}$ Schon damals wurde in der Diskussion die Forderung erhoben, Sterilität als Krankheit anzuerkennen und ihre Behandlung zur Kassenleistung zu erklären.

Als Randbemerkung interessiert vielleicht abschließend, dass Jörgen Lövset aus Bergen bei diesem Kongress seine Methode der Armlösung bei Beckenendlage vorstellte, die sich noch heute in den Lehrbüchern der Geburtshilfe findet. Er habe die Technik bereits 83-mal erfolgreich angewandt, darunter einmal bei einer Erstgebärenden, deren Kind dann 6 Kilogramm wog, erklärte Lövset damals. ${ }^{411}$

\section{7: G. A. Wagner sucht den Kompromiss mit Conti} $\nabla$

„Ernste Sorgen“, so konstatierte G.A. Wagner in seiner Eröffnungsrede für den Berliner Kongress 1937, „macht uns ein [...] Streit, der tief eingreift in die Möglichkeit der Erfüllung der uns auferlegten Pflichten und der besonders diejenigen unter uns Geburtshelfern trifft, welche geburtshilfliche Anstalten zu leiten haben“. Damit thematisierte er als Präsident der DGG vor geladenen Behörden- und Parteivertretern, insbesondere aber auch in Anwesenheit der Reichsfrauenführerin Gertrud Scholtz-Klink, die seit Jahren schwelende Auseinandersetzung um die Stellung der Hebammen und der Hausgeburt im Verhältnis zur Anstaltsgeburtshilfe. Ausschlaggebend für diesen Schritt dürfte wohl die damals erst kurz zurückliegende Tagung der RAG „Mutter und Kind“ gewesen sein, die Leonardo Conti wieder zu einer Attacke gegen die akademischen Geburtshelfer und die Anstaltsgeburten genutzt hatte. Noch suchte die DGG in Gestalt ihres Präsidenten allerdings nicht die offene Konfrontation. Vielmehr blieb Wagner in seiner Rede trotz deutlicher Worte sehr verbindlich und versuchte zudem, Kompromissbereitschaft zu signalisieren - freilich letztlich vergeblich, wie sich in der bereits beschriebenen Eskalation 2 Jahre später zeigen sollte.

Wagner hielt die Angelegenheit schon damals für so wichtig, dass er ihr einen großen Teil seiner Rede widmete und auch bei der Erörterung anderer Themenkomplexe immer wieder den Bogen schlug zu der „besonderen Aufgabe des Geburtshilfe treibenden Arztes“. In seiner Argumentation bemühte er sich, die gegen die Anstaltsgeburtshilfe ins Feld geführten Vorwürfe zu entkräften und ihre Vorteile darzustellen, ohne dabei der Hausgeburtshilfe jede Berechtigung abzusprechen. Er kam zu dem Schluss: „Damit wäre die Frage: ,Anstalts- oder Hausgeburt‘ für unser Volk abgelehnt mit dem Satze: ,Anstalts- und Hausgeburt'."412 Gleichzeitig feierte er den damaligen Staatsrat Conti als großen Mediator, dem es gelungen sei, endlich den Streit „Hie wissenschaftlich fundiertes Arzttum, hie Naturheilkundige“ einvernehmlich zu beenden. Dies sei ein glänzendes Beispiel dafür, wie „auch die scheinbar schwersten Gegensätze dem zähen Willen zu einheitlicher Zusammenfassung aller nützlichen Kräfte weichen müssen“. 413

Die von Wagner in seiner Eröffnungsrede als „besonderes $\mathrm{Ar}$ beitsgebiet der Charité-Frauenklinik“ angekündigte endokrinologische Sektion des Kongresses zum Thema Ovarialinsuffizienz stellte zweifellos einen Schwerpunkt der Veranstaltung dar. Einschließlich der Korreferate und Diskussionen beanspruchte sie später in den Verhandlungsberichten rund ein Viertel der Gesamtdarstellung. Für die Sektion hatte Wagner 2 Gastredner gewinnen können: den Anatomen Earl Theron Engle aus New York sowie den Internisten Louis Grote aus Dresden: Engle hatte 1927 an Mäusen gezeigt, dass der Hypophysenvorderlappen die Gonadenfunktion unterhält. In Berlin referierte er über „Gonadotrope Stoffe im Blut, Harn und anderen Körperflüssigkeiten“. Grote, der bereits zur Kongresseröffnung in Vertretung des Reichsärzteführers ein Grußwort gesprochen hatte, war seit 1933 internistischer Chefarzt des Rudolf-Heß-Krankenhauses in Dresden und an einem Projekt zur Synthese von Naturheilkunde und Schulmedizin im Rahmen der „Neuen Deutschen Heilkunde“ beteiligt. ${ }^{414}$ Er bearbeitete den internistischen Aspekt des Sitzungsthemas. An dieser Stelle soll nur auf das Referat von Wagners Oberarzt Carl Kaufmann eingegangen werden, der über die Behandlung der Ovarialinsuffizienz sprach. Kaufmann hatte sich bereits Anfang der 1930er-Jahre mit der Auslösung einer echten Menstruationsblutung bei einer kastrierten Frau durch Gabe von Hormonen in der Fachwelt einen Namen gemacht („Kaufmann-Schema“) $(\odot$ Abb. 21). 415

In seinem Referat musste Kaufmann einräumen, dass die Therapie der mit einer Ovarialinsuffizienz assoziierten Krankheitsbilder auf erhebliche Schwierigkeiten stoße. Er begründete dies mit der Komplexität des Zusammenspiels der endokrinen Organe

\footnotetext{
409 Mönch: Mikropathologie [Verhandlungen 1935] (1936), S. 78.

410 Schultze: Ehen [Verhandlungen 1935] (1936).

411 Lövset: Schulterentwicklung [Verhandlungen 1935] (1936), S. 397. Der Titel des Beitrags, „Schulterentwicklung ohne Armlösung bei natürlicher und künstlicher Beckenendlage“, steht nur scheinbar im Widerspruch zur heutigen Bezeichnung der Technik.

412 Wagner: Eröffnungs-Ansprache [Verhandlungen 1937] (1938), S. 6.

413 Ebd., S. 7

414 Heidel/Lienert (Hrsg.): Professoren (2005), S. 35 f.

415 Kaufmann: Menstruation (1933).
} 
sowie des Gesamtorganismus. Nur selten dürfe man annehmen, „die zu behandelnde Störung sei einzig und allein durch ein Plus oder Minus eines Hormones bedingt“ ${ }^{416}$ Auf die rasanten Fortschritte in der Steroidchemie, der zwischen 1929 und 1935 die Reindarstellung von Östron, Östriol und Östradiol sowie Progesteron gelungen war, ging Kaufmann nicht detaillierter ein, obwohl erst damit die Phase der Organopräparate beendet und der Weg für die Behandlung mit definierten Substanzen freigemacht werden konnte. ${ }^{417}$

Kaufmann erklärte, die Frage nach der zweckmäßigen Dosierung von Follikelhormon sei „weiter im Fluss“. Für das Progesteron erhoffte er sich Aufschlüsse darüber von weiteren Untersuchungen zur Ausscheidung des Metaboliten Pregnandiol im Urin. Von großer Bedeutung seien ferner Erkenntnisse, die sich aus der Forschung zur Abhängigkeit der Hormonwirkung von der Applikationsart ergäben.

Zu den Krankheitsbildern, zu deren Behandlung Kaufmann sich äußerte, gehörten die primäre und sekundäre Amenorrhö, Regeltempostörungen, die glandulär-zystische Hyperplasie des Endometriums sowie klimakterische Beschwerden. Dabei räumte er der Hormontherapie der primären Amenorrhö kaum Aussichten auf Dauerheilung ein. Besser stehe es bei der sekundären Form der Störung, wobei die Erfolgsaussichten umso größer seien, je früher mit der Behandlung begonnen werde. Hinsichtlich der glandulär-zystischen Hyperplasie empfahl Kaufmann eine von Clauberg inaugurierte Therapie mit hohen Progesterondosen. Die Frage der Behandlung von Ausfallserscheinungen bezeichnete Kaufmann insofern als gelöst, als es sich hier um den seltenen Fall handle, in dem nur eine Substanz ersetzt werden müsse. Vor zu hohen Dosen sei allerdings zu warnen. Unter Berufung auf Knaus ging Kaufmann auch auf die Behandlung von Blutungen in der Schwangerschaft, habituellen Aborten und Frühgeburtlichkeit mit Progesteron ein. Knaus habe gezeigt, dass das Corpus luteum „einen Schutz gegen die Wirkung des Hypophysenhinterlappenhormons“ herbeiführe. Erfolgreiche Behandlungen dazu seien „in den zusammenfassenden Werken von Clauberg erwähnt“. ${ }^{418}$

\section{1: Ein verhinderter Nobelpreisträger als Gastredner} $\nabla$

Hans Fuchs, der 1941 wenige Monate nach der Beilegung des Streites um die Geburtshilfe auch die Reichshebammenführerin Nanna Conti zur Kongresseröffnung in Wien begrüßen durfte ( $\triangle$ Abb. 22a und b), stellte seinen Kongress „im Gefolge der Zeitenwende 1933“ unter das „übergeordnete Prinzip einer umfassenden positiven Volksgesundheitspflege“. ${ }^{419}$ Dementsprechend sollten fachärztliche Einzelfragen in den Hintergrund treten. Schwerpunkte des Tagungsprogramms lagen deshalb bei Maßnahmen der Krebsfrüherkennung und - 10 Jahre nach dem um-

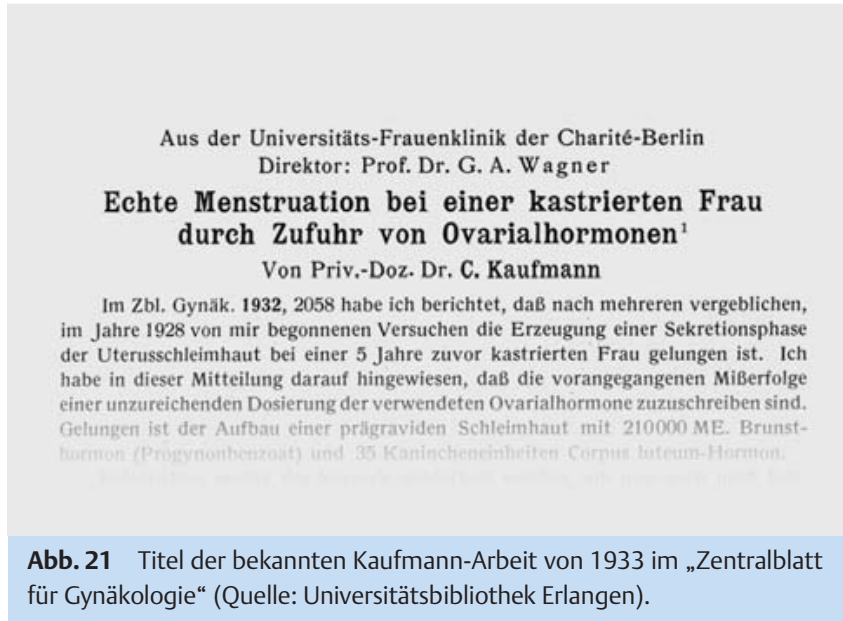

fassenden Referat von Hirsch - wieder bei der ärztlichen Schwangerschaftsvorsorge. Außerdem stellte Gustav Haselhorst die lange angemahnte Sammelstatistik zu den Ergebnissen der Klinikentbindung vor. Als prominenter Gastreferent wurde der Pathologe, Bakteriologe, Pharmakologe und Entdecker der antibakteriellen Wirkung des Sulfonamids Prontosil (Sulfamidochrysoidin), Gerhard Domagk, zu einem Referat über die Chemotherapie der bakteriellen Infektionen eingeladen. Die Tatsache, dass man mit ihm den deutschen Nobelpreisträger für Medizin des Jahres 1939 zu Gast hatte, verschwiegen sowohl Fuchs als auch der Verhandlungsbericht: Domagk hatte den Preis auf Befehl Hitlers nicht annehmen dürfen. ${ }^{420}$

In seiner Eröffnungsrede vor den Kongressteilnehmern, unter denen er immer noch ausländische Gäste aus 16 Staaten begrüßen konnte, beschränkte sich Fuchs fast völlig auf eine knapp gefasste Darstellung des geplanten Programms. Kritische Punkte wie die beigelegte Auseinandersetzung um die Geburtshilfe, die von Wagner noch vor dem Plenum erörtert worden war, separierte er in die Mitgliederversammlung. Auch über die Schwierigkeiten mit der Terminierung des Kongresses, der mehrfach verschoben und schließlich um einen Tag verkürzt werden musste, verlor Fuchs kein Wort. ${ }^{421}$

In der Sitzung über die Möglichkeiten zur Krebsbekämpfung sprach zunächst Peter Esch, Ordinarius in Münster, über „Die Bedeutung der Volksaufklärung für die Krebsbekämpfung“. Dabei stellte er Daten aus Westfalen vor, die zeigen sollten, dass einschlägige Maßnahmen zu einer früheren Behandlung erkrankter Frauen führen konnten: Die Operabilität der diagnostizierten Gebärmutterkrebse sei von 22,3 auf 36,3\% gestiegen. ${ }^{422}$ Eine ähnliche Entwicklung beobachtete auch Felix von Mikulicz-Radecki in Königsberg, wo seit 1938 Aufklärung in großem Stil nicht nur bei

\footnotetext{
${ }^{416}$ Kaufmann: Behandlung [Verhandlungen 1937] (1938), S. 113.

417 Vgl. Simmer: Endokrinologie (1987).

418 Kaufmann: Behandlung [Verhandlungen 1937](1938), S. 124

419 Fuchs: Eröffnungs-Ansprache [Verhandlungen 1941] (1942).

420 CDSB, S. 208 (1981); Deichmann: Flüchten (2001), S. 310; Eckart: Medizin (2012), S. 260

421 Fuchs: Eröffnungs-Ansprache [Verhandlungen 1941] (1942). Über die Probleme mit dem Kongress existiert ein relativ ausführlicher Briefwechsel unter den Vorstandsmitgliedern. Gustav Döderlein hatte damit viel Arbeit, Heinrich Martius klagte über hohe Kosten: BSB München, Nachlässe, Ana 691, Ordner DGG 1941-1948.

422 Esch: Bedeutung [Verhandlungen 1941] (1942), S. 52.
} 


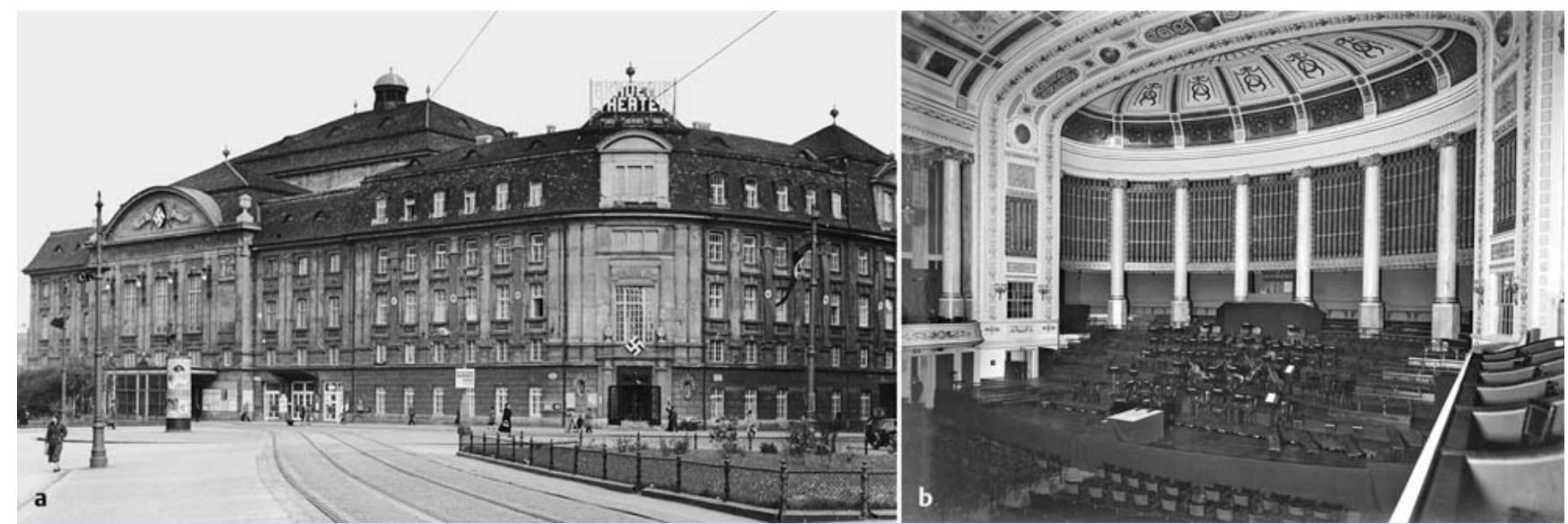

Abb. 22a und b a Das Wiener Konzerthaus an der Lothringerstraße, Ort des DGG-Kongresses 1941 (Quelle: Österreichische Nationalbibliothek Wien). b Der Große Saal des Wiener Konzerthauses, in dem die DGG-Tagung 1941 abgehalten wurde (Quelle: Österreichische Nationalbibliothek Wien).

der weiblichen Bevölkerung, sondern auch bei den praktischen Ärzten betrieben wurde. Der Anteil dieser Ärzte an der Verschleppung von Krebsdiagnosen sei deshalb bereits gesunken, sagte Mikulicz-Radecki. Er betrage aber noch immer knapp 21\%. Weitere Verbesserungen seien deshalb nötig. Ferner berichtete Mikulicz-Radecki von „Vorsichtsuntersuchungen“ an 7080 Frauen in den Jahren zwischen 1934 und 1941, bei denen insgesamt 9 zuvor unbekannte Unterleibskrebse entdeckt worden seien, von denen sich nur 2 als inoperabel erwiesen hätten. ${ }^{423}$

Schließlich kam auch wieder Friedrich Karl Lönne zu Wort, dessen Entwurf für ein Krebsgesetz seit 1933 im Dickicht der Zuständigkeiten unterwegs war. Er teilte nun mit, in Düsseldorf seien unter anderem mit Unterstützung des Reichsausschusses für Krebsbekämpfung alle Vorbereitungen für eine zunächst lokale Umsetzung seiner einschlägigen Planungen getroffen worden. Sie umfassten ein Vier-Punkte-Programm von Aufklärung, Früherfassung und Behandlung, Nachbehandlung und nachgehender Fürsorge sowie statistischer Auswertung. Der Kriegsausbruch habe den Start des Programms aber seit 1939 verhindert. ${ }^{424}$

Gustav Döderlein, der ungeachtet der Initiativen von Hirsch wohl wegen seiner praxisnahen Vorschläge als der Begründer der Schwangerenvorsorge in Deutschland gilt, stellte sein Konzept unter dem Titel „Ärztliche Schwangerschaftsvorsorge und ihre gesetzliche Regelung“ vor. Dabei warnte er ausdrücklich davor, die Schwangerschaft zu pathologisieren. Dennoch könne nicht übersehen werden, dass nach den verfügbaren Daten und aufgrund theoretischer Überlegungen etwa 8-15\% der Schwangeren einer besonderen gesundheitlichen Betreuung bedürften, um schwere Komplikationen zu vermeiden. Von daher sei eine allgemeine Vorsorge gerechtfertigt. Döderlein sagte, 3 Untersuchungen im 3., 7. und 10. Lunarmonat sollten die Regel werden. Dazu stellte er ein Schema für die Dokumentation vor, das in sei- nen wesentlichen Teilen der noch heute üblichen klinischen Diagnostik im Mutterpass entspricht. Als besonders wichtig bezeichnete Döderlein die Lues-Diagnostik bei der Erstvorstellung der Schwangeren, da die Durchseuchung $2-4 \%$ betrage und $70-$ $80 \%$ der werdenden Mütter nichts von ihrer Erkrankung wüssten. Ein Mutterschutzgesetz, das alle gesetzlichen Grundlagen für die von ihm vorgeschlagenen Maßnahmen schaffen solle, sei in Vorbereitung. ${ }^{425}$

Gerhard Domagk stellte in seinem Beitrag ausführlich die eigenen Arbeiten sowie die nach seiner Entdeckung entstandene internationale Literatur zur antibiotischen Therapie mit Sulfonamiden vor und diskutierte sie im Hinblick auf ihren Wert für die Frauenheilkunde. ${ }^{426}$ Indikationen waren vor allem die Gonorrhö, puerperale Infektionen, septische Aborte und Harnwegsinfektionen. Das Referat von Domagk wurde durch eine Reihe von Vorträgen von DGG-Mitgliedern ergänzt, die über eigene Erfahrungen berichteten. ${ }^{427}$ In der lebhaften Diskussion betonte man die Bedeutung einer frühzeitigen Behandlung für den Erfolg - auch hinsichtlich der Erhaltung der Fertilität. Teilweise wurden Sulfonamide auch schon zur Prophylaxe bei erhöhtem Infektionsrisiko eingesetzt. ${ }^{428}$

Die von Haselhorst vorgelegten Ergebnisse der Anstaltsentbindungen erwiesen sich als Sammelstatistik aus 27 Universitätsfrauenkliniken und Hebammenlehranstalten der Jahrgänge 1936 bis 1938, für die insgesamt 109719 Entbindungen mit ihrem Ausgang bis 10 Tage nach der Geburt bearbeitet wurden. Extrauniversitäre Entbindungsanstalten waren also nicht berücksichtigt. Der Referent wies deshalb in seiner Bewertung der Ergebnisse eindringlich auf die begrenzte Aussagefähigkeit der Studie hin. In seiner Untersuchung ermittelte er eine mütterliche Mortalität von 4,37 Promille. Die kindliche Mortalität gab Haselhorst einschließlich der intrauterin abgestorbenen Kinder und der Früh-

\footnotetext{
423 Mikulicz-Radecki: Bedeutung [Verhandlungen 1941] (1942).

424 Lönne: Früherfassung [Verhandlungen 1941] (1942); Atzl/Helms: Krebsgesellschaft (2012), S. 55-66.

425 Döderlein: Schwangerschaftsvorsorge [Verhandlungen 1941] (1942).

426 Domagk: Chemotherapie [Verhandlungen 1941] (1942).

427 Verhandlungen 1941, Arch Gyn 173 (1942), S. 460-482.

428 Verhandlungen 1941, Arch Gyn 173 (1942), S. 482-491.
} 
geburten mit 54,21 Promille an. ${ }^{429}$ Zusammenfassend stellte Haselhorst fest, dass die Ergebnisse „in geburtshilflichen Anstalten, die wirklich solche sind, als außerordentlich günstig, ja als hervorragend bezeichnet werden können“. Wegen der „Besonderheit des Behandlungsgutes“ sei es aber „unstatthaft, die Ergebnisse ohne ausführlichen Kommentar zu Vergleichen heranzuziehen". 430

\section{Besondere Initiativen der DGG bei den Kongressen 1931-1941 \\ $\nabla$}

Auf dem Kongress von Mayer 1935 verabschiedeten die Mitglieder 3 Resolutionen. Dabei handelte es sich zum einen um einen Appell an die „maßgebenden Stellen“, bei der Besetzung leitender Positionen in Kliniken die personelle Trennung von Chirurgie und Frauenheilkunde weiter voranzutreiben. Es gehe nicht an, dass große Krankenhäuser noch immer in Stellenausschreibungen Chefärzte für „chirurgisch-gynäkologische“ Abteilungen suchten. Angesichts der Entwicklung des Faches reiche eine chirurgische Vorbildung nicht mehr aus. Zudem werde zum Nachteil der Volksgesundheit der gynäkologische Nachwuchs ausbleiben, wenn Chirurgen „ohne die nötige Fachausbildung, jungen Gynäkologen mit vieljähriger Vorbildung die Betätigungsmöglichkeit wegnehmen““. ${ }^{431}$ In der zweiten Resolution setzte sich die DGG für ein Verbot der Herstellung und Anwendung der ,gesundheitsschädlichen und lebensgefährlichen“ intrauterinen Kontrazeptiva ein. Sie richtete sich unter anderem gegen den von Ernst Gräfenberg entwickelten und nach ihm benannten Ring. Initiator war der Frauenarzt Victor Ohnesorge, der kurz zuvor im „Zentralblatt für Gynäkologie“ über die „Gefahren der intrauterinen Schutzmittel“ publiziert hatte, die bereits seit längerem Gegenstand der Diskussion waren. ${ }^{432}$ In der dritten Resolution, die nicht in der Mitgliederversammlung, sondern im Anschluss an das Referat von Gustav Haselhorst über „Weibliche Sterilität“ angenommen wurde, forderte die DGG die Staatsregierung dazu auf, die Krankenkassen zur Übernahme der Behandlungskosten bei Sterilität zu verpflichten. ${ }^{433}$

Die 3 Resolutionen wurden nach dem Kongress von Mayer dem Innenministerium, dem Kultusministerium, dem Reichsärzteführer sowie dem Reichsgesundheitsamt zugeleitet. Stoeckel hatte sich zuvor Mayer gegenüber bereit erklärt, sie in seiner Eigenschaft als „Verbindungsmann“ durch persönliche Vorsprache zusätzlich zu unterstützen. Für diesen „Gang ins Ministerium“ regte Mayer bei Stoeckel die Klärung weiterer Fragen an, die die Kostenübernahme durch die Krankenkassen bei verschiedenen Maßnahmen betraf, darunter die Anstaltsgeburtshilfe. ${ }^{434}$
„Dem Individuum dienen, ohne die Art zu schädigen“ Um Fragen der Kostenübernahme ging es auch in einer Resolution, die wiederum von Lönne 1937 bei Wagners Kongress eingebracht und dann auch beschlossen wurde: Ziel war es einerseits, die Finanzierung medizinischer Leistungen bei Komplikationen in der Schwangerschaft sicherzustellen. Andererseits sollten alle Versicherungen auch dazu verpflichtet werden, die Kosten vorbeugender Schwangerschaftsuntersuchungen zu übernehmen. Lönne führte dazu als Beispiel eine Versicherung an, die als „freiwillige Mehrleistung“ bereits 3 ärztliche Beratungen vergütete. In der Begründung des Antrags erklärte er, es widerspreche „grundlegend den bevölkerungs-politischen Bestrebungen unseres Staates, die deutsche Frau gerade in der Zeit einem unvollständigen Versicherungsschutz zu überlassen, während deren [sic] sie ihrer höchsten Aufgabe, der Erhaltung des Volksbestandes, dient". 435

Veranlasst durch einen Vortrag von August Mayer über „Konservatives Operieren unter der Schonung der Fortpflanzungsfähigkeit" brachte Kurt-Otto von Stuckrad eine Resolution ein, deren Umsetzung dazu beitragen sollte, „das Volkswohl schädigende Mißstände in der Anzeigestellung zur operativen Therapie“ zu beseitigen. Gemeint war die Neigung mancher Frauenärzte, allzu großzügig z.B. die Entfernung von Gebärmüttern oder Eierstöcken und Eileitern zu indizieren. Mayer hatte im Gegensatz dazu in seinem Vortrag Möglichkeiten vorgestellt, „dem Individuum [zu] dienen, ohne die Art zu schädigen“. ${ }^{436}$ Dazu wurde der Vorstand aufgefordert, seinen Einfluss geltend zu machen und sich dabei der Unterstützung der Kassenärztlichen Vereinigung zu bedienen. Auch diese Resolution wurde - wie es hieß - „nach kurzer Aussprache“ angenommen. ${ }^{437}$

Schließlich setzte die Mitgliederversammlung 1937 noch 2 Ausschüsse ein. Der erste unter dem Vorsitz von Hermann Wintz sollte eine Stellungnahme der Gesellschaft zur geplanten Einrichtung von Zentralröntgeninstituten an den Universitätskrankenhäusern erarbeiten - einer staatlichen Initiative, die den Bestand der von Gynäkologen in den vorangegangenen Jahren aufgebauten, bedeutenden radiologischen Abteilungen an ihren Kliniken gefährdet hätte. Bei dem zweiten Ausschuss, für den zunächst offenbar niemand nominiert worden war, handelte es sich um ein Gremium, das die bereits mehrfach erwähnte, aussagekräftige Datensammlung zur Leistungsfähigkeit der klinischen Geburtshilfe in Deutschland erstellen sollte. ${ }^{438}$

\section{Fuchs rechtfertigt sich}

In der Mitgliederversammlung des Kongresses von 1941 sah sich Präsident Hans Fuchs offensichtlich genötigt, die Arbeit des Vorstandes in den vorangegangenen Jahren eingehender zu rechtfer-

\footnotetext{
429 Haselhorst: Ergebnisse [Verhandlungen 1941] (1942), S. 252.

430 Ebd., S. 253.

431 Generalversammlung [Verhandlungen 1935] (1936), S. 22. Initiator war der Stoeckel-Schüler und Chefarzt der Städt. Frauenklinik Dortmund, Fritz Engelmann.

432 Zu Gräfenberg und seinem Ring existiert umfangreiche Literatur. Überblick in: Baldauf/Tönnes/Simon/David: Report (2014), S. 1023-1025. Die intrauterine Kontrazeption war bereits 1931 auf dem DGG-Kongress scharf kritisiert worden. Zu einer Rehabilitation und Renaissance der Methode kam es Ende der 1950er-/Anfang der 1960er-Jahre.

433 Verhandlungen 1935, Arch Gyn 161 (1936), S. $121 \mathrm{f}$.

434 UAT 150/33,41: Mayer an Stoeckel (16.11.1935).

435 Mitgliederversammlung [Verhandlungen 1937] (1938), S. 22 f.

436 Mayer: Operieren [Verhandlungen 1937] (1938), S. 324-326.

437 Mitgliederversammlung [Verhandlungen 1937] (1938), S. 23.

438 Mitgliederversammlung [Verhandlungen 1937] (1938), S. $21 \mathrm{f}$.
} 
tigen. Der Grund dafür dürfte in den oben angesprochenen Defiziten zu sehen sein, die sicherlich nicht nur in der zitierten Korrespondenz evident wurden. Auch der Rechenschaftsbericht birgt Ungereimtheiten: So bezeichnete Fuchs Ernst Bach als Nachfolger von Stoeckel im Amt des „Verbindungsmannes“ zu den Behörden ab 1935. 1939 und 1940 sei dann aber Stoeckel für die Verhandlungen mit Reichsgesundheitsführer Conti in Sachen Hebammen und Hausgeburtshilfe „noch einmal [...] in Aktion getreten“ und habe „mit Energie, diplomatischem Geschick und Takt unsere Sache geführt und entscheidend zu der Bereinigung beigetragen“. Gleichzeitigt kündigte Fuchs nun für die bevorstehende Sitzung den schon 1939 von Lönne ironisch angemahnten Bericht über die „Leistungen der klinischen Geburtshilfe" an, der bereits dargestellt wurde. Im Übrigen, so Fuchs, habe sich die Prophezeiung Stoeckels erfüllt, dass der Vorstand keines Verbindungsmannes mehr bedürfe. ${ }^{439}$

Anschließend listete Fuchs eine Reihe von „Hauptfragen“ auf, zu denen in den vergangenen 4 Jahren seiner Amtsführung offizielle Stellungnahmen der DGG angefordert worden seien. Er nannte dabei unter anderem Gutachten für das Reichsinnenministerium zur Hebammenausbildung und für einen Erlass zur Ausbildung von Laienhelferinnen für Hilfestellung bei überraschend eintretenden Geburten; ferner Gutachten für den Reichsgesundheitsführer zu den Gefahren medizinisch indizierter Schwangerschaftsabbrüche sowie insbesondere durch „chirurgo-gynäkologische Polypragmasie“ gekennzeichnete geburtshilfliche Fehlbehandlungen. Mit dem Reichswirtschaftsministerium sei über die Früherfassung des Karzinoms und deren Finanzierung gesprochen worden - offenbar in Zusammenhang mit der Lönne'schen Initiative von 1933. Schließlich führte Fuchs noch die Beteiligung der DGG bei der Aufstellung eines Forschungsplans des Reichsgesundheitsamtes gegen Alkohol-und Tabakschäden sowie zur Bekämpfung des Puerperalfiebers mit dem „neuen chemo-therapeutischen Rüstzeug“ an. Hinsichtlich der geplanten Röntgenzentralinstitute teilte Fuchs ohne Nennung weiterer Einzelheiten mit, die Sache sei für die Gynäkologie „günstig gelaufen“: Die Hauptvertreter der Röntgenologie wollten die selbständigen Strahlenstationen der Frauenkliniken nicht antasten. ${ }^{440}$ 


\section{Die Mitglieder der DGG}

„Sie fordern mich auf, den Zweijahresbeitrag für die deutsche Gesellschaft für Gynäkologie zu überweisen. Ehe ich ihn bezahle, möchte ich mir die Frage erlauben, warum ich dieses Jahr keine Einladung zum Gynäkologenkongress nach Wien bekommen habe. Da die Teilnahme am Gynäkologenkongress das Einzige ist, was uns die Deutsche Gesellschaft für Gynäkologie für unseren Beitrag bietet, so habe ich doch den letzten Zweijahresbeitrag vollkommen umsonst bezahlt.“441

Der hier zitierte Brief der Reichenbacher Frauenärztin Else Riedel vom 8. Dezember 1941 ist eine der wenigen Anfragen eines Mitglieds an den Vorstand der Gesellschaft, die aus dem untersuchten Zeitraum überliefert sind. Dass den Mitgliedern der DGG trotz der spärlichen Quellenlage ein eigenes Kapitel gewidmet werden soll, liegt nicht zuletzt darin begründet, dass sie das eigentliche Konstituens der Gesellschaft waren und, wenn nicht als Individuen, so doch als mehr oder minder diffuse Gruppe Einfluss auf Entscheidungen des Vorstands nehmen konnten.

Was versprachen sich Ärztinnen und Ärzte von der Mitgliedschaft in einer Fachgesellschaft wie der DGG und wodurch legitimierte sich diese? Else Riedels Brief lässt erahnen, dass die Meinungen darüber auseinandergehen konnten. War es für die einen das Bedürfnis, am fachlichen Diskurs teilzunehmen, berufliche Netzwerke zu knüpfen und sich durch Präsenz und Beiträge auf Tagungen als Wissenschaftler zu profilieren, standen für andere Mitglieder standespolitische Interessen im Vordergrund; das Anliegen, die gesellschaftliche und ökonomische Stellung des Arztes zu sichern, erschien in wirtschaftlich prekären Zeiten dringlicher denn je. Wie andere Fachgesellschaften auch bewegte sich die DGG damit im „Spannungsfeld zwischen einem Verband zur Vertretung von Standesinteressen und einem am Gemeinwohl orientierten Verein zur Förderung der Wissenschaft“" ${ }^{442}$ der vage formulierte Gesellschaftszweck, die „gynäkologischen Kräfte zu einigen“, ${ }^{443}$ ließ beide Auslegungen zu.

\section{Die Mitgliedschaft gemäß Satzung \\ $\nabla$}

Die Bedingungen einer Aufnahme als Mitglied wurden auf dem Gründungskongress im Jahr 1886 wie folgt formuliert: „§ 3. Mitglied der Gesellschaft kann Jeder werden, der sich mit Gynäkologie beschäftigt, unter den in $\S 8$ aufgeführten Bedingungen. [...] $\S 8$. Die Aufnahme neuer Mitglieder erfolgt zur Zeit der Versammlungen. Der neu Aufzunehmende muss durch 3 Mitglieder vorgeschlagen werden. Der gesamte Ausschuss entscheidet über die Aufnahme durch Stimmenmehrheit.“444

Bis 1945 wurde die knappe und - angesichts eines nicht abgeschlossenen Prozesses der Abgrenzung und Professionalisierung - recht unspezifische Passage mehrmals modifiziert. 1923 trat der wissenschaftliche Anspruch der Gesellschaft zunächst in den Vordergrund. Mitglied konnten nun ausschließlich Personen werden, die „in der Gynäkologie literarisch tätig gewesen“ sind. ${ }^{445}$ Zehn Jahre später, im Zuge der weitreichenden Statutenänderungen des Jahres 1933, wurde die Einschränkung zurückgenommen. Bis nach Kriegsende hieß es nun: „Mitglied der Gesellschaft kann [...] jeder Frauenarzt und jede Frauenärztin und jeder Arzt und jede Ärztin werden, der sich für Geburtshilfe und Gynäkologie interessiert. “446 Neben dem Verzicht auf einen Nachweis der wissenschaftlichen Qualifikation wurde erstmals ausdrücklich auf die Geburtshilfe Bezug genommen. ${ }^{447}$ Eine gewisse Exklusivität behielt die Gesellschaft durch den Verweis auf die Berufsbezeichnung Arzt (nicht jedoch Facharzt), die den Ausschluss medizinischer Laien bedingte. Dagegen war eine Beschränkung auf das Deutsche Reich oder den deutschen Sprachraum zu keiner Zeit gegeben oder gewünscht. Ausländische Ärzte konnten, sofern sie vorgeschlagen wurden, ordentliche Mitglieder der Gesellschaft werden. ${ }^{448}$

Der alle 2 Jahre erhobene Mitgliedsbeitrag, das zweite „Exklusivitätskriterium“449 jeder Vereinigung, lag mit 20 Reichsmark im mittleren Bereich. Klagen über die Höhe des Beitrags und Vor-

\footnotetext{
441 BSB München, Nachlässe Ana 691: Riedel an Martius (08.12.1941).

442 Kinzelbach: Gesellschaft (2012), S. 8. In erster Linie verstand sich die DGG jedoch als wissenschaftliche Gesellschaft, was in zahlreichen Eröffnungsansprachen zum Ausdruck kommt.

443 Vgl. z. B. Statuten, in: Arch Gyn 144 (1931), XI ( $§ 1)$; die Formulierung war bereits Ende des 19. Jahrhunderts in die Statuten aufgenommen worden.

444 Statuten, in: Arch Gyn 12 (1877), S. 262

445 Statuten, in: Arch Gyn 120 (1923), XI.

446 Statuten, in: Arch Gyn 156 (1934), VIII.

447 Die Ergänzung des Gesellschaftsnamens um die Geburtshilfe wurde bereits in den 1930er-Jahren diskutiert, aber erst 1974 umgesetzt.

448 Zu den „ausländischen“ Mitgliedern der DGG siehe S. 69-73.

449 Vgl. Goschler: Vereinsmenschen (2000), S. 44 f.
} 


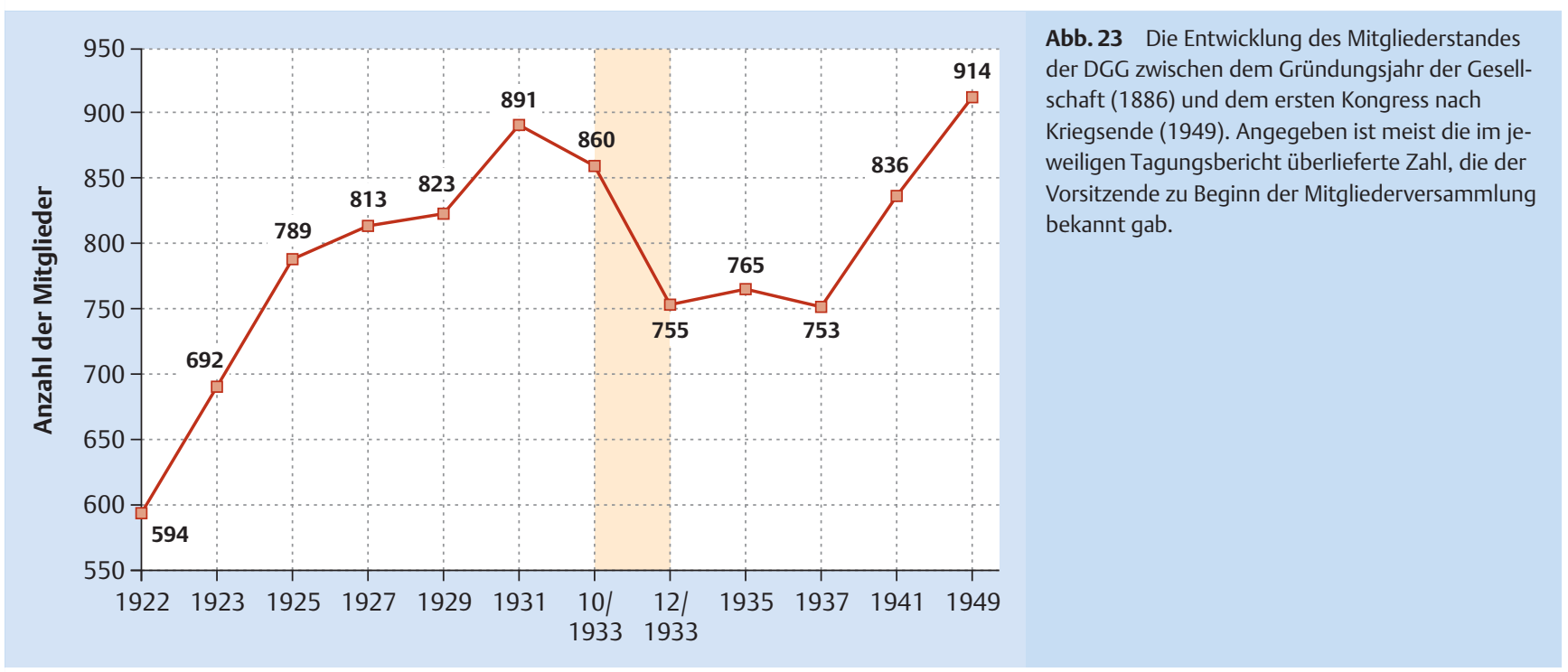

schläge zu dessen Senkung sind in den Korrespondenzen und Tagungsberichten allerdings ebenso häufig überliefert wie Anspielungen des Kassenwarts auf die mangelhafte Zahlungsmoral der Mitglieder. ${ }^{450}$ Wohl auch als Reaktion auf einen Einbruch der Mitgliederzahlen zu Beginn der 1930er-Jahre wurde 1935 beschlossen, den Beitrag für Mitglieder, die noch keine „selbständige Stelle“ innehatten, auf 10 Reichsmark zu senken. ${ }^{451}$ Ab 1937 zahlten auch Ruheständler den ermäßigten Satz.

\section{Die Zusammensetzung der Mitgliederschaft 1931-1941}

Dank eines kontinuierlichen Zuwachses hatte sich die Zahl der DGG-Mitglieder zwischen 1922 und 1931 um die Hälfte erhöht. Knapp 900 Personen gehörten am Vorabend des NS-Regimes der Gesellschaft an - eine Zahl, die erst über ein Jahrzehnt später wieder erreicht werden sollte. Der bemerkenswerte Anstieg der Mitgliederzahl Ende der 1930er-Jahre, offenbar das Resultat einer durch den Vorstand angeregten Werbekampagne an den Universitäten und im zwischenzeitlich „angeschlossenen“ Wien, ${ }^{452}$ beendete eine seit 1933 andauernde Phase, in der die Zahl der Mitglieder hinter den Stand der frühen 1920er-Jahre zurückgefallen war. Allein zwischen Juli 1931 und Dezember 1933 waren rund 160 Personen - darunter viele als jüdisch geltende Mitglieder - aus der Gesellschaft ausgeschieden ( $\bullet$ Abb. 23).

Wichtigste Quelle für die Zusammensetzung und Veränderung der Mitgliederschaft in der Zeit des Nationalsozialismus sind die
Mitgliederverzeichnisse, die in den Jahren 1922-1937 im „Archiv für Gynäkologie“ gedruckt wurden. Zwischen 1922 und 1933 sowie 1937 wurden dort außerdem die beim jeweiligen Kongress anwesenden Mitglieder markiert $\left({ }^{*}\right)$. Wenngleich die erfassten Teilnehmerzahlen nicht zuverlässig sind ${ }^{453}$ - selbst Vortragende wurden nicht immer als anwesend gekennzeichnet -, können sie in ihrer Größenordnung und Tendenz als aussagekräftig gelten.

In den Jahren 1931-1941 454 waren, laut offizieller Statistik, insgesamt 1225 Personen Mitglied der Gesellschaft; 389 ausgeschiedenen Mitgliedern, davon rund 100 Verstorbene, standen in diesem Zeitraum 334 Neuzugänge gegenüber - über die Hälfte davon (175) zwischen 1937 und 1941. Identifiziert werden konnten, mit wenigen Ausnahmen, alle Mitglieder, die zwischen 1931 und 1937 mit ihrem Namen und ihrer Anschrift in den Verzeichnissen gelistet sind: insgesamt 1043 Personen, von denen eine knappe Mehrheit über 1945 hinaus Mitglied war. Auf Grundlage der erhobenen Daten lassen sich grundsätzliche Aussagen über Charakteristika, Tendenzen und Veränderungen in Bestand und Zusammensetzung der Mitgliederschaft bis 1937 treffen:

Im untersuchten Zeitraum waren 97,5\% der Mitglieder männlich, 2,5\% weiblich. ${ }^{455}$ Das Durchschnittsalter im Jahr 1931 betrug 48 Jahre. Die überwiegende Mehrheit der Mitglieder war in den letzten beiden Jahrzehnten des 19. Jahrhunderts geboren. Wie den meisten Angehörigen ihrer Generation galt ihnen der Erste Weltkrieg, den nicht wenige als Soldat erlebt hatten, als wichtiger politischer und biografischer Bezugspunkt. Den Zusammenbruch

\footnotetext{
450 Vgl. z. B. Generalversammlung [Verhandlungen 1933] (1934), LVI.

451 Vgl. Generalversammlung [Verhandlungen 1935] (1936), S. 19.

452 UAT 150/33,41: Besprechung (17.08.1935); BSB München, Nachlässe Ana 691, Martius an Fuchs (05.12. 1941); Mitgliederversammlung [Verhandlungen 1941] (1942), S. 9. Auch andere Fachgesellschaften lancierten Mitte der 1930er-Jahre Werbekampagnen, um den Mitgliederschwund auszugleichen; vgl. Jahnke-Nückles: Kinderheilkunde (1992), S. 77; Schmuhl: Neurologen (2016), S. 136.

453 Die mangelnde Vollständigkeit der Teilnehmerliste wurde von Mayer bereits in den 1930er-Jahren bemängelt; UAT 150/33,41: Gegenstände der letzten Vorstandssitzung und eigene Beobachtungen.

454 Der untersuchte Zeitraum wurde auf das Jahr 1931 ausgedehnt, um die weitreichenden Veränderungen in der Mitgliederschaft zwischen 1931 und 1933 zu erfassen.

455 Zu den weiblichen Mitgliedern der DGG siehe S. $68 \mathrm{f}$.
} 


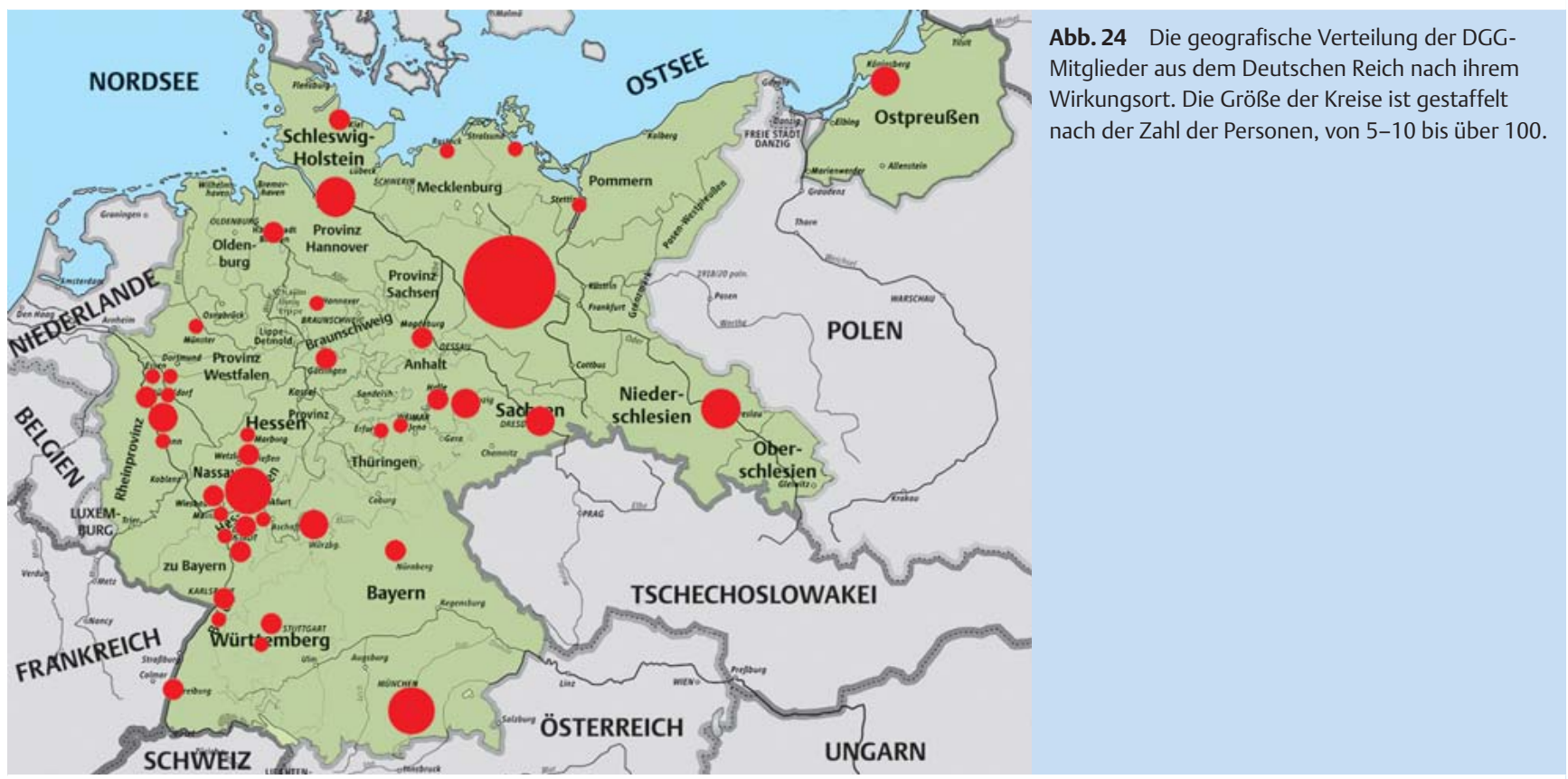

des Kaiserreichs erlebten die häufig deutschnational gesinnten Ärzte als Schock, die Gesundheits- und Sozialpolitik der Weimarer Republik war ihnen mindestens suspekt. ${ }^{456}$ Nur geringe Unterschiede bestanden in dieser Hinsicht zwischen den Mitgliedern christlicher Herkunft und den Mitgliedern, die ab 1933 als Juden galten. Betont werden muss allerdings, dass gerade im „Bildungsbürgertum“ ein pseudowissenschaftlich begründeter Antisemitismus, als Teil des elitären Selbstverständnisses, zu einem „Signum kultureller Identität“ avancierte. ${ }^{457}$ Die Neigung, jüdische Ärzte für die beschriebenen Missstände verantwortlich zu machen, war keineswegs auf den ärztlichen Nachwuchs beschränkt.

Etwa 75\% der DGG-Mitglieder praktizierten und lehrten innerhalb der Grenzen des Deutschen Reiches. Die Zahl der Ärzte, die einem universitären Lehrkörper angehörten oder, meist in leitender Position, an Krankenhäusern tätig waren, entsprach im Jahr 1931 ungefähr der Zahl der in freier Praxis niedergelassenen Ärzte. ${ }^{458}$

Von 770 deutschen Mitgliedern praktizierten über 100 in der Reichshauptstadt Berlin. Auf dem zweiten und dritten Rang der am häufigsten vertretenen Wirkungsorte lagen Frankfurt am Main und München mit jeweils rund 40 sowie Breslau und Hamburg mit jeweils rund 30 Ärzten. Über ein Drittel der Mitglieder war im untersuchten Zeitraum in diesen 5 Städten tätig. Weitet man den Kreis auf alle Orte aus, an denen mindestens 5 Mitglieder wirkten, sind bereits drei Viertel der deutschen Mitglieder erfasst. Das restliche Viertel - etwa 190 Personen - verteilte sich auf weitere 130 Orte, von denen rund 90 nur ein einziges Mitglied stellten ( $\bullet$ Abb. 24).
Bemerkenswert sind die Verschiebungen, die sich im Laufe der 1930er-Jahre vollzogen: Während die meisten Orte zahlenmäßig „stabil“ blieben, verzeichneten manche Städte enorme Einbrüche: Kamen 1931 noch 91 Mitglieder aus Berlin, waren es 6 Jahre später nur noch 55, die Frankfurter und Breslauer „Fraktionen“ halbierten sich von 36 auf 16 bzw. von 29 auf 15 Mitglieder, von den 32 Münchner Mitgliedern des Jahres 1931 lassen sich 1937 nur noch 16 nachweisen; allerdings konnte München, wie andere Städte auch, die Verluste durch zahlreiche Neuzugänge einigermaßen ausgleichen. Der Grund für die auffälligen Veränderungen liegt in der Verdrängung der als jüdisch geltenden Mitglieder, die in den genannten Städten in besonders großer Zahl tätig waren. Der Schwund in Berlin, Frankfurt und Breslau trug maßgeblich dazu bei, dass sich die Mitgliederzahl zwischen 1931 und 1937 um 138 Personen verringerte.

Über die Zusammensetzung der Mitgliederschaft nach 1937 lassen sich mangels überlieferter Mitgliederverzeichnisse nur wenige Aussagen treffen. Lediglich als Anhaltspunkt können die Namen der Personen dienen, die auf der Tagung von 1941 einen Vortrag hielten, wobei unter diesen auch Gäste waren - auf den Kongressen der 1930er-Jahre hatten stets mehrere Nichtmitglieder gesprochen. Von den Vortragenden des Jahres 1941 stand jedenfalls ein Drittel (knapp 50 Personen) 4 Jahre zuvor noch nicht im Mitgliederverzeichnis.

Nicht mit Sicherheit beantworten lässt sich die Frage, welcher Anteil der im Deutschen Reich wirkenden Frauenärztinnen und Frauenärzte in der DGG organisiert war. Legt man die im Reichsmedizinalkalender (RMK) 1931 veröffentlichte Statistik der „praktizierenden Ärzte (einschl. Anstaltsärzte)“ zugrunde, die

456 Vgl. Gerst: Standesorganisation (2004), S. 15.

457 Volkov: Antisemitismus (2000), S. 23.

458 Siehe hierzu auch S. 62. 
von 1585 Fachärzten für Geburtshilfe und Frauenkrankheiten ausgeht, ${ }^{459}$ ergäbe sich, bei 640 deutschen Mitgliedern im Jahr 1931, ein Organisationsgrad von rund $40 \% .460$ Weitaus höher liegt jedoch die Zahl der Namen, die im RMK mit dem Symbol der Geburtszange gekennzeichnet sind: für 1931 wurden rund 2600 Ärzte gezählt, was einem Organisationsgrad von nur 25\% entspräche. ${ }^{461}$

\section{Teilnahme und Beteiligung an den Kongressen $\nabla$}

Legt man die Angaben der Mitgliederverzeichnisse zugrunde, nahmen zwischen 1922 und 1931 durchschnittlich rund 300 Personen oder 40\% der Mitglieder an den Tagungen teil. ${ }^{462}$ Der 1927 in Bonn aufgestellte Teilnehmerrekord - 372 Personen wurden als anwesend markiert - konnte wohl erst nach 1945 überboten werden. ${ }^{463}$ Deutlich ins Auge fällt die niedrige Teilnehmerzahl des Jahres 1933: Nur 223 Ärzte waren laut Verzeichnis zum Kongress in Berlin erschienen - bei 860 Mitgliedern ein Anteil von $26 \%$ oder, bei Nichtberücksichtigung der ausländischen Mitglieder, ein gutes Drittel. Allerdings sind diese Zahlen mit Vorsicht zu genießen, denn die Anwesenheit einer Person wurde nur dann dokumentiert, wenn sie im Mitgliederverzeichnis mit Stand vom 15. Dezember 1933 gelistet war und selbst dies nicht immer zuverlässig. Da über 100 Personen offenbar erst nach dem Kongress aus der Gesellschaft austraten, kann ihre Teilnahme nicht ausgeschlossen werden.

Dass die Tagung von 1933 vergleichsweise schlecht besucht war, ist dennoch wahrscheinlich. ${ }^{464}$ Viele Mitglieder jüdischer Herkunft, darunter „Stammgäste“ wie Paul Straßmann und Bernhard Zondek, blieben dem Kongress in ihrer Heimatstadt aus naheliegenden Gründen fern. Den österreichischen Ärzten, von denen 1931 noch über 20 erschienen waren, war die Ausreise ins Deutsche Reich aus politischen Gründen untersagt worden, wie Stoeckel in seiner Eröffnungsansprache bedauernd hervorhob. 465 In seinen Erinnerungen beschreibt der Vorsitzende die angespannte Lage im Vorfeld der Tagung: „Die Unruhe, die Hitlers Machtergreifung verursacht hatte, wirkte sich auf die Kongreßfreudigkeit lähmend aus. Viele Mitglieder, namentlich in Süddeutschland, zögerten, nach Berlin zu kommen, und unter den ausländischen Teilnehmern herrschte begreifliche Ratlosigkeit."466
Es passt ins Bild, dass Mayer zu Beginn der folgenden Tagung seiner Freude über den „gut gefüllten Saal“ Ausdruck verlieh, denn „[e]ine Weile sah es so aus, als ob der Kongreßbesuch nicht allzu groß ausfallen würde“. ${ }^{467}$ Als Ursache dieser Befürchtung nannte Mayer in einem Schreiben an Ernst Bach den „Ausfall durch die nicht-arischen Ärzte“; er habe sich deshalb vertraulich an die Gauobmänner des Nationalsozialistischen Deutschen Ärztebundes (NSDÄB) gewandt und darum gebeten, die dem Bund angehörenden Frauenärzte anzuweisen, „doch möglichst an der Tagung teilzunehmen“. 468 Eine „Anwesenheitsliste“ ist für 1935 nicht überliefert. Zwei Jahre später wurden immerhin 308 Teilnehmer gezählt, womit erstmals seit 1931 wieder über 40\% der Mitglieder erfasst wurden; bezogen auf diejenigen aus dem Deutschen Reich waren sogar mindestens zwei Drittel anwesend.

Für 146 von 540 Mitgliedern, die von 1931 bis 1937 ohne Unterbrechung Mitglied der Gesellschaft waren, ließ sich im gesamten Zeitraum keine Tagungsteilnahme nachweisen. Ein Drittel von ihnen lebte dauerhaft im Ausland.

Von der ohnehin nur lückenhaft dokumentierten Anwesenheit auf den Tagungen abgesehen, brachte sich nur ein Teil der Mitglieder in das Gesellschaftsleben ein. Auf den 4 Kongressen zwischen 1931 und 1937 wurden von rund 200 verschiedenen Referenten - 19\% der erfassten Mitglieder - rund 420 Vorträge gehalten. Bezieht man die Diskussionsbeiträge mit ein, kommt man auf eine Zahl von 370 Mitgliedern (ca. 35\%), die im untersuchten Zeitraum als „aktiv“ bezeichnet werden können. Die überwiegende Mehrheit stammte aus dem universitären Umfeld. Niedergelassene Ärzte stellten zwar einen beachtlichen Teil der Mitglieder, blieben auf den Tagungen jedoch unterrepräsentiert. Eine bemerkenswerte Ausnahme stellt die rege Beteiligung niedergelassener Ärzte jüdischer Herkunft dar, die nicht nur vergleichsweise zahlreich zu den Tagungen erschienen, sondern auch in überdurchschnittlichem Maße zum wissenschaftlichen Programm beitrugen. Möglicherweise diente der Kongressbesuch niedergelassenen und klinisch tätigen Ärzten wie Paul Straßmann, die sich selbst als Wissenschaftler verstanden, als Kompensation für die oftmals erfolglos angestrebte universitäre Karriere. $^{469}$

Über die Zahl der Teilnehmer an den Mitglieder- oder Generalversammlungen, die sich meist unmittelbar an die Eröffnungsansprache des Vorsitzenden anschlossen, liegen für den untersuchten Zeitraum keine Aufzeichnungen vor. Ein für 1933 überliefertes Abstimmungsergebnis belegt, dass sich in diesem Jahr

\footnotetext{
459 RMK 1931, S. 486 f.

460 Dies entspräche ungefähr dem Organisationsgrad der Augenärzte, von denen während der NS-Zeit etwa 43\% Mitglied der DOG waren; vgl. Rohrbach: Augenheilkunde (2007), S. 62. Mit 57,7\% (1933) deutlich höher lag der Anteil bei den Kinderärzten, wobei auch hier von unterschiedlichen Zahlen ausgegangen wurde; vgl. Seidler: Kinderärzte (2007), S. 21.

461 Vermutlich lag der offiziellen Statistik ein exklusiveres Facharztkriterium zugrunde als dem auf Selbstauskunft beruhenden Namensverzeichnis.

462 Von den offiziellen Zahlen stark abweichende Schätzung in Stoeckel: Erinnerungen (1966), S. 390.

463 Allerdings schätzte Gustav Döderlein, dass 1941 ca. 500 Personen am Kongress teilgenommen hätten; vgl. BSB München, Nachlässe Ana 691, Döderlein an Eberhart.

464 Auch die erste Tagung der DGfK nach der Machtübernahme der Nationalsozialisten konnte nur eine sehr geringe Teilnahme verzeichnen; vgl. Seidler: Kinderärzte (2007), S. 25.

465 Stoeckel: Eröffnungs-Ansprache [Verhandlungen 1933] (1934), XLII.

466 Stoeckel: Erinnerungen (1966), S. 390.

467 Mayer: Eröffnungs-Ansprache [Verhandlungen 1935] (1936), S. 1. Vgl. auch einen Brief Mayers an Stoeckel (UAT 150/33,41: 20.04.1935), in dem Mayer über das geringe Interesse am Kongress klagt und spekuliert, dass die augenblickliche „Zeitlage“ der wissenschaftlichen Forschung eher abträglich sei.

468 UAT $150 / 33$

469 Vgl. David: Straßmann (2007), S. 104.
} 
mindestens 151 Mitglieder im Saal befanden, ${ }^{470}$ was zwar nur knapp 18\% der Gesamtheit, aber immerhin gut zwei Dritteln der erfassten Kongressteilnehmer entspricht. Trotz der - zumindest in diesem Fall - relativ hohen Anwesenheit hielt sich die aktive Beteiligung der Mitglieder an der Versammlung offenbar in Grenzen. Anregungen und Beschwerden, etwa zur Höhe des Mitgliedsbeitrages oder zur Kongressführung, wurden nicht öffentlich vorgebracht, sondern den Vorstandsmitgliedern schriftlich oder in Einzelgesprächen mitgeteilt; die überlieferten Korrespondenzen gewähren aufschlussreiche Einblicke in die vielfältigen Interessen und Befindlichkeiten einzelner Mitglieder oder Mitgliedergruppen, die der Vorstand bei seiner Arbeit berücksichtigen, abwägen und antizipieren musste.

Die offiziellen Sitzungsprotokolle lassen von alldem wenig erahnen; hier tritt das Plenum fast ausschließlich durch „lang anhaltenden“ und „lebhaften“ Beifall in Erscheinung. ${ }^{471}$ Die weitreichende Statutenänderung des Jahres 1933 wurde von mindestens zwei Drittel der über 150 Anwesenden ohne Debatte angenommen. ${ }^{472}$ Längere Diskussionen über Entscheidungen des Vorstands fanden im untersuchten Zeitraum offenbar überhaupt nicht statt, ein einziges Mal wird auf eine „kurze Aussprache“ verwiesen. ${ }^{473}$ Inwieweit dies den tatsächlichen Abläufen entspricht oder der Redaktionsarbeit des Vorstandes geschuldet ist, muss offen bleiben. Die ausführlichen Diskussionsprotokolle früherer Tagungen, die bisweilen „lebhaften Widerspruch“ und Zwischenrufe dokumentieren, zeichnen jedenfalls ein ganz anderes Bild. ${ }^{474}$

Hitzig diskutiert wurde im untersuchten Zeitraum allenfalls die wiederkehrende Frage des Tagungsortes, ${ }^{475}$ die durchaus - und nicht erst seit 1933 - eine politische Konnotation besaß; so wurden Einladungen und Vorschläge, in Danzig, Breslau oder Wien zu tagen, bisweilen mit „nationalpolitischen“ Verpflichtungen der Gesellschaft begründet. ${ }^{476}$ Die wiederholt debattierten Alternativen „Stabilisieren“ (vorzugsweise in Berlin) und „Wandern“ berührten Fragen des Gesellschaftszwecks und der Profilierung, aber auch organisatorische und finanzielle Belange. ${ }^{477} 1935$ wurde die langjährige Streitfrage sang- und klanglos durch den Vorstand entschieden: Die Tagungen sollten fortan abwechselnd in Berlin, München und „hoffentlich bald auch“ Wien stattfinden. ${ }^{478}$ Unter den Mitgliedern erregte dieser Beschluss offenbar keinen Widerspruch und wurde auf Bitte des Vorsitzenden August Mayer ohne Aussprache angenommen.

\section{Nationalsozialistische Gynäkologenkarrieren}

$\nabla$

Verbrecherische Menschenversuche in Konzentrationslagern, „Operationstraining“ an Zwangsarbeiterinnen in einer Hochschulklinik, rabiate Verfolgung jüdischer Kollegen: all diese ex- tremen Phänomene gehören ebenso zur Frauenheilkunde im Nationalsozialismus wie die „normalen“ Karrieren loyaler „Kampfgenossen“ und angepasster Karrieristen, die von der nationalsozialistischen Machtübernahme zu profitierten wussten.

Galt die Aufmerksamkeit bislang der DGG als Organismus mit seinen Binnenstrukturen und seiner Wirkung nach außen gleichsam als Handelsplatz von Ressourcen zwischen Gynäkologie, Politik und Gesellschaft -, soll die Perspektive für die folgenden biografischen Skizzen erweitert werden. An knapp gehaltenen Beispielen exemplarischer Karrieren von Frauenärzten, sämtlich Mitglieder der DGG, soll verdeutlicht werden, auf welchen Wegen und in welchem Umfang gynäkologische Expertise im Herrschaftssystem und den gesellschaftlichen Strukturen des Nationalsozialismus spezifische Karrieren beförderte. Die Skizzen eröffnen ein weiteres Feld, das nicht mehr Gegenstand dieser Untersuchung ist - das der Gynäkologie im Nationalsozialismus -, das aber das Umfeld darstellt, in dem sich auch eine präziser gefasste Geschichte der DGG im Nationalsozialismus bewegt.

\section{Alte Kämpfer und Blutordensträger}

Beinahe die Hälfte aller Ärzte, die während der NS-Zeit im Deutschen Reich praktizierten, war Mitglied der NSDAP. ${ }^{479}$ Während die meisten der Partei erst nach dem 30. Januar 1933 beitraten nicht zuletzt, um ihre Karriere zu befördern -, hatten sich einige Ärzte der „Bewegung“ bereits lange vorher angeschlossen und den Aufstieg der NSDAP seit ihren Anfängen in München begleitet. Die später heroisch überhöhten „Alten Kämpfer“ waren integraler Bestandteil des Märtyrer- und Heldenkultes um den Marsch auf die Feldherrnhalle im Rahmen des missglückten Putschversuchs im November 1923. Äußeres Zeichen der exklusiven Stellung war der „Blutorden“, der zunächst ausschließlich an Teilnehmer des „Hitlerputsches“, später auch an andere verdiente Parteimitglieder verliehen wurde. Mit der nationalsozialistischen Machtübernahme war die Stunde der „Alten Kämpfer“ gekommen, denen als loyale „Weggefährten“ viele Türen offen standen und die sich, in Abgrenzung zu den nach 1933 der NSDAP beigetreten „Märzgefallenen“, als nationalsozialistische Elite verstanden. Die weitreichenden organisatorischen und personellen Umwälzungen im Zuge von „Säuberung“ und „Gleichschaltung“ ermöglichten rasante und ungewöhnliche Karrieren, wie die Beispiele Arnulf Streck und Ernst Bach zeigen.

Mit dem glühenden Antisemiten und Blutordensträger Arnulf Streck hatte die DGG bis Mitte 1935 einen besonders üblen Vertreter der Partei in ihren Reihen ( Abb. 25). Streck, der als Freiwilliger im Ersten Weltkrieg verwundet wurde, hatte 1916 in München ein Tiermedizinstudium mit der Approbation abgeschlossen. Als er diesen Beruf wegen seiner Verwundung nicht ausüben konnte, schloss er ein Studium der Humanmedizin an und promovierte - neben zahlreichen Freikorps-Aktivitäten - in

\footnotetext{
470 Vgl. Generalversammlung [Verhandlungen 1933] (1934), LIX.

471 Arch Gyn 156 (1934), XLVII; 161 (1936), S. 10; 166 (1938), S. 20

472 Vgl. dazu Heuvelmann: Abschaffung (1999), S. 133; siehe auch S. 27-29 in diesem Band.

473 Mitgliederversammlung [Verhandlungen 1937] (1938), S. 23.

474 Vgl. z. B. Verhandlungen (1911), S. 732-743.

475 Stoeckel stellte 1933 gereizt fest, dass man nun bereits seit 20 Jahren über das Thema streite; vgl. Generalversammlung [Verhandlungen 1933] (1934), LIV.

476 Vgl. UAT 150/33,41: Mayer an Albrecht (11.01.1936); Mitgliederversammlung [Verhandlungen 1937] (1938), S. 19.

477 Wiederum Stoeckel: „Gegen das Wandern spricht weiter, daß eine Kongreßtradition, die das Ansehen der Gesellschaft festigt und ihre Geltung vermehrt, beim Herumziehen von Ort zu Ort nicht recht geschaffen werden kann.“; vgl. Generalversammlung [Verhandlungen 1933] (1934), LV.

478 Generalversammlung [Verhandlungen 1935] (1936), S. 19 f.

479 Vgl. Kater: Doctors (1989) S. 252.
} 


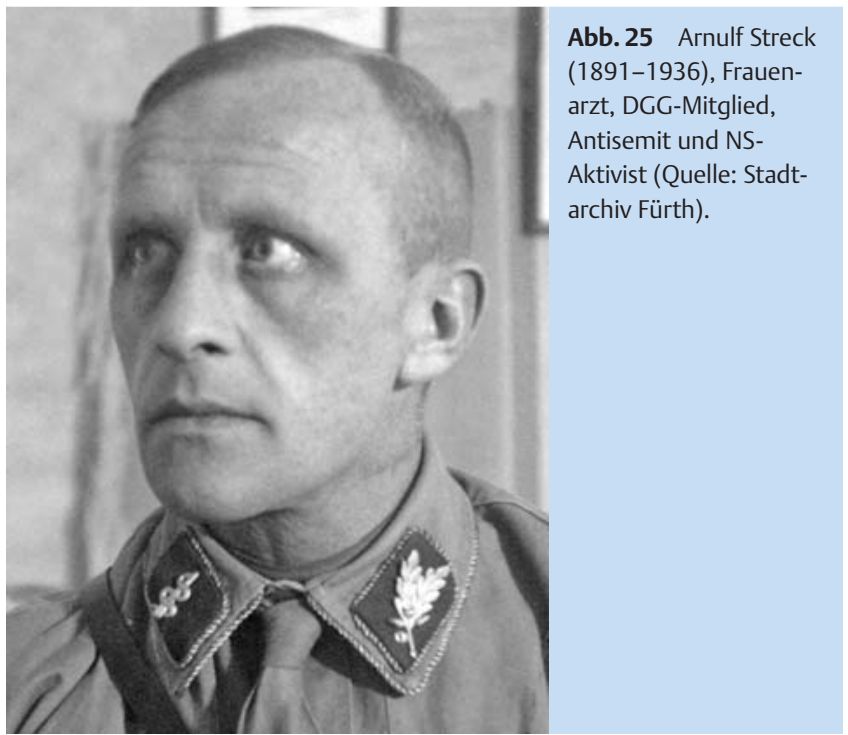

beiden Fächern (1919 und 1922). Nach entsprechender Weiterbildung war er dann als Frauenarzt tätig, zuletzt von 1931 bis 1935 in Fürth. ${ }^{480}$ Dort entfaltete sich sein politischer und antisemitischer Radikalismus in seinen Funktionen als SA-Brigadeführer und Vorsitzender des ärztlichen Bezirksvereins ab 1933 besonders deutlich: Streck sorgte für die Amtsenthebung aller jüdischen Ärzte, übernahm selbst die Leitung des renommierten jüdischen Nathanstiftes und beteiligte sich an einer Kampagne gegen den politisch missliebigen Oberbürgermeister Robert Wild, die rasch zu dessen Rücktritt führte. Ende 1934 lud er im Parkhotel der „ehemaligen roten Judenhochburg Fürth“ zu einer später im Deutschen Ärzteblatt ausführlich referierten Propagandaveranstaltung ein, in deren Mittelpunkt die speziellen Ziele der NS-Medizin standen und an der neben Parteiprominenz „fast die ganze Medizinische Fakultät der Universität Erlangen“ teilnahm. ${ }^{481}$

In der DGG war Streck seit Ende der 1920er-Jahre einfaches Mitglied ohne Amt. Ähnlich wie in seiner Heimatstadt Fürth versuchte er jedoch auch hier, einen rigoros antisemitischen Kurs durchzusetzen. 1935 drängte er auf den Ausschluss aller jüdischen Mitglieder und drohte andernfalls mit seinem eigenen Austritt. ${ }^{482}$ Strecks Antrag war im Februar 1935 Gegenstand einer Sitzung in Stuttgart, an der neben August Mayer als Vorsitzendem auch die Schriftführer Eduard Martin und Moritz Tausch sowie der Beisitzer Hans Albrecht teilnahmen. Zu einer gemeinsamen Haltung kam es damals offenbar nicht. Bei der nächsten Sitzung im August 1935 konnte, zur Erleichterung des Vorstands, Strecks überraschender Austritt konstatiert werden - er hatte die Tätigkeit als Frauenarzt eingestellt, um sich seiner Parteikarriere widmen zu können. ${ }^{483}$ Nun sah man sich in der DGG mit Streck allerdings auf andere Weise konfrontiert: Es war bekannt geworden, dass er bei dem Kongress im Oktober in München als Vertreter des Reichsärzteführers Gerhard Wagner sprechen sollte. Dort konnte er befriedigt feststellen, dass es sich um die erste ,judenfreie" Tagung der Gesellschaft handle. ${ }^{484}$ Ein Jahr später starb er im Alter von 45 Jahren an den Folgen eines Magenkarzinoms.

Während Streck seine ärztliche Tätigkeit zugunsten einer Parteikarriere ruhen ließ, nutzte Ernst Bach die privilegierte Stellung als „Alter Kämpfer“, um seiner universitären Laufbahn einen Schub zu verleihen. Bach war im März 1917 als Freiwilliger in den Ersten Weltkrieg gezogen und hatte sich während seines Studiums an Freikorps-Aktivitäten sowie an der militärischen Ausbildung Studierender beim Pionier-Bataillon München unter der Leitung von General von Epp beteiligt. Bereits 1922 war er Mitglied der NSDAP geworden und hatte sich im folgenden Jahr am Hitlerputsch beteiligt. Vermutlich war er ebenfalls Träger des „Blutordens“. 485

Ähnlich wie Streck gelang auch Bach nach 1933 ein rascher Aufstieg. Ab 1933 leitete er die Ärztekammer München-Oberbayern, später war er medizinischer Referent im Reichsministerium für Wissenschaft, Erziehung und Volksbildung. Das Regime besaß in Bach einen „weltanschaulich gefestigten“, absolut loyalen Unterstützer aus dem Hochschulbereich. Diese Haltung wurde dann auch mit dem Marburger Ordinariat belohnt, für das die dortige Fakultät eigentlich Gustav Döderlein gelistet hatte. Bach war jedoch seit Längerem an einem Wechsel von Berlin nach Marburg interessiert und wurde, wahrscheinlich auf Initiative des Ministeriums, auf die Liste gesetzt. ${ }^{486}$ G.A. Wagner schrieb dann 1944 auch vielsagend, dass Bach die Klinik „[d]urch äußere Einflüsse“ bekommen habe. ${ }^{487}$

Als brillanter Wissenschaftler und Gynäkologe war er bislang kaum in Erscheinung getreten. Eine Mitgliedschaft in der DGG für die meisten wissenschaftlich engagierten Hochschulmediziner eine Selbstverständlichkeit - ist für Bach erst ab 1937 dokumentiert. Zuvor war er in seiner Eigenschaft als Funktionär der NSDAP im Reichswissenschaftsministerium in die Vorbereitungen des Münchner Kongresses von 1935 eingebunden gewesen. Die Unterlagen des damaligen Präsidenten August Mayer zeigen, dass er sich an der Auswahl „geeigneter“ Referenten für die Sitzung zu den Zwangssterilisationen beteiligte. ${ }^{488}$ Möglicherweise wurde ihm in diesem Rahmen - und nicht zuletzt aufgrund seiner Stellung im Ministerium - der Eintritt in die DGG nahegelegt und das Amt eines Beisitzers angetragen, das er im Jahr 1937, dem Jahr seiner erstmaligen Erwähnung im Mitgliederverzeichnis, wahrnahm. Am 11. September 1944, wenige Tage vor seinem 44. Geburtstag, erlag Ernst Bach einem Herzinfarkt.

\footnotetext{
480 GK 1928; GK 1939; http://www.fuerthwiki.de/wiki/index.php?title=Arnulf_Streck.

481 Dross: „Juden“ (2012), S. $106 \mathrm{f}$.

482 UAT 150/33,41: Kongressvorbesprechung (23.02.1935).

483 UAT 150/33,41: Besprechung (17.08.1935).

484 Streck: [Grußwort, Verhandlungen 1935] (1936), S. 11

485 Grundmann: Einfluss (2001), S. 181.

486 Vgl. Beddies: Universitätspsychiatrie (2005), S. 55-72, S. 65 f.; Grundmann: Berufungsverfahren (2001), S. 269 f.

487 BArch Berlin, R 4901, Bl. 369.

488 UAT 150/33,41: Besprechung (26.07.1935).
} 


\section{Opfer von Zwangssterilisationen als}

\section{"Menschenmaterial“}

Menschenverachtende Humanexperimente waren im Nationalsozialismus nicht auf Konzentrations- und Vernichtungslager beschränkt. Auch außerhalb der Lager als Orte des Terrors eigener Qualität konnte eine „normale“ Universitätsfrauenklinik systematisch zum Ort von Verbrechen werden. Ehrgeizige Kliniker zögerten nicht, die im Rahmen der nationalsozialistischen Gesetzgebung gebotenen Möglichkeiten für Forschungszwecke zu nutzen, um sich durch neuartige Erkenntnisse als Wissenschaftler zu profilieren. Als „Menschenmaterial“ dienten den Universitätskliniken vor allem, aber nicht ausschließlich, zur Zwangssterilisation verurteilte Frauen. Es mutet besonders zynisch an, dass ausgerechnet an diesem Personenkreis unter anderem Ursachen und Behandlungsmöglichkeiten der - im Sinne des Pronatalismus unerwünschten Sterilität untersucht werden sollten.

Die bisher größten bekannten klinischen Medizinverbrechen in der Frauenheilkunde der NS-Zeit hat der Grazer Ordinarius Karl Ehrhardt zu verantworten: Operativ relativ unerfahren, versuchte er seine chirurgischen Fähigkeiten durch das „Training“ onkologischer Eingriffe an „Ostarbeiterinnen“ zu optimieren, die zu Zwangsabtreibungen eingewiesen worden waren. Außerdem nutzte er Zwangssterilisationen und Schwangerschaftsabbrüche für menschenverachtende Experimente, darunter Kontrastmitteluntersuchungen an den Feten. Mit den Kontrastmitteluntersuchungen an Schwangeren, bei denen ein Abbruch durchgeführt werden sollte, hatte Ehrhardt nach Tierversuchen bereits Anfang der 1930er-Jahre als Assistent unter Seitz in Frankfurt am Main begonnen. Anfänglich ging es um die radiologische Darstellung der Plazentalokalisation durch intravenöse Applikation. Unmittelbar vor und dann nach seiner Berufung an die Grazer UFK weitete er diese Untersuchungen erheblich aus. ${ }^{489}$

Die Berufung des überwiegend strahlentherapeutisch ausgebildeten Ehrhardt an die Grazer Klinik mit ihrer großen operativen Tradition war offensichtlich politisch motiviert. ${ }^{490}$ Seine Fähigkeiten als Operateur, aber auch als Diagnostiker und Klinikleiter wurden schon in den ersten Jahren seiner Tätigkeit so in Zweifel gezogen, dass sich das Reichswissenschaftsministerium 1942 genötigt sah, eine Untersuchungskommission der DGG nach Graz zu entsenden. Das Gremium unter der Leitung von G.A. Wagner kam jedoch zu dem Ergebnis, dass Ehrhardt den Anforderungen genüge. Zwar sei es „keine Frage, daß dem Prof. Ehrhardt Vorfälle beim Operieren unterlaufen sind“. Er habe aber „durch fleissiges Operieren an der Leiche, durch wiederholte Reisen zu anerkannten Operateuren [...] viel dazugelernt“. ${ }^{491}$ Offenbar nicht genug wie seine späteren „Übungen“ an den Ostarbeiterinnen zeigen.

Daneben war - unter anderem mit Unterstützung der Deutschen Forschungsgemeinschaft - die Erforschung der intrauterinen fetalen Lebensvorgänge nach intraamnialer Kontrastmittelgabe das Ziel der in Graz durchgeführten Menschenversuche. Ergebnisse wurden beispielsweise unter dem Titel „Atmet das Kind im

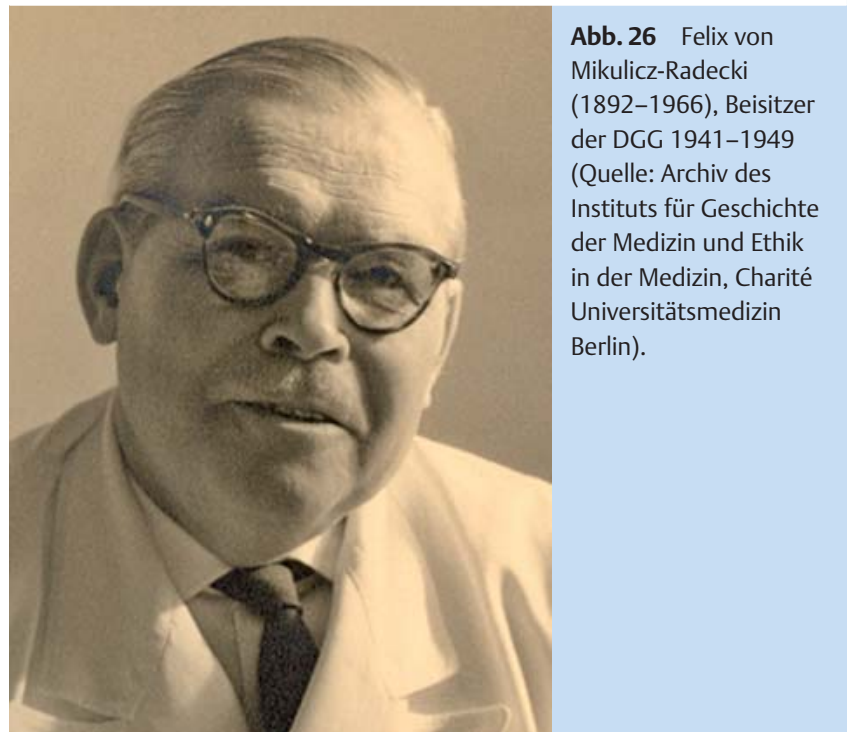

Mutterleib“ in der Münchener Medizinischen Wochenschrift veröffentlicht. ${ }^{492}$ Bei den Schwangerschaftsabbrüchen für diese Studien bevorzugte Ehrhardt die Sectio parva. Ziel dieser Eingriffe war es vor allem, den noch lebenden Fetus möglichst in der intakten Fruchthülle zu bergen, damit weitere Untersuchungen an ihm vorgenommen werden konnten. Bei einem anderen Forschungsansatz ging es Ehrhardt darum, die endokrine Aktivität des Corpus luteum zu quantifizieren. Dazu schälte er bei Schwangeren im Rahmen der Sterilisation den Gelbkörper aus und beobachtete dann das Schicksal der Gravidität unter Substitution mit einem Hormonpräparat in abnehmender Dosierung. Der folgende Abbruch konnte sich dabei um Wochen verzögern. Auch darüber wurde publiziert - im Zentralblatt für Gynäkologie. ${ }^{493}$

DFG-Förderung und Veröffentlichungen in renommierten Fachzeitschriften zeigen, dass sich die Forschung an Opfern der Sterilisationsgesetze in den Strukturen wissenschaftlicher Institutionen und der Forschung bewegte. Auch waren Ehrhardts Versuche, „der Natur wieder einmal ein Geheimnis abzulauschen“ ${ }^{494}$ wie er es ausdrückte, kein Einzelfall. Felix von Mikulicz-Radecki war ebenfalls von der Gunst der Stunde angetan. Die Jahre 1932-1945, die er als Ordinarius an der UFK Königsberg verbrachte, beschrieb er rückblickend als „glückliche Jahre - bis auf das Kriegsende -, in denen klinisch und wissenschaftlich aus dem Vollen geschöpft werden konnte““. 495

Mikulicz-Radecki war ein Lieblingsschüler und Freund Walter Stoeckels ( $\bigcirc$ Abb. 26). Er folgte ihm als Assistenz- und später Oberarzt auf allen Karrierestationen von Kiel über Leipzig bis nach Berlin. Erst der Ruf an die UFK Königsberg 1932 ließ ihn eigene Wege gehen. Den Pro- und Antinatalismus der Nationalsozialisten unterstützte Mikulicz-Radecki als einer der anerkannten Experten für reproduktionsmedizinische Fragen gleichermaßen.

\footnotetext{
489 Vgl. Czarnowski: „Material“ (2004), S. 254.

490 Ehrhardt war in Graz der Nachfolger der aus politischen Gründen in den Ruhestand versetzten Hans Zacherl.

491 Zit. n. Czarnowski: „Material“ (2004), S. 238. Vgl. auch S. 34f. dieser Arbeit.

492 Ehrhardt: Kind (1939).

493 Ehrhardt: Erfahrungen (1941); vgl. Czarnowski: „Material“ (2004), S. 255 f.

494 Zit. n. Doetz: Alltag (2011), S. 196.

495 Zit. n. Czarnowski: Frauenpolitik (1990), S. 113.
} 
Im Jahr 1935 sprach das engagierte DGG-Mitglied auf dem Kongress in München über die operative Behandlung der Sterilität; im selben Jahr präsentierte er im Rahmen der Debatte über die Mortalität der chirurgischen Zwangseingriffe eine große Sammelstatistik, mit der Kritiker des Gesetzes mundtot gemacht werden sollten. ${ }^{496}$ Zugleich nutzte er die gesetzlichen Zwangssterilisationen für illegale Forschung, die eine effektivere Behandlung „erbhochwertiger“ Frauen mit unerfülltem Kinderwunsch zum Ziel hatte. Dafür mussten sich die Sterilisandinnen weitergehenden Maßnahmen wie flankierenden Hormonbehandlungen, Kürettagen und Salpingografien unterziehen. Die Eingriffe wurden häufig zyklusabhängig geplant und vorgenommen. ${ }^{497}$ An den illegalen Forschungen in der Königsberger Klinik war auch Carl Clauberg beteiligt, der 1933 von Mikulicz-Radecki habilitiert wurde und ab 1942 verbrecherische Versuche an weiblichen Häftlingen in den Konzentrationslagern Auschwitz und Ravensbrück durchführte.

\section{Das Konzentrationslager als gynäkologisches Labor}

In den Konzentrationslagern wurde der Völkermord als perverse Option einer bis dato nicht gekannten, menschenverachtenden Experimentalpraxis genutzt. Im Dienste „kriegswichtiger Wissenschaft", aber auch im Rahmen der Krebs- und Sterilitätsforschung nahmen Mediziner an Häftlingen grausame Versuche vor, die den Tod der Versuchspersonen gezielt herbeiführten oder billigend in Kauf nahmen. Bei den Ärzten, die an diesen Verbrechen beteiligt waren, handelte es sich keineswegs um „obskure, medizinische Außenseiter [...], sondern um in das Wissenschaftskollektiv ihrer Zeit eingebettete Mediziner“" ${ }^{498}$ die mit ihrer Arbeit, wie der Königsberger Carl Clauberg, mitunter bereits vor 1933 zu Ansehen gelangt waren. ${ }^{499}$

Clauberg hatte sich in seiner Tätigkeit als Arzt und Wissenschaftler frühzeitig dem Thema Sterilität zugewandt, dem er auch sein Leben lang verbunden blieb. Bis zu Beginn der 1940er-Jahre galten alle seine Bemühungen der Behandlung der weiblichen Unfruchtbarkeit. Nach dem Schwinden seiner Hoffnungen auf Fortsetzung seiner Universitätskarriere empfahl er sich jedoch Heinrich Himmler mit dem Versprechen, eine einfache Methode zur Massensterilisation von Frauen zu entwickeln. Dies öffnete ihm das Konzentrationslager Auschwitz als „Labor“ für grausame Versuche an weiblichen Häftlingen. ${ }^{500}$

An Claubergs Biografie lässt sich exemplarisch nachvollziehen, wie das bereits in den 1920er-Jahren wichtige Thema der Sterilität während des Nationalsozialismus zu einem herausragenden wurde und wie gleitend die Übergänge zwischen der Beseitigung der Sterilität (bei „erwünschten“ Müttern) und deren Herbeiführung (bei „unerwünschten“ Müttern) waren. Besonders greifbar wird dies durch den bizarren Umstand, dass offenbar für beide Eingriffe eine „Clauberg'sche Methode“ zur Anwendung kommen konnte. Diesem Umstand ist es geschuldet, dass die Beteiligung des Greifswalder Ordinarius Günter K.F. Schultze an Claubergs
Sterilisationsexperimenten in Auschwitz bis heute ungeklärt ist. $^{501}$

Schultze tauchte 1941 auf einer Liste des Reichsarztes-SS Ernst Grawitz zu mit „der Behandlung weiblicher Unfruchtbarkeit nach der Methode Prof. Clauberg beauftragten Fachkräften“ auf. Im Kontext mit den bekannten Medizinverbrechen Claubergs wird dieses Faktum, zu dem bisher offenbar keine ergänzenden oder erläuternden weiteren Dokumente aufgefunden werden konnten, stets als Hinweis auf eine mögliche Verwicklung von Schultze in die Clauberg'schen Sterilisationsexperimente in Auschwitz gesehen. So heißt es beispielsweise bei Klee: „Es darf angenommen werden, daß damit eine Behandlung zur Unfruchtbarmachung gemeint ist."502 Dies muss aber keineswegs so sein, denn Clauberg hat sich eben auch mit der Therapie der Sterilität befasst: So stellte er 1935 auf dem DGG-Kongress in München als damals noch renommierter gynäkologischer Endokrinologe einige Beobachtungen über die Wirkung einer Follikelhormon-Behandlung auf komplett undurchgängige oder schlecht passierbare infantile Tuben vor, aus denen er folgerte, hochdosierte Östrogengaben könnten in bestimmten Fällen tubarer Sterilität therapeutisch hilfreich sein. ${ }^{503}$ Es erscheint nicht ausgeschlossen, dass dieses von ihm später auch andernorts noch publizierte Verfahren in Behördenakten als „Methode Prof. Carl Clauberg zur Sterilitätsbehandlung“ Eingang fand und nun fälschlicherweise mit Claubergs KZ-Experimenten zur Massensterilisation in Verbindung gebracht wird.

Carl Clauberg wurde 1898 als Sohn eines Handwerkers in Wupperhof (Bergisches Land) geboren und studierte nach einem Kriegseinsatz an der Westfront und einer mehrjährigen britischen Kriegsgefangenschaft Medizin in Kiel, Hamburg und Graz. In der großen Aufbruchphase der Endokrinologie und Reproduktionsmedizin in den 1920er- und 1930er-Jahren lieferte er wichtige Beiträge zur Entwicklung dieses Gebietes. Claubergs Karriere als Reproduktionsmediziner begann während seiner Assistentenzeit an der UFK Kiel bei Robert Schröder, der durch seine bahnbrechenden morphologischen Untersuchungen zu den Beziehungen zwischen dem Funktionszustand des Endometriums und den Vorgängen im Ovar größte Reputation erworben hatte. So entwickelte Clauberg eine Vereinfachung des Corner-AllenTests zum Nachweis gestagener Aktivität im Tierversuch, die als „Clauberg-Test“ große Bedeutung erlangte.

In seiner Zeit als Assistent und Oberarzt der UFK Königsberg bei von Mikulicz-Radecki führte er in Zusammenarbeit mit der Berliner Firma Schering-Kahlbaum klinische Untersuchungen zur Wirksamkeit und möglichen therapeutischen Nutzung neu entwickelter Hormonpräparate durch, darunter auch das spätere „Pillen-Östrogen“ Ethinylestradiol. 1940 hinsichtlich seiner Universitätskarriere in eine Sackgasse gelangt, übernahm er die Position als Chefarzt der Frauenkliniken im St. Hedwigs- sowie im Knappschaftskrankenhaus in Königshütte.

\footnotetext{
496 Mikulicz-Radecki: Eiauffangsmechanismus [Verhandlungen 1935] (1936); Mikulicz-Radecki: Sammelstatistik (1935). Vgl. hierzu auch S. 46 dieser Arbeit.

497 Czarnowski: Frauenpolitik (1990).

498 Doetz: Alltag (2011), S. 199.

499 Siehe hierzu auch die Kurzbiografie von Percival Treite im Anhang.

500 Vgl. Grosch: Clauberg (1993); Wolf: Vernunft (2008), S. 393.

501 Siehe S. 54 und die Kurzbiografie im Anhang.

502 Klee: Auschwitz (1997), S. 437.

503 Clauberg: Tubenwachstum [Verhandlungen 1935] (1936).
} 
Seine Versuche zur Entwicklung einer nicht-operativen, zur Massensterilisation geeigneten Methode führte Clauberg zunächst an Tieren durch. Ab Ende 1942 erprobte er das Verfahren, für das Kontrastmittel für die Hysterosalpingografie mit einer gewebetoxischen 10\%igen Formalinlösung versetzt war, an in Auschwitz inhaftierten Frauen ( $\bullet$ Abb. 27). Unterstützt wurde er dabei durch den Pharmakologen Paul Göbel, den er sich dafür von Schering ausgeliehen hatte. Als Auschwitz wegen der herannahenden sowjetischen Truppen aufgegeben werden musste, setzte Clauberg seine Versuche noch im Januar 1945 in Ravensbrück fort. ${ }^{504}$ Überlebende berichteten, dass bei Claubergs Versuchen mit großer Brutalität und unter Missachtung aller Regeln der Hygiene vorgegangen wurde. Es kam deshalb häufig zu Komplikationen, mindestens 4 Frauen starben.

Am Beispiel von Hans Hinselmann lässt sich erläutern, dass das Konzentrationslager Auschwitz neben seiner Bedeutung als „medizinisches Labor“ - wie bei Clauberg gezeigt - auch für auf den ersten Blick wenig einschlägige universitäre wissenschaftliche Arbeit als „Forschungsinfrastruktur“ eine Rolle spielen konnte. Die Rede ist von verbrecherischen Untersuchungen zur Frühdiagnose des Zervixkarzinoms, bei denen die von Hinselmann seit den 1920er-Jahren entwickelte Kolposkopie an weiblichen Häftlingen zum Einsatz kam. Diese Methode machte ihren Inaugurator und über Jahrzehnte letztlich erfolgreichen Vorkämpfer weltberühmt. Inwieweit er in die Versuche im KZ involviert war, ist nicht abschließend geklärt. Unter Fachkollegen hat jedoch seit 2012 eine zunehmende Distanzierung von seiner Person eingesetzt. 505

Hinselmann wurde am 6. August 1884 in Neumünster geboren ( Abb. 28). Nach dem Medizinstudium begann er eine gynäkologische Fachausbildung. Sein wichtigster klinischer Lehrer wurde Otto von Franqué, mit dem er 1912 von Gießen an die Bonner UFK wechselte. Dort fand Hinselmann Mitte der 1920er-Jahre in den Bemühungen um die kolposkopische Frühdiagnose des Zervixkarzinoms das wissenschaftliche Thema seines Lebens - fast ein halbes Jahrhundert vor der Einführung des zytologischen Screenings nach Papanicolaou in Deutschland.

Hinselmanns wissenschaftliche Aktivitäten wurden nicht gebremst, als er 1925 Bonn verließ und die Leitung der gynäkologischen Abteilung am Allgemeinen Krankenhaus sowie ab 1933 auch der Frauenklinik in der Bülowstraße übernahm - beide Häuser im späteren Hamburger Bezirk Altona gelegen. Ab 1930 hatte er, zum Professor ernannt, an der Medizinischen Fakultät der Universität einen regelmäßigen Lehrauftrag zu „Kolposkopie und Frühdiagnose des Uteruscarcinoms“.

Zwischen 1934 und 1937 machten Zwangssterilisationen rund ein Drittel aller Eingriffe in seiner Klinik aus, wobei eine von ihm entwickelte spezielle Methode zur Anwendung kam (Tubensterilisation nach Hinselmann). Der abdominale Eingriff war häufig mit einer Abrasio kombiniert - wobei unklar ist, ob letztere eine möglicherweise bereits bestehende Schwangerschaft be-

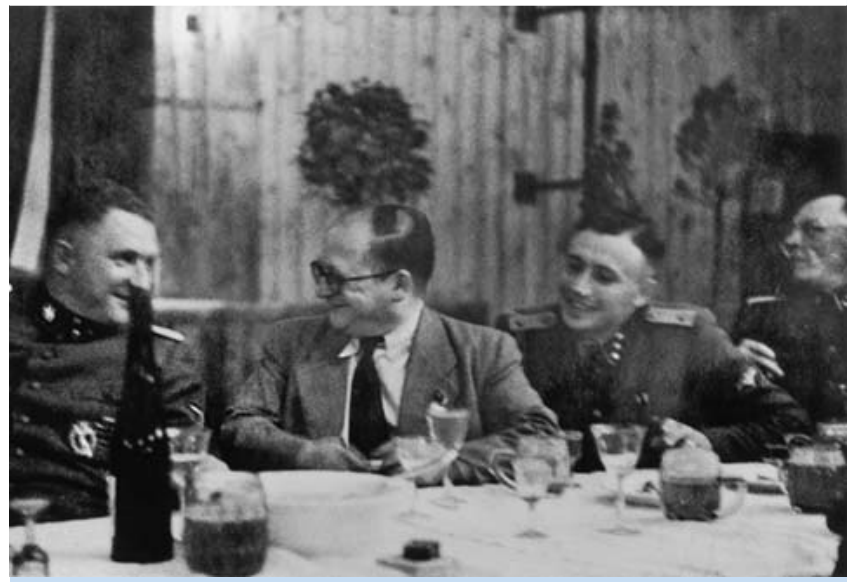

Abb. 27 Carl Clauberg (1898-1957), SS-Arzt in Auschwitz und Ravensbrück. Die Aufnahme zeigt Clauberg (Mitte) bei den Feierlichkeiten zur Eröffnung des neuen SS-Krankenhauses in Auschwitz im September 1944. Zu seiner Rechten sitzt Richard Baer, der letzte Lagerkommandant des KZ Auschwitz, zu seiner Linken dessen Adjutant Karl-Friedrich Höcker (Quelle: United States Holocaust Memorial Museum, Washington, DC).

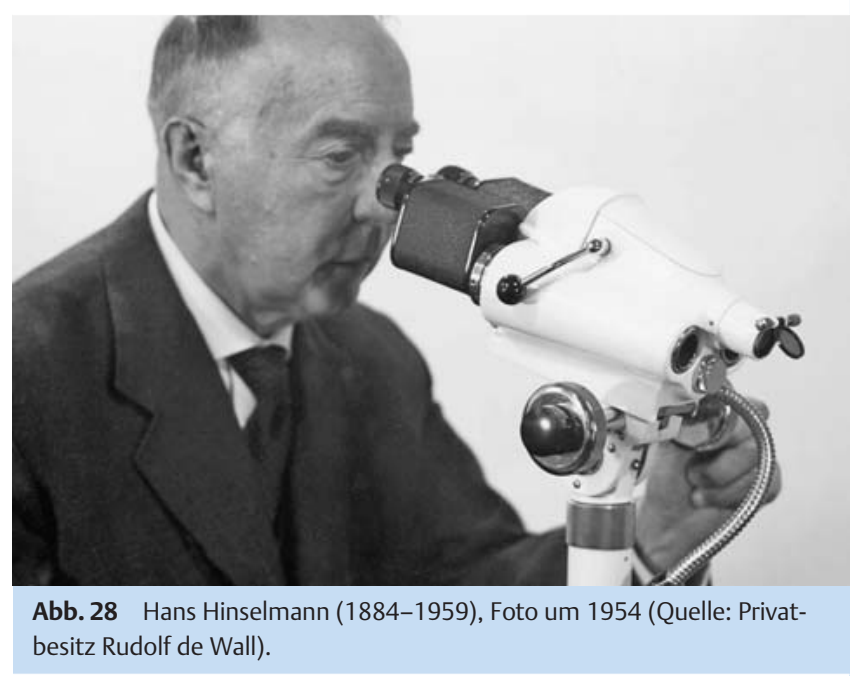

enden sollte oder ob sie illegalen wissenschaftlichen Ziele diente. ${ }^{506}$

Soweit bekannt, kam die Verbindung Hinselmanns mit den Experimenten in Auschwitz über einen seiner Assistenten zustande. Es handelte sich um Helmut Wirths, dessen Bruder Eduard Wirths dort seit 1942 SS-Standortarzt war. ${ }^{507}$ Die beiden Brüder verabredeten eine Zusammenarbeit. Mit Hilfe eines Kolposkops aus der Klinik von Hinselmann wurden dann im berüchtigten Block 10 des KZ Auschwitz an überwiegend jüdischen Frauen zwangsweise Untersuchungen des Gebärmutterhalses vorgenommen. Dabei kam es zu diagnostischen Eingriffen, die nach Zeugenaussagen von der Biopsie bis zur Konisation bzw. Zervixamputation reichten. Das bei den offensichtlich brutal durch-

\footnotetext{
504 Vgl. Grosch: Clauberg (1993).

505 Kühn/Gieseking/Küppers/Lellé/Menton: Hinselmann (2015).

506 Lehmann: Chronik (1995), S. $44 \mathrm{f}$.

507 Hübner: Verbrechen (2015): Hübner: Kolposkopie (2012); Lehmann: Chronik (1995), S. 40-49; Klee: Auschwitz (1997), S. 410-412.
} 


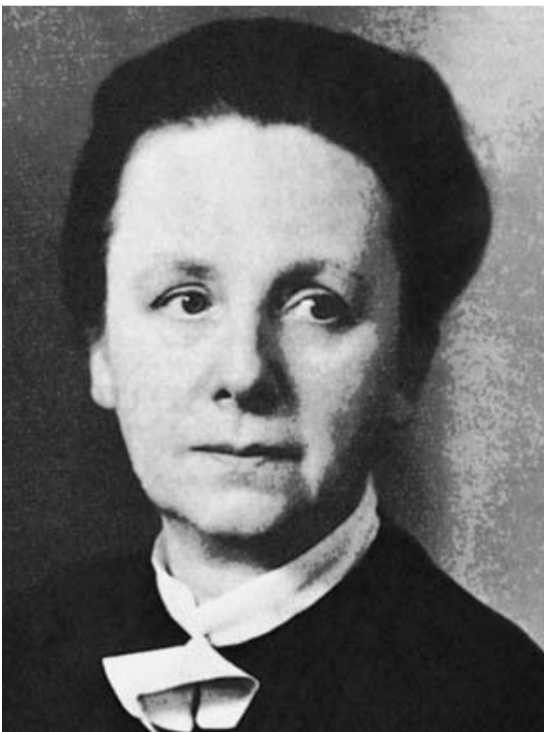

Abb. 29 Die Magdeburger Kinderärztin Marie Elise Kayser (1885-1950), Initiatorin der ersten Frauenmilchsammelstelle in Deutschland, zählte zu den engagiertesten weiblichen Mitgliedern der DGG (aus: Deutsches Ärzteblatt 1969).

geführten, komplikationsreichen Maßnahmen gewonnene Untersuchungsmaterial wurde zusammen mit der Dokumentation der klinischen Befunde nach Hamburg zu Hinselmann geschickt. ${ }^{508}$ Es ist schwer vorstellbar, dass er nichts über dessen Herkunft und die grausamen Umstände seiner Gewinnung wusste. Weitere Nachforschungen sind hier wünschenswert.

\section{Die weiblichen Mitglieder der DGG}

Die einschneidende Satzungsänderung des Jahres 1933 schien bereits beschlossen, als die Frauenärztin Hermine Heusler-Edenhuizen das Wort erbat und der Vorsitzende Walter Stoeckel sich deshalb gezwungen sah, die Annahme der neuen Statuten um 2 Tage zu verschieben. Sicher mit Erleichterung stellte er wenig später fest, dass Heusler-Edenhuizens Einspruch „gar kein Einspruch" ${ }^{509}$ sei und sich nicht etwa auf eine der politisch brisanten Passagen bezog, sondern auf den Paragrafen, der die Aufnahme neuer Mitglieder regelte. Hier, so die Bitte der Ärztin, sollten die Wörter „Arzt“ und „Frauenarzt“ um ihre weiblichen Formen ergänzt werden.

Dass diese, wenn auch unzeitgemäß, so doch vergleichsweise harmlos erscheinende Kritik am generischen Maskulinum durchaus eine politische Note besaß, wird deutlich, wenn man sich die
Situation deutscher Ärztinnen zu diesem Zeitpunkt vor Augen hält.

Wenige Jahrzehnte nach Einführung des Frauenstudiums ${ }^{510}$ gab es um 1930 bereits über 3000 Ärztinnen im Deutschen Reich. Das Bedürfnis, Anerkennung und Gehör zu finden, bewog viele von ihnen dazu, standespolitischen Organisationen und Vereinen beizutreten. ${ }^{511}$

Im untersuchten Zeitraum hatte die DGG, in deren Mitgliederverzeichnis erstmals 19222 Frauen gelistet waren, ${ }^{512}$ insgesamt 26 weibliche Mitglieder, was einem durchschnittlichen Anteil an der Mitgliederschaft von 2,5\% entspricht. ${ }^{513}$ Trotz des vergleichsweise sogar recht hohen Anteils ${ }^{514}$ waren Frauenärztinnen in der Gesellschaft unterrepräsentiert. ${ }^{515}$ Vorstandsämter blieben ihnen auf lange Sicht verwehrt und die Möglichkeit, sich am fachwissenschaftlichen Diskurs zu beteiligen, war für die meist niedergelassenen Ärztinnen ${ }^{516}$ begrenzt. Von rund 590 Vorträgen zwischen 1931 und 1941 wurden nur 7 von Frauen gehalten, davon allein 3 von Marie Elise Kayser, die in Magdeburg die erste Muttermilchsammelstelle eingerichtet hatte und 1937 eine Ausstellung zu diesem Thema präsentierte ( $\bullet$ Abb. 29).

Womöglich um den kaum vorhandenen Gestaltungsspielraum zu kompensieren, wollten die in der DGG organisierten Ärztinnen zumindest auf den Tagungen Präsenz zeigen. 1931 waren 7 von 18 weiblichen Mitgliedern als anwesend markiert, darunter Hertha Riese und Käthe Littauer, die wenige Jahre später wegen ihrer jüdischen Herkunft verfolgt wurden. Vergleichsweise hoch war der weibliche Anteil auch 1937, als mindestens 11 von 21 Ärztinnen am Kongress teilnahmen. Vor diesem Hintergrund erscheint es umso bemerkenswerter, dass im Oktober 1933 offenbar nur 2 weibliche Mitglieder zur Tagung erschienen. ${ }^{517}$ Wie lässt sich die auffallende Absenz erklären?

Die Vermutung, dass ein Zusammenhang mit der wenige Monate zurückliegenden „Machtergreifung“ besteht, ist naheliegend. Emanzipatorische Bestrebungen widersprachen dem misogynen Rollenverständnis der Nationalsozialisten, das Frauen in erster Linie als „passiven, fürsorglichen, mütterlichen“ Gegenpol zum Mann verstand und die Frauenerwerbstätigkeit zu reduzieren suchte. ${ }^{518}$ Darüber hinaus wurden Ärztinnen von ihren männlichen Kollegen in Zeiten der Massenarbeitslosigkeit als unliebsame Konkurrenz aufgefasst und, neben den Juden, für die „Überfüllung“ des Ärztestandes verantwortlich gemacht. ${ }^{519}$ Bereits 1933 führte die Regierung einen Numerus clausus ein, der den

\footnotetext{
508 Lang: Frauen (2013), S. 144-166.

509 Generalversammlung [Verhandlungen 1933] (1934), LIX.

510 Vgl. dazu Birn: Anfänge (2015).

511 Dazu zählten insbesondere der 1924 gegründete Bund deutscher Ärztinnen (BDÄ), in dem zeitweilig die Hälfte aller Ärztinnen organisiert war, aber auch medizinische Fachgesellschaften.

512 Es handelt sich um Gabriele Broer-Lindemann aus Mainz und Klara Schoenhof aus Prag. 1923 nahmen erstmals Frauen an der Tagung teil, 1927 stand der erste Vortrag eines weiblichen Mitglieds (Schoenhof) auf dem Programm.

513 Die meisten praktizierten im Deutschen Reich, je eine wirkte in Finnland, der Tschechoslowakei, Österreich, Jugoslawien und Rumänien. Mit einer Ausnahme waren alle weiblichen Mitglieder der DGG zwischen 1878 und 1902 geboren.

514 Vgl. Kinzelbach: Gesellschaft (2012), S. 21; Goschler: Vereinsmenschen (2000), 43-48.

515 Nur bis zu 20\% aller reichsweit praktizierenden Frauenärztinnen waren in der Gesellschaft organisiert; vgl. Wittern-Sterzel: Frauenärztinnen (2012).

516 Vgl. Bleker: Anerkennung (1994), S. 134.

517 Es handelte sich um Else Riedel (siehe S. 59), die im sächsischen Reichenbach eine Privatklinik leitete und zur Durchführung der Zwangssterilisierung zugelassen war, sowie die eingangs erwähnte Hermine Heusler-Edenhuizen, die allerdings in keinem der offiziellen Mitgliederverzeichnisse erscheint.

518 Vgl. Eckelmann: Ärztinnen (1992), S. 37.

519 Vgl. Schwoch: Standespolitik (2001), S. 263; Eckelmann: Ärztinnen (1992), S. 52.
} 
Anteil der neu eingeschriebenen Studentinnen auf 10\% beschränken sollte. Die Unsicherheit einer Phase, in der Ärztinnen um ihre berufliche Existenz bangen mussten, mag erklären, weshalb viele weibliche Mitglieder von einem Besuch der Tagung im Oktober 1933 absahen. Sie erklärt aber auch, weshalb es Hermine Heusler-Edenhuizen - der ersten in Deutschland offiziell anerkannten Frauenärztin und einer Pionierin des Frauenstudiums ein Bedürfnis gewesen sein muss, die gleichberechtigte Stellung der Ärztin an prominenter Stelle in den Statuten der Gesellschaft zu verankern.

Abhängigkeit und Rechtfertigungsdruck mögen schließlich auch dazu beigetragen haben, dass viele Ärztinnen sich dem Regime bereitwillig andienten. ${ }^{520}$ Offensive Bekenntnisse zur rassenund gesundheitspolitischen Agenda der NS-Regierung verfolgten das Ziel, die Rolle der Ärztin im Nationalsozialismus neu zu definieren und zu legitimieren. ${ }^{521}$ Lotte Kürzel, ab 1936 als Mitglied der DGG gelistet, schrieb 1934 in „Ziel und Weg“, der Verbandszeitschrift des NSDÄB:

„Da ist das Gesetz zur Verhütung erbkranken Nachwuchses, von jeder deutschen Mutter innerlich bejaht, wenn sie das Elend erbkranker Kinder gesehen hat; umso mehr, von der Aerztin, die sich das warmherzige mütterliche Fühlen trotz strenger wissenschaftlicher Schulung wahrte. Hier von Frau zu Frau zu beruhigen - ein Gesetz, das so in anscheinend Allerpersönlichstes eingreift, schreckt ja doch zunächst - aufzuklären, zu belehren, wird oft unsere Aufgabe sein." 522

Das Argument, dass Frauen dank ihrer „natürlichen“ Rolle als helfende und heilende Mutter für die Ausübung des Arztberufes prädestiniert seien, war von der Frauenbewegung schon im 19. Jahrhundert vorgebracht worden, um die Notwendigkeit einer Öffnung der Universitäten für das Frauenstudium zu untermauern. ${ }^{523}$

Ab 1935 verbesserten sich die Bedingungen für Ärztinnen im Deutschen Reich. Mit Rücksicht auf die Kriegsvorbereitungen und eine sinkende Arbeitslosenzahl wurde die Zulassungsbeschränkung zu den Universitäten stillschweigend aufgehoben, später sogar für das Frauenstudium geworben. Zwischen 1932 und 1942 verdreifachte sich die Zahl weiblicher Ärzte, gegen Kriegsende stieg der Anteil der Medizinstudentinnen an den Universitäten auf bis zu 75\%. ${ }^{524}$ Aus den Zahlen geht hervor, dass die Frauenpolitik des NS-Regimes keiner klaren Linie folgte, sondern vielmehr an pragmatischen Erwägungen orientiert war, die ideologischen Verlautbarungen mitunter widersprachen. Spätestens 1937 dürfte sich die Lage auch für die weiblichen Mitglieder der DGG beruhigt haben. Immerhin 7 Frauen traten der Gesellschaft zwischen 1933 und 1937 bei.

\section{„Ausländer" in der DGG \\ $\nabla$}

„Empfangen Sie meinen besten Dank für die große Ehre, daß Sie so gütig waren, mich, den Ausländer, in den Vorstand dieses hohen Vereins zu wählen. Ich halte dies für eine der größten Auszeichnungen meiner ärztlichen Laufbahn. Wir wissen, was wir der deutschen Wissenschaft schuldig sind und kommen mit dankbarem Herzen hierher zum Urquell mit dem Wunsche, möge die deutsche ärztliche Wissenschaft auch weiterhin die Fahnenträgerin der ganzen Welt sein und möge die vielgeprüfte deutsche Nation wieder mächtig und glücklich werden.“525

Als Stephan von Tóth seine Ansprache auf dem Kongress von 1933 beendet hatte, konnte der Vorstand zufrieden sein: der ungarische Gynäkologe ${ }^{526}$ war seiner Funktion als ausländischer Beisitzer und den damit verbundenen Erwartungen offensichtlich gewachsen; als Vertreter der Gesellschaft würde er im Ausland die Fahne der deutschen Gynäkologie hochhalten und dazu beitragen, Sorgen und Vorbehalte abzubauen. Drei Jahre später stellte August Mayer anlässlich einer Reise nach Budapest fest: „Tatsächlich stehen wir [...] auch heute noch in Ungarn hoch im Kurs. “527

Für das Selbstverständnis und die Außendarstellung der DGG spielten ihre internationalen Verbindungen eine nicht zu unterschätzende Rolle. Äußerst zwiespältig ist allerdings das Bild der „Ausländer“ in den überlieferten Quellen: Stehen sie in den Tagungsberichten für Völkerverständigung, Prestige und länderübergreifende Vernetzung, bedeuten sie in den Korrespondenzen des Vorstands fast immer Gefahr: Wie würden die „Ausländer“ auf die „Gleichschaltung“, wie auf den Ausschluss jüdischer Mitglieder reagieren? Würden sie die Diskussion über die eugenische Sterilisation durch kritische Argumente sabotieren? Und sollte man nicht den Mitgliedsbeitrag senken, um „valutaschwache“ Ausländer nicht zu vergraulen? Beinahe jedes Thema, das die DGG in der Zeit des Nationalsozialismus umtrieb, war elementar mit den „ausländischen“ Mitgliedern verknüpft; stets waren sie die Kraft, mit der man rechnen musste, und ihre - vermutete - Reaktion galt in allen Fragen als gewichtiges Argument.

Gegen Ende des 19. Jahrhunderts hatte die länderübergreifende Zusammenarbeit von Wissenschaftlern einen gewaltigen Aufschwung erfahren. Bedingt und begünstigt wurde das „goldene Zeitalter des Internationalismus“ 528 durch die Institutionalisierung und infrastrukturelle Erleichterung der Kommunikation, vor allem aber durch das, gerade in den Naturwissenschaften, gestiegene Bedürfnis nach einem Austausch über Tendenzen und Erkenntnisse der internationalen Forschung. ${ }^{529}$ Wohl nicht zuletzt aus diesem Grund hatte schon Franz von Winckel, der erste

\footnotetext{
520 Der männlich dominierten NSDAP traten Frauen zwar nur selten bei, rund $21 \%$ aller Ärztinnen waren allerdings im Bund deutscher Mädel organisiert; die DGG-Mitglieder Erna Orlopp-Pleick und Irma Krauß übernahmen das Amt einer BDM-Ärztin, das als „Sprungbrett für die weitere berufliche Karriere“ gesehen wurde; vgl. Gamper: Pflicht (2006), S. 20.

521 Vgl. Eckelmann: Ärztinnen (1992), S. 47-50

522 Kürzel: Aerztin (1934), S. 209 f.

523 Vgl. Brinkschulte: Einführung (2006).

524 Vgl. Bleker: Anerkennung (1994), S. 126.

525 Generalversammlung [Verhandlungen 1933] (1934), LII.

526 Biografische Eckdaten in Frigyesi: Tóth [Nachruf] (1936).

527 UAT 150/33,41: Mayer an den Rektor der Universität Tübingen (13.12.1935); Anlass der Reise war die Beerdigung von Tóths.

528 Metzler: Deutschland (2010), S. 57.

529 Vgl. Metzler: Deutschland (2010), S. 57-59.
} 


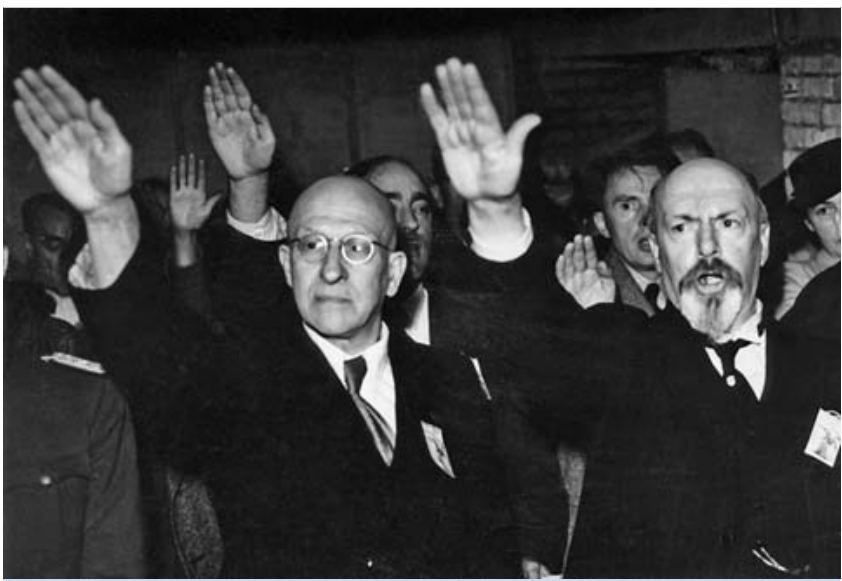

Abb. 30 Der Genter Professor Frans Daels (1882-1974; mit Brille, links vorne), Beisitzer der DGG 1935-1937, zeigt bei einer Wallfahrt zu Ehren der flämischen Gefallenen des Ersten Weltkriegs (IJzerbedevaart) in Diksmuide (Westflandern/Belgien) den Hitlergruß. Foto von 1941 (Quelle: Nationaal Archief, Den Haag).

Präsident der DGG, einen intensiven Kontakt mit dem Ausland gesucht. ${ }^{530}$

Der Ausbruch des Ersten Weltkriegs markierte das vorläufige Ende des Internationalismus; noch lange nach Kriegsende war Deutschland wissenschaftlich isoliert. Die Nachwehen des „Boykotts“ klingen in der Eröffnungsansprache der DGG-Tagung von 1923 an, als Carl Menge in der Anwesenheit einiger „uns treu gebliebener Freunde aus dem Auslande" ein Zeichen erkannte, dass „die Freundschaft kein lehrer [sic] Wahn ist, und daß die deutsche Wissenschaft noch immer in Vorkriegswährung steht" ${ }^{531}$ Erschienen waren freilich vor allem Mitglieder aus ehemals verbündeten oder neutralen Nationen. Noch 1931 würdigte Ludwig Seitz die Kongressteilnehmer aus „uns ehedem feindlichen Staaten“ - gemeint waren offenbar 2 belgische Ärzte -, was nur bedeuten könne, „daß der bisherige Bann gebrochen ist“. 532

Um Aussagen wie diese im historischen Kontext bewerten zu können, muss betont werden, dass Wissenschaftsbeziehungen in der ersten Hälfte des 20. Jahrhunderts in einem Spannungsverhältnis zwischen internationalistischem Ethos und vaterländischer Orientierung standen. Als „Quelle nationalen Prestiges“ besaß die „Ersatzmacht“ Wissenschaft ${ }^{533}$ einen ausgeprägt kompetitiven Charakter und reagierte zugleich - im Sinne eines Ressourcentauschs - auf Ansprüche der deutschen (Außen-)Politik. ${ }^{534}$ Gerade der Reputationsverlust des „Wissenschaftsstand- orts“ Deutschland im Zuge des Ersten Weltkriegs führte in den Nachkriegsjahren, vor allem jedoch ab 1933, zu einem trotzigen Beharren auf dem Narrativ der „Weltgeltung deutscher Wissenschaft" ${ }^{335}$, das durch internationale Kontakte gestützt werden sollte.

\section{Zahl und Verteilung der „ausländischen“ Mitglieder}

Wer waren die in den Korrespondenzen des Vorstands meist pauschal als „Ausländer“ bezeichneten Mitglieder? Die implizite Begriffsbestimmung war denkbar einfach: Gemeint waren alle Ärzte, deren Wirkungsort außerhalb der Grenzen des Deutschen Reiches lag. Zwischen 1931 und 1937 traf dieses Kriterium auf mindestens 280 Ärztinnen und Ärzte aus über 30 Ländern zu, womit die „Ausländer“, bei insgesamt sinkender Gesamtzahl, recht konstant ein Viertel aller Mitglieder ausmachten. ${ }^{536}$

Die meisten „ausländischen“ Mitglieder, insgesamt 76, wirkten in Österreich, am zweitstärksten war Ungarn mit etwa 40 Personen vertreten, noch vor der Schweiz mit rund 30 Personen. Über die Hälfte der ausländischen Mitglieder kam aus diesen 3 Ländern, deren Vertreter auch die Hälfte der 75 Vorträge bestritten, die zwischen 1933 und 1941 von „ausländischen“ Mitgliedern - ausnahmslos in deutscher Sprache - gehalten wurden. Deutlich kleinere, aber immer noch relativ starke „Fraktionen“ gaben als Wirkungsort die Tschechoslowakei, die Niederlande, Schweden, Finnland, die USA, Lettland, Jugoslawien, Dänemark und Rumänien an. Andere (west-)europäische Länder, darunter die ehemaligen Kriegsgegner Frankreich, Italien und Großbritannien, waren nur marginal oder gar nicht vertreten. ${ }^{537}$

Herkunft, Nationalität und Muttersprache spielten bei der Unterscheidung zwischen deutschen und ausländischen Mitgliedern keine Rolle; ein Großteil der sogenannten Ausländer kam aus deutschsprachigen oder ehemals deutschen bzw. österreichischen Gebieten, galt als „auslandsdeutsch“ oder hatte deutsche Wurzeln. Wenngleich sich manche von ihnen, zumal in den nach 1918 „gewaltsam abgetrennten Gebieten“, als Deutsche gefühlt haben mögen, wurden sie - entgegen zeittypischer „Heim ins Reich“-Rhetorik - offiziell als „Ausländer“ geführt, solange sie in dieser „Funktion“ für die Internationalität der Gesellschaft bürgten. ${ }^{538}$

\section{Die Rolle der „Ausländer“ 1933-1945}

„Mögen Sie von unserer Tagung ein richtiges Bild des neuen Deutschland in ihre Heimat mitnehmen und dazu beitragen, daß die Zerrbilder der Verleumdung zerrissen werden.“539 Es waren wenig subtile Worte, mit denen Walter Stoeckel die 1933 in Berlin erschienenen „Mitglieder und Freunde“ aus dem Ausland be-

\footnotetext{
530 Vgl. Ludwig: Gründung (2005), S. 930; Verhandlungen (1886), S. 5. Bereits 1911 lag der Anteil „ausländischer“ Mitglieder bei 27\%.

531 Menge: Eröffnung [Verhandlungen 1923] (1924), XXXIV.

532 Seitz: [Eröffnungsansprache, Verhandlungen 1931] (1931), XLVI.

533 Dazu Paul Zweifel auf dem Kongress von 1920: „Wenn uns auch alle Kolonien genommen worden sind, hier ist uns Neuland zu finden gestattet, das uns kein äußerer Feind rauben kann“; Zweifel: [Schlusswort, Verhandlungen 1920] (1921), S. 180.

534 Vgl. Metzler: Deutschland (2010), S. 55. Metzler: Wissenschaft (2000), S. 25.

535 Vgl. Paletschek: Weltgeltung (2010); Metzler: Deutschland (2010), S. 70.

536 Zum Vergleich: Die Gesellschaft Deutscher Neurologen und Psychiater und die Deutsche Ophthalmologische Gesellschaft hatten Mitte der 1930er-Jahre, bei vergleichbarer Mitgliederzahl, „Ausländeranteile“ von 17,5\% bzw. 30\%; vgl. Schmuhl: Neurologen (2016), S. 136; Rohrbach: Augenheilkunde (2007), S. 121 .

537 Andere Gesellschaften bieten ein ähnliches Bild; für die Anatomische Gesellschaft vgl. Winkelmann: Gesellschaft (2012), S. 245.

538 Lediglich G. A. Wagner, selbst „,ehemaliger Auslandsdeutscher“, hob die Ausländer „deutschen Stammes, die uns als blutsverwandt so nahe stehen“ in seiner Eröffnungsansprache eigens hervor; vgl. Wagner: Eröffnungs-Ansprache [Verhandlungen 1937] (1938), S. 1.

539 Stoeckel: Eröffnungs-Ansprache [Verhandlungen 1933] (1934), XLII. Mayer und Wagner äußerten sich auf den folgenden Tagungen mit ganz ähnlichen Worten.
} 
grüßte. Die DGG-Kongresse der NS-Zeit boten demnach nicht nur eine willkommene Gelegenheit, die „Weltgeltung“ deutscher Wissenschaft zu postulieren; 540 sie dienten auch dem Zweck, das Ansehen des nationalsozialistischen Staates im Ausland zu fördern und das in der internationalen Presse verbreitete Bild Stichwort: „Greuelpropaganda“ - im Sinne der Machthaber zu korrigieren. Die Begrüßung der Ausländer und die Aufzählung ihrer Herkunftsländer - Mayer notierte 1935: „Ja keinen vergessen“541 - nahm stets einen prominenten Platz in den Eröffnungsansprachen ein. Befriedigt bemerkte Stoeckel in seiner nach Kriegsende verfassten Autobiografie, dass die Rede von 1933 auch bei den ausländischen Gästen Beifall gefunden habe und zitierte stolz aus deren Danksagungen. ${ }^{542}$

Unangenehm bemerkbar machte sich 1933 allein das Fernbleiben der österreichischen „Fraktion“, der die Einreise ins Reich verweigert worden war. ${ }^{543}$ Nicht zuletzt aus diesem Grund wurden in Berlin nur 29 „ausländische“ Kongressbesucher erfasst statt der üblichen 50 bis 75. Da es dem „Ansehen der Deutschen Gesellschaft [...] nur nützen“ könne, „wenn der Kongress durch das Ausland möglichst stark besucht wird“, setzte sich Mayer 2 Jahre später persönlich beim Ministerialdirektor dafür ein, den Österreichern die Teilnahme zu erleichtern. ${ }^{544}$ Nachdem sich die politische Lage infolge des 1936 geschlossenen Juliabkommens zwischen Österreich und dem Deutschen Reich normalisiert hatte, konnten 1937 wieder 50 ausländische Tagungsteilnehmer, darunter mindestens 10 Österreicher, gezählt werden.

Über die Zahl der Ausländer, die noch 1941, im dritten Kriegsjahr, den Kongress in Wien besuchten, liegen keine Aufzeichnungen vor. ${ }^{545}$ Hans Fuchs versäumte es jedenfalls nicht, die „Fachkameraden aus dem Auslande, die uns teils waffenbrüderlich, teils freundschaftlich verbunden sind“ willkommen zu heißen. ${ }^{546}$

Dass die Zahl der „ausländischen“ Mitglieder, die in 6 Jahren von 218 auf 187 gefallen war, bis 1945 weiter zurückging, ist allerdings aus mehreren Gründen plausibel: 47 ehemals „ausländische“ Mitglieder wurden seit dem „Anschluss“ Österreichs und der „Zerschlagung der Rest-Tschechei“ als Deutsche gezählt oder aus rassischen Gründen verfolgt, 70 weitere Mitglieder, darunter ebenfalls mehrere „Juden“, erlebten nach 1939 die Besetzung ihrer Heimat durch die Wehrmacht.
Das hohe Maß an Sensibilität, das der Vorstand der DGG im Umgang mit ausländischen Mitgliedern an den Tag legte, dürfte - gerade in der Frühphase des Regimes - ganz im Sinne der nationalsozialistischen Führung gewesen sein, die in Zeiten politischer und wirtschaftlicher Konsolidierung bestrebt war, einer Isolation des Deutschen Reiches vorzubeugen. Das vom Geist der nationalsozialistischen Revolution getragene Plädoyer des fanatischen Antisemiten Arnulf Streck für ein „rigoroses“ Vorgehen gegen die „Ausländer“547 - gemeint war vermutlich der Ausschluss aller „Ausländer“ oder zumindest aller ausländischen Mitglieder jüdischer Herkunft - ging an der Realität vorbei und blieb ohne Resonanz. Zwar hatte sich um 1935 offenbar auch Reichsärzteführer Wagner in ähnlicher Weise geäußert, ${ }^{548}$ vieles spricht jedoch dafür, dass dem internationalen Ansehen der Gesellschaft unter keinen Umständen geschadet werden sollte. Von anderen Gesellschaften ist bekannt, dass die Aufnahme ausländischer Mitglieder und die Einladung internationaler Referenten - beides unterlag freilich einer strengen Kontrolle - den Wünschen und Empfehlungen des Reichsgesundheitsamtes und des Reichsinnenministeriums entsprachen, insbesondere wenn damit eine „Stärkung des Deutschtums“ im Ausland einherging. ${ }^{549}$ Dass sich die DGG nach 1933 um die Werbung internationaler Mitglieder bemühte, geht aus den Quellen hervor; 550 ein Drittel der im untersuchten Zeitraum neu aufgenommenen Mitglieder wirkte im Ausland. Als Richtlinie des Reichsgesundheitsamtes galt ab 1937, dass Ausländer in wissenschaftliche Gesellschaften aufgenommen werden können, „sofern sie als deutschfreundlich bekannt sind und vom engeren Vorstand ausdrücklich vorgeschlagen werden“. „Nichtarische“ Ausländer besaßen vorläufig noch die Möglichkeit, als außerordentliche Mitglieder aufgenommen zu werden. 551

Bereits 1933 hatte Conti dem Vorstand der DGG bestätigt, dass gegen „die Einreise und das Sprechen ausländischer Juden in wissenschaftlichen Sitzungen“ keine Bedenken bestünden. ${ }^{552}$ Zwar hoffte Mayer im Vorfeld seines Kongresses 1935, dass sich „nicht allzuviele Nicht-Arier zu Vorträgen melden“ - „denn das erleichtert uns die Sache nicht“553 - und versuchte zudem, nach Möglichkeit keine Ausländer jüdischer Herkunft in die Gesellschaft aufzunehmen; ${ }^{554}$ ein offizielles Sprechverbot oder gar die Einforderung eines „Ariernachweises“ standen jedoch offenbar nicht zur Debatte. Dass die Gesellschaft gut daran tat, zeigt eine Episode aus dem Jahr 1939. Als der 1928 erstmals erschienene Gynäkologenkalender, ein biografisch-bibliografisches Verzeichnis

\footnotetext{
540 Vgl. z. B. Wagner: Eröffnungs-Ansprache [Verhandlungen 1937] (1938), S. 3: „Die große Zahl der erschienenen ausländischen Fachgenossen ist uns ein stolzer Beweis, dass nach wie vor die deutsche Wissenschaft in der ganzen Welt Geltung hat und Achtung genießt.“

541 UAT 150/33,41: Besprechung (17.08.1935).

542 Vgl. Stoeckel: Erinnerungen (1966), S. 393.

543 Siehe S. 62.

544 Mayer an den Rektor der Universität Tübingen (23.07.1935); Mayer an den Ministerialdirektor (02.09.1935).

545 Laut Fuchs waren Vertreter aus 16 Nationen erschienen; vgl. Fuchs: Eröffnungs-Ansprache [Verhandlungen 1941] (1942), S. 1.

546 Fuchs: Eröffnungs-Ansprache [Verhandlungen 1941] (1942), S. 1. Unter den Teilnehmern befanden sich auch Mitglieder aus neutralen Ländern wie der Schweiz und Schweden.

547 BSB München, Nachlässe Ana 691, Mayer an Martius.

548 UAT 150/33,41: Gegenstände der letzten Vorstandssitzung und eigene Beobachtungen.

549 Vgl. UAT 150/33,41: Mayer an das Akademische Rektoramt Tübingen (11.05.1935) in der Angelegenheit Knaus („zuverlässiger Träger des Deutschtums in Prag“). Vgl. Jahnke-Nückles: Kinderheilkunde (1992), S. 87 f.

550 Vgl. UAT 150/33,41: Besprechung (17.08.1935).

551 „Richtlinien hinsichtlich der Aufnahme von jüdischen und ausländischen Mitgliedern“, zit. n. Schmuhl: Neurologen (2016), S. 148.

552 Zit. n. Stoeckel: Erinnerungen (1966), S. 391.

553 UAT 150/33,41: Mayer an Stoeckel (01.06.1935).

554 BSB München, Nachlässe, Ana 691; 150/33,41, Mayer an Stoeckel (11.10.1935).
} 
deutscher bzw. deutschsprachiger Frauenärzte, unter anderem mit Mitteln der DGG ${ }^{55}$ neu aufgelegt werden sollte, entbrannte ein Konflikt mit den Deutschschweizer Ärzten, da der Fragebogen, mit dem ihre Daten erfasst werden sollten, ein Bekenntnis zur „reinarischen“ Abstammung verlangte. Die Schweizer Ärzte verwahrten sich gegen diese untragbare Bedingung und baten den Berner Ordinarius Hans Guggisberg um eine Kontaktaufnahme mit Walter Stoeckel, der als Herausgeber des Gynäkologenkalenders firmierte. Stoeckels Antwort fiel unverblümt eindeutig aus: „Wir wollen [...] keine Juden aufnehmen - auch keine Juden, die in der Schweiz leben, und haben deshalb von vorneherein die Fragebogen nur an solche Kollegen geschickt, die wir für arisch halten." Daraufhin verzichtete die Deutschschweizer Gesellschaft auf eine Aufnahme ihrer Mitglieder - ob „jüdisch“ oder nicht - in das Verzeichnis. ${ }^{556}$

Ein derart unangenehmer Zwischenfall blieb der DGG, auch in späteren Jahren, erspart. Die „Entjudung“ der Gesellschaft vollzog sich langsam, geräuschlos und ohne explizite Druckausübung. Von mindestens 38 „ausländischen“ Mitgliedern, die im Sinne der nationalsozialistischen Rassenideologie als Juden oder Halbjuden galten, schieden die meisten bis 1937 „freiwillig“ aus.

Als zweite, sogar noch größere Belastungsprobe für die internationalen Beziehungen wurde vom Vorstand das für 1935 geplante Referat über die eugenische Sterilisation wahrgenommen - und das nicht ohne Grund. Schon 1933 hatte sich der deutsch-österreichische Gynäkologe Albert Niedermeyer auf der Tagung gegen das GzVeN ausgesprochen. In seiner Autobiografie vermutete er, dass es „nur der Anwesenheit zahlreicher ausländischer Gäste [...], auf die man Wert legte“ zu verdanken war, „daß meine Verhaftung unterblieb“. ${ }^{557}$ Ein niederländischer Frauenarzt, der ebenfalls am Kongress teilgenommen hatte, griff den Vorfall für einen Artikel im „Roomsch katoliek Artsenblad“ auf und berichtete unter der Überschrift „Een krachtig Verweer“ („Eine kraftvolle Verteidigung“) über Niedermeyers Versuch, die Sterilisation abzuwehren. ${ }^{558}$

Zwei Jahre später stand nun die Befürchtung im Raum, dass „inund ausländische Gegner des Gesetzes von einer großen Mortalität sprechen und das Gesetz in Misskredit bringen“. ${ }^{559}$ Man erwog, die Diskussion zu unterbinden oder das Referat, „aus Scheu vor einer unerwünschten Kritik seitens des Auslandes“, 560 ganz abzusetzen, befürchtete aber, dass internationale Besucher auch darauf „argwöhnisch“ reagieren würden, „als ob man etwas zu verbergen hätte“. 561

Nachdem, wie an anderer Stelle beschrieben, ${ }^{562}$ alles glimpflich verlaufen war, verlieh Mayer seiner Erleichterung und Genugtuung Ausdruck: „Zu meiner besonderen Befriedigung hatten mir die Ausländer ihre größte Zufriedenheit mit allen Teilen des Kongresses teils mündlich teils schriftlich ausgesprochen." So habe man nicht nur die Gegner des Gesetzes „entwaffnet“, sondern auch „dem Ansehen der Deutschen Wissenschaft im Ausland [handschriftliche Ergänzung: das uns sonst ja so gerne angreift] einen wertvollen Dienst geleistet". 563 Aufmerksam nahm der Vorstand die positive internationale Resonanz zur Kenntnis und leitete sie zur „publizistischen Auswertung“ an die Kongresszentrale weiter. ${ }^{564}$

Trotz aller Lobeshymnen blieben kritische Stimmen nicht aus. Das Ausland, mahnte Mayer in einem Schreiben von 1935, empfinde „den politischen Einfluss auf wissenschaftliche Kongresse als unangenehm“. Von 2 Schweizer Mitgliedern ist bekannt, dass sie der DGG aus diesem Grund den Rücken kehrten: der Berner Frauenarzt K.G. Rudolf von Fellenberg „aus Protest gegen unsere Gleichschaltung“, Walter (?) Bigler aus St. Gallen aus „persönlichen Gründen“ und „weltanschaulicher Haltung“. 565

\section{„Ausländer" im Vorstand und als Ehrenmitglieder}

Angesichts des Unbehagens, das ausländische Mitglieder im Hinblick auf die Politisierung der Gesellschaft empfanden, sah sich Mayer 1935 zu der Frage veranlasst, ob man Ausländer überhaupt „im Vorstand haben wolle, so lange wir noch immer wieder innerdeutsche Angelegenheiten zu verhandeln haben“. ${ }^{566} \mathrm{Re}-$ lativ schnell herrschte jedoch Einigkeit darüber, dass unter den Beisitzern auch künftig „das Ausland vertreten“ sein solle; 567 der Vorstand entschied sogar, die Zahl der Beisitzer von 4 auf 6, später sogar auf bis zu 11, zu erhöhen, um „das Ausland auch genügend berücksichtigen zu können“" ${ }^{568}$ Kriterien für die Auswahl der ausländischen Beisitzer waren ihre „politische Zuverlässigkeit“ - sie mussten, wie der als loyal eingeschätzte Stephan von Tóth, „deutschfreundlich“ $\operatorname{sein}^{569}$ - und, gerade nach den Erfahrungen von 1935, eine Übereinstimmung in Leitfragen der Erbgesundheitspolitik. Die meisten hatten sich, wie der bereits erwähnte Guggisberg, für eugenisch begründete Sterilisationen ausgesprochen $^{570}$ oder waren durch eine stramm rechtskonservative Haltung aufgefallen. So besetzte der flämische Nationalist Frans Daels ab 1940 eine leitende Position im Flämischen Natio-

\footnotetext{
555 Beschlossen auf der Mitgliederversammlung [Verhandlungen 1937] (1938), S. 21.

556 Vgl. Ehrler: „Arier“ (1978).

557 Niedermeyer: Wahn (1956), S. 279. Vgl. S. 42 f. dieser Arbeit.

558 Ebd.

559 UAT 150/33,41: Protokoll einer Besprechung (26.07.1935). Die Schuld dafür suchte Mayer bezeichnenderweise bei „unseren Emigranten“, die im Ausland Lügen über das GzVeN verbreiten würden; vgl. UAT 150/33,41: Mayer an Albrecht (05.08.1935).

560 UAT 150/33,41: Mayer an das REM (23.12.1935).

561 UAT $150 / 33,41$.

562 Siehe S. $46 \mathrm{f}$.

563 UAT 150/33,41: Mayer an Wagner (21.12.1935).

564 UAT 150/33,41: Wirz an Mayer (08.01.1936).

565 UAT 150/33,41: Mayer an Stoeckel (01.06.1935).

566 UAT 150/33,41: Mayer an Stoeckel (11.10.1935).

567 UAT 150/33,41: Manuskript zur Vorstandsitzung (22.10.1935).

568 UAT 150/33,41: Gegenstände der letzten Vorstandssitzung und eigene Beobachtungen.

569 Vgl. Schmuhl: Neurologen (2016), S. 148. Bei der Entscheidung für den Hermannstädter Frauenarzt Fritz Süssmann spielte wohl auch die Stärkung des „Siebenbürger Deutschtum[s]“ eine Rolle; vgl. UAT 150/33,41: Gegenstände der letzten Vorstandssitzung und eigene Betrachtungen.

570 Vgl. Ziegler: Frauen (1999), S. 295 f.
} 
nalverband (Vlaams Nationaal Verbond), der mit den deutschen Besatzern kollaborierte ( $\bullet$ Abb. $\mathbf{3 0})$.

Auf den Tagungen von 1935 und 1937 wurden insgesamt 5 ausländische Mitglieder zu Ehrenmitgliedern gewählt, sodass nunmehr 10 von 32 Ehrenmitgliedern im Ausland wirkten. Die Geehrten waren Elis Essen-Möller aus Lund, Emilio Alfieri aus Mailand, Ernst Gaifami aus Rom, Sir Comyns Berkeley aus London und der gebürtige Deutsche Hermann J. Boldt aus New York City. ${ }^{571}$ Als erstes korrespondierendes Mitglied wurde zudem 1937 der Argentinier Josué Beruti in die Gesellschaft aufgenommen.

Keines der neuen Ehrenmitglieder hatte in den 10 Jahren zuvor auf einer Tagung der DGG gesprochen; Alfieri, Berkeley und Gaifami tauchen 1937, dem Jahr ihrer Ehrung, erstmals im Mitgliederverzeichnis auf, nahmen jedoch offenbar nicht an der Tagung teil. Essen-Möller, laut Mayer „ein eifriger, überall geschätzter Besucher unserer Kongresse“ ${ }^{\text {“572, war }} 1923$ immerhin Beisitzer gewesen. Wichtiger als die wissenschaftliche Leistung oder das Engagement für die Gesellschaft scheint auch bei der Wahl internationaler Ehrenmitglieder das Anliegen gewesen zu sein, das Ausland in Gestalt „geeigneter“ Persönlichkeiten zu würdigen. Die Kriterien „Deutschenfreundlichkeit“ und „Linientreue“ treffen auf den Hitler-Sympathisanten Boldt ${ }^{573}$ ebenso zu wie auf EssenMöller, der die Sterilisation als Alternative zur teuren Anstaltsunterbringung empfahl, ${ }^{574}$ sowie Beruti, der sich in einem Vortrag über Eugenik und ideale Mutterschaft auf Goebbels bezog. ${ }^{575}$

\section{Internationale Beziehungen nach 1945}

Wie schon nach dem Ersten Weltkrieg war die deutsche Wissenschaft nach der bedingungslosen Kapitulation des 8. Mai 1945 weitgehend isoliert. „Bei einem Versuch, die Deutsche Gesellschaft zu neuem Leben zu erwecken“, konstatierte Eduard Martin 1946, „kann naturgemäss von einer Berücksichtigung der nichtdeutschen früheren Mitglieder keine Rede sein“. ${ }^{576}$ Tatsächlich blieben die 1941 in den Vorstand gewählten „Ausländer“ dem ersten Nachkriegskongress 1949 in Karlsruhe fern. Dies hinderte den Vorsitzenden, Rudolf Theodor von Jaschke, nicht daran, auch nach der zweiten vernichtenden Niederlage innerhalb von 30 Jahren am Topos der „Weltgeltung“ festzuhalten: Dass Deutschland „in der Wissenschaft und ärztlichen Kunst um 1 1 J Jahrzehnte zurückgeblieben wäre“, sei unzutreffend; die Tagung „möge der Welt zeigen“, dass man „trotz aller Schwierigkeiten und Nöte das hohe Niveau von einst zu halten imstande“ sei. ${ }^{577}$ Als Kronzeugen ungebrochener Reputation dienten - einmal mehr - die ausländischen Kollegen, die in nicht überlieferter Zahl erschienen waren. Zwei Jahre später wurden in Bad Pyrmont bereits 100 Personen aus 15 Nationen gezählt. In seinem Schlusswort würdigte August Mayer den „ungewöhnlich starken Kongreß- besuch durch das Ausland“ als „eine wichtige Vorarbeit zu der so nötigen Wiederannäherung der Völker“ und fügte nicht unbescheiden hinzu: „Mir scheint [...], wir haben auch einen Schritt vorwärts getan auf dem Weg zu ,Pan-Europa und unser Kongreß ist bereits ein in diese Richtung weisender aufgehender Stern." ${ }^{578}$ Das neue Zeitalter des Internationalismus, so schien es, hatte begonnen.

\section{Die „missliebigen“ Mitglieder der DGG \\ $\nabla$}

„Revolutionszeiten [...] sind Gebärzeiten - hart, schwer, erschütternd und schmerzerfüllt" - dies war das Motto, unter das Walter Stoeckel auf dem DGG-Kongress im Oktober 1933 seine Ausführungen zur politischen Lage stellte. ${ }^{579}$ Bei der „unbeirrbaren Verfolgung großer politischer Zukunftsziele“ müsse die NS-Führung „unerbittliche Härte“ zeigen und „vieles, was dauerhaft schien“ ohne Rücksicht zerschlagen - auch „alte Bindungen und Arbeitsgemeinschaften“. Mit „dem festen Blick auf Deutschlands national-völkische Gestaltung“ gehe die Bewegung „schicksalhaft über Einzelschicksale hinweg“.

„Wir bedauern“, räumte Stoeckel ein, „dass diese Entwicklung auch Kollegen schwer getroffen hat, deren Persönlichkeit wir hoch schätzen und deren wissenschaftliche Leistungen wir hoch bewerten. Wir können ihr Geschick nicht wenden; sie sind die beklagenswerten Opfer einer Härte geworden, die für die Gesundung des deutschen Volkes notwendig geworden war“.

„Ich hoffe und ich erwarte“, fügte der Vorsitzende hinzu, „daß mit dieser Erklärung die Einstellung der Deutschen Gesellschaft für Gynäkologie richtig und klar genug wiederzugeben ist, und daß sie genügt, um unsere Verhandlungen bei einer für sie selbst wünschenswerten Zurückhaltung der Betroffenen reibungslos ablaufen zu lassen“.

Es sollte, wie sich zeigen wird, das einzige Mal bleiben, dass ein Vertreter der Gesellschaft öffentlich zur Verdrängung „missliebiger" Ärzte Stellung bezog. Wer aber waren die Mitglieder, denen Stoeckel auf so unmissverständliche Weise zu verstehen gab, dass sie in der Gesellschaft von nun an unerwünscht waren?

„Missliebig“ konnte eine Person in den Augen der Nationalsozialisten aus vielen Gründen sein: aufgrund ihrer Abstammung, ihrer politischen Einstellung oder ihrer sexuellen Orientierung, nicht zuletzt infolge einer kritischen oder ablehnenden Haltung zum Nationalsozialismus. In erster Linie bezog sich Stoeckel aber auf all jene Mitglieder, die ab 1933 als „Nichtarier“, „Juden“ oder „Mischlinge“ galten und aufgrund dieser Zuschreibung entrech-

\footnotetext{
571 Um 1944 wurde darüber hinaus die Verleihung der Ehrenmitgliedschaft an Victor Cònill, Barcelona, beschlossen. Der Finne Seth Edvin Wichmann starb vor der geplanten Ehrung; vgl. die Kurzbiografien im Anhang.

572 Generalversammlung [Verhandlungen 1935] (1936), S. 16.

${ }^{573}$ Vgl. Stamper: Vision (2007), S. 13 f.; The Evening Independent (13.01.1943). Als Auszeichnung für seine Ernennung zum Ehrenmitglied habe Boldt aus dem Außenministerium eine signierte Fotografie des „Führers“ erhalten.

574 Vgl. Barow: Volksheim (2009), S. 64; bei Barow auch Hintergründe zur Eugenik-Debatte in Schweden.

575 Vgl. Guy: Women (2009), S. 127. Zum Einfluss der deutschen Erbgesundheitslehre auf die argentinische Ärzteschaft vgl. Reggiani: Medicina (2005).

576 BSB München, Nachlässe, Ana 691, Martin an Martius (1946).

577 Jaschke: Eröffnungs-Ansprache [Verhandlungen 1949] (1950), S. 3,7.

578 Mayer: [Schlusswort] (1951), S. 349.

579 Vgl., auch für die folgenden Zitate, Stoeckel: Eröffnungs-Ansprache [Verhandlungen 1933] (1934), XLI-XLII.
} 


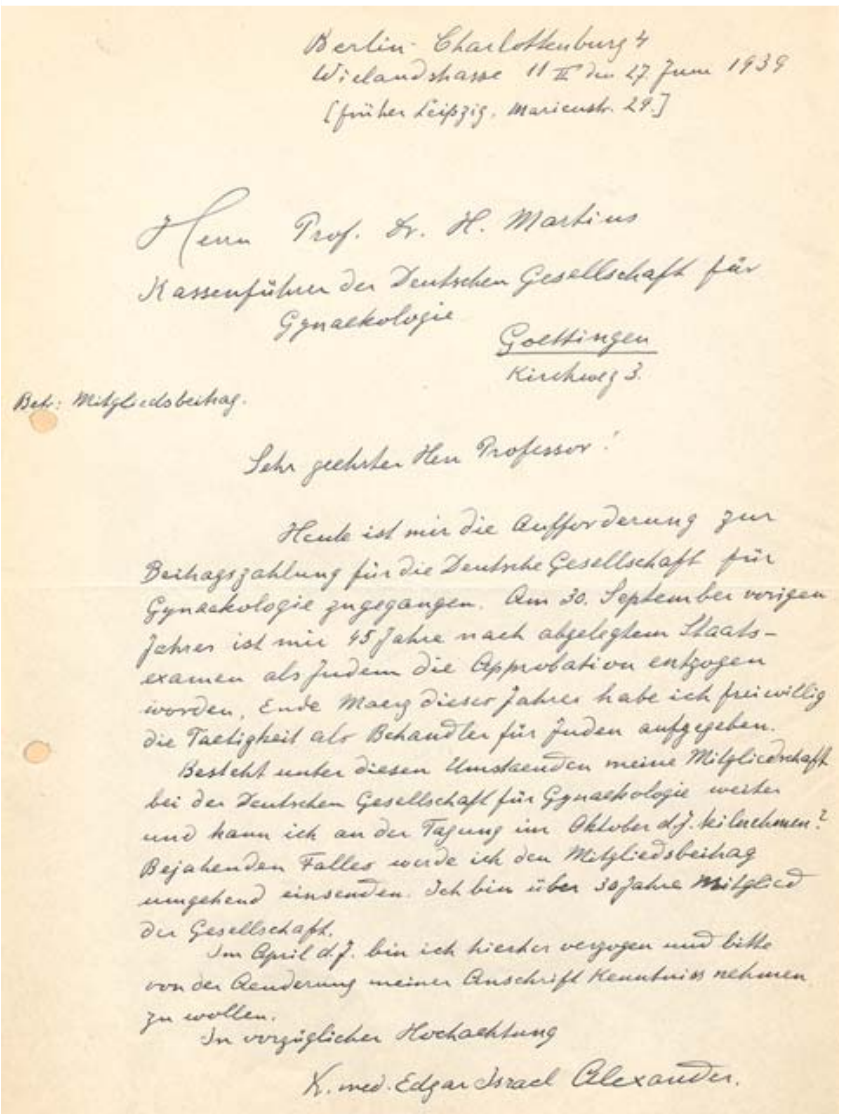

Abb. 31 Schreiben des als jüdisch geltenden Leipziger Frauenarztes Edgar Alexander (1868-1942, Theresienstadt) an Heinrich Martius, den Kassenwart der DGG (Quelle: Bayerische Staatsbibliothek München).

tet, vertrieben und ermordet wurden. ${ }^{580}$ Sie stellen - auch innerhalb der DGG - die zahlenmäßig größte und am besten fassbare Opfergruppe des Nationalsozialismus dar.

Vor dem Hintergrund der Stoeckel-Rede überraschend erscheint der Befund, dass noch im Dezember 1937 knapp 40 „Nichtarier“ (etwa 5\% der Mitglieder) im Mitgliederverzeichnis der Gesellschaft gelistet waren. Beim Blick auf andere medizinische Fachgesellschaften wird allerdings deutlich, dass es sich mitnichten um einen Sonderfall handelt: So verzeichneten die Gesellschaft Deutscher Neurologen und Psychiater und die Deutsche Gesellschaft für Kinderheilkunde zur selben Zeit ähnlich viele jüdische Mitglieder. ${ }^{581}$

Eines der verbliebenen jüdischen Mitglieder der DGG, der Leipziger Frauenarzt Edgar Alexander, wandte sich am 27. Juni 1939 in einem handschriftlichen Brief an Heinrich Martius, Ordinarius in Göttingen und Kassenwart der Gesellschaft ( Abb. 31):
„Sehr geehrter Herr Professor!

Heute ist mir die Aufforderung zur Beitragszahlung für die Deutsche Gesellschaft für Gynaekologie zugegangen. Am 30. September vorigen Jahres ist mir 45 Jahre nach abgelegtem Staatsexamen als Juden die Approbation entzogen worden, Ende Maerz dieses Jahres habe ich freiwillig die Taetigkeit als Behandler für Juden aufgegeben.

Besteht unter diesen Umstaenden meine Mitgliedschaft bei der Deutschen Gesellschaft für Gynaekologie weiter und kann ich an der Tagung im Oktober d.J. teilnehmen?

Bejahenden Falles werde ich den Mitgliedsbeitrag umgehend einsenden. Ich bin über 30 Jahre Mitglied der Gesellschaft.“582

Unterzeichnet ist der Brief mit „Dr. med. Edgar Israel Alexander“ - seit Januar 1939 waren alle Juden gezwungen, einen stigmatisierenden Zweitnamen zu tragen.

Glaubte Edgar Alexander tatsächlich, dass dem Vorstand der DGG an seiner Mitgliedschaft gelegen sein könnte, dass man ihn gar zu einer Tagungsteilnahme ermuntern würde? Oder wollte er vielmehr die Vertreter der Gesellschaft in die unangenehme Lage bringen, schriftlich zu seinem Fall Stellung beziehen zu müssen? Immerhin schienen seitens des Vorstands keine Bedenken zu bestehen, den Mitgliedsbeitrag in Höhe von 20 Reichsmark einzufordern.

Ob Edgar Alexander eine Antwort erhielt, ist nicht bekannt. Sein bemerkenswertes Schreiben - 5 Jahre nach Stoeckels Rede verfasst - wirft jedoch ein bezeichnendes Licht auf den Umgang der DGG mit jüdischen Mitgliedern und offenbart eine wechselhafte, an Sachzwängen orientierte „Judenpolitik“, wie sie für die Anfangsjahre des Nationalsozialismus kennzeichnend ist. ${ }^{583}$

\section{Die Situation jüdischer Ärzte im Deutschen Reich vor 1933}

Die Entkopplung des „Jüdischseins“ von der Religionszugehörigkeit erschwert es, die Zahl der im Deutschen Reich rassisch verfolgten Personen auch nur einigermaßen exakt zu erfassen. Einer Volkszählung vom 16.Juni 1933 zufolge rechneten sich etwa 500000 Staatsangehörige - weniger als 1\% der Gesamtbevölkerung - der jüdischen Religionsgemeinschaft zu. ${ }^{584}$ Aus dem etwa zur selben Zeit erstellten Reichsarztregister geht hervor, dass von rund 50000 Ärzten im Deutschen Reich 6500 (13\%) der jüdischen Glaubensgemeinschaft angehörten. ${ }^{585}$ Nicht erfasst wurden in beiden Fällen Personen, die zum Christentum konvertiert waren, sich nicht als jüdisch identifizierten oder das Land bereits verlassen hatten. Schätzungen gehen daher von etwa 9000 Ärztinnen und Ärzten (rund 17\% der deutschen Ärzteschaft) aus, die ab 1933 als Juden galten. ${ }^{586}$ Gerade mit Blick auf die große

\footnotetext{
580 Maßgeblich für die Unterscheidung zwischen „Ariern“ (bzw. „Deutschen“) und „Juden“ waren weder das religiöse Bekenntnis noch der Grad der kulturellen „Assimilation“, sondern ausschließlich rassenideologisch definierte Kriterien. Im Folgenden ist der Begriff „Jude“ daher stets vor dem Hintergrund der nationalsozialistischen Definition und unabhängig vom Verhältnis der Person zum Judentum zu verstehen.

581 GDNP: 49 im Jahr 1937; vgl. Schmuhl: Neurologen (2016), S. 148; DgfK: 57 im Jahr 1938; vgl. Jahnke-Nückles: Kinderheilkunde (1992), S. 77.

582 BSB München, Nachlässe Ana 691, Alexander an Martius (27.06.1939).

583 Vgl. Longerich: Judenverfolgung (2006), S. 55, 67; Hoffmann: Verfolgung (1997), S. 386.

584 Vgl. Benz (Hrsg.): Dimensionen (1991), S. 23.

585 Vgl. Schwoch: Standespolitik (2001), S. 248-251, 257.

586 Vgl. Schwoch: Standespolitik (2001), S. 255-262; Kümmel: Ausschaltung (1985), S. 62.
} 
Zahl niedergelassener jüdischer Ärzte, darunter auffallend viele Fachärzte, muss betont werden, wie maßgeblich deren Anteil an der Sicherstellung der ärztlichen Versorgung war. Dies gilt insbesondere für Städte wie Berlin, Frankfurt am Main und Breslau, in denen zu Beginn der 1930er-Jahre ein beträchtlicher Teil der Ärzteschaft jüdischer Herkunft war.

Auch an den Universitäten waren jüdische Hochschullehrer um 1930 relativ stark vertreten. Ihre Chancen auf eine wissenschaftliche Karriere erwiesen sich allerdings auch 60 Jahre nach der gesetzlichen Gleichstellung als vergleichsweise gering; ein Ordinariat konnten nur wenige ungetaufte Wissenschaftler erlangen. Nicht zuletzt aus diesem Grund strebten die meisten Medizinabsolventen jüdischer Herkunft eine selbstständige Tätigkeit an. ${ }^{587}$

Dass der Anteil jüdischer Ärzte an der Gesamtärzteschaft verhältnismäßig groß war, hatte traditionelle und historische Gründe: Der Arztberuf war eine Profession, die Juden seit Längerem ohne Einschränkung offenstand und als „Eintrittsbillet in die bürgerliche Gesellschaft“ gesellschaftliche Integration und sozialen Aufstieg versprach. ${ }^{588}$ Lange vor 1933 bot die empfundene Dominanz jüdischer Ärzte allerdings Anlass für Neid und Missgunst, antisemitische Angriffe und Ressentiments, die im konservativ/ deutsch-national geprägten Ärztestand gerade vor dem Hintergrund unsicherer beruflicher Perspektiven und politischer Krisen auf fruchtbaren Boden fielen. ${ }^{589}$

\section{Die jüdischen Mitglieder der DGG}

Am 1. Juli 1931 hatte die DGG mindestens 170 Mitglieder jüdischer Herkunft. Dass keine genaue Zahl genannt werden kann, liegt daran, dass im Reichsmedizinalkalender (RMK) 1937, dem zuverlässigsten Hilfsmittel zur Identifizierung als jüdisch geltender Ärztinnen und Ärzte - ihre Namen sind mit einem Doppelpunkt gekennzeichnet ( Abb. 32) -, keine Personen erfasst sind, die 1936 bereits verstorben waren, nicht mehr als Arzt praktizierten, das Land verlassen hatten oder bereits vor 1933 im Ausland lebten. Von den deutschen Mitgliedern der DGG, die nach 1933 rassisch verfolgt wurden, ist im RMK 1937 nur die Hälfte verzeichnet. In über 100 Fällen konnten Mitglieder durch Nachrufe in ausländischen Zeitungen, Adress- und Telefonbücher, Online-Genealogien, Einwohnerkarteien, Entschädigungs- und Wiedergutmachungsakten oder Hinweise in der Sekundärliteratur als Opfer rassischer Verfolgung identifiziert werden. Lediglich bei 22 von rund 770 deutschen Mitgliedern kann über Herkunft und Lebensweg nach 1933 keine gesicherte Aussage getroffen werden.

Zur Abstammung von Personen, deren Heimatländer nicht der nationalsozialistischen Gesetzgebung unterworfen waren, liegen nur in wenigen Fällen zuverlässige Informationen vor. Obwohl

\section{Hermesweg 3}

Jonas o, Charlotte, geb. Winckler-Krämer 34, 〜W35, Admiral-v.-Schröder-Str. 19

: Jonas, willy 09, S $\sim \mathrm{W}$ 62, Lützowplatz 4

Jona $\beta$ q, Margarete, 0 112, Frankfurter Allee 67

: JonaB O, Richard 84, SR, Schöneb., Goltzstr. 27

Jordan, Heinz 36, HilfsA, Lichterf., Unter den Eichen $44 / 46$

: Joseph, Alfred 23, 国, $\sim \mathrm{W}$ 50, Pariser Str. 1

: Joseph, Karl 96, Charl. 5, Windscheidstr. 38

: Joseph, Siegbert 19, D正, $\sim$ NW 87 , Brückenallee 36

: Josephsohn, John 95, SR, SW 29, Bergmannstr. 31
Abb. 32 In der 1937 erschienenen Auflage des Reichsmedizinalkalenders wurden die als jüdisch geltenden Ärztinnen und Ärzte -

hier u. a. die Berliner DGG-Mitglieder Willy Jonas (1884-1984, London) und Siegbert Joseph (1894-1944, Ghetto Libau?) - mit einem Doppelpunkt markiert (Quelle: Universitätsbibliothek Erlangen).

daher bei der Erfassung jüdischer Mitglieder aus dem Ausland keine Vollständigkeit beansprucht werden kann, werden sie im Folgenden mit berücksichtigt, da sie durch ihre Mitgliedschaft in einer deutschen Fachgesellschaft mit der antisemitischen Ideologie in Berührung kamen. ${ }^{590}$

Legt man die Minimalzahl von 170 jüdischen Mitgliedern zugrunde, ergibt sich für das Jahr 1931 ein beachtlicher Anteil von beinahe $20 \%$ an der Mitgliederschaft. ${ }^{591}$ Nicht alle waren von der Machtübernahme der Nationalsozialisten zur gleichen Zeit und in gleichem Ausmaß betroffen: Fast ein Viertel der identifizierten Personen lebte und wirkte im Ausland: 24 in Wien (von insgesamt 41 Wiener DGG-Mitgliedern), 5 in der Tschechoslowakei, jeweils bis zu 3 in den Vereinigten Staaten, in Ungarn, in der Schweiz und in Schweden.

Unmittelbar nach der Machtübernahme der Nationalsozialisten waren rund 125 im Deutschen Reich lebende Mitglieder von rassisch motivierter Diskriminierung betroffen. Sie verteilten sich im Wesentlichen auf die Großstädte Berlin, Breslau, Frankfurt am Main, Köln, München, Leipzig und Nürnberg, in denen große jüdische Gemeinden existierten. Eine besondere Rolle kommt der Reichshauptstadt zu: Hier wohnte ein Drittel aller im Reich lebenden Juden, die Hälfte aller in Berlin praktizierenden Ärzte war jüdischer Herkunft. ${ }^{592}$ Dieser Umstand spiegelt sich im Mitgliederverzeichnis der DGG wider: Von 113 Berliner Gynäkologen, die 1931 Mitglied der Gesellschaft waren, galten 2 Jahre später 47 als „Nichtarier“. Ähnlich hoch war der Anteil nur unter den Frankfurter, den Breslauer und den Wiener Mitgliedern.

\footnotetext{
587 Vgl. Rudloff/Ludwig: Gynecologists (2005), S. 246; Beddies/Baader sprechen in diesem Zusammenhang von einer „Unvollendetheit“ jüdischer Ärzte; vgl. Beddies/Baader: Ärzte (2014), S. 17. Auch in Österreich endeten universitäre Karrieren „gewöhnlich beim Berufstitel eines ao. Professors“; vgl. Angetter/ Kanzler: Eltern (2014), S. 59.

588 Vgl. Lässig: Bürgertum (2004), S. 596-614.

589 Zunehmender Konkurrenzdruck, miserable Einstellungschancen und niedrige Einkommen hatten insbesondere den ärztlichen Nachwuchs in eine äußerst prekäre Lage gebracht. Die Weltwirtschaftskrise ab 1929 verschlimmerte die Situation noch einmal erheblich; vgl. Damskis: Biografien (2009), S. 27; Beddies/Baader: Ärzte (2014), S. 28.

590 Siehe S. $71 \mathrm{f}$

591 Zum Vergleich: In der DGfK galten etwa 30\% der Mitglieder als Juden; vgl. Jahnke-Nückles: Kinderheilkunde (1992), S. 64; Seidler: Kinderärzte (2007), S. 21.

592 Vgl. dazu Schwoch (Hrsg.): Kassenärzte (2009), S. 21-23.
} 


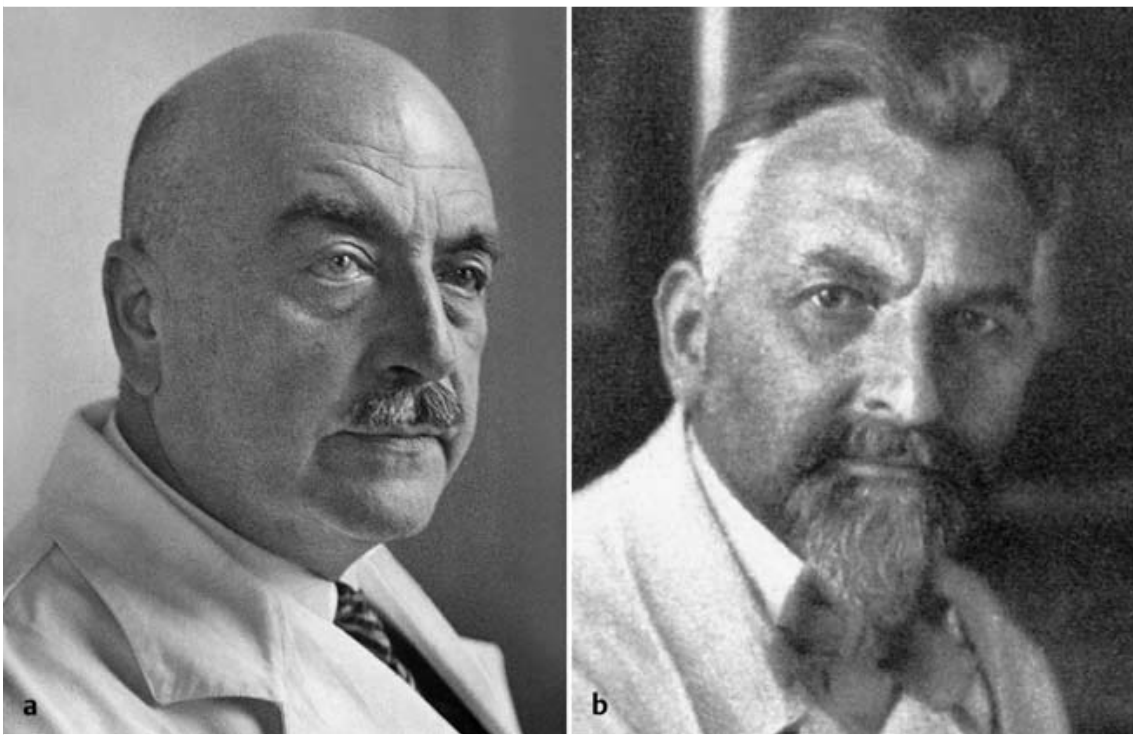

Abb. 33a und b a Sigfrid Hammerschlag (18711948) (Quelle: Ullstein Bild) und b Ludwig Fraenkel (1870-1951) (aus: Archiv für Gynäkologie 1930) wurden 1933 ihrer jüdischen Herkunft wegen zum Rücktritt aus dem DGG-Vorstand gedrängt.

Über 70\% der rund 125 deutschen Mitglieder jüdischer Herkunft praktizierten als niedergelassene Ärzte oder leiteten eine Privatklinik, knapp 20\% waren als (außerordentliche) Professoren oder Privatdozenten an Universitäten - abermals vor allem in Berlin, Breslau, Frankfurt und München - beschäftigt.

Insgesamt waren schätzungsweise 35-40\% aller im Nationalsozialismus als jüdisch geltenden deutschen Gynäkologen in der DGG organisiert. ${ }^{593}$ Zu einer Zeit, da Vereine und Fachgesellschaften dem aufstrebenden jüdischen Bürgertum als „Integrationsbrücken“ dienten, ${ }^{594}$ schien die 1886 auf Initiative des jüdischen Gynäkologen Wilhelm Alexander Freund ${ }^{595}$ gegründete DGG ein Musterbeispiel gelungener Integration zu sein. Seit den frühen 1920er-Jahren hatte die Zahl der Ärzte und Wissenschaftler jüdischer Herkunft, die sich aktiv am Gesellschaftsleben beteiligten und die wissenschaftlichen Sitzungen mit Vorträgen bereicherten, kontinuierlich zugenommen. Viele der ab 1933 verfolgten Ärzte hatten kaum einen Kongress versäumt. 1931 waren in Frankfurt am Main, bei 365 gezählten Kongressteilnehmern, über 60 Personen anwesend, die sich nur wenige Jahre später ihrer existenziellen Grundlage beraubt sahen. Unter ihnen waren namhafte Forscher, die mit insgesamt rund 20 Vorträgen - hervorzuheben sind die Referate von Max Hirsch, Ludwig Fraenkel, Selmar Aschheim und Bernhard Zondek - maßgeblich zum Gelingen der Tagung beitrugen. ${ }^{596}$

\section{Zum Umgang der DGG mit ihren jüdischen Mitgliedern}

Wie andere Vereine und Verbände stand die DGG nach der „Machtergreifung“ vor dem Problem, wie mit den als nichtarisch definierten Mitgliedern zu verfahren sei, die teils zu den, auch international, bekanntesten und angesehensten Vertretern ihres Faches zählten. Wenngleich die „Revolutionszeit“ von Walter Stoeckel auf dem Kongress von 1933 emphatisch begrüßt wurde, machte sich im Vorstand eine gewisse Ratlosigkeit breit, wann immer es um die Frage der jüdischen Mitglieder ging, zumal man in den ersten Jahren der nationalsozialistischen Diktatur höchstens eine ungefähre Vorstellung von der Zahl der „Betroffenen“ gehabt haben dürfte. Stoeckel verstand die Situation als „Ansporn“, wie er nach Kriegsende in seinen Memoiren mitteilte: „Dieses Mal [1933] mußten wir zeigen, was wir allein konnten ohne Juden und ohne Ausland! "597

Als vergleichsweise unproblematisch erwies sich die im März 1933 unter anderem vom Ärztevereinsbund geforderte „Säuberung“ des Vorstandes. ${ }^{598}$ Stoeckel formuliert es folgendermaßen: „Zwei sehr angesehene jüdische Vorstandsmitglieder, die Gynäkologen [Sigfrid] Hammerschlag, Berlin, und [Ludwig] Fraenkel, Breslau, erklärten freiwillig ihren Rücktritt. Das erleichterte unsere Verhandlungen mit der Regierung. “599 Auf der im Tagungsband abgedruckten Einladung sind die Namen der beiden Ärzte noch genannt ( $\triangle$ Abb. 33a und b) ${ }^{600}$ Hammerschlag emigrierte wenig später nach Persien. Fraenkel, der noch 1931 als künftiger Vorsitzender der Gesellschaft gehandelt worden war, 601 ging als Berater der Regierung von Uruguay nach Montevideo. Am 2. April

\footnotetext{
593 Als Grundlage der Schätzung dient eine Statistik von 1934, der das rassische Kriterium zugrunde liegt und die von 274 jüdischen Frauenärzten ausgeht; vgl. Hadrich: Ärzte (1934), S. 1245.

594 Heinz-Peter Schmiedebach, zitiert nach Villiez: Wegbereiter (o.J.), S. 14

595 Im Jahr 1878 war Freund der erste Jude, der in ein gynäkologisches Ordinariat berufen wurde; vgl. Ebert: Freund (2007), S. 55.

596 Siehe auch S. $52 \mathrm{f}$.

597 Stoeckel: Leben (1954), S. 118.

598 Kurz nachdem sich der Deutsche Ärztevereinsbund und der Hartmannbund der Führung Dr. Gerhard Wagners, Präsident des NSDÄB, unterstellt hatten, erging am 25. März 1933 die Aufforderung, „,beschleunigt dafür Sorge zu tragen, dass aus Vorständen und Ausschüssen die jüdischen Mitglieder ausscheiden und Kollegen, die sich innerlich der Neuordnung nicht anschliessen können, ersetzt werden“; vgl. Doetz/Kopke: Kampagnen (2014), S. 39.

599 Vgl. Stoeckel: Erinnerungen (1966), S. 391.

600 Einladung, in: Arch Gyn 156 (1934), XXXVII-XXXIX.

601 Vgl. Rudloff/Ludwig: Gynecologists (2005), S. 248
} 
1933 konnte Reichsärzteführer Wagner verkünden, dass alle jüdischen und marxistischen Ärzte aus den führenden Positionen der Spitzenverbände und Fachgesellschaften entfernt worden seien. ${ }^{602}$

Völlig anders gestaltete sich die Situation hinsichtlich der übrigen jüdischen Mitglieder. Da diesbezüglich zunächst keine Direktiven der Regierung und der Verbände existierten, vollzog sich die „Säuberung“ standespolitischer Gesellschaften und Vereine auf unterschiedliche Weise. Vorauseilendem Gehorsam und dem Bedürfnis, „dem Führer entgegenzuarbeiten“, 603 standen Unentschlossenheit, abwartender Pragmatismus und die Suche nach „einfachen Lösungen“ gegenüber. ${ }^{604}$

Im Unterschied zu anderen Gesellschaften nahm die DGG keinen „Arierparagraphen“ in ihre Satzung auf, der Juden eine Mitgliedschaft prinzipiell untersagt hätte. ${ }^{605}$ Dass nach Möglichkeit keine Juden als Neuzugänge aufgenommen werden sollten, verstand sich freilich von selbst. Da für die DGG ansonsten kaum aufschlussreiche Quellen vorliegen, soll ein diachroner Vergleich der überlieferten Mitgliederverzeichnisse als erster Anhaltspunkt für die Verdrängung missliebiger Ärzte aus der Gesellschaft dienen.

Die überwiegende Mehrheit der jüdischen Mitglieder - rund 75\% - verschwand bereits vor 1938 aus den Mitgliederlisten. Nur in wenigen Fällen ist bekannt, ob es sich um einen Austritt aus eigener Initiative oder um eine Streichung durch den Vorstand - womöglich gegen den Willen und ohne das Wissen der betroffenen Person - handelte. Von Freiwilligkeit kann in keinem Fall die Rede sein. Gesichert ist, dass, abzüglich der Todesfälle, rund 50 Mitglieder jüdischer Herkunft bereits im Dezember 1933 nicht mehr verzeichnet waren, obwohl die meisten von ihnen vorerst in Deutschland blieben. Von 15 Mitgliedern, die das Land bereits verlassen hatten, finden sich nur Hans Schlossmann und Marcel Traugott noch in der Liste, für Wilhelm Gustav Liepmann ist eine Istanbuler Adresse angegeben. Wie viele der übrigen Emigrierten zu den 14 Mitgliedern zählten, die auf dem Kongress im Oktober als „unbekannt verzogen“ bilanziert wurden, ${ }^{606}$ lässt sich nicht sagen.

Unter den vor Dezember 1933 Ausgeschiedenen waren außerdem 15 ausländische Mitglieder, darunter 11 österreichische und tschechoslowakische Ärzte, die zwar im nationalsozialistischen Sinne als Juden galten, von den antisemitischen Maßnah- men der Regierung aber zunächst nicht unmittelbar betroffen waren und die Gesellschaft womöglich aus Protest verließen.

Als Stoeckel auf der Tagung im Oktober 1933 auf die „beklagenswerten Opfer" der nationalen Erhebung zu sprechen kam, saßen laut Mitgliederverzeichnis mindestens 8 Ärzte im Publikum, die sich angesprochen fühlen konnten. Hans Sänger, der von 2 jüdischen Großeltern abstammte, hielt zum Referat „Eingriffe aus eugenischer Indikation“ noch einen Vortrag über die „Zuverlässigkeit der Tubensterilisation nach Madlener“, in dem er empfahl, „eingreifendere Maßnahmen nur für alleinige Sterilisation bei gutem körperlichem Zustand geistig Minderwertiger oder sonst wie Belasteter zu reservieren““ ${ }^{607}$ Nur einen Monat später wurde er aus dem bayerischen Staatsdienst entlassen und emigrierte kurz darauf nach Norwegen. ${ }^{608}$

Eine auffallende Diskrepanz besteht zwischen der Zahl der im Mitgliederverzeichnis vom 15. Dezember 1933 erfassten Personen (755) und der von Stoeckel am 11. Oktober 1933 verkündeten offiziellen Mitgliederzahl (860). Wahrscheinlich ist, dass eine größere Zahl von Austritten jüdischer Mitglieder erst in den letzten Wochen des Jahres erfolgte - womöglich unter dem Eindruck der Stoeckel-Rede, die ein Eintreten der Gesellschaft für ihre bedrängten Mitglieder als illusorisch erscheinen ließ.

Zwei Jahre später, im Oktober 1935, konnte der Vertreter des Reichsärzteführers, Arnulf Streck, zufrieden von der erstmalig „judenfreien“ Tagung sprechen. ${ }^{609}$ Ob die Aussage zutreffend ist, lässt sich nicht überprüfen, da gerade in diesem Jahr auf eine Dokumentation der Anwesenheit verzichtet wurde. Eine Notiz Mayers könnte darauf hindeuten, dass man den jüdischen Mitgliedern im Vorfeld der Tagung empfohlen hatte, „nicht zu kommen“. 610 Nikolaus Čukor, ein Kurarzt aus dem damals noch tschechoslowakischen Franzensbad (Františkovy Lázně), der zum Referat „Klima-, Licht- und Bäderbehandlung“ über „Methoden und Erfolge der Balneotherapie“ sprach, war vermutlich das letzte Mitglied jüdischer Herkunft, das während der NS-Zeit auf einer Tagung der DGG das Wort ergriff. Im Januar 1939, wenige Monate nach dem „Anschluss“ des Sudetenlandes, erschien Čukors Name auf einer im Hetzblatt „Der Stürmer“ gedruckten Liste „ehemaliger Judenärzte“ aus Franzensbad. ${ }^{611}$

Im Mitgliederverzeichnis des Jahres 1937 sind noch 4 Personen als anwesend gekennzeichnet, die zwar mehrheitlich als „nicht vollarisch“ galten, seit 1936 aber nicht mehr zu den ,jüdischen Ärzten“ gezählt wurden. ${ }^{612}$ Dennoch hatten sie aufgrund ihrer

602 Vgl. Ärztliche Mitteilungen 34 (1933), S. 309-312.

603 Vgl. Kershaw: Hitler (1998), S. 663 f.

604 Einen Überblick über den Umgang von Standesorganisationen und Fachgesellschaften mit ihren jüdischen Mitgliedern bieten Doetz/Kopke: Kampagnen (2014), S. 47-50.

605 Explizit ausgeschlossen wurde die Mitgliedschaft von Juden beispielsweise von der Deutschen Gesellschaft für Zahn-, Mund- und Kieferheilkunde; vgl. Kinzelbach: Gesellschaft (2012), S. 20. Auch aus dem Deutschen Verband für psychische Hygiene mussten 1933 alle jüdischen Mitglieder ausscheiden; vgl. Doetz/Kopke: Kampagnen (2014), S. 49. Rechtsmediziner und Urologen behalfen sich mit der Neugründung rein „arischer“ Gesellschaften; vgl. Herber: Gerichtsmedizin (2002), S. 209; Krischl/Moll/Fangerau: Urologie (2011).

606 Generalversammlung [Verhandlungen 1933] (1934), XLVIII. Ausführlich zu Liepmann: Ebert/Namal (2010): Vertreibung.

607 Saenger: Zuverlässigkeit [Verhandlungen 1933] (1934), S. 159.

608 Vgl. Dross: „Juden“ (2012), S. $101 \mathrm{f}$.

609 Streck: [Grußwort, Verhandlungen 1935] (1936), S. 11

610 UAT 150/33,41.

611 Stürmer 01/1939. Der Verfasser dankt Dr. Ulrike Zischka für die Auskünfte. Zum „Stürmer“ siehe auch S. 82 f.

612 Vgl. Schwoch: Standespolitik (2001), S.318. „Vierteljuden“ und „Halbjuden“, die nicht der jüdischen Religionsgemeinschaft angehörten und in einer „Mischehe“ lebten, wurden ab 1936 zu den „deutschen“ Ärzten gezählt. 
Abstammung berufliche Einschränkungen und persönliche Demütigungen zu erleiden:613 Der in Halle praktizierende Frauenarzt Bernhard von Lippmann wurde wegen eines jüdischen Großvaters Opfer einer Erpressung, ${ }^{614}$ Hans Hermann Schmid musste nach der Besetzung Prags aus dem Lehrkörper der Deutschen Universität ausscheiden, da er „Halbjude“ sei, ${ }^{615}$ der ebenfalls als „Halbjude“ geltende Mannheimer Klinikdirektor Isaak Kurt Laemmle beschwerte sich bei Reichsinnenminister Frick über einen ungerechtfertigten Boykottaufruf gegen seine Praxis, da er nach den „Nürnberger Rassegesetzen“ nicht mehr zu den jüdischen Ärzten gezählt werde. ${ }^{616}$ Jacob Moritz Blumberg, Frauenarzt aus Berlin, emigrierte 1939 nach London. ${ }^{617}$

Wie bereits erwähnt, wurden noch im Dezember 1937 knapp 40 „Nichtarier“ als Mitglieder der Gesellschaft geführt, darunter 8 Ärzte aus Wien und der Tschechoslowakei. Bei Erich Fels, Wilhelm Gustav Liepmann, Marcel Traugott und Erwin Straßmann, die vor 1937 ins Ausland geflohen waren, sind Anschriften in Buenos Aires, Istanbul, Zürich und Rochester (Minnesota) angegeben. Die Zahl der in der Gesellschaft verbliebenen Juden belegt, dass der Vorstand der DGG darauf verzichtete, die „nichtarischen“ Mitglieder geschlossen aus dem Mitgliederverzeichnis zu streichen und wohl auch keinen „freiwilligen“ Austritt nahe legte. Womöglich schreckte man davor zurück, den Mitgliederstand, der ohnehin auf den niedrigsten Stand seit 1923 gefallen war, noch mehr zu reduzieren und durch rigorose Maßnahmen weitere Austritte, vor allem ausländischer Ärzte, zu provozieren. ${ }^{618}$ Von Gesellschaften, die ähnlich verfuhren, ist bekannt, wie sehr man sich der Gefahr internationaler Proteste und der Auswirkung eines starken Mitgliederschwunds auf die finanzielle Stabilität der Gesellschaft bewusst war. ${ }^{619}$ Eine rigorose damnatio memoriae erschien daher, nicht zuletzt aus pragmatischen Gründen, als kontraproduktiv; 620 so ließ der Vorstand im Tagungsbericht 1935 die Porträts der Vorsitzenden jüdischer Herkunft drucken und gedachte bis 1941 fast aller verstorbenen jüdischen Mitglieder.

Gestrichen wurde ein Mitglied in der Regel nur dann, wenn es selbst die Initiative übernahm oder die Streichung laut Satzung vorgesehen war. Dies betraf insbesondere säumige Zahler: Die meisten Emigrierten ließen ihre Mitgliedschaft durch Einstellung der Beitragszahlungen auslaufen; Zondek, Hammerschlag und andere wurden nach zweimaliger Mahnung aus der Liste entfernt. ${ }^{621}$ Die finanzielle Notlage, in die jüdische Ärzte durch ihre Entlassung oder die Einschränkung ihrer beruflichen Tätigkeit gedrängt wurden, dürfte die sukzessive „Säuberung“ der Fachgesellschaften beschleunigt haben. Andere Mitglieder kehrten der Gesellschaft aus Enttäuschung über das Verhalten ihrer Kollegen oder als Zeichen solidarischen Protests den Rücken. ${ }^{622}$ So hatten die meisten österreichischen Juden die DGG bereits vor Beginn des Jahres 1938 verlassen oder die Beitragszahlung eingestellt. Stoeckel kommentierte dies lakonisch: „Ich nehme an, dass viele von diesen nichts mehr von uns wissen wollen. Diese muss man nun streichen, wenn sie trotz Aufforderung nicht bezahlen."623 Darüber hinaus wurde der Vorstand in der Regel nicht aktiv. Einzig im Fall des Berliner Gynäkologen Wilhelm Gustav Liepmann ist eine Anfrage G.A. Wagners bei der Berliner Ärztekammer überliefert, „ob nicht vielleicht gegen ihn politisch oder moralisch irgendetwas vorliegt, was seinen Ausschluss aus der Gesellschaft rechtfertigen könnte, auch wenn er seinen Mitgliedsbeitrag gezahlt hat"“ ${ }^{624}$

Davon abgesehen verlief die „Arisierung“ der Gesellschaft nahezu geräuschlos und in scheinbar „geordneten Bahnen“, der befürchtete Eklat blieb aus. Mit keinem Wort sollte auf den Tagungen auf das Schicksal und den Verbleib der einst hochgeschätzten und gern gesehenen Kollegen eingegangen werden. In Mayers Manuskript zur Vorstandssitzung am 22. Oktober 1935 findet sich dazu der Vermerk: „Austritt von Juden nicht eigens nennen“. 625

Gedeckt wurde dieses Vorgehen durch eine Verständigung Stoeckels mit dem späteren Reichsgesundheitsführer Leonardo Conti, der 1933 mitteilte, dass Mitgliederverzeichnisse wissenschaftlicher Fachgesellschaften „nicht ,judenrein“ zu sein“ bräuchten und gegen „die Einreise und das Sprechen ausländischer Juden in wissenschaftlichen Sitzungen [...] keine Bedenken“ bestünden. „Inländische Juden“ sollten hingegen nicht sprechen und sich „in ihrem eigenen Interesse zurückhalten“. ${ }^{626}$ Stoeckel griff diese Haltung wenige Monate später in seiner Eröffnungsansprache auf, als er bei den Betroffenen eine „für sie selbst wünschenswerte[n] Zurückhaltung“ anmahnte. ${ }^{627}$ Die Drohung des Fürther Frauenarztes und fanatischen Antisemiten Arnulf Streck, aus der Gesellschaft auszutreten, „solange noch Juden in ihr sind“, konnte den internen Druck nur kurzzeitig erhöhen, ${ }^{628}$ ansonsten bestimmte bis mindestens 1937 Contis Weisung den Kurs. ${ }^{629}$

Eine härtere Gangart wurde vermutlich erst Ende 1938 eingeschlagen, als das Reichsgesundheitsamt neue Richtlinien für den Umgang mit jüdischen Mitgliedern erließ. Demnach seien „[i]nländische Juden [...], nachdem ihre Bestallung als Arzt erlo-

\footnotetext{
613 Vgl. auch die Biografie des Göttinger Ordinarius und DGG-Kassenwarts Heinrich Martius, S. $23 \mathrm{f}$.

614 Vgl. Olbrich: Zucker-Museum (2004), S. 42.

615 UAR, Personalakte Hans-Hermann Schmid; Eintrag von Hans-Hermann Schmid im Catalogus Professorum Rostochiensium.

616 Vgl. Sauer: Dokumente (1966), S. 133.

617 Vgl. Schwoch (Hrsg.): Kassenärzte (2009), S. 112.

618 Siehe S. 71.

619 Vgl. Jahnke-Nückles: Kinderheilkunde (1992), S. 72; Neumann-Redlin von Meding/Conrad: Ärzte (2013), S. 19 f.; BArch Berlin, R 1501-126406, Bl. 147.

620 Vgl. aber Heuvelmann: Abschaffung (1999), S. 131.

621 BSB München, Nachlässe Ana 691, Martius an Wagner (06.08.1936); Martius an Naujoks (15.12.1937).

622 Vgl. Seidler: Kinderärzte (2007), S. 25.

623 UAT 150/33,41: Protokoll einer Vorstandssitzung (1935).

624 BSB München, Nachlässe Ana 691, Wagner an Martius (18.08.1937).

625 UAT 150/33,41: Manuskript zur Vorstandssitzung (22.10.1935).

626 Stoeckel: Erinnerungen (1966), S. 391; vgl. UAT 150/33,41: Kongressvorbesprechung (23.02.1935).

627 Stoeckel: Eröffnungs-Ansprache [Verhandlungen 1933] (1934), XLII.

628 UAT 150/33,41: Kongressvorbesprechung (23.02.1935).

629 Vgl. Schmuhl: Neurologen (2016), S. 148; auch BSB München, Nachlässe, Ana 691: Wagner an Martius (10.08. 1937).
} 
schen ist, in den Mitgliederlisten zu streichen. Beiträge sind von ihnen nicht mehr einzufordern oder anzunehmen“.630 Da im Tagungsband für das Jahr 1941 kein Mitgliederverzeichnis abgedruckt wurde - Grund war die kriegsbedingte Papierrationierung ${ }^{631}$-, lässt sich die Umsetzung dieser Anordnung nicht nachvollziehen. Im Tagungsbericht ist lediglich von 48 Mitgliedern die Rede, die „aus den verschiedensten Gründen“ gestrichen worden seien. ${ }^{632}$ Es ist nicht unwahrscheinlich, dass sich hinter dieser Chiffre die rund 40 bis zu diesem Zeitpunkt in der Gesellschaft verbliebenen Juden verbargen, deren Ausschluss infolge des Bestallungsentzugs perfiderweise sogar satzungskonform war.

Wenngleich der Vorstand - jedenfalls bis 1938 - von einem prinzipiellen Ausschluss missliebiger Mitglieder absah, war er aktiv und wissentlich an der Ausgrenzung jüdischer Kolleginnen und Kollegen beteiligt, nicht zuletzt als willfähriger Komplize staatlicher Stellen. Vermutlich war es ein seit 1933 herrschendes Klima des „Nicht-Willkommenseins“ 633 - man denke an Stoeckels Rede -, das zahlreiche Mitglieder zum, nur scheinbar freiwilligen, Austritt bewog. Der Verzicht auf einen „Arierparagraphen“ und die formelle Duldung jüdischer Ärzte als Ausweis einer moderaten „Judenpolitik“ aufzufassen, wie dies beispielsweise die DOG nach Kriegsende tat, ${ }^{634}$ wäre vor diesem Hintergrund völlig verfehlt. Wie in den meisten anderen Fachgesellschaften war es Juden zwar auch in der DGG bis weit in die 1930er-Jahre hinein gestattet, Mitglied zu bleiben; faktisch besaßen sie jedoch keine Möglichkeit mehr, ihre Mitgliedschaft wahrzunehmen und sich ihren Neigungen entsprechend in die Gesellschaft einzubringen. Die in diesem Zusammenhang von Conti getroffene Übergangsregelung ist nicht als Verhandlungserfolg des Vorstands zu werten, wie es Stoeckel in seinen Memoiren suggeriert, 635 sondern als einvernehmliches Zugeständnis an äußere politische Umstände.

Mit dem Verlust der Möglichkeit, sich an den Tagungen der Gesellschaft zu beteiligen und mit Kollegen in Austausch zu treten, wurden die jüdischen Mitglieder eines wesentlichen Teils ihrer beruflichen Identität beraubt. Paul Straßmann, der auf den Kongressen der DGG regelmäßig als Vortragender firmiert hatte, notierte 1936 in sein Tagebuch: „Ohne Teilnahme am geistigen Leben des Faches fühle ich mich als handwerklicher Schlachtenbummler.“636

\section{Die Ausschaltung der jüdischen Ärzteschaft}

So schmerzhaft die Ausgrenzung aus der DGG für Mitglieder jüdischer Herkunft gewesen sein mag, war sie doch nur ein Glied in einer langen Kette diskriminierender und existenzbedrohender legislativer Maßnahmen, die bereits ab 1933 von willkürlichem Terror flankiert wurden. Erklärtes Ziel der Gesetzgebung war die „Ausschaltung“ der jüdischen Bevölkerung aus dem Erwerbsleben. Dass dem Ärztestand von Anfang an ein besonderes Augenmerk galt, lag nicht zuletzt daran, dass ihm eine herausragende Verantwortung für den Erhalt der „Rassereinheit“ zugeschrieben wurde. Jüdische Ärzte, denen man die vorsätzliche Sabotage der „Volksgesundheit“ zum Vorwurf machte, sollten möglichst schnell aus allen medizinischen Berufen und dem universitären Lehrbetrieb verdrängt werden. ${ }^{637}$ Dies galt insbesondere für Frauen- und Kinderärzte, von denen überdurchschnittlich viele jüdischer Herkunft waren. ${ }^{638}$

Wie rasch und in welchem Ausmaß ein Arzt mit beruflichen Repressalien zu kämpfen hatte, hing in der Frühphase des Regimes von seinem Umfeld und seiner beruflichen Stellung ab. Im öffentlichen Dienst stehende Mediziner waren auf andere Weise betroffen als niedergelassene Ärzte. Da an dieser Stelle nicht auf jedes einzelne der zahlreichen Gesetze und jede Einzelmaßnahme eingegangen werden kann, orientiert sich der folgende chronologische Abriss an den wichtigsten Stationen der Verdrängung, Ausgrenzung und Entrechtung jüdischer Ärzte bis zum faktischen Berufsverbot 1938. Durch eine breite Auswahl exemplarischer Einzelschicksale soll die enorme Bandbreite der Verfolgung und ihrer Mechanismen veranschaulicht werden.

\section{3: Das „Gesetz zur Wiederherstellung}

des Berufsbeamtentums“

Nur 2 Wochen nach der Verabschiedung des „Ermächtigungsgesetzes“ wurde am 7.April 1933 das „Gesetz zur Wiederherstellung des Berufsbeamtentums“ erlassen, das alle im Hochschul- oder Kommunaldienst tätigen Beamten verpflichtete, den Nachweis ihrer Abstammung zu erbringen. Damit schuf das „Berufsbeamtengesetz“ (BBG) die formal-rechtliche Grundlage, „nichtarische“ Personen aus der Verwaltung, der Justiz und den Universitäten des Reiches zu entfernen. Als nichtarisch im Sinne des Gesetzes galt, „wer von nicht arischen, insbesondere jüdischen Eltern oder Großeltern“ abstammte. ${ }^{639}$ Ein jüdischer Eltern- oder Großelternteil reichte aus, um der beruflichen Laufbahn ein Ende zu setzen - die Betroffenen wurden entlassen oder „in den Ruhestand“640 versetzt. Zahlreiche Durchführungsverordnungen ergänzten das BBG und weiteten es auf nichtbeamtete Hochschullehrer und Dozenten aus. Als Ausnahmeregelung fungierte der auf Initiative Hindenburgs formulierte „Frontkämpferparagraph“ ( $\$ 3,2)$, demzufolge das Gesetz „für Beamte, die bereits seit dem 1. August 1914 Beamte gewesen sind oder die im Weltkrieg an der Front für das Deutsche Reich oder für seine Verbündeten gekämpft haben oder deren Väter und Söhne im Weltkrieg gefallen sind“ nicht zur Anwendung kommen sollte. ${ }^{641} \mathrm{Ju}-$ ristische Winkelzüge boten jedoch in vielen Fällen die Möglich-

\footnotetext{
630 Zit. n. Schmuhl: Neurologen (2016), S. 149. Betroffen waren womöglich auch die aus Deutschland emigrierten Mitglieder, während Juden ausländischer Staatsangehörigkeit „wie Ausländer zu behandeln“ seien.

631 UAT 150/33,41: Naujoks an Martin (29.08.1941); Naujoks an Martius (28.11.1941).

632 Mitgliederversammlung [Verhandlungen 1941] (1942), S. 6.

633 Vgl. Seidler: Kinderärzte (2007), S. 24.

634 Walther Löhlein, ab 1934 Vorsitzender der Deutschen Ophthalmologischen Gesellschaft, betonte 1949, dass die Gesellschaft „in dieser ganzen hinter uns liegenden Zeit kein Mitglied aus politischen, rassischen oder nationalen Gründen aus ihrer Mitgliederliste gestrichen hat"; zit. n. Rohrbach: Augenheilkunde (2007), S. 123. Ähnlich argumentierte die Anatomische Gesellschaft; vgl. Winkelmann: Gesellschaft (2012).

635 Vgl. Stoeckel: Erinnerungen (1966), S. 390 f.

636 David: Straßmann (2007), S. 111.

637 Vgl. Reichsärzteführer Wagner im Völkischen Beobachter vom 25.03.1933; siehe auch S. 82 f.

638 Vgl. die Aufschlüsselung bei Hadrich: Ärzte (1934), S. 1245.

639 1. VO zur Durchführung des BBG (11.04.1933), 2,1.

640 BBG $\S 3,1$.

${ }^{641} \mathrm{BBG} \S 3,2$.
} 
keit, den „Frontkämpferparagraphen“, auf den sich überraschend viele „nichtarische“ Ärzte berufen konnten, zu umgehen.

Bis 1945 verloren die deutschen Universitäten auf Grundlage des BBG insgesamt 19,3\% ihres Lehrkörpers, darunter mindestens 458 Mediziner. ${ }^{642}$ Für Forschung, Lehre und Patientenversorgung stellten die Massenentlassungen einen nicht zu ersetzenden Verlust dar. Zahlreiche hoch angesehene Wissenschaftler setzten ihre Arbeit im Ausland fort, Wissenschaftszweige wie die gynäkologische Endokrinologie und die Soziale Gynäkologie verloren einige ihrer namhaftesten Vertreter oder wurden, wie die Sexualwissenschaft, als jüdische Erfindung verfemt. ${ }^{643}$

Die betont justizförmige „Säuberung“ des Lehrkörpers vollzog sich an den meisten Universitäten ohne öffentlich artikulierten Protest. ${ }^{644}$ Gerade an den Medizinischen Fakultäten, die von den Machthabern frühzeitig in ihre gesundheitspolitische Agenda eingebunden wurden, stieß die Vertreibung „nichtarischer“ Hochschullehrer selten auf Widerspruch; ein, im Vergleich zu anderen Berufsgruppen, erheblicher Teil des Lehrpersonals trat nicht zuletzt aus Karrieregründen - der NSDAP bei. ${ }^{645}$ „Säuberung“ und „Neuaufbau“ der Universitäten eröffneten den nicht verfolgten Hochschullehrern Möglichkeiten der politischen Mitgestaltung und des beruflichen Aufstiegs. Nicht nur fanatisch antisemitische „Jungärzte“ hatten nach einer perspektivlosen Zeit während der Weimarer Republik vielfach kein Problem damit, ihrer Karriere durch die Besetzung frei gewordener Stellen einen Schub zu verleihen. Das radikalisierte Klima des „revolutionären Umbruchs“, das nicht zuletzt von nationalsozialistischen Studentengruppen getragen wurde, beförderte „Störaktionen“, Diffamierungen und Denunziationen. ${ }^{646}$

Über 30 in Deutschland praktizierende DGG-Mitglieder waren aufgrund ihrer Abstammung vom BBG betroffen. ${ }^{647}$ Anhand ihrer individuellen Verfolgungsgeschichten lässt sich nachzeichnen, auf welch unterschiedliche Weise die Vertreibung „nichtarischer“ Ärzte aus dem Hochschuldienst betrieben wurde: verdiente Professoren wurden in den Ruhestand versetzt, geltende Verträge nicht verlängert oder rückwirkend aufgehoben, mitunter legte man den Betroffenen eine „freiwillige“ Kündigung nahe. ${ }^{648}$

Bereits am 20. April 1933 wurde Maximilian Neu, seit 1914 außerordentlicher Professor in Heidelberg, „bis auf Weiteres beurlaubt“. Als „Rechtsgrundlage“ diente ein Erlass des badischen Staatskommissars für Kultus und Unterricht vom 6. (!) April. Da Neu schon 1907 in das Beamtenverhältnis eingetreten war, konnte er sich auf die Ausnahmeregelung berufen und reichte beim Senat, zum Nachweis seiner Befähigung, Zeugnisse des früheren
Heidelberger Klinikleiters Carl Menge und ein wohlwollendes Gutachten des Internisten Ludolf von Krehl ein. Nachdem der Einspruch im Juli 1933 vom Kultusministerium zunächst anerkannt worden war, ließ das Ministerium im Herbst desselben Jahres verlauten, dass Neu aufgrund der Entschließung des Reichsstatthalters die Lehrbefugnis entzogen werde. Zwar schien Neu den Beschluss mit Fassung zu tragen, da er die UFK bereits 1919 verlassen hatte und seine Lehrtätigkeit lediglich als „Nebenverdienst" betrachtete; die legislative Diskriminierung niedergelassener Ärzte stellte jedoch auch seine Existenz als Leiter einer Privatklinik auf eine harte Probe. ${ }^{649}$

Im Fall des am Pharmakologischen Instituts der Medizinischen Akademie Düsseldorf tätigen Oberarztes Hans Schlossmann gelang es den Verantwortlichen, die Ausnahmeregelung des „Frontkämpferparagraphen“ gänzlich zu umgehen. Nachdem Schlossmann seine Entlassung mit Hinweis auf seinen Militärdienst angefochten hatte, legitimierte der stellvertretende Direktor der Krankenanstalten, Ernst Edens, die Kündigung kurzerhand auf andere Weise: Durch die Entlassung des „nichtarischen“ Institutsleiters Philipp Ellinger stehe eine Neubesetzung des Lehrstuhls bevor, die Schlossmanns Stelle als Oberarzt mit einschließe. Der „Unterausschuß zur Prüfung der ärztlichen Belange der Medizinischen Akademie“, in dem unter anderem das DGGMitglied Friedrich Siegert saß, billigte den Vorgang. Schlossmann musste die von seinem Vater Arthur Schlossmann mitbegründete Medizinische Akademie verlassen und emigrierte noch im selben Jahr nach Cambridge. ${ }^{650}$

Entlassen wurden ab 1933 auch Ärzte, die an kommunalen oder kirchlichen Krankenhäusern tätig waren - oftmals, wie im Fall des evangelisch-jüdischen Kölner Arztes Kurt Frankenstein, ohne juristische Grundlage. Die Begründung, mit der Frankenstein, Leiter des Evangelischen Krankenhauses in Köln-Kalk, am 3. Mai 1933 aufgefordert wurde, seine Kündigung einzureichen, lautete schlicht, dass man sich der „Zeitströmung“ nicht entgegenstellen könne, ohne den Interessen des Krankenhauses zu schaden. ${ }^{651}$

Ein scheinbar vom BBG unabhängiges Argument lag auch der Entlassung des Magdeburger Arztes Walter Fürst zugrunde, der seit Oktober 1931 als Direktor der Röntgenabteilung der Städtischen Krankenhäuser tätig war. Die Kündigung zum 31. Dezember 1933 wurde mit der Auflösung des erst 2 Jahre zuvor eingerichteten Strahleninstituts begründet, die „der Stadt wesentliche Ersparnisse bringen“ sollte. Fürst emigrierte 1934 nach Zürich, wo er von 1927 bis 1931 die Röntgenabteilung der UFK geleitet und die Venia legendi erworben hatte. ${ }^{652}$

642 Vgl. Grüttner/Kinas: Vertreibung (2007), S. 131; Rohrbach: Augenheilkunde (2007), S. 97. Im Vergleich der einzelnen Universitäten lassen sich erhebliche quantitative Unterschiede feststellen.

643 Vgl. Sigusch: Geschichte (2008), S. 371

644 Siehe auch S. $85 \mathrm{f}$.

645 Insgesamt waren im Jahr 1937 über 43\% aller deutschen Ärzte Mitglied der Partei, 26\% gehörten der SA an; vgl. Kater: Doctors (1989) S. 252. Auch der 1929 gegründete, politisch orientierte Nationalsozialistische Deutsche Ärztebund (NSDÄB) verzeichnete nach 1933 raschen Zulauf; vgl. Beddies/Baader: Ärzte (2014), S. $30 \mathrm{f}$.

646 Opfer einer solchen studentischen Störaktion wurde beispielsweise der Breslauer Ordinarius Ludwig Fraenkel; vgl. Grüttner: Studenten (1995), S. 69.

647 Oskar Polano entging der Entlassung durch seinen frühen Tod im Juli 1934; vgl. Dross: „Juden“ (2012), S. $101 \mathrm{f}$.

648 Vgl. die Unterscheidung zwischen verwaltungsmäßig „korrekten“ Entlassungen und „entlassungsähnlichen Fällen“ bei Grüttner/Kinas: Vertreibung (2007), S. $131 \mathrm{f}$.

${ }^{649}$ Rotzoll/Wiedemann: Judendeportation (2012); Drüll: Gelehrtenlexikon (1986), S. 190; siehe auch S. 81 in diesem Band.

650 Vgl. Woelk: Ärzte (1997), S. 75.

651 Lekebusch: Not (1995), S. 46.

652 Auskunft des Stadtarchivs Magdeburg vom 29.09.2015. 
In hohem Maße war nach dem „Anschluss“ Österreichs die Universität Wien von den rassischen „Säuberungen“ betroffen: 51\% der Wiener Hochschullehrer galten nach den Nürnberger Gesetzen als Juden oder Mischlinge, im Fach Gynäkologie mussten 11 von 19 Universitätslehrer die Hochschule verlassen. ${ }^{653}$ In einem Beitrag zur Geschichte der Bayerischen Gesellschaft für Geburtshilfe und Frauenheilkunde geht Gabriele Czarnowski auf einige Einzelschicksale ein. ${ }^{654}$ Sämtliche der dort behandelten Personen - Heinrich Kahr, Ludwig Adler, Bernhard Aschner, Oskar Frankl, Emanuel Klaften und Wilhelm Latzko - waren Mitglied der DGG.

\section{3: Boykott und Entzug der Kassenzulassung}

Wenngleich niedergelassene jüdische Ärzte von den Regelungen des BBG in der Regel unberührt blieben, hatten auch sie von Anfang an unter diskriminierenden Gesetzen und Aktionen zu leiden. Am 1. April 1933 leitete der reichsweite „Judenboykott“ die erste Phase der antisemitischen Ausgrenzungspolitik ein und ebnete dem BBG den Weg. Ärzte zählten zu den am schwersten betroffenen Berufsgruppen des „Boykotts“: Behandlungsräume wurden verwüstet, Fenster und Fassaden mit antisemitischen Parolen beschmiert; durch Schilder mit der Aufschrift „Meidet jüdische Ärzte und Rechtsanwälte“", vielfach aber auch durch verbale Drohungen und körperliche Gewalt, sollten nichtjüdische Patientinnen und Patienten davon abgehalten werden, jüdische Arztpraxen zu betreten ( $\bullet$ Abb. 34).

Für viele deutsche Juden stellte der Boykott eine einschneidende, traumatische Erfahrung dar. Vor der Praxis des Konstanzer Frauenarztes Samuel „Semi“ Moos, der zuletzt 1931 als Mitglied der DGG geführt wurde, postierten sich bereits am Abend des 31. März bewaffnete SA-Posten; am nächsten Morgen wurde Moos am Betreten des Vincentius-Krankenhauses, seiner langjährigen Wirkstätte, gehindert. Unter dem Eindruck der schockierenden Ereignisse wanderte er nur eine Woche später, am 7. April 1933, nach Frankreich aus. ${ }^{655}$

Am 22. April trat die vom Reichsarbeitsministerium verabschiedete „Verordnung über die Zulassung von Ärzten zur Tätigkeit bei den Krankenkassen“ in Kraft, die „Nichtarier“ oder Ärzte, die sich - im weitesten Sinne - kommunistisch betätigt hatten, von der Tätigkeit bei den gesetzlichen, später auch bei den privaten Krankenkassen ausschloss. ${ }^{656}$ Für eine große Zahl der betroffenen Ärzte bedeutete dies den Verlust ihrer Haupteinnahmequelle und führte dazu, dass sie ihre Praxen schließen oder in kostengünstigere Räumlichkeiten verlegen mussten. ${ }^{657}$ Dass der Heidelberger Maximilian Neu um 1936 seine Heidelberger Privatklinik aufgab, hängt vermutlich ebenso mit dem Verlust der Kassenzulassung zusammen wie die Emigration des Nürnberger Arztes Willi Straus im August 1933. ${ }^{658}$ Auch die Privatklinik des Berliner Frauenarztes Paul Straßmann war nach dem Entzug der Kassenzulassung von der Insolvenz bedroht. Straßmanns ehemaliger

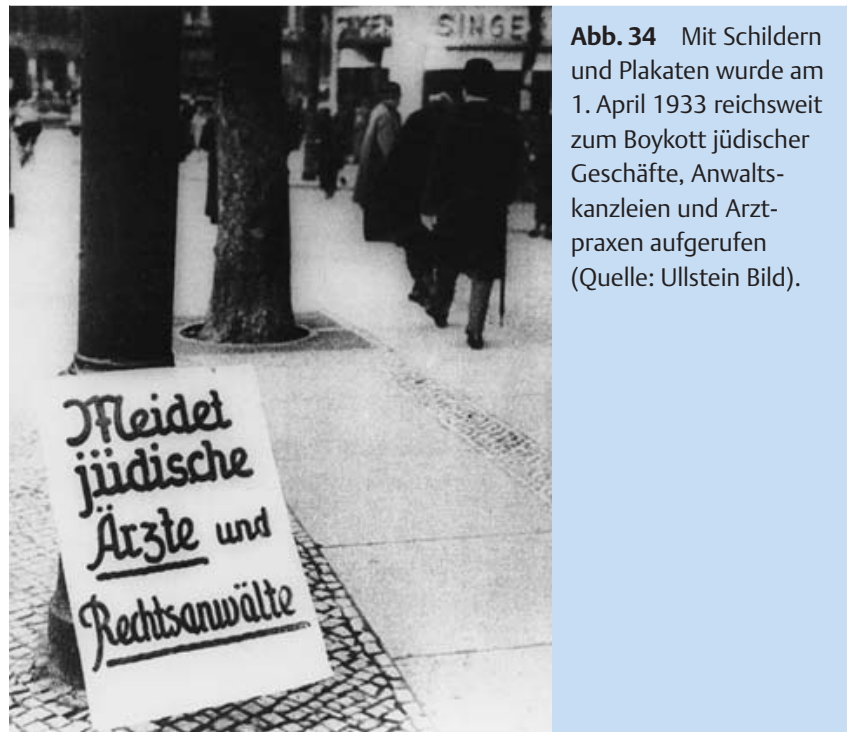

Oberarzt, das DGG-Mitglied Martin Jung, soll hier exemplarisch für all jene Ärzte stehen, die von der Vertreibung ihrer jüdischen Kollegen zu profitieren suchten: Jung hatte seinen Vorgesetzten als Juden denunziert und spekulierte darauf, die Klinik übernehmen zu können. ${ }^{659}$ Angesichts der brenzligen Situation notierte Straßmanns Sohn Gustav in sein Tagebuch: „Hauptsache jetzt für mich - Englisch lernen“. 660

\section{5-1937: „Nürnberger Rassegesetze“}

Nach einer Phase relativer Ruhe markierten die „Nürnberger Rassegesetze“ vom 15. September 1935 eine neue Dimension in der Ausgrenzung jüdischer Menschen im Deutschen Reich. Mit dem Inkrafttreten des „Reichsbürgergesetzes“ verloren auch die letzten "nichtarischen“ Hochschullehrer und Beamten ihre Stellung. Der Gesetzestext besagte, dass „Reichsbürger“ nur Staatsangehörige „deutschen und artverwandten Blutes“ sein konnten. ${ }^{661}$ „Staatsbürger“, die dieses Kriterium nicht erfüllten, verloren ihre politischen Rechte und konnten kein öffentliches Amt mehr bekleiden. Die Ausnahmeregelungen des „Frontkämpferparagraphen“ waren damit obsolet. Am 22. Februar 1936 wurden die Berliner Gynäkologen Selmar Aschheim, Robert Meyer und Ludwig Pick in einem unpersönlichen Schreiben des Rektors Krüger davon in Kenntnis gesetzt, dass ihnen rückwirkend zum 31. Dezember 1935 die Lehrbefugnis entzogen worden sei. ${ }^{662}$

Mit beruflichen Konsequenzen hatten spätestens ab diesem Zeitpunkt auch Ärzte zu rechnen, deren Ehepartner im Sinne des „Blutschutzgesetzes“ als Nichtarier galten. Zum 30. September 1937 sollten alle „Mischlinge“, „jüdisch Versippten“ oder mit „Mischlingen“ Verheirateten aus dem Hochschuldienst entfernt

653 Vgl. Hubenstorf: Ende (1994), S. 41 f.; Hubenstorf: Fakultät (1989), S. 240.

654 Vgl. Czarnowski: „Anschluss“ (2012), S. 138 f.; darüber hinaus Bauer-Merinsky: Auswirkungen (1980).

655 Vgl. Burchardt/Schott/Trapp: Konstanz (1990), S. 232, 235; Mack: Ärzteschaft (2001), S. 82.

656 Vorläufig ausgenommen waren abermals Ärzte, die einen Einsatz im Ersten Weltkrieg nachweisen konnten.

657 Vgl. Rüther: Standeswesen (1997), S. 151. Ab 1936 häufen sich die Adresswechsel unter jüdischen Mitgliedern der DGG.

658 Vgl. Rotzoll/Wiedemann: Judendeportation (2012); Höffken: Schicksale (2013), S. 361.

659 Vgl. Strassmann: Strassmanns (2006), S. 177. Jungs Ansinnen scheiterte, Paul Straßmann konnte seine Praxis noch bis 1936 aufrechterhalten und musste sie dann für einen Spottpreis an die Charité veräußern.

660 Strassmann: Strassmanns (2006), S. 178.

661 RBG $§ 2,1$.

662 Simmer: Pick (2000), S. 290-292. 


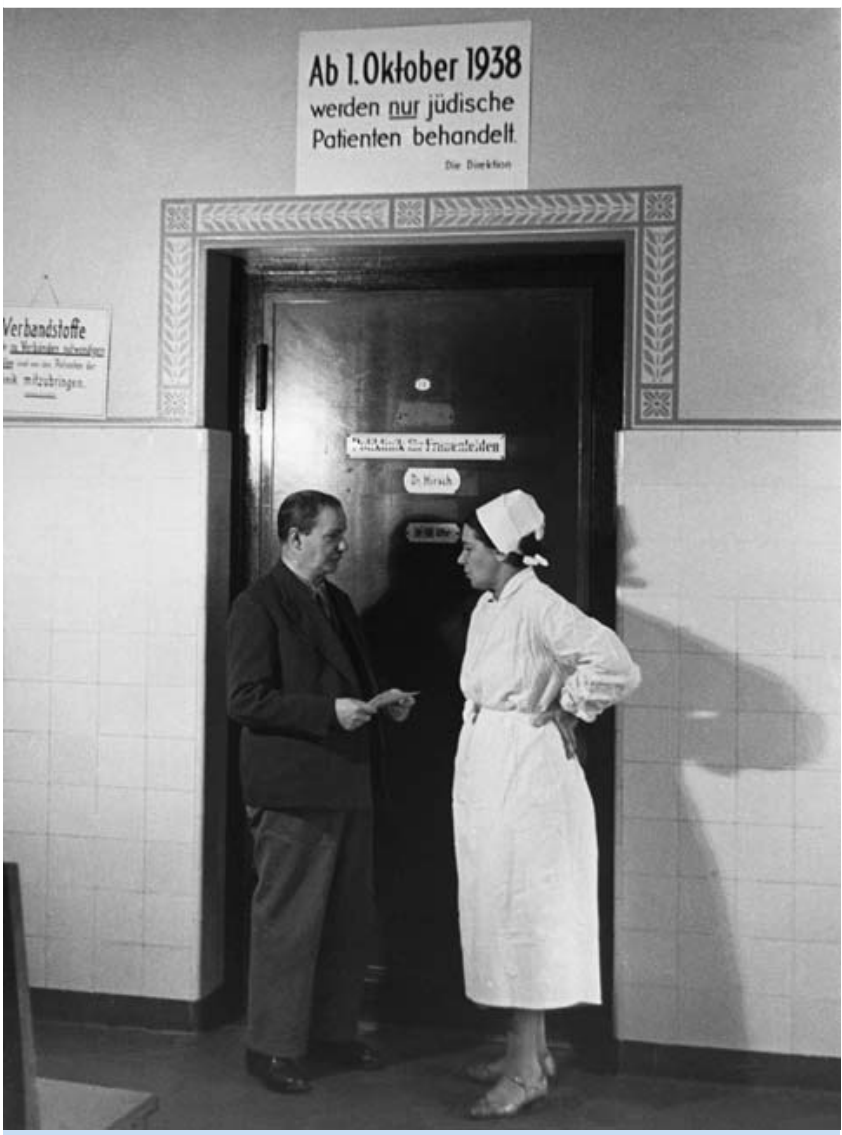

Abb. 35 Die Poliklinik für Frauenleiden im Jüdischen Krankenhaus, Iranische Straße, Berlin. Nur wenige jüdische Ärztinnen und Ärzte durften nach dem Approbationsentzug vom 30. September 1938 noch ärztlich tätig sein und unter der diskriminierenden Bezeichnung „Krankenbehandler" ausschließlich jüdische Patientinnen und Patienten betreuen. Foto von Abraham Pisarek vom 15.11.1938 (Quelle: Bildarchiv Pisarek/ akg-images).

werden. ${ }^{663}$ Innerhalb der DGG war unter anderem Ernst Ritter von Seuffert von den Implikationen des „Blutschutzgesetzes“ betroffen: Wegen der „nichtarischen“ Abstammung seiner Ehefrau Leonie, der Tochter des Physikers Leo Graetz, verlor er 1937 die Lehrbefugnis und wurde wenig später, im Alter von 58 Jahren, in den Ruhestand versetzt. Auf Seufferts DGG-Mitgliedschaft hatte die Entlassung indes keine Auswirkungen; Naujoks und Martius beschlossen 1939 sogar, dass der hochangesehene Arzt auch dann Mitglied bleiben dürfe, wenn er keinen Mitgliedsbeitrag zahle. ${ }^{664}$

\section{8: Entzug der Bestallung und Novemberpogrome}

Mit der Vierten Verordnung zum Reichsbürgergesetz verloren die rund 3000 im Reich verbliebenen jüdischen Ärzte zum 30. September 1938 die Bestallung, womit ihre wirtschaftliche
Existenz und berufliche Identität mit einem Schlag vernichtet war. Nur 709 Ärzten, darunter mindestens 7 DGG-Mitglieder, war es auf Widerruf gestattet, unter der diskriminierenden Bezeichnung „Krankenbehandler“ ausschließlich Familienangehörige und jüdische Patienten zu versorgen $\left(\odot\right.$ Abb. 35) ${ }^{665}$

Mit dem Erlöschen der Bestallung war die in der völkischen Publizistik seit Jahrzehnten geforderte „Entjudung“ des deutschen Ärztestandes innerhalb von 5 Jahren zu einem Abschluss gekommen. Wenige Wochen später markierte der exzessive Terror der Reichspogromnacht ein bis dato ungekanntes Ausmaß der Radikalität. Die Zerstörung von Synagogen und Privatwohnungen sowie die willkürliche Verhaftung und Misshandlung jüdischer Bürgerinnen und Bürger verschärften die wirtschaftliche und soziale Ausgrenzung durch eine massive physische Bedrohung und stellten den Auftakt zum Massenmord dar.

\section{Antisemitische Publizistik vor und nach 1933}

Insbesondere jüdische Ärzte waren bereits im ersten Drittel des 20. Jahrhunderts häufiges Ziel antisemitischer Attacken und Kampagnen in der völkischen und nationalsozialistischen Publizistik gewesen. „Der Stürmer“, eine 1923 von Julius Streicher in Nürnberg gegründete Zeitung, sollte auf diesem Gebiet eine besonders nachhaltige Wirkung entfalten. Die primitive Brachialrhetorik des auflagenstarken Blattes trug dazu bei, „das Klima in Deutschland zu vergiften und den Boden für die späteren nationalsozialistischen Vernichtungsaktionen mit zu bereiten“. ${ }^{666}$ Selbst Walter Stoeckel, der sicher nicht zur Zielgruppe des „Stürmers“ zählte, ließ in seiner Autobiografie durchblicken, dass ihm der „Nürnberger Streicher-Jargon“ durchaus vertraut war. ${ }^{667}$

Auf Grundlage pseudowissenschaftlicher Theorien und schockierender „Tatsachenberichte“ gab der „Stürmer“ vor, wertvolle Aufklärungsarbeit zu leisten. Das „Verbrechen der Rassenschande“ und die Vergiftung „arischen Blutes“ durch „artfremden Samen“ wurden in zahllosen Artikeln verhandelt. Jüdische Ärzte zählten zu den wiederkehrenden Themen des Blattes, da sie für das „Gebräu [...] aus Pornografie und Judenhass“, 668 das den „Stürmer“ kennzeichnete, eine denkbar geeignete Vorlage boten. ${ }^{669}$ Geldschneiderei und Klientelwirtschaft, Menschenversuche und Materialismus, mangelnde Hygiene und Quacksalberei wurden den „Judenärzten“ ebenso vorgeworfen wie Abtreibung, „Rassenschändung“ und „widernatürliche Unzucht“. ${ }^{670}$ Der Karikaturist des „Stürmers“, Philipp Rupprecht („Fips“), zeichnete 1937 eine „Schreckenskammer“ verschiedener „Judentypen“, in der auch ein jüdischer Frauenarzt dargestellt ist, wohl nicht zufällig in einer Reihe mit dem Sittlichkeitsverbrecher und dem Lustmörder (๑ Abb. 36). ${ }^{671}$

Neben allgemein gehaltenen Abhandlungen über den verderblichen Einfluss des Judentums zählte von Anfang an die Diffamierung einzelner, namentlich genannter Personen zu den bevorzugten Methoden des Hetzblattes. So wurde der regelmäßig ab-

663 Vgl. Grüttner/Kinas: Vertreibung (2007), S. 137 f.

664 BSB München, Nachlässe, Ana 691: Naujoks/Martius (12.1938/01.1939).

665 Zur Zahl und Situation der Krankenbehandler vgl. Schwoch: „Krankenbehandler“ (2012).

666 Roos: Streicher (2014), S. 397.

667 Stoeckel: Erinnerungen (1966), S. 437.

668 Roos: Streicher (2014), S. 138.

669 Vgl. z.B. Stürmer 08/1935; 17/1935; 08/1937; 10/1937.

670 Vgl. insbesondere den Leitartikel „Judenärzte. Frauenschänder \& Mörder“ in Stürmer 17/1935.

671 Stürmer 13/1937. 
gedruckte Aufruf „Geht nicht zu jüdischen Ärzten!“ gelegentlich durch Listen jüdischer Ärzte ergänzt.

Immer wieder waren auch DGG-Mitglieder Ziel der Hetzpropaganda und Opfer fingierter Vorwürfe. Die kurzzeitige Rückkehr Ludwig Fraenkels nach Breslau, wo der ehemalige Ordinarius eine Sitzung der Medizinischen Fakultät besuchte, diente 1935 als Aufhänger eines Artikels über die „verjudeten“ Zustände an der Breslauer Universität. ${ }^{672}$ In einer der folgenden Ausgaben stellte der "Stürmer“ den Wuppertaler Frauenarzt Hans Röttgen als stereotypen jüdischen Vertreter seines Faches dar: Der „gewerbsmäßige[r] Abtreiber“ habe sich „deutschen Frauen und Mädchen gegenüber in schamverletzender Weise" gezeigt. ${ }^{673}$ Zwei Jahre später fand der Frauenarzt Walter Redlich in einem Artikel über „Talmudjuden in Neisse“ Erwähnung - als Demokrat und früherer Ortsvorsitzender des jüdischen Central-Vereins sei er „eine besonders interessante Gestalt“

In besonderer Weise betroffen waren Ärzte, die sich mit dem Vorwurf der Abtreibung, der Vergewaltigung oder der „Rassenschande" konfrontiert sahen. Bereits in den ersten Ausgaben des Jahres 1923 war der Nürnberger Frauenarzt Max Schwab Gegenstand einer Verleumdungskampagne, die seine außereheliche Beziehung zur Nichtjüdin Anna Winkler thematisierte. Die Artikelserie sollte „das wahre Gesicht eines jüdischen Frauenarztes“ zeigen und zitierte ausführlich aus privaten Briefen. ${ }^{675} \mathrm{Im}$ April 1924 berichtete der „Stürmer“, Schwab sei verhaftet worden, weil er „an deutschen Frauen Eingriffe vorgenommen“ habe, „die nicht allein gegen das Gesetz verstoßen, sondern auch eine Schändung deutscher Frauenkörper bedeuten “ ${ }^{676}$

Noch schlimmer traf es den Münchner Frauenarzt Hans Bab, der 1938 wegen des Vorwurfs der „Rassenschande“ für 12 Wochen in "Schutzhaft" genommen wurde. ${ }^{677}$ Der „Stürmer“ hatte ihm ein Verhältnis zu einer verheirateten Nichtjüdin nachgesagt, die „den Juden nicht nur in seiner Sprechstunde und Privatwohnung“ besucht, sondern auch „während der beruflichen Abwesenheit ihres Gatten zu späten Abendstunden in ihrer Wohnung“" empfangen und sich mit ihm „selbst auf öffentlichen Straßen“ gezeigt habe. ${ }^{678}$ Nach seiner Entlassung aus dem Gefängnis emigrierte Bab nach Großbritannien.

\section{Nonkonformität und Solidarisierung}

Politisch „missliebige“ Mitglieder

Dass ein beträchtlicher Teil der deutschen Ärzteschaft - sei es aus Überzeugung, Opportunismus oder beruflichem Ehrgeiz - mit dem nationalsozialistischen Regime kooperierte, ist bereits angeklungen. Das Bild bedarf jedoch einer Differenzierung: Manche

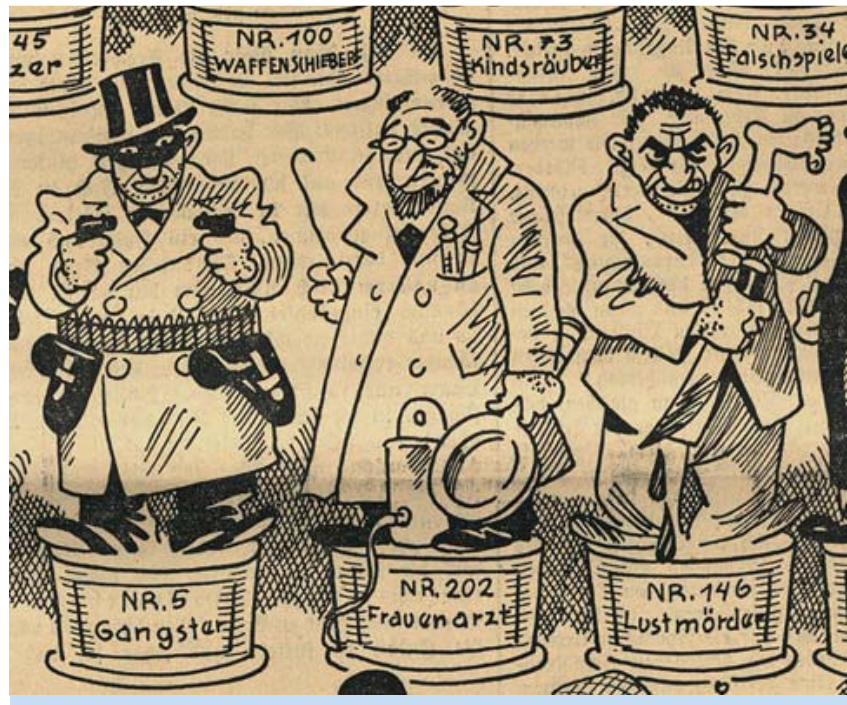

Abb. 361937 erschien im „Stürmer“ die stereotyp-antisemitische Karikatur eines jüdischen Frauenarztes, hier vermutlich mit primitivem Abtreibungsinstrument dargestellt, im Rahmen einer „Schreckenskammer“ verschiedener „Judentypen“ (Quelle: Bayerische Staatsbibliothek München).

Maßnahmen der Regierung stießen durchaus auf ärztlichen Widerspruch; dieser wurde allerdings in der Regel nicht von den „gleichgeschalteten“ Organisationen artikuliert, sondern von Einzelpersonen. ${ }^{679}$ Nur in wenigen Fällen ist dabei von einer fundamentalen und konsequenten Ablehnung der Diktatur auszugehen. Weitaus häufiger waren Fälle punktueller Nonkonformität und Verweigerung - eine partielle Opposition, die sich lediglich auf einen Teilbereich der nationalsozialistischen Agenda bezog und nicht zwingend politisch motiviert sein musste. ${ }^{680}$

Wer sich gegen nationalsozialistische Auffassungen von negativer und positiver Eugenik aussprach, wer gegen die Zwangssterilisierung oder für Abtreibung und Empfängnisverhütung Stellung bezog, setzte seine berufliche Zukunft aufs Spiel. Publikationen des dänischen Arztes Jonathan von Leunbach, des Prager Ordinarius Hermann Knaus und der Berliner Frauenärztin AnneMarie Durand-Wever zu Problemen der Geburtenkontrolle standen zumindest zeitweilig auf der „Liste des schädlichen und unerwünschten Schrifttums“. ${ }^{681}$ Franz Anton Weber, Vorstand der II. UFK in München, nahm sich 1933 das Leben, nachdem gegen ihn eine Untersuchung wegen positiver Gutachten zur Schwangerschaftsunterbrechung eingeleitet worden war. ${ }^{682} \mathrm{Zu} 4$ Jahren Gefängnis wegen „gewerbsmäßiger Abtreibung“ wurde 1940

\footnotetext{
672 Stürmer 03/1935.

673 Stürmer 10/1935

674 Stürmer 30/1937.

675 Stürmer 05/1923.

676 Stürmer 3/1924. Im Jahr 1937 wurde Schwab von seiner evangelischen Frau Vera geschieden und kurz darauf nach New York abgemeldet, wo er 1970 starb; vgl. Höffken: Schicksale (2013), S. 343; CRT, Case No. CV96-4849.

677 LA Berlin, WGA 446/49-448/49; BayerHStaatsA, M LEA 4807.

678 Stürmer 50/1938.

${ }^{679}$ Als einziger Versuch, als Gesellschaft gegen die nationalsozialistische Politik Stellung zu beziehen, kann die „Denkschrift“ gelten; siehe S. 33 f.; vgl. auch Winau: Gynäkologie (1994), S. 17.

680 Die Begrifflichkeiten orientieren sich an Peukert: Volksgenossen (1982), S. 96 f.; eine Diskussion des Widerstandsbegriffes liefert Grüttner: Reich (2014), S. 520-526.

${ }^{681}$ Liste (1935), S. 30, 66; Liste (1938), S. $28,84$.

682 Vgl. Anthuber/Beckmann/Dietl/Dross/Frobenius (Hrsg.): Herausforderungen (2012), S. 319 [Kurzbiografie].
} 
der Kölner Frauenarzt Heinrich Offergeld verurteilt; im selben Jahr entzog ihm die Universität Bonn die Doktorwürde. ${ }^{683}$ Offergelds 1931 erschienenes Buch „Die Wirkung des Geschlechtsverkehrs auf die eheliche Treue" stand bereits seit 1935 auf dem Index. ${ }^{684}$ Dass allerdings Verbote und punktueller Dissens nicht ohne weiteres Rückschlüsse auf den politischen Standort der inkriminierten Person zulassen, ließe sich an mehreren der oben genannten Personen illustrieren.

Vergleichsweise gering ausgeprägt war der ärztliche Widerstand gegen das GzVeN, dem eine jahrzehntelange Debatte über Rassenhygiene und Eugenik den Boden bereitet hatte. Selbst kritisch eingestellte Ärzte fügten sich meist den gesetzlichen Vorschriften. Singulär ist der Fall des Deutsch-Österreichers Albert Niedermeyer, dessen offen artikulierte Ablehnung der Zwangssterilisation nicht nur unter Mitgliedern der DGG die Ausnahme blieb. ${ }^{685}$ Der Sozialgynäkologe, Jurist und katholische Theologe bezog beim Berliner DGG-Kongress im Oktober 1933 als einziger Diskussionsredner gegen das GzVeN Stellung und erntete dafür das eisige Schweigen der Versammlungsteilnehmer. ${ }^{686}$ Seine kompromisslose, im katholischen Glauben verwurzelte Kritik an der NS-Rassenpolitik hatte Niedermeyer schon vor diesem Auftritt in Schwierigkeiten gebracht: Als er im Sommer 1933 als operativ tätiger Gynäkologe in Görlitz die Durchführung eugenischer Sterilisationen verweigerte, wurde ihm die belegärztliche Tätigkeit untersagt und seiner Praxis die Kassenzulassung entzogen. Wenig später floh Niedermeyer nach Wien und erhielt dort die österreichische Staatsbürgerschaft zurück, die er während seiner Breslauer Jahre gegen die deutsche Staatsbürgerschaft eingetauscht hatte. Nach dem „Anschluss“ Österreichs führten seine andauernden publizistischen Aktivitäten gegen die NS-Rassenpolitik am 25. März 1938 zu seiner Verhaftung und Internierung im KZ Sachsenhausen, aus dem er am 19. September 1938, vermutlich infolge von Interventionen einflussreicher Freunde, gegen die Auflage künftigen Schweigens entlassen wurde. ${ }^{687} \mathrm{Im}$ Zweiten Weltkrieg war Niedermeyer als Arzt in Wiener Lazaretten tätig; nach 1945 begann er seine Hochschulkarriere als Pastoralmediziner, die in einer Tätigkeit als außerordentlicher Professor und Leiter eines entsprechenden Universitätsinstitutes ihren Höhepunkt fand.

Zu den missliebigen Mitgliedern der Gesellschaft zählten nach 1933 auch Personen, die als „politisch unzuverlässig“ eingeschätzt wurden. In ihrer Rolle als Mitglieder der DGG waren sie nicht stärker betroffen als rassisch verfolgte Personen: Hoffnungen auf ein Vorstandsamt konnten sie sich nach 1933 zwar nicht mehr machen, ihre Mitgliedschaft wurde aber nicht infrage ge- stellt. Deutlich schwerer wog auch hier die nationalsozialistische Gesetzgebung: Laut BBG sollten „Beamte, die nach ihrer bisherigen politischen Betätigung nicht die Gewähr dafür bieten, daß sie jederzeit rückhaltlos für den nationalen Staat eintreten“ aus dem Dienst entlassen werden. ${ }^{688}$ Da die Umsetzung des Paragrafen wesentlich auf Denunziation beruhte, konnten nationalsozialistische Studentenverbände durch organisierte Boykottaktionen gegen unliebsame Professoren eine enorme Wirkung entfalten. ${ }^{689}$ Im Vergleich zur rassisch motivierten „Säuberung“ war die Zahl der aus politischen Gründen entlassenen Hochschullehrer allerdings eher gering - die Mehrheit war ohnehin am rechten Rand des Parteienspektrums zu verorten. Unter den Mitgliedern der DGG konnten 5 Personen identifiziert werden, deren Ausscheiden aus dem universitären Dienst explizit politisch begründet wurde.

Bereits am 28. April 1933 wurde der Göttinger Dozent Robert Brühl wegen seiner Mitgliedschaft in der Zentrumspartei mit einem Leseverbot belegt. Allein dem Einsatz wohlgesinnter Kollegen, darunter Otto von Franqué und Walter Stoeckel, hatte er es zu verdanken, dass er sich noch im selben Jahr nach Bonn umhabilitieren durfte. Den Wechsel von Göttingen an den Rhein beschrieb Brühl rückblickend als „Weg in die Verbannung“. Da er auch in Bonn politisch motivierten Anfeindungen ausgesetzt war, ging er 1936 als niedergelassener Frauenarzt nach Völklingen und schließlich nach Trier, wo er die geburtshilflich-gynäkologische Abteilung des Herz-Jesu-Krankenhauses leitete. 1940 trat er, laut eigener Aussage auf Druck von Parteifunktionären, in die NSDAP ein, um seine berufliche Existenz nicht erneut zu gefährden. Seit 1989 erinnert in der Aula der Universität Göttingen eine Ehrentafel an Brühl und andere vertriebene Hochschullehrer. 690

Aufgrund ihrer „politischen Unzuverlässigkeit“ suspendiert oder gar nicht erst für ein Amt zugelassen - wurden darüber hinaus der als „Judenfreund“ diffamierte Bernhard Schweitzer, 691 Karl Julius Anselmino wegen angeblicher Beziehungen zur kommunistischen Partei, ${ }^{692}$ Hans Zacherl aufgrund seiner Mitgliedschaft in der Vaterländischen Partei Österreichs ${ }^{693}$ und Rudolf Hubert, der sich als DVP-Mitglied gegen eine Wahl Hitlers zum Reichskanzler ausgesprochen hatte. ${ }^{694}$ Daneben gab es eine Anzahl von Mitgliedern, die sich nach Kriegsende - beispielsweise im Rahmen eines Entnazifizierungsverfahrens - als Gegner bzw. Opfer der NS-Diktatur darstellten, ohne dass ihre Aussagen im Rahmen dieser Arbeit verifiziert werden konnten. ${ }^{695}$

Dass der Vorwurf „politischer Unzuverlässigkeit“ mitunter auch instrumentalisiert wurde, um sich unliebsamer Konkurrenten

\footnotetext{
683 Forsbach: Fakultät (2006), S. 426.

684 Vgl. Liste (1935), S. 89.

685 Siehe S. $42 \mathrm{f}$.

686 Vgl. Niedermeyer: Wahn (1956), S. 277-279.

687 Vgl. ebd., S. 417-435.

688 BBG $§ 4$.

689 Vgl. Eberle: Martin-Luther-Universität (2002), S. 39.

690 Vgl. Forsbach: Fakultät (2006), S. 234 f.; Szabó: Vertreibung (2000), S. 167 f.; Höpfner: Bonn (1999), S. 47 f.

691 Vgl. Heidel: Ärzte (2005), S. $91 \mathrm{f}$.

692 Vgl. Dusemund: Geschichte (1973), S. 71; $126 \mathrm{f}$.

693 Vgl. Czarnowski: „Anschluss“ (2012), S. 140

694 Vgl. Notz: Frauen (2003), S. 227.

695 So bezeichnete sich Otto Kneise, Professor in Halle, als „Feind des Nazi-Regimes“, der „nur um Haaresbreite am Konzentrationslager vorbeigegangen“ sei; vgl. Eberle: Martin-Luther-Universität (2002), S. 335.
} 
zu entledigen, legt der Fall des Freiburger Oberarztes Hermann Franken nahe. ${ }^{696}$ Kurz nach dem Amtsantritt des neuen Klinikdirektors Friedrich Siegert ${ }^{697}$ im Jahr 1934 kam es zwischen diesem und Franken zu scharfen Auseinandersetzungen. Franken hatte sich offenbar Hoffnungen auf die Nachfolge des verstorbenen Otto Pankow gemacht, musste nun aber enttäuscht feststellen, dass die verantwortlichen Stellen den linientreuen Siegert vorzogen, der bereits 1932 in die NSDAP eingetreten war. Siegert war entschieden darum bemüht, den Ambitionen Frankens entgegen zu treten; er verbot dem Konkurrenten, sich innerhalb der Klinik mit „Professor“ anreden zu lassen und legte ihm nahe, das Haus bis 1935 zu verlassen. In dieser Weise unter Druck gesetzt, reichte Franken zwar am 15. Dezember 1934 die Kündigung ein, versäumte es aber nicht, das Kultusministerium über die besonderen Umstände seines Ausscheidens zu unterrichten. Siegert, der dies als persönlichen Angriff verstand, ließ daraufhin über seinen Anwalt mitteilen, dass „der heutige Staat die von ihm berufenen Professoren [...] zu schützen wisse " und fügte vielsagend hinzu: „Ich habe die Überzeugung, daß Sie in diesem Fall auch Ihr in der Nachmärzzeit 1933 erworbenes SA-Kleid nicht wird schützen können“. In Schreiben an das Kultusministerium und das Kreisgericht der NSDAP ließ Siegert wissen, dass er gegen Franken „aus politischen Gründen große Bedenken“ hege, da dieser „lediglich aus Opportunitätsgründen“ in die SA eingetreten sei und die Nationalsozialisten vor 1933 abgelehnt habe, wofür es an der Freiburger Klinik zahlreiche Zeugen gebe. Zwar blieb ein von Siegert forciertes Parteigerichtsverfahren offenbar ohne Folgen, an die Universität Freiburg konnte Franken dennoch erst ein Jahrzehnt später zurückkehren: 1945 übernahm er die kommissarische Leitung der UFK und beerbte in dieser Funktion seinen einstigen Gegenspieler, den von den Alliierten suspendierten Friedrich Siegert.

\section{Solidarisierung mit rassisch und politisch Verfolgten}

Es sind ungewohnt selbstkritische Töne, die Walter Stoeckel in seinen Memoiren anschlägt, wenn er bezüglich des Umgangs mit jüdischen Ärzten konstatiert, „daß wir deutschen Universitäts-Professoren insgesamt versagt haben, als es darum ging, in schwerer Zeit Solidarität zu zeigen - eine Solidarität der Herzen“. ${ }^{698}$ Freilich habe man sich, so Stoeckels rückblickende Einschätzung, „gegen den braunen Terror nicht auflehnen“ können. Doch hatte es von Seiten der - durchaus einflussreichen - Ärzteschaft und der DGG überhaupt Versuche gegeben, gegen die rassisch und politisch begründete Ausgrenzung von Kollegen das Wort zu ergreifen?

Zweifellos gab es Mitglieder, die Bekannten und Patienten „in schwerer Zeit“ beistanden. Dazu zählen Ärzte wie Bernhard Schweitzer und Kurt Warnekros, die sich auch unter enormem
Druck nicht davon abbringen ließen, jüdische Frauen zu behandeln, ${ }^{699}$ oder Wernher Wiemer, der rassisch verfolgten Personen im Bochumer Elisabeth-Hospital Unterschlupf bot. ${ }^{700}$ Auch sind in Einzelfällen Versuche bekannt, Entlassungen „missliebiger“ Gynäkologen aus dem Hochschulbetrieb zu verhindern. ${ }^{701}$ Diese richteten sich allerdings nicht gegen die „Säuberungspolitik“ als solche, sondern waren stets auf einzelne Personen bezogen, für die man Ausnahmen vor allem deshalb erwirken wollte, weil sie für Forschung und Lehre als unersetzlich galten. Als der an der UFK Münster tätige Oberarzt Karl Adler 1934 aus rassischen Gründen - er galt als „Vierteljude“ - aus dem Dienst entlassen werden sollte, verfasste Peter Esch, Direktor der Klinik, ein Gutachten, in dem er für einen Verbleib seines begabten Schülers an der Universität plädierte. ${ }^{702}$ Weder er „noch jemand in der Fakultät“, beteuerte Esch, habe bei Adler „auch nur vermutet, dass einer seiner Großeltern jüdischer Rasse sein könnte“. Im Übrigen sei Adler „4-jähriger Frontkämpfer“, national gesinnt und stünde der NSDAP seit 1934 nahe. Letztlich wogen sämtliche Argumente die jüdische Abstammung nicht auf; Adler musste die Universität Münster verlassen und ließ sich als Frauenarzt in Emden nieder. Dort war er weiteren Anfeindungen ausgesetzt war: In einem Boykottaufruf, den die Ostfriesische Tageszeitung 1935 druckte, ist auch sein Name aufgeführt. ${ }^{703}$

Wenngleich alle genannten Vorfälle Mitglieder der DGG betrafen, sind sie doch unabhängig von der DGG zu betrachten. Von deren Vorstand und auf deren Tagungen war kein Wort der Solidarität mit den über 100 rassisch und politisch verfolgten Mitgliedern und Kollegen zu vernehmen. Einige Jahre zuvor, im Frühjahr 1923, hatte sich der Vorstand in anderer Angelegenheit durchaus kämpferisch gezeigt: Obwohl die Gesellschaft „als ärztlich-wissenschaftliche Körperschaft zu rein politischen Maßnahmen keine Stellung zu nehmen“ habe, fühlte sich der 1. Vorsitzende, Carl Menge, dazu verpflichtet, gegen die „Verletzung eines der vornehmsten und vordinglichsten Menschlichkeitsgedankens auf das schärfste protestieren zu sollen“ ${ }^{704}$ Anlass der deutlich artikulierten Empörung war die Behandlung deutscher Ärzte im besetzten Rheinland, denen durch Beschluss der französischen Alliierten „aus fadenscheinigen Gründen ihrer Existenzmöglichkeit“ genommen worden sei. ${ }^{705}$

Anders als die rheinischen Ärzte konnten die nach 1933 verfolgten DGG-Mitglieder Unterstützung und Fürsprache von Seiten der Gesellschaft in der Regel nicht erwarten. Sofern sie sich von dem Verband eine Verteidigung ihrer „Existenzmöglichkeit“ versprochen hatten, wurde diese Hoffnung bereits durch die Eröffnungsworte des Vorsitzenden Walter Stoeckel auf der Tagung 1933 zerschlagen, als dieser die Verdrängung jüdischer Kollegen zum notwendigen „Kollateralschaden“ im Interesse der „Gesun-

\footnotetext{
696 Vgl. dazu Franken: Erinnerungen (1990), S. 42-47.

697 Zu Siegert siehe auch S. 47 (Fußnote 344) und S. 80.

698 Stoeckel: Erinnerungen (1966), S. 436 f.

699 Vgl. Heidel: Ärzte (2005), S. 91 f.; Kailitz: Experiment (2012).

700 Vgl. Piorr: Wertheim (2011).

701 So setzten sich Walter Stoeckel für Robert Meyer und G.A. Wagner - zum Missfallen der NS-Führung - für Selmar Aschheim ein; vgl. Hinz/Ebert/Goetze: Exodus (1994); Ulrich/Ebert: Wagner (1994), S. 202.

702 Vgl. Heitkötter: Münster (2012), S. 37-39, CLVII-CLIX.

703 Vgl. Garz/Janssen: Mangel (2006), S. 153 f.

704 Menge: Eröffnung [Verhandlungen 1923] (1924), XXXIV.

705 Ebd. In diesen Kontext gehört auch, dass sich die DGG 1925 in einer scharfen Resolution gegen die ihrer Ansicht nach ungerechtfertigte Beurlaubung von Erwin Kehrer als Direktor der Staatlichen Dresdner Frauenklinik wandte. Bei der Tagung wurde eine Kommission zur Aufklärung des Falles eingesetzt, der auch Stoeckel angehörte. Gleichzeitig warnte die Gesellschaft alle Mitglieder, in Verhandlungen wegen der Übernahme der Klinik einzutreten. Die Sache erledigte sich dadurch, dass Kehrer Ordinarius in Marburg wurde. Basisdaten zur Person in den Kurzbiografien im Anhang.
} 
dung“ des deutschen Volkes erklärte und im Namen der Gesellschaft betonte, das „Geschick“ der Betroffenen nicht wenden zu können. Im Unterschied zu 1923, so die implizite Logik, galt es diesmal eben nicht, bedrängte Kollegen gegen äußere Gefahren zu verteidigen - vielmehr galten die „artfremden“ jüdischen Ärzte nun selbst als äußere Gefahr für „Volksgemeinschaft“ und „Volksgesundheit“. Sämtliche Gepflogenheiten und Gebote der ärztlichen Kollegialität waren damit außer Kraft gesetzt; die Gesellschaft, die manche der Betroffenen noch wenige Jahre zuvor geehrt hatte, führte ihren standespolitischen Auftrag ad absurdum.

Von Stoeckels Rede einmal abgesehen, hielten sich die Vertreter der DGG nach außen mit lärmender antisemitischer Rhetorik zurück, nach innen fügten sie sich den Forderungen staatlicher Stellen. Das in den Tagungsberichten vermittelte Bild eines bedingungslosen Einvernehmens und ständigen „langanhaltenden Beifalls“ sollte indes nicht darüber hinwegtäuschen, dass unter den Mitgliedern durchaus gemäßigte, kritische und nachdenkliche Stimmen zu vernehmen waren. Abweichende Meinungen und Solidaritätsbekundungen, das war bereits 1933 den meisten klar, wurden freilich nicht auf den Kongressen geäußert, sondern im Privaten und Verborgenen, in persönlichen Schreiben oder einem „verstohlenen Händedruck“ ${ }^{706}$ Unbekannt ist, wie viele Ärzte der Gesellschaft aus Protest gegen „Gleichschaltung“ und „Rassenpolitik“ den Rücken kehrten. Bei 65 Personen, die zwischen 1931 und Dezember 1933 aus dem Mitgliederverzeichnis gestrichen wurden, ist über den Grund ihres Ausscheidens nichts bekannt, politische Beweggründe können nicht ausgeschlossen werden.

Der, je nach Rolle und Funktion, unterschiedlich empfundene Handlungsspielraum sowie die Abwägung persönlicher und professioneller Interessen waren bei der Entscheidung, für verfolgte Kollegen einzutreten, zwei nicht zu unterschätzende Faktoren. Eine höchst widersprüchlich erscheinende Figur wie Walter Stoeckel konnte - in seinen Augen: musste - die antisemitische Politik der Regierung in seiner Rolle als Vorsitzender der DGG rückhaltlos vertreten, während er zur gleichen Zeit, diesmal in der Rolle des einflussreichen und erfolgsorientierten Klinikleiters, für den rassisch verfolgten Robert Meyer eintrat ${ }^{707}$ und, in seiner Rolle als selbstbewusster Herausgeber, noch im Dezember 1937 einen Aufsatz des „Nichtariers“ Paul Straßmann für das Zentralblatt für Gynäkologie annahm. ${ }^{708}$

\section{Erzwungene Emigration und Neubeginn in der Fremde}

Es war schon dunkel, als der Berliner Frauenarzt Max Hirsch einen alarmierenden Anruf erhielt. Der Gesprächsteilnehmer stellte sich als Generaldirektor vor; seine Frau habe starke Blutungen, Hirsch solle sofort vorbeikommen, ein Wagen sei bereits unterwegs, um ihn abzuholen. „Noch während Hirsch hinunterging“, so Albert Niedermeyer, in dessen Autobiografie der Vorfall über- liefert ist, „hielt bereits eine große Luxuslimousine, in der neben dem Chauffeur noch ein Mann saß. In rasender Fahrt ging es in den Grunewald, wo an einsamer Stelle der Wagen hielt, die beiden Männer heraussprangen, den Arzt herauszogen und unter vorgehaltenem Revolver aufs schwerste bedrohten und mißhandelten und ihm schließlich sagten: ,Wenn du nicht sofort nach Palästina verschwindest, wirst du kaltgemacht! ‘“709

Vor dem Hintergrund der extremen Zwangslage und der physischen Bedrohung, der die jüdische Bevölkerung bereits ab 1933 ausgesetzt war, sind die Begriffe „Auswanderung“ und „Emigration“ fast immer im Sinne einer Flucht zu verstehen. ${ }^{710}$ Nach einem rasanten Anstieg der Emigration ab Januar 1933 und einer zweiten Auswanderungswelle nach Bekanntgabe der „Rassegesetze“ flohen die meisten Juden in den Jahren 1938 und 1939. Für viele Ärzte hatte der Approbationsentzug im September 1938 den Ausschlag gegeben: Das Erlöschen der Bestallung zerstörte endgültig die Hoffnung, in Deutschland weiterhin als Arzt tätig sein zu können. Massiv erhöht wurde der Emigrationsdruck wenig später durch die reichsweiten Gewaltexzesse im November 1938: Zehntausende Juden, darunter auch Max Hirsch, ${ }^{711}$ wurden im Zuge des Pogroms in „Schutzhaft“ genommen, in Konzentrationslager verschleppt und erst dann wieder freigelassen, wenn sie ihrer Auswanderung zugestimmt hatten.

Der Ausbruch des Krieges führte noch einmal zu einem Anstieg der - nun deutlich erschwerten - Fluchtbewegungen, ehe am 1. Oktober 1941 der jüdischen Bevölkerung die Ausreise untersagt wurde. Ab diesem Zeitpunkt wurde die „Lösung der Judenfrage“ nicht mehr durch forcierte Emigration und Vertreibung angestrebt, sondern durch die systematische Vernichtung der „jüdischen Rasse“.

\section{Mitglieder der DGG in der Emigration}

Mehr als der Hälfte der in Deutschland und Österreich lebenden Juden gelang bis 1945 die Flucht ins Ausland, darunter bis zu 75\% aller rassisch verfolgten Ärzte. ${ }^{712}$ Von rund 150 jüdischen Mitgliedern der DGG, die im Einflussbereich der Nationalsozialisten lebten, emigrierten nachweislich 95, möglicherweise sogar 105, was ebenfalls einem Anteil von 60-70\% entspricht. Offenbar nur 5 von ihnen kehrten nach Kriegsende dauerhaft nach Deutschland zurück.

Bemerkenswert und, bedingt durch das vergleichsweise hohe Durchschnittsalter der Mitglieder, untypisch ist das Alter der Emigranten: Mehr als die Hälfte war bei der Auswanderung über 50 Jahre alt, 20 sogar 60 und älter; der Wiener Arzt Carl Fleischmann musste seine Heimat noch im Alter von 79 Jahren verlassen und ließ sich 1938 in London nieder. ${ }^{713}$ Arthur Simon, bis 1936 niedergelassener Frauenarzt in Berlin, legte mit 59 Jahren das New Yorker Medizinexamen ab und führte bis ins hohe Alter eine eigene Praxis; er starb 1979 mit 102 Jahren. ${ }^{714}$

\footnotetext{
706 Vgl. Niedermeyer: Wahn (1956), S. 279.

707 Vgl. Neumann-Redlin von Meding/Conrad: Ärzte (2013), S. 53 f.

708 Vgl. David/Stürzbecher/Ebert: Straßmann (1994), S. 157. Straßmann notierte in sein Tagebuch: „Alle Achtung, daß Stoeckel auch diesen Druck so gewagt hat."

709 Niedermeyer: Wahn (1956), S. 285.

710 Vgl. Grüttner: Reich (2014), S. 185.

711 Vgl. Neumann-Redlin von Meding/Conrad: Ärzte (2013), S. 46.

712 Vgl. Kröner: Emigration (1988), S. 84, 86.

713 Vgl. Österreichische Nationalbibliothek (Hrsg.): Handbuch (2002), S. 336.

714 Vgl. AJR (= Association of Jewish Refugees in Great Britain) Information XXXV, 3 (1980), S. 7.
} 
Die Hauptauswanderungsländer USA (Anlaufstation für ca. 50\% aller emigrierten Ärzte), Palästina (20\%) und Großbritannien (12\%) wurden auch von den Mitgliedern der DGG präferiert: Von 95 nachweislich emigrierten Personen flohen 46 direkt oder über Umwege in die Vereinigten Staaten, 16 nach Großbritannien, 6 nach Palästina. 27 Emigranten verteilten sich auf 16 weitere Staaten auf allen Kontinenten.

Der „Anschluss“ Österreichs, die Besetzung der Tschechoslowakei und die deutschen Vorstöße im Zweiten Weltkrieg brachten rund 30000 aus Deutschland emigrierte Juden abermals in Gefahr, darunter mindestens 10 Mitglieder der DGG. Die 1933 nach Frankreich ausgewanderte Sexualwissenschaftlerin Hertha Riese wurde durch den Einmarsch der Wehrmacht 1940 erneut zur Flucht gezwungen; über Casablanca und Kanada gelang ihr die Einreise in die USA. ${ }^{715}$ Selmar Aschheim, der 1936 nach Paris geflohen war, überlebte die Jahre der deutschen Besatzung im Untergrund. ${ }^{716}$ Ebenfalls in akuter Gefahr schwebte Hans Sänger, der 1933 nach Norwegen, das Herkunftsland seiner Mutter, ausgewandert war. Die ständige Furcht vor einer Verhaftung habe dazu beigetragen, dass Sänger, der seit seiner Flucht an Schlafstörungen litt, 1943 im Alter von nur 58 Jahren starb. ${ }^{717}$ Nicht allen DGG-Mitgliedern gelang die erneute Flucht: Irma Jacoby und Max Samuel wurde die Besetzung ihrer Aufnahmeländer zum Verhängnis; sie wurden von den Nationalsozialisten aufgegriffen und nach Auschwitz deportiert. ${ }^{718}$

Die meisten der 16 österreichischen DGG-Mitglieder, ${ }^{719}$ die ab 1938 der rassischen Verfolgung ausgesetzt waren, dürften eine Vorstellung von dem besessen haben, was ihnen bevorstand. ${ }^{720}$ Mindestens 14 von ihnen verließen das Land noch im Jahr des „Anschlusses“ oder im darauffolgenden Jahr. Bis 1941 gelang allen die Flucht. ${ }^{721}$

Von den 6 tschechoslowakischen Mitgliedern jüdischer Herkunft emigrierte dagegen kein einziges. Eduard Arnstein, Viktor Hahn und Julius Wechsberg fielen, wie der größte Teil der tschechoslowakischen Juden, der Shoa zum Opfer, ${ }^{722}$ Ferdinand Schenk starb am 17. Mai 1945 mit 75 Jahren unter nicht bekannten Umständen in Prag, ${ }^{723}$ Robert Benda 2 Jahre später ebenfalls in Prag; er wurde 57 Jahre alt. ${ }^{724}$ Hans Hermann Schmid, der nach nationalsozialistischer Definition als „Halbjude“ galt, konnte seine Privatpraxis in Reichenberg bis 1945 fortführen, nachdem er als Direk- tor der Städtischen Frauenklinik suspendiert worden war; er starb 1963 in Rostock. ${ }^{725}$

\section{Voraussetzungen und Hürden der Auswanderung}

Die Bestimmungen über Einwanderung und Wiederzulassung zur ärztlichen Tätigkeit variierten von Land zu Land und waren auch zeitlich beträchtlichen Schwankungen unterworfen. ${ }^{726}$ Insbesondere in Ländern, die sich, wie etwa Großbritannien, als Durchgangsstation verstanden, war eine Zulassung von Flüchtlingen zur ärztlichen Tätigkeit in der Regel nicht vorgesehen. Zwar existierten vielerorts Hilfsorganisationen, die Neuankömmlingen beim Aufbau einer Existenz behilflich waren; als ungleich wirkmächtiger erwiesen sich jedoch ärztliche Lobbyverbände und politische Parteien, die, mitunter äußerst polemisch, eine strikte Begrenzung der Einwanderung forderten; zur Begründung wurde nicht nur auf den drohenden Konkurrenzdruck verwiesen, sondern auch auf die, wenige Jahre nach Beginn der Weltwirtschaftskrise, als untragbar empfundenen Kosten, die durch eine Versorgung der vielen mittellosen Flüchtlinge entstünden. ${ }^{727}$

Der zuletzt genannte Aspekt verweist auf eine weitere, nicht zu unterschätzende Auswanderungshürde: eine systematische Ausplünderungspolitik, unter anderem auf Grundlage der „Reichsfluchtsteuer", hatte gerade die emigrationsbereiten Juden in den finanziellen Ruin getrieben. ${ }^{728}$ Aus Wiedergutmachungs- und Entschädigungsakten geht hervor, wie selbst wohlhabende Ärzte Schritt für Schritt ihrer Existenzgrundlage beraubt wurden. Eindrucksvoll legt der Münchner Gynäkologe Hans Bab dar, wie sich seine Ersparnisse in den 2 Jahren vor seiner Auswanderung nach Großbritannien von 66000 RM auf 23600 RM reduzierten womit er immer noch zu einer Minderheit deutlich besser gestellter Emigranten zählte. ${ }^{729}$ Hält man sich vor Augen, dass es Monate dauern konnte, bis geflohene Ärzte in ihrem Aufnahmeland einem geregelten Beruf nachgehen konnten und der Aufbau einer Praxis mit erheblichen Kosten verbunden war, wird deutlich, wie rasch selbst ein beachtliches Vermögen aufgebraucht sein konnte.

In den ersten Wochen und Monaten kamen die Geflohenen daher meist bei Angehörigen oder Bekannten unter, die nicht selten selbst emigriert waren. Der Frankfurter Arzt Leo Hess, der noch 5 Jahre nach seiner Ankunft in New York und 3 Jahre nach Ablegung des US-Examens, auf fremde Beihilfe angewiesen war, ist in

\footnotetext{
715 Vgl. Kühl: Riese (2009), S. 591-593.

716 Vgl. Schagen: Vertreibungen (2008), S. 58.

717 Vgl. Hem/Børdahl: Tyskland (2000).

718 Siehe S. 92-94.

719 Die österreichischen DGG-Mitglieder jüdischer Herkunft wirkten ausnahmslos in Wien, die meisten an den UFK.

720 Vgl. Czarnowski: „Anschluss“ (2012), S. 138.

721 Mit Ausnahme des Wiener Hochschuldozenten Robert Joachimovits gingen sie in die USA oder nach Großbritannien; vgl. Bauer-Merinsky: Auswirkungen (1980).

722 Siehe S. 91-93.

723 Vgl. Österreichische Nationalbibliothek (Hrsg.): Handbuch (2002), S. 1192 f. Am 17. Juli 1939 stand Schenks Name auf einer Liste von Professoren, deren Geburtstage laut einer Weisung des Propagandaministeriums „nicht zu gedenken“ sei; vgl. NS-Presseanweisungen (2001), S. 704.

724 Vgl. Wlaschek: Biografia (1995), S. 19.

725 Vgl. Engelmann: Reichenberg (2012), S. 121; 265; Guntau: Schmid (2009).

726 Einen Überblick bietet Villiez: Emigration (2014).

727 Vgl. Pearle: Medicine (1991), die ausführlich auf den Fall des DGG-Mitglieds Benno Liegner eingeht, der 1936 in einem Aufsehen erregenden Prozess mit Erfolg gegen die Entscheidung der New Yorker Universität vorging, sein in Breslau abgelegtes Examen nicht anzuerkennen.

728 Bis 1940 beliefen sich die Einnahmen aus der „Reichsfluchtsteuer“ - fällig wurden 25\% des Vermögens ab einem Vermögen von 500000 RM oder einem Jahreseinkommen von mehr als 20000 RM - auf rund 900 Millionen Reichsmark; vgl. Hilberg: Vernichtung (1982), S. 101.

729 LA Berlin, WGA 446/49-448/49.
} 


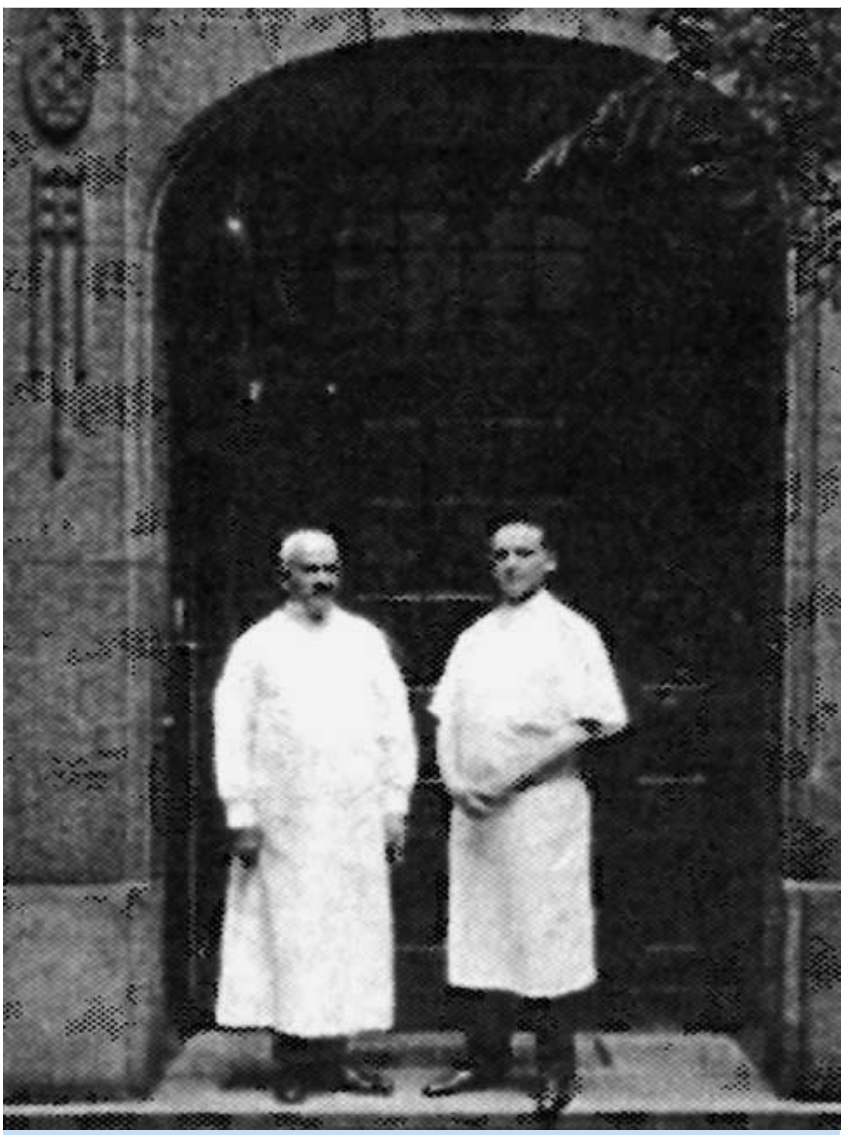

Abb. 37 Der angesehene Berliner Gynäkologe Paul Straßmann (18661938) mit seinem Sohn, dem Gynäkologen Erwin Straßmann (1895-1972). Während Erwin 1936 in die USA floh, lehnte sein Vater die Emigration bis zu seinem Tod im Jahr 1938 ab (aus: David M, Ebert A. Berühmte Frauenärzte in Berlin; mit freundlicher Genehmigung des Mabuse-Verlags und von Matthias David und Andreas Ebert, Berlin).

dieser Hinsicht sicher kein Einzelfall unter den geflohenen DGGMitgliedern. ${ }^{730}$ Eine Odyssee über mehrere Kontinente nahm der Konstanzer Arzt Samuel „Semi“ Moos nach seiner Emigration im April 1933 auf sich: Nachdem sämtliche Versuche, in Frankreich, Marokko, der Schweiz, Palästina und den USA eine Existenz aufzubauen, gescheitert waren, ließ er sich 1941 in Melbourne nie$\operatorname{der}^{731}$

Vielfach im Dunkeln bleiben die enormen psychischen Belastungen, die der beschwerliche Neuanfang mit sich brachte. Mit Kultur und Sprache ${ }^{732}$ ihres Aufnahmelandes nicht vertraut, gelang es manchen Ärzten nur schwer, in der Fremde Fuß zu fassen. Hinzu kamen quälendes Heimweh sowie die Sorge um in Deutsch- land gebliebene Verwandte und Freunde. Nicht zuletzt sahen sich emigrierte Juden auch im Ausland mit antisemitischen Ressentiments konfrontiert, nach 1939 zudem mit einer kriegsbedingten Deutschenfeindlichkeit. ${ }^{73}$ Der Verdacht, dass sich unter den Flüchtlingen deutsche Spione befänden, machte in den Vereinigten Staaten ebenso Schlagzeilen wie die Furcht vor einer kommunistischen Unterwanderung durch jüdische Immigranten. ${ }^{734}$

Dass der emotionale Ausnahmezustand der Ausgrenzung und der erzwungenen Emigration gravierende Auswirkungen auf die psychische und körperliche Gesundheit der Betroffenen haben konnte, legen mehrere der untersuchten Emigrantenschicksale nahe. So berichtet die Frau des aus Bremen vertriebenen Arztes Walther Cohen in ihrem Antrag auf Entschädigung, dass ihr Mann nach seiner Flucht in die USA „weiterhin viel von Deutschland gesprochen“ habe und oft "niedergeschlagen und nervoes“ gewesen sei. Dass Cohen 1954 an Parkinson erkrankte und seine Praxis aufgeben musste, führte seine Frau auf die enorme psychische Belastung während der NS-Zeit zurück. ${ }^{735}$

Erwähnt werden sollte allerdings auch, dass es emigrierten Medizinern - im Unterschied zu Emigranten anderer Berufsgruppen - in den meisten Fällen gelang, wieder in ihrem Berufsfeld tätig zu sein. ${ }^{736}$ Die Mitglieder der DGG waren in dieser Hinsicht keine Ausnahme. Insbesondere die auch finanziell besser gestellten Hochschulmediziner hatten durch Kongressbesuche Kontakte ins Ausland geknüpft, die sich nun als unschätzbarer Vorteil erwiesen. ${ }^{737}$ Dem Berliner Gynäkologen Erwin Straßmann etwa brachte eine seit 1929 bestehende Freundschaft mit Will und Charles Mayo eine befristete Stelle als „Beobachter amerikanischer Diagnose- und Therapiemethoden“ an der Mayo-Klinik in Rochester ein $\left(\bullet\right.$ Abb. 37). ${ }^{738}$

Besonders reibungslos gestaltete sich die Auswanderung in den seltenen Fällen, in denen eine Einladung oder ein Ruf ins Ausland erging. So konnte der Breslauer Gynäkologe Erich Fels bereits 1934 eine Stelle als Leiter der neu gegründeten Abteilung für Biopathologie und Experimentelle Chirurgie an der UFK Buenos Aires antreten und seine vielversprechende Karriere erfolgreich und vergleichsweise bruchlos fortsetzen. ${ }^{739}$ Mindestens 2 DGGMitglieder, Ludwig Schoenholz und Wilhelm Liepmann, folgten einer Einladung der türkischen Regierung, die ausgewählten jüdischen Wissenschaftlern Aufnahme gewährte, um mit ihrer Unterstützung das türkische Hochschul- und Gesundheitswesen aufzubauen und zu reformieren. ${ }^{740}$ Medizinische „Aufbauarbeit“ war auch im britischen Mandatsgebiet Palästina zu leisten; hier trugen profilierte Mediziner wie Bernhard Zondek maßgeblich zur Etablierung eines modernen Gesundheitswesens bei.

\footnotetext{
730 Vgl. Drexler-Gormann: Ärzte (2009), S. 69.

731 Auskunft des Stadtarchivs Konstanz.

732 Vereinzelt finden sich in Akten und Memoiren Hinweise auf Schwierigkeiten beim Spracherwerb; vgl. Meyer/Novak: Autobiography (1949), S. 95.

733 Vgl. Moll/Engel: Emigration (2011), S. 222.

734 Gerber: Anti-Semitism (1986), S. 184; Ueberschär: Hitlergegner (2011), S. 352 f.

735 StaatsAB, 4,54 E - 10128, Bl. 139. Letztlich wurde der Antrag auf Entschädigung wegen Schaden an Körper oder Gesundheit abgelehnt. Wegen der Parkinsonerkrankung wurde Cohen aber eine monatliche Rente anstatt einer einmaligen Entschädigungszahlung zugestanden.

736 Vgl. Villiez: Emigration (2014), S. 191.

737 Vgl. Meyer/Novak: Autobiography (1949), S. 93.

738 Vgl. David: Straßmann (2007), S. 111.

739 Vgl. Engelhardt (Hrsg.): Enzyklopädie (2002), S. 169.

740 Vgl. dazu Erichsen: Medizinemigration (2004), S. 65 f.; Namal: Emigranten (2015).
} 


\section{Gründe gegen die Emigration}

Allen Schikanen und Demütigungen zum Trotz war der Entschluss zur Auswanderung ein schwerer Schritt, der mitunter lange, manchmal zu lange, hinausgezögert wurde. Alter und Krankheit, der Verlust der vertrauten Heimat und unsichere Perspektiven im Ausland, die Sorge um Angehörige, aber auch die Bindung an Patienten sind nur einige Aspekte, die sich hemmend auf die Emigrationsbereitschaft auswirken konnten. Hinzu kam nicht selten die trügerische Hoffnung, dass der nationalsozialistische „Spuk“ bald vorüber sei oder seinen Höhepunkt überschritten habe. Zu spät erkannten viele Ärzte, dass Ausnahmeregelungen und „Privilegien“ keinen verlässlichen und dauerhaften Schutz bieten konnten.

Zusätzlich begünstigt wurde der Wille zum Bleiben durch eine oftmals nur geringe Identifizierung mit der jüdischen Glaubensgemeinschaft und eine nicht zuletzt durch Jahrzehnte der Assimilation bedingte Verwurzelung im deutschen Kultur- und Geistesleben. Von den als jüdisch geltenden DGG-Mitgliedern war ein erheblicher Teil zum Christentum konvertiert oder in höherer Generation christlich getauft. Nicht weniger als ihre „nichtjüdischen" Altersgenossen legten viele einen ausgeprägten Patriotismus an den Tag und betonten ihre Zugehörigkeit zur deutschen Nation; die meisten waren teils hochdekorierte Weltkriegsveteranen. Wie weit die Verbundenheit mit dem Vaterland gehen konnte, zeigt eine Äußerung des 1895 zum Protestantismus konvertierten Paul Straßmann, dessen Sohn Hellmuth 1916 in Frankreich gefallen war. Anlässlich der Ernennung Hitlers zum Reichskanzler bekannte er, „selbstverständlich mit ganzem Herzen auf dem Boden der nationalen Erhebung " zu stehen. ${ }^{741}$ Angesichts dieses "naiven Patriotismus“742 verwundert es nicht, dass der international bestens vernetzte Straßmann 1934 von einer Vortragsreise in die USA nach Deutschland zurückkehrte, offenbar ohne die Auswanderung ernsthaft erwogen zu haben. ${ }^{743}$ Nachvollziehbar wird auch, weshalb vor allem ältere Ärzte mit Unverständnis und trotzigem Stolz auf ihre Ausgrenzung reagierten: Als der Kölner Arzt Maximilian Samuel am 9. November 1938 von 2 Gestapo-Beamten aufgesucht wurde, trat er ihnen demonstrativ in seiner Weltkriegsuniform entgegen. Eine ähnliche Signalwirkung dürfte der Pforzheimer Frauenarzt Rudolf Kuppenheim im Sinn gehabt haben, als er seine Weltkriegsorden auf einem Samtkissen drapierte, ehe er sich mit seiner Frau das Leben nahm. ${ }^{744}$

Den meisten der bis 1938 in Deutschland gebliebenen Juden stand nach den Novemberpogromen eine rapide Verschlechterung ihrer Lebensumstände bevor. Sie wurden gezwungen, ihren Wohnsitz zu verlassen und in "Judenhäuser“ umzuziehen. Die Pflicht, den Zweitnamen Israel oder Sara zu führen und den gelben Stern zu tragen, verschärfte die permanente Erfahrung von
Demütigung und Stigmatisierung, während Gesetze wie die „Judenvermögensabgabe" auf den endgültigen finanziellen Ruin der jüdischen Bevölkerung abzielten. Ärzten blieb nach dem Entzug der Approbation nur die Tätigkeit in einem der verbliebenen Jüdischen Krankenhäuser bzw. die Degradierung zum „Krankenbehandler".

Die massiven Einschränkungen und Schikanen veranlassten noch einmal zahlreiche Juden zur Emigration. Eines der letzten DGGMitglieder, dem vor dem Auswanderungsverbot die Flucht ins sichere Ausland gelang, war der prominente Berliner Gynäkologe Ernst Gräfenberg, der sich erst nach einem längeren Gefängnisaufenthalt wegen angeblichen Devisenschmuggels zur Emigration entschloss und über Sibirien und Japan in die Vereinigten Staaten gelangte. ${ }^{745}$

\section{In den Tod getrieben und deportiert}

Von rund 40 „nichtarischen“ Mitgliedern der Gesellschaft, die nachweislich nicht emigrierten, erlebten nur 5 das Ende der nationalsozialistischen Gewaltherrschaft in ihrer Heimat. ${ }^{746}$ 15 DGG-Mitglieder starben zwischen 1933 und 1945 - die meisten in der Frühphase des Regimes - eines, soweit wir wissen, natürlichen Todes; 9 wurden zwischen 1938 und 1943 in den Selbstmord getrieben. 11 weitere Mitglieder fielen dem antisemitischen Terror und der Vernichtung unmittelbar zum Opfer.

\section{Erzwungener Selbstmord als Flucht in den Tod}

Tausende rassisch und politisch verfolgte Menschen wurden in der Zeit des Nationalsozialismus in den Selbstmord getrieben, darunter mindestens 300 Ärztinnen und Ärzte - die Dunkelziffer liegt vermutlich wesentlich höher. ${ }^{747}$ Angesichts der verzweifelten Notlage, in der sich die Betroffenen befanden, diente die „extremste Form der Flucht" mitunter als letzter Akt der Selbstbehauptung. ${ }^{748}$ Aus den Reihen der DGG-Mitglieder sind 9 Personen bekannt, die den Suizid als letzte Option ansahen, der rassischen Verfolgung zu entgehen. ${ }^{749}$ Was sie verbindet, ist ihr relativ hohes Alter - 70 Jahre im Schnitt -, ein Faktor, der bei der Entscheidung gegen eine Auswanderung womöglich von Bedeutung war. ${ }^{750}$ In beinahe allen Fällen lässt sich der Entschluss zum Suizid mit einem konkreten äußeren Anlass in Verbindung bringen.

Oskar Frankl, seit 1920 Professor an der Universität Wien und 1925 Beisitzer beim Wiener Kongress, setzte seinem Leben am 18. März 1938 ein Ende - 5 Tage nach dem „Anschluss“ seiner Heimat an das Deutsche Reich. ${ }^{751}$ Den Tod führte er durch eine Überdosis des damals zu diesem Zweck häufig benutzten Schlafmittels Veronal herbei.

Im Zusammenhang mit den Novemberpogromen des Jahres 1938 steht der Suizid des Frankfurter Arztes Bernhard Rosenthal, der

\footnotetext{
741 David: Straßmann (2007), S. 110.

742 Strassmann: Strassmanns (2006), S. 176.

743 David: Straßmann (2007), S. 102. Ludwig Pick und Ernst Gräfenberg schlugen ähnliche Angebote aus; vgl. Simmer: Pick (2000), S. 301.

744 Siehe S. 90 (Kuppenheim) und S. 93 f. (Samuel).

745 Vgl. Beller: Einfluss (1986), S. 386 f.

746 Robert Benda und Ferdinand Schenk in Prag, Heinrich Kahr und Josef Schiffmann in Wien, Paul Meyer in Berlin.

747 Vgl. Ohnhäuser: Verfolgung (2014), S. 273-276.

748 Kwiet/Eschwege: Selbstbehauptung (1984), S. 194.

749 Dass der bekannte Berliner Gynäkologe Paul Straßmann sich 1938 das Leben genommen habe, wie zuletzt bei Grüttner/Kinas: Vertreibung (2007), S. 156 zu lesen, gilt mittlerweile als widerlegt; vgl. Rudloff/Ludwig: Gynecologists (2005), S. 253.

750 Siehe S. 89 .

751 Zum Anstieg der Suizide in Österreich im März 1938 vgl. Botz: Nationalsozialismus (2011), S. 137.
} 


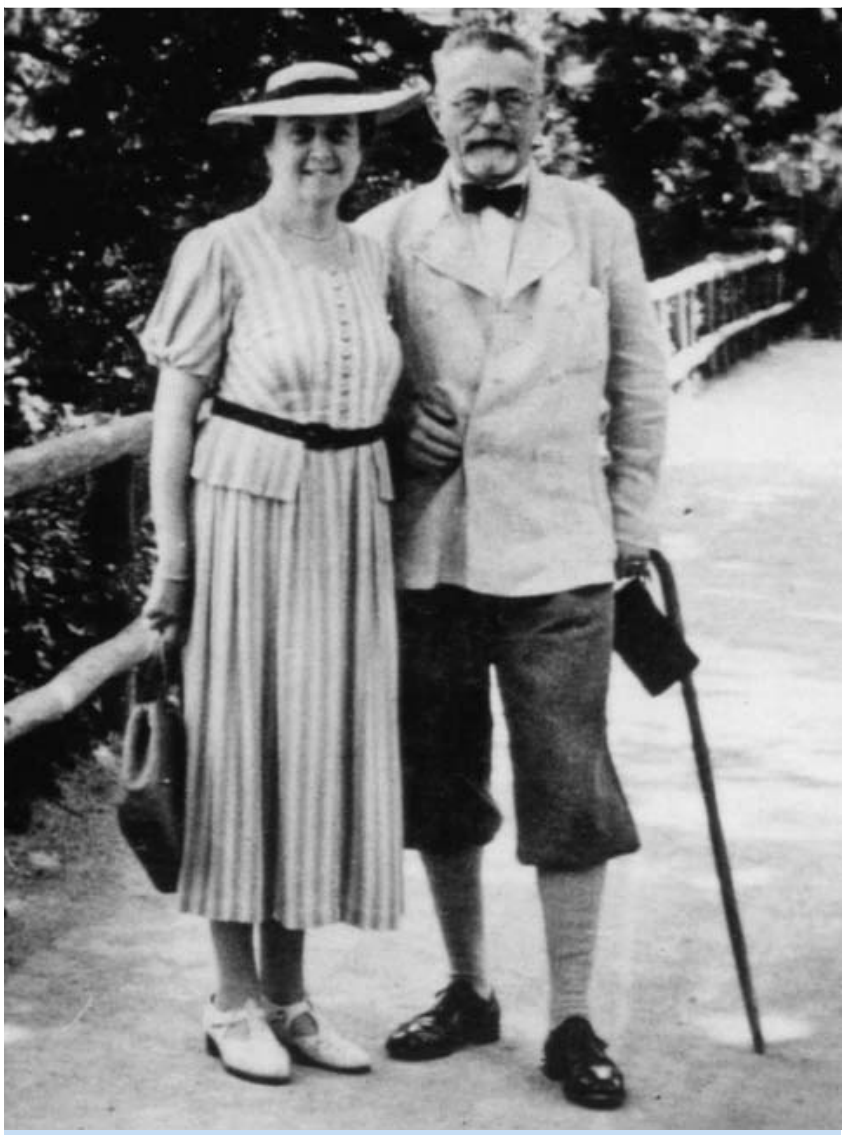

Abb. 38 Maximilian Neu (1877-1940), Frauenarzt aus Heidelberg, bei einem Spaziergang mit seiner Frau Louise, genannt Zilla (1885-1940). Angesichts der bevorstehenden Deportation nahmen sich die Eheleute im Oktober 1940 das Leben (Quelle: Privatbesitz Michael Goerig, Hamburg).

die gynäkologische Abteilung des Krankenhauses der Israelitischen Gemeinde leitete. Als er in der Nacht vom 9. auf den 10 . November verhaftet werden sollte, weigerte er sich, seine Patienten im Stich zu lassen. Unter dem Vorwand, sich umziehen zu wollen, nahm er sich in einem Nebenzimmer das Leben. Seine ebenfalls als jüdisch geltende Ehefrau Nora, eine britische Staatsbürgerin, wanderte 5 Monate später mit den gemeinsamen Kindern nach London aus. ${ }^{752}$

Eines der in den 1920er-Jahren aktivsten Mitglieder der DGG, der Heidelberger Arzt Maximilian Neu, entzog sich am 22. Oktober 1940, gemeinsam mit seiner Frau Zilla, der bevorstehenden Deportation in das südfranzösische Lager Gurs ( $\bullet$ Abb. 38). Bereits kurz nach dem Verlust seiner Bestallung hatte der im 64. Lebensjahr stehende Neu ein Testament aufgesetzt, das in erster Linie den regimekritischen Pfarrer Hermann Maas bedachte. Von diesem wurde das getaufte Ehepaar, „unter schwerem Protest der zuständigen Behörde“, auf dem „Nichtarierfeld“ des evangelischen Bergfriedhofs beigesetzt. ${ }^{753}$

Am selben Tag und aus demselben Anlass wie Neu nahmen sich Rudolf Kuppenheim und seine Frau Lily das Leben. Am 1. April 1933, dem Tag des „Judenboykotts“, hatte Kuppenheim als Arzt des Pforzheimer Krankenhauses Siloah zurücktreten müssen, seine Privatpraxis konnte er bis 1938 aufrecht erhalten. Obwohl beide Söhne in die USA emigriert waren, lehnte der 74-Jährige die Auswanderung ab. Als das Ehepaar Kuppenheim am Morgen des 22. Oktober 1940 von der unmittelbar bevorstehenden Deportation nach Gurs erfuhr, fiel der Entschluss zum Suizid. Kuppenheim, Protestant und DNVP-Mitglied, breitete seine Weltkriegsauszeichnungen auf einem Samtkissen aus, damit sie von den zu seiner Abholung anrückenden SA-Männern gefunden würden; anschließend nahmen er und seine Frau Gift. Sie verstarben am folgenden Tag im Pforzheimer Krankenhaus.

Vermutlich ebenfalls in Zusammenhang mit den beginnenden Deportationen stehen die Selbstmorde der Berliner Ärzte Robert Müllerheim, Emil Engel und Richard Freund im Sommer und Herbst des Jahres 1942. Über die Verfolgungsgeschichte des Privatklinikleiters Müllerheim, der seinem Leben einen Tag vor seinem 80. Geburtstag ein Ende setzte, konnte nichts in Erfahrung gebracht werden. ${ }^{754}$ Engel war nach dem Approbationsentzug als „Krankenbehandler“ tätig gewesen. Seine Witwe Klara Steinberg wurde einen Monat nach dem Suizid ihres Mannes nach Theresienstadt deportiert, wo sie Anfang 1943 ermordet wurde. ${ }^{755}$ Richard Freund, Sohn des DGG-Gründungsmitglieds Wilhelm Alexander Freund, war ab 1909 außerordentlicher Professor in Berlin gewesen und vermutlich 1933 entlassen worden. An dem Tag, an dem er die Vermögenserklärung ausfüllen musste, die einer Deportation unmittelbar vorausging, wählte Freund den Tod. ${ }^{756}$

Bis zur letzten Minute wartete Alex Czempin, Professor in Berlin und zuletzt 1931 als Mitglied der DGG gelistet. Als er 1943 zur Großen Hamburger Straße beordert wurde, wo die SS die Deportationen nach Theresienstadt und Auschwitz organisierte, schien dem 82-Jährigen bewusst zu sein, welches Schicksal ihm bevorstand. In einem Abschiedsbrief äußerte sich Czempin zu den Beweggründen für seinen Suizid: „Ich bin alt und habe so die Möglichkeit, in meinem Bett zu sterben. [Das ist] besser als von Unmenschen auf grausamste Art in den Tod getrieben zu werden. So wird an meinem Grabe vielleicht noch ein Rabbiner (falls es in Berlin noch einen gibt!) für mich das Kaddisch sagen. Ich habe mich ein Leben lang bemüht, ein ordentlicher Mensch zu sein und vor allem meine Pflicht zu tun. So komisch es klingen mag,

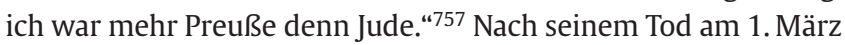
1943 wurde Czempin in Berlin bestattet. Zwei seiner Kinder waren bereits 1938 und 1941 in den Selbstmord getrieben worden. ${ }^{758}$

\footnotetext{
752 Vgl. Barkow/Gross/Lenarz (Hrsg.): Novemberpogrom (2008), S. 390.

753 Vgl. Rotzoll/Wiedemann: Judendeportation (2012); Cser: Geschichte (1996), S. 517.

754 Vgl. Schwoch (Hrsg.): Kassenärzte (2009), S. 636; Gedenkbuch BArch.

755 Vgl. ebd., S. 204; Gedenkbuch BArch.

756 Vgl. ebd., S. 251; Gedenkbuch BArch.

757 Rigg: Soldaten (2003), S. 314.

758 Gedenkbuch BArch; Schwoch (Hrsg.): Kassenärzte (2009), S. 177.
} 
Das letzte Mitglied der DGG, das seinem Leben angesichts der zunehmenden Verfolgung am 26. November 1943 ein Ende setzte, war der Breslauer Arzt Georg Schiffer. Er wurde 78 Jahre alt; über die näheren Umstände seines Todes ist nichts bekannt. ${ }^{759}$

Mitglieder der DGG als Opfer von Terror und Vernichtung Schon in den ersten Monaten des NS-Regimes waren Juden im Deutschen Reich einer physischen Bedrohung ausgesetzt. Das erste Mitglied der DGG, das einer sogenannten „Einzelaktion“ nationalsozialistischer Schlägertrupps zum Opfer fiel, war der Münchner Frauenarzt Gustav Wiener, der im März 1933 in seiner Wohnung von einer Horde SA-Leute brutal misshandelt wurde und Ende des Jahres seinen schweren Verletzungen erlag. ${ }^{760}$ Im Mitgliederverzeichnis vom 15. Dezember 1933 taucht sein Name schon nicht mehr auf.

Im Oktober 1941 begannen die systematischen Deportationen von Juden aus dem „Altreich“. Unter schätzungsweise 2000 jüdischen Ärzten, die der Vernichtung zum Opfer fielen, ${ }^{761}$ befinden sich mindestens 11 Mitglieder der DGG. ${ }^{762}$ Fast alle waren zum Zeitpunkt ihrer Deportation über 50, der Großteil weit über 60 Jahre alt. Über viele ist bislang wenig mehr bekannt als das Datum ihrer Deportation und das Datum ihres Todes. Die in den Akten vermerkten Todesursachen - meist „Herzschwäche“ oder „Gehirnblutung“ - waren nicht selten fiktiv.

Die meisten Mitglieder der DGG wurden in das Lager Theresienstadt deportiert, das unter der euphemistischen Bezeichnung „Altersghetto“ firmierte und als Sammelstelle „ausgesuchter deutscher Juden“, darunter sogenannte „Prominente“ und Christen jüdischer Herkunft, diente. ${ }^{763}$ Zeitweise sollen dort bis zu 1000 jüdische Ärzte interniert gewesen sein. ${ }^{764}$ Vor allem aufgrund der katastrophalen hygienischen Zustände, unzureichender medizinischer Versorgung und mangelnder Ernährung fanden Zehntausende von Menschen im vermeintlichen „Vorzeigelager" den Tod, viele weitere wurden gegen Kriegsende in die östlich gelegenen Vernichtungslager deportiert. Von den 7 DGGMitgliedern, die nach Theresienstadt kamen, starben die meisten nach kurzer Zeit:

Eduard Arnstein, der in Teplitz-Schönau eine Privatklinik geführt hatte, wurde am 12. Februar 1942 von Prag nach Theresienstadt deportiert, wo er wenige Monate später, am 25. Juni 1942, umkam. Seine Ehefrau Pavlína und 2 seiner Kinder fielen ebenfalls der Vernichtung zum Opfer. ${ }^{765}$
Auch der Berliner Frauenarzt Georg Dorpalen starb bereits ein Vierteljahr nach seiner Ankunft, am 17. Dezember 1942. Seine Frau Alice überlebte ihn um 7 Monate. ${ }^{766}$ Im Rahmen eines Wiedergutmachungsverfahrens gab Dorpalens Tochter zu Protokoll, dass ihr Vater „nach Erziehung, Werdegang und Gesinnung“ Patriot gewesen sei und daher unter den Verhältnissen im „Dritten Reich“, „denen er sich anfangs nicht beugen wollte, auch seelisch ganz besonders“ gelitten habe. ${ }^{767}$

Wenige Tage nach Dorpalen kamen der Berliner Arzt Walter Priebatsch und seine Frau Rosa in das Lager. Priebatsch, der bereits 1938 in das KZ Sachsenhausen verschleppt worden war, sei am 2. Januar 1943 einer „Herzmuskelentartung“ erlegen; seine Witwe wurde am 16. Mai 1944 nach Auschwitz deportiert und dort ermordet. $^{768}$

Der Sanitätsrat Richard Cohn aus Breslau starb am 23. August 1942, 2 Wochen nach der Ankunft in Theresienstadt, an „Herzschwäche“, ${ }^{769}$ sein Breslauer Kollege Otto Fuchs am 12.April 1944. ${ }^{770}$

Ebenfalls im Frühjahr 1944 erlag der Berliner Pathologe Ludwig Pick einer akuten Pneumonie, nachdem er vermutlich mehrere Monate auf der Krankenstation gelegen hatte. Ein Jahr vor seinem Tod war er in Berlin von der Gestapo verhaftet worden. ${ }^{771}$ Pick hatte noch 1933 einen Ruf an die University of Chicago abgelehnt, da er „dem Vaterland Deutschland auch in der schweren Zeit“ beistehen wolle. ${ }^{772}$

Edgar Alexander, der in Leipzig bis 1938 eine kleine Privatklinik mit 3 Betten geleitet hatte, verkaufte am 28. März 1939 einige Wertgegenstände aus Edelmetall an das Städtische Leihhaus und zog wenige Tage später nach Berlin, wo Teile seiner Familie lebten. Möglicherweise hoffte er, in der Anonymität der Metropole der rassischen Verfolgung entgehen zu können. Die Tätigkeit als „Krankenbehandler“ gab Alexander im Zuge dessen auf. Ende Juni 1939, 2 Monate vor Kriegsbeginn, verfasste er den an anderer Stelle zitierten Brief an Heinrich Martius, den Kassenwart der DGG, in dem er sich nach dem Fortbestehen seiner Mitgliedschaft in der Gesellschaft erkundigte. ${ }^{773}$ Nachdem Anfang Juni 1942 sein Vermögen durch die Gestapo eingezogen worden war, wurde Edgar Alexander am 20. Juli 1942 nach Theresienstadt deportiert. Der Todesfallanzeige zufolge starb er dort am 1. Dezember 1942 an einer „Gehirnblutung“. 774

759 Gedenkbuch BArch.

760 Vgl. Dross: „Juden“(2012), S. 98. Auch das DGG-Mitglied Hans Röttgen war bereits im März 1933 Ziel eines Mordanschlags, den der Wuppertaler Arzt durch Glück überlebte; Auskunft des Stadtarchivs Wuppertal vom 25.09.2015.

761 Vgl. Ohnhäuser: Verfolgung (2014), S. 270; Mack: Ärzteschaft (2001), S. 59.

762 Als Quellen dienten das Gedenkbuch des Bundesarchivs, Deportationslisten und Todesfallanzeigen.

763 Vgl. Benz: Theresienstadt (2013).

764 Vgl. Doetz/Kopke: Kampagnen (2014), S. 56.

765 Vgl. holocaust.cz, Database of Victims.

766 Vgl. Schwoch (Hrsg.): Kassenärzte (2009), 186; Gedenkbuch BArch.

767 LA Berlin, 55 WGA 20309-13/59.

768 Vgl. Schwoch (Hrsg.): Kassenärzte (2009), S. 704; Gedenkbuch BArch.

769 Gedenkbuch BArch. Über das Schicksal seiner Frau Berta, die mit ihm im Lager war, konnte nichts in Erfahrung gebracht werden.

770 Gedenkbuch BArch. Bei der ebenfalls in Theresienstadt umgekommenen Hedwig Fuchs könnte es sich um die Ehefrau handeln.

771 Vgl. Simmer: Pick (2000), bes. S. 334-351.

772 Neumann-Redlin von Meding/Conrad: Ärzte (2013), S. 35.

773 Siehe S. 74.

774 Gedenkbuch BArch; holocaust.cz, Database of Victims. 


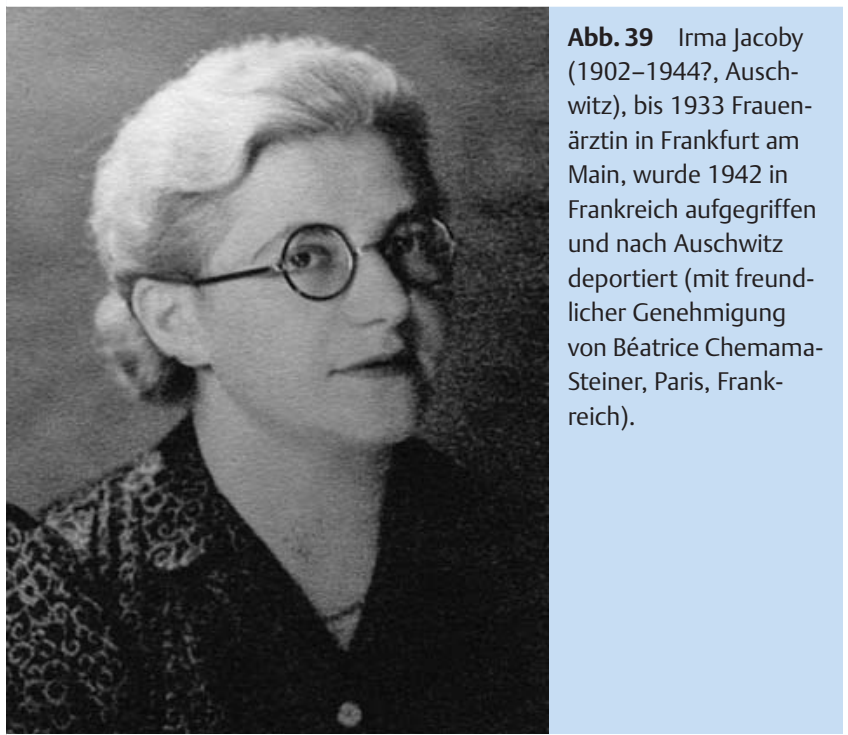

Das einzige DGG-Mitglied, das Theresienstadt überlebte, war der Leipziger Gynäkologe Felix Otto Skutsch, der der Gesellschaft seit ihrer Gründung angehörte. ${ }^{775}$ Im September 1933 hatte er seine Lehrbefugnis an der Universität Leipzig, 2 Jahre später die Kassenzulassung verloren. Ein Emigrationsvorhaben - Skutschs Kinder waren frühzeitig in die USA und nach England geflohen scheiterte 1941 am Auswanderungsverbot. Nach 4 Wohnungswechseln wurden Skutsch und seine Frau Helene 1943 in ein Leipziger „Judenhaus“ einquartiert und wenig später nach Theresienstadt deportiert. Im Lager hatte der verdiente Professor, der sich auf der Frauenstation ärztlich betätigte und medizinische Vorträge hielt, den Status eines sogenannten „Prominenten“ inne. Wohl allein der damit verbundenen „Vorzugsbehandlung“ ist es zu verdanken, dass Skutsch die Strapazen des Lagers trotz seines hohen Alters von über 80 Jahren überstand. Im Mai 1945 wurde Skutsch von sowjetischen Truppen befreit und kehrte nach Leipzig zurück; seine Frau war im Januar 1944 an Hunger und Entkräftung im Lager gestorben.

Nicht in Theresienstadt starben der Berliner Frauenarzt Hans Oppenheim - er kam am 28. März 1942 im Ghetto Piaski bei Trawniki $u^{776}$ - und Julius Wechsberg, Leiter einer Privatklinik in Mährisch-Ostrau, der laut Aussage seines Schwagers 1942 im Gefängnis von Ostrau von deutschen Wachen ermordet wurde. Seine Frau Else hatte sich wahrscheinlich ein Jahr zuvor durch die Einnahme von Lysol das Leben genommen. ${ }^{777}$

Nicht abschließend geklärt ist das Schicksal des Berliner Frauenarztes Siegbert Joseph, der in den 1920er-Jahren zu den popu- lärsten Geburtshelfern Moabits zählte. 1933 musste er das dortige Krankenhaus verlassen, nach dem Approbationsentzug 1938 entschloss er sich zur Flucht. Nachdem er in Berlin einige Edelmetallgegenstände verpfändet und sein Reisegepäck ins vermeintlich sichere Triest vorausgeschickt hatte, ${ }^{778}$ wanderte Joseph im August 1939 nach Riga aus, um dort das Eintreffen seiner Einreisegenehmigung nach Palästina zu erwarten. Der Einmarsch der Wehrmacht in Lettland setzte der Flucht ein jähes Ende. Joseph wurde in das Rigaer Ghetto verschleppt, wo er sich durch seine aufopfernde Tätigkeit als Leiter der Ghetto-Frauenklinik „einen legendären Ruf als Häftlingsarzt“ erwarb. ${ }^{779}$ Seine Frau Grete wurde vermutlich am 8. Dezember 1941 erschossen, ${ }^{780}$ über Siegbert Josephs Schicksal sind in den Wiedergutmachungsakten widersprüchliche Aussagen überliefert. Einem Bekannten zufolge sei er „wenige Tage vor der Befreiung Rigas durch die Russen anlässlich eines schweren Bombardements der Stadt in einem Schutzkeller, in den er sich geflüchtet hatte, [...] durch einen Volltreffer getötet worden“. ${ }^{781}$ Davon abweichend berichtet ein weiterer Zeuge, dass Joseph kurz vor der Befreiung Rigas in das Ghetto Libau deportiert worden und dort umgekommen sei. ${ }^{782}$

Drei Mitglieder der DGG wurden in den letzten Kriegsjahren im Vernichtungslager Auschwitz ermordet:

Irma Jacoby, 1902 in Magdeburg geboren, war unter Ludwig Seitz Assistentin an der UFK in Frankfurt gewesen ( $\bullet$ Abb. 39). Im Oktober 1932 kündigte sie im „Gemeindeblatt der Israelitischen Gemeinde Frankfurt am Main“ die Eröffnung einer frauenärztlichen Praxis an, emigrierte aber schon im folgenden Jahr mit ihrer Mutter nach Paris. Neun Jahre später, im Juli 1942, wurde sie dort im Rahmen einer Großrazzia (Rafle du Vélodrome d'Hiver) von der französischen Polizei festgenommen. Während die Mutter wegen ihres hohen Alters in Paris bleiben durfte, wurde Irma Jacoby in das südlich der Hauptstadt gelegene Durchgangslager Pithiviers gebracht. Von dort sandte sie Ende Juli 1942 einen Brief nach Paris, in dem sie um Schuhe, Kleidung, Decken und Teller bat und der Hoffnung Ausdruck verlieh, sich als Lagerärztin bald nützlich machen zu können. Zwei Tage später wurde Irma Jacoby nach Auschwitz deportiert und dort 1944 ermordet. ${ }^{783}$

Der Teplitzer Frauenarzt Viktor Hahn war unter den 87000 Personen, die in den letzten Kriegsjahren von Theresienstadt in die Vernichtungslager im Osten deportiert wurden. Hahn und seine Frau Katerina waren Ende 1941 mit einem der ersten Züge in Theresienstadt eingetroffen. Am 30. Januar 1942 wurde der erfahrene Gynäkologe vom Ältestenrat des Lagers mit dem Aufbau einer „Gesundheitseinheit“ in der „Hamburger Kaserne“, einer reinen Frauenunterkunft, betraut. In einer von den Häftlingen aufwendig gestalteten Jubiläumsschrift zum 1-jährigen Bestehen der Kaserne blickte Hahn Anfang 1943 auf das Erreichte zurück

\footnotetext{
775 Zu Skutsch vgl. Kästner: Skutsch (2013).

776 Gedenkbuch BArch.

777 yadvashem.org, Zentrale Datenbank der Namen der Holocaustopfer.

778 Josephs Privatbesitz wurde wahrscheinlich gegen Ende des Krieges nach Berlin gebracht und dort an die ausgebombte Bevölkerung verteilt.

779 Pross: Krankenhaus (1984), S. 163.

780 Laut Aussage eines Überlebenden wurde sie getötet, „um Platz fuer die vielen Tausenden, die neu ankamen, zu machen“; LA Berlin, 52 WGA 7562-7563/59.

781 LA Berlin, 52 WGA 7562-7563/59.

782 LA Berlin, 52 WGA 7562-7563/59; vgl. auch Gedenkbuch BArch.

783 Vgl. Kallmorgen: Heilkunde (1936), S. 210; Gemeindeblatt der Israelitischen Gemeinde Frankfurt am Main 2/1932, S. 49. Der Verfasser dankt Béatrice Steiner und Helen Hermann für die Auskünfte.
} 


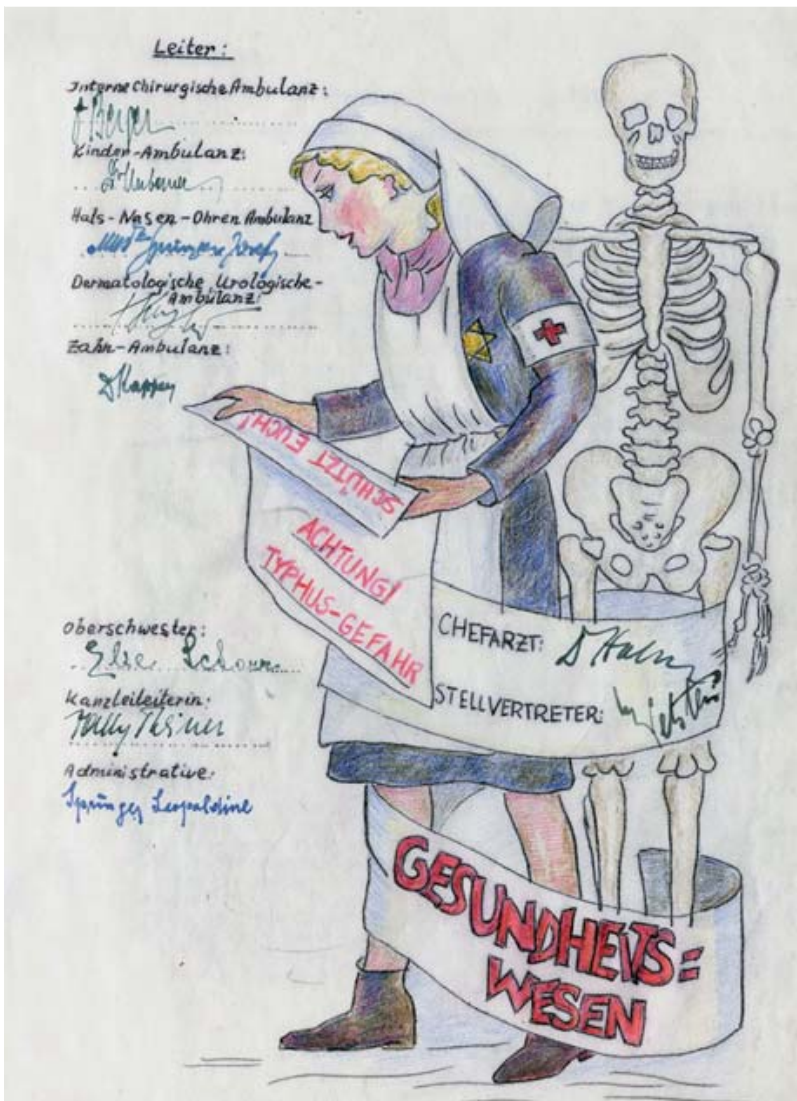

Abb.40 Zum einjährigen Bestehen der „Hamburger Kaserne“ im KZ Theresienstadt gestalteten Häftlinge im Januar 1943 eine aufwendige Festschrift. Das Titelblatt des Kapitels über das Gesundheitswesen zeigt eine Krankenschwester mit „Judenstern“ und trägt die Unterschrift von Chefarzt Viktor Hahn (1891-1944), der 1944 nach Auschwitz deportiert und dort ermordet wurde (Quelle: Jüdisches Museum Prag).

( Abb. 40). Trotz anfangs widriger Umstände sei mittlerweile ein Kreißsaal eingerichtet und 15 Geburten „glatt verlaufen“. Am 23. Oktober 1944 wurden Hahn und seine Frau mit einem der letzten Deportationszüge nach Auschwitz gebracht und dort offenbar sofort nach ihrer Ankunft vergast. ${ }^{784}$

Auch über das Schicksal des Kölner Frauenarztes Maximilian Samuel sind wir näher informiert ( $\triangle$ Abb. 41). Diverse Zeitzeugenaussagen zeichnen das Bild eines sympathischen und überaus beliebten Arztes, der das Vertrauen seiner Patientinnen genoss und mittellose Frauen kostenlos behandelte. ${ }^{785}$ Auch nach 1933 sei seine Praxis von vielen nichtjüdischen Patientinnen und sogar den Frauen hochrangiger Nationalsozialisten frequentiert worden. Wie viele deutschnational eingestellte Juden schien Samuel die Gefahr des NS-Regimes zunächst unterschätzt zu haben. Den Ratschlag seines Oberarztes, das Land zu verlassen, habe er unter

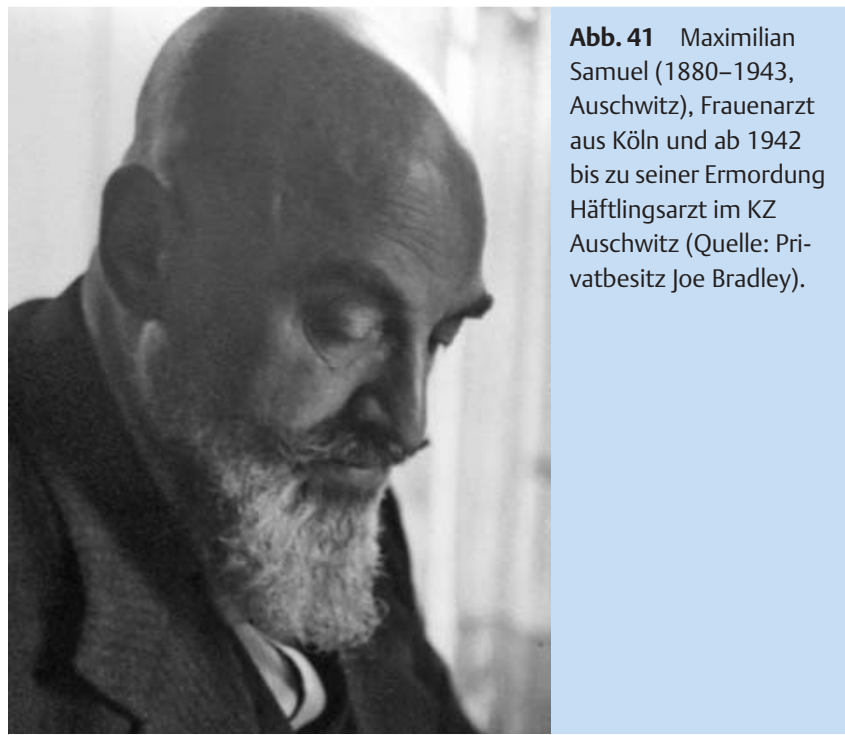

Verweis auf seinen Einsatz im Ersten Weltkrieg abgelehnt. Als er am 9. November 1938 von 2 Gestapoleuten mitgenommen werden sollte, habe er seine Offiziersuniform mit hochrangigen Auszeichnungen angelegt, woraufhin ihn die offenbar peinlich berührten Beamten vorerst in Ruhe gelassen hätten. ${ }^{786}$ Als sie in der Nacht zurückkamen, um Samuel zu verhaften, war dieser geflohen. Ein Bekannter berichtete später, dass ein „große[r] Nazi“, dessen Frau Samuel behandelt hatte, dem Arzt bei der Ausreise in die Niederlande geholfen habe. ${ }^{787}$ In Belgien traf Samuel mit seiner Frau Hedwig und der 19-jährigen Tochter Liese-Lotte zusammen; eine geplante Weiterreise in die USA kam nicht mehr zustande. Im August 1942 wurde die Familie vor der französischschweizerischen Grenze aufgegriffen und nach kurzer Internierung im französischen Sammellager Drancy ins KZ Auschwitz deportiert. 918 der 957 Personen, die mit diesem Transport das Lager erreichten, wurden sofort vergast, darunter Samuels Ehefrau Hedwig. Max Samuel, dessen Überlebenschancen als 62-Jähriger eigentlich äußert gering waren, wurde vermutlich nur deshalb verschont, weil seine Dienste als Gynäkologe im Lager gefragt waren. So war seine Ankunft in Auschwitz mit dem Vermerk angekündigt worden, ,ihm möglichst gute Lebensbedingungen einzuräumen“. Auf Wunsch des SS-Standortarztes Eduard Wirths wurde er im Mai 1943 aus der Ambulanzabteilung des Nebenlagers Auschwitz-Monowitz zum berüchtigten Versuchsblock 10 ins Stammlager überstellt. ${ }^{788}$ Dort nahm er als Häftlingsarzt an den verbrecherischen Menschenversuchen von Carl Clauberg ${ }^{789}$ teil, indem er bei sterilisierten Frauen Teile des Gebärmutterhalses und die Eierstöcke entfernte. Nach dem Krieg kritisierten Überlebende der Versuche den „Übereifer“ des Häftlingsarztes Samuel, der ein „ganz abscheulicher Mann“ gewesen sei. ${ }^{790}$ In jüngerer Zeit geraten dagegen vermehrt Aussagen in den Blick,

\footnotetext{
784 Vgl. holocaust.cz, Database of Victims.

785 Vgl. Müller-Hill: Samuel (2006).

786 Vgl. auch Siegel: Auschwitz (2014), S. 455, der eine abweichende Zeugenaussage überliefert.

787 Müller-Hill: Samuel (2006), S. 233.

788 Siegel: Auschwitz (2014), S. 455.

789 Siehe S. $66 \mathrm{f}$.

790 Müller-Hill: Samuel (2006), S. 231. Aussagen in Langbein: Menschen (1972), Samuels Einordnung als Kollaborateur bei Lifton: Doctors (1986), S. 250.
} 
die Samuel als durchaus fürsorglichen Arzt charakterisieren, der die Menschenversuche sogar manipuliert und sabotiert habe. ${ }^{791}$ Die widersprüchlichen Berichte werfen ein bezeichnendes Licht auf die moralische Zwangslage der Häftlingsärzte, die unter enormem Druck standen und trotz ihrer vergleichsweise privilegierten Stellung der Willkür der Lagerleitung ausgesetzt waren. In Samuels Fall kam hinzu, dass man ihn womöglich gezielt mit dem Leben seiner ebenfalls nach Auschwitz deportierten Tochter Liese-Lotte erpresste.
Im November 1943, noch vor Beendigung der Sterilisierungsversuche, wurde Samuel, vermutlich auf Weisung seines Vorgesetzten Wirths, nach Birkenau gebracht und dort unter nicht geklärten Umständen ermordet. ${ }^{792}$ Auch seine Tochter überlebte das Vernichtungslager nicht. Zu den Gründen, die zu Samuels Ermordung geführt hatten, sind unterschiedliche, teils höchst spekulative Aussagen überliefert: Er sei alt, krank und geschwätzig gewesen, sein arrogantes Auftreten habe zu Konflikten mit Wirths und Clauberg geführt und man habe sich des Geheimnisträgers frühzeitig entledigen wollen. Nicht von der Hand zu weisen ist schließlich die durch eine Aussage des Lagerarztes Hans Münch gestützte Vermutung, dass Samuel von Wirths der Sabotage überführt worden war und dies mit seinem Leben bezahlte. ${ }^{793}$

\footnotetext{
791 Nadav: Zwangslagen (2005), S. 157 f.; Siegel: Auschwitz (2014), S. 464; Lang: Häftlingsärzte (2016).

792 Siegel: Auschwitz (2014), S. 464.

793 Vgl. Siegel: Auschwitz (2014), S. 466.
} 


\section{Keine Stunde Null: Die DGG nach Diktatur und Krieg}

\section{Im Schatten der Vergangenheit: die Tagungen 1949 und 1951 $\nabla$}

„Das Schicksal hat unser Vaterland schwer geschlagen. Aber auch die Deutsche Gesellschaft für Gynäkologie ist schwer geschlagen worden." Was genau Rudolf Theodor Edler von Jaschke zur Eröffnung des ersten Nachkriegskongresses mit diesen Sätzen vor allem meinte, lässt sich seinen weiteren Ausführungen entnehmen: die Situation der Wissenschaft in den Kriegs- und Nachkriegsverhältnissen, aber auch den Verlust des „glänzenden traditionellen Rahmen[s]“, in dem die Gesellschaft sonst zusammentrat und der "so sehr dazu beigetragen hat, ihre Anziehungskraft zu erhöhen und zahllose menschlich und wissenschaftlich fruchtbare Freundschaften anzubahnen“. ${ }^{794}$

Als die DGG am 20. April 1949 zu ihrem ersten Nachkriegskongress in Karlsruhe ( $\boldsymbol{O} \mathbf{A b b} . \mathbf{4 2})$ zusammenkam, war die Beseitigung der Trümmer in der barocken Residenzstadt noch nicht abgeschlossen. Auch der Präsident der Gesellschaft zeigte sich in mehrfacher Hinsicht angeschlagen: Schon im Mai 1945 hatten ihm die Sieger im Zuge der ersten Entnazifizierungsmaßnahmen die Leitung der zerstörten und evakuierten UFK Gießen sowie den Professorentitel entzogen. ${ }^{795}$ Darüber hinaus war Jaschke von einer Krebserkrankung gezeichnet, als er - wie er sagte - als „stimmbehinderter Mann“ - zu seiner Eröffnungsrede vor die Mitglieder trat. Sie war wie viele andere Ansprachen der ersten Nachkriegsjahre geprägt von einer zeittypischen Mischung aus Selbstmitleid, Sentimentalität und Verbitterung. ${ }^{796}$

Ähnlich umstandslos wie 1933 ließ sich die Satzung auch 1949 an die geänderten Verhältnisse anpassen. Schon am Vortag des ersten Nachkriegskongresses hatte der Vorstand die entsprechenden Maßnahmen vorgenommen. Dazu wurden die drei 1933 eingefügten Paragrafen ersatzlos gestrichen, mit denen die "Gleichschaltung“" der Gesellschaft vorgenommen worden war. Es handelte sich um $\S 2$ (Mitgliedschaft in der Reicharbeitsgemeinschaft Mutter und Kind), $§ 10$ (Bestätigung des Vorstands durch die NS-Regierung, Möglichkeit der Abberufung) sowie um $\S 14$ (Bestätigung von Vorstands- und Mitgliederbeschlüssen durch das Reichsinnenministerium). Außerdem war der Satz in

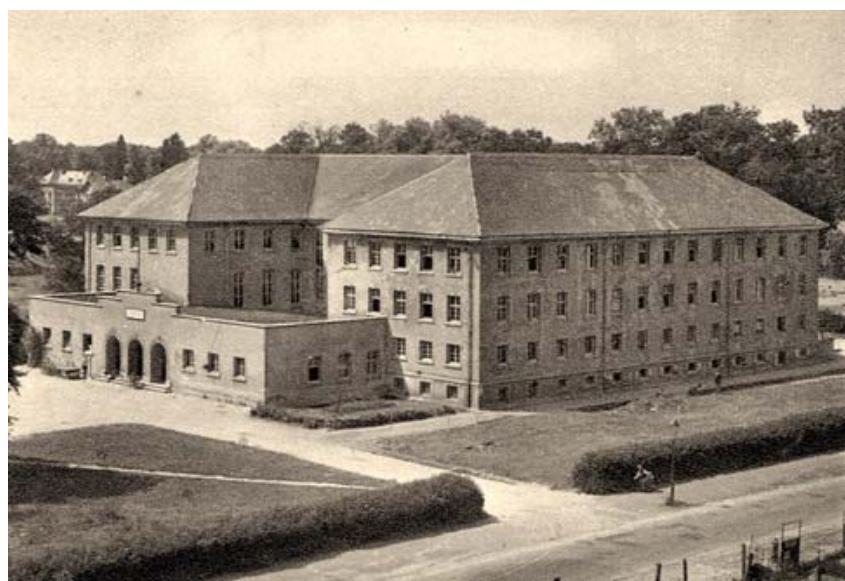

Abb. 42 Das Studentenhaus auf dem Campus der Technischen Hochschule in Karlsruhe, Ort der ersten Nachkriegstagung im April 1949 (Quelle: Stadtarchiv Karlsruhe).

$\S 17 \mathrm{zu}$ entfernen, wonach auch jede Änderung der Statuten vom Reichsinnenministerium bestätigt werden musste.

Paragraf 1 der Satzung, in dem die Ziele der Gesellschaft umrissen sind, wurde durch einen Vorschaltsatz ergänzt, der die DGG zu einem gemeinnützigen Verein machte. Ferner ersetzte die Vorstandschaft den Begriff „Vorsitzender“ durch die Bezeichnung „Präsident“. Weitere Veränderungen waren dem Vereinsstatus geschuldet: je ein neuer Paragraf regelte die Verwaltung und Kontrolle der Finanzen entsprechend den Bestimmungen für die Gemeinnützigkeit $(\S 6)$ sowie die Verwendung des Vereinsvermögens im Falle der Auflösung oder des Verlustes der Gemeinnützigkeit (§16). Die neue Satzung wurde ebenso wie die Geschäftsordnung am Folgetag von der Mitgliederversammlung beschlossen. In der Geschäftsordnung war die einzige Veränderung die Latinisierung des „Vorsitzenden“ zum „Präsidenten“. 797

In seiner Rede konstatierte Jaschke, die Gynäkologen hätten in den letzten Jahren oft hören müssen, dass Deutschland in der Wissenschaft und ärztlichen Kunst um 1 1 1/2 Jahrzehnte zurückgeblieben sei. Daran sei „nicht mehr wahr“, als dass die schweren

\footnotetext{
794 Jaschke: Eröffnungs-Ansprache [Verhandlungen 1949] (1950), S. 1.

795 Siehe S. $20 \mathrm{f}$.

796 Vgl. Reichel/Schmid/Steinbach: Geschichte (2009).

797 Verhandlungen (1951), V-VII.
} 
Jahre des Krieges so manchen aussichtsreichen jungen, aber auch älteren Forscher um die Früchte jahrelanger Arbeit gebracht hätten. Viele seien von ihrer Arbeit fortgerissen worden, wertvollste Bibliotheken, Manuskripte sowie Protokolle verloren gegangen und Arbeitsstätten zerstört worden. Auch jetzt bestünden noch „vielerlei Hemmungen“. Dazu komme häufig mangelndes Verständnis zuständiger Regierungsstellen „und noch mehr mangelnde Bewegungsfreiheit auf finanziellem Gebiete““.798

Die Forderung nach stärkerer Unterstützung nutzte Jaschke, um den Blick auf die scheinbar nur ruhmreiche Vergangenheit des Fachs zu lenken: Er müsse „mit großem Ernst“ darauf hinweisen, was auf diesem Gebiet an deutschem Ansehen zu verlieren sei, sagte er. Gerade in der Gynäkologie und Geburtshilfe habe Deutschland „mit die größten Lehrmeister für die Welt gestellt“. ${ }^{799}$ In der folgenden Auflistung wissenschaftlicher Großtaten werden nun auch wieder die Namen jüdischer Frauenärzte hervorgehoben - darunter Wilhelm Alexander Freund, Josef Halban, Robert Meyer, Ludwig Fraenkel und Bernhard Zondek. Diese Würdigung „einiger Männer unserer Geschichte“ beweise, „dass die Deutsche Gesellschaft für Gynäkologie auf ihre Vergangenheit stolz sein darf“. ${ }^{800}$ Dass Meyer, Fraenkel und Zondek vor rassischer Verfolgung aus dem Deutschen Reich fliehen mussten, erwähnte Jaschke ebenso wenig wie die Rechtfertigung dieses Umgangs mit jüdischen Wissenschaftlern im Namen der DGG durch Walter Stoeckel in seiner „Gleichschaltungsrede“ von 1933.

Wie mit der Vergangenheit der DGG umgegangen werden sollte, demonstrierte auch Heinrich Martius 2 Jahre später in der Rede zur Kongresseröffnung 1951 in aller Deutlichkeit. Zwar konstatierte er, dass in der schnelllebigen Gegenwart unter der „Wucht der täglichen Ereignisse im öffentlichen Leben der Welt [...] von dem Vergangenen vieles gar zu schnell vergessen wird“. Dann machte er aber deutlich, worauf sich das Erinnern beschränken sollte: auf den Prozess der Restauration alter wissenschaftlicher Beziehungen in der unmittelbaren Nachkriegszeit und die übliche Würdigung der Leistungen anerkannter Vertreter des Faches. Die NS-Vergangenheit war für ihn offenbar erledigt: „Meine Damen und Herren!“, rief er dem Kongress zu, „[i]n diesen Verhandlungen ist die deutsche Gynäkologie vorbehaltlos und in ihrer Gesamtheit wieder in die weltumfassende Organisation unseres Faches aufgenommen worden“. 801

Folgerichtig wandte er sich dann nach der Totenehrung ausführlich der Geschichte der UFK Göttingen zu, wofür das 200-jährige Jubiläum der ersten Geburtsleitung durch Johann Georg Roederer, dem Urvater der klinischen Geburtshilfe in Deutschland, einen willkommenen Anlass bot. Ein kritischer Ansatz in Bezug auf die jüngste Vergangenheit ist nur in seinen Ausführungen zu den Aufgaben des Faches für die Zukunft zu finden. Hier beklagte er, dass sich die junge Medizinergeneration „auf Grund einer jahrelangen Erziehung zur Unfreiheit“ bei ihren Entscheidungen nicht mehr frage, „was ist richtig und was ist falsch, was hilft und was ist schädlich“. Vielmehr frage sie, „was ist erlaubt und was ist verboten?“ Dieselbe Bereitschaft, irgendeine übergeordnete Stelle „um Rat zu fragen und sich ihr zu unterwerfen“, sei auch bei den schon in der Praxis stehenden Kollegen zu beobachten. Eine der Hauptaufgaben der zentralen Leitung des Berufes und der akademischen Lehrer müsse deshalb darin bestehen, den Arzt wieder „auf das Fundament der eigenen Verantwortung zu stellen“. ${ }^{802}$ Wie sehr und mit welchen Folgen sich die eigene Generation „übergeordneten Stellen“ unterworfen hatte, blieb ebenso unerwähnt wie in der Mitgliederversammlung das Schicksal der Juden Ludwig Fraenkel und Felix Skutsch, denen die Ehrenmitgliedschaft verliehen wurde. ${ }^{803}$

Ein anderes Problem stellte sich der Gesellschaft im Umgang mit noch lebenden Mitgliedern, die ganz offensichtlich den Maßstab „Was hilft und was ist schädlich“ überschritten hatten. Dies wurde zuerst bei Carl Clauberg und seinen in Auschwitz vorgenommen Menschenversuchen ruchbar. Noch im Juni 1945 inhaftiert und im Juli 1948 in der Sowjetunion zu 25 Jahren Haft verurteilt, kehrte er im Oktober 1955 zurück, um seine gynäkologische Tätigkeit an der UFK Kiel wieder aufzunehmen. Bald darauf wandte sich der Auschwitz-Überlebende Hermann Langbein mit der Forderung an die DGG, sich von Clauberg und seinen Kollegen zu distanzieren. ${ }^{804}$ Der Zentralrat der Juden in Deutschland erstattete Anzeige vor dem Landgericht Kiel, im Dezember 1956 wurde die Anklage erhoben. Daraufhin hat die DGG Clauberg noch im selben Jahr ausgeschlossen. ${ }^{805}$ Noch vor der Eröffnung seines Verfahrens starb Clauberg am 9. August 1957 in Untersuchungshaft an einem tödlichen Schlaganfall.

Fast gleichzeitig mit dem Ausschluss Claubergs ernannte die DGG ebenfalls 1956 den Hamburger Hans Hinselmann zu ihrem Ehrenmitglied. Dies, obwohl Hinselmann mit einigen Kollegen von einem britischen Gericht unmittelbar nach dem Krieg wegen „Verbrechens gegen die Menschlichkeit“ zu 3 Jahren Haft verurteilt worden war, „weil sie eine Anzahl Zigeunerabkömmlinge sterilisierten, um die Vermehrung dieser Rasse zu verhindern“. 806 Im März 1947 wurde das Urteil bei einer Berufung bestätigt, das Strafmaß allerdings auf $1 \frac{1}{2}$ Jahre herabgesetzt.

Erst als Jahrzehnte später eine Verbindung von Hinselmanns Forschung zu Eingriffen an weiblichen KZ-Häftlingen immer unübersehbarer wurde, ging die Gesellschaft auf Distanz. Die Arbeitsgemeinschaft für Zervixpathologie und Kolposkopie in der DGGG hat angesichts der vorliegenden Erkenntnisse 2012 empfohlen, bei Vorträgen, Diskussionen oder in Publikationen zur Kolposkopie auf die Rolle Hinselmanns im Nationalsozialismus hinzuweisen. Der Vorstand der DGGG beschloss am 26. März 2015, Hans Hinselmann nicht mehr in der Liste der Ehrenmitglieder zu führen. ${ }^{807}$

\footnotetext{
798 Jaschke: Eröffnungs-Ansprache [Verhandlungen 1949] (1950), S. 3

799 Ebd.

800 Ebd., S. 7.

801 Martius: Eröffnungs-Ansprache [Verhandlungen 1951] (1951), S. 3.

802 Ebd., S. 10.

803 Verhandlungen 1951, S. XXXII und XXXVII.

804 Vgl. Stengel (Hrsg.): Langbein (2012), S. 180

805 Vgl. Czarnowski: „Material“ (2004), S. 229.

806 Zit. n. Lehmann: Chronik (1995), S. 48.

807 Kühn/Gieseking/Küppers/Lellé/Menton: Hinselmann (2015), S. 302.
} 


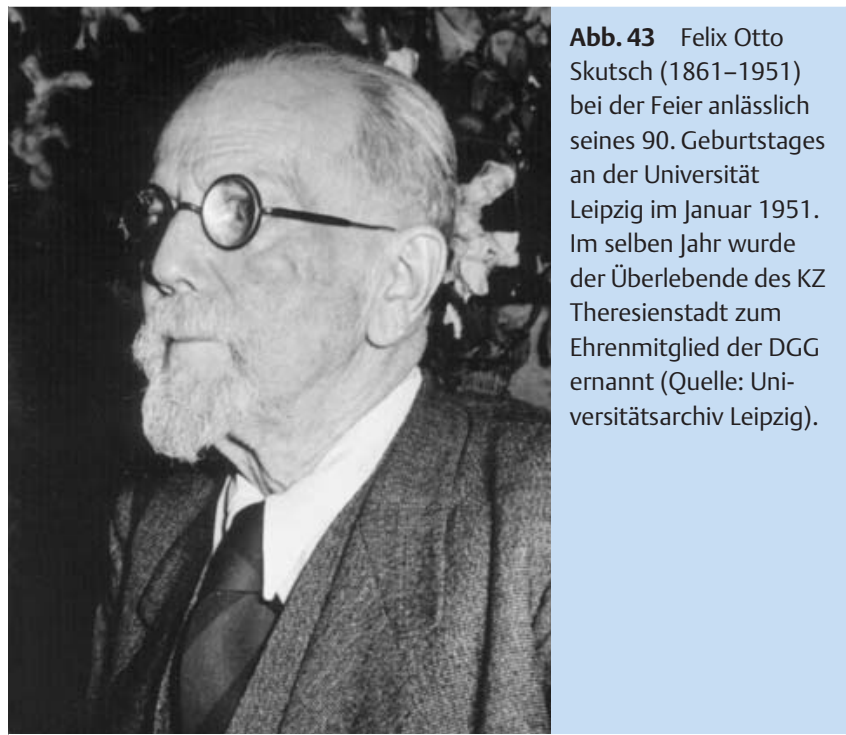

\section{Totengedenken}

$\nabla$

Für jedermann nachvollziehbar waren die von Jaschke als weiterer Schicksalsschlag betrauerten vielen Toten, die die Gesellschaft seit ihrer letzten Tagung zu beklagen hatte. Auch wenn nicht überliefert ist, wie viele Ärzte an der ersten Tagung nach Kriegsende teilnahmen, wird kaum einer der Anwesenden niemanden aus seinem Bekanntenkreis vermisst haben. Selbst über die tatsächliche Gesamtzahl der Mitglieder - mit 914 im Mitgliederverzeichnis gelisteten Personen war 1949 scheinbar ein neuer Höchststand erreicht - lassen sich für diese Zeit nur ungefähre Angaben machen: Neben unberechtigten „Totmeldungen“, die beim Vorstand eingegangen waren, konnte über den Verbleib zahlreicher „Alt-Mitglieder“ über Jahre hinweg nichts in Erfahrung gebracht werden. ${ }^{808}$

Jaschkes Aufzählung im Rahmen des Gedenkens, die bei den bedeutendsten Vertretern der Gesellschaft jeweils mit einem kurzen biografischen Hinweis versehen war, begann mit den beiden Präsidenten G.A. Wagner und Hans Fuchs und umfasste $57 \mathrm{Na}$ men. Mit Ausnahme von Heinrich Kahr und Robert Meyer ungenannt blieben die über 30 Kolleginnen und Kollegen jüdischer Herkunft, die seit 1941 teils in der Emigration, mehrheitlich aber in Konzentrations- und Vernichtungslagern oder von eigener Hand gestorben waren. Die meisten waren freilich lange vor 1941 aus der Gesellschaft ausgeschieden, ihr Schicksal blieb manchmal über Jahre hinweg ungeklärt. ${ }^{809}$

Von den 57 verstorbenen Mitgliedern, deren Namen Jaschke in seiner Eröffnungsrede 1949 verlas, hatte mindestens 10 ein unnatürlicher Tod ereilt. Die Berliner Oberärzte Wilhelm Breipohl und Paul Caffier waren bei der Einnahme Berlins von sowjetischen Soldaten erschossen worden; ${ }^{810}$ das Gleiche widerfuhr Heinrich Rossenbeck, dem Direktor der Landesfrauenklinik und Hebammenschule Brünn. ${ }^{811}$ Franz Unterberger hatte sich offenbar kurz nach der Einnahme Königsbergs durch die Rote Armee das Leben genommen. ${ }^{812}$ Selbstmord begingen auch der 1949 nicht genannte Kurt-Otto von Stuckrad, Leiter der Geburtshilflich-Gynäkologischen Abteilung des Berliner Rittberg-Krankenhauses, sowie der Greifswalder Ordinarius und Dozentenbundführer Günter K.F. Schultze. ${ }^{813}$ Otto Bokelmann, Chefarzt am Krankenhaus Moabit, hatte sich im April 1947 das Leben genommen; er sei nach Kriegsende ein „seelisch gebrochener Mann“ gewesen. ${ }^{814}$ Weitere Mitglieder, darunter der Pforzheimer Chefarzt Paul Feldweg, waren im Krieg gefallen ${ }^{815}$ oder, wie der Offenbacher Klinikleiter Ernst Grein, infolge eines Fliegerangriffs ums Leben gekommen. ${ }^{816}$ Kurt Riediger aus Königsberg starb an den Folgen der Kriegsgefangenschaft, 817 der ebenfalls nicht genannte Breslauer Arzt Arthur Dienst offenbar auf der Flucht vor der Roten Armee. ${ }^{818}$

Von den über 100 verdrängten und vertriebenen jüdischen Ärzten tauchen die meisten in den Mitgliederverzeichnissen nach 1945 nicht mehr auf. Eine der wenigen Ausnahmen ist Paul Meyer, der nach 1938 als „Krankenbehandler“ tätig gewesen war und offenbar bis 1945 in Berlin gelebt hatte; bereits auf der ersten Nachkriegstagung stand er mit einem Vortrag über „Die Penicillinbehandlung in Gynäkologie und Geburtshilfe“ auf dem Programm. ${ }^{819}$ Ebenso bemerkenswert wie singulär ist der Fall des bereits erwähnten Felix Otto Skutsch, der kurz nach der Befreiung des Lagers Theresienstadt in seine Heimatstadt Leipzig zurückkehrte und an der dortigen Universität noch mit über 85 Jahren Vorlesungen hielt ( $\bullet$ Abb. 43). ${ }^{820}$ Bei der posthumen Auszeichnung Skutschs zum DGG-Ehrenmitglied im Jahr 1951 wurde nur erwähnt, dass der Verstorbene „an fast allen Tagungen unserer Gesellschaft seit ihrer Gründung im Jahre 1886 teilgenommen“ habe. ${ }^{821}$ Der ebenfalls 1951 geehrte Ludwig Fraenkel lebte seit 1937 in Uruguay und war nicht persönlich erschienen. Nur der nach Paris emigrierte und 1952 mit der Ehrenmitgliedschaft bedachte Selmar Aschheim nahm die Urkunde persönlich entgegen und hielt einen Vortrag über „Verkannte Schwanger-

808 Mitgliederversammlung (1951), XXXVI-XXXVII.

809 In Gauß/Wilde: Geburtshelferschulen (= GW 1956) enden die Biografien vieler emigrierter und ermordeter Gynäkologen mit dem schlichten Hinweis „Weitere Lebensdaten fehlen“.

810 Vgl. David: Sinnlosigkeit (2007); Stoeckel: Erinnerungen (1966), S. 502.

811 Ebert/Namal: Liepmann (2010), S. 246.

812 Vgl. Scholz/Schroeder: Ärzte (1970), S. 140.

813 Vgl. die Kurzbiografie im Anhang bzw. S. 54 und 66.

814 Pross: Krankenhaus (1980), S. 250.

815 Vgl. Pforzheimer Zeitung 128 (04.06.2011), S. 50.

816 NN: 1903 (o.J.).

817 Vgl. Scholz/Schroeder: Ärzte (1970), S. 151.

818 DBE, Bd. 2, S. 597.

819 Meyer: Penicillinbehandlung [Verhandlungen 1949] (1950)

820 Vgl. Kästner: Skutsch (2013), S. 489.

821 Mitgliederversammlung [Verhandlungen 1951] (1951), XXXVII. Skutsch selbst übernahm das Schlusswort der Tagung und endete mit den Worten: „Möge die Deutsche Gesellschaft für Gynäkologie blühen und gedeihen und möge sie dazu beitragen, das Ansehen der Deutschen Wissenschaft in der Welt zum alten Glanze emporzuführen.“ 
schaft". Sofern die Ehrungen einzelner vertriebener Kollegen als Versuch einer „Wiedergutmachung“ angelegt waren, wurde dies auf den Tagungen und in den überlieferten Korrespondenzen nicht entsprechend thematisiert. Ob die Gesellschaft den Kontakt mit ehemaligen, rassisch verfolgten Mitgliedern suchte, konnte nicht ermittelt werden. Erst in den späten 1970er- und den 1980er-Jahren zeigte die „Mauer des Schweigens“ erste Risse, als bei Kongressen an einige der vertriebenen Mitglieder, namentlich Aschheim, Zondek, Gräfenberg, Robert Meyer, Fraenkel und Fels, erinnert wurde - wenn auch ohne konkreten Hinweis auf die Rolle der DGG in diesem Zusammenhang. ${ }^{822}$

Vergleichsweise früh konnten ehemals rassisch und politisch Verfolgte Ansprüche auf eine Kompensation nationalsozialistischen Unrechts geltend machen. Als juristische Grundlagen dienten das „Gesetz zur Wiedergutmachung nationalsozialistischen Unrechts“ von 1948 und die Bundesergänzungsgesetze von 1953 und 1956. Sie sollten die Wiedergutmachung von Schäden gewährleisten, die den Verfolgten zugefügt worden waren, darunter „Schaden am Leben“, „Schaden an Körper oder Gesundheit“, „Schaden an Freiheit“, „Schaden an Eigentum und Vermögen“, aber auch „Schaden im beruflichen Fortkommen“ sowie Existenz- und Verfolgungsschäden. ${ }^{823}$

Zahlreiche Ärzte - oder deren Hinterbliebene - machten von ihrem Recht Gebrauch; 824 für viele der rassisch verfolgten DGGMitglieder sind Entschädigungs- oder Wiedergutmachungsakten überliefert. Die eidesstattlichen Erklärungen, in denen oftmals die Geschädigten selbst Auskunft über ihre Verfolgungsgeschichte geben, sind als Quelle für die Rekonstruktion von Einzelschicksalen, wie im Fall der Ärzte Hans Bab, Walther Cohen und Siegbert Joseph, von unschätzbarer Bedeutung. ${ }^{825}$ Darüber hinaus vermitteln die Anträge einen Eindruck von dem gewaltigen Ausmaß, in dem sich das Regime, aber auch zahlreiche Privatleute, an den Verfolgten bereicherten: Bankguthaben wurden beschlagnahmt, Immobilien zu Spottpreisen erworben, enteignete und hinterlassene Wertgegenstände versteigert oder, wie die Kunstsammlung des Berliner Arztes Ferdinand Mainzer, an Museen verkauft. 826

Nicht alle Verfahren endeten zugunsten der Geschädigten: Fristversäumnisse, verschollene oder vernichtete Unterlagen und juristische „Spitzfindigkeiten“ erschwerten den Wiedergutmachungsprozess und zogen ihn in die Länge. Ein Antrag auf die Rückerstattung von Bankguthaben, den Angehörige des 1941 verstorbenen DGG-Mitglieds Otto Bakofen im Jahr 1957 stellten, scheiterte an dem Umstand, dass das Berliner Bankhaus E. Meyer seinen Sitz im sowjetischen Sektor hatte und die „behauptete ungerechtfertigte Entziehung [...] daher in Ostberlin erfolgt“ sei. ${ }^{827}$
Ebenfalls erfolglos blieb der Versuch, eine „Wiedergutmachung“ für den Berliner Gynäkologen Ernst Gräfenberg zu erreichen, der 1937 wegen angeblichen Devisen- und Briefmarkenschmuggels verhaftet worden war, bis 1940 im Gefängnis saß und nach seiner Freilassung in die USA emigrierte. Das Devisenstrafverfahren, die Inhaftierung und der damit verbundene Verlust des Vermögens könne nur dann „als diskriminierend angesehen werden, wenn ein Notstand des Verfolgten vorlag“ und er sich „die Mittel für die Begründung einer neuen Existenz im Ausland sichern musste“. 828 „Eine solche Notsituation“, so das Urteil der Behörde, „lag hier nicht vor. [...]“. Vielmehr habe Gräfenberg offenbar selbst keine besondere Gefahr für sich gesehen, da er sowohl im April als auch im Juni 1933 von Auslandsreisen wieder nach Deutschland zurückgekehrt sei. In Bezug auf das Devisenvergehen könne ebenfalls kein Notstand angenommen werden. Gräfenberg hätte nur von den Auswanderungsmöglichkeiten Gebrauch machen müssen. „Es ist zwar richtig“, räumte die Behörde mit Blick auf die „Reichsfluchtsteuer“ ein, „daß dem Beschwerdeführer in diesem Falle eine nicht unbeträchtliche Besteuerung auferlegt worden wäre." Er habe sich aber im Vergleich zu zahlreichen Glaubensgenossen in einer guten Vermögenslage befunden, sodass „auch nach Abzug der Steuern ein genügendes Kapital vorhanden gewesen wäre, um ihm als namhaften Arzt die Schaffung eine Existenz im Ausland zu erleichtern. Standen dem Beschwerdeführer solche Möglichkeiten zur Verfügung, dann hätte er sie verwerten müssen.“

\section{Die eugenische Tradition}

$\nabla$

Nach dem Ende der Diktatur blieb eine Anerkennung der zwangssterilisierten Frauen und Männer als Opfer mit Entschädigungsansprüchen lange aus. ${ }^{829}$ Die eugenische Tradition war nicht nur in Deutschland, sondern auch etwa in den USA oder Schweden über einschlägige Gesetzgebung noch durchaus lebendig. ${ }^{830}$ Hinselmanns Verurteilung durch ein britisches Militärgericht im Jahr 1946 bezog sich ausdrücklich auf ein rassistisch motiviertes Verbrechen bei der Sterilisation von „Zigeunerabkömmlingen“, für die keine „wirklich medizinischen Gründe vorlagen“ - dies wurde mithin auch von dem britischen Militärgericht für die ganz überwiegende Zahl von „gesetzestreuen“ Sterilisationen durchaus unterstellt. ${ }^{831}$ Ein Rundschreiben der Ärztekammer und Kassenärztlichen Vereinigung in Hamburg aus dem Jahr 1947 machte die Mitteilung der Gesundheitsverwaltung bekannt, „dass eine Rückgängigmachung der Sterilisierung zur Zeit gesetzlich nicht möglich ist“" 832 - offenbar war bereits mehrfach der Wunsch danach geäußert worden.

\footnotetext{
822 Siehe hierzu Reden von Josef Zander (1978), Lutwin Beck (1986) und Hans Ludwig (1986), zitiert in: Ludwig: Reden (1999), S. 326-327, 365, 375-376. 823 BEG.

824 Zum Verfahren vgl. Damskis: Biografien (2009), S. 173-187.

825 Vgl. Grau: Rückerstattungsakten (2004); Damskis: Biografien (2009), S. 17-18.

826 LA Berlin, 73 WGA 2047-2050/59; 73 WGA 779-781/55.

827 LA Berlin, 43 WGA 2353-2355/57.

828 LA Berlin, 21 WGA $21730-31 / 59$ (auch für die folgenden Zitate).

829 Zur Nachgeschichte des GzVeN siehe vor allem Westermann: Leid (2010); Tümmers: Anerkennungskämpfe (2011).

830 Vgl. Westermann: Leid (2010), S. 60-81; in der Rubrik „Recht für den Arzt“ gab das Deutsche Ärzteblatt 1987 Empfehlungen der Bundesärztekammer zur „Zulässigkeit einer Sterilisation geistig Behinderter aus eugenischer oder sozialer Indikation“; DÄ 84 (1987), 43, A2846-A2851.

831 Lehmann: Chronik (1995), S. $48 \mathrm{f}$.

832 Zit. n. Lehmann: Chronik (1995), S. 116 f.
} 
Die Opfer organisierten sich seit den 1950er-Jahren, ohne vorerst auf größere Anerkennung zu stoßen: ${ }^{833}$ Für den Umgang mit ihnen mag charakteristisch gewesen sein, dass der im Dezember 1950 auf eine Veranstaltung des Zentralverbands der Sterilisierten im Münchner Hofbräuhaus geladene Vertreter des bayerischen Landesentschädigungsamtes später nach einem Tumult von „800 mehr oder weniger schwachsinnigen und sehr erregten Menschen“ sprach. ${ }^{834}$ Im Februar 1957 konstatierte der Deutsche Bundestag vorerst abschließend, dass das GzVeN kein typisches nationalsozialistisches Gesetz gewesen sei; mit Wiedergutmachungsangelegenheiten befasste Behörden beriefen sich in abschlägigen Bescheiden daher darauf, dass „in der Sterilisierung keine typisch nationalsozialistische Verfolgungsmaßnahme zu erblicken [sei]. Sterilisierungsgesetze gab es auch in anderen Ländern. Sie waren dort schon eingeführt, als es in Deutschland noch keinen Nationalsozialismus gab“. 835

Auch innerhalb der gynäkologischen Fachverbände stand zunächst nicht das Bemühen um die Opfer, sondern im Gegenteil eine aktualisierte gesetzliche Neuregelung der Sterilisation auf dem Programm. Sie wurde - zusammen mit der Beseitigung von Rechtsunsicherheiten bei der Abtreibung - schon 1951 auf der DGG-Sitzung in Bad Pyrmont behandelt und als Desiderat bezeichnet. 1962 stand „Die Sterilisierung der Frau“ bei der Jahrestagung der Bayerischen Gesellschaft für Geburtshilfe und Frauenheilkunde in Rothenburg ob der Tauber auf dem Programm. ${ }^{836}$

Beim Kongress 1951 war unter dem Thema „Schwangerschaftsunterbrechung und Sterilisierung“ in den Ausführungen von Hans Naujoks ein deutliches Unbehagen wahrnehmbar, das vor allem die eugenischen Sterilisationen betraf. Eine Fixierung des Standpunktes dazu, sagte er, sei zur Zeit sehr schwierig, „weil bei uns in Deutschland noch zuviel unerfreuliche Reminiszenzen, Gegensätzlichkeiten und Missverständnisse, politische Schlagworte und Ressentiments bestehen, die eine sachliche, ruhige Aussprache unmöglich machen“. ${ }^{837}$ Er bezog sich damit offensichtlich auf die beginnenden Bemühungen der Zwangssterilisierten um Anerkennung ihrer Ansprüche. ${ }^{838}$ Jedenfalls erwähnte er in diesem Zusammenhang einen „Versuch“ in Frankfurt vor einem „besonderen Forum“, der dies gezeigt habe. Konkreter wurde er nicht.

Das bis dato bei den Kongressen der DGG stets im Zusammenhang mit Abtreibungen erörterte Thema hatte sich aber nicht vermeiden lassen. Beiden gemeinsam war die Rechtsunsicherheit nach dem Zusammenbruch des NS-Regimes. ${ }^{839}$ Gegen Kriegsende und in den ersten Nachkriegsjahren kam es zu massenhaften Vergewaltigungen durch die Besatzungstruppen. Nach Schätzungen waren zwischen rund 860000 und mehreren Millionen Frauen betroffen. In einer aktuellen Studie wird angenommen, dass jede zehnte dieser Vergewaltigungen zu einer Schwangerschaft führte. Da vermutlich nur 1 von 10 dieser Schwangerschaften ausgetragen wurde, sahen sich die Ärzte mit einer riesigen Zahl von Abtreibungswünschen konfrontiert. ${ }^{840}$ Auch vor diesem Hintergrund ist die Tatsache zu sehen, dass das Thema „Schwangerschaftsunterbrechung und Sterilisation“ bereits 1951 wieder zu einem Hauptpunkt bei einer Tagung der DGG wurde.

Als Hauptreferenten hatte Heinrich Martius neben Naujoks den Heidelberger Strafrechtler Eberhardt Schmidt eingeladen. Schmidt dürfte Martius aus seiner Zeit als Ordinarius in Göttingen bekannt gewesen sein, sein Wechsel nach Heidelberg lag erst kurze Zeit zurück. Naujoks, inzwischen Direktor der UFK Frankfurt, hatte gerade erst eine Neubearbeitung seines mit Winter herausgegebenen Buches „Die künstliche Schwangerschaftsunterbrechung“ veröffentlicht. ${ }^{841}$ Martius erhoffte sich, wie er einleitend sagte, von beiden Referaten und der Diskussion eine Darstellung der „standesrechtlichen Grundlagen“ als Basis für die Beseitigung der bestehenden Unsicherheiten. Indikationen und Techniken sollten ausdrücklich nicht besprochen werden. ${ }^{842}$

Schmidt befasste sich zunächst mit der Rechtslage bei Schwangerschaftsabbrüchen. Sie sei nicht mehr ganz so verworren wie unmittelbar nach Kriegsende, sagte er. Unklarheiten gebe es dennoch reichlich. An der Geltung des $§ 218$ sei aber nicht zu zweifeln. Sicher sei auch die grundsätzliche Zulässigkeit von Abbrüchen aus medizinischer Indikation. Hinsichtlich der Meldepflicht bei Fehl- und Frühgeburten gebe es dagegen große Unsicherheit. Schwangerschaftsunterbrechungen aus eugenischer, sozialer und ethischer Indikation könnten durch nichts gerechtfertigt werden. Darüber bestehe im juristischen Schrifttum Einigkeit.

Unsicherheiten im Detail bei den Abbrüchen aus medizinischer Indikation bestanden Schmidt zufolge, weil die Zulässigkeit des Eingriffs in den einzelnen Ländern unterschiedlich begründet sei - so z.B. mit der fortdauernde Gültigkeit eines einschlägigen Paragrafen aus dem GzVeN oder aber - wo das gesamte Gesetz für ungültig erklärt bzw. die Tätigkeit der Erbgesundheitsgerichte eingestellt worden war - mit Entscheidungen des Reichsgerichtes von 1927 und $1938 .{ }^{843}$ Ob in einem konkreten Fall von einer medizinischen Indikation gesprochen werden könne, liege außerhalb der Zuständigkeit des Juristen. Die Frage sei, ob zur Klärung Gutachterkommissionen eingesetzt werden müssten. Er rate dringend, an der Mitwirkung einer Gutachterstelle festzuhalten „und die Statthaftigkeit des Eingriffs, von Notfällen abgesehen, von der Einverständniserklärung dieser Stelle abhängig zu machen". 844

Zusammenfassend forderte Schmidt vom Bundesgesetzgeber die Aufstellung wieder ganz einheitlicher Normen für die gesamte

\footnotetext{
833 Topp: Geschichte (2013), S. 202-213.

834 Zit. n. Westermann: Leid (2010), S. 93-96.

835 Zit. n. Tümmers: Anerkennungskämpfe (2011), S. 9.

836 Siehe hierzu Ley: Debatte (2012), insbesondere S. 204-205.

837 Naujoks: Schwangerschaftsunterbrechungen (1951), S. 318.

838 Topp: Geschichte (2013), S. 202-213.

839 Gante: Rechtspolitik (1993).

840 Gebhardt: Soldaten (2015).

841 Winter: Schwangerschaftsunterbrechung (1949).

842 Martius: Eröffnung [Verhandlungen 1951] (1951).

843 Schmidt: Schwangerschaftsunterbrechung (1951), S. 290: § 14 Abs. 1 nebst den Artikel 2-7, 12, 14 der 4. Ausführungsverordnung vom 18 . Juli 1935.

844 Ebd., S. 296.
} 
Problematik der Schwangerschaftsunterbrechung aus medizinischer Indikation. Vorschläge für eine künftige Gesetzgebung zur eugenischen, sozialen oder ethischen Indikation wollte er nicht machen. Dabei werde dem Arzt ein Kalkül zugemutet, „das den fetalen Lebenswert unter die Berechnung einer sozialen Tauglichkeit und Erwünschbarkeit“ stelle. „In dieser Richtung den ersten Schritt zu tun, bedeutet in ein Zweckdenken hineinzugeraten, an dessen Ende dann wieder die Massentötungen von Geisteskranken stehen, wofür totalitärer Zynismus das Wort ,Gnadentod' geprägte hatte“, erklärte er. ${ }^{845}$

$\mathrm{Zu}$ den Sterilisationen sagte Schmidt, die „Unmöglichkeit zwangsweiser Sterilisationen“ sei natürlich „über jeden Zweifel erhaben“. Die nihilistische Auffassung, die sich freiwilligen Sterilisationen gegenüber verbreitet habe, vermöge er allerdings nicht zu teilen. Im Gegensatz zur Abtreibung habe man es hier immer nur mit einem Rechtsgut zu tun, nämlich dem Interesse des Betroffenen an seiner körperlichen Integrität. Es sei die Frage, ob die Verfügung über dieses Rechtsgut im Hinblick auf die Sterilisationswirkungen dem Einzelnen schlechthin entzogen sei. Diese Frage zu bejahen, bestehe aber auch nach dem Fortfall des Erbgesundheitsgesetzes „nicht der mindeste Anlaß““846 Vielmehr habe der Wegfall des Gesetzes sogar die Folge, dass nunmehr nicht nur die medizinische und eugenische, sondern auch die soziale Indikation zur Rechtfertigung des Eingriffs führen könne. Schmidt begründete dies damit, dass nun der $§ 226$ a des Strafgesetzbuches ausschlaggebend für die Beurteilung werde. Dieser stelle - wie auch im Zusammenhang mit anderen Operationen die zugrunde liegende einverständliche Körperverletzung straffrei, wenn sie „den guten Sitten“ entspreche. Dies wiederum werde bei jeder sachgemäß durchgeführten und korrekt indizierten Operation unterstellt. Dennoch benötige die Ärzteschaft dafür Rechtssicherheit auf der Grundlage eines speziellen Sterilisationsgesetzes, in dem die Einzelheiten geregelt seien. Dies sei Aufgabe des Bundesgesetzgebers. ${ }^{847}$

Naujoks erklärte, er stimme mit seinem Korreferenten in den Hauptpunkten weitgehend überein. Im Gegensatz zu der im Nationalsozialismus vor allem von Seitz getroffenen Feststellung, wonach die Frauenärzte die Vollstrecker des Gesetzeswillens seien, sah er sich und seine Kollegen nun in der Pflicht, sich einen eigenen Standpunkt zu verschaffen und zu fixieren, „denn letzten Endes stützt sich die juristische Definition und Entscheidung meist auf das ärztliche Urteil und Gutachten. Gesetzgeber und Richter könnten nicht die Aufgabe haben, die ärztlichen Handlungen festzulegen und dem Arzt die Verantwortung abzunehmen“. Sowohl bei der Schwangerschaftsunterbrechung als auch bei Sterilisierung handle es sich um ein wichtiges sittliches Problem, „um die ethische Grundhaltung des Arztes überhaupt“ 848

Die willkürliche, unbegründete Vernichtung eines menschlichen Wesens, so Naujoks weiter, „ob Krüppel, Idiot oder gesund, ob ge- boren oder ungeboren“, könne niemals Aufgabe des Arztes sein. An diesem Prinzip dürfe auch in Notzeiten, infolge Unsicherheit oder aus anderen Gründen nicht gerüttelt werden. Die „bekannten Hinweise“, mit denen Abtreibung gerechtfertigt werden solle, wie etwa Überbevölkerung, Arbeitslosigkeit, Nahrungsmangel und Wohnungsnot oder das Recht der Frau auf den eigenen Körper, müsse er vor diesem Gremium nicht erörtern. Als Ausnahme nannte er nur die strenge medizinische Indikation.

Sehr verklausuliert befasste sich Naujoks auch ganz speziell mit den Verantwortlichkeiten für die Zwangssterilisationen. Dabei zeigt sich deutlich der Versuch der Fremdzuschreibung der Verantwortung für die eugenischen Zwangsmaßnahmen jener Zeit, die er zuvor nachhaltig unterstützt hatte. ${ }^{849}$ Es könne, so sagte er, „der Arzt sekundär in diesen Fragenkomplex hineingezogen werden; [...] wenn nämlich der Staat und seine verantwortlichen Führer in ihrer Verpflichtung, die Lebensverhältnisse des Volkes zu sichern [...], sich entschließen sollten, als letzte und äußerste Maßnahme zur Behebung des Notstandes die Tötung des keimenden Lebens als Recht zu proklamieren, so könnte für den Arzt die Pflicht erwachsen, dem Staate dabei zu helfen“. Die letzten Jahre hätten in erschreckender Weise gezeigt, in welche „entsetzlichen Konflikte“ der Arzt kommen könne, wenn er sich dazu verpflichten oder missbrauchen lasse, „auf Befehl zu töten, geisteskranke Menschen, idiotische Kinder oder die Frucht im Mutterleibe aus wirtschaftlichen Gründen zu beseitigen“. .50

\section{Die „späte Entschuldigung“}

Die Diskussion über einschlägige staatliche Regulierungsmaßnahmen hatte zur Folge, dass die Rechtmäßigkeit der nationalsozialistischen Zwangssterilisierungen lange nicht hinterfragt wurde. ${ }^{851}$ Erst 1988 wurden sie als nationalsozialistisches Unrecht anerkannt. Weitere 10 Jahre dauerte es, bis die Beschlüsse der Erbgesundheitsgerichte aufgehoben wurden. 2007 wurde das GzVeN als Unrecht geächtet; die Anerkennung zwangssterilisierter Frauen und Männern als Verfolgte des Nationalsozialismus steht jedoch weiter aus, und sie besitzen bis heute keinen Rechtsanspruch auf eine Entschädigung nach dem Bundesentschädigungsgesetz. Nicht wenige Opfer und selbst deren Kinder - soweit überhaupt vorhanden - schämten und schämen sich für die attestierte „Erbkrankheit“ und verzichteten deshalb auf Entschädigungsanträge. ${ }^{852}$ In diesem Zusammenhang sind 2010 und 2011 von Stefanie Westermann und Henning Tümmers 2 umfangreiche und gründliche historische Arbeiten zum „verschwiegenen Leid“ und den „Anerkennungskämpfen“ der Opfer von Zwangssterilisierungen erschienen. ${ }^{853}$

Vor diesem Hintergrund nimmt es nicht Wunder, dass die historische Beschäftigung mit den Zwangssterilisierungen im Unterschied zum nationalsozialistischen Krankenmord („Euthanasie“)

\footnotetext{
845 Schmidt: Schwangerschaftsunterbrechung (1951), S. 297.

846 Ebd., S. 298.

847 Ebd., S. 303.

848 Naujoks: Schwangerschaftsunterbrechung [Verhandlungen 1951] (1951), S. 305.

849 Vgl. Topp: Argument (2013), S. 318-326.

850 Naujoks: Schwangerschaftsunterbrechung (1951), S. 308 f.

851 Vgl. Hahn: Biopolitik (2000); Obermann-Jeschke: Eugenik (2008).

852 Westermann: Leid (2010), 241-269.

853 Westermann: Leid (2010); Tümmers: Anerkennungskämpfe (2011).
} 


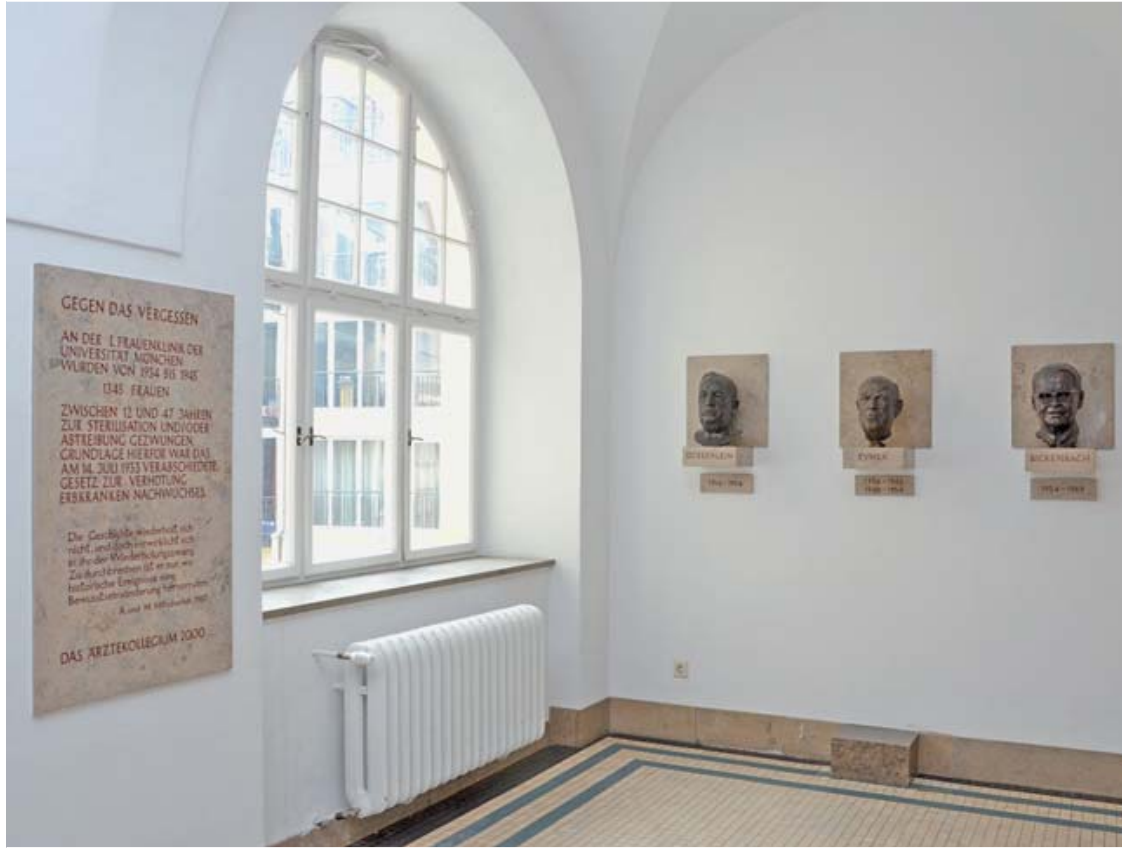

Abb. 44 Mahnmal für die Opfer von Zwangssterilisationen und -abtreibungen in der LMU-Frauenklinik (ehemals I. UFK München) an der Maistraße. Links: Gedenktafel; rechts: Büsten der Klinikdirektoren Albert Döderlein, Heinrich Eymer und Werne Bickenbach (Foto: Stephan Beißner, LMU-Frauenklinik München).

und den ebenfalls mörderischen Menschenversuchen verspätet einsetzte. Während für Letztere bereits im Nürnberger Ärzteprozess wichtiges Material gesammelt und durch Mitscherlich und Mielke publiziert worden war, ${ }^{854}$ begann die Auseinandersetzung mit den Zwangssterilisierungen erst, als mit dem Verweis auf die eugenisch-rassenhygienischen Grundlagen der nationalsozialistischen Ideologie systematische Aspekte der Verbindung von Medizin und Nationalsozialismus zunehmend in den Fokus gerieten. ${ }^{855}$

Die fachinterne Auseinandersetzung in der Frauenheilkunde verdankt vieles dem Umstand, dass Günther Kindermann 1987 in das Ordinariat an der I. UFK in der Münchner Maistraße berufen wurde. ${ }^{856}$ Mit ihm kam der in den späten 1960er-Jahren in Berlin sozialgynäkologisch sozialisierte Oberpfälzer Manfred Stauber als leitender Oberarzt. Von einem Studenten auf weiterhin eingesetzte Lehrfilme aus dem Nationalsozialismus aufmerksam gemacht, begann Stauber, sich näher mit der Klinikgeschichte zu beschäftigen und stieß im Rahmen einschlägig vergebener Doktorarbeiten auf das Problem der Zwangssterilisationen. Im Keller der Klinik lagerten die Krankenakten, anhand derer die Vorgänge genauer geklärt werden konnten; im Verlauf der Arbeiten konnte Robert Haselwarter als Interviewpartner und Zeitzeuge gewonnen werden. Er hatte in seiner 1939 publizierten Dissertation die an der Klinik unter dem Direktorat von Heinrich Eymer zwischen 1934 und 1937 durchgeführten Zwangssterilisierungen dokumentiert. ${ }^{857}$
Zum Eklat führte die Weihnachtsfeier der Klinik am 18. Dezember 1991, gleichzeitig das 75-jährige Jubiläum der I. UFK in den Räumlichkeiten an der Maistraße. ${ }^{858}$ Stauber erlaubte sich, in einer Festansprache auf die an der Klinik durchgeführten Zwangssterilisierungen einzugehen ( $\triangle$ Abb. 44) sowie die in der Klinik aufgestellte Büste des ehemaligen Leiters Heinrich Eymer mit dem Gesicht zur Wand zu drehen, was zu einer per Aushang kliniköffentlichen Korrespondenz mit dem Laborleiter Erich Kuß führte. ${ }^{859}$

Hier wurden die Konfliktlinien etabliert, anhand derer die Debatte für geraume Zeit sehr heftig geführt wurde: Auf der einen Seite stand das Bemühen um die Klärung der Frage, in welchem Umfang die Frauenheilkunde und deren Vertreter an einer als Unrecht aufgefassten Geschichte der nationalsozialistischen Zwangssterilisierungen ihren spezifischen Anteil hatten. Auf der anderen Seite stand dagegen die Vergewisserung des wissenschaftlichen und klinischen Fortschritts im Rahmen einer „Fachgeschichte“, die den Nationalsozialismus als eine - wenngleich mörderische - kurze und für die fachliche Entwicklung kaum ergiebige Episode betrachtete. In diesem Sinne etwa beurteilte es Naujoks in seinem Nachruf auf Hinselmann 1959 als eine „schicksalhafte Tragik“, dass Hinselmann für die aus „rassischen Gründen“ sterilisierten „Zigeunerinnen“ verurteilt wurde, „ohne daß er diese Art der angeordneten Sterilisierungen übersah“. 860

Diese Diskrepanz der historischen Deutung führte die Auseinandersetzung um die nationalsozialistische Vergangenheit der deutschen Gynäkologie und ihrer Vertreter auf einen neuen,

\footnotetext{
854 Zuerst als Mitscherlich/Mielke (Hrsg.): Diktat (1947); Mitscherlich/Mielke (Hrsg.): Medizin (1960) (und öfter); vgl. Freimüller: Flaschenpost (2010).

855 Zur Forschungsgeschichte vgl. Tümmers: Anerkennungskämpfe (2011), S. 15-21; Schmuhl: Zwangssterilisation (2011).

856 Stauber: Vergangenheitsbewältigung (2012).

857 Haselwarter: Zusammenstellung (1939).

858 Stauber: Vergangenheitsbewältigung (2012).

859 Die publizistische Auseinandersetzung lässt sich nach Kuß: Eymer (2011) und Stauber: Vergangenheitsbewältigung (2012) nachvollziehen.

860 Zit. n. Lehmann: Chronik (1995), S. 121-124.
} 
Abb. 45 Über die späte Entschuldigung bei den Opfern der Zwangssterilisierungen, die auf der Tagung der DGGG 1994 ausgesprochen wurde, wurde deutschlandweit berichtet: im Ressort „Natur und Wissenschaft“ in der Frankfurter Allgemeinen Zeitung und im Feuilleton der Süddeutschen Zeitung (Bild: Collage aus Zeitungsausschnitten, Quelle: Frankfurter Allgemeine Zeitung vom 07.09.1994, Süddeutsche Zeitung vom 31.08.1994).

\section{Eine späte Entschuldigung \\ Die deutschen Gynakologen und die NS-Vergangenheit}

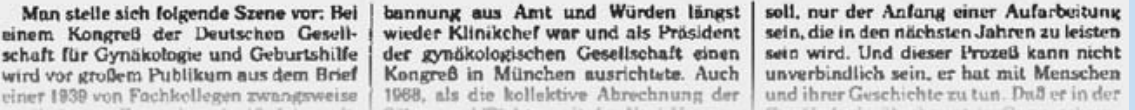

wohl letzten Höhepunkt. Sie konzentrierte sich zunächst auf Heinrich Eymer, den weite Kreise innerhalb der Gesellschaft als zu Unrecht persönlich angegriffen sahen. ${ }^{861}$ Erich Kuß hat deshalb im Zusammenhang einer größeren historischen Arbeit im Jahr 2011 beim Deutschen Bundestag angefragt, ob mit der Ächtung des GzVeN „auch die Direktoren deutscher Universitätsfrauenkliniken, die diesem Gesetz folgend Sterilisierungen durchführten und/oder durchführen ließen“ geächtet wurden. ${ }^{862}$

Gleichzeitig zog die Initiative Staubers weitere Kreise. 1993 befasste sich der Jahreskongress der Deutschen Gesellschaft für Psychosomatische Geburtshilfe und Gynäkologie in einer eigenen Sektion mit dem Thema „Gynäkologie und Nationalsozialismus“. 8631994 erregte eine öffentliche „späte Entschuldigung“ auf dem 50. Kongress der DGGG in München große Aufmerksamkeit: Die Gesellschaft hatte dorthin Opfer der Zwangssterilisierungen eingeladen. Durch ihren Vorsitzenden Hermann Hepp bekannte sie, „dass es unser zentrales Anliegen anlässlich dieses 50. Kongresses der DGGG ist, zu bekennen und eine ,späte‘ Entschuldigung darüber auszusprechen, dass wir im Prozess des Verdrängens über 5 Jahrzehnte das von uns bewirkte körperliche und seelische Leid nicht thematisiert haben und nicht auf die leidenden Frauen zugegangen sind“ ( $\bullet$ Abb. 45). ${ }^{864}$

Der Vorstand der DGGG hatte sich im September 1998 erneut mit dem Thema Nationalsozialismus zu befassen - nun aber auf allgemeinerer Ebene. Damals waren gerade die ersten Exemplare der von Hans Ludwig im Auftrag des Vorstands besorgten Edition der präsidialen Eröffnungsansprachen auf den Konferenzen der Gesellschaft von 1886-1998 ausgeliefert worden. ${ }^{865}$ Dies geschah offenbar in großer Eile, um rechtzeitig zur 52. Konferenz in Nürn- berg vorzuliegen. Das wenig professionell gesetzte Buch erwähnt den Springer-Verlag lediglich auf dem Umschlag, das Titelblatt führt weder Verlag noch Jahr, eine ISBN-Nummer wurde auf der Rückseite des Titels nachträglich eingeklebt. Im Vorwort mahnte der Vorsitzende der Jahre 1996-1998, Dietrich Berg, dass die in einer Reihe mit Menschenversuchen und Selektionen in Konzentrationslagern genannten Zwangssterilisationen „im Rahmen der Zeit, in der sie geschahen, gewertet werden müssen“;;66 der Herausgeber verwies in seiner Einführung auf vereinzelt aufklingende „pathetische Aufrufe oder auch staatsfromme Appelle“ in den Äußerungen der Vorsitzenden, „wie z.B. aus Reden, die in den Jahren des Dritten Reiches gehalten wurden“. ${ }^{867}$ Noch im September 1998 fiel allerdings auf, dass ohne weitere Kennzeichnung zumindest aus Stoeckels Rede von 1933 ganze Passagen und das den pathetischen Schluss bildende Grußtelegramm an Reichspräsident Hindenburg und Reichskanzler Hitler gestrichen worden waren.

Volker Lehmann, der sich kurz zuvor mit der Geschichte seiner Altonaer Klinik und seinem Vorgänger Hans Hinselmann auseinandergesetzt hatte, ${ }^{868}$ wandte sich daraufhin in einem Protestschreiben an Ludwig, das gleichzeitig auch an den scheidenden Präsidenten Berg und den neuen Vorsitzenden Günther Kindermann ging: „Durch Ihren Kommentar und Ihre Streichungen haben Sie die Möglichkeit zur historischen Erinnerung wesentlich eingeschränkt und den Prozeß des Verdrängens fortgesetzt, der eigentlich - so hatte es sich Herr Hepp gewünscht - spätestens nach dem 50 . Kongress beendet sein sollte." ${ }^{869}$ Ludwig entgegnete, dass „Kürzungen vor allem dort angebracht [waren], wo es sich um politische, berufsständische oder ausschliesslich lokale Bezüge handelte. [...] Es konnte deshalb nicht in der Absicht

\footnotetext{
861 Vgl. die Nachweise in Ludwig (Hrsg.): Reden (1999), S. 313, Fußnote 10 und 11; Kuß: Eymer (2011); Stauber: Vergangenheitsbewältigung (2012), $248-251$.

862 Kuß: Eymer (2011), S. 24. Im Literaturverzeichnis ist die Auseinandersetzung speziell um Eymer umfangreich dokumentiert.

863 Kentenich/Rauchfuß/Diederichs (Hrsg.): Gynäkologie (1994).

864 Zit. n. Stauber: Vergangenheitsbewältigung (2012), S. 247 f.

865 Ludwig (Hrsg.): Reden (1998).

866 Ebd., Vorwort Berg, V-VI.

867 Ebd., Einführung Ludwig, VII-VIII, vgl. die Einleitung zu den Reden im Kapitel „Drittes Reich“, S. 149 f.

868 Lehmann: Chronik (1995).

869 Scheiben Lehmanns an Ludwig vom 28.09.1998. Wir danken Volker Lehmann für die Überlassung seiner Korrespondenz in dieser Angelegenheit.
} 
des Herausgebers liegen, einzelne Persönlichkeiten wegen ihrer politischen Rücksichtnahmen aus der Zeit des Dritten Reiches zu verunglimpfen“. Den Vorwurf der „Verunglimpfung“ ließ Lehmann nicht gelten: - „Ein Redner kann durch seine Rede nicht verunglimpft werden. Er kann sich dabei höchstens offenbaren“, lautete seine Antwort. ${ }^{870}$ Der Vorstand der DGGG unter dem Vorsitz von Günther Kindermann traf schließlich die - kostspielige Entscheidung, das durch die Gesellschaft finanzierte, inkriminierte Werk nicht weiter auszuliefern, nach Möglichkeit bereits ausgelieferte Exemplare einzuziehen und eine ergänzte zweite Auflage mit den ungekürzten Originalreden zu präsentieren. ${ }^{871}$

Knapp 2 Jahrzehnte später - im Mai 2016 - wird das Thema Gynäkologie und Nationalsozialismus mit dem Abschluss des Manuskriptes für den vorliegenden Band durchaus nicht endgültig behandelt sein. Wir erleben derzeit die wohl letzten Gerichtsprozesse gegen NS-Verbrecher. Damit ist die Zeit der Aufrechnung von persönlicher Schuld und auch die Zeit der Furcht um eine mögliche Rufschädigung eventuell sogar des eigenen Lehrers ebenfalls Vergangenheit. Der historischen Betrachtung steht we- der ein juristisches noch ein moralisches Urteil zu - was nicht heißt, dass Historikerinnen und Historiker - ebenso wie Frauenärztinnen und Frauenärzte - abseits von persönlichen Wertmaßstäben urteilen könnten oder sollten. ${ }^{872}$ Die aktuellen Probleme in der Medizin und deren Diskussion, auch und gerade in der Frauenheilkunde, ${ }^{873}$ scheinen jede Erinnerung daran überflüssig zu machen, in welchem Umfang die medizinisch-wissenschaftliche Debatte in die gesellschaftlichen und politischen Diskurse involviert ist und sein muss, daraus allgemeinere Ziele übernimmt und dorthin legitimierte Ideen von der gesunden Mutter und dem gesunden Kind exportiert. Dabei spielen unsere gegenwärtigen Vorstellungen von der Beschaffenheit zukünftiger Generationen und deren steuerbare Machbarkeit eine gewichtige Rolle. Der in der Einleitung angesprochene Ressourcentausch ist durchaus kein exklusiv historisches Phänomen - die historische Betrachtung, und insbesondere die Auseinandersetzung darum, mag dabei helfen, die Tauschgüter und Handelswege besser zu verstehen, verantwortlicher mit und in unserer Gegenwart zu handeln und etwas zurückhaltender mit der Zukunft kommender Generationen umzugehen.

870 Schreiben Lehmanns an Ludwig vom 14.10.1998.

871 Ludwig (Hrsg.): Reden (1999).

872 Labisch: Urteilen (2003).

873 Vgl. http://www.dggg.de/leitlinienstellungnahmen/aktuelle-stellungnahmen/. 


\section{Statuten der Deutschen Gesellschaft für Gynäkologie}

Die Statuten der Deutschen Gesellschaft für Gynäkologie gehen auf einen Entwurf von 1877 zurück, der auf dem ersten DGGKongress im Jahr 1886 nahezu unverändert übernommen wurde (Archiv für Gynäkologie 12 [1877], S.262-265; vgl. Ludwig: Gründung [2005]; Edition in Anthuber/Beckmann/Dietl/Dross/ Frobenius [Hrsg.]: Herausforderungen [2012], S. 270-272).

Nachfolgend abgedruckt sind die Statuten in ihrer letzten Fassung vor der Machtübernahme der Nationalsozialisten (Archiv für Gynäkologie 144 [1931], XI-XII), sodann in der am 11. Oktober 1933 auf dem Berliner Kongress angenommenen Fassung, die im Kern bis zur Satzungsänderung auf der ersten Nachkriegstagung Bestand hatte (Archiv für Gynäkologie 156 [1934], VIIIIX), und schließlich in eben dieser, der ersten nach Kriegsende beschlossenen Fassung vom 19.April 1949 (Verhandlungen [1951], V-VII).

Das Augenmerk der vorliegenden Edition liegt dabei auf den wesentlichen Änderungen, die während und nach der Zeit des Nationalsozialismus erfolgten - ihr Zweck ist es, diese Änderungen möglichst augenfällig zu dokumentieren. Wortgleiche, sinngemäß gleiche oder in eigenständige Paragrafen ausgelagerte Passagen werden nicht wiederholt und sind entsprechend gekennzeichnet.

\section{Statuten der Deutschen Gesellschaft für Gynäkologie (1931) $\nabla$}

$\S 1$. Die „Deutsche Gesellschaft für Gynäkologie“ hat den Zweck, die gynäkologischen Kräfte zu einigen, durch persönlichen Verkehr den Austausch der Ideen zu erleichtern und gemeinsame Arbeiten zu fördern.

$\S 2$. Die Versammlungen der Gesellschaft finden alle 2 Jahre in der zweiten Hälfte der Pfingstwoche statt. Die Verhandlungen der Gesellschaft werden durch die anliegende Geschäftsordnung geregelt.

$\S 3$. Mitglied der Gesellschaft kann jeder werden, der in der Gynäkologie literarisch tätig gewesen ist, unter den in $\S 8$ bezeichneten Bedingungen. Außerdem wird der Ausschuß ermächtigt, Ehrenmitglieder und Ehrenvorsitzende zu ernennen, wozu ein jedesmaliger einstimmiger Beschluß erforderlich ist.
$\S 4$. Teilnehmer an den Sitzungen können durch Mitglieder eingeführt werden; diese dürfen jedoch nur mit Genehmigung des Vorsitzenden Vorträge halten oder an der Debatte teilnehmen.

$\S 5$. In der ersten jedesmaligen Sitzung wählt die Versammlung durch einfache Stimmenmehrheit den Ort der nächsten Versammlung und für die Dauer der nächsten 2 Jahre einen Ausschuß, bestehend aus einem Vorsitzenden, einem stellvertretenden Vorsitzenden, zwei Schriftführern, einem Kassenführer, vier anderen Mitgliedern, von denen zwei den Universitätskreisen nicht angehören.

Die fünf zuerst genannten Personen bilden das Bureau des Kongresses.

Der Ausschuß ist befugt, den gewählten Ort der Versammlung zu ändern, falls sich hinterher für die Abhaltung des Kongresses daselbst Hindernisse einstellen.

Die Mitglieder haben das Recht der Kooptation.

Die Amtsführung des neugewählten Vorstandes beginnt erst dann, wenn die Verhandlungen des vorangegangenen Kongresses im Druck erschienen sind.

$\S$ 6. Der Ausschuß leitet die Angelegenheiten der Gesellschaft für die Dauer von 2 Jahren, namentlich:

a) berät etwaige Abänderungen der Statuten und der Geschäftsordnung,

b) entscheidet über die Aufnahme neuer Mitglieder,

c) besorgt die Publikation der Verhandlungen,

d) sorgt für Verwahrung der Archive und Gelder der Gesellschaft.

Ist der Ausschuß versammelt, so finden seine Verhandlungen mündlich, im anderen Falle schriftlich statt.

$\S 7$. Der Beitrag der Mitglieder und Teilnehmer ist für 2 Jahre festgesetzt. Sollte dieser Beitrag, nach zweimaliger Erinnerung, für 2 oder mehrere Jahre nicht gezahlt worden sein, so wird der Name 
des Betreffenden aus der Liste gestrichen. Der Wiedereintritt in die Gesellschaft kann ohne weiteres erfolgen, sobald die fehlenden Beiträge nachgezahlt worden sind.

Ehrenmitglieder zahlen keinen Beitrag und erhalten die Verhandlungen der Gesellschaft umsonst.

$\S 8$. Die Aufnahme neuer Mitglieder erfolgt, abgesehen von der Zeit der Versammlung, zu Neujahr und auf der Tagung der Gesellschaft. Der neu Aufzunehmende muß durch drei Mitglieder vorgeschlagen werden, welche das Aufnahmegesuch persönlich unterschreiben müssen. Der Ausschuß entscheidet über die Wahl durch Stimmenmehrheit.

$\S 9$. Die Verhandlungen der Gesellschaft werden selbständig veröffentlicht; der Abdruck der Vorträge erfolgt, wenn irgend möglich, nach dem vom Vortragenden einzureichenden Manuskripte, anderenfalls nach den stenographischen Aufzeichnungen. Jedes Mitglied, vorausgesetzt, daß der vorjährige Beitrag gezahlt worden ist, erhält unentgeltlich ein Exemplar.

Der Vorsitzende hat das Recht, Vorträge zurückzuweisen, deren Inhalt schon veröffentlicht worden ist.

$\S 10$. Etwaige Abänderungen der vorliegenden Statuten können, nach vorgängiger Beratung im Ausschuß, nur durch eine Majorität von zwei Dritteln der in einer Sitzung anwesenden Mitglieder der Versammlung beschlossen werden.

\section{Satzungen der Deutschen Gesellschaft für Gynäkologie (1933) \\ $\nabla$}

$\S 1$. [wie 1931, §1]

$\S 2$. Die Gesellschaft gehört der Reichsarbeitsgemeinschaft für Mutter und Kind und durch diese der Reichszentrale für Gesundheitsführung (Reichsministerium des Innern) an.

$\S 3$. Mitglied der Gesellschaft kann unter den in $\S 6$ angeführten Bedingungen jeder Frauenarzt und jede Frauenärztin und jeder Arzt und jede Ärztin werden, der sich für Geburtshilfe und Gynäkologie interessiert.

$\S 4 .[v g l .1931, \S 3]$

$\S 5$. [im Wesentlichen wie 1931, §7]

§6. [im Wesentlichen wie 1931, §8]

$\S 7$. [im Wesentlichen wie 1931, §4]

$\S 8$. [im Wesentlichen wie 1931, §2]

§. [im Wesentlichen wie $1931, \S 5]$

$\S 10$. In der gleichen Sitzung wählt die Versammlung für die Dauer von 4 Jahren aus den Mitgliedern des Vorstandes einen Vertreter für die Reichsarbeitsgemeinschaft, der die Gesellschaft gegenüber allen Behörden vertritt. [1937 auf Antrag Stoeckels wieder gestrichen]
$\S 11$. Der Vorstand bedarf der Bestätigung durch das Reichsministerium des Innern und kann von ihm abberufen werden.

$\S 12 .[$ vgl. $1931, \S 5]$

$\S 13 .[$ vgl. 1931, §5]

$\S 14$. [im Wesentlichen wie 1931, §6]

$\S 15$. Beschlüsse des Vorstandes und der Mitgliederversammlung können durch das Reichsministerium des Innern ausgesetzt oder aufgehoben werden.

$\S 16 .[v g l .1931, \S 9]$

$\S 17 .[v g l .1931, \S 9]$

$\S 18$. Abänderungen der Statuten werden vom Vorstand beraten und von der Mitgliederversammlung beschlossen, wozu eine Majorität von zwei Dritteln der anwesenden Mitglieder erforderlich ist. Die abgeänderten Statuten bedürfen der Bestätigung durch das Reichsministerium des Innern. [vgl. 1931, §10]

\section{Satzungen der Deutschen Gesellschaft für Gynäkologie (1949) \\ $\nabla$}

[Streichung der $\S \S 2,11$ und 15 der Fassung von 1933]

$\S 1$. Die Deutsche Gesellschaft für Gynäkologie ist ein gemeinnütziger Verein. Sie dient der Förderung der Wissenschaft und verfolgt den Zweck, die gynäkologischen Kräfte zu einigen, durch persönlichen Verkehr den Austausch der Ideen zu erleichtern und gemeinsame Arbeiten zu fördern.

\section{$\S 2$. [im Wesentlichen wie 1933, §3]}

$\S 3$. Der Vorstand ist ermächtigt, Ehrenmitglieder (und Ehrenvorsitzende) sowie korrespondierende Mitglieder zu ernennen, wozu jedesmal ein einstimmiger Beschluss der Vorstandsmitglieder erforderlich ist.

\section{§4. [im Wesentlichen wie 1931, § 7 bzw. 1933, § 5]}

§5. [im Wesentlichen wie 1931, §8 bzw. 1933, §6]

$\S 6$. Alle Mittel der Gesellschaft (Vermögen, Einnahmen aus Beiträgen, Zahlungen für Leistungen der Gesellschaft, Spenden usw.) sind für die gemeinnützigen Zwecke gebunden und werden entweder laufend für diese Zwecke verwendet oder einem zweckgebundenen Fond zugeführt. Der Schatzmeister hat den Nachweis über die Verwendung des Vermögens in dem genannten Sinne in der Rechnung zu führen.

§7. [im Wesentlichen wie 1931, § 4 bzw. 1933, §7]

§ 8. [im Wesentlichen wie 1931, § 2 bzw. 1933, § 8]

§ 9. [im Wesentlichen wie 1931, § 5 bzw. 1933, § 9]

$\S 10$. [vgl. 1931, § 5 bzw. 1933, § 12] 
$\S 11$. [vgl. 1931, §5 bzw. 1933, §13]

§12. [im Wesentlichen wie 1931, § 6 bzw. 1933, § 14]

§13. [vgl. 1931, § 9 bzw. 1933, § 16]

§14. [vgl. 1931, § 9 bzw. 1933, § 17]

$\S 15$. [im Wesentlichen wie 1931, § 10 bzw., unter Streichung des letzten Satzes, 1933, §18]
$\S 16$. Das Vermögen der Gesellschaft ist bei ihrer Auflösung oder Aufhebung oder bei Wegfall ihres bisherigen Zweckes ausschließlich und unmittelbar zu gemeinnützigen Zwecken zu verwenden. Beschlüsse darüber, wie das Vermögen zu verwenden ist, dürfen erst nach Zustimmung des zuständigen Finanzamtes ausgeführt werden. 


\section{Mitglieder des Vorstands 1931-1949}

Die folgende Tabelle beruht auf den Protokollen der Mitgliederversammlungen, in deren Rahmen der künftige Vorstand gewählt oder berufen wurde, sowie auf den von der DGG veröffentlichten Listen der „Mitglieder des Ausschusses der ,Deutschen Gesellschaft für Gynäkologie‘ auf den einzelnen Tagungen“. Beide Quellen sind in den jeweiligen Tagungsberichten abgedruckt.

Über die Wahl des 1. Vorsitzenden und der Beisitzer wurde im untersuchten Zeitraum auf der Mitgliederversammlung im Rahmen des Kongresses entschieden. Den stellvertretenden Vorsitz übernahm traditionell der scheidende 1. Vorsitzende; der 2. Schriftführer wurde in der Regel vom designierten 1. Vorsitzenden bestimmt. Nicht regelmäßig neu besetzt wurden das Amt des 1. (oder „ständigen“) Schriftführers und das Amt des Schatzmeisters oder Kassenwarts. Gemäß der im Oktober 1933 beschlossenen Satzung bedurfte der Vorstand in der Zeit des Nationalsozialismus der Bestätigung durch das Reichsministerium des Innern.

Zu den Aufgaben des Vorstands (siehe hierzu auch das entsprechende Kapitel) zählten in erster Linie die Vorbereitung des Kongresses sowie die Drucklegung des Tagungsberichts, der als Sonderband des „Archivs für Gynäkologie“ erschien. Offiziell endete die Amtszeit der Vorstandsmitglieder erst mit der Veröffentlichung des Bandes. Die in der folgenden Tabelle genannten Amtszeiten beginnen jeweils mit der Wahl bzw. Ernennung des neuen Vorstands und enden zum folgenden Kongress. Einen Sonderfall stellt die Vorstandswahl des Jahres 1941 dar, da bis 1949 kein Kongress zustande kam.

Tab. 1 Mitglieder des Vorstands 1929-1949.

\begin{tabular}{|c|c|c|c|c|c|c|}
\hline $\begin{array}{l}\text { Amts- } \\
\text { zeit }\end{array}$ & 1. Vorsitzender & 2. Vorsitzender & Beisitzer & $\begin{array}{l}\text { 1. Schrift- } \\
\text { führer }\end{array}$ & $\begin{array}{l}\text { 2. Schrift- } \\
\text { führer }\end{array}$ & $\begin{array}{l}\text { Kassenwart/ } \\
\text { Schatzmeister }\end{array}$ \\
\hline $\begin{array}{l}1929- \\
1931\end{array}$ & $\begin{array}{l}\text { Seitz, Ludwig } \\
(1872-1961)\end{array}$ & $\begin{array}{l}\text { Sellheim, Hugo } \\
\text { (1871-1936) }\end{array}$ & $\begin{array}{l}\text { Kupferberg, Heinz (1862-1942) } \\
\text { Mayer, August (1876-1968) } \\
\text { Pankow, Otto (1876-1934) } \\
\text { Siedentopf, Heinrich Wilhelm (1901-1986) }\end{array}$ & $\begin{array}{l}\text { Martin, } \\
\text { Eduard } \\
(1879-1966)\end{array}$ & $\begin{array}{l}\text { Guthmann, } \\
\text { Heinrich } \\
(1893-1968)\end{array}$ & $\begin{array}{l}\text { Franqué, } \\
\text { Otto von } \\
\text { (1867-1937) }\end{array}$ \\
\hline $\begin{array}{l}1931- \\
1933\end{array}$ & $\begin{array}{l}\text { Stoeckel, Walter } \\
(1871-1961)\end{array}$ & $\begin{array}{l}\text { Seitz, Ludwig } \\
\text { (1872-1961) }\end{array}$ & $\begin{array}{l}\text { Fraenkel, Ludwig (1870-1951), } \\
1933 \text { „zurückgetreten“ } \\
\text { Hammerschlag, Sigfrid (1880-1948), } \\
1933 \text { „zurückgetreten“ } \\
\text { Hüssy, Paul (1884-1946) } \\
\text { Knauer, Emil (1867-1935) } \\
\text { Tóth, Stephan von (1865-1935) }\end{array}$ & $\begin{array}{l}\text { Martin, } \\
\text { Eduard } \\
(1879-1966)\end{array}$ & $\begin{array}{l}\text { Frommolt, } \\
\text { Günther } \\
(1892-1972)\end{array}$ & $\begin{array}{l}\text { Franqué, } \\
\text { Otto von } \\
(1867-1937)\end{array}$ \\
\hline $\begin{array}{l}1933- \\
1935\end{array}$ & $\begin{array}{l}\text { Mayer, August } \\
\text { (1876-1968) }\end{array}$ & $\begin{array}{l}\text { Stoeckel, Walter } \\
\text { (1871-1961) }\end{array}$ & $\begin{array}{l}\text { Albrecht, Hans (1878-1944) } \\
\text { Bauereisen, (Johann) Adam (1875-1961) } \\
\text { Kehrer, Erwin (1874-1959) } \\
\text { Kirstein, Friedrich (1880-1937) } \\
\text { Schubert, Gotthard (1875-1938) } \\
\text { Snoo, Klaas de (1877-1949) }\end{array}$ & $\begin{array}{l}\text { Martin, } \\
\text { Eduard } \\
(1879-1966)\end{array}$ & $\begin{array}{l}\text { Tausch, } \\
\text { Moritz } \\
(1899-1939)\end{array}$ & $\begin{array}{l}\text { Martius, } \\
\text { Heinrich } \\
(1885-1965)\end{array}$ \\
\hline
\end{tabular}


Tab. 1 Mitglieder des Vorstands 1929-1949. (Fortsetzung)

\begin{tabular}{|c|c|c|c|c|c|c|}
\hline $\begin{array}{l}\text { Amts- } \\
\text { zeit }\end{array}$ & 1. Vorsitzender & 2. Vorsitzender & Beisitzer & $\begin{array}{l}\text { 1. Schrift- } \\
\text { führer }\end{array}$ & $\begin{array}{l}\text { 2. Schrift- } \\
\text { führer }\end{array}$ & $\begin{array}{l}\text { Kassenwart/ } \\
\text { Schatzmeister }\end{array}$ \\
\hline $\begin{array}{l}1935- \\
1937\end{array}$ & $\begin{array}{l}\text { Wagner, G(eorg) } \\
\text { A(ugust) } \\
\text { (1873-1947) }\end{array}$ & $\begin{array}{l}\text { Mayer, August } \\
(1876-1968)\end{array}$ & $\begin{array}{l}\text { Alvensleben, Alkmar von (1874-1946) } \\
\text { Bach, Ernst (1899-1944) } \\
\text { Daels, Frans (1882-1974) } \\
\text { Jaschke, Rudolf Theodor Edler von } \\
\text { (1881-1963) } \\
\text { Sigwart, Walter (1876-1948) } \\
\text { Stoeckel, Walter (1871-1961) } \\
\text { Süssmann, Fritz (1881-1967?) } \\
\text { Wichmann, Rudolf (1891-1973) } \\
\text { Wintz, Hermann (1887-1947) }\end{array}$ & $\begin{array}{l}\text { Naujoks, Hans } \\
\text { C(hristian) } \\
\text { (1892-1959); } \\
\text { Naujoks über- } \\
\text { nahm das } \\
\text { Amt } 1936 \text { von } \\
\text { Martin nach } \\
\text { dessen Rück- } \\
\text { tritt (siehe } \\
\text { hierzu S. } 21 \mathrm{f} .)\end{array}$ & $\begin{array}{l}\text { Kaufmann, } \\
\text { Carl } \\
(1900-1980)\end{array}$ & $\begin{array}{l}\text { Martius, } \\
\text { Heinrich } \\
(1885-1965)\end{array}$ \\
\hline $\begin{array}{l}1937- \\
1941\end{array}$ & $\begin{array}{l}\text { Fuchs, Hans } \\
(1873-1942)\end{array}$ & $\begin{array}{l}\text { Wagner, G(eorg) } \\
\text { A(ugust) } \\
\text { (1873-1947) }\end{array}$ & $\begin{array}{l}\text { Amreich, Isidor Alfred (1885-1972), } \\
\text { nach dem Kongress 1937 berufen } \\
\text { Bach, Ernst (1899-1944) } \\
\text { Fetzer, Max (1878-1946) } \\
\text { Guggisberg, Hans (1880-1977) } \\
\text { Heynemann, Theodor (1878-1951) } \\
\text { Hinselmann, Hans (1884-1959) } \\
\text { Lönne, Friedrich (1891-1958) } \\
\text { Nürnberger, Ludwig (1884-1959) } \\
\text { Olow, John (1883-1948) } \\
\text { Rooy, A(drianus) H(enricus) M(aria) } \\
\text { J(osephus) van (1880-1937), } \\
\text { vor dem Kongress 1941 verstorben } \\
\text { Weibel, Wilhelm (1876-1945), } \\
\text { nach dem Kongress 1937 berufen }\end{array}$ & $\begin{array}{l}\text { Naujoks, Hans } \\
\text { C(hristian) } \\
\text { (1892-1959) }\end{array}$ & $\begin{array}{l}\text { Döderlein, } \\
\text { Gustav } \\
\text { (1893-1980) }\end{array}$ & $\begin{array}{l}\text { Martius, } \\
\text { Heinrich } \\
(1885-1965)\end{array}$ \\
\hline $\begin{array}{l}1941 \\
\text { (Wahl) }\end{array}$ & $\begin{array}{l}\text { Jaschke, Rudolf } \\
\text { Theodor Edler von } \\
\text { (1881-1963) }\end{array}$ & $\begin{array}{l}\text { Fuchs, Hans } \\
(1873-1942)\end{array}$ & $\begin{array}{l}\text { Benthin, Walther (1882-1950) } \\
\text { Björkenheim, Robert Edvard Albert } \\
\text { (1877-1970) } \\
\text { Burger, Karl Johann (1893-1962) } \\
\text { Cònill i Montobbio, Victor (1886-1970) } \\
\text { Hengge, Anton (1873-1945) } \\
\text { Knaus, Hermann (1892-1970) } \\
\text { Mikulicz-Radecki, Felix von (1892-1966) } \\
\text { Philipp, Ernst (1893-1961) } \\
\text { Schröder, Robert (1884-1959) } \\
\text { Stuckrad, Kurt-Otto von (1893-1945) }\end{array}$ & $\begin{array}{l}\text { Naujoks, Hans } \\
\text { C(hristian) } \\
\text { (1892-1959) }\end{array}$ & $\begin{array}{l}\text { Rech, Walter } \\
(1896-1975)\end{array}$ & $\begin{array}{l}\text { Martius, } \\
\text { Heinrich } \\
(1885-1965)\end{array}$ \\
\hline 1949 & $\begin{array}{l}\text { Jaschke, Rudolf } \\
\text { Theodor Edler von } \\
\text { (1881-1963) }\end{array}$ & $\begin{array}{l}\text { Mayer, August } \\
(1876-1968)\end{array}$ & $\begin{array}{l}\text { Benthin, Walther (1882-1950) } \\
\text { Burger, Karl Johann (1893-1962) } \\
\text { Döderlein, Gustav (1893-1980) } \\
\text { Mikulicz-Radecki, Felix von (1892-1966) } \\
\text { Philipp, Ernst (1893-1961) } \\
\text { Schröder, Robert (1884-1959) }\end{array}$ & $\begin{array}{l}\text { Naujoks, Hans } \\
\text { C(hristian) } \\
\text { (1892-1959) }\end{array}$ & $\begin{array}{l}\text { Roemer, Hans } \\
\text { (1907-1973) }\end{array}$ & $\begin{array}{l}\text { Martius, } \\
\text { Heinrich } \\
(1885-1965)\end{array}$ \\
\hline
\end{tabular}




\section{Kurzbiografien}

\section{Einleitung}

Das folgende Verzeichnis enthält biografische Skizzen sämtlicher in diesem Band genannten Mitglieder des DGG-Vorstands zwischen 1933 und 1949 in alphabetischer Reihenfolge. Genannt werden Basisdaten wie Geburts- und Sterbedatum mit den dazugehörigen Orten, daneben die wichtigsten Stationen der Ausbildung und beruflichen Karriere, schließlich die Mitgliedsdaten in der DGG und das Engagement in der Gesellschaft im Untersuchungszeitraum, etwa durch Vorträge auf den Kongressen. Dies ermöglicht es einerseits, bei den im Haupttext eingehender und häufig auch an mehreren Stellen behandelten Persönlichkeiten auf die (mehrfache) Aufzählung dieser Daten in den Fußnoten zu verzichten; andererseits können zu im Hauptteil eher am Rande erwähnten Personen an dieser Stelle kurze Charakterisierungen ihrer Stellung und ihres Verhaltens während des Nationalsozialismus gegeben werden, während dies für die im Hauptteil ausführlich behandelten Personen hier unterbleibt.

Die Einbeziehung der während des Nationalsozialismus aus rassischen und/oder weltanschaulichen Gründen aus der DGG verdrängten Mitglieder - etwa im Sinne eines Gedenkbuches - hätte den Umfang dieser Kurzübersicht vervielfacht. Sie war deshalb im Rahmen dieser Publikation nicht möglich. Ein entsprechendes Verzeichnis bleibt ein an anderer Stelle zu erfüllendes Desiderat.

\section{Albrecht, Hans \\ $\nabla$}

geb. 14.06.1878, Sonthofen (Allgäu)

gest. 26.05.1944, München

katholisch

Familie

Vater: Michael Albrecht, Vorstand der Tierärztlichen Hochschule München

๑1) 1905; 1931 geschieden; 2) 1931; 1 Sohn

\author{
Ausbildung \\ 1901 Approbation (München)
}

\section{Akademische Karriere}

1901 Promotion (München); 1921 Habilitation (München); 1925

a. o. Prof. (München)
Weiterbildung und berufliche Karriere

1902-1904 Ass. in der chir. Abt. des KH rechts der Isar München; 1905 Ass. an der geburtsh. Station der I. UFK München (v. Winckel); bis 1914 und 1918/19 an der II. Gyn. Klinik München (Amann), zunächst Ass., dann OA; 1914-1918 Kriegsdienst (Oberstarzt der Reserve); 1922-1944 Chefarzt am KH Rotes Kreuz München

\section{Mitgliedschaft/Funktionen in der DGG}

1933-1935 Beisitzer; 1935 Mitorganisator des Münchner Kongresses; Vorträge: 1933, 1935

\section{NS-Organisationen}

01.04.1933 Förderndes Mitglied der SS

\section{Vita}

Hans Albrecht, als langjähriger Chef des Münchner Krankenhauses „Rotes Kreuz“ mit den lokalen Gegebenheiten bestens vertraut, hat den in Tübingen residierenden DGG-Vorsitzenden August Mayer 1935 bei der Organisation des Kongresses in der bayerischen Landeshauptstadt tatkräftig unterstützt. Er tat dies in seiner Funktion als Beisitzer im Vorstand. Moritz Tausch, dem als 2. Schriftführer und Oberarzt von Mayer diese Aufgabe eigentlich zugefallen wäre, konnte seinem Chef nur in Tübingen zur Hand gehen. Albrecht sprang darüber hinaus bei dem Kongress mit der Übernahme des Referates zum Thema „Periodische Fruchtbarkeit und Unfruchtbarkeit der Frau“ ein. Dem ursprünglich vorgesehenen Redner, Hermann Knaus, hat Mayer aus politischen Gründen abgesagt. Die durch die Forschung von Knaus eröffneten Möglichkeiten zur Kontrazeption waren den Nationalsozialisten ein Dorn im Auge - zunächst ungeachtet der Tatsache, dass seine Erkenntnisse auch dazu benutzt werden konnten, die Wahrscheinlichkeit einer Konzeption zu erhöhen. Die NS-Funktionäre, auf deren Bestrebungen die Knaus-Absage zurückging, hatten offenbar übersehen, dass sich auch Albrecht in Veröffentlichungen zur „Geburtenregelung auf natürlichem Weg“ geäußert hatte. Albrecht genoss in den 1930er-Jahren im DGG-Vorstand größte Wertschätzung und wurde intern als einer der nächsten Präsidenten gehandelt.

Archivalische Quellen

UAT $150 / 33,41$.

\section{Gedruckte Quellen}

GK 1928, S. 3; GK 1939, S. 3 f.; GW 1956, S. 180; Eymer: Albrecht [Nachruf] (1944); Stoeckel: Albrecht [Nachruf] (1944). 


\section{Alvensleben, Alkmar von}

$\nabla$

geb. 07.10.1874, Schollene bei Rathenow

gest. 30.08.1946, Wernigerode

\section{Familie}

Vater: Udo III. von Alvensleben (1823-1910), Autor, Land-/Forstwirt, preußischer Hauptmann; Mutter: Agnes, geb. von Pritzelwitz (1835-1911)

œ 1918: Martha, geb. Leonhard (1885-1963); 3 Söhne: Udo (1919-1949), Wichard (1921-1932), Alkmar (1924-1977)

\section{Ausbildung}

1894 Abitur (Wernigerode); 1894-1897 Studium der Rechte (Göttingen, München, Berlin); 1898-1902 Medizinstudium (Freiburg i. Br., Kiel); 1902 Staatsexamen; 1904 Approbation (Freiburg i. Br.)

\section{Akademische Karriere \\ 1904 Promotion (Freiburg i. Br.)}

\section{Weiterbildung und berufliche Karriere}

1902-1904 Ass. am Städt. KH Konstanz (Kappeler); 1904 Schiffsarzt des Norddeutschen Lloyd; 1904/05 Volontärarzt an der Charité Berlin (Bumm); 1905-1909 Ass. an der UFK Kiel, dort Ausbildung zum Frauenarzt (Werth, Pfannenstiel); 01.06.1909-1945 Dir. der Landesfrauenklinik Magdeburg; im Ersten Weltkrieg landsturmpflichtiger Arzt; Rechtsritter des Johanniterordens; 1945 oder 1946 Anstellung an einer Privatfrauenklinik in Wernigerode

\section{Mitgliedschaft/Funktionen in der DGG 1935-1937 Beisitzer}

\section{Gedruckte Quellen}

GK 1928, S. 4; GK 1939, S. 4; GW 1956, S. 144.

\section{Internetquellen}

http://www.familie-von-alvensleben.de/index.php/personen-vonhistorischem-interesse-mainmenu-34/nach-1850-mainmenu-214 alkmar-schollene-1874-1946-mainmenu-217

\section{Amreich, Isidor Alfred \\ $\nabla$}

geb. 22.04.1885, Gars am Kamp (Österreich)

gest. 08.09.1972, Wien

katholisch

Familie

Vater: Gemeindearzt

๑1905: Augusta Josefa, geb. Deysther; keine Kinder

\section{Ausbildung}

1903 Matura (Humanist. Gymnasium Krems/Donau); bis 1910 Medizinstudium (Wien)

\section{Akademische Karriere}

1910 Promotion (Wien); 1923 Habilitation (Wien); 1936 o. Prof. (Innsbruck); 1939 o. Prof. (Wien); 1945 Entzug der Lehrbefugnis

\section{Weiterbildung und berufliche Karriere}

1910-1912 Ass. am II. Anat. Inst. (Hochstetter); 1912-1914 sowohl Ass. der I. UFK (Piskacek, Schauta) als auch der I. Chir. Klinik (Eiselberg); 1914-1918 Frontdienst in der IV. mob. Chirurgengruppe Eifelsberg, Dienstgrad: Landgr. OA; 1923 Habilitation für Gyn. und Geburtsh.; 1928-1936 Privatpraxis; 1936/37 Leiter der UK für Gyn. und Geburtsh. Innsbruck; ab 1939 Dir. der I., später der II. UFK Wien; 05/1945 Entzug der Lehrbefugnis; kurzfristige Internierung im Entnazifizierungslager Wolfsberg; anschl. in Privatpraxis tätig; 1953 Ruhestand

\section{NS-Organisationen}

11.01.1934 NSDAP; 1934 SA; ab 03/1938 SS (SS-Winkelträger, Julleuchter, 1942 Obersturmführer, 12/1944 Antrag auf Aufnahme in die „Akademische Legion“ des Höheren SS- und Polizeiführers Wiens); NSV

\section{Mitgliedschaft/Funktionen in der DGG \\ 1938 (?)-1941 Beisitzer; Ehrenmitglied; Vortrag: 1949}

Vita

Isidor Alfred Amreich, einer der bedeutenden österreichischen Frauenärzte, schloss sich den Nationalsozialisten nicht aus Opportunismus, sondern aus Überzeugung an. Bereits 1934, als die Partei in Österreich noch verboten war, trat er der NSDAP und der SA bei. Im März 1938, offenbar kurz nach dem „Anschluss“ Österreichs, wurde er Mitglied der SS (ab 1942 Obersturmführer). Amreich war damit der einzige Wiener Hochschullehrer, der allen 3 Organisationen angehörte. Als Leiter der I. UFK beerbte er im Jahr 1939 den aus rassischen Gründen vertriebenen Heinrich Kahr; ab 1940 wurden an der Wiener Klinik Zwangssterilisationen und Zwangsabtreibungen durchgeführt.

Wegen seiner Zugehörigkeit zur SS wurde Amreich am 10. Mai 1945 suspendiert und später im Entnazifizierungslager Wolfsberg in der Steiermark interniert. Zwei ehemalige Kollegen, darunter der rassisch verfolgte und in die USA emigrierte Emanuel Klaften, setzten sich erfolgreich für seine Freilassung ein. Wenngleich Amreichs klinische und universitäre Laufbahn an ihr Ende gelangt war - der Betriebsrat des Allgemeinen Krankenhauses Wien bezeichnete ihn als radikalen Nationalsozialisten, dessen „Ausscheidung dringend geboten“ sei -, konnte er ab 1948 wieder eine gynäkologische Praxis betreiben.

Amreichs Verdienste um das Fachgebiet liegen vor allem im operativen Bereich. Er hat als Vertreter der österreichischen Schule Wesentliches zur Weiterentwicklung der vaginalen Operation des Zervixkarzinoms nach Schauta beigetragen und sich mit großem Engagement sowie viel Geduld der Ausbildung des Nachwuchses auf diesem Gebiet gewidmet. Seine OP-Technik gilt als das radikalste aller beschriebenen Verfahren. Außerdem übernahm Amreich nach dem Tod von Josef Halban dessen Rolle als Mitherausgeber des vielbändigen Handbuchs „Biologie und Pathologie des Weibes“, das neben ihm von Ludwig Seitz verantwortet wurde. 1964 hat die Universität Innsbruck Amreich zum Ehrensenator ernannt, die DGG verlieh ihm nach Kriegsende die Ehrenmitgliedschaft.

Archivalische Quellen

BArch Berlin, BDC, DS B 026 


\section{Gedruckte Quellen}

GK 1939, S. 5; GW 1956, S. 249; Fauvet: Operation (1964), S. 210 f.; Richter: Beziehungen (1986), S. 294-296; Schaller: Wertheim-Klinik (1992), S. 180-183; Wolf: Vernunft (2008), S. 406; Spring: Krieg (2009), S. 263.

\section{Baatz, Hans \\ $\nabla$}

geb. 13.09.1906, Danzig

gest. 25.06.1996, Bad Pyrmont

evangelisch

Familie

Vater: Frauenarzt

\section{Ausbildung}

1925-1930 Medizinstudium (Königsberg i. Pr., München, Prag, Gießen); 1931 Approbation

\section{Akademische Karriere \\ 1932 Promotion (Gießen); 1938 Habilitation (Bonn); 1939 Do- zent für Geburtsh. und Gyn. (Berlin)}

\section{Weiterbildung und berufliche Karriere}

1930 Inn. Med. KH Dresden-Friedrichstadt; 1931-1933 Chir. Westend-KH Berlin; 1933-1936 Ass. an der Frauenklinik der Charité Berlin (G.A. Wagner); 10/1936 zwangsbeurlaubt; zur weiteren Laufbahn widersprüchliche Angaben (GK 1939; GK 1960: 1937-1945 I. UFK Berlin bei Stoeckel; 1942-1945 Leiter eines „Instituts für experimentelle Krebsforschung“ in Berlin); ab 1951 Frauen- und Badearzt in Bad Pyrmont (1956-1981 Leiter der gyn. Abt. des Balneolog. Inst.)

\section{NS-Organisationen}

1933 SS (1940 Obersturmführer); 1937 NSDAP; 1938 Leiter des Auslandsamtes der Dozentenschaft in Berlin und Sonderbeauftragter des Reichsdozentenführers

\section{Mitgliedschaft/Funktionen in der DGG}

1980-1984 Vorsitz Sektion gynäkologische Balneotherapie

Archivalische Quellen

BArch Berlin, R 4901/1347-1348.

\section{Gedruckte Quellen}

GK 1939, S. 12; GW 1956, S. 249 f.; DÄ 83, 48 (1986), S. 3387; Frauenarzt 38 (1996), S. 1532-1534; Grüttner: Lexikon (2004), S. 16 f.

\section{Bach, Ernst \\ $\nabla$}

geb. 20.09.1899, Mindelheim

gest. 11./26.09.1944 (?), Marburg/Lahn

katholisch

Familie

Vater: Ernst Bach, Arzt; Mutter: Clothilde, geb. Singer

๑1) 20.01.1922: Magdalena, geb. Herren; geschieden; 1 Tochter: Sophie (geb. 20.01.1927); 2) Elisabeth, geb. Meine; 2 Töchter: Gerlinde (geb. 12.07.1934), Monika Ursula (geb. 19.06.1935)

\section{Ausbildung}

1919 Abitur (Ludwigsgymnasium München); 1919-1924 Medizinstudium (München); Herbst 1924 Staatsexamen (München); 27.12.1925 Approbation (München)

\section{Akademische Karriere}

07.01.1926 Promotion (München); 1935 Habilitation (München); 10.01.1935 PD (München); 22.04.1939 apl. Prof. (München); 10/1939 o. Prof. (Marburg/Lahn); 1941-1944 Prorektor der Universität Marburg/Lahn; 1941-1943 Dekan der Med. Fak. Marburg/Lahn.

\section{Weiterbildung und berufliche Karriere}

01.01.1926-30.06.1926 Volontär an der I. UFK München; 01.07.1926-31.03.1927 Hilfsass. an der Hebammenschule München; 01.04.1927-31.05.1934 Ass. an der I. UFK München (A. Döderlein/Eymer); 1930 FA für Frauenheilk.; Niederlassung als Frauenarzt in Augsburg; 1931-1934 OA an der I. UFK München; 1933 Leiter der Ärztekammer München/Oberbayern; 06/ 1934 erneut Niederlassung als FA für Frauenheilk. und Geburtsh.; 10.01.1935 PD für Geburtsh. und Frauenkrankh. (München); 01.03.1938 Medizinalrat 1. Klasse und Berufung in das Ministerium für Erziehung und Volksbildung; 1936-1939 Med. Fachreferent im Reichsministerium für Wissenschaft; ab 1940 Dir. der UFK Marburg/Lahn.

\section{NS-Organisationen}

Herbst 1922 NSDAP (Blutorden), Mitbegründung der NSDAPOrtsgruppe Nymphenburg; 01.12.1931 Wiedereintritt NSDAP (Mitglieds-Nr. 771 397); NSDÄB (Mitglieds-Nr. 2237); 1932 erster Einsatz für NSDAP; 01.04.1933 SA (01.09.1933 Sturmführer, 10.12.1933 Standartenführer, 30.01.1939 Sanitätsoberführer); 1933 Gauobmann NSDÄB; 1935 Gauamtsleiter für Volksgesundheit in München; 01.05. 1935 NSV; 1938 mit Führerbefehl Nr. 67 der Obersten SA-Führung in den Stab der OSAF versetzt; 1944 Mitglied des Führerkreises im NSDDB

\section{Mitgliedschaft/Funktionen in der DGG 1937-1941 Beisitzer; Vortrag: 1941}

\section{Archivalische Quellen}

BArch Berlin, BDC, DS800 A 2, DS B026, 2082-2084, 2086-2096, SA 15; BArch Berlin, R 4901/13284 (sog. Professorenkartei).

\section{Gedruckte Quellen}

GK 1939, S. 13 (Vermerk: Fragebogen nicht beantwortet); GW 1956 S. 181; Catalogus (1979), S. 186; Nagel: Philipps-Universität (2000); Klee: Personenlexikon (2003), S. 22 f.; Süß: „Volkskörper“ (2003); Grüttner: Lexikon (2004), S. 17.

\section{Bauereisen, Johann Adam \\ $\nabla$}

geb. 27.10.1875, Heilsbronn

gest. 11.02.1961, Bad Sachsa

katholisch

Familie

œ1) 1905; 1931 geschieden; 1 Sohn: Erich (1913-1985); 2) 1931 


\section{Ausbildung}

Medizinstudium in Tübingen und Erlangen; 1901 Approbation (Erlangen)

\section{Akademische Karriere}

24.06.1901 Promotion (Erlangen); 1910 Habilitation (Marburg/ Lahn); 1915 a. o. Prof. (Kiel); 1953 Emeritierung

\section{Weiterbildung und berufliche Karriere}

1902-1905 Ass. an der UFK Erlangen (Gessner, Veit, Menge); 1907/08 Schiffsarzt beim Norddeutschen Lloyd; 1909/10 UFK Marburg/Lahn (Stoeckel); 1910-1921 UFK Kiel (Stoeckel); 19141918 Stabsarzt an der Westfront; 1921-1953 Dir. der Städt. Frauenklinik im Sudenburger KH Magdeburg; 01.10.1952 Ruhestand

\section{NS-Organisationen}

Förderndes Mitglied der SS

\section{Mitgliedschaft/Funktionen in der DGG}

1933-1935 Beisitzer

\section{Gedruckte Quellen}

GK 1928, S. 13; GK 1939, S. 19 f.; GW 1956, S. 145; Fischer, S. 87; Rech: Geburtstag (1955); Schwedt: In Memoriam (1961).

\section{Internetquellen}

http://www.uni-magdeburg.de/mbl/Biografien/0199.htm

\section{Benthin, Walther}

geb. 18.12.1882, Köritz bei Neustadt/Donau

gest. 03.12.1950, Rheydt (Rheinland)

Familie

Vater: Carl Benthin, Postsekretär; Mutter: Martha, geb. Kassube

๑ 1909: Gertrud, geb. Diezel; 1 Tochter, 1 Sohn

\section{Ausbildung}

Medizinstudium in Berlin und Freiburg i. Br.; 1908 Approbation

\section{Akademische Karriere}

1908 Promotion (Kiel); 1913 Habilitation (Königsberg i. Pr.); 1918 a. o. Prof. (Königsberg i. Pr.); 1924/25 Lehrstuhlvertreter für Winter (Königsberg i. Pr.); nach 1945 Gast- und Honorarprof. (Bonn)

\section{Weiterbildung und berufliche Karriere}

1909-1911 Volontär am Path. Inst. Rudolf-Virchow-KH Berlin (v. Hansemann); 1911/12 Städt. Frauenklinik Frankfurt/Main; 1912-1917 Ass., ab 1919 OA an der UFK Königsberg i. Pr. (Winter), unterbrochen durch Kriegsdienst (1914-1918, Oberstabsarzt); 1924/25 komm. Dir. der UFK Königsberg i. Pr.; 1925 Dir. der gyn. Abt. des Städt. KH Königsberg i. Pr.; nach der Flucht aus Königsberg i. Pr. ab 1945 Praxis in Rheydt

\section{NS-Organisationen}

1933 NSLB; NSDDB
Mitgliedschaft/Funktionen in der DGG

1949 Beisitzer (1941 gewählt); Vortrag: 1941

\section{Vita}

Walther Benthin, 1941 als Beisitzer in den Vorstand der DGG gewählt, gehört zu den Schülern des Pioniers der Krebsfrüherkennung in Deutschland, Georg Winter. Er verbrachte fast sein gesamtes Berufsleben im ostpreußischen Königsberg - davon mehr als eine Dekade an der dortigen UFK, wo er zunächst als Assistent, dann als Oberarzt und schließlich als kommissarischer Leiter der Klinik seines 1924 emeritierten Lehrers wirkte. Benthin war auch nach der Übernahme des Direktorates der gynäkologischen Abteilung des Städtischen Krankenhauses in Königsberg wissenschaftlich tätig und hat insgesamt eine lange Publikationsliste hinterlassen, in der fast die ganze Breite des Faches abgebildet ist. Dazu gehören mehrere Monografien sowie Beiträge für das berühmte Handbuch von Halban und Seitz. Beim Kongress 1941 in Wien trat Benthin nochmals als engagierter Unterstützer seines Lehrers hervor, der sich vor allem auch für Maßnahmen zur Aufklärung der weiblichen Bevölkerung und der Ärzteschaft eingesetzt hatte („Propaganda“). Winter selbst war bei dem Kongress mit einem Vortrag zur Zukunft der Früherkennung des Krebses präsent, der allerdings aus gesundheitlichen Gründen von einem seiner jüngeren Schüler, Hans Naujoks, vorgetragen werden musste. Benthin hielt außerdem unmittelbar nach Gerhard Domagk ein Referat über die Erfahrungen mit Sulfonamiden in der Therapie gynäkologischer Infektionen.

\section{Gedruckte Quellen}

GK 1928, S. 17 f.; GK 1939, S. 26-28; Tilitzki: Königsberg (2012), S. 499. Ebert/David: Gynäkologen (2016), S. 235-238.

\section{Bickenbach, Werner}

geb. 14.04.1900, Solingen

gest. 15.07.1974, München

Familie

Vater: Bankier

\section{Ausbildung}

Studium der Rechte in Würzburg; Medizinstudium in Würzburg, München und Bonn; 1924 Approbation (Berlin)

Akademische Karriere

1925 Promotion (Bonn); 1929 Habilitation (Bonn); 1929 PD (Bonn); 1935 a. o. Prof. (Göttingen); 1944 o. Prof. (Münster i.W.); 1950-1954 o. Prof. (Tübingen); 1954-1969 o. Prof. (München)

\section{Weiterbildung und berufliche Karriere}

1924 Med. UK Bonn; 1924/25 Physiolog. Inst. Bonn; 1926-1933 Ass., später OA an der UFK Bonn (v. Franqué); Wechsel als OA zu Martius an die UFK Göttingen; 1944 Dir. der UFK Münster i.W.; 1950-1954 Dir. der UFK Tübingen; 1954-1969 Dir. der I. UFK München; 1969 Emeritierung

Mitgliedschaft/Funktionen in der DGG

1962-1964 Präsident; Ehrenmitglied; Vorträge: 1931, 1935, 1937, 1941, 1949 


\section{Vita}

Werner Bickenbach, von 1962 bis 1964 Präsident und später Ehrenmitglied der DGGG, gehörte am Ende seiner Karriere sicherlich zu den bedeutenden deutschen Frauenärzten des 20. Jahrhunderts. Mit Ausnahme von 1933 war er im Untersuchungszeitraum bei allen DGG-Kongressen mit einem Vortrag präsent. Das Themenspektrum reichte dabei von der Grundlagenforschung (Plazentafunktion) bis zu Fragen der klinischen Praxis (Funktionsprüfung des Kreislaufs vor Operationen). 1939 wurde er zusammen mit dem Rostocker Ordinarius Gustav Haselhorst von der DGG in der Auseinandersetzung mit Reichsgesundheitsführer Conti über die Geburtshilfe mit der Erhebung von Daten zu den Ergebnissen klinischer Entbindungen beauftragt. Bickenbach war damals Oberarzt von Heinrich Martius, der sich wegen seiner ohnehin bestehenden Schwierigkeiten mit dem Regime vermutlich nicht selbst exponieren wollte. Während Bickenbach Ergebnisse aus der Göttinger Klinik schon 1940 publizierte, konnte Haselhorst erst 1941 beim DGG-Kongress in Wien Daten präsentieren. Sie umfassten dann allerdings die geburtshilflichen Ergebnisse von 27 Universitätsfrauenkliniken. In der Göttinger Klinik führte Bickenbach im NS von allen dort tätigen Ärzten die meisten Zwangssterilisationen durch. Im Gegensatz zur überwiegenden Mehrzahl seiner Fachgenossen konnte er sich aber im Nachhinein zu einer kritischen Haltung dazu durchringen.

$\mathrm{Zu}$ den großen Verdiensten von Bickenbach gehört sein Beitrag zur Etablierung der Perinatologie in Deutschland. Hervorgehoben wird stets auch eine Publikation zur Hemmung der Follikelreifung durch Progesteron aus dem Jahr 1944.

\section{Archivalische Quellen}

BSB München, Nachlässe, Ana 691, Schwarzer Ordner: Martius an Döderlein (20.01.1940).

\section{Gedruckte Quellen}

GK 1939, S. 30 f.; GW 1956, S.114; Bickenbach: Müttersterblichkeit (1940); Anthuber/Beckmann u. a. (Hrsg.): Herausforderungen (2012), S. $284 \mathrm{f}$.

\section{Björkenheim, Robert Edvard Albert}

geb. 02.02.1877, Eurajoki (Finnland)

gest. 07.02.1970, Helsinki

Familie

Vater: Carl Axel Fredrik Björkenheim; M Sigrid Lovisa Charlotta, geb. von Julin

๑1) 1904: Anna, geb. Hindström; 1913 geschieden; 1 Kind;

2) 1915: Fanny Helena, geb. von Born; 4 Kinder

Mitgliedschaft/Funktionen in der DGG

1941 zum Beisitzer berufen

\section{Gedruckte Quellen}

Kuka kukin on (1954), S.68. = Who's who in Finland, Helsingissä: Otava 1954 , S. 68

\section{Breipohl, Wilhelm}

$\nabla$

geb. 10.02.1907, Bielefeld

gest. 01.05.1945, Berlin

Familie

Vater: Hermann Heinrich Emil Breipohl, Bäckermeister

๑1935: Marie Luise, geb. Klönne; 6 Kinder

Ausbildung

1926 Abitur; Medizinstudium in München, Berlin und Bonn; 1933 Approbation

\section{Akademische Karriere}

1932 Promotion (Bonn); 1938 Habilitation (Königsberg i. Pr.); 03/1945 apl. Prof. (Berlin)

\section{Weiterbildung und berufliche Karriere}

09/1933-1941 zunächst Ass., später OA an der UFK Königsberg i. Pr. (Mikulicz-Radecki); 1934 Hospitation an der I. UFK Berlin bei dem Pathologen Robert Meyer; 1941 mehrere Monate Vertretung als ltd. OA an der Gaufrauenklinik Danzig; nach einem Intermezzo an der UFK Greifswald ab 10/1942 Ass. an der I. UFK Berlin (Stoeckel)

\section{NS-Organisationen}

1933 NSDAP; ab 1934 Standortarzt bei der HJ; NSV; NSDDB; Reichslehrerbund; Reichsbund der Kinderreichen

\section{Mitgliedschaft/Funktionen in der DGG}

Vorträge: 1935, 1937, 1941

\section{Vita}

Wilhelm Breipohl muss, obwohl 1933-1941 an der UFK Königsberg i. Pr. ausgebildet, zum Kreis der Schüler von Walter Stoeckel gerechnet werden: Sein Lehrer in Königsberg war der StoeckelZögling Felix von Mikulicz-Radecki, den gynäkopathologischen „Feinschliff“" erhielt er 1934 bei einer Hospitation an der I. UFK Berlin bei Robert Meyer. 1942 kehrte er als einfacher Assistent an die Stoeckel'sche Klinik in Berlin zurück, obwohl er andernorts bereits Oberarztpositionen eingenommen hatte. Seine Mitgliedschaft in zahlreichen NS-Organisationen spricht dafür, dass er zumindest aus Karrieregründen die Nähe zum System suchte. Der Dekan der Medizinischen Fakultät in Berlin bezeichnete ihn als Nationalsozialisten, wie er besser nicht sein könne. Seine Forschungen in Königsberg nahm er an exstirpierten Eileitern von Frauen vor, die gezielt in definierten Zyklusphasen zwangssterilisiert und zum Teil aus experimentellen Gründen auch mit Hormonen vorbehandelt worden waren. Wilhelm Breipohl wurde am 1. Mai 1945 zusammen mit seinem Oberarzt Paul Caffier vor dem Bunker der I. UFK von einem sowjetischen Soldaten erschossen. Stoeckel hatte gehofft, Breipohl würde auf längere Sicht den in die Emigration gezwungenen Robert Meyer ersetzen können.

\section{Gedruckte Quellen}

GK 1939, S. 46 f.; GW 1956, S. 147; Stoeckel: Leben (1954), S. 153 f.; David: Sinnlosigkeit (2007); Doetz: Alltag (2011), S. 226-228.

\section{Internetquellen}

http://runeberg.org/kuka/1954/0068.html (Digitalisat von Kuka kukin on, 1954, S. 68) 


\section{Burger, Karl Johann}

geb. 25.09.1893, Budapest

gest. 22.05.1962, Konstanz

Familie

Vater: Großkaufmann

$\varpi$ Margit

\section{Ausbildung}

ab 1911 Medizinstudium (Budapest), unterbrochen durch Sanitätsdienst im 1. Weltkrieg; 1919 ärztl. Diplom

\section{Akademische Karriere}

1919 Doktorgrad; 1927 Habilitation (Budapest); 1932 a.o. Prof. (Budapest); 1936 o.o.. Prof. (II. UFK Budapest); ab 1944 zunächst in Halle/Saale, dann Gast an der UFK Göttingen; 1946 o. Prof. (Würzburg); 1958 Emeritierung

\section{Weiterbildung und berufliche Karriere}

1919-1925 Ass. an der I. UFK Budapest und in Szeged; 19331936 Dir. der Kgl. Ungarischen Hebammenanstalt Budapest; ab 1936 Dir. der II. UFK Budapest; ab 1944 zunächst in Halle/Saale, dann Gast an der UFK Göttingen

\section{Mitgliedschaft/Funktionen in der DGG}

1949 Beisitzer (1941 gewählt); Ehrenmitglied; Vorträge: 1937, 1941

\section{Vita}

Karl Johann Burger zählte zu den besonders engagierten ungarndeutschen Mitgliedern der Gesellschaft. Nach dem Ende des Zweiten Weltkriegs aus Budapest kommend, wurde er 1946 zum Ordinarius an die UFK Würzburg berufen. Die Berufung Burgers, die sich innerhalb weniger Wochen vollzogen und die Medizinische Fakultät aus einer sehr schwierigen Lage befreit hatte, wird von einem Biografen retrospektiv als "Glückstreffer“ bezeichnet. In der Tat war damit nicht nur für die bayerische Frauenheilkunde ein nach vielen Auslandsaufenthalten auch international hoch angesehener Fachvertreter gewonnen worden. Burger galt als glänzender Operateur, war Verfasser zahlreicher Lehrbücher in deutscher sowie ungarischer Sprache und arbeitete wissenschaftlich in der ganzen Breite des Fachgebietes. Dabei widmete er sich auch experimentellen rekonstruktiven Verfahren zur Beseitigung der Vaginalaplasie, befasste sich mit der Therapie der Harninkontinenz und bearbeitete aktuelle geburtshilfliche sowie endokrinologisch-reproduktionsmedizinische Themen. Auf der DGG-Tagung 1949 übernahm Burger das Amt eines Beisitzers, in das er 1941, damals noch als „Ausländer“, berufen worden war.

\section{Gedruckte Quellen}

GW 1956, S. 216; Anthuber/Beckmann u. a. (Hrsg.): Herausforderungen (2012), S. 288.

\section{Caffier, Paul Ottomar Johannes \\ $\nabla$}

geb. 19.12.1898, Leipzig

gest. 01.05.1945, Berlin

Familie

Vater: Großkaufmann

œ 1936: Maria Charlotta, geb. Manfroni; 6 Kinder

\section{Ausbildung}

1917 Notabitur; Kriegsteilnahme; ab 11/1918 Medizinstudium (Greifswald, Freiburg i. Br., Jena, Leipzig), 1923-1925 außerdem Philosophie; 1924 Approbation (Dresden)

\section{Akademische Karriere}

1923 Promotion (Leipzig); 1931 Habilitation (Berlin); 1936 apl. Prof. (Berlin); 1939 a. o. Prof. (Berlin)

\section{Weiterbildung und berufliche Karriere}

1924 Path. Inst. St. Georg Leipzig; 1925-1931 Ass. an der I. UFK Berlin (Stoeckel); 1932-1934 OA an der UFK Königsberg i. Pr. (Mikulicz-Radecki); ab 10/1938 OA an der I. UFK Berlin (Stoeckel); zu Beginn des 2. Weltkrieges (bis 10/1940) Stabsarzt in einem Lazarett

\section{NS-Organisationen \\ 05/1933 NSDAP; 10/1933 SA}

\section{Mitgliedschaft/Funktionen in der DGG} Vorträge: 1931, 1933, 1935, 1937, 1941

\section{Vita}

Paul Caffier, fast 20 Jahre lang zunächst Assistent und dann Oberarzt von Walter Stoeckel, wurde am 1. Mai 1945 zusammen mit Wilhelm Breipohl vor dem Bunker der I. UFK Berlin von einem sowjetischen Soldaten erschossen. In einer Grabrede bezeichnete Stoeckel ihn als „besonders zukunftsreichen Repräsentanten“ seiner Schule, dessen Berufung in ein Ordinariat nur der Krieg verhindert habe. Ein Schwerpunkt von Caffiers breit gefächerten wissenschaftlichen Interessen lag bei Fragen der Reproduktion, die er zu Beginn der 1930er-Jahre zunächst an Fledermäusen studierte. Später setzte er seine Untersuchungen an Frauen fort, die mit hoher Wahrscheinlichkeit zur Zwangssterilisation in die Klinik eingewiesen worden waren. Ziel war dabei das Studium der Wirkung einer 5-tägigen parenteralen Östrogen-Vorbehandlung an den exstirpierten Tuben und am Endometrium. Letzteres bedingte neben der Resektion der Eileiter auch eine Kürettage zu reinen Forschungszwecken. Offensichtlich auch aus wissenschaftlichen Gründen hormonell vorbehandelt wurden ferner prämenopausale Frauen, die wegen eines Deszensus operiert werden sollten. Bei diesen Patientinnen wurde der OP-Termin in die Zyklusmitte gelegt, in der Hoffnung, eine Ovulation beobachten zu können.

\section{Gedruckte Quellen}

GK 1928, S. 36; GK 1939, S. 56-58; GW 1956, S. 148; Stoeckel: Ansprachen (1952), S. 36 f.; Stoeckel: Leben (1954), S. 153 f.; David: Sinnlosigkeit (2007); Doetz: Alltag (2011), S. 226-228. 


\section{Clauberg, Carl}

$\nabla$

geb. 28.09.1898, Wupperhof (Bergisches Land)

gest. 09.08.1957, Kiel

Familie

verheiratet; 2 außereheliche Kinder mit Ilse Geyer

\section{Ausbildung}

1916 Abitur (Bremen); Kriegsdienst; 1917-1919 in brit. Kriegsgefangenschaft; 1920-1924 Medizinstudium (Kiel, Hamburg, Graz); 1925 Approbation (Kiel)

\section{Akademische Karriere}

1925 Promotion (Kiel); 1933 Habilitation (Königsberg i. Pr.); 1937 apl. Prof. (Königsberg i. Pr.); 1939 a.o. Prof. (Königsberg i. Pr.)

\section{Weiterbildung und berufliche Karriere}

1925-1932 Ass. an der UFK Kiel (R. Schröder); 1932-1939 Ass., ab 1934 OA an der UFK Königsberg i. Pr. (Mikulicz-Radecki); nach Kriegsbeginn Militärarzt; ab 1940 Chefarzt der Frauenkliniken im St. Hedwigs- sowie im Knappschaftskh. in Königshütte (heute Chorzów); ab Herbst 1942 im ca. 50 km entfernten KZ Auschwitz Sterilisationsversuche an weiblichen Häftlingen, die im Januar 1945 in Ravensbrück fortgesetzt wurden; 1957 Entzug der Approbation

\section{NS-Organisationen}

1933 NSDAP; SA-Sanitätsobersturmführer; NSLB; NSDDB; NSDÄB

\section{Mitgliedschaft/Funktionen in der DGG}

1956 ausgeschlossen; Vorträge: 1935, 1937, 1941

\section{Gedruckte Quellen}

GK 1939, S. 58 f.; GW 1956, S. 148; Sehn: Unfruchtbarmachungs-Versuche (1959), S. 3-32; Lifton: Doctors (1986); Schübelin: Ärzteverbrechen (1988), S. 186-204; Grosch: Clauberg (1993); Wilking: Rassismus (2001); Klee: Auschwitz (2008), S. 436-441.

\section{Cònill i Montobbio, Victor \\ $\nabla$}

geb. 1886, Barcelona

gest. 1970, Barcelona

Familie

Vater: Rechtsanwalt

Sohn: Víctor Cònill Serra, Gynäkologe

\section{Ausbildung}

bis 1909 Medizinstudium u.a. in Barcelona

\section{Akademische Karriere}

1912 Doktorgrad (Madrid); ab 1933 Lehrstuhl für Geburtsh. und Gyn. (Santiago de Compostela); ab 1934 Prof. (Barcelona)

\section{Weiterbildung und berufliche Karriere}

zahlreiche Auslandsaufenthalte, u.a. in München (Döderlein)

\section{Mitgliedschaft/Funktionen in der DGG}

1941 zum Beisitzer gewählt; um 1944 Ehrenmitglied; Vorträge: 1935,1941

\section{Vita}

Der aus Barcelona stammende Gynäkologe Victor Cònill zählt zu den ausländischen Mitgliedern der DGG, die mit dem Nationalsozialismus sympathisierten und für ihr öffentliches Bekenntnis zu Deutschland und zur deutschen Wissenschaft von der Gesellschaft belohnt wurden. Auf der Tagung 1941 berief der Vorstand Cònill zum Beisitzer. Dass er das Kriterium der „Deutschenfreundlichkeit" erfüllte, stellte er am selben Tag mit einem im Programm nicht vorgesehenen Referat über „Geist und Inhalt der spanischen Frauenkunde“ unter Beweis. In dem Vortrag, der direkt an Paul Diepgens Referat über die „Kulturgeschichte der Frau und die Frauenheilkunde“ anschloss, pries Cònill „die politische und moralische Entwicklung Eures großen Volkes, dem bestbegabtesten [sic] Europas“, die er über 30 Jahre mit Leidenschaft verfolgt habe. Hinsichtlich der künftigen Entwicklung der spanischen Gynäkologie setzte er große Hoffnungen in die „brüderliche[r] Hilfe der deutschen Macht und der italienischen Gewogenheit“ und schloss mit dem Satz: „Dieselbe tiefe Dankbarkeit, die jeder wohlgeborene Spanier für unseren Caudillo [span. „Führer“, gemeint ist Franco] fühlt, fühlt schon jetzt jeder verständige Europäer für Euren genialen Führer, den Führer im erlösenden Kreuzzug der europäischen Zivilisation und Leiter der Neuordnung Europas." Drei Jahre nach diesem Auftritt sollte Cònill „auf Anregung des Reichsgesundheitsführers“, wie Jaschke in einem Brief an Martius schrieb, zum Ehrenmitglied der DGG ernannt werden. Aus dem Briefwechsel geht hervor, dass bei dieser Entscheidung weniger die wissenschaftlichen Leistungen des durchaus profilierten Cònill, sondern vielmehr politische Erwägungen ausschlaggebend gewesen sein dürften. So erkundigte sich Jaschke bei Martius, ob dieser ihm „irgendetwas Näheres über die Leistungen von Professor Conill mitteilen“ könne, „damit ich das in der Ehrenurkunde irgendwie verwenden kann". Martius, dem Cònill „von dem letzten Kongress her noch in sehr lebhafter Erinnerung" war, antwortete mit einem schlichten Hinweis auf den oben zitierten Vortrag über „Geist und Inhalt der spanischen Frauenheilkunde“ („Vielleicht können Sie aus diesem kurzen Referat einiges für ihre Begründung entnehmen.“). Ansonsten sei ihm nur bekannt, „dass Conill als der führende spanische Gynäkologe anzusehen ist“.

\section{Archivalische Quellen}

BSB München, Nachlässe, Ana 691: Briefwechsel Jaschke - Martius (23./ 28.04.1944)

\section{Gedruckte Quellen}

Conill: Geist [Verhandlungen 1941] (1942); Usandizaga: Conill [Nachruf] (1970).

\section{Internetquellen}

http://www.galeriametges.cat/galeria-fitxa.php?icod=JGD

\author{
Daels, Frans \\ $\nabla$ \\ geb. 07.01.1882, Antwerpen \\ gest. 22.12.1974, Gent
}

Familie

1 Sohn: Paul (1921-1988) 


\section{Ausbildung}

Medizinstudium in Leuven und Gent

\section{Akademische Karriere}

1920-1944 Prof. für Geburtsh. und Gyn. (Gent)

Mitgliedschaft/Funktionen in der DGG 1935-1937 Beisitzer; Vorträge: 1931, 1933, 1935, 1937

Vita

Der Genter Professor Frans Daels war im untersuchten Zeitraum eines der aktivsten ausländischen Mitglieder der Gesellschaft: Er trat auf allen Tagungen der 1930er-Jahre als Vortragender auf und wurde 1937, nicht zuletzt wegen seiner „politischen Zuverlässigkeit“, zum Beisitzer gewählt.

Daels' außeruniversitäres Wirken war eng mit seinen Erfahrungen als Militärarzt im Ersten Weltkrieg verknüpft. Intensiv engagierte er sich für die Belange der flämischen Nationalisten und nahm führende Positionen in der „Frontbeweging“ und der Flämischen Bewegung ein; nach 1918 organisierte er als Vorsitzender des „IJzerbedevaartcomité“ (Yser-Wallfahrt-Komitee) Wallfahrten zu den Gräbern gefallener Soldaten. Zu seinen deutschen Kollegen pflegte Daels zeitlebens eine besondere Nähe. Offenbar war das Auswärtige Amt bereits 1933 an ihn herangetreten, „um ihm neue und immer stärkere Eindrücke von unserem neuen Deutschland zu vermitteln", die er in seiner Heimat verbreiten solle. Nach der Besetzung Belgiens durch die Wehrmacht kollaborierte Daels als hochrangiges Mitglied des rechtskonservativen „Vlaams Nationaal Verbond“ (Flämischer Nationalverband) mit den Nationalsozialisten und setzte sich dafür ein, belgische Jugendliche für eine Beteiligung am Russlandfeldzug zu gewinnen.

Kurz vor der Befreiung Belgiens durch die Alliierten floh Daels in die Schweiz; zwei Jahre später wurde der Kollaborateur von einem belgischen Gericht in Abwesenheit zum Tod verurteilt. Nach einer Begnadigung kehrte Daels in seine Heimat zurück und ließ sich als Arzt im flämischen Bonheiden nieder.

Gedruckte Quellen

Shelby: Nationalism (2014).

Internetquellen

http://www.ugentmemorie.be/personen/daels-frans-1882-1974

\section{Döderlein, Gustav}

$\nabla$

geb. 19.05.1893, Leipzig

gest. 19.03.1980, München

Familie

Vater: Albert Sigmund Gustav Döderlein, Gynäkologe; Mutter: Anna, geb. Deichert

œ Marta, geb. Hess, 2 Töchter: Annamarie, Adele

\section{Ausbildung}

Medizinstudium in Berlin und München; 1920 Staatsexamen (München); 1921 Approbation (München)

\section{Akademische Karriere}

1921 Promotion (München); 1928 Habilitation (Berlin); 1933 apl. Prof. (Berlin); 1946 o. Prof. (Jena); 1959 Emeritierung

\section{Weiterbildung und berufliche Karriere}

1921-1924 Ass. am Path. Inst. München; 1924-1926 Ass. an der I.UFK München (A. Döderlein); 1926-1929 Ass. an der I. UFK Berlin (Stoeckel); 1929-1936 OA an der Charité Berlin (G. A. Wagner); 1936-1945 Dirig. Arzt der Abt. Geburtsh. und Frauenkrankh. am Staatskh. der Polizei Berlin; 1938 Oberfeldarzt und 1944 Oberstarzt der Polizei; ab 1943 Dir. des Staatskh. der Polizei Berlin; 1946-1959 Dir. der UFK Jena; 1959 Emeritierung

\section{NS-Organisationen}

NSLB; 1934 Förderndes Mitglied der SS; SA Reserve II der Charité Berlin

\section{Mitgliedschaft/Funktionen in der DGG}

1937-1941 2. Schriftführer; 1949 Beisitzer; 1956-1958 Vorsitzender; Ehrenmitglied; Vorträge: 1931, 1933, 1935, 1941, 1949

\section{Vita}

Gustav Döderlein, Sohn des berühmten Münchner Gynäkologen Albert Döderlein, hat sich vor allem in den letzten Vorkriegsjahren und im Zweiten Weltkrieg um die DGG verdient gemacht: Er unterstützte ab 1937 den aus mehreren Gründen schwachen Präsidenten Hans Fuchs nach Kräften. Besondere organisatorische Probleme bereiteten ihm dabei die wohl auch auf einsame Entscheidungen von Fuchs zurückgehenden, mehrfachen Verschiebungen des ursprünglich für 1939 geplanten Kongresses. Döderlein war darüber hinaus einer der Initiatoren der Denkschrift, mit der die Gesellschaft sich gegen die von den Nationalsozialisten gewünschte Stärkung der Hausgeburt und der Stellung der Hebammen zur Wehr setzte. Die DGG dankte ihm für sein Engagement, indem sie ihn 1956 zum Präsidenten und später auch zum Ehrenmitglied wählte.

Döderlein gilt als Wegbereiter der Schwangerenvorsorge in Deutschland. Ein entsprechendes Konzept, das in seinen Grundlagen noch heute Gültigkeit besitzt, stellte er beim DGG-Kongress 1935 in München vor. Vor der gynäkologischen hatte er eine pathologische Fachausbildung absolviert - ein Umstand, der sich auch in seiner wissenschaftlichen Tätigkeit niederschlug. So beschäftigte er sich mit der Histologie des weiblichen Genitalkrebses und dessen Bedeutung für die Prognose ebenso wie etwa mit der Adenomyosis.

Nach Kriegsende galt er als vom Nationalsozialismus unbelastet. Der isoliert von einer Augsburgerin in den 1980er-Jahren erhobene Vorwurf, in der von Döderlein nach 1936 geleiteten Abteilung des Berliner Polizeikrankenhauses seien ,rassisch“ motivierte Zwangsterilisationen vorgenommen worden, ließ sich bisher nicht erhärten. Seine Bemühungen um ein Ordinariat, die im Nationalsozialismus unter anderem an der Bevorzugung besonders linientreuer Bewerber scheiterten, führten erst 1946 mit dem Ruf nach Jena zum Erfolg.

\section{Archivalische Quellen}

BArch Berlin, BDC, PK B 0334; BArch Berlin, R 4901/1347, R 4901/1348, R $4901 / 12919$. 


\section{Gedruckte Quellen}

GK 1928, S.45; GK 1939, S. 74 f.; GW 1956, S. 253; Schmid: Döderlein (1959); Klee: Personenlexikon (2003), S.114; David: Döderlein (2007); Czarnowski: Gynäkologie (2008), S. 139.

\section{Ehrhardt, Karl}

geb. 24.02.1895, Weyer

gest. 27.05.1993, Frankfurt/Main

Familie

Vater: Karl Ehrhardt, Lehrer; Mutter: Karoline, geb. Duill

1 Sohn bekannt: Wolfgang

Ausbildung

1922 Approbation (Darmstadt); 1922 Path. Inst. Gießen

\section{Akademische Karriere}

1923 Promotion (Gießen); 1931 Habilitation (Frankfurt/Main); 1937 a. o. Prof. (Frankfurt/Main); 1939 o. Prof. (Graz)

\section{Weiterbildung und berufliche Karriere}

1922-1925 (intern.)-chir. Abt. des Städt. KH Offenbach/Main; 1925-1938 UFK Frankfurt/Main (Seitz), dort zunächst Ass., später OA; 1939-1945 o. Prof. und Dir. der UFK Graz; nach dem 2. Weltkrieg Niederlassung als Frauenarzt in Frankfurt/Main

\section{NS-Organisationen}

1933 NSDAP; 1933 SS (später SS-Sturmbannführer)

Archivalische Quellen

Standesamt Mitte, Frankfurt/Main, Sterbefall 3166/1993

\section{Gedruckte Quellen}

GK 1928, S. 50; GK 1939, S. 84-86; GW 1956, S. 188; Czarnowski: „Material“ (2004); Czarnowski: Österreich (2012).

\section{Fetzer, Max}

geb. 26.08.1878, Stuttgart

gest. 22.07.1946, Stuttgart

\section{Ausbildung}

Medizinstudium in Tübingen; 1902 Approbation

\section{Akademische Karriere}

1903 Promotion (Tübingen); PD (Königsberg i. Pr.)

\section{Weiterbildung und berufliche Karriere}

1903-1914 Path. Inst. Tübingen (v. Baumgarten); UFK Straßburg (Fehling); Physiolog.-Chem. Inst. Straßburg (Schmiedeberg); UFK Tübingen (Sellheim); UFK Königsberg i. Pr. (Winter); PD (Königsberg i. Pr.); 1918-1946 Dir. der Württemberg. Landeshebammenlehranstalt Stuttgart

\section{Mitgliedschaft/Funktionen in der DGG} 1937-1941 Beisitzer

\author{
Gedruckte Quellen \\ GK 1928, S. 60; GK 1939, S. 107; GW 1956, S. 151.
}

\section{Fraenkel, Ludwig}

geb. 23.04.1870, Leobschütz (Schlesien)

gest. 10.07.1951, Bad Ischl

jüdisch

Familie

Vater: Heinrich Fraenkel, Malzfabrikant; Mutter: Dorothea, geb. Bothländer

๑ 1900: Felicia Dora Berta (Lilli), geb. Conrad; 1 Tochter: Maria (Maja) (geb. 1903), 1 Sohn: Heinz (geb. 1910)

\section{Ausbildung}

1888 Abitur; Medizinstudium in Würzburg, Berlin, Greifswald, München und Freiburg i. Br.; 1893 Staatsexamen (Freiburg i. Br.)

\section{Akademische Karriere}

1892 Promotion (Berlin); 1905 PD (Breslau); 1909 apl. Prof. (Breslau); 1921 a. o. Prof. (Breslau); 1922 o. Prof.

\section{Weiterbildung und berufliche Karriere}

1893-1900 Greifswald, Leipzig, Freiburg i. Br.; 1896 an der Privatklinik seines Onkels Ernst Fraenkel in Breslau; Straßburg (Grawitz, Hegar, Saenger, Freund); 1905 PD (Breslau); 1909 apl. Prof. (Breslau); ab 1921 a.o. Prof. (Breslau); ab 1922 Lehrstuhlinhaber (Breslau); 1934 Entlassung auf Grundlage des BBG; 1936 Emigration über Brasilien nach Montevideo (Uruguay); dort dann an der Univ. Montevideo tätig

\section{Mitgliedschaft/Funktionen in der DGG}

bis 1936 Mitglied; 1931-1933 Beisitzer („freiwilliger“ Rücktritt vor dem Kongress 1933); 1951 Ehrenmitglied; Vortrag: 1931

\section{Vita}

Ludwig Fraenkel, einer der herausragenden Forscher in der gynäkologischen Endokrinologie, gehörte bis zu seiner Vertreibung zu den profiliertesten Mitgliedern der DGG. Innerhalb der DGG war er zu dieser Zeit der einzige Ordinarius jüdischer Herkunft. Auf der Tagung 1931 hielt er - sozialhygienisch engagiert - ein kontrovers diskutiertes, liberales Referat über „Sterilisierung und Konzeptionsverhütung“. Bei dieser Tagung wurde er zum Beisitzer gewählt und als einer der künftigen Vorsitzenden gehandelt. Es kam anders: Im März 1933 erging die Weisung, die Vorstände medizinischer Fachgesellschaften von Juden zu „säubern“. Fraenkel trat - angeblich freiwillig - vom Amt des Beisitzers zurück.

In den Jahren zuvor hatte Fraenkel in Breslau, zunächst als extrauniversitär tätiger Wissenschaftler, später als Direktor der UFK, wesentliche Beiträge zur Aufklärung der Funktion des Corpus luteum geleistet. Als „spiritus rector“ einer Arbeitsgruppe, der unter anderem Erich Fels und Karl Slotta angehörten, war er auch an der Reindarstellung des Progesterons beteiligt, über die 1934 vier Arbeitsgruppen unabhängig voneinander erstmals berichteten. Zur Bedeutung des Corpus luteum für die Erhaltung der Schwangerschaft hatte er bereits 1901 auf der DGG-Tagung in Gießen gesprochen. Mit der nationalsozialistischen Macht- 
übernahme und dem „Berufsbeamtengesetz“ endete die fruchtbare Zusammenarbeit der Breslauer Gruppe: Fels und Fraenkel wurden aufgrund ihrer jüdischen Abstammung entlassen; Slotta, der Fraenkels Tochter Maja geheiratet hatte, wegen einer nichtarischen Ehefrau. Alle 3 wanderten nach Südamerika aus: Fels nach Buenos Aires (Argentinien), Slotta nach Sao Paulo (Brasilien), Fraenkel im Jahr 1936 auf Einladung des uruguayischen Gesundheitsministers nach Montevideo. Dort konnte der 67-Jährige seine Forschungen erfolgreich fortführen und erneut einen Schülerkreis um sich sammeln. Die Universität Montevideo verlieh ihm die Ehrenprofessur.

Ludwig Fraenkel starb am 10. Juli 1951 während einer Europareise in Bad Ischl (Österreich). Kurz zuvor hatte ihm die DGG die Ehrenmitgliedschaft zuerkannt.

\section{Gedruckte Quellen}

GK 1928, S. 65; Bettendorf: Geschichte (1995), S. 151 f.; Frobenius: Fraenkel (1998); Ludwig: Fraenkel (2004); Ebert/David: Gesetz (2014).

\section{Franqué, Otto Friedrich Wilhelm Paul von}

geb. 11.09.1867, Würzburg

gest. 11.04.1937, Schloß Kalkum bei Düsseldorf

katholisch

Familie

Vater: Otto von Franqué, habil. Gynäkologe; Mutter: Marguerite, geb. Pascault

œ 07.04.1902: Erna, geb. Prym (1883-1973); 3 Söhne, 3 Töchter

\section{Ausbildung}

1885 Abitur (Würzburg); Medizinstudium in München und Würzburg; 1890 Approbation (Würzburg)

\section{Akademische Karriere}

1889 Promotion (Würzburg); 1894 Habilitation (Würzburg); 1901 a. o. Prof.; 1903 o. Prof. (Dt. Univ. Prag); 1907 o. Prof. (Gießen); 1912 o. Prof. (Bonn); 1916/17 Dekan und 1922/23 Rektor (Bonn); 1935 Emeritierung

\section{Weiterbildung und berufliche Karriere}

1890 Path. Inst. Würzburg (v. Rindfleisch); 1891-1902 Ass. in Würzburg (M. Hofmeier); ab 1899 Leiter des Laboratoriums der UFK Würzburg; Direktorate an der UFK Prag (1902), Gießen (1907) und schließlich Bonn (1912-1935)

\section{NS-Organisationen}

keine

\section{Mitgliedschaft/Funktionen in der DGG}

1912-1933 Kassenwart; 1925-1927 Präsident; 1933 Ehrenmitglied; Vortrag: 1931

\section{Vita}

Otto von Franqué, langjähriger Kassenwart, Präsident und schließlich Ehrenmitglied der DGG, gehörte zu den Ordinarien, die neben der gesamten Breite des Faches auch dessen spezielle Histopathologie beherrschten. Offenbar durch seine Ausbildung bei dem Würzburger Pathologen und Virchow-Schüler Eduard von Rindfleisch inspiriert, stellten Untersuchungen zur Entstehung, Ausbreitung und Behandlung vor allem des Zervixkarzinoms ein zentrales Thema seiner wissenschaftlichen Arbeit dar. Die Untersuchungen Franqués zur Bedeutung lokaler Zellatypien und Leukoplakien fanden später in den bahnbrechenden Arbeiten seines Schülers Hans Hinselmann zur kolposkopischen Frühdiagnose maligner und prämaligner Veränderungen der Zervix ihre erfolgreiche Fortsetzung. Die zahlreichen Veröffentlichungen Franqués berührten aber auch viele andere Aspekte des Faches einschließlich der Strahlentherapie. In einer Geschichte der Bonner Medizinischen Fakultät im „Dritten Reich“ wird Otto von Franqué als „NS-Gegner von deutschem Adel“ apostrophiert. Dennoch stand er - wie viele seiner Fachkollegen - bestimmten Elementen der NS-Ideologie im Zusammenhang mit dem Pround Antinatalismus sowie der Unterordnung des Individuums gegenüber dem „Volksganzen“ nahe. Zum Ende seines Direktorats wurde in der Bonner Frauenklinik mit der konsequenten Umsetzung des „Gesetzes zur Verhütung erbkranken Nachwuchses“ begonnen. Trotz erheblicher organisatorischer Schwierigkeiten und personeller Engpässe berichtete Franqué für die Zeit von Mai bis Oktober 1934 schon von 108 einschlägigen Eingriffen.

\section{Gedruckte Quellen}

GK 1928, S. 68-70; GW 1956, S. 120; Martius: Franqué [Nachruf] (1937); Buchheim: Franqué (1961); Künzel/Oehmke (Hrsg.): Präsidenten (1996), S. 104-106; Forsbach: Fakultät (2006), S. 233-235, 517 f.

\section{Frommolt, Günther}

geb. 23.02.1892, Oschatz

gest. 27.12.1972, Monza (Italien)

Familie

Vater: Sanitätsrat

verheiratet; keine Kinder

\section{Ausbildung}

ab 1911 Medizinstudium (Genf, Jena, München, Kiel, Leipzig); 1915-1918 Kriegsdienst, zuletzt als Feldhilfsarzt, schwer verwundet; 1919 Approbation (Dresden)

\section{Akademische Karriere}

1919 Promotion (Leipzig); 1926 Habilitation (Berlin); 1931 a.o. Prof. (Berlin); 1934 apl. Prof. (Halle/Saale); 1936 Senator der Univ. Halle/Saale; 1945 Entzug der Lehrbefugnis

\section{Weiterbildung und berufliche Karriere}

1920/21 Ass. an der Univ.-Kinderklinik Leipzig; 1922-1926 Ass. an der UFK Leipzig (Stoeckel); 1926/27 OA an der I. UFK Berlin (Stoeckel); 1927-1930 Dozent an der Su-Yat-Sen-Univ. in Kanton (China); 1931-1934 OA an der I. UFK Berlin (Stoeckel); ab 1934 Leiter der geburtsh.-gyn. Abt. im Evang. Diakonissenhaus Halle/ Saale; 1938/39 Richter am Erbgesundheitsobergericht Naumburg/Saale; ab 1954 Chefarzt der Frauenklinik Dr. Bohnen in Helmstedt 


\section{NS-Organisationen}

05/1933 NSDAP; 05/1933 SA; 1934 Vertrauensmann der NSDAP an der Med. Fak. Halle/Saale; Beauftragter des Reichsärzteführers und Vertreter des NS-Ärztebundes; Unterzeichner eines NSDAPWahlaufrufs zur November-Wahl 1932

\section{Mitgliedschaft/Funktionen in der DGG}

1931-1933 2. Schriftführer; Vorträge: 1933, 1937

\section{Vita}

Günther Frommolt, 1892 als Sohn eines Sanitätsrates im sächsischen Oschatz geboren und im Ersten Weltkrieg 1917 als Hilfsfeldarzt schwer verwundet, gehört zu den Assistenten von Walter Stoeckel, die ihrem Lehrer bei dessen Schritten auf der Karriereleiter über viele Jahre gefolgt sind, bis sie als Ordinarien oder Leiter eine außeruniversitären Klinik Selbständigkeit erlangten. Frommolt stellt allerdings in einer Beziehung eine Ausnahme dar: Er war, damals schon Stoeckels Oberarzt, von 1927 bis 1930 im Rahmen der deutsch-chinesischen Kooperation an der Su-YatSen-Universität in Kanton tätig, bevor er 1934 Leiter einer geburtshilflich-gynäkologischen Abteilung in Halle und apl. Professor der dortigen Universität wurde. In Berlin hatte Frommolt seinen Chef Stoeckel 1933 noch bei der „Gleichschaltung“ der DGG und der Vorbereitung ihrer Tagung unterstützt, in Halle diente er der NSDAP als Vertrauensmann in der Medizinischen Fakultät und „bespitzelte seine Fachkollegen“. Als Dozent las er „Systematik der Rassenkunde“; ab 1938 war er Mitglied des Erbobergerichtes Naumburg und gehörte dem Rassepolitischen Amt der NSDAP an. Schon in China hatte er „anthropologischen Beobachtungen" an Chinesinnen angestellt und darüber publiziert, weitere einschlägige Arbeiten folgten Mitte der 1930er-Jahre in Halle. Schrille NS-Rhetorik findet man darin allerdings nicht.

\section{Archivalische Quellen}

BArch Berlin, BDC, SA 157; BArch Berlin, R 73/16745: Beihilfeakten: Frommolt, Günther; R 4901/13284 (sog. Professorenkartei).

\section{Gedruckte Quellen}

GK 1928, S. 73; GK 1939, S. 120 f.; GW 1956, S. 152; Stoeckel: Leben (1954), S. 118; Wiss. Zeitschr. Gesellschafts- und sprachwiss. Reihe 37, 4-6 (1988), S. 48; Seidler/Scriba u. a. (Hrsg.): Elite (1995), S. 230; Eberle: Martin-Luther-Universität (2002), S. 87,119 f.; Rupieper: Beiträge (2002), S.487; Klee: Personenlexikon (2003), S. 170; Grüttner: Lexikon (2004), S. 54; Peter: Einbruch (2004); Jahr: Machtübernahme (2012), S. 310 f.

\section{Fuchs, Hans}

geb. 11.08.1873, Berlin

gest. 28.10.1942, Posen

Familie

Vater: Karl Fuchs, Musikprofessor

๑1905; 5 Kinder

\section{Ausbildung}

Humanist. Gymnasium (Danzig); Medizinstudium in Breslau, Freiburg i. Br. und Berlin; 1897 Approbation (Würzburg)

\section{Akademische Karriere}

1896 Promotion (Würzburg); 1931 Prof. (Breslau?); 1935 o. Prof. (Danzig); 1939 Emeritierung; 1942 Ernennung zum Honorarprof. der Reichsuniversität Posen

\section{Weiterbildung und berufliche Karriere}

1898-1903 Ass. an der UFK Kiel (Werth); 1904-1929 Leiter einer Privatklinik in Danzig; im 1. Weltkrieg als Arzt an der Ostfront; ab 1930 Leiter der Staatl. Frauenklinik Danzig; 1935 Mitbegründer der Akademie für prakt. Medizin Danzig; 1939 Emeritierung und Übernahme der Gaufrauenklinik und Hebammenlehranstalt Posen

\section{Mitgliedschaft/Funktionen in der DGG}

1937-1941 1. Vorsitzender; 1941 designierter 2. Vorsitzender

Archivalische Quellen

BArch Berlin, R 4901/2827, Bl. 300, 308-309.

\section{Gedruckte Quellen}

GK 1928, S. 73 f.; GK 1939, S. 121-123; GW 1956, S. 152; Wagner: Fuchs [Nachruf] (1942).

\section{Gauß, Carl Joseph \\ $\nabla$}

geb. 29.10.1875, Rittergut Lohne bei Hannover gest. 11.02.1957, Bad Kissingen

\section{Familie}

Vater: Carl August Adolf Gauß; Mutter: Ana Johanna Sophie Charlotte, geb. Ebmaier

๑ 1919: Marlene, geb. Bingel (bringt 2 Kinder mit in die Ehe)

\section{Ausbildung}

1894 Abitur (Hameln); 1894-1898 Medizinstudium (Tübingen, Erlangen, Kiel, Würzburg, München); 1899 Staatsexamen/Approbation (München)

\section{Akademische Karriere}

1898 Promotion (München); 1909 Habilitation (Freiburg i. Br.); 1912 a.o. Prof. (Freiburg i. Br.); 1923 o. Prof. (Würzburg); 1945 Amtsenthebung durch die US-Militärregierung

\section{Weiterbildung und berufliche Karriere}

1899/1900 Schiffsarzt; 1900/01 Volontärass. am Path.-Anat. Inst. Göttingen; 1901-1904 Ass. an der UFK Berlin; 1904 chir. Volontärass. am KH Westend Berlin; 1904-1922 Ass., später OA an der UFK Freiburg i. Br.; 1922 Leiter der Abt. für Geburtsh., Gyn. und Strahlenbehandlung am Diakonissenkh. Freiburg i. Br.; 01.05.1923-10.08.1945 Dir. der UFK Würzburg; 1945 Amtsenthebung durch die US-Militärregierung; 1949-1956 Leiter der gyn.-geburtsh. Abt. des Elisabethkh. Bad Kissingen

\section{NS-Organisationen \\ 01.05.1933 NSDAP}

Mitgliedschaft/Funktionen in der DGG Ehrenmitglied; Vorträge: 1931, 1933, 1937, 1941 
Vita

Carl Joseph Gauß gehört zu den Pionieren der gynäkologischen Strahlentherapie. Seine zusammen mit Hermann Lembcke in der ersten Dekade des 20. Jahrhunderts an der Freiburger UFK durchgeführten Untersuchungen stellten einen Meilenstein in der Entwicklung dar. Sie wurden 1912 unter dem Titel „Röntgentiefentherapie - ihre theoretischen Grundlagen, ihre praktische Anwendung und ihre klinischen Erfolge“ publiziert. Im „Dritten Reich“ präsentierte sich Gauß, der 1933 NSDAP-Mitglied geworden war, als überzeugter Parteigenosse und trat vehement für die rassenhygienischen Ziele der Machthaber ein. Als er sich 1935 in der „Münchener Medizinischen Wochenschrift“ mit dem Hinweis auf hohe Komplikations- und Mortalitätsraten der chirurgischen Zwangssterilisationen für die damals gesetzlich noch nicht mögliche Strahlensterilisation aussprach, fiel er zumindest zeitweise in Ungnade: Vor allem die Machthaber fürchteten, dadurch könnte ihr eugenisches Programm diskreditiert werden und verhinderten seinen Auftritt auf dem damaligen Kongress der DGG. Gauß setzte seine Bemühungen um die Strahlensterilisierung jedoch fort. Bedenken wegen der Kastrationsfolgen bei den betroffenen Frauen spielte er herunter. Schon ein Jahr später wurde die Strahlensterilisation unter bestimmten Bedingungen legalisiert. In der UFK Würzburg wurden unter der Ägide von Gauß 994 Sterilisationen, 29 eugenische Abtreibungen sowie 148 Schwangerschaftsabbrüche bei „Ostarbeiterinnen“ durchgeführt. Eine kritische Auseinandersetzung mit seiner Rolle im Nationalsozialismus verweigerte er auch nach 1945 .

\section{Gedruckte Quellen}

GK 1928, S.77-79; GK 1939, S.127-131; GW 1956, S.191; Frobenius: Röntgenstrahlen (2003); Wolf: Gauß (2008); Anthuber/Beckmann u. a. (Hrsg.): Herausforderungen (2012), S. 299 f.; Moser: „Röntgenkunde“ (2014).

\section{Guggisberg, Hans}

geb. 03.02.1880, Bern

gest. 11.04.1977, Köniz (Schweiz)

Familie

Vater: Rudolf Guggisberg (1853-1913), Lehrer; Mutter: Anna Maria, geb. Stauffer (1853-1938)

œ 06.10.1906: Hanny/Fanny Olga, geb. Andres (26.05.187919.01.1959); 2 Töchter: Margaritha Fanny, Heidi (02.07.191302.02.1985)

\section{Ausbildung}

1898-1903 Medizinstudium (Bern, München); 1906 Approbation

\section{Akademische Karriere}

11.01.1905 Promotion (Bern); 1908 Habilitation (Bern); 1911 apl. Prof. (Bern); 1912 o. Prof. (Bern); 1919/20 Rektor der Univ. Bern; 2-mal Dekan der Med. Fak. Bern

\section{Weiterbildung und berufliche Karriere}

1903-1906 Ass. am Frauenspital Bern (P. Müller); Ass. an der Chir. Klinik Amsterdam (O. Lanz); 1906 Praxis in Bern; 19071911 wiss. Mitarbeiter am Bakteriolog. Inst. (Kolle); ab 1911 Leiter der Kantonalen Entbindungsanstalt Bern als apl. Prof.; 1912-
1950 o. Prof. für Geburtsh. und Gyn. (Bern) und Dir. des Kantonalen Frauenspitals Bern

\section{Mitgliedschaft/Funktionen in der DGG}

1937-1941 Beisitzer; Ehrenmitglied; Vorträge: 1931, 1941

\section{Vita}

Der Schweizer Hans Guggisberg, eines der ausländischen Ehrenmitglieder der DGGG, spielte in der ersten Hälfte des 20. Jahrhunderts nicht nur fachlich für die Frauenheilkunde eine wichtige Rolle. Als 2-maliger Dekan der Medizinischen Fakultät sowie Rektor der Universität Bern, Gründer und Präsident der Gynäkologischen Gesellschaft der deutschen Schweiz sowie ärztlicher Funktionär übte er jahrzehntelang großen Einfluss aus. Auf dem Kongress der DGG 1931 war er mit einem großen Referat über die Funktion des Hypophysenhinterlappens Korreferent von Selmar Aschheim und Bernhard Zondek, 1937 wurde er zum Beisitzer gewählt. Mit dem „heimlichen Dauervorsitzenden“ der DGG, Walter Stoeckel, liefert sich Guggisberg 1938 im Zusammenhang mit der Neuauflage des Gynäkologenkalenders eine heftige Kontroverse: Für die Aufnahme in das von Stoeckel herausgegebene Verzeichnis zum wissenschaftlichen Werdegang deutscher Frauenärzte, das von der DGG finanziell unterstützt wurde, sollten Schweizer Ärzte ein Bekenntnis zur „rein arischen“ Abstammung ablegen. Dies wurde von Guggisberg, der den eugenischen Konzepten der Nationalsozialisten durchaus nahestand, im Namen seiner Kollegen scharf abgelehnt. Sie finden sich deshalb in dieser Auflage des Verzeichnisses nicht. Für Guggisberg war dieser Vorfall jedoch kein Grund, mit der DGG zu brechen. An der Tagung von 1941 nahm er als Beisitzer teil. Die wissenschaftliche Bedeutung von Guggisberg zeigt sich unter anderem darin, dass er für die erste Auflage des damals von Josef Halban und Ludwig Seitz herausgegebenen, neunbändigen Handbuchs „Biologie und Pathologie des Weibes“ mehrere Beiträge lieferte.

\section{Gedruckte Quellen}

GK 1928, S. 88 f.; GW 1956, S.235; Fischer, S. 559; Klaesi: Guggisberg (1950); Ludwig: Guggisberg (1950); Berger: Guggisberg [Nachruf] (1977); Ehrler: „Arier“ (1978); Moser: Guggisberg (2014).

\section{Hammerschlag, Sigfrid \\ $\nabla$}

geb. 16.01.1871, Magdeburg

gest. 16.05.1948, Iran

jüdisch

Familie

Vater: Kaufmann

œ1) 1906: Helena, geb. Deutsch; 2) Hedwig

\section{Ausbildung}

Medizinstudium in Würzburg, Leipzig, Kiel und Berlin; 28.12.1894 Approbation

Akademische Karriere

1893 Promotion (Berlin); 1904 PD (Berlin); 1908 Prof. (Berlin) 
Weiterbildung und berufliche Karriere

1895-1909 Berlin (A. Martin, Waldeyer, Olshausen), Königsberg i. Pr. (G. Winter); ab 1908 Prof.; ab 1913 Dir. der Landesfrauenklinik Brandenburg; 01.11.1933 Versetzung in den Ruhestand aufgrund des „Gesetzes zur Wiederherstellung des Berufsbeamtentums“

\section{Mitgliedschaft/Funktionen in der DGG}

bis 1937 Mitglied; 1931-1933 Beisitzer („freiwilliger“ Rücktritt vor dem Kongress 1933)

\section{Vita}

Sigfrid Hammerschlag war als langjähriger Direktor der Provinzial-Hebammen-Lehranstalt in Neukölln und Leiter der Brandenburgischen Landesfrauenklinik ein stadtbekannter und hochangesehener Arzt, als er am 1. November 1933 in den Ruhestand versetzt wurde. „[O]ffenbar infolge des neu geweckten Rassegefühls in der Bevölkerung“', so die Provinzialverwaltung, sei die Zahl der Patientinnen an der Landesfrauenklinik deutlich zurückgegangen, weshalb es im Interesse der Klinik sei, die Stelle mit einem „arischen“ Arzt zu besetzen. Offiziell erfolgte die Pensionierung Hammerschlags, der als „Frontkämpfer“ galt, auf eigenen Wunsch, doch kann zu diesem Zeitpunkt von Freiwilligkeit keine Rede mehr sein. Offensichtlich ebenso wenig aus freiem Entschluss legte Hammerschlag 1933 das Amt eines Beisitzers im DGG-Vorstand nieder. Vier Jahre später wurde er auf Weisung des Schriftführers Heinrich Martius aus dem Mitgliederverzeichnis gestrichen - er hatte den Mitgliedsbeitrag nicht gezahlt.

In den 15 Jahren vor seiner Entlassung hatte Hammerschlag als Gründungsdirektor maßgeblich am Aufbau der größten preußischen Hebammenlehranstalt mitgewirkt und sich als Lehrer und Autor um die Hebammenausbildung verdient gemacht. Hammerschlags hervorragender Ruf trug dazu bei, dass sich die persische Regierung schon bald nach seiner Pensionierung um ihn bemühte. Im Oktober 1934 übernahm er, zunächst für 3 Jahre, die Leitung des Krankenhauses in Mesched und engagierte sich dort beim Aufbau einer gynäkologischen Lehranstalt. 1941 wurde ihm die iranische Staatsangehörigkeit verliehen. Sigfrid Hammerschlag starb am 16. Mai 1948 in der Emigration.

\section{Gedruckte Quellen}

GK 1928, S. 93 f.; Fischer, S.585; Stoeckel: Erinnerungen (1966), S.391; Stürzbecher: Hammerschlag (1998).

\section{Haselhorst, Gustav Heinrich Friedrich}

geb. 28.03.1893, Westkilver (Westfalen)

gest. 27.10.1955, Mainz

Familie

Vater: Friedrich Haselhorst, Landwirt; Mutter: Karoline Haselhorst, geb. Kollmeyer

๑ Sigrid, geb. Lindau; 2 Kinder

\section{Ausbildung}

1912 Abitur (Bielefeld); 1912-1920 Medizinstudium (Kiel, Heidelberg, Freiburg i. Br., Göttingen); 1914-1919 Kriegsdienst; anschl. Medizinalpraktikant und Volontärass. an der chir. und gyn. Abt. des KH Hannover; 1920 Approbation (Göttingen)

\section{Akademische Karriere}

1920 Promotion (Hamburg); 1926 Habilitation (Hamburg); 1930 a. o. Prof. (Hamburg); 1933-1945 o. Prof. (Rostock); 1941-1944 Dekan der Med. Fak. Rostock

\section{Weiterbildung und berufliche Karriere} 1920-1924 Ass. an der UFK Hamburg; bis 1926 Chir. UK Hamburg; anschl. bis 1933 OA an der UFK Hamburg; 1933-1945 Dir. der UFK Rostock; 1945 Suspendierung und Amtsverzicht; ab 1947 Chefarzt der Städt. Frauenklinik Wiesbaden

\section{NS-Organisationen}

01.05.1933 NSDAP; Dozentenschaftsführer; NS-Altherrenbund; NSLB; NSDÄB

\section{Mitgliedschaft/Funktionen in der DGG \\ Vorträge: 1931, 1933, 1935, 1937, 1941}

\section{Vita}

Gustav Haselhorst, langjähriges DGG-Mitglied, wurde 1939 vom Vorstand dazu ausersehen, die für die Auseinandersetzung mit Reichsgesundheitsführer Leonardo Conti über die Frage der Haus- bzw. Klinikentbindung wichtige Datensammlung zu den Ergebnissen der klinischen Geburtshilfe zu koordinieren. Das Ergebnis legte er 1941 auf dem Wiener Kongress der DGG in Form einer Sammelstatistik für 27 Universitätsfrauenkliniken und Hebammenlehranstalten vor. Haselhorst gehörte zu den habilitierten Nachwuchsgynäkologen, die 1933 in die NSDAP eintraten und kurze Zeit später in ein Ordinariat berufen wurden. Zu Beginn seiner Tätigkeit als Direktor der UFK Rostock engagierte er sich als Dozentenschaftsführer, von 1941 bis 1944 war er Dekan der Medizinischen Fakultät. Haselhorst hat die NS-Eugenik in verschiedenen Publikationen unterstützt. In seiner Klinik wurden bis 1937 mindestens 402 Zwangsterilisationen durchgeführt. Nach seiner Amtsenthebung im Zuge der ersten Entnazifizierungsmaßnahmen der sowjetischen Besatzer verzichtete er auf seine Ämter in Rostock und verließ den sowjetischen Einflussbereich.

\section{Archivalische Quellen}

BSB München, Nachlässe, Ana 691, Schwarzer Ordner.

\section{Gedruckte Quellen}

GK 1928, S.97; GK 1939, S.161-163; Buddrus/Fritzlar: Professoren (2007), S. $178 \mathrm{f}$

\section{Internetquellen}

http://cpr.uni-rostock.de/metadata/cpr_person_00003407

\section{Hengge, Anton \\ $\nabla$}

geb. 11.11.1873, Donauwörth

gest. 30.10.1945, München

Ausbildung

1898 Approbation

\section{Akademische Karriere}

1898 Promotion 
Weiterbildung und berufliche Karriere

1898-1901 gyn. Poliklinik der Univ. München (G. Klein) und Dt. UFK Prag (Saenger); 1901-1904 UFK Greifswald (A. Martin); später Ltd. Arzt der geburtsh. Station der Diakonissenanstalt München

\section{NS-Organisationen}

01.05.1933 NSDAP; SA, DA; NSV; NSDÄB

\section{Mitgliedschaft/Funktionen in der DGG}

1941 zum Beisitzer gewählt, vor der Tagung 1949 gestorben

\section{Vita}

Anton Hengge, 1941 zum Beisitzer der DGG gewählt, war der letzte Vorsitzende der Bayerischen Gesellschaft für Geburtshilfe und Frauenheilkunde (BGGF) vor dem Zweiten Weltkrieg. 1927/ 28 hatte er den Vorsitz in der Münchener Gynäkologischen Gesellschaft inne. Seine Berufung in das DGG-Gremium verdankte er, wie die Wahl in den BGGF-Vorsitz, neben seiner Präsenz in lokalen Fachgesellschaften vermutlich vor allem seiner guten Vernetzung in der ärztlichen Selbstverwaltung - offenbar auch in der Zeit nach 1933: Heinrich Eymer, Vorgänger Hengges im BGGF-Vorsitz, empfahl ihn jedenfalls für seine Nachfolge ausdrücklich mit dem Hinweis, Hengge nehme „in der ärztlichen Organisation der Partei wichtige Stellungen ein" ein. In der DGG war er - soweit ersichtlich - nicht besonders aktiv.

Archivalische Quellen

BArch Berlin, BDC.

\section{Gedruckte Quellen}

GK 1928, S. 105; GK 1939, S. 176; GW 1956, S. 194; Zander/Zimmer: Gesellschaft (1987), S. 71. Anthuber/Beckmann u. a. (Hrsg.): Herausforderungen (2012).

\section{Heynemann, Theodor}

$\nabla$

geb. 20.08.1878, Lemgo

gest. 15.12.1951, Hamburg

evangelisch

Familie

unverheiratet

\section{Ausbildung}

Medizinstudium in Würzburg, München und Kiel; 1903 Approbation

\section{Akademische Karriere}

1903 Promotion (Kiel); 1910 Habilitation (Halle/Saale); 1919 o. Prof. (Hamburg); 1950 Emeritierung

\section{Weiterbildung und berufliche Karriere}

1903/04 Path. Inst. des Allg. KH St. Georg Hamburg (Simmonds); 1904-1906 Inn. Med. des Allg. KH St. Georg Hamburg (Jolasse); 1906/07 1. chir. Abt. und Röntgeninst. des Allg. KH St. Georg Hamburg (Wiesinger, Albers-Schönberg); 1907-1914 zunächst Ass., dann OA an der UFK Halle/Saale (Veit); 1914-1918 Kriegsdienst; 1918/19 stellv. Dir. der UFK Halle/Saale; 1919 OA der gyn. Abt. des KH Barmbeck; ab 1919 bis 1951 Dir. der Frauenklinik im UK Hamburg-Eppendorf, 1950 Emeritierung
NS-Organisationen

1933 NSLB; 01.05.1937 NSDAP

\section{Mitgliedschaft/Funktionen in der DGG}

1937-1941 Beisitzer; Ehrenmitglied; Vorträge: 1931, 1933, 1935, 1941, 1949

\section{Vita}

Theodor Heynemann, der 1937 als Beisitzer in den erweiterten Vorstand der DGG gewählt war, zählt zu den Hochschullehrern, die sich nach 1933 rasch mit dem Regime arrangierten, ohne als überzeugte Nationalsozialisten gelten zu können. Nach dem Ersten Weltkrieg war Heynemann an die UFK in Hamburg-Eppendorf berufen worden, die er von ihrer Gründung 1919 bis zu seiner Emeritierung im Jahr 1950 leitete. Wie viele seiner Kollegen stand Heynemann der eugenischen Sterilisation bereits in den 1920er-Jahren aufgeschlossen gegenüber und befürwortete auf der Tagung der DGG im Jahr 1931 die Sterilisierung „bei bestimmten Geisteskrankheiten und gewissen verbrecherischen Anlagen". Nach dem Inkrafttreten des GzVeN wurden auch in Eppendorf Unfruchtbarmachungen vorgenommen. Im Jahr 1936 beschwerte sich Heynemann bei der Unterrichtsbehörde darüber, dass „der Zugang an eugenischen Sterilisierungen fast völlig aufgehört" habe, was dem akademischen Unterricht zu diesem wichtigen Thema abträglich sei. Das Feilschen um die Zuteilung von Sterilisierungspatienten im Interesse der Konkurrenzfähigkeit der Eppendorfer Frauenklinik offenbart die unkritische Haltung, die Heynemann in dieser Frage einnahm. Dennoch zählte er nach Kriegsende zu den wenigen Hamburger Professoren, die von den Alliierten im Amt belassen wurden. 1951, 1 Jahr nach seiner Emeritierung, starb Heynemann im Alter von 73 Jahren.

\section{Gedruckte Quellen}

GK 1928, S. 111 f.; GK 1939, S. 185-187; GW 1956, S. 123; Fischer, S. 639; Bussche/Bottin (Hrsg.): Wissenschaft (1989); Quellmann: Heynemann (2002).

\section{Hinselmann, Hans \\ $\nabla$}

geb. 06.08.1884, Neumünster

gest. 18.04.1959, Hamburg-Othmarschen

Familie

Vater: Hans-Peter Gustav Hinselmann, Braumeister; Mutter: Magdalene, geb. Baeder, Gastwirtstochter

verheiratet; 7 Kinder

Ausbildung

Medizinstudium in Heidelberg und Kiel; 1909 Approbation (Kiel)

Akademische Karriere

1908 Promotion (Kiel); 1913 Habilitation (Bonn); 1921 a.o. Prof. (Bonn); ab 1931 a.o. Prof. (Hamburg); ab 1939 apl. Prof. (Hamburg); 1945 von der brit. Militärregierung suspendiert; nach Haftstrafe und „Entnazifizierung“ 1949 Wiedererteilung der Venia legendi, „aus Altersgründen“ keine Wiederaufnahme der Lehrtätigkeit 


\section{Weiterbildung und berufliche Karriere}

ab 1910 Ass. an den UFK Jena (Henkel) und Gießen (v. Franqué); ab 1912 OA an der UFK Bonn (v. Franqué); 1914-1918 Kriegsdienst; ab 1925 Leiter der gyn. Abt. am Allg. KH Altona; ab 1933 Chefarzt der Frauenklinik Altona; 1946 Entlassung als Klinikchef durch die brit. Militärregierung und Verurteilung zu einer dreijährigen Haftstrafe wegen „Verbrechen gegen die Menschlichkeit“" (später verkürzt auf 18 Monate)

\section{NS-Organisationen}

01.05.1933 NSDAP (Mitgliedsnummer: 2727 321)

\section{Mitgliedschaft/Funktionen in der DGG}

1935-1937 Beisitzer; 1956 Ehrenmitglied (2015 auf Vorstandsbeschluss der DGGG gestrichen); Vortrag: 1933

\section{Gedruckte Quellen}

GK 1928, S.113-115; GK 1939, S.190-193; GW 1956, S.124; Fischer, S. 656; Martius: Hinselmann (1959); MacLean: Life (1979); Klee: Personenlexikon (2003), S. 257; Powell: Sketch (2004)

Bussche/Schmiedebach: Grenzübertritte (2014), S. 263-268; Ebert/David: Erfindung (2014); Kühn/Gieseking u. a.: Hinselmann (2015).

\section{Hüssy, Paul \\ $\nabla$}

geb. 02.06.1884, Safenwil (Schweiz)

gest. 29.06.1959, Aarau (Schweiz)

\section{Ausbildung \\ 1908 Approbation}

\section{Akademische Karriere} 1921 PD (Basel)

\section{Weiterbildung und berufliche Karriere}

1908-1920: Frauenklinik Pavia (Clivio); Hyg. Inst. Halle/Saale; Path. Inst. Wien; Frauenklinik Basel (v. Herff, Labhardt); II. Gyn. Klinik München (Amann); 1921-1946 PD (Basel) und Chefarzt am Kantonspital Aarau; 1935-1946 Dir. des Kantonspitals Aarau

\section{Mitgliedschaft/Funktionen in der DGG \\ 1931-1933 Beisitzer}

Gedruckte Quellen

GK 1928, S. 126 f.; GW 1956, S. 219 f.; Stoll: Dorfhebamme (2010), S. 190 f.

\section{Jaschke, Rudolf Theodor Edler von \\ $\nabla$}

geb. 17.08.1881, Pettau (Österreich)

gest. 30.12.1963, Garmisch-Partenkirchen

\section{Familie}

Vater: Hans Edler von Jaschke, Feldmarschallleutnant; Mutter: Cäcilie. geb. Hofmann

๑ Elsbeth, geb. Deiters; 5 Kinder: Herbert (1912-2010), Ruth, Inge, Priska (geb. 1920), Wolfgang; laut Fischer wohl 2 Ehen

\section{Ausbildung}

ab 1899 Medizinstudium (Innsbruck, Berlin, Wien, Freiburg i. Br.); 1905 Staatsexamen (Innsbruck)

\section{Akademische Karriere}

1905 Promotion (Innsbruck); 1912 Habilitation (Gießen); 1916 a. o. Prof. (Gießen); 23.03.1918 o. Prof. (Gießen); Wintersemester 1933/34 Dekan der Med. Fak. Gießen; 1945 Entlassung aus allen Ämtern durch die Militärbehörden; 1950 Wiederverleihung des Titels o. Prof. und Pensionierung; 1952 Emeritierung mit Wirkung ab 1950; 1960 Ehrendoktorwürde der Univ. Gießen

\section{Weiterbildung und berufliche Karriere}

1905-1907 Anat. Innsbruck (Hochstetter), Inn. Med. Wien (Ortner), München (F.v. Müller), Chir. Linz (Brenner sen.); 1907-1910 gyn. Fachausbildung in Heidelberg und Wien (v. Rosthorn); 1910/ 11 Greifswald (Kroemers); 1912 OA in Düsseldorf (Opitz), danach an der UFK Gießen (Opitz); 23.03.1918-1947 Dir. der Frauenklinik Gießen (1944 evakuiert); 05/1945 Entlassung aus allen Ämtern durch die Militärbehörden; 1946/47 Beschäftigung ohne Leitungsfunktion; 1947-05/1949 Chefarzt und Leiter der Städt. Frauenklinik Offenbach/Main; dann bis 1954 Tätigkeit an privater Frauenklinik in Offenbach/Main

\section{NS-Organisationen}

01.04.1933 NSDAP (Mitgliedsnummer: 1766 504); Förderndes Mitglied der SS; NSKK; NSV; NS-Altherrenbund; NSDDB; 01.12.1933 NSLB

\section{Mitgliedschaft/Funktionen in der DGG}

1935-1937 Beisitzer; 1949 1. Vorsitzender (1941 gewählt); Ehrenmitglied; Vortrag: 1937

Archivalische Quellen

BArch Berlin, BDC, DS C042, Bl. 2950-2952.

\section{Gedruckte Quellen}

GK 1928, S.129-131; GK 1939, S.213-217; GW 1956, S. 259 f.; Fischer S. 722; Lang: Jaschke (1989); Klee: Personenlexikon (2003), S. 285; Oehler-Klein (Hrsg.): Gießen (2007).

\section{Kaufmann, Carl \\ $\nabla$}

geb. 21.08.1900, Malmedy (Belgien)

gest. 18.08.1980, Köln

Familie

Vater: Dr. jur. Karl Kaufmann

œ Erika Kaufmann

Ausbildung

Medizinstudium in Göttingen und Berlin; 1923 Approbation (Göttingen)

\section{Akademische Karriere}

1925 Promotion (Göttingen); 1931 Habilitation (Berlin); 1936 a. o. Prof. (Berlin); 1946 o. Prof. (Marburg/Lahn); 1954 o. Prof. (Köln); 1968 Emeritierung 
Weiterbildung und berufliche Karriere

1926 Ass. in Hamburg und am Path. Inst. der I. UFK Berlin (R. Meyer); 1926 Ass., später OA an der Charité Berlin (Bracht, dann G.A. Wagner); 1935 OA; ab 02/1945 zunächst vertretungsweise, dann komm. Leiter der II. UFK Berlin (Charité); ab 06/1946 o. Prof. (Marburg/Lahn) und Dir. der UFK Marburg/Lahn; ab 1954 Dir. der UFK Köln (dort bis 1970); 1961 Mitglied des Wissenschaftsrates

\section{NS-Organisationen \\ 1933 SA; 1933 NSKK}

\section{Mitgliedschaft/Funktionen in der DGG}

1935-1937 2. Schriftführer; Ehrenmitglied; Vorträge: 1931, 1937

Vita

Carl Kaufmann, der zu den bedeutendsten deutschen Gynäkologen des 20.Jahrhunderts zählt, unterstützte 1937 seinen klinischen Lehrer G.A. Wagner in dessen Eigenschaft als Präsident der DGG bei der Vorbereitung und Durchführung des Kongresses in Berlin. Kaufmann, damals Oberarzt der II. UFK (Charité) und 2. Schrifttührer der DGG, hatte ein distanziertes Verhältnis zum Nationalsozialismus und wurde vermutlich nicht zuletzt deshalb Ziel einer Intrige aus dem Kollegenkreis. Obwohl die folgende Auseinandersetzung zu seinen Gunsten ausging, blieb Kaufmann im Fadenkreuz der NS-Aktivisten und war in der Folge bis zum Ende des Zweiten Weltkriegs immer wieder von Entlassung bedroht.

Kaufmanns bedeutendste wissenschaftliche Leistungen ergaben sich in den 1930er-Jahren auf dem Gebiet der aufstrebenden gynäkologischen Endokrinologie. Als klassisch gilt eine Arbeit, die 1933 unter dem Titel „Echte Menstruation bei einer kastrierten Frau durch Zufuhr von Ovarialhormonen“ im Zentralblatt für Gynäkologie erschien. Das daraus abgeleitete, später im Detail vielfach modifizierte diagnostische und therapeutische Prinzip ging als „Kaufmann-Schema“ in die Literatur ein. Kaufmann bewirkte auch, dass sich die international propagierte Behandlung der drohenden Frühgeburt mit dem synthetischen Östrogen Diethylstilbestrol in Deutschland nicht durchsetzen konnte, die Jahre später zu gehäuftem Auftreten von Vaginalkrebs bei weiblichen Nachkommen führte. In der Nachkriegszeit beeinflusste seine Arbeit vor allem den Fortschritt in der Frühdiagnostik und in der individuellen Therapie des Zervixkarzinoms. Ihm zu Ehren wurde die Carl-Kaufmann-Medaille der DGGG gestiftet.

Archivalische Quellen

BArch Berlin, R4901/1347-48, 2827; BSB München, Nachlass Carl Kaufmann, Ana 693.

\section{Gedruckte Quellen}

GK 1928, S.136; GK 1939, S. 299 f.; GW 1956, S. 261; Zander: Kaufmann [Nachruf] (1981); Dohm: Geschichte (2001), S. 1893; Klee: Personenlexikon (2003), S. $300 \mathrm{f}$.

\section{Kehrer, Erwin Karl Adolf \\ $\nabla$}

geb. 19.04.1874, Gießen

gest. 13.12.1959, Heidelberg

evangelisch
Familie

Vater: Ferdinand Adolf Kehrer (1837-1914), Prof. für Medizin; Mutter: Emilie Kehrer, geb. Frisch (1849-1924)

๑ 1) 07.06.1905: Antonia, geb. Schönle; 2 Töchter; 2) 26.09.1958: Karoline Emma Hildegard, geb. Stiens

\section{Ausbildung}

1893 Abitur (Speyer); 1893-1898 Medizinstudium (Heidelberg, München, wieder Heidelberg); 1898 Approbation

\section{Akademische Karriere}

1899 Promotion (Freiburg i. Br.); 1903 Habilitation (Heidelberg); 1910 o. Prof. (Bern); 1925 o. Prof. (Marburg/Lahn); 1939 Emeritierung

\section{Weiterbildung und berufliche Karriere}

1897 Ass. am Path.-Anat. Inst. Heidelberg; 1899/1900 Volontärass. an der UFK Heidelberg (Chrobak, Schauta); kurzzeitig an der UFK Wien; ab 1900 Ass. an der UFK Freiburg i. Br. (A. Hegar); 1901 Ass. an der UFK Bonn (Fritsch); 1902 Ass. an der UFK Heidelberg (F.A. Kehrer); 1902-1905 Ass. an der UFK Heidelberg (v. Rosthorn); 1905-1910 Privatklinik in Heidelberg und wiss. Arbeiten im Labor der UFK und im Physiolog. und Pharmakolog. Inst.; 1910/11 Vorstand der UFK Bern; 1911-1925 Dir. der Staatl. Frauenklinik Dresden; 1925-1939 o. Prof. und Dir. der UFK Marburg/Lahn

\section{NS-Organisationen \\ 03/1934 NSLB}

\section{Mitgliedschaft/Funktionen in der DGG} 1933-1935 Beisitzer; Vortrag: 1937

\section{Vita}

Erwin Kehrer, Sohn des berühmten Gynäkologen und DGG-Ehrenmitgliedes Ferdinand Adolf Kehrer, zählt zu den Ordinarien, die sich nach 1933 mit dem Regime arrangierten. Seit 1925 Leiter der Marburger UFK unterzeichnete er im November 1933 das „Bekenntnis der deutschen Professoren zu Adolf Hitler“ und trat wenig später dem Nationalsozialistischen Lehrerbund bei - womöglich, wie Grundmann vermutet, als „Ausweichmanöver“, um nicht in die Partei eintreten zu müssen, „andererseits aber auch nicht als Gegner zu erscheinen“. Allerdings scheute sich Kehrer nicht, im September 1933 einen Maschinisten der Marburger Frauenklinik als „Marxisten“ zu denunzieren, um dessen Entlassung herbeizuführen.

Dass sich Kehrer nach Kriegsende als Opfer des NS-Regimes betrachtete, liegt in seiner Emeritierung im Jahr 1939 begründet. Seit der Verabschiedung des „Gesetzes über die Entpflichtung und Versetzung von Hochschullehrern aus Anlass des Neuaufbaus des Hochschulwesens“ (1935) konnten Hochschullehrer bereits mit 65 Jahren emeritiert werden statt wie zuvor nach Vollendung des 68. Lebensjahres. Dies bot den Nationalsozialisten die Möglichkeit, politisch zurückhaltende oder distanzierte Ordinarien durch linientreue „Hardliner“ zu ersetzen und den „Neuaufbau“ der Universitäten zu beschleunigen. Zum Nachfolger Kehrers an der UFK Marburg wurde der „Alte Kämpfer“ Ernst Bach bestimmt. 
Kehrer, der sich erfolglos um eine Verlängerung des Dienstverhältnisses bemüht hatte, gab im Rahmen seines Entnazifizierungsverfahrens zu Protokoll, dass er entlassen worden sei, weil er in den 1930er-Jahren die Beschneidung eines jüdischen Knaben in seiner Klinik zugelassen habe - eine nicht zu belegende Behauptung, die von der Spruchkammer auch nicht anerkannt wurde.

1925 unterstützte die DGG Kehrer, als er wegen bisher nicht näher bekannter Vorwürfe von der Leitung der Staatlichen Frauenklinik Dresden beurlaubt worden war, mit einer scharfen Resolution. Gleichzeitig setzte sie eine Kommission zur Aufklärung des Falles ein, der auch Stoeckel angehörte. An die Mitglieder erging eine Warnung, in Nachfolgeverhandlungen für Kehrers Position einzutreten. Die Sache erledigte sich allerdings dadurch, dass Kehrer Ordinarius in Marburg wurde. Die Kommission gab deshalb 1927 die Einstellung ihrer Arbeit bekannt, ohne ein Ergebnis vorzulegen.

\section{Gedruckte Quellen}

GK 1928, S. 137 f.; GK 1939, S. 232-234; GW 1956, S. 262; Aumüller: Fakultät (2011). Verhandlungen (1925), S. XLVII-XLVII.

Internetquellen

http://www.lagis-hessen.de/pnd/116093404

\section{Kirstein, Friedrich \\ $\nabla$}

geb. 20.03.1880, Helsingfors (Finnland)

gest. 03.08.1937

Familie

Vater: Richard Kirstein, Pastor

verheiratet; 4 Kinder

Ausbildung

Studium in Marburg, Berlin und Rostock; 1905-1907 Städt. KH Hildesheim (Becker); 1906 Approbation

\section{Akademische Karriere 1905 Promotion (Rostock); 1913 Habilitation (Marburg/Lahn); 1919 a. o. Prof. (Marburg/Lahn)}

\section{Weiterbildung und berufliche Karriere}

1908-1912 UFK Göttingen (Runge sen., Jung); 1912-1922 UFK Marburg/Lahn (Zangemeister), unterbrochen vom Kriegsdienst; ab 01.05.1922 Leiter der Frauenabt. am Ev. Diakonissenhaus Bremen

\section{Mitgliedschaft/Funktionen in der DGG 1933-1935 Beisitzer}

\section{Vita}

Friedrich Kirstein, Leiter der Frauenabteilung am Evangelischen Diakonissenhaus in Bremen und 1933 zum Beisitzer des DGGVorstandes gewählt, gehörte beim Frankfurter Kongress 1931 zu den schärfsten Kritikern des Referates von Ludwig Fraenkel über Sterilisation und Kontrazeption. Er befürchtete, es könne dadurch in der Öffentlichkeit der Eindruck entstehen, „daß wir Frauenärzte die Methoden des Volksselbstmordes herausbringen“. Kir- stein war in Bremen seit Anfang der 1920er-Jahre unter anderem als Mitbegründer und Vorsitzender der Ortsgruppe Bremen der Deutschen Gesellschaft für Rassenhygiene aktiv. In einem 1937 erschienenen Nachruf formulierte Peter Esch, Ordinarius für Frauenheilkunde in Münster: „Er eilte seiner Zeit wegweisend voran." Kirstein erlag unerwartet den Folgen einer Operation wegen einer malignen Erkrankung.

\section{Gedruckte Quellen}

GK 1928, S. 14; GW 1956, S. 160; Esch: Kirstein [Nachruf] (1937); Weindling: Health (1989), S.319; Nitschke: „Erbpolizei“ (1999), S.63; Frewer: Medizin (2000), S. 57.

\section{Knauer, Emil \\ $\nabla$}

geb. 27.02.1867, Pressburg

gest. 14.05.1935, Graz

evangelisch

Familie

Vater: Georg (1822-1878), Bäckermeister; Mutter: Karoline (1829-1905)

œ1903 Angela, geb. Kugler (1883-1954); 5 Söhne, 3 Töchter

\section{Ausbildung}

ab 1885 Medizinstudium (Wien)

\section{Akademische Karriere}

16.05.1891 Promotion (Wien); 1901 Habilitation (Wien); 1901 PD (Wien); 1903 o. Prof. (Graz)

\section{Weiterbildung und berufliche Karriere}

1889-1891 Klinik Nothnagel Wien; 1891-1893 chir. UK Wien (Billroth); 1893-1903 Ass. an der UFK Wien (Chobrak); 19031935 o. ö. Prof. und Dir. der UFK Graz; Ablehnung von Rufen an andere Universitäten (u.a. Wien)

\section{Mitgliedschaft/Funktionen in der DGG 1931-1933 Beisitzer}

\section{Vita}

Emil Knauer, 1931 zum Beisitzer der DGG gewählt, wird zu den Pionieren der gynäkologischen Endokrinologie gezählt. Knauer berichtete 1896 als junger Assistent der II. UFK Wien über Wirkungen der Transplantation von Ovarien auf zuvor kastrierte Tiere. Entsprechende Experimente hatte er auf Anregung seines Lehrers Rudolf Chrobak vorgenommen. Den Schluss daraus, wonach Ovarien eine innere Sekretion haben, zogen allerdings wenig später erst Hermann Rafael Rubinstein sowie Josef Halban. Knauer hat seine Untersuchungen zur inneren Sekretion nicht fortgesetzt. Eine steile Karriere führte ihn schon 2 Jahre nach seiner Habilitation auf den Lehrstuhl für Frauenheilkunde in Graz. Dort widmete er sich neben seinen Bemühungen um den Neubau der Frauenklinik anderen Themen. Er förderte allerdings seinen endokrinologisch interessierten Schüler Hermann Knaus, der mit seiner Lehre von der periodischen Fruchtbarkeit der Frau unter anderem für die DGG-Kongresse der 1930er-Jahre eine große Rolle spielte. Auch seine Antrittsvorlesung in Graz hatte Knauer noch der Endokrinologie gewidmet: Er sprach damals über den 
„Einfluß und die Bedeutung der weiblichen Keimdrüse für den gesamten Organismus“.

\section{Gedruckte Quellen}

GK 1928, S. 144 f.; GW 1956, S.263; Fischer, S. 802; Medvei: History (1993), S. 443; Simmer: Endokrinologie (1986), S.189; Pickel: Knauer (2016).

\section{Knaus, Hermann Hubert \\ $\nabla$}

geb. 19.10.1892, St. Veit an der Glan

gest. 22.10.1970, Graz

katholisch

Familie

Vater: Friedrich Knaus, Kaufmann; Mutter: Amalia, geb. Schäbart

๑ 1934: Maria, geb. Saal (1909-1951); 1 Tochter

\section{Ausbildung}

1911 Matura (Knittelfeld); 1912-1920 Medizinstudium (Wien, Graz), unterbrochen durch Kriegsdienst

\section{Akademische Karriere}

1920 Promotion (Graz); 1927 Habilitation (Graz); 1930 a. o. Prof. (Graz); 1934 o. Prof. (Dt. Univ. Prag); Ablehnung von Rufen nach Graz und Innsbruck; 1939-1941 Dekan der Med. Fak. Dt. Univ. Prag; 10/1948-03/1949 Gastprof. am Hammersmith Hospital der Univ. London; Ablehnung von Rufen nach Halle/Saale und Gießen

\section{Weiterbildung und berufliche Karriere}

1920 Volontär am Inst. path. Anat. Graz (H. Albrecht); anschl. Chir. Klinik Graz (v. Hacker) und Gyn.-geburtsh. Klinik Graz (Knauer); ab 1923 a.o. Ass. an der Gyn.-geburtsh. Klinik Graz; 1924 Rockefeller-Stipendiat am Pharmak. Inst. der Univ. London (Clark) und am Physiolog. Inst. der Univ. Cambridge (Dixon, Marshall); 1930 als Gast an urol. Abt. in Berlin (v. Lichtenberg) und Paris; 1934-45 Vorstand der UFK Prag (Dt. Univ.); nach 1945 Frauenarzt in Graz; 1950-1960 Leiter der gyn. Abt. des Lainzer KH Wien

\section{NS-Organisationen 1939 NSDAP}

\section{Mitgliedschaft/Funktionen in der DGG}

1941 zum Beisitzer gewählt; Kongressbeiträge: 1933, 1935, 1937, 1941

\section{Vita}

Der Österreicher Hermann Knaus, für seine Methode zur Geburtenkontrolle weltberühmt und 1941 zum Beisitzer der DGG gewählt, lieferte in den 1930er- und 1940er-Jahren für die Verhandlungen der Gesellschaft regelmäßig Beiträge zur Frage der Geburtenregelung, obwohl er aus unterschiedlichen Gründen ständig mit politisch bedingten Problemen zu kämpfen hatte. Für den Berliner „Gleichschaltungskongress“ 1933 - Knaus war damals noch Assistent an der UFK Graz - untersagten ihm die Heimatbehörden die Reise in das Einflussgebiet der damals in Österreich verbotenen NSDAP. Der von ihm für den Kongress vorgesehene Beitrag über einen „Entwurf zur Geburtenregelung der
Zukunft" wurde aber im Verhandlungsband gedruckt, obwohl sich darin ein der NS-Ideologie konträres Plädoyer für das weibliche Recht auf Eigenverantwortlichkeit in Fragen der Kontrazeption findet. 1935 scheiterte August Mayer mit dem Versuch, den nun nach Prag berufenen, international angesehenen Knaus als Referenten zum Thema der „periodischen Fruchtbarkeit und Unfruchtbarkeit der Frau“ in das Programm zu nehmen, am Widerstand von NS-Funktionären. Bei der Veranstaltung selbst kam Knaus trotzdem in der Diskussion zu Wort, weil sich die Haltung ihm gegenüber innerhalb der NS-Polykratie kurzfristig geändert hatte. Auch 1937 bereicherte Knaus das Kongressprogramm durch mehrere Diskussionsbeiträge. Anfang der 1940er-Jahre geriet er - damals zeitweise Dekan der Medizinischen Fakultät an der Deutschen Universität Prag - unter anderem wegen eines negativen Gutachtens zu den OP-Ergebnissen des der Fakultät aufgezwungen ehemaligen Berliner Chirurgen Kurt Strauß erneut in die Mühlen der NS-Polykratie. Da er unter den Nationalsozialisten Gegner und Unterstützer hatte, blieb dies ohne gravierendere Folgen für ihn („Verwarnung“). Beim Kongress 1941 in Wien konnte er erfreut zur Kenntnis nehmen, dass seine Forderung nach Führung von exakten Menstruationskalendern von der UFK Königsberg unterstützt wurde. Knaus, der seine Erkenntnisse über die fruchtbaren Phasen im Zyklus nahezu zeitgleich, aber unabhängig von dem Japaner Kyūsaku Ogino gewonnen hatte, kehrte nach dem Zweiten Weltkrieg wieder nach Österreich zurück und war von 1950 bis 1960 Leiter der gynäkologischen Abteilung des Lainzer Krankenhauses in Wien. In seiner Prager Zeit hatte er Rufe auf Ordinariate nach Graz und Innsbruck abgelehnt. Die Methode der Geburtenkontrolle nach Knaus-Ogino, der Hans Albrecht auf dem Kongress 1933 den „natürlichen Charakter“ im pastoralmedizinischen Sinn abgesprochen hatte (Ersatz einer chemischen durch eine rechnerische Methode), wurde 1951 von der katholischen Kirche als Methode der Kontrazeption akzeptiert.

\section{Archivalische Quellen}

UAT 150/33,41.

\section{Gedruckte Quellen}

GK 1928, S.145; GK 1939, S. 244 f.; Siefert: Knaus (1979). Ebert/David: Knaus (2015).

\section{Lönne, Friedrich Karl \\ $\nabla$}

geb. 17.02.1891, Essen (?)

gest. 12.06.1958, Büderich bei Düsseldorf

Familie

Vater: Kaspar Lönne, Fabrikant; Mutter: Maria, geb. Werner

\section{Ausbildung \\ 1917 Approbation}

\section{Akademische Karriere}

1914 Promotion Dr. rer. pol.; 1916 Promotion Dr. med.; 1920 Habilitation in Geburtsh., Gyn. und Strahlentherapie (Göttingen); ab ca. 1920 PD (Göttingen); 1927 a.o. Prof. (Göttingen), Titel 1939 wegen Nichterfüllung des Lehrdeputats entzogen; 1940 Honorarprof. (Münster i.W.) 


\section{Weiterbildung und berufliche Karriere}

Gyn.-geburtsh. Weiterbildung an der Akadem. Frauenklinik Köln sowie an den UFK Bonn (v. Franqué) und Göttingen (Reifferscheid); 1922-1933 Chefarzt an der Vestischen Frauenklinik und Entbindungsanstalt Gelsenkirchen-Göttingen; ab 1933 Chefarzt am Theresienhospital Düsseldorf sowie Ltd. Arzt der dortigen geburtsh.-gyn. und strahlentherap. Klinik; 1934 Mitglied im Reichsausschuss für Krebsforschung; ab 1937 Krebsbeauftragter für den Gau Düsseldorf; nach dem 2. Weltkrieg Chefarzt der Frauenklinik und Entbindungsanstalt Rheydt (heute zu Mönchengladbach)

\section{NS-Organisationen \\ NSDAP; NSDÄB}

\section{Mitgliedschaft/Funktionen in der DGC}

1935-1937 Beisitzer; Vorträge: 1931, 1933, 1935, 1941

\section{Vita}

Friedrich Karl Lönne, ein Vertreter der habilitierten extrauniversitär tätigen Chefärzte in der DGG, war sozialgynäkologisch engagiert und verfasste das Kapitel „Soziologie der Frauenkrankheiten“ für Adolf Gottsteins „Handbuch der Sozialen Hygiene und Gesundheitsfuersorge“ (Bd 5, 1927). Zusammen mit dem langjährigen Königsberger Ordinarius Georg Winter muss er zu den Vorkämpfern einer institutionalisierten Krebsfrüherkennung in Deutschland gezählt werden. Während Winter bereits an der Schwelle zum 20. Jahrhundert in Ostpreußen mit breit angelegten Aufklärungsaktionen für Frauen, Hebammen sowie Ärzte begann und schließlich auch staatliche Förderung fand, setzte sich Lönne darüber hinaus gehend seit Beginn der 1930er-Jahre für eine gesetzliche Regelung ein. Dabei fand er die Unterstützung der DGG, zu deren besonders aktiven Mitgliedern er gehörte und die ihn 1937 als Beisitzer in den erweiterten Vorstand wählte.

Die von ihm formulierte „Lex Lönne“ - später ein Topos für die entsprechenden Bemühungen - stellte die erste Initiative der DGG bei der Zusammenarbeit mit den Machthabern im NS dar und fand auf der Tagung von 1933 in Berlin die Zustimmung der Mitglieder. Eine gesetzliche Regelung der Früherkennung war von Lönne zuvor schon in der „Münchener Medizinischen Wochenschrift" gefordert worden. Das Gesetz, dessen Intentionen 1941 auf dem DGG-Kongress erneut eine Rolle spielten, scheiterte allerdings am Widerstand der Chirurgen. 1937 nutzte Lönne den Kongress, um die DGG zur Verabschiedung einer Resolution zur Einführung von durch die Krankenkassen finanzierten Vorsorgeuntersuchungen in der Schwangerschaft zu veranlassen. Außerdem initiierte Lönne Ende 1939 zusammen mit Gustav Döderlein den massiven Widerstand der Gesellschaft gegen Bestrebungen der Reichsgesundheits- und Reichshebammenführung zur Einschränkung der ärztlichen Klinikgeburtshilfe zugunsten häuslicher Entbindungen durch Hebammen. Im Rahmen seiner Bemühungen um die Krebsfrüherkennung war Lönne offenbar so engagiert, dass er seine Lehrverpflichtungen in Göttingen nicht erfüllte, was zum Entzug des Professorentitels führte. Wegen seiner Verdienste entschädigte man ihn aber schon wenig später in Münster i.W. mit dem Titel eines Honorarprofessors.

\section{Archivalische Quellen}

BSB München, Nachlässe, Ana 691, Schwarzer Ordner.

\section{Gedruckte Quellen}

GK 1939, S. 292 f.; GW 1956, S. 164; Heitkötter: Geschichte (2012), CLXIIICLXVI; Ebert/David: Gynäkologen (2016).

\section{Martin, Eduard Balduin Karl Victor \\ $\nabla$}

geb. 17.01.1879, Berlin

gest. 23.10.1957, München

evangelisch

Familie

Vater: August Eduard Martin (14.07.1847-26.11.1933), zul. Ordinarius für Frauenheilkunde (Greifswald); Mutter: Maria Luise, geb. Neesen

œ1) Wilma, geb. Müller; ab 1932 getrennt, 14.05.1949 geschieden; 2) 25.05.1949: Margarete Lydia, geb. Rahm

Ausbildung

1903 Staatsexamen; 1904 Approbation

\section{Akademische Karriere}

1904 Promotion; 1912 Habilitation (Berlin); 31.08.1921 a.o. Prof. (Berlin)

\section{Weiterbildung und berufliche Karriere}

10.10.1905-30.09.1906 Ass. an der UFK Greifswald (bei seinem Vater August Eduard Martin); 01.12.1906-01.10.1912 Ass., später OA an der II. UFK Berlin (Charité) und an der I. UFK Berlin (jeweils bei Bumm); 1912 Niederlassung in Berlin; 1914-1918 Kriegsdienst; 1919-1936 Dir. der Hebammenlehranstalt Elberfeld; 1936 Rücktritt „aus persönlichen Gründen“, anschl. bis 1952 wieder Tätigkeit in privater Praxis

\section{NS-Organisationen}

1933-1934 NSDAP (ausgeschlossen wegen Zugehörigkeit zu einer Loge, Mitgliedsbeiträge weiterbezahlt)

\section{Mitgliedschaft/Funktionen in der DGG}

1920-1936 1. Schriftführer

\section{Archivalische Quellen}

LANRW, 110, Nr.1087, Bl. 44-50; ALVR, PA Martin, LVR 25617, 25626; BArch Berlin; GStAPK Berlin, R 86/5636 (n. p.); StadtA Mü, Sterbebücher 1957, Nr. 2313.

\section{Gedruckte Quellen}

GK 1928, S.177; GK 1939, S. 302 f.; GW 1956, S. 239 f; Blassing: Hebammenlehranstalt (2010).

\section{Martius, Heinrich Fedor Emil \\ $\nabla$}

geb. 02.01.1885, Berlin

gest. 17.02.1965, Göttingen

Familie

Vater: Friedrich Martius (1850-1923); Mutter: Martha, geb. Leonhard (1861) 
œ 1919: Berta (1894-1965), geb. Weinlig; 1 Tochter: Ella Maria Friederike (geb. 1919), 5 Söhne: u. a. Gerhardt (geb. 1924), Prof. der Gynäkologie; Alexander (geb. 1928), Diplomat

\section{Ausbildung}

1904 Abitur (Humanist. Gymnasium Rostock); Medizinstudium in Freiburg i. Br., Leipzig, Rostock; 17.04.1909 Staatsexamen

\section{Akademische Karriere}

26.06.1910 Promotion (Rostock); 06.10.1919 Habilitation (Bonn); 18.07.1922 a. o. Prof. (Bonn); 20.05.1926 o. Prof (Göttingen); 1954 Emeritierung

\section{Weiterbildung und berufliche Karriere}

Medizinalpraktikant am Eppendorfer KH in der Path. (E. Fraenkel) und Inn. Med. (Lenhartz); 4 Monate Schiffsarzt; 01.06.07.10.1912 chir. Ass. im Elisabeth-KH Berlin (Rinne); 01.01.1913-1925 Ass., später OA an der UFK Bonn (Franqué), unterbrochen von Kriegsdienst; 1926-1954 Dir. der UFK Göttingen

\section{Mitgliedschaft/Funktionen in der DGG}

1933-1949 Kassenwart; 1949-1951 Präsident; Ehrenmitglied; Vorträge: 1931, 1933, 1935, 1941, 1949

\section{Archivalische Quellen}

BArch Berlin, BDC, PK H 397, Bl. 18-38 (dort Bl. 26-38 eigenhändiger Lebenslauf und Publikationsverzeichnis); BArch Berlin, R 86/5635 (Beratungen zur Empfängnisverhütung).

\section{Gedruckte Quellen}

GK 1928, S. 178 f.; GK 1939, S. 304-306; GW 1956, S.129; Kirchhoff: Geburtstag (1965); Stürzbecher: Martius (1990); Hagene: Martius (2006); Martius: Deutschland (2002/2003); Ludwig: Martius (2006); Ebert/David: Martius (2015)

\section{Mayer, August}

geb. 28.06.1876, Felldorf

gest. 11.10.1968, Stuttgart

katholisch

Familie

Vater: Anton Mayer, Gutspächter; Mutter: Julie Mayer, geb. Löffler

unverheiratet

\section{Ausbildung}

Humanist. Gymnasium (Rottenburg, Rottweil); 1895 Abitur; 1895-1900 Medizinstudium (Tübingen, Freiburg i. Br., Gießen), unterbrochen von mehrmonatigem Militärdienst; 05.06.1900 Staatsexamen (Gießen)

\section{Akademische Karriere}

1900 Promotion (Gießen); 1908 Habilitation (Heidelberg, Tübingen); 1913 a. o. Prof. (Heidelberg, Tübingen); 1917 o. Prof. (Tübingen); 1949 Emeritierung

\section{Weiterbildung und berufliche Karriere}

1900 Volontärarzt am Path. Inst. Tübingen und Ass. bei einem prakt. Arzt in Mühlacker; 1901-1904 Ass. an der UFK Freiburg i. Br.; 1904 Volontärarzt an der Psychiat. UK Freiburg i. Br.; 1904/
05 Ass. an der gyn. Abt. des Vincentius-KH Freiburg i. Br.; 19051907 Volontärarzt an der UFK Heidelberg; 1907-1917 OA an der UFK Tübingen; 1917-1950 Dir. der UFK Tübingen; Ablehnung von Rufen nach Münster i.W. und Königsberg i. Pr.

NS-Organisationen

1933 SA; 1937 NSDAP

\section{Mitgliedschaft/Funktionen in der DGG}

1933-1935 1. Vorsitzender; 1935-1937 2. Vorsitzender; 1949 2. Vorsitzender (für den verstorbenen Hans Fuchs); Vorträge: 1931, 1937, 1941

Archivalische Quellen

UAT 150/33,41; BSB München, Nachlässe, Ana 691.

\section{Gedruckte Quellen}

GK 1928, S. 179-181; GK 1939, S. 307-312; GW 1956, S. 223; Klee: Personenlexikon (2003), S.397; Doneith: Mayer (2007); Bayer: „Frage“ (2008); Frobenius: BGGF-Ehrenmitglieder (2012), S. $130 \mathrm{f}$.

\section{Mikulicz-Radecki, Felix von}

geb. 17.07.1892, Breslau

gest. 27.03.1966, Sibichhausen am Starnberger See

Familie

Vater: Johann von Mikulicz-Radecki, Prof. für Chirurgie (Breslau)

œ Katharina, geb. Finzenhagen; 5 Kinder

Ausbildung

1911-1920 Medizinstudium (Paris, Bonn, Freiburg i. Br., Kiel), unterbrochen vom 1. Weltkrieg; 1920 Approbation (Kiel)

\section{Akademische Karriere}

1920 Promotion (Kiel); 1925 Habilitation (Leipzig); 1929 a.o. Prof. (Berlin); 1932-1945 o. Prof. (Königsberg i. Pr.); 1953 o. Prof. (FU Berlin); 1961 Emeritierung

\section{Weiterbildung und berufliche Karriere}

1920 Inn. Med. am UK Kiel (Schittenhelm); 1921 zunächst Gynäkopathologie an der I. UFK Berlin (R. Meyer); dann bis 1932 Ass., später OA bei Stoeckel an den UFK Kiel, Leipzig und Berlin; 19321945 Dir. der UFK Königsberg i. Pr.; nach Kriegsende prakt. Frauenarzt; Chefarzt am St. Franziskus-Hospital Flensburg und Gastprofessor in Kiel; 1953-1961 Dir. der UFK und der Städt. Frauenklinik Berlin-Charlottenburg

\section{NS-Organisationen}

01.05.1933 NSDAP; SA; NSDÄB; NSDDB

\section{Mitgliedschaft/Funktionen in der DGG}

1949 Beisitzer (1941 gewählt); Vorträge: 1933, 1935, 1937, 1941

\section{Gedruckte Quellen}

GK 1928, S.189; GK 1939, S.321-323; GW 1956, S.166; Zimmermann: Mikulicz-Radecki (1994); Czarnowski: „Beherrschung“ (2001); Klee: Personenlexikon (2003), S. $411 \mathrm{f}$. 


\section{Naujoks, Hans Christian}

$\nabla$

geb. 02.09.1892, Jessen (Kreis Insterburg)

gest. 29.09.1959, Frankfurt/Main

Familie

Vater: Landwirt

๑ Marilies, geb. Uffenorde; 4 Kinder

\section{Ausbildung}

Abitur (Insterburg); ab 1911 zunächst Studium der Mathematik und Naturwissenschaften (Königsberg i. Pr.); verm. ab 1912 Medizinstudium (Berlin, Königsberg i. Pr.); 08/1914-01/1919 freiwilliger Militärdienst; 09.10.1919 Staatsexamen (Rostock)

\section{Akademische Karriere}

11.10.1919 Promotion (Rostock); 1925 Habilitation (Königsberg i. Pr.); 12.04. 1929 a. o. Prof. (Marburg/Lahn); 1934 o. Prof. (Köln); 1937 Dekan der Med. Fak. Köln; 01.04.1945 o. Prof. (Marburg/ Lahn); 28.10.1945 Amtsenthebung durch die US-Militärbehörden; nach Entlastung im Spruchkammerverfahren (26.11.1946) ab 08/1947 bis zu seinem Tod 1959 o. Prof. (Frankfurt/Main)

\section{Weiterbildung und berufliche Karriere}

1919 Volontärarzt im Path. und Mikrobiolog. Inst. Königsberg i. Pr.; ab 1920 gyn.-geburtsh. Ausbildung zunächst an der Städt. Krankenanstalt, ab 1921 UFK Königsberg i. Pr. (G. Winter); 1926 Wechsel an die Univ. Marburg/Lahn (E. Kehrer), dort OA; ab 1934 Dir. der UFK Köln; 1945 Dir. der UFK Marburg/Lahn; ab 08/1947 bis zu seinem Tod 1959 Dir. der UFK Frankfurt/Main

\section{NS-Organisationen \\ 1933 NSDAP; SA; NSLB; NSDÄB; NSV}

\section{Mitgliedschaft/Funktionen in der DGG}

1936-1956 1. Schriftführer; 1956-1958 Präsident; Vorträge: 1933, 1935, 1937, 1941

\section{Archivalische Quellen}

BArch Berlin, BDC, DS B 036, 2658-2662; BSB München, Nachlässe, Ana 691.

\section{Gedruckte Quellen}

GK 1928, S. 194; GK 1939, S. 334-336; GW 1956, S. 167; Naujoks: Eingriffe (1934); Naujoks: Legalisierung (1934); Martius: Naujoks [Nachruf] (1960); Golczewski: Universitätslehrer (1988); Klee: Personenlexikon (2003) S. 428 f.; Schäfer/Mallmann: Alltag (2005); Franken: „Nationalsozialist“" (2008), S. 100-134, 189-191; Franken/Schäfer: Handeln (2011).

\section{Niedermeyer, Albert}

geb. 24.09.1888, Wien

gest. 22.03.1957, Wien

katholisch

Familie

Vater: Leopold Niedermeyer, Geschäftsmann; Mutter: Ernestine Caroline, geb. Schwarz œ1) 1918: Johanna, geb. Müller; 5 Kinder; 08/1940 verwitwet; 2) 02/1942: Paula, geb. Drescher

\section{Ausbildung}

1906 Matura (Wien); bis 1910 Studium der Naturwissenschaften und Philosophie; 1910-1912 Ass. des Zoologen Willy Georg Kükenthal (Breslau), dabei Beginn des Medizinstudiums (Breslau, Greifswald);1916 Approbation; bis 1924 Studium der Rechte als Externer mit regelmäßigen Präsenzphasen (Breslau)

\section{Akademische Karriere}

1910 Promotion Dr. phil. (Wien); 1916 Promotion Dr. med. (Breslau); 1924 Promotion Dr. jur. (Breslau); 1945 Habilitation für Pastoralmedizin an der Theolog. Fak. Wien; 1950 dort a. o. Prof.

\section{Weiterbildung und berufliche Karriere}

1914-1918 Militärdienst und Abkommandierung an die UK Breslau; 1918 Niederlassung in Schönberg (Oberlausitz) als prakt. Arzt und Geburtshelfer; zunehmende Spezialisierung in Geburtsh. und Gyn. durch regelmäßige Hospitationen an der UFK Breslau (Küstner, Fraenkel); 1927 Wechsel nach Görlitz und Facharztanerkennung; Kassenarztpraxis und operative Tätigkeit als Belegarzt; 1934 Rückkehr nach Wien; Leiter der Eheberatung und der Schwangerenfürsorge der Stadt Wien; im 2.Weltkrieg ärztliche Tätigkeit in Lazaretten in Wien; 1948 Eröffnung des Inst. für Pastoralmedizin an der Univ. Wien

\section{Gedruckte Quellen}

GK 1928, S. 199; Niedermeyer: Wahn (1956); Eben/Frewer: Ethik (2001).

\section{Internetquellen}

https://www.wien.gv.at/wiki/index.php/Albert_Niedermeyer\#tab= Personendaten

\section{Nürnberger, Ludwig}

geb. 17.07.1884, Aschbach bei Bamberg gest. 03.04.1959, München

evangelisch

Familie

Vater: Pfarrer und Kirchenrat

\section{Ausbildung}

1903 Abitur (Hof); ab 1904 Medizinstudium (Erlangen, München); 1908 Staatsexamen (München); 1910 Approbation

\section{Akademische Karriere}

1910 Promotion (München); 1919 Habilitation (lt. Nachruf); ab 1924 a. o. Prof. (Hamburg); 1926 o. Prof. (Halle/Saale); 10/1945 Entzug der Venia legendi, 04/1946 Wiedererteilung der Lehrbefugnis; ab 01.09.1947 o. Prof. (Köln); 1954 Emeritierung

\section{Weiterbildung und berufliche Karriere}

1910/11 Ass. am Path. Inst. Erlangen (Hauser); 1911-1919 Ass. an der UFK München (Döderlein); 1914/15 Truppen- und Lazarettarzt; 1919-1926 Sekundärarzt an der UFK Hamburg (Heynemann); ab 1924 a. o. Prof. (Hamburg); 1926-1945 o. Prof. (Halle/ Saale) und Leiter der UFK Halle/Saale; 10/1945 Entlassung; 04/ 
1946 Wiedererteilung der Lehrbefugnis auf Befehl der SMAD; 1947-1955 Leiter der UFK Köln

\section{NS-Organisationen \\ 1938 NSDAP (davor bis 1930 DNVP; ab 1945 LDP)}

Mitgliedschaft/Funktionen in der DGG

1937-1941 Beisitzer; Ehrenmitglied; Vorträge: 1931, 1937

\section{Vita}

Ludwig Nürnberger, Ehrenmitglied der DGGG, befasste sich bereits in den 1920er-Jahren intensiv mit der Diagnostik und Therapie von Sterilität. In einem Beitrag zu dem von Halban und Seitz herausgegebenen Handbuch „Biologie und Pathologie des Weibes“ vertrat er schon 1924 die Ansicht, dass die Ursachen unerfüllten Kinderwunsches etwa zu gleichen Teilen bei Frauen und Männern bzw. bei beiden liegen. Daraus ergab sich für ihn die Forderung, „nicht mehr sterile Frauen, sondern [...] sterile Ehen“ zu behandeln. Ferner setzte er sich ausführlich mit der Frage der Keimschädigung durch ionisierende Strahlung auseinander. In diesem Zusammenhang hatte er Anfang der 1930er-Jahre 2 große Auftritte bei Tagungen der Bayerischen Gesellschaft für Geburtshilfe und Frauenheilkunde (BGGF). Damals standen die therapeutische „temporäre Sterilisierung“ durch Röntgenstrahlung sowie dazu kritische Resolutionen erbwissenschaftlicher und eugenischer Fachgesellschaften im Mittelpunkt. Die NS-Eugenik hat Nürnberger zweifellos unterstützt: An seiner Klinik in Halle wurden zwischen 1934 und 1945 insgesamt 1417 Zwangssterilisationen vorgenommen, davon 86 kombiniert mit einer Abtreibung. Drei Frauen starben nach der Operation. In mindestens einem Fall lässt sich nachvollziehen, dass die für die Abtreibung auch nach dem GzVeN nötige Zustimmung der betroffenen Frau nicht eingeholt wurde.

\section{Archivalische Quellen}

UAHW, Rep. 11, PA 5632 (Nürnberger), Rep. 6, Nr. 1407; Leopoldina, MM 3773.

\section{Gedruckte Quellen}

GK 1928, S. 201 f.; GK 1939, S. 347; GW 1956, S. 132; Fikentscher: Nürnberger [Nachruf] (1959); Semm: Einfluß (1986), S. 268; Grimm: Zwangssterilisation (2004); Frobenius: Strahlentherapie (2012).

Internetquellen

http://www.catalogus-professorum-halensis.de/nuernbergerludwig.html

\section{Olow, John}

geb. 30.12.1883, Malmö

gest. 09.11.1948

Ausbildung

1902 Abitur (Malmö); 1910 Approbation

\section{Akademische Karriere}

1913 Promotion; 1923 Prof. (Uppsala); 1931/33 Prof. (Stockholm)

Mitgliedschaft/Funktionen in der DGG

1937-1941 Beisitzer

\section{Gedruckte Quellen}

Nordisk familjebok. Konversationslexikon och realencyklopedi. Ny, rev. och rikt illustrerad uppl. 37. Bandet, Supplement L-Riksdag, Stockholm: Nordisk familjeboks förlags aktiebolag 1925, Sp. 905

\section{Internetquellen}

http://runeberg.org/nfcq/0501.html (Digitalisat von Nordisk familjebok, 37 (1925), Sp. 905)

\section{Ottow, Benno}

geb. 14.05.1884, Insel Dagö/Hiiumaa in Kärdla (Estland) gest. 29.05.1957, Stockholm

\section{Familie}

Vater: Richard Ottow, Arzt; Mutter: Adelheid Amalie, geb. Tobien

œ Elisabeth, geb. von Mühlendahl

\section{Ausbildung}

ab 08/1904 Medizinstudium (Jurjew/Dorpat, Rostock), mit Unterbrechungen u.a. wegen der russischen Revolution; 1911 Staatsexamen

\section{Akademische Karriere}

1920 Promotion (Tartu/Dorpat); 1920-1924 PD (Tartu); 1928 PD (Berlin); 1931 a.o. Prof. (Berlin)

\section{Weiterbildung und berufliche Karriere}

ab 1912 „specialärztliche Ausbildung“ an den UFK Berlin (Bumm, Franz), Kiel (Stoeckel) und Dresden, unterbrochen von ärztlicher Tätigkeit im russischen (1914-1917) und estnischen (1919/20) Heer; ab 11/1925 wieder Ass. bei Stoeckel, zunächst an der UFK Leipzig, dann an der I. UFK Berlin; 1933-1945 Dir. der Brandenburg. Landesfrauenklinik Berlin-Neukölln; 1945 Beendigung der ärztl. Laufbahn und Emigration nach Stockholm; bis zur Pensionierung 1958 wiss. Mitarbeiter des Naturhist. Reichsmuseums Stockholm

\section{NS-Organisationen}

01.03.1932 NSDAP; NSDÄB; NSDDB; Hauptamt für Volksgesundheit der NSDAP; Rassenpolitisches Amt der NSDAP

\section{Mitgliedschaft/Funktionen in der DGG} Vorträge: 1935, 1937

\section{Vita}

Der deutsch-baltische Frauenarzt, Medizinhistoriker und Naturwissenschaftler Benno Ottow, im „Dritten Reich“ einer der engagiertesten ärztlichen Vollstrecker des GzVeN, gehört zu den Assistenten, auf die Walter Stoeckel besonders große Stücke hielt. Er sah in Ottow denjenigen Schüler, der „die gynäkologische Urologie in ihrem ganzen Umfang am besten wissenschaftlich und praktisch beherrscht". Ottow übernahm 1933 den Posten des von den Nazis verdrängten „Nichtariers“ Sigfrid Hammerschlag als Direktor der Brandenburgischen Landesfrauenklinik BerlinNeukölln. Dort hatte Ottow zwischen 1934 und 1938 über 1600 Zwangssterilisationen zu verantworten und verfügte damit nach dem Urteil eines prominenten Fachkollegen „über die wohl größte klinische Erfahrung“ in diesem Bereich. Ottow publizierte diese Erfahrungen detailliert und referierte darüber auch vor der DGG. Neben der Erörterung operationstechnischer Fragen ent- 
hielten seine Veröffentlichungen praktische Ratschläge dazu, wie der Widerstand von Zwangssterilisandinnen am besten zu unterlaufen sei. Ottow sprach sich bei den Sterilisationen für komplette Entfernung der Eileiter aus und plädierte sogar dafür, dieses radikale Vorgehen als Kommentar dem $\S 1$ des GzVeN hinzuzufügen. Ferner war Ottow Mitglied des Berliner Erbgesundheitsgerichtes und erarbeitete entsprechende Gutachten. Nach Kriegsende gab er die ärztliche Tätigkeit völlig auf, emigrierte nach Schweden und wurde in Stockholm bis 1958 als Mitarbeiter des Naturhistorischen Reichsmuseums nach dem Urteil eines Vorgesetzten ein „Gewinn für die schwedische Wissenschaft“. Ottow hat eine von Umfang und thematischer Breite her eindrucksvolle Publikationsliste hinterlassen.

\section{Gedruckte Quellen}

GK 1928, S. 205; GK 1939, S. 355 f.; GW 1956, S. 168; Stoeckel: Erinnerungen (1966), S.219; Hinz-Wessels: NS-Erbgesundheitsgerichte (2004); Czarnowski: „Volkswachstum“ (2008), S. 141-150; Hansson/Peters u. a.: Sterilisierungsoperateur (2011).

\section{Philipp, Ernst}

$\nabla$

geb. 22.10.1893, Münsterberg (Niederschlesien)

gest. 24.12.1961, Kiel

Familie

Vater: Höherer Beamter

verheiratet; Kinder

\section{Ausbildung}

1912 Abitur (Magdeburg); 1912-1920 Medizinstudium (Berlin), unterbrochen durch den Kriegsdienst (1914-1918); 1919 Freikorps (u.a. Bataillonsarzt im Freikorps v. Oven); 1920 Approbation (Berlin)

\section{Akademische Karriere}

1920 Promotion (Berlin); 1928 Habilitation (Berlin); 1933 a.o. Prof. (Berlin); 1934 o. Prof. (Greifswald); 1937-1961 o. Prof. (Kiel); 1943-1945 Dekan der Med. Fak. Kiel

\section{Weiterbildung und berufliche Karriere}

kurzfristig prakt. Arzt in Wanzleben bei Magdeburg; 1921-1925 Ass. an der I. UFK Berlin (Bumm, Stoeckel); 1928/29 Studienaufenthalt an der Johns-Hopkins-Univ. (Baltimore) als Fellow der Rockefeller Foundation; 1932 OA an der I. UFK Berlin (Stoeckel); 1934 Dir. der UFK Greifswald; 1937-1961 Dir. der UFK Kiel

\section{NS-Organisationen}

1933 NSDAP; 1933 SA; 1937 kurzfristig Leiter der Dozentenschaft und Dozentenbundführer der Univ. Greifswald; in Kiel stellv. Dozentenbundsführer und Ehrenrichter; 1944 Mitglied im wiss. Beirat von Karl Brandt

\section{Mitgliedschaft/Funktionen in der DGG}

1949 Beisitzer (1941 gewählt); 1959-1961 Präsident; Vorträge: 1933, 1935, 1937, 1941

\section{Vita}

Ernst Philipp, nach dem Zweiten Weltkrieg zunächst Beisitzer und später Präsident der DGG, war einer der Lieblingsschüler Walter Stoeckels. Er blieb seinem Lehrer auch nach Übernahme der Ordinariate in Greifswald (1934) und Kiel (1937) lebenslang freundschaftlich verbunden. Philipp gehört zu den Hochschullehrern, die im Nationalsozialismus Karriere machten und sich systemkonform verhielten. Nach Teilnahme am Ersten Weltkrieg hatte er sich 1919 in Freikorps engagiert und eigenen Angaben zufolge seit 1931 stets NSDAP gewählt, war der Partei jedoch erst 1933 beigetreten.

Besonders hoch schätzte Stoeckel die Arbeiten von Philipp über die hormonelle Aktivität der Plazenta ein, die in den 1930er-Jahren entstanden sind und deren Bedeutung im Kontext der zeitgenössischen Endokrinologie-Forschung bisher nur unzureichend untersucht ist. Weitere Schwerpunkte der wissenschaftlichen Arbeit Philipps waren die Infektiologie und die Endometriose. Stoeckel hat Philipp 1957 sogar für den Medizin-Nobelpreis vorgeschlagen, als das Osloer Komitee ihn aufforderte, einen Kandidaten zu benennen.

Neben seiner Mitgliedschaft in der NSDAP gehörte Philipp ab 1933 auch der SA an. Zeitweise bekleidete er Ämter in hochschulpolitischen NS-Organisationen. Unter seinem Direktorat wurde in Greifswald mit den Zwangsterilisationen begonnen. Publikationen zu NS-spezifischen Themen sind von ihm nicht bekannt abgesehen von einem nicht auffindbaren Artikel über die „Stellung der Hebamme zum Sterilisierungsgesetz“. In Kiel fand die Fakultät unter seinem Dekanat zwischen 1943 und 1945 zunehmend vom Führer- zum Kollegialitätsprinzip zurück. Allerdings verantwortete er offensichtlich im Alleingang die Annahme einer extrem rassistischen Dissertation sowie deren Bewertung mit der Note „sehr gut“. 1944 wurde Philipp, wie auch sein Lehrer Stoeckel, in den wissenschaftlichen Beirat des ranghöchsten NSMediziners, Karl Brandt, berufen. Philipp leitete die Kieler UFK politisch unangefochten bis zu seinem Tod 1961. Allerdings fehlt sein Name in den ersten Nachkriegs-Vorlesungsverzeichnissen bis zum Sommersemester 1947.

\section{Gedruckte Quellen}

GK 1928, S. 211; GK 1939, S. 365-367; GW 1956, S. 169; Stoeckel: Erinnerungen (1966), S. 598; Klee: Personenlexikon (2003), S. 460; Grüttner: Lexikon (2004), S. 129 f.; Jonat/Andree u. a. (Hrsg.): Kiel (2005), S. 42-45; Cornelissen/Mish (Hrsg.): Wissenschaft (2009); Köhler: Achse (2010), S. 59 f.; Ratschko: Hochschulmediziner (2014); Eberle: „Instrument" (2015).

\section{Rech, Walter}

geb. 08.10.1896, Köln

gest. 21.09.1975, München

katholisch

Familie

Vater: Jakob Rech, Gynäkologe

๑1) Marie Gertrud, geb. Quincke; 1934 geschieden; 2) Renate; 3 Kinder

\section{Ausbildung}

1914-1920 Medizinstudium (Heidelberg, Bonn), unterbrochen durch Kriegsdienst; 1921 Approbation (Heidelberg) 
Akademische Karriere

1921 Promotion (Heidelberg); 1929 Habilitation (Heidelberg); 1936 a. o. Prof.; 1946-1949 Lehrstuhlvertreter in Erlangen

\section{Weiterbildung und berufliche Karriere}

1921/22 Path. Inst. Heidelberg; 1922-1924 Physiolog. Inst. Würzburg (v. Frey); 1924-1934 Ass. an der UFK Heidelberg (Menge, Eymer); 1934-1945 I. OA an der UFK München (Eymer); 1936 a. o. Prof.; 1946-1949 komm. Dir. der UFK Erlangen; ab 1950 wieder OA an der I. UFK München; 1961 Ruhestand

\section{NS-Organisationen 1939 NSDAP}

\section{Mitgliedschaft/Funktionen in der DGG}

1941 zum 2. Schriftführer berufen; Vorträge: 1931, 1933, 1935, 1941

\section{Vita}

Walter Rech, Schüler von Carl Menge in Heidelberg sowie langjähriger Assistent und Oberarzt von Heinrich Eymer in Heidelberg und München, gehört offensichtlich zu den Hochschullehrern der Gynäkologie und Geburtshilfe, die sich im „Dritten Reich" politisch vergleichsweise wenig angepasst haben. Jedenfalls äußerte sich die NS-Dozentenschaft mehrfach kritisch zu seinem Engagement für die Ziele der Partei und beklagte, von Rech würden in der Klinik „oft genug andere Volontäre mehr gefördert als gerade unser nationalsozialistischer Nachwuchs". Trotzdem erscheint er als der große Verlierer bei der Wiederbesetzung der gynäkologisch-geburtshilflichen Ordinariate in Bayern nach 1945: Von den Amerikanern ursprünglich für die Eymer-Nachfolge in München ins Kalkül gezogen, ging er von 1946 bis 1949 als kommissarischer Klinikchef nach Erlangen. Auch für den Lehrstuhl in Würzburg als Nachfolger von Gauß stand er auf der Berufungsliste. Trotz zahlreicher Versprechungen fand sich Rech schließlich - aufgerieben durch vielerlei Intrigen - 1950 in München auf seiner alten Position wieder. Es half ihm nichts mehr, dass er in diesem Jahr auch noch einmal auf einer Liste für die Besetzung der II. Münchner Frauenklinik auftauchte. Zu den Vorwürfen, mit denen sich Rech konfrontiert sah, gehörte die schon 1945 widerlegte Behauptung, er habe sich aus rassistischen Gründen 1933 von seiner ersten Ehefrau getrennt, die daraufhin zusammen mit ihrer Tochter in ein $\mathrm{KZ}$ gebracht worden sei. Allerdings hat er sich offensichtlich an den eugenischen Zwangsmaßnahmen in der Eymer'schen Klinik beteiligt: 1935 berichtete Rech auf dem Kongress der DGG über die dort überwiegend angewandte Sterilisationstechnik nach Menge.

1941 war Rech von Rudolf Theodor von Jaschke als 2. Schriftführer vorgeschlagen worden. Die für Oktober 1943 in München geplante DGG-Tagung, die Rech als dort ansässiger Oberarzt maßgeblich organisiert hätte, kam jedoch kriegsbedingt nicht zustande. Erst 1949 konnte wieder ein Kongress stattfinden - allerdings nicht in München, sondern in Karlsruhe. Das Amt des 2. Schriftführers übernahm einer der Schüler Jaschkes, Hans Roemer aus Gießen.

\section{Gedruckte Quellen}

GK 1928, S. 219; GK 1939, S. 378; GW 1956, S. 204; Der Spiegel 29/1950, S. 6-9; Erlanger Nachrichten (08./09.09.1950, 06. 10.1950); Erlanger Tagblatt (08.09.1950); Wittern-Sterzel (Hrsg.): Professoren (1999), S. 148; Anthuber/Beckmann u. a. (Hrsg.): Herausforderungen (2012), S. 312 f.; Frobenius: Wiederbesetzung (2012).

\section{Roemer, Hans}

$\nabla$

geb. 23.12.1907, Illenau bei Achern gest. 30.04.1973, Tübingen

\section{Ausbildung}

1928 Abitur (Karlsruhe); ab 1928 Medizinstudium (Wien, Heidelberg, Halle/Saale); 1934 Approbation (Heidelberg)

\section{Akademische Karriere}

1933 Promotion (Heidelberg); 1940 Habilitation (Gießen); 1951 apl. Prof. (Gießen); 1952 o. Prof. (Gießen); 1956 o. Prof. (Tübingen); 1972 Emeritierung

\section{Weiterbildung und berufliche Karriere}

1933/34 Med. UK Halle/Saale (Brugsch); 1934/35 Univ.-Nervenklinik Marburg/Lahn (Kretschmer) und I. UFK München (Eymer); ab 1935 zunächst Ass., dann OA (1942) an der UFK Gießen (v. Jaschke); 1946-1952 Dir. der Frauenklinik Karlsruhe; 1952-1956 Dir. der UFK Gießen; 1956-1972 Dir. der UFK Tübingen

\section{Mitgliedschaft/Funktionen in der DGG}

1949 2. Schriftführer; Vortrag: 1949

\section{Vita}

Hans Roemer, ein Schüler von Jaschkes aus dessen Gießener Tagen, diente dem ersten Nachkriegskongress der DGG in Karlsruhe als 2. Schriftführer. Seine Person dürfte nicht nur für die Organisation, sondern auch für die Wahl des Kongressortes von nicht unerheblicher Bedeutung gewesen sein: er war nämlich seit 1946 Direktor der örtlichen Frauenklinik und verfügte damit über die nötigen Beziehungen und das Personal, um unter den schwierigen Nachkriegsbedingungen einen reibungslosen Tagungsablauf zu gewährleisten. Etwas erstaunlich ist allerdings in diesem Zusammenhang, dass von Jaschke in seiner Eröffnungsrede zwar dem Oberbürgermeister der Stadt, nicht aber seinem 2. Schriftführer für die Unterstützung dankte. Roemer, der auf dem Kongress auch ein größeres Referat über „Die Klinik der Laktation" hielt, machte später weiter Karriere als Ordinarius zunächst in Gießen und dann in Tübingen. Sein Name ist mit der Entwicklung der Psychosomatik in der Frauenheilkunde eng verknüpft. Außerdem gehörte er zu den ersten deutschen Frauenärzten, von denen die Methode der „angstfreien Geburt“ nach Grantly Dick Read praktiziert wurde - ein Umstand, der auf die Tübinger Geburtshilfe großen Einfluss hatte. Die von ihm gegründete Hans-Roemer-Stiftung schreibt noch heute einen Preis für die wissenschaftliche Arbeit aus, mit der die Integration psychosomatischer Fragestellungen in die Allgemeinmedizin oder in die klinischen Fächer der Medizin am besten gefördert wird. Im Nationalsozialismus dürfte Hans Roemer an den in der Gießener Klinik unter der Leitung von Jaschkes durchgeführten mindesten 634 Zwangssterilisationen beteiligt gewesen sein.

\section{Gedruckte Quellen}

GK 1939, S. 392; GK 1960, S. 415 f.; Prill: Entwicklung (1986); Grüßner: Roemer (1989); Frobenius: Frauenklinik (2015).

Archivalische Quellen

UAT 193/68, Personalakte Roemer. 


\section{Rooy, Adrianus Henricus Maria Josephus van}

geb. 27.12.1880, Rotterdam

gest. 24.11.1937, Nijmegen

\section{Ausbildung \\ 1897-1903 Medizinstudium (Amsterdam); 1904 Approbation}

\section{Weiterbildung und berufliche Karriere}

ab 1904 Ass. an der chir. Klinik Rotterdam (v. Stockum); 19061909 Ass. an der Univ. Amsterdam (Treub); 1910 Niederlassung als Gynäkologe in Rotterdam; 1918 Leiter der Frauenklinik der Joanna-van-Lynden-Stiftung; 1920 Prof. (Amsterdam)

\section{Akademische Karriere}

22.07.1911 Promotion (Gent); 03.11.1920 Habilitation (Amsterdam); 1920 Prof. (Amsterdam)

\section{Mitgliedschaft/Funktionen in der DGG}

1937 zum Beisitzer gewählt, kurz darauf verstorben

\section{Gedruckte Quellen}

Tongeren: Rooy [Nachruf] (1938).

\section{Runge, Hans \\ $\nabla$}

geb. 18.04.1892, Neustrelitz (Mecklenburg)

gest. 16.10.1964, München

Familie

Vater: Carl Runge; Mutter: Käthe, geb. Giese

\section{Ausbildung}

Medizinstudium in Tübingen, Leipzig und Rostock; 1919 Staatsexamen/Approbation (Rostock)

\section{Akademische Karriere}

1920 Promotion (Rostock); 1924 Habilitation (Kiel); 1928 a.o. Prof. (Kiel); 1932 o. Prof. (Greifswald); 1934 o. Prof. (Heidelberg)

\section{Weiterbildung und berufliche Karriere}

1919 Path. Inst. Rostock (Schwalbe); 1920 Univ.-Kinderklinik Rostock; 1920/21 Hebammenlehranstalt Elberfeld (Martin); 1921/22 UFK Rostock (Sarwey); 1922-1932 UFK Kiel (R. Schröder), unterbrochen von einem Aufenthalt am Kaiser-WilhelmInst. für physikal. Chemie in Berlin-Dahlem (1924/25); ab 1932 Dir. der UFK Greifswald, ab 1934 Dir. der UFK Heidelberg; 19371939 Dekan der Med. Fak. Heidelberg; nach der Besetzung Frankreichs 1940 mit dem Aufbau der Med. Fak. an der „Reichsuniversität“ Straßburg betraut; 1945-1964 (mit einer kurzen Unterbrechung) Leiter der UFK Heidelberg

\section{NS-Organisationen}

1933 NSDAP; 1933 SA

\section{Mitgliedschaft/Funktionen in der DGG}

1954-1956 Präsident; Ehrenmitglied; Vorträge: 1933, 1937, 1941
Vita

Hans Runge, von 1954 bis 1956 Präsident der DGG und später zum Ehrenmitglied ernannt, gehörte zu den überzeugten Nationalsozialisten in der Gesellschaft. 1933 trat er als Ordinarius in Greifswald mit allen Assistenten geschlossen in die NSDAP ein; auch in Heidelberg waren unter seinem Direktorat ab 1934 fast alle ärztlichen Mitarbeiter Mitglieder der Partei oder einer ihrer Organisationen. Runge unterstützte die Ziele der NS-Eugenik. An der UFK Heidelberg nahmen die Ärzte allein 1935 mehr als 500 Zwangssterilisationen vor; hinzu kamen bis August 193510 eugenische Abtreibungen. Während seiner Tätigkeit als Dekan zwischen 1937 und 1939 wurde an der Fakultät die „Neue Deutsche Heilkunde“ etabliert. Bei einem Kongress der RAG „Mutter und Kind“ 1937 in Berlin vermied er eine Konfrontation mit dem späteren Reichsgesundheitsführer Leonardo Conti in der mit der DGG strittigen Frage des Stellenwerts der Hausgeburtshilfe. Die Karriere von Runge, die trotz einer kurzzeitigen Einstufung als „ardent Nazi“ durch die Amerikaner 1945 nahezu ungebrochen verlief und mit dem DGG-Präsidentenamt und der Ehrenmitgliedschaft sogar weitere Höhen erreichte, ist ein Beispiel für die Kontinuitäten zwischen der NS-Zeit und der Nachkriegsgesellschaft. 1964 wurde Runge während der Tagung der DGG in München Opfer eines Verkehrsunfalls.

\section{Gedruckte Quellen}

GK 1928, S. 229; GK 1939, S. 401-403; GW 1956, S. 242; Bröer: Frauenheilkunde (2004); Eckart: Medizin (2012), S. 255-259.

\section{Schröder, Robert}

geb. 03.08.1884, Rostock gest. 13.10.1959, Leipzig

evangelisch-lutherisch

Familie

Vater: Robert Schröder, Kaufmann und Schiffskapitän; Mutter: Helmine, geb. Arppe

ఐ Ella, geb. Burchard

\section{Ausbildung}

1903 Abitur (Rostock); 1903-1908 Medizinstudium (Rostock, Freiburg i. Br., Berlin); 1909 Approbation

\section{Akademische Karriere}

1909 Promotion (Rostock); 1914 Habilitation (Rostock); 1914 PD (Rostock); 1919 a.o. Prof. (Rostock); 1922 o. Prof. (Kiel); SS1934 und WS1935 Dekan der Med. Fak. Kiel; 1936 o. Prof. (Leipzig); 1937-1940 Dekan Med. Fak. Leipzig; 1956 Emeritierung

\section{Weiterbildung und berufliche Karriere}

1908/09 Medizinalprakt. Inn. Med. Heidelberg, Path. Inst. Rostock (Schwalbe); 1909/10 Ass. am Path. Inst. Rostock; 1910/11 Ass. am Path. Inst. der Akademie für Prakt. Med. Köln-Lindenau (Jores); 1911-1922 UFK Rostock (Sarwey), ab 1914 als OA; 1914-1918 Kriegsdienst; 1922-1936 Dir. der UFK Kiel; 1936-1956 Dir. der UFK Leipzig (1945-1947 teilweise als Hochschullehrer sowie Klinikdirektor suspendiert und nur in Klinik sowie Forschung tätig) 
NS-Organisationen

1933 NSDAP; 1934 NSDÄB; 1935 NSDDB; NSV; NS-Altherrenbund

\section{Mitgliedschaft/Funktionen in der DGG}

1949 Beisitzer (1941 gewählt); 1952-1954 Präsident; Ehrenmitglied; Vorträge: 1931, 1933

\section{Vita}

Robert Schröder, Präsident und Ehrenmitglied der DGG, gehört zu den bedeutenden, auch international hoch angesehenen deutschen Gynäkologen. Im Nationalsozialismus agierte er nach einer neueren Untersuchung ab 1933 zwar als überzeugter Parteigenosse, bemühte sich aber in seiner Stellung als Dekan der Medizinischen Fakultät der Universität Kiel, die Interessen der Universität gegenüber Ansprüchen der Politik durchzusetzen. Die Vorgaben der NS-Eugenik setzte er in seiner Klinik um, obwohl er sich ursprünglich gegen Zwang bei Sterilisationen ausgesprochen hatte.

Schröders hohes wissenschaftliches Ansehen gründet vor allem auf histomorphologischen Arbeiten. Die wichtigsten davon entstanden in den ersten beiden Dekaden des 20. Jahrhunderts im Anschluss an die Erstbeschreibung des zyklischen Wandels des Endometriums durch Hitschmann und Adler (1907/08). Schröder ergänzte sie durch die Erkenntnis, dass die Mucosa uteri aus einer Basalis und einer Funktionalis besteht, wobei nur letztere in der Menstruation abgestoßen wird und sich dann wieder aus der Basalis regeneriert. Die im Intermenstruum entstehenden typischen Bilder der Proliferations- und Sekretionsphase korrelierte Schröder als erster mit den dazugehörigen Veränderungen im Ovar. Aufgrund seiner Beobachtungen vermutete er bereits einen Zusammenhang zwischen der Hyperplasie des Endometriums und einer Persistenz des ovariellen Follikels. Möglich wurden die Entdeckungen Schröders durch die akribische Sammlung, Aufarbeitung und Katalogisierung aller einschlägigen Operationspräparate der Kliniken, in denen er wirkte.

Zwischen April 1934 und April 1936 wurden in der UFK Kiel 315 Zwangssterilisationen durchgeführt. Operateure waren vor allem Schröder und sein Oberarzt Robert Kessler. 1936 nahm Schröder einen Ruf nach Leipzig an, offenbar weil ihm der NS-Einfluss in der Kieler Fakultät zu stark wurde. Von 1937 bis 1940 war Schröder dann Dekan der Medizinischen Fakultät in Leipzig. Ämter in der DGG hat er erst in der Zeit nach dem Zweiten Weltkrieg bekleidet. Die DDR zeichnete ihn mit dem Nationalpreis II. Klasse (1949) und mit dem Vaterländischen Verdienstorden aus (1954). In einem Nachruf von Hans Runge heißt es: „Wir nehmen Abschied von einem Mann, dessen vorbildliche soziale und humanitäre Haltung niemals durch äußere Ereignisse geändert werden konnte.

\section{Gedruckte Quellen}

GK 1928, S. 248 f.; GK 1939, S. 429-431; Runge: Gedenken [Nachruf] (1960); O'Dowd/Philipp: History (1994), S. 71,298, 572; Jonat/Andree u. a. (Hrsg.): Kiel (2005), S. 39-41; Piechatzeck, Jana: Auswirkungen (2009); Ratschko: Hochschulmediziner (2014).

\section{Internetquellen}

https://www.uni-leipzig.de/unigeschichte/professorenkatalog/leipzig/ Schroeder_536/; http://www.bundesstiftung-aufarbeitung.de/wer-warwer-in-der-ddr-\%2363\%3B-1424.html?ID=3161

\section{Schubert, Gotthard \\ $\nabla$}

geb. 21.12.1875, Petrigau

gest. 1939, Bad Ischl

\section{Ausbildung}

1903 Approbation (Breslau)

\section{Akademische Karriere}

1904 Promotion (Breslau)

\section{Weiterbildung und berufliche Karriere}

1903-1909 Path. Inst. Breslau (Ponfick); chir. Station WenzelHancke'sches KH Breslau (Heintze); UFK Breslau (O. Küstner); später Praxis in Beuthen/Oberschlesien

\section{Mitgliedschaft/Funktionen in der DGG}

1933-1935 Beisitzer

Archivalische Quellen

BArch Berlin, R 4901/1347.

\section{Gedruckte Quellen}

GK 1928, S. 249 f.; GK 1939, S. 432 f.; GW 1956, S. 171; Stoeckel: Schubert [Nachruf] (1939).

\section{Schultze, Günter Karl Friedrich \\ $\nabla$}

geb. 24.08.1896, Heringsdorf (Pommern)

gest. 01.05.1945, Greifswald [Suizid]

Familie

Vater: Lederwarenfabrikant

œ Margarete

\section{Ausbildung}

1913 Abitur; anschl. militärische Ausbildung in einem Dragonerregiment; 1914-1918 Kriegsdienst; ab 1919 Medizinstudium (Berlin, Heidelberg), unterbrochen von Dienst im Freikorps „Brigade Ehrhardt“; 1922 Approbation

\section{Akademische Karriere}

1923 Promotion (Berlin); 1930 Habilitation (Berlin); 1937 a.o. Prof. (Berlin); 1938-1945 o. Prof. (Greifswald)

\section{Weiterbildung und berufliche Karriere}

1923-1933 Ass. an der I. UFK Berlin (Bumm, Stoeckel); ab 1933 OA, ab 01.10.1938 Dir. der UFK Greifswald und Leiter der dortigen Hebammenschule

\section{NS-Organisationen}

1933 NSDAP; 1934 SS (bis 1938 Aufstieg zum Brigadeführer); Obmann des NSDDB an der Univ. Berlin; 1939 Referent des NSDDB an der Univ. Greifswald; Berater des NS-Vereins „Lebensborn e.V."

Mitgliedschaft/Funktionen in der DGG

Vorträge: 1931, 1933, 1935, 1937, 1941 


\section{Vita}

Der 1896 in Heringsdorf geborene Stoeckel-Schüler Günter K.F. Schultze, in der DGG einfaches Mitglied ohne Amt, galt in den 1930er- und 1940er-Jahren als Koryphäe in der Sterilitätsdiagnostik und -therapie. Er spielte deshalb in der NS-Rassenpolitik eine Rolle, die noch weiterer Aufklärung harrt. So taucht sein Name mehrfach im Zusammenhang mit Aktivitäten des Reichsarztes-SS, Ernst Grawitz, auf, der für Menschenversuche in den Konzentrationslagern verantwortlich war. Bisher erscheint es jedoch eher so, als wäre Schultze daran nicht beteiligt gewesen.

Eine für die wissenschaftlichen und therapeutischen Bemühungen Schultzes wesentliche Methode war die Hysterosalpingografie, die er über viele Jahre evaluierte und zu einem Standardverfahren in der Röntgendiagnostik des inneren Genitale ausbaute. Die entsprechenden Kenntnisse und Erfahrungen, die auch mit Untersuchungen ohne Einverständnis der Patientinnen erworben sein dürften, sammelte er an der I. UFK Berlin, wo er 1923 von Ernst Bumm eingestellt und nach dessen Tod von Walter Stoeckel übernommen worden war. Nach seiner Berufung zum Ordinarius in Greifswald baute er die dortige UFK zu einem Zentrum für Sterilitätsbehandlung aus. In Diagnostik und Therapie steriler Paare legte er großen Wert auf die - damals durchaus noch nicht selbstverständliche - Einbeziehung der Männer, deren Beteiligung an dem Problem er an einem großen Kollektiv nachgewiesen hatte. Sehr zum Missvergnügen seines Mentors Stoeckel gehörte auch die homologe und die heterologe Insemination zum Spektrum seiner Behandlungsmethoden.

Über seinen beruflichen und politischen Hintergrund konnte Schultze sich in wesentlichen Teilen mit der NS-Ideologie identifizieren. Neben seiner systemkonformen pronatalistischen Tätigkeit war er auch ein Befürworter der Zwangssterilisationen und engagierte sich nach der Machtübernahme zusätzlich parteipolitisch. Im Zusammenhang mit den Sterilisationen forderte er den routinemäßigen Einsatz der Salpingografie vor jedem Eingriff, um Frauen mit Hinweisen auf einen vorbestehenden Eileiterverschluss vor der Operation zu identifizieren und ihnen so unter Umständen den Eingriff zu ersparen.

Schultzes Verbindung zum Reichsarzt-SS Ernst Grawitz beruht auf 2 spärlichen archivalischen Hinweisen. Danach hat er zum einen 1942 zusammen mit Grawitz auf Anregung des Reichsführers-SS über „Mensesbeginn und Fruchtbarkeitsdauer“ einen Bericht erstattet. Zum anderen wird auf eine 1941 von Grawitz erstellte Liste „der mit der Behandlung weiblicher Unfruchtbarkeit nach der Methode Prof. Clauberg beauftragten Fachkräfte“ verwiesen, in der neben dem Grazer Ordinarius Ehrhardt auch der Name von Schultze auftaucht. Bei Klee heißt es dazu: „Es darf angenommen werden, daß damit eine Behandlung zur Unfruchtbarmachung gemeint ist.“

Beweise für die Vermutung, Schultze könnte an den menschenverachtenden Sterilisationsversuchen Carl Claubergs in den Konzentrationslagern Auschwitz bzw. Ravensbrück beteiligt gewesen sein, sind jedoch auch in der neuesten Literatur nicht zu finden. Dagegen ist festzustellen, dass Clauberg schon ab Mitte der 1930er-Jahre mehrfach über die Behandlung verschlossener bzw. unterentwickelter Eileiter mit Follikelhormon berichtet hat. Es erscheint durchaus möglich, dass dies hier als „Methode Clauberg zur Behandlung weiblicher Unfruchtbarkeit“ apostrophiert wurde. Zudem begann Clauberg seine Versuche zur Massensterilisierung erst 1942.

Schultze, dessen Name manchen Zeitgenossen noch in dem Eponym „Schultze'sches Gerät“ zur Bezeichnung eines speziellen Hysterosalpingografie-Instrumentariums erinnerlich ist, beging am 1. Mai 1945 zusammen mit seiner Frau Selbstmord. Vorausgegangen war eine Massenvergewaltigung in der Frauenklinik durch sowjetische Soldaten, von der auch Schultzes Frau betroffen war und der er hilflos zusehen musste.

\section{Archivalische Quellen}

BArch Berlin, NS19/3684; ZSt, 413 AR 1463/65, S. 7 (zit. n. Klee).

\section{Gedruckte Quellen}

GK 1928, S. 250 f.; GK 1939, S. 436 f.; GW 1956, S. 171; Schultze: Röntgendiagnostik (1939), S. 194-200; Klee: Auschwitz (1997), S. 437; Grüttner: Lexikon (2004), S. 155; Köhler: Achse (2010), S. 60 f.; Doetz: Alltag (2011), S. 224-226; David/Ebert: Instrumente (2012); David/Ebert: „Lebensborn“ (2013); Eberle: „Instrument“ (2015).

\section{Seitz, Ludwig \\ $\nabla$}

geb. 24.05.1872, Pfaffenhofen an der Roth gest. 19.06.1961, Pfaffenhofen an der Roth

\section{Familie}

Vater: Franz Seitz, Landwirt und Brauereibesitzer; Mutter: Josepha Seitz, geb. Dirr

\section{œ1905 Hedwig, geb. Kerschensteiner; 5 Kinder}

\section{Ausbildung}

1893-1898 Medizinstudium (München, Berlin, Heidelberg, wieder München); 1898 Staatsexamen/Approbation (München)

\section{Akademische Karriere}

1898 Promotion (München); 1903 Habilitation (München); 1910 o. Prof. (Erlangen); Ablehnung von Rufen nach Tübingen, Freiburg i. Br. (1918) und Wien (1920); 1921 o. Prof. (Frankfurt/ Main); 01.10.1938 Emeritierung

\section{Weiterbildung und berufliche Karriere}

1998 Volontärass. am Orthopäd. Ambulatorium der Chir. Klinik des Allg. Städt. KH links der Isar München; 16.02.1899 Klin. Ass. an der chir. Abt. des Städt. KH Augsburg; ab 01.05.1899 Ass., später OA an der I. UFK München (v. Winckel, A. Döderlein); ab 01.04.1910 Dir. der Frauenklinik und Leiter der Hebammenschule Erlangen; ab 01.04.1921 Dir. der UFK Frankfurt/Main

\section{Mitgliedschaft/Funktionen in der DGG}

1929-1931 1. Vorsitzender; 1931-1933 2. Vorsitzender; Ehrenmitglied; Vorträge: 1933, 1941

\section{Gedruckte Quellen}

GK 1928, S. 256 f.; GK 1939, S. 449-451; GW 1956, S. 209; Seitz: Verkoppelung (1933); Kleinert: Radium-Jubel (1988); Taubert: Zwangssterilisierungen (1998), S. 23; Wittern-Sterzel (Hrsg.): Professoren (1999), S. $181 \mathrm{f}$;; Frobenius: Röntgenstrahlen (2003), S. 420-424; Klee: Personenlexikon (2003), S. 577 f.; Frobenius: BGGF-Ehrenmitglieder (2012), S. 129. 


\section{Sigwart, Walter}

$\nabla$

geb. 22.05.1876, Tübingen

gest. 1948

\section{Ausbildung \\ 1900 Approbation}

\section{Akademische Karriere}

1900 Promotion (Tübingen); 1911 Habilitation (Berlin); Prof.

\section{Weiterbildung und berufliche Karriere}

1901-1920 UFK Halle/Saale, I. und II. UFK Berlin; Dir. der Frauen-

klinik des Hospitals zum Hl. Geist Frankfurt/Main

\section{Mitgliedschaft/Funktionen in der DGG \\ 1935-1937 Beisitzer; Vortrag: 1931}

\section{Gedruckte Quellen}

GK 1928, S. 259 f.; GK 1939, S. 467 f.; GW 1956, S. 243.

\section{Snoo, Klaas de}

geb. 26.01.1877, Geervliet (Niederlande)

gest. 01.04.1949, Utrecht

\section{Ausbildung}

ab 1895 Medizinstudium (Utrecht); 1902 Approbation

\section{Akademische Karriere}

1926 Prof. (Utrecht); 1947 Emeritierung

\section{Weiterbildung und berufliche Karriere}

1905-1926 Vroedvrouwenschool Rotterdam, ab 1907 als Dir.; 1926-1947 Prof. (Utrecht); 15.09.1947 Emeritierung

\section{Mitgliedschaft/Funktionen in der DGG \\ 1933-1935 Beisitzer; Vortrag: 1931}

\section{Archivalische Quellen}

UAT $150 / 33,41$.

\section{Internetquellen}

https://profs.library.uu.nl/index.php/profrec/getprofdata/1955/401/508/0

\section{Stoeckel, Walter}

$\nabla$

geb. 14.03.1871, Stobingen bei Insterburg (Ostpreußen)

gest. 12.02.1961, Berlin

katholisch

Familie

Vater: Carl Moritz Stoeckel, Gutsbesitzer und Beamter; Mutter: Mary Luise, geb. Heinitz

œ 29.12.1900: Aenne, geb. Fritsch; 7 Kinder
Ausbildung

1890-1895 Medizinstudium (Leipzig, München, Jena, Königsberg i. Pr.); 1895 Staatsexamen/Approbation (Königsberg i. Pr.)

\section{Akademische Karriere}

1896 Promotion (Königsberg i. Pr.); 1903 Habilitation (Erlangen); 1904 Umhabilitation (Berlin); 1905 a. o. Prof. (Berlin); 1907 o. Prof. (Marburg/Lahn); 1910 o. Prof. (Kiel), 1921 o. Prof. (Leipzig); 1925 o. Prof. (Berlin); 01.09.1950 Emeritierung

\section{Weiterbildung und berufliche Karriere}

1896/97 Schiffsarzt; ab 01.09.1897 Volontärass. an der UFK Bonn, später Ass. (1898) und OA (1901); zwischenzeitlich am Path.-Anat. Inst. Marburg/Lahn sowie Studienaufenthalte am Path. Inst. Würzburg und an der Urolog. Klinik Breslau; 1903 Wechsel nach Erlangen, dort im Sommersemester 1904 Lehrstuhlvertretung für Geburtsh. und Gyn.; 14.09.1904 OA an der Charité Berlin; 1907 Ablehnung von Rufen nach Greifswald und Tübingen; Direktor der UFK Marburg/Lahn; ab 1910 Direktor der UFK Kiel; 1917 Ablehnung eines Rufes nach Halle/Saale; ab 1922 Direktor der UFK Leipzig; 19.03.1926-01.09.1950 Dir. der I. UFK Berlin an der Artilleriestraße (jetzt: Tucholskystraße)

\section{NS-Organisationen}

Förderndes Mitglied der SS; NSV; NSDDB; 1944 Aufnahme in den wiss. Beirat des Generalkommissars für das Sanitäts- und Gesundheitswesen, Karl Brandt

\section{Mitgliedschaft/Funktionen in der DGG}

1931-1933 1. Vorsitzender; 1933-1935 2. Vorsitzender; 19331937 Vertreter der DGG beim Reichsministerium des Inneren und bei den Behörden; Ehrenmitglied; Vorträge: 1935, 1949

Archivalische Quellen

UAT 150/33,41; BSB München, Nachlässe, Ana 691; BBAW, Nachlass Stoeckel.

\section{Gedruckte Quellen}

GK 1928, S. 268-270; GK 1939, S. 482-485; GW 1956, S. 175; Stoeckel: Leben (1954); Stoeckel: Erinnerungen (1966); Ulrich/Ebert u. a.: Kaiserreich (1994); Wittern-Sterzel (Hrsg.): Professoren (1999), S.190-192; David: Stoeckel (2007); Ludwig/Jonat: Programm (2008), S.60-63; Schagen: Stoeckel (2010); Doetz: Alltag (2011).

\section{Streck, Arnulf \\ $\nabla$}

geb. 07.06.1891, München

gest. 01.11.1936, Berlin

Familie

Vater: Josef Streck, Bauingenieur; Mutter: Marie, geb. Gleissner

\section{Ausbildung}

Studium der Tier- und Humanmedizin (München); 07/1916 tierärztl. Approbation

\section{Akademische Karriere}

1919 Promotion Dr. med. vet. (München); 1920 Promotion Dr. med. (München) 


\section{Weiterbildung und berufliche Karriere}

1931 Niederlassung als Frauenarzt in Fürth; 1933 Vorsitzender des Ärztl. Bezirksvereins Fürth; 1933 Leiter des Fürther Nathanstifts; 1935 Sonderbeauftragter des Reichsärzteführers in Berlin; 1935/36 Leiter der medizinischen Betreuung der Reichsparteitage in Nürnberg

\section{NS-Organisationen}

1931 NSDAP (Blutorden, Goldenes Parteiabzeichen); 1931 SA

\section{Mitgliedschaft/Funktionen in der DGG}

bis 1935 Mitglied, dann ausgetreten; 1935 Grußwort

\section{Archivalische Quellen}

UAT 150/33,41, Mappe Kongressunterlagen, n. p.

\section{Gedruckte Quellen}

Jahresverzeichnis (1921), S. 568; Jahresverzeichnis (1925), S. 837; Dross: „Juden“ (2012).

Internetquellen

http://www.fuerthwiki.de/wiki/index.php?title=Arnulf_Streck

\section{Stuckrad, Kurt-Otto von}

$\nabla$

geb. 09.04.1893, Ladysmith, Natal (Südafrika)

gest. 1945, Berlin-Lichterfelde [Suizid]

\section{Ausbildung \\ 1920 Approbation (Berlin) \\ Akademische Karriere \\ 1920 Promotion (Berlin)}

\section{Weiterbildung und berufliche Karriere}

1920-1923 gyn.-geburtsh. Weiterbildung an der I. UFK Berlin (Bumm); 1923/24 Ass. an der Privatfrauenklinik Seegert in Berlin; 1924-1938 Ltd. Arzt des Berliner Wöchnerinnenheims am Urban; anschl. bis 1945 Ltd. Arzt der geburtsh.-gyn. Abt. des Gräfin-Rittberg-KH vom Roten Kreuz in Berlin-Lichterfelde

\section{Mitgliedschaft/Funktionen in der DGG \\ 1941 zum Beisitzer gewählt}

\section{Vita}

Kurt-Otto von Stuckrad, langjähriger Leiter von Berliner Frauenkliniken, ist vom DGG-Vorstand Ende 1939 vermutlich in seiner Eigenschaft als Vorsitzender der Berliner Gesellschaft für Geburtshilfe und Gynäkologie in die Auseinandersetzung mit der Reichsgesundheits- und Reichshebammenführung um die Hausbzw. Klinikgeburt involviert worden. Er nahm an einer entsprechenden Vorstandssitzung teil und war an der Formulierung der Denkschrift der Gesellschaft beteiligt, mit der letztlich erfolgreich gegen die Diskreditierung der Klinikgeburt vorgegangen wurde. 1941 wählte ihn die DGG als Beisitzer in den erweiterten Vorstand. Zu Kriegsende verübte Stuckrad angesichts der vorrückenden russischen Truppen zusammen mit seiner Frau und seinen beiden erwachsenen Töchtern Suizid. Er ist in einem Gemeinschaftsgrab mit Opfern von Krieg und Gewalt auf dem Gelände des Krankenhauses beigesetzt, in dem er bis zuletzt tätig war.

\section{Archivalische Quellen}

BSB München, Nachlässe, Ana 691, Schwarzer Ordner.

\section{Gedruckte Quellen}

GK 1939, S. 488; GW 1956, S. 244.

Internetquellen

https://de.wikipedia.org/wiki/Rittberg-Krankenhaus

\section{Süssmann, Fritz}

geb. 02.02.1881, Hermannstadt

gest. 01.02.1967 (?), vermutl. Sibiu/Hermannstadt (Rumänien)

\section{Ausbildung \\ 1904 Approbation}

\section{Akademische Karriere \\ 1904 Promotion}

Weiterbildung und berufliche Karriere

1904-1906 II. UFK Budapest (Tauffer); 1906-1912 Hilfsarzt und Sekundärarzt am Franz-Josef-Bürger-Spital Hermannstadt (W. Otto); ab 1912 Dir. der Staatl. Frauenklinik; Prof. und Dir. der Frauenklinik Hermannstadt

\section{Mitgliedschaft/Funktionen in der DGG} 1935-1937 Beisitzer; Vorträge: 1937, 1949

\section{Gedruckte Quellen}

GK 1928, S. 274; GK 1939, S. 489; GW 1956, S. 226; Siebenbürgische Zeitung $4 / 1967$.

\section{Tausch, Moritz}

geb. 10.12.1899, Haunstetten (1972 nach Augsburg eingemeindet)

gest. 13.03.1939, Augsburg

\section{Ausbildung \\ 1924 Approbation (München)}

\section{Akademische Karriere \\ 1925 Promotion (München); 1936 Habilitation (Tübingen)}

\section{Weiterbildung und berufliche Karriere}

1924 Inn. Med.; 1925 Path. Anatomie; 1926-1928 Frauenabt. Rotkreuz-Klinik München (Albrecht); Bayer. Landeshebammenschule Bamberg (Göttling); ab 1929 UFK Tübingen (Mayer); 1930 Ass., dann 2. OA, 1934 schließlich 1. OA an der UFK Tübingen; 1928-1935 Hebammenlehrer; 1934 Lehrauftrag für Frauenheilk.

\section{Mitgliedschaft/Funktionen in der DGG}

1933-1935 2. Schriftführer; Vortrag: 1937

\section{Vita}

Moritz Tausch, langjähriger Oberarzt von August Mayer, genoss offensichtlich das besondere Vertrauen seines Chefs: Mayer bestimmte ihn 1933 nach seiner Wahl zum Präsidenten der DGG für die Vorbereitung des Münchner Kongresses 1935 zum 
2. Schriftführer der Gesellschaft. Darüber hinaus förderte er den durch eine im Ersten Weltkrieg akquirierte, chronische Streptokokken-Infektion eingeschränkten Assistenten nach Kräften, indem er ihm die Habilitation ermöglichte und sich dafür einsetzte, dass auch eine Professur für ihn eingerichtet wurde. Deren kurz bevorstehende Verleihung hat Tausch freilich nicht mehr erlebt. Er starb im März 1939 an einer Endocarditis lenta.

Der Nachruf Mayers auf Tausch gleicht einem Hohen Lied auf den idealen Oberarzt und dessen Bedeutung für eine Klinik, deren Belegschaft einschließlich des Direktors und nicht zuletzt für das Wohlergehen der Patientinnen. In der Klinik Mayers war Tausch an den dort im Nationalsozialismus durchgeführten Zwangssterilisationen beteiligt. Sein Name fällt im Zusammenhang mit zwei tödlichen Zwischenfällen, deren Ursachen als ungeklärt bezeichnet werden müssen. Eine der Frauen starb nach einer Sedierung wegen ihrer Agitiertheit, die andere erlag postoperativ einer Peritonitis.

\section{Archivalische Quellen}

StadtA Tü, Signatur A 573 Nebenregister (Moritz Tausch)

\section{Gedruckte Quellen}

GK 1939, S. 491; GW 1956, S. 227; Mayer: Tausch [Nachruf] (1939); Doneith: Mayer (2007).

\author{
Treite, Percival (Percy) \\ $\nabla$ \\ geb. 10.09.1911, Berlin \\ gest. 08.04.1947, Hamburg [Suizid]
}

Familie

verheiratet

\section{Ausbildung}

1931 Abitur (Berlin); Medizinstudium (Berlin); 1936 Staatsexamen (Berlin); bis 12/1937 Medizinalass. an der 2. Med. Klinik der Charité Berlin (v. Bergmann) und an der I. UFK Berlin (Stoeckel); 1938 Approbation (Berlin)

\section{Akademische Karriere \\ 1938 Promotion (Berlin); 1943 Habilitation (Berlin)}

\section{Weiterbildung und berufliche Karriere}

1938 zunächst Volontärarzt, dann Ass. an der I. UFK (Stoeckel, R. Meyer); 01.04.1943 Einberufung zur Waffen-SS; ab 09/1943 Lagerarzt im KZ Ravensbrück; 03.02.1947 von einem britischen Militärgericht in Hamburg zum Tod verurteilt

\section{NS-Organisationen}

1934 SS (1944 Obersturmführer); 1937 NSDAP; 1939 NSV; NSDDB

\section{Vita}

Percival (Percy) Treite wurde als Sohn eines Engländers 1911 in Berlin geboren. Sein Interesse für die Frauenheilkunde und speziell für die Gynäkopathologie entdeckte er während seiner Medizinalassistentenzeit in der Klinik von Walter Stoeckel. Dort fertigte er eine einschlägige Dissertation an und wurde als Assistent gezielt für die Nachfolge des berühmten Gynäkopathologen Robert Meyer ausgebildet, dessen Stellung als „Nichtarier“ seit 1933 bedroht war und der schließlich 1939 emigrieren musste. Treite machte sich in kurzer Zeit einen Namen als Wissenschaftler, und Stoeckel hielt große Stücke auf ihn. Im April 1943 wurde er zur Waffen-SS einberufen und im September 1943 in das FrauenKonzentrationslager Ravensbrück abkommandiert. Dort führte er Zwangsterilisationen durch und brach Schwangerschaften ab, an denen „Ostarbeiter“ beteiligt waren. Darüber hinaus wurden 1946/47 in dem Verfahren, das die Engländer im 1. Ravensbrück-Prozess unter anderem gegen Treite angestrengt hatten, von ehemaligen KZ-Insassinnen Vorwürfe wegen verbrecherischer Menschenversuche erhoben, darunter die Beteiligung an den Sterilisationsversuchen von Carl Clauberg. Außerdem lasteten sie Treite an, zu Übungszwecken Strumaoperationen mit zum Teil tödlichem Ausgang vorgenommen zu haben. Als Lagerarzt war er zudem an Selektionen beteiligt, die nicht arbeitsfähige Häftlinge dem Tod in der Gaskammer überantworteten. In dem Verfahren, das am 3. Februar 1947 mit seiner Verurteilung zum Tod durch den Strang endete, traten daneben jedoch ehemalige Gefangene auf, die sich für Treite einsetzten. Offenbar hatte er im KZ auch lebensrettende Eingriffe durchgeführt und für eine Verbesserung der hygienischen Verhältnisse gesorgt. Stoeckel schrieb in seiner Autobiografie von 1953, auch er habe sich in einem Gnadengesuch für Treite eingesetzt, von dem er hoffte, er würde Meyer fast vollwertig ersetzen. Nach Bestätigung des Todesurteils beging Treite am 8. April 1947 in seiner Zelle Selbstmord durch Vergiftung.

\section{Gedruckte Quellen}

Der Spiegel 6/1947, S. 3; Stoeckel: Leben (1954), S. 161; Schäfer: Selbstverständnis (2002), S. 148-153; Klee: Personenlexikon (2003), S. 629 f.; Doetz: Alltag (2011), S. 222-224; Hübner: Verbrechen (2015).

\section{Tóth, Stephan von \\ $\nabla$}

geb. 12.12.1865/67, Szatmárnémeti (Ungarn)

gest. 25.11.1935

Familie

Vater: Schuldirektor

Akademische Karriere

1890 Promotion; 1899 Habilitation; 1908 a. o. Prof. (Budapest)

Weiterbildung und berufliche Karriere

1899 OA an der II. UFK Budapest (Tauffer); 1909-1917 Chefarzt der geburtsh. Abt. des St.-Rochus-Spitals Budapest; 1917-1935

Leiter der II. UFK Budapest

Mitgliedschaft/Funktionen in der DGG

1931-1933 Beisitzer; Vortrag: 1931

Gedruckte Quellen

GW 1956, S. 227; Frigyesi: Tóth [Nachruf] (1936).

\section{Wagner, Georg August (G. A.) \\ $\nabla$}

geb. 23.09.1873, Prag

gest. 15.08.1947, Garmisch-Partenkirchen

wahrscheinlich Konversion zum kath. Glauben, da Wagners 2. Ehefrau Maria Katholikin war 
Familie

Vater: Julius Wagner; Mutter: Wilhelmine, geb. Geukert

๑1) Lucia Maria, geb. Schuppanczyk von Frankenbach (geb. 08.04.1880); 3 Söhne; 2) 24.05.1922: Maria Josefa Ferdinande, geb. Taschek; 1 Sohn: Erich, 1 Tochter: Marietta

Ausbildung

1893-1901 Medizinstudium (Prag, Graz); 1900 Approbation

\section{Akademische Karriere}

18.03.1901 Promotion (Graz); 09.08.1913 Habilitation (Wien); 1917 o. Prof. (Dt. Univ. Prag); 1928 o. Prof. (Berlin)

\section{Weiterbildung und berufliche Karriere}

Gyn. und Geburtsh. in Heidelberg und Wien (v. Rosthorn, Chrobak, Wertheim); 1917 Dir. der Dt. Frauenklinik Prag II; ab 1928 Dir. der II. UFK Berlin (Charité)

\section{Mitgliedschaft/Funktionen in der DGG}

1935-1937 1. Vorsitzender; 1937-1941 2. Vorsitzender; Ehrenmitglied

\section{Archivalische Quellen}

Ahnennachweis (= Familiengeschichte); BArch Berlin, BDC, DS A 0072, Bl. 1352-1356; BArch Berlin, R 4901/1347; GStAPK Berlin, I. HA, Rep. 76A, Kultusministerium.

Gedruckte Quellen

GK 1928, S. 290-292; GK 1939, S. 513-516; GW 1956, S. 277; Ebert/David: Wien (2014).

\section{Weibel, Wilhelm \\ $\nabla$}

geb. 15.11.1876, Wien

gest. 30.04.1945, Wien

Familie

Vater: Friedrich Weibel, Eisenbahningenieur; Mutter: Pauline, geb. Altmann

$œ$ Alice, geb. Collmann; 1 Tochter: Doris

Ausbildung

Medizinstudium in Wien; 1900 Approbation (Wien)

\section{Akademische Karriere \\ 1901 Promotion (Wien); 1913 Habilitation (Wien); 1913 PD (Wien); 1919 a. o. Prof. (Wien); 1928 o. Prof. (Dt. Univ. Prag); 1932 o. Prof. (Wien), 1935 aus politischen Gründen seines Amtes enthoben; 1936 wiedereingesetzt; 1942 Emeritierung \\ Weiterbildung und berufliche Karriere \\ 1903-1908 Ass. am Elisabeth-Spital Wien (Wertheim); 1909- 1919 Ass. an der II. UFK Wien (Wertheim); 1919 a.o. Prof. (Wien); 1922 Leiter der Frauenabt. der Rudolfstiftung Wien; ab 1928 o. Prof. Dt. Univ. Prag; 1932-1942 Direktor der II. UFK Wien; 1935 aus politischen Gründen seines Amtes enthoben; 1936 wie- dereingesetzt}

\section{NS-Organisationen}

11.06.1938 Förderndes Mitglied der SS
Mitgliedschaft/Funktionen in der DGG

1938 (?)-41 Beisitzer; Vorträge: 1931, 1937

Vita

Wilhelm Weibel war einer der Lieblingsschüler von Ernst Wertheim. Nach dessen frühem Tod wurde er 12 Jahre später einer seiner Nachfolger im Direktorat der II. UFK Wien und pflegte dort das Gedenken an seinen Lehrer auf vielerlei Art. Weibel war von Wertheim zur Frauenheilkunde gebracht worden. Eigentlich hatte er sich am Wiener Elisabeth-Spital zum Algemeinarzt ausbilden lassen wollen, als Wertheim ihm eine Assistentenstelle anbot. 1922 übernahm Weibel dann als erfahrener Frauenarzt und glänzender Operateur zunächst die Leitung der Frauenabteilung der Wiener Rudolfstiftung, 1928 folgte er einem Ruf in das Ordinariat an der Deutschen Universität Prag. Die Rückkehr Weibels 1932 nach Wien und die Übernahme der "Wertheim-Klinik“ stand zunächst unter keinem guten Stern. 1935 wurde er seines Amtes enthoben, da er im Verdacht „staats- und regierungsfeindlicher Äußerungen“ gegen die Schuschnigg-Regierung stand. Hinzu kam, dass bei den Dreharbeiten für einen Unterrichtsfilm ein Kind unter der Geburt gestorben war. Die Vorwürfe gegen Weibel konnten aber nicht erhärtet werden, seine Wiedereinsetzung erfolgte 1936. Nach dem „Anschluss“ Österreichs wurde er Förderndes Mitglied der SS, blieb aber "politisch unbequem“. 1942, ein Jahr, nachdem er als Beisitzer am DGG-Kongress in Wien teilgenommen hatte, emeritierte man den damals 66-jährigen Weibel wegen „Alterserscheinungen“.

Archivalische Quellen

BArch Berlin, BDC, DS B 043; ÖStA, AdR, BMI, GA, 62.169.

\section{Gedruckte Quellen}

GK 1939, S. 525-527; GW 1956, S. 278; Schaller: Wertheim-Klinik (1992).

\section{Wichmann, Seth Edvin}

\section{$\nabla$}

geb. 25.01.1885, Pyhäjoki (Finnland)

gest. 23.07.1939, Helsinki (Finnland)

Familie

Vater: Emil August Wichmann (1831-1886); Mutter: Charlotta Wilhelmina, geb. Schroderus (1841-1927)

œ 1917: Gertrud (Gerty) Johanna, geb. Lönnroth (1896-1993); 3 Kinder: Irma Gertrud, Lotte Gertrud, Karri Kristian

\section{Ausbildung}

1903 Abitur; 1912 Staatsexamen

\section{Akademische Karriere}

1913 Promotion (Helsinki); 1924 a. o. Prof., 1925 o. Prof. (Helsinki)

\section{Weiterbildung und berufliche Karriere}

1911-1913 Ass. am Path. Inst. Helsinki; 1920-1922 OA an der UFK Helsinki; ab 1925 Dir. der UFK Helsinki; 1934 Dir. der neuen Frauenklinik Helsinki

\section{Mitgliedschaft/Funktionen in der DGG}

1935-1937 Beisitzer 
Vita

Der finnische Gynäkologe Seth Edvin Wichmann nahm in den 1930er-Jahren regelmäßig an DGG-Tagungen teil. In einem Brief an August Mayer brachte er im Dezember 1935 seine große Bewunderung für die deutsche gynäkologische Forschung zum Ausdruck und gelobte im Namen der finnischen Ärzteschaft, die „kulturellen Beziehungen nach Deutschland [...] auch in der Zukunft nach unseren Kräften“ aufrechtzuerhalten. Voll des Lobes für die hervorragende Kongressorganisation war Wichmann auch in einem Interview mit der finnischen Presse, das vom Kultusministerium und dem Auswärtigen Amt in Berlin aufmerksam zur Kenntnis genommen wurde. Reichsärzteführer Gerhard Wagner erteilte Mayer den Auftrag, „die Mitteilung über das Urteil von Professor Wichmann, Helsingfors, sowie nach Möglichkeit noch andere Äusserungen von Ausländern in der Presse umgehend der Deutschen Kongress-Zentrale [...] bekanntzugeben, damit diese die publizistische Auswertung in Deutschland darüber vornehmen kann“. Für die DGG-Tagung des Jahres 1937 wurde Wichmann, der seine „deutschenfreundliche“ Haltung hinreichend unter Beweis gestellt hatte, zum Beisitzer bestimmt. Er starb im Juli 1939, wenige Monate, bevor er zum Ehrenmitglied der DGG ernannt werden sollte.

\section{Archivalische Quellen}

UAT 150/33,41.

\section{Gedruckte Quellen}

GK 1928, S. 300; GK 1939, S. 532; Turunen: Wichmann [Nachruf] (1939).

Internetquellen

http://matrikel.uni-rostock.de/id/200010217

\section{Wintz, Hermann Ludwig}

geb. 30.08.1887, Speyer

gest. 11.06.1947, Zusmarshausen bei Augsburg

katholisch

Familie

Vater: Michael Wintz, Möbelfabrikant; Mutter: Katharina Wintz, geb. Holdermann

๑1) 1922: Pauline Heinricke, geb. Zitzmann; 1940 geschieden; keine Kinder; 2) 1940: Emma Maria, geb. Vogler; keine Kinder

\section{Ausbildung}

1893-1907 Privatschule und Humanist. Gymnasium (Speyer); 1907-1911 Studium der Medizin, Mathematik, Physik und Chemie (Freiburg i. Br., Heidelberg, Erlangen); 1912 Staatsexamen (Erlangen); anschl. Medizinalpraktikant an der Med. Klinik und am physiolog.-chem. Laborat. Heidelberg; ab 03/1913 zunächst ebenfalls Medizinalpraktikant, dann wiss. Ass. an der UFK Erlangen; 1914 Approbation

\section{Akademische Karriere}

1914 Promotion Dr. med. (Erlangen); 1918 Habilitation (Erlangen); 1920 Promotion Dr. phil. (Erlangen); 1920 a. o. Prof. (Erlangen); 1921 o. Prof. (Erlangen); 1938-1944 Rektor der Univ. Erlangen

\section{Weiterbildung und berufliche Karriere}

1914-1921 zunächst Ass., dann OA an der UFK Erlangen (Seitz); ab 1921 Dir. der UFK Erlangen und des Röntgeninst. der Klinik; 04/1945 Internierung durch die US-Militärregierung; 06.06.1945 Entlassung aus allen Ämtern

\section{NS-Organisationen}

1935 NSDAP; NSKK; 1936 NSDDB; 1938 Förderndes Mitglied der SS

\section{Mitgliedschaft/Funktionen in der DGG} 1935-1937 Beisitzer; Vortrag: 1941

\section{Vita}

Hermann Wintz, 1920 Präsident der Deutschen Röntgengesellschaft und 1937 Vorstandsmitglied der DGG, gehört zu den Pionieren der gynäkologischen Radiologie in Deutschland. Vielseitig begabt und ausgebildet etablierte er nach seinem Eintritt als Assistent in die Erlanger UFK 1913 innerhalb von knapp 10 Jahren zusammen mit seinem klinischen Lehrer Ludwig Seitz mit dem Röntgeninstitut der Klinik ein Forschungs-, Ausbildungs- und Behandlungszentrum von internationalem Rang. Möglich wurde dies durch ein Joint Venture mit dem ortsansässigen Medizintechnik-Unternehmen Reiniger, Gebbert \& Schall (RGS), das später in der Firma Siemens aufging. Unterstützt von dem RGSOberingenieur Leonhard Baumeister konstruierte Wintz zahlreiche technische Verbesserungen für Röntgenröhren und die dazugehörigen Apparate. Parallel dazu entwickelte er mit Seitz ein in sich geschlossenes Konzept zur „Röntgen-Tiefentherapie“ vor allem gynäkologischer Krebserkrankungen. Im Nationalsozialismus wurden Wintz und seine Mitarbeiter zu Helfershelfern der verbrecherischen Rassenpolitik: An der Klinik, deren Direktorat Wintz schon seit 1921 als Nachfolger von Seitz innehatte, wurden mindestens 512 Zwangssterilisationen und 136 Abtreibungen bei sogenannten „Ostarbeiterinnen“ durchgeführt. 1945 enthob die US-Militärbehörde Wintz, der von 1938 bis 1945 auch Rektor der Universität war, aller seiner Ämter. 1947 starb Wintz, erst 59 Jahre alt, an den Folgen einer chronischen Erkrankung.

\section{Gedruckte Quellen}

GK 1928, S. 304 f.; GK 1939, S. 542-544; GW 1956, S. 213; Wittern-Sterzel (Hrsg.): Professoren (1999), S. 220 f.; Frobenius: Röntgenstrahlen (2003), S. 381-419; Klee: Personenlexikon (2003), S. 679 f.; Krüger: Zwangsterilisation (2003), S. 110-126; Leven/Plöger (Hrsg.): Universitätsklinikum (2016). 


\section{Quellen und Literatur}

\section{Archivalische Quellen}

Archiv der Deutschen Akademie der Naturforscher Leopoldina

(Leopoldina)

- MM 3773 (Nürnberger)

\section{Archiv der I. Universitätsfrauenklinik München}

Archiv des Landschaftsverbandes Rheinland Pulheim (ALVR)

- Archivalien der Hebammenlehranstalt Elberfeld und der Landesfrauenklinik Wuppertal

Archiv der Berlin-Brandenburgischen Akademie der Wissenschaften (BBAW)

- Nachlass Walter Stoeckel

Bayerisches Hauptstaatsarchiv München (BayerHStaatsA)

- M LEA: Landesentschädigungsamt (Bab)

Bayerische Staatsbibliothek München (BSB)

- Nachlass Josef Zander, Ana 691

- Nachlass Carl Kaufmann, Ana 693

Bundesbeauftragter für die Stasi-Unterlagen (BStU)

- MfS, HA VIII IR FI (Stoeckel)

Bundesarchiv Berlin (BArch)

- Rep. 2: Finanzministerium

- Rep. 43/II: Reichskanzlei

- Rep. 73: Deutsche Forschungsgemeinschaft

- Rep. 86: Reichsgesundheitsamt

- Rep. 1501: Reichsministerium des Inneren

- Rep. 4901: Ministerium für Wissenschaft, Erziehung, Volksbildung

Berlin Document Center (BDC)

- Recherchen zu: Hans Albrecht, Isidor Amreich, Ernst Bach, Gustav Döderlein, Günther Frommolt, Erwin Kehrer, Heinrich Martius, August Mayer, Felix Mikulicz-Radecki, Hans Naujoks, Walter Stoeckel, Georg August Wagner, Wilhelm Weibel, Hermann Wintz

Geheimes Staatsarchiv Preußischer Kulturbesitz (GStAPK)

- Rep. 76A: Kultusministerium
Landesarchiv Berlin (LA Berlin)

- B Rep. 025: Wiedergutmachungsämter Berlin

- C Rep 902: Berufsakten

Landesarchiv Nordrhein-Westfalen (LANRW)

- 110, Nr. 1087 Eduard Martin

Stadtarchiv München (StadtA Mü)

- Sterbebücher 1957, Nr. 2313

Staatsarchiv Bremen (StaatsAB)

- 4,54 E: Landesamt für Wiedergutmachung

Staatsarchiv Posen

- 301, 2159

Universitätsarchiv Humboldt-Universität Berlin (UA HUB)

- Personalakten (Frommolt, Ottow, Stoeckel)

- Sammlung Rott

- Universitäts-Kurator

Universitätsarchiv Tübingen (UAT)

- Nachlass August Mayer

- Personalakte Hans Roemer

Stadtarchiv Tübingen (StadtA Tü)

- Einwohnermeldekartei

Universitätsarchiv der Martin-Luther-Universität Halle-Wittenberg (UAHW)

- Rep. 6, Nr. 1407

- Rep. 11, PA 5632 (Nürnberger)

Universitätsbibliothek Göttingen (UB Göttingen)

- Personalakte Heinrich Martius

Zentrale Landesbibliothek Berlin (ZLBB)

- Historische Sammlungen, Springer-Archiv 


\section{Gedruckte Quellen und Literatur}

$\nabla$

1. VO BBG = Erste Verordnung zur Durchführung des Gesetzes zur Wiederherstellung des Berufsbeamtentums vom 11. April 1933. In. Reichsgesetzblatt 1933 I, S. 195.

Albrecht, Hans. Periodische Fruchtbarkeit und Unfruchtbarkeit. In: Archiv für Gynäkologie 161 (1936), S. 23-51.

Aly, Götz/Chroust, Peter/Heilmann, Hans-Dieter. Biedermann und Schreibtischtäter. Materialien zur deutschen Täter-Biographie. Berlin 1987.

Angetter, Daniela/Kanzler, Christine. „Eltern, Wohnung, Werte, Ordination, Freiheit, Ehren verloren!“ Das Schicksal der in Wien verbliebenen jüdischen Ärzte von 1938 bis 1945 und die Versorgung ihrer jüdischen Patienten. In: Thomas Beddies/Susanne Doetz/Christoph Kopke (Hrsg.): Jüdische Ärztinnen und Ärzte im Nationalsozialismus. Entrechtung, Vertreibung, Ermordung. Berlin 2014, S. 58-74.

Anthuber, Christoph/Beckmann, Matthias W./Dietl, Johannes/Dross, Fritz/ Frobenius, Wolfgang (Hrsg.). Herausforderungen. 100 Jahre Bayerische Gesellschaft für Geburtshilfe und Frauenheilkunde. Stuttgart 2012.

Aschheim, Selmar. Vorderlappen der Hypophyse in Geburtshilfe und Gynäkologie. In: Archiv für Gynäkologie 144 (1931), S. 165-184.

Ash, Mitchell G./Ehmer, Josef (Hrsg.). Universität - Politik - Gesellschaft. Göttingen 2015.

Ash, Mitchell G. Wissenschaft und Politik als Ressourcen füreinander. Programmatische Überlegungen am Beispiel Deutschlands. In: Jürgen Büschenfeld/Heike Franz/Frank-Michael Kuhlemann (Hrsg.): Wissenschaftsgeschichte heute. Festschrift für Peter Lundgreen. Bielefeld 2001, S. 117134.

Ash, Mitchell G. Wissenschaft(en) und Öffentlichkeit(en) als Ressourcen füreinander. Weiterführende Bemerkungen zur Beziehungsgeschichte. In: Sybilla Nikolow/Arne Schirrmacher (Hrsg.): Wissenschaft und Öffentlichkeit als Ressourcen füreinander. Studien zur Wissenschaftsgeschichte im 20. Jahrhundert. Frankfurt am Main 2007, S. 349-362.

Ash, Mitchell G. Wissenschaft und Politik. Eine Beziehungsgeschichte im 20. Jahrhundert. In: Archiv für Sozialgeschichte 50 (2010), S. 11-46.

Atzl, Isabel/Helms, Roland. Die Geschichte der Deutschen Krebsgesellschaft. Germering 2012.

Aumüller, Gerhard/Grundmann, Kornelia/Krähwinkel, Esther/Lauer, Hans H./Remschmidt, Helmut (Hrsg.). Die Marburger Medizinische Fakultät im „Dritten Reich“. München 2011.

Ayaß, Wolfgang. „Asoziale“ im Nationalsozialismus. Stuttgart 1995.

Baatz, Hans. Beziehungen zwischen dem Krebswachstum und dem inkretorischen Milieu. Biologische Untersuchungen am Spontan- und Impftumor der Maus. Bonn 1938.

Baldauf, P./Tönnes, R./Simon, S./David, M. A Report on the Hysteroscopic Removal of a Gräfenberg Ring After Almost Fifty Years in Utero. In: Geburtshilfe und Frauenheilkunde 74 (2014), S. 1023-1025.

Barbaryka, Gregor. Das Pathologische Institut der Universität München in der Ära Max Borst von 1910 bis 1946. In: Elisabeth Kraus (Hrsg.): Die Universität München im Dritten Reich. Aufsätze, Teil 2. München 2008, S. 63131.

Barkow, Ben/Gross, Raphael/Lenarz, Michael (Hrsg.). Novemberpogrom 1938. Die Augenzeugenberichte der Wiener Library, London. Frankfurt am Main 2008.

Barow, Thomas. Kein Platz im Volksheim? Die „Schwachsinnigenfürsorge“ in Schweden 1916-1945. Bad Heilbrunn 2009.
Bauer-Merinsky, Judith. Die Auswirkungen der Annexion Österreichs durch das Deutsche Reich auf die Medizinische Fakultät der Universität Wien im Jahre 1938. Biographien entlassener Professoren und Dozenten. Wien 1980

Bayer, Barbara. „Es ist nun die Frage, wohin mit ihr“. Zwangsarbeiterinnen und ihre Kinder als Patientinnen und Patienten in der Universitätsfrauenklinik Tübingen 1939-1945. Tübingen 2008.

BBG $=$ Gesetz zur Wiederherstellung des Berufsbeamtentums. In: Reichsgesetzblatt 1933 I, S. 175-177.

Beck, Lutwin (Hrsg.). Zur Geschichte der Gynäkologie und Geburtshilfe. Aus Anlaß des 100jährigen Bestehens der Deutschen Gesellschaft für Gynäkologie und Geburtshilfe. Berlin/Heidelberg/New York u. a. 1986.

Beddies, Thomas/Baader, Gerhard. Jüdische Ärzte in der Weimarer Republik. In: Thomas Beddies/Susanne Doetz/Christoph Kopke (Hrsg.): Jüdische Ärztinnen und Ärzte im Nationalsozialismus. Entrechtung, Vertreibung, Ermordung. Berlin 2014, S. 16-35.

Beddies, Thomas/Schmiedebach, Hans-Peter. „Euthanasie“-Opfer und Versuchsobjekte. Kranke und behinderte Kinder in Berlin während des Zweiten Weltkriegs. In: Medizinhistorisches Journal 39 (2004), S. 165-196.

Beddies, Thomas. Die Universitätspsychiatrie im Dritten Reich. Die Nervenklinik der Charité unter Bonhoeffer und de Crinis. In: Rüdiger vom Bruch/ Rebecca Schaarschmidt (Hrsg.): Universität in der NS-Zeit, Bd. 2: Fachbereiche und Fakultäten. Stuttgart 2005, S. 55-72.

Beller, Fritz K. Der Einfluß deutscher Frauenärzte auf die Akademische Medizin der Vereinigten Staaten. In: Lutwin Beck (Hrsg.): Zur Geschichte der Gynäkologie und Geburtshilfe. Aus Anlaß des 100jährigen Bestehens der Deutschen Gesellschaft für Gynäkologie und Geburtshilfe. Berlin/Heidelberg/New York u. a. 1986, S. 381-401.

Belonoschkin, Boris. Biologie der Spermatozoen im menschlichen Hoden und Nebenhoden. In: Archiv für Gynäkologie 174 (1942), S. 357-368.

Benz, Wolfgang (Hrsg.). Dimensionen des Völkermords. Die Zahl der jüdischen Opfer des Nationalsozialismus. München 1991.

Benz, Wolfgang. Theresienstadt. Eine Geschichte von Täuschung und Vernichtung. München 2013.

Benzenhöfer, Udo. Zur Genese des Gesetzes zur Verhütung erbkranken Nachwuchses. Münster i. W. 2006.

Berger, Max. Prof. Dr. med. Hans Guggisberg zum Gedenken [Nachruf]. In: Der Bund 86 (1977), S. 13.

Bettendorf, Gerhard (Hrsg.). Zur Geschichte der Endokrinologie und Reproduktionsmedizin. Berlin 1995.

Beushausen, Ulrich/Dahms, Hans-Joachim/Koch, Thomas/Massing, Almuth/ Obermann, Konrad. Die Medizinische Fakultät im Dritten Reich. In: Heinrich Becker/Hans-Joachim Dahms/Cornelia Wegeler (Hrsg.): Die Universität Göttingen unter dem Nationalsozialismus. 2., erw. Aufl. München 1998, S. $183-286$

Bickenbach, Werner. Über die Müttersterblichkeit bei klinischer Geburtshilfe. In: Zentralblatt für Gynäkologie 64 (1940), S. 818-836.

Birn, Marco. Die Anfänge des Frauenstudiums in Deutschland. Das Streben nach Gleichberechtigung von 1869-1918, dargestellt anhand politischer, statistischer und biographischer Zeugnisse. Heidelberg 2015.

Blassing, Sabine. Die Hebammenlehranstalt Wuppertal-Elberfeld in den Jahren 1904 bis 1938. In: Daniel Schäfer (Hrsg.): Rheinische Hebammengeschichte im Kontext. Kassel 2010, S. 103-118. 
Bleker, Johanna. Anerkennung durch Unterordnung? Ärztinnen und Nationalsozialismus. In: Eva Brinkschulte (Hrsg.): Weibliche Ärzte. Die Durchsetzung des Berufsbildes in Deutschland. Berlin 1994, S. 126-135.

Bock, Gisela. Zwangssterilisation im Nationalsozialismus. Studien zur Rassenpolitik und Frauenpolitik. Opladen 1986.

Bock, Gisela. Zwangssterilisation im Nationalsozialismus. Studien zur Rassenpolitik und Geschlechterpolitik. Nachdr. der Erstausg. Münster i. W. 2010.

Böhm, Helmut. Von der Selbstverwaltung zum Führerprinzip. Die Universität München in den ersten Jahren des Dritten Reiches (1933-1936). Berlin 1995.

Botz, Gerhard. Nationalsozialismus in Wien. Machtübernahme, Herrschaftssicherung, Radikalisierung 1938/39. Überarb. und erw. Neuaufl. Wien 2008 .

Braß, Christoph. Zwangssterilisation und „Euthanasie“ im Saarland 19331945. Paderborn 2004.

Brinkschulte, Eva. Weibliche Ärzte. Die Durchsetzung des Berufsbildes in Deutschland. Berlin 1994.

Brinkschulte, Eva. Historische Einführung. Medizinstudium und ärztliche Praxis von Frauen in den letzten zwei Jahrhunderten. In: Susanne Dettmer/Gabriele Kaczmarczyk/Astrid Bühren: Karriereplanung für Ärztinnen. Heidelberg 2006, S. 9-35.

Bröer, Ralf. Frauenheilkunde im Dienst der Eugenik. Ärztliche Karrieren an der Universitätsfrauenklinik Heidelberg im Nationalsozialismus. In: Geburtshilfe und Frauenheilkunde 64, 10 (2004), S. 1090-1097.

Bröer, Ralf. Geburtshilfe und Gynäkologie. In: Wolfgang Uwe Eckart/Volker Sellin/Eike Wolgast (Hrsg.): Die Universität Heidelberg im Nationalsozialismus. Berlin 2006, S. 845-892.

Bruch, Rüdiger vom/Tenorth, Heinz-Elmar. Geschichte der Universität Unter den Linden, Bd. 2: Die Berliner Universität zwischen den Weltkriegen 1918-1945. Berlin 2012

Bruns, Florian. Medizinethik im Nationalsozialismus. Stuttgart 2009.

Buchheim, Liselotte. Franqué, Otto Friedrich Wilhelm Paul von. In: Neue Deutsche Biographie 5 (1961), S. 352.

Buddrus, Michael/Fritzlar, Sigrid. Die Professoren der Universität Rostock im Dritten Reich. Ein biographisches Lexikon. München 2007.

Bumke, Oswald. [Eingriffe aus eugenischer Indikation]. In: Archiv für Gynäkologie 156 (1934), S. 109-117.

Burchardt, Lothar/Schott, Dieter/Trapp, Werner. Konstanz im 20. Jahrhundert. Die Jahre 1914 bis 1945. Konstanz 1990.

Bussche, Hendrik van den/Bottin, Angela (Hrsg.). Medizinische Wissenschaft im „Dritten Reich“. Kontinuität, Anpassung und Opposition an der Hamburger Medizinischen Fakultät. Berlin/Hamburg 1989.

Bussche, Hendrik van den/Schmiedebach, Heinz-Peter. Ethische Grenzübertritte. Forschungen an Minderwertigen. In: Hendrik van den Bussche (Hrsg.): Die Hamburger Universitätsmedizin im Nationalsozialismus. Forschung - Lehre - Krankenversorgung. Hamburg 2014, S. 259-273.

Catalogus Professorum Academiae Marburgensis. Bd.2, bearb. von Inge Auerbach. Marburg 1979.

Clauberg, Carl. Künstlich erzeugtes Tubenwachstum, ein Mittel zur Behandlung des Eileiterverschlusses. In: Archiv für Gynäkologie 161 (1936), S. $140-143$

Conill, Victor. Geist und Inhalt der spanischen Frauenkunde. In: Archiv für Gynäkologie 174 (1942), S. 37-40.
Conti, Leonardo. Eröffnungsansprache. In: 1.Tagung der Reichsarbeitsgemeinschaft für Mutter und Kind in Berlin am 26. April 1935. Bericht im Auftrage der Reichsarbeitsgemeinschaft für Mutter und Kind, hrsg. von Kurt Fenner, Stellvertreter des Leiters der Reichsarbeitsgemeinschaft für Mutter und Kind. Berlin 1935, S. 5.

Conti, Leonardo. [Begrüßungsansprache]. In: Bericht über die II. Tagung der Reichsarbeitsgemeinschaft für Mutter und Kind am 21. und 22. Mai 1937 in Bad Wildbad. Berlin 1937, S. 5.

Conti, Leonardo. Geburtshilfe und Hebammenwesen in Deutschland. In: Bericht über die II. Tagung der Reichsarbeitsgemeinschaft für Mutter und Kind am 21. und 22. Mai 1937 in Bad Wildbad. Berlin 1937, S. 5-20.

Cornelissen, Christoph/Mish, Carsten (Hrsg.). Wissenschaft an der Grenze. Die Universität Kiel im Nationalsozialismus. Essen 2009.

Cser, Andreas. Geschichte der Juden in Heidelberg. Heidelberg 1996.

Czarnowski, Gabriele. Nationalsozialistische Frauenpolitik und Medizin. Der Zusammenhang von Zwangssterilisation und Sterilitätsforschung am Beispiel des Königsberger Universitätsgynäkologen Felix von Mikulicz-Radecki. In: Leonore Siegele-Wenschkewitz/Gerda Stuchlik (Hrsg.): Frauen und Faschismus in Europa. Der faschistische Körper. Pfaffenweiler 1990 S. 90-113.

Czarnowski, Gabriele. Das kontrollierte Paar. Ehe- und Sexualpolitik im Nationalsozialismus. Weinheim 1991.

Czarnowski, Gabriele. „Die restlose Beherrschung dieser Materie“. Beziehungen zwischen Zwangssterilisation und gynäkologischer Sterilitätsforschung im Nationalsozialismus. In: Zeitschrift für Sexualforschung 14 (2001), S. 226-246.

Czarnowski, Gabriele. Vom „reichen Material ... einer wissenschaftlichen Arbeitsstätte“. Zum Problem missbräuchlicher medizinischer Praktiken an der Grazer Universitäts-Frauenklinik in der Zeit des Nationalsozialismus. In: Wolfgang Freidl/Werner Sauer (Hrsg.): NS-Wissenschaft als Vernichtungsinstrument. Rassenhygiene, Zwangssterilisation, Menschenversuche und NS-Euthanasie in der Steiermark. Wien 2004, S. 225-273.

Czarnowski, Gabriele. „... das unheilbar Erkrankte aus dem Volkswachstum ausschalten“. Politische Gynäkologie an den Berliner Universitätsfrauenkliniken im Nationalsozialismus. In: Sabine Schleiermacher/Udo Schagen (Hrsg.): Die Charité im Dritten Reich. Die Indienstnahme der medizinischen Wissenschaft im Nationalsozialismus. Paderborn 2007, S. $133-150$

Czarnowski, Gabriele. Österreichs „Anschluss“ an Nazi-Deutschland und die österreichische Gynäkologie. In: Christoph Anthuber/Matthias W. Beckmann/Johannes Dietl/Fritz Dross/Wolfgang Frobenius (Hrsg.): Herausforderungen. 100 Jahre Bayerische Gesellschaft für Geburtshilfe und Frauenheilkunde. Stuttgart 2012, S. 138-148.

Damskis, Linda Lucia. Zerrissene Biografien. Jüdische Ärzte zwischen nationalsozialistischer Verfolgung, Emigration und Wiedergutmachung. München 2009.

David, Matthias/Ebert, Andreas D. (Hrsg.). Geschichte der Berliner Universitäts-Frauenkliniken. Strukturen, Personen und Ereignisse in und außerhalb der Charité. Berlin/New York 2010

David, Matthias/Ebert, Andreas D. Günther Karl Friedrich Schultze und das Hysterosalpingografiegerät. In: Geburtshilfe und Frauenheilkunde 72, 5 (2012), S. 376-377.

David, Matthias/Ebert, Andreas D. Medizin im Nationalsozialismus. Der nationalsozialistische „Lebensborn e. V.“ - Anmerkungen zur Rolle der beratenden Gynäkologen. In: Geburtshilfe und Frauenheilkunde 73, 3 (2013), S. 211-212.

David, Matthias/Stürzbecher, Manfred/Ebert, Andreas D. Paul Ferdinand Straßmann. Vertreter einer Berliner Ärztedynastie. In: Andreas D. Ebert/ Hans Karl Weitzel (Hrsg.): Die Berliner Gesellschaft für Geburtshilfe und Gynäkologie 1844-1944. Berlin/New York 1994, S. 146-160. 
David, Matthias. Albert (1860-1941) und Gustav (1893-1980) Döderlein. In: Matthias David/Andreas D. Ebert (Hrsg.): Berühmte Frauenärzte in Berlin. Frankfurt am Main 2007, S. 89-100.

David, Matthias. Paul Ferdinand Straßmann (1866-1938). In: Matthias David/Andreas D. Ebert (Hrsg.): Berühmte Frauenärzte in Berlin. Frankfurt am Main 2007, S. 101-112.

David, Matthias. Von der Sinnlosigkeit des Krieges - zum Tod von Wilhelm Breipohl und Paul Caffier am 1. Mai 1945. In: Matthias David/Andreas D. Ebert (Hrsg.): Berühmte Frauenärzte in Berlin. Frankfurt am Main 2007, S. $181-189$

David, Matthias. Walter Stoeckel (1871-1961). In: Matthias David/Andreas D. Ebert (Hrsg.): Berühmte Frauenärzte in Berlin. Frankfurt am Main 2007, S. $113-122$.

Decker, Karola. Divisions and Diversity. The Complexities of Medical Refuge in Britain, 1933-1948. In: Bulletin of History of Medicine 77, 4 (2003), S. 850-873.

Deichmann, Ute. Flüchten, Mitmachen, Vergessen. Chemiker und Biochemiker in der NS-Zeit. Weinheim u. a. 2001.

Der Stürmer. Deutsches Wochenblatt zum Kampf um die Wahrheit, hrsg. von Julius Streicher. Nürnberg 1923-1945.

Deutsche Biographische Enzyklopädie. 12 Bde., hrsg. von Rudolf Vierhaus. 2., überarb. und erw. Ausg. München 2005-2008.

Dienel, Christiane. Das 20. Jahrhundert (I). Frauenbewegung, Klassenjustiz und das Recht auf Selbstbestimmung der Frau. In: Robert Jütte (Hrsg.): Geschichte der Abtreibung. Von der Antike bis zur Gegenwart. München 1993, S. 140-167.

Dietrich, Johannes. Nachruf für einen Freund [Hans Baatz]. In: Der Frauenarzt 37, 10 (1996), S. 1532-1534.

Döderlein, Albert. Die Eingriffe zur Unfruchtbarmachung der Frau. In: Arthur Gütt/Ernst Rüdin/Falk Ruttke (Hrsg.): Gesetz zur Verhütung erbkranken Nachwuchses vom 14. Juli 1933 (mit Auszug aus dem Gesetz gegen gefährliche Gewohnheitsverbrecher und über Maßregeln der Sicherung und Besserung vom 24. Nov. 1933). München 1934, S. 224-227.

Döderlein, Gustav. Ärztliche Schwangerschaftsvorsorge und ihre gesetzliche Regelung. In: Archiv für Gynäkologie 173 (1942), S. 175-196.

Döderlein, Gustav. Georg August Wagner [Nachruf]. In: Zentralblatt für Gynäkologie 69 (1947), S. 1045.

Doetz, Susanne/Kopke, Christoph. Die antisemitischen Kampagnen und Verfolgungsmaßnahmen gegen die jüdische Ärzteschaft seit 1933. In: Thomas Beddies/Susanne Doetz/Christoph Kopke (Hrsg.): Jüdische Ärztinnen und Ärzte im Nationalsozialismus. Entrechtung, Vertreibung, Ermordung. Berlin 2014, S. 16-35.

Doetz, Susanne. „Daß uns der liebe Herrgott hat so klein bleiben lassen, nun dafür können wir ja schließlich nichts“. Widerspruch und Eigen-Sinn zwangssterilisierter Frauen. In: Medizin, Gesellschaft und Geschichte 30 (2011), S. 111-127.

Doetz, Susanne. Alltag und Praxis der Zwangssterilisation. Die Berliner Universitätsfrauenklinik unter Walter Stoeckel 1942-1944. Berlin 2011.

Dohm, Georg. Geschichte der Histopathologie. Berlin 2001.

Domagk, Gerhard. Chemotherapie der bakteriellen Infektion. In: Archiv für Gynäkologie 173 (1942), S. 431-459.

Doneith, Thorsten. August Mayer - Direktor der Universitäts-Frauenklinik Tübingen 1917-1949. Tübingen 2007.

Doneith, Thorsten. August Mayer. Ein Klinikdirektor in Weimarer Republik, Nationalsozialismus und Nachkriegszeit. Stuttgart 2008.
Dressel, Katrin. Leben und wissenschaftliches Werk des Gynäkologen Robert Schröder (1884-1959). Leipzig 2001.

Drexler-Gormann, Birgit. Jüdische Ärzte in Frankfurt am Main 19331945. Isolation, Vertreibung, Ermordung. Frankfurt am Main 2009.

Dross, Fritz. „Von den Juden, die nicht mehr in der Gesellschaft sein dürfen ..." - „Gleichschaltung“ und „Arisierung“ am Beispiel der BGGF. In: Christoph Anthuber/Matthias W. Beckmann/Johannes Dietl/Fritz Dross/Wolfgang Frobenius (Hrsg.): Herausforderungen. 100 Jahre Bayerische Gesellschaft für Geburtshilfe und Frauenheilkunde. Stuttgart 2012, S. 95-114.

Drüll, Dagmar. Heidelberger Gelehrtenlexikon 1803-1932. Berlin/Heidelberg 1986.

Dusemund, Klaus. Die Geschichte der Frauenklinik an der Universität Düsseldorf 1907-1971. Düsseldorf 1973.

Eben, Antonia K./Frewer, Andreas. Philosophie, Medizin und Religion. Ärztliche Ethik in Leben und Werk von Albert Niedermeyer. In: Andreas Frewer (Hrsg.): Medizingeschichte und Medizinethik. Kontroversen und Begründungsansätze 1900-1950. Frankfurt am Main/New York 2001, S. 247-276.

Eberle, Henrik. Die Martin-Luther-Universität in der Zeit des Nationalsozialismus. Halle/Saale 2002.

Eberle, Henrik. „Ein wertvolles Instrument“. Die Universität Greifswald im Nationalsozialismus. Köln 2015.

Ebert, Andreas D./David, Matthias. August Eduard Martin. Werden und Wirken eines deutschen Frauenarztes. In: Andreas D. Ebert/Hans Karl Weitzel (Hrsg.): Die Berliner Gesellschaft für Geburtshilfe und Gynäkologie 1844-1944. Berlin/New York 1994, S. 76-92.

Ebert, Andreas D./David, Matthias. Eduard Arnold Martin - Gründer der Berliner Gesellschaft für Gynäkologie. In: Andreas D. Ebert/Hans Karl Weitzel (Hrsg.): Die Berliner Gesellschaft für Geburtshilfe und Gynäkologie 1844-1944. Berlin/New York 1994, S. 25-37.

Ebert, Andreas D./David, Matthias. Das Born-Fraenkel'sche Gesetz - zur Erinnerung an Ludwig Fraenkel (1870-1951). In: Geburtshilfe und Frauenheilkunde 74 (2014), S. 920-922.

Ebert, Andreas D./David, Matthias. Die Erfindung der Kolposkopie. Hans Hinselmann (1884-1959): „Von Anfang an stand über diesem Unternehmen ein unglücklicher Stern.“ In: Geburtshilfe und Frauenheilkunde 74, 7 (2014), S. 631-633.

Ebert, Andreas D./David, Matthias. Von Wien über Prag nach Berlin. Georg August Wagner (1873-1947) - ein Operateur macht Schule. In: Geburtshilfe und Frauenheilkunde 74 (2014), S. 43-45.

Ebert, Andreas D./David, Matthias. Heinrich Martius (1885-1965) - ein wenig Bekanntes und etwas Vergessenes aus seinem Leben. In: Geburtshilfe und Frauenheilkunde 75, 9 (2015), S. 897-899.

Ebert, Andreas D./David, Matthias. Hermann Knaus und „die periodische Fruchtbarkeit und Unfruchtbarkeit des Weibes“. In: Geburtshilfe und Frauenheilkunde 75 (2015), S. 39-40.

Ebert, Andreas D./David, Matthias. „Es muss gelingen!“ - Georg Winter (1856-1946) und die Anfänge der „Krebsbekämpfung durch Früherfassung“ in Ostpreußen. In: Geburtshilfe und Frauenheilkunde 76, 3 (2016), S. $235-238$

Ebert, Andreas D./Namal, Arin. Wilhelm Gustav Liepmann (1878-1939). Vertreibung vom ersten Lehrstuhl für Soziale Gynäkologie an der Berliner Universität ins Exil an die Universität Istanbul. In: Matthias David/Andreas D. Ebert (Hrsg.): Geschichte der Berliner Universitäts-Frauenkliniken. Strukturen, Personen und Ereignisse in und außerhalb der Charité. Berlin/New York 2010, S. 238-250. 
Ebert, Andreas D./Weitzel, Hans Karl (Hrsg.). Die Berliner Gesellschaft für Geburtshilfe und Gynäkologie 1844-1944. Berlin/New York 1994, S. 146160.

Ebert, Andreas D. Wilhelm Alexander Freund (1833-1917). In: Matthias David/Andreas D. Ebert (Hrsg.): Berühmte Frauenärzte in Berlin. Frankfurt am Main 2007, S. 35-66.

Ebert, Andreas D. Wilhelm Gustav Liepmann (1878-1939). In: Matthias David/Andreas D. Ebert (Hrsg.): Berühmte Frauenärzte in Berlin. Frankfurt am Main 2007, S. 123-150.

Ebert, Andreas D. Es kommt nicht darauf an, wer Recht hat, sondern was richtig ist. Robert Meyers Wirken an den Frauenkliniken der königlichen Charité (1908-1912) und der Berliner Friedrich-Wilhelms-Universität (1912-1939). In: Matthias David/Andreas D. Ebert (Hrsg.): Geschichte der Berliner Universitäts-Frauenkliniken. Strukturen, Personen und Ereignisse in und außerhalb der Charité. Berlin/New York 2010, S. 219-237.

Eckart, Wolfgang Uwe. Medizin in der NS-Diktatur. Ideologie, Praxis, Folgen. Wien 2012.

Eckelmann, Christine. Ärztinnen in der Weimarer Zeit und im Nationalsozialismus. Eine Untersuchung über den Bund Deutscher Ärztinnen. Wermelskirchen 1992.

Ehrhardt, Karl. Atmet das Kind im Mutterleib? Eine röntgenologische Studie. In: Münchener Medizinische Wochenschrift 86 (1939), S. 915-918.

Ehrhardt, Karl. Weitere Erfahrungen mit meiner Methode der intraamnialen Thoriuminjektion (Fetale Organographie). In: Zentralblatt für Gynäkologie 65 (1941), S. 114-120.

Ehrler, Paul. Als Gynäkologen „Arier“ sein sollten. Ein medizin-historisches Dokument aus den dreissiger Jahren. In: Der Bund 5 (1978), o. S.

Einhaus, Carola. Zwangssterilisation in Bonn (1934-1945). Die medizinischen Sachverständigen vor dem Erbgesundheitsgericht. Köln/Weimar/ Wien 2006.

Engelhardt, Dietrich von (Hrsg.). Biographische Enzyklopädie deutschsprachiger Mediziner. Bd. 1: A-Q; Bd. 2: R-Z. München 2002.

Engelmann, Isa. Reichenberg und seine jüdischen Bürger. Zur Geschichte einer einst deutschen Stadt in Böhmen. Münster i. W. 2012.

Erichsen, Regine. Medizinemigration in die Türkei. In: Albrecht Scholz/Caris-Petra Heidel (Hrsg.): Emigrantenschicksale. Einfluss der jüdischen Emigranten auf Sozialpolitik und Wissenschaft in den Aufnahmeländern. Frankfurt am Main 2004, S. 65-82.

Esch, Peter. Friedrich Kirstein [Nachruf]. In: Zentralblatt für Gynäkologie 43 (1937), S. 2574-2576.

Esch, Peter. Die Bedeutung der Volksaufklärung für die Krebsbekämpfung. In: Archiv für Gynäkologie 173 (1942), S. 41-55.

Eymer, Heinrich. Die Eingriffe zur Unfruchtbarmachung der Frau. In: Arthur Gütt/Ernst Rüdin/Falk Ruttke (Hrsg.): Gesetz zur Verhütung erbkranken Nachwuchses vom 14. Juli 1933 nebst Ausführungsverordnungen. München 1936, S. 327-346.

Eymer, Heinrich. Hans Albrecht [Nachruf]. In: Münchener Medizinische Wochenschrift 91 (1944), S. 390-391.

Fangerau, Heiner. Urologie im Nationalsozialismus. Eine medizinische Fachgesellschaft zwischen Professionalisierung und Vertreibung. In: Matthis Krischel/Friedrich H. Moll/Julia Bellmann/Albrecht Scholz/Dirk Schultheiss (Hrsg.): Urologen im Nationalsozialismus. Zwischen Anpassung und Vertreibung, Bd. 1. Berlin 2011, S. 13-21.

Fauvet, Egon. Die vaginale Operation des Cervixkrebses (Schuchardt, Schauta, Amreich). In: Nikolai Guleke/Rudolf Zenker (Hrsg.): Allgemeine und spezielle chirurgische Operationslehre. Begründet von Martin Kirsch- ner. 2. Aufl., 9. Bd.: Karl-Günther Ober/Helmut Meinrenken (Hrsg.): Gynäkologische Operationen. Berlin/Göttingen u. a. 1964, S. 210-241.

Fikentscher, Richard. Ludwig Nürnberger [Nachruf]. In: Zentralblatt für Gynäkologie 30 (1959), S. 1169-1172.

Fischer $=$ Fischer, Isidor (Hrsg.). Biographisches Lexikon der hervorragenden Ärzte der letzten fünfzig Jahre. Bd. 1: Aaser - Komoto [Erstausgabe Berlin/Wien 1932]. München 1962; Bd. 2: Kon - Zweig; Nachträge und Berichtigungen [Erstausgabe Berlin/Wien 1933]. München 1962; Bd.3: Nachträge und Ergänzungen. Abu - Korn, bearb. und hrsg. von Peter Voswinckel. Hildesheim 2002.

Fischer, Eugen. [Ärztliche Eingriffe aus Gründen der Eugenik]. In: Archiv für Gynäkologie 156 (1934), S. 117-128.

Fischer, Eugen. [Schlusswort]. In: Archiv für Gynäkologie 156 (1934), S. $160-161$.

Forsbach, Ralf/Hofer, Hans-Georg. Die Deutsche Gesellschaft für Innere Medizin in der NS-Zeit. Ausstellung aus Anlass des 121. Kongresses der Deutschen Gesellschaft für Innere Medizin, 18.-21. April 2015 in Mannheim. Wiesbaden 2015.

Forsbach, Ralf. Die Medizinische Fakultät der Universität Bonn im „Dritten Reich“. München 2006.

Fraenkel, Ludwig. [Schlusswort]. In: Archiv für Gynäkologie 144 (1931), S. 379-383.

Fraenkel, Ludwig. Sterilisierung und Konzeptionsverhütung. In: Archiv für Gynäkologie 144 (1931), S. 86-132.

Franken, Franz Hermann. Auf schmalem Grat. Erinnerungen an eine bürgerliche Jugend in Deutschland. Bern/München/Wien 1990.

Franken, Irene/Schäfer, Daniel. Professionelles Handeln in der Diktatur. Hans Christian Naujoks und die deutsche Frauenheilkunde während des „Dritten Reiches“. In: Dominik Groß/Axel Karenberg/Stefanie Kaiser/Wolfgang Antweiler (Hrsg.): Medizingeschichte in Schlaglichtern. Beiträge des „Rheinischen Kreises der Medizinhistoriker“. Kassel 2011, S. 243-250.

Franken, Irene. ,... dass ich kein rabiater Nationalsozialist gewesen bin“. NS-Medizin an Kölner Unikliniken am Beispiel von Hans C. Naujoks (1892-1959), Direktor der Universitäts-Frauenklinik. In: 100 Jahre Klinik „auf der Lindenburg“. Festschrift des Universitätsklinikums Köln, hg. vom Vorstand der Uniklinik Köln. Köln 2008, S. 99-134.

Frewer, Andreas. Medizin und Moral in Weimarer Republik und Nationalsozialismus. Die Zeitschrift „Ethik“ unter Emil Abderhalben. Frankfurt am Main 2000.

Frigyesi, Josef von. Stephan v. Tóth [Nachruf]. In: Zentralblatt für Gynäkologie 2 (1936), S. 65-70.

Frobenius, Wolfgang/Kinzelbach, Annemarie/Anthuber, Christoph/Dross, Fritz. German gynecologic societies investigating their Nazi past. In: Archives of Gynecology and Obstetrics 290, 5 (2014), S. 925-928.

Frobenius, Wolfgang/Kinzelbach, Annemarie/Dross, Fritz. Die bayerischen Gynäkologen und ihre Fachgesellschaft im Nationalsozialismus. In: Matthis Krischel/Mathias Schmidt/Dominik Groß (Hrsg.): Medizinische Fachgesellschaften im Nationalsozialismus. Bestandsaufnahme und Perspektiven. Berlin 2016, S. 115-127.

Frobenius, Wolfgang/Thoms, Ulrike/Dross, Fritz. Mühsame Spurensuche in fremden Archiven. In: Geburtshilfe und Frauenheilkunde 74, 9 (2014), S. 802-803.

Frobenius, Wolfgang. Ludwig Fraenkel. „spiritus rector“ of the early progesterone research. In: European Journal of Obstetrics \& Gynecology and Reproductive Biology 83 (1999), S. 115-119. 
Frobenius, Wolfgang. Röntgenstrahlen statt Skalpell. Die Universitäts-Frauenklinik Erlangen und die Geschichte der gynäkologischen Radiologie von 1914-1945. Erlangen 2003.

Frobenius, Wolfgang. Abtreibungen bei „Ostarbeiterinnen“ in Erlangen. Hochschulmediziner als Helfershelfer des NS-Regimes. In: Andreas Frewer/Günther Siedbürger (Hrsg.): Medizin und Zwangsarbeit im Nationalsozialismus. Einsatz und Behandlung von „Ausländern“ im Gesundheitswesen. Frankfurt am Main/New York 2004, S. 283-307.

Frobenius, Wolfgang. „The Rabbits are Prepared ...“ The Development of Ethinylestradiol and Ethinyltestosterone. In: Journal für Reproduktionsmedizin und Endokrinologie 8, Special Issue 1 (2011), S. 32-75.

Frobenius, Wolfgang. BGGF-Ehrenmitglieder und das „Dritte Reich“. In: Christoph Anthuber/Matthias W. Beckmann/Johannes Dietl/Fritz Dross/ Wolfgang Frobenius (Hrsg.): Herausforderungen. 100 Jahre Bayerische Gesellschaft für Geburtshilfe und Frauenheilkunde. Stuttgart 2012, S.115137.

Frobenius, Wolfgang. Die Strahlentherapie auf den BGGF-Tagungen von 1912 bis 1939. In: Christoph Anthuber/Matthias W. Beckmann/Johannes Dietl/Fritz Dross/Wolfgang Frobenius (Hrsg.): Herausforderungen. 100 Jahre Bayerische Gesellschaft für Geburtshilfe und Frauenheilkunde. Stuttgart 2012, S. 60-86

Frobenius, Wolfgang. Die Wiederbesetzung der gynäkologisch-geburtshilflichen Lehrstühle in Bayern nach 1945. In: Christoph Anthuber/Matthias W. Beckmann/Johannes Dietl/Fritz Dross/Wolfgang Frobenius (Hrsg.): Herausforderungen. 100 Jahre Bayerische Gesellschaft für Geburtshilfe und Frauenheilkunde. Stuttgart 2012, S. 149-185.

Frobenius, Wolfgang. 125 Jahre Frauenklinik der Universität Tübingen [Unveröffentlichtes Manuskript, 2015].

Fuchs, Hans/Lork, Erich C. Röntgenkontrollen tubarer Sterilisationen. In: Monatsschrift für Geburtshilfe und Gynäkologie 88 (1931), S. 199-212.

Fuchs, Hans. Pertubationen und Salpingostomien zur Heilung der Sterilität. In: Monatsschrift für Geburtshilfe und Gynäkologie 75 (1926), S. 5664.

Fuchs, Hans. Zur Tubensterilisierung. In: Zentralblatt für Gynäkologie 61 (1935), S. 1876-1879.

Fuchs, Hans. Eröffnungs-Ansprache. In: Archiv für Gynäkologie 173 (1942), S. $1-5$.

Gamper, Martina. „Du hast die Pflicht, gesund zu sein“. BDM-Ärztinnen in Wien. In: Ingrid Arias (Hrsg.): Im Dienste der Volksgesundheit. Frauen Gesundheitswesen - Nationalsozialismus. Wien 2006, S. 15-30.

Gante, Michael. Das 20. Jahrhundert. Rechtspolitik und Rechtswirklichkeit 1927-1976. In: Robert Jütte: Geschichte der Abtreibung. Von der Antike bis zur Gegenwart. München 1993, S. 169-207.

Garz, Detlef/Janssen, Gesine. Über den Mangel an Charakter des deutschen Volkes. Zu den autobiographischen Aufzeichnungen des jüdischen Arztes und Emigranten Dr. Julian Kretschmer aus Emden. Oldenburg 2006.

Gauß, Carl Joseph. Die Anwendung der Strahlenmenolyse bei der gesetzlichen Unfruchtbarmachung der Frau. In: Münchener Medizinische Wochenschrift 82 (1935), S. 488-492.

Gebhardt, Miriam. Als die Soldaten kamen. Die Vergewaltigung deutscher Frauen am Ende des Zweiten Weltkriegs. 2. Aufl. München 2015.

Generalversammlung. In: Archiv für Gynäkologie 156 (1934), XLVII-LIX.

Generalversammlung. In: Archiv für Gynäkologie 161 (1936), S. 13-23.

Gerber, David A. Anti-Semitism in American History. Urbana 1986.

Gerst, Thomas. Ärztliche Standesorganisation und Standespolitik in Deutschland 1945-1955. Stuttgart 2004.
Gerst, Thomas. Ein Schriftleiter muss gehen: Dr. med. Siegmund Vollmann. In: Deutsches Ärzteblatt 1-2/2005, A33-A34.

Geschäftssitzung. In: Archiv für Gynäkologie 144 (1931), XLVIII-LIX.

GK 1928 = Deutscher Gynäkologenkalender. Biographisch-bibliographisches Verzeichnis der deutschen Frauenärzte, hrsg. von Walter Stoeckel, bearb. von Friedrich Michelsson. Leipzig 1928.

GK 1939 = Deutsches Gynäkologen-Verzeichnis. Wissenschaftlicher Werdegang und wissenschaftliches Schaffen deutscher Gynäkologen, hrsg. von Walter Stoeckel, bearb. von Friedrich Michelsson. 2. Aufl. Leipzig 1939.

Goebbels, Joseph. Tagebücher, hrsg. von Elke Fröhlich. Teil I: Aufzeichnungen 1923-1941, 14 Bde. München 1998-2005; Teil II: Diktate 1941-1945, 15 Bde. München 1993-1996; Teil III: Register mit Einleitung zur Gesamtedition (1923-1945), 3 Bde. München 2007-2008.

Golczewski, Frank. Kölner Universitätslehrer und der Nationalsozialismus. Personengeschichtliche Ansätze. Köln 1988.

Goschler, Constantin. Wissenschaftliche „Vereinsmenschen“. Wissenschaftliche Vereine in Berlin im Spannungsfeld von Wissenschaft und Öffentlichkeit. In: Constantin Goschler (Hrsg.): Wissenschaft und Öffentlichkeit in Berlin 1870-1930. Stuttgart 2000, S. 31-63.

Göz, Hans. Bisherige Erfahrungen mit der eugenischen Sterilisierung. In: Archiv für Gynäkologie 161 (1936), S. 452-458.

Göz, Hans. Bemerkungen zum Ehegesundheitsgesetz vom Standpunkt des Erbgesundheitsrichters. In: Beiträge zur Klinik der Tuberkulose und spezifischen Tuberkulose-Forschung 89, 6 (1937), S. 759-768.

Grimm, Jana. Zwangssterilisation von Mädchen und Frauen während des Nationalsozialismus. Eine Analyse der Krankenakten der UniversitätsFrauenklinik Halle von 1934 bis 1945. Halle/Saale 2003.

Grosch, Helmut. Carl Clauberg und die Bevölkerungspolitik des Nationalsozialismus. In: Eckhard Heesch (Hrsg.): Heilkunst in unheilvoller Zeit. Frankfurt am Main 1993, S. 85-118.

Grunau, Martin. Der Schwachsinn im Erbgesundheitsverfahren. In: Zeitschrift der Akademie für Deutsches Recht 3 (1935), S. 769-776.

Grundmann, Kornelia. Der Einfluß der politischen Organisationen auf den Lehrkörper der Medizinischen Fakultät. In: Gerhard Aumüller/Kornelia Grundmann/Esther Krähwinkel/Hans H. Lauer/Helmut Remschmidt (Hrsg.): Die Marburger Medizinische Fakultät im „Dritten Reich“. München 2011, S. 168-204.

Grundmann, Kornelia. Die Berufungsverfahren. In: Gerhard Aumüller/Kornelia Grundmann/Esther Krähwinkel/Hans H. Lauer/Helmut Remschmidt (Hrsg.): Die Marburger Medizinische Fakultät im „Dritten Reich“. München 2011, S. 249-280.

Grüßner, Susanne. Hans Roemer (1907-1973). In: Wolfgang Künzel/Jost Benedum (Hrsg.): Vom Accuchierhaus zur Frauenklinik. 175 Jahre Klinik für Geburtshilfe und Frauenheilkunde in Gießen. Gießen 1989, S. 249255.

Grüttner, Michael/Kinas, Sven. Die Vertreibung von Wissenschaftlern aus den deutschen Universitäten 1933-1945. In: Vierteljahrshefte für Zeitgeschichte 55 (2007), S. 123-186.

Grüttner, Michael. Studenten im Dritten Reich. Geschichte der deutschen Studentenschaft 1933-1945. Paderborn 1995.

Grüttner, Michael. Biographisches Lexikon zur nationalsozialistischen Wissenschaftspolitik. Heidelberg 2004.

Grüttner, Michael. Das Dritte Reich 1933-1939 (Gebhardt Handbuch der deutschen Geschichte 19). Stuttgart 2014.

Guggisberg, Hans. Der Hinterlappen der Hypophyse. In: Archiv für Gynäkologie 144 (1931), S. 185-216. 
Gütt, Arthur/Rüdin, Ernst/Ruttke, Falk (Hrsg.). Gesetz zur Verhütung erbkranken Nachwuchses vom 14. Juli 1933 nebst Ausführungsverordnungen. 2., neubearb. Aufl. München 1936.

Guy, Donna J. Women Build the Welfare State. Performing Charity and Creating Rights in Argentina, 1880-1955. Durham/London 2009.

GW 1956 = Gauß, Carl Joseph/Wilde, Bernhard: Die deutschen Geburtshelferschulen. Bausteine zur Geschichte der Geburtshilfe. München-Gräfelfing 1956.

GzVeN = Gesetz zur Verhütung erbkranken Nachwuchses vom 14. Juli 1933. In: Reichsgesetzblatt Jg. 1933 I, Nr. 86, S. 529-531.

Hadrich, Julius. Die nichtarischen Ärzte in Deutschland. In: Deutsches Ärzteblatt 51 (1934), S. 1243-1245.

Hagene, Claudia. Heinrich Martius (1885-1965). Göttinger Gynäkologe und Wissenschaftler. Göttingen 2006.

Hahn, Daphne. Biopolitik und Modernisierung. Sterilisation und Schwangerschaftsabbruch in Deutschland nach 1945. Frankfurt am Main 2000.

Halling, Thorsten/Moll, Friedrich H./Fangerau, Heiner. Urologie 19451990. Entwicklung und Vernetzung der Medizin in beiden deutschen Staaten. Berlin/Heidelberg 2015.

Handbuch österreichischer Autorinnen und Autoren jüdischer Herkunft, 18. bis 20. Jahrhundert. Bd.1: A-I; Bd.2: J-R; Bd. 3: S-Z, hrsg. von der Österreichischen Nationalbibliothek. München 2002.

Hansson, Nils/Peters, Anja/Tammiksaar, Erki. Sterilisierungsoperateur und Forscher: Leben und Karriere Benno Ottows (1884-1975). In: Medizinhistorisches Journal 46, 3/4 (2011), S. 212-237.

Haselhorst, Gustav. Ergebnisse der Klinikentbindung (Sammelstatistik aus 27 Universitäts-Frauenkliniken und Hebammenlehranstalten). In: Archiv für Gynäkologie 173 (1942), S. 247-254.

Haselwarter, Robert. Zusammenstellung der vom 1. Januar 1934 bis 1. Juli 1937 aus eugenischen Gründen vorgenommenen Sterilisierungen an der I. Universitäts-Frauenklinik München. München 1939.

Heiber, Helmut. Universität unterm Hakenkreuz, Teil 2, Bd. 1. München 1992.

Heidel, Caris-Petra/Lienert, Marina (Hrsg.). Die Professoren der Medizinischen Fakultät Carl Gustav Carus Dresden und ihrer Vorgängereinrichtungen 1814-2004. München 2005

Heidel, Caris-Petra. Ärzte und Zahnärzte in Sachsen 1933-1945. Eine Dokumentation von Verfolgung, Vertreibung, Ermordung. Frankfurt am Main 2005.

Heitkötter, Birthe Franziska. Die Geschichte der Frauenklinik der Universitätsklinik der Westfälischen Wilhelms-Universität Münster (Westf.) in den Jahren 1925-1950 unter besonderer Berücksichtigung der Jahre im Nationalsozialismus unter der Leitung des Klinikdirektors Peter Esch. Münster i. W. 2012.

Heitzer, Horst W. Zwangssterilisation in Passau. Die Erbgesundheitspolitik des Nationalsozialismus in Ostbayern. Köln/Weimar/Wien 2005.

Hem, Erlend/Børdahl, Per E. „Nu er jeg beskeden. Og mer enn det.“ Fra Tyskland til Norge i 1934. In: Tidsskrift for Den norske legeforening 120 (2000), S. 3683-3687.

Herber, Friedrich. Gerichtsmedizin unterm Hakenkreuz. Leipzig 2002.

Heuvelmann, Magdalene. Auf dem Weg zur Abschaffung der weiblichen Mutterschaft? Deutschsprachige akademische Gynäkologie 1920 bis 1939. Frankfurt am Main 1999
Hilberg, Raul. Die Vernichtung der europäischen Juden. Die Gesamtgeschichte des Holocaust, hrsg. von Ulf Wolter, übers. von Christian Seeger u. a. Berlin 1982.

Hildebrandt, Sabine. The Anatomy of Murder. Ethical Transgressions and Anatomical Science During the Third Reich. New York 2016.

Hinselmann, Hans. [Schlusswort]. In: Archiv für Gynäkologie 156 (1934), S. 305.

Hinz, Georg/Ebert, Andreas D./Goetze, Birgit. Der Exodus. Robert Meyer, Selmar Aschheim und Bernhard Zondek. Drei Namen für Tausende. In: Andreas D. Ebert/Hans Karl Weitzel (Hrsg.): Die Berliner Gesellschaft für Geburtshilfe und Gynäkologie 1844-1944. Berlin/New York 1994, S. 206 242.

Hinz-Wessels, Annette. NS-Erbgesundheitsgerichte und Zwangssterilisation in der Provinz Brandenburg. Berlin 2004.

Hirsch, Max. Mutterschaftsfürsorge. In: Archiv für Gynäkologie 144 (1931), S. 34-85.

Höffken, Bernd. Schicksale jüdischer Ärzte aus Nürnberg nach 1933. Berlin 2013

Hoffmann, Christhard. Verfolgung und Alltagsleben der Landjuden im nationalsozialistischen Deutschland. In: Monika Richarz/Reinhard Rürup (Hrsg.): Jüdisches Leben auf dem Lande. Tübingen 1997, S. 373-398.

Höpfner, Hans-Paul. Die Universität Bonn im Dritten Reich. Akademische Biographien unter nationalsozialistischer Herrschaft. Bonn 1999.

Hubenstorf, Michael. Medizinische Fakultät 1938-1945. In: Gernot Heiß/ Siegfried Mattl/Sebastian Meissl/Edith Saurer/Karl Stuhlpfarrer (Hrsg.): Willfährige Wissenschaft. Die Universität Wien 1938 bis 1945 . Wien 1989 , S. 233-282.

Hubenstorf, Michael. Ende einer Tradition und Fortsetzung als Provinz. Die Medizinischen Fakultäten der Universitäten Berlin und Wien 1925-1950. In: Christoph Meinel/Peter Voswinckel (Hrsg.): Medizin, Naturwissenschaft, Technik und Nationalsozialismus. Kontinuitäten und Diskontinuitäten. Stuttgart 1994, S. 33-53.

Hübner, Jutta. Kolposkopie ohne Menschlichkeit. In: Hamburger Ärzteblatt 4 (2012), S. 34-35.

Hübner, Jutta. Verbrechen an der Menschlichkeit. In: Hamburger Ärzteblatt 2 (2015), S. 34-35.

Jahnke-Nückles, Ute. Die Deutsche Gesellschaft für Kinderheilkunde in der Zeit der Weimarer Republik und des Nationalsozialismus. Freiburg i. Br 1992.

Jahr, Christoph. Die nationalsozialistische Machtübernahme und ihre Folgen. In: Rüdiger vom Bruch/Heinz-Elmar Tenorth (Hrsg.): Geschichte der Universität Unter den Linden, Bd.2: Die Berliner Universität zwischen den Weltkriegen 1918-1945. Berlin 2012, S. 295-324.

Jahresverzeichnis der an den Deutschen Universitäten und Technischen Hochschulen erschienenen Schriften, hrsg. von der Preußischen Staatsbibliothek. 36. Jg.: 1920. Berlin 1921.

Jahresverzeichnis der an den Deutschen Universitäten und Technischen Hochschulen erschienenen Schriften, hrsg. von der Preußischen Staatsbibliothek. 39. Jg.: 1923. Berlin 1925.

Jahresverzeichnis der deutschen Hochschulschriften 1938: Zusammenfassung der in der „Deutschen Nationalbibliographie“ erschienenen Titel von Dissertationen, Habilitationsschriften, Rektoratsreden und sonstigen akademischen Veröffentlichungen, bearb. von der Deutschen Bücherei. 54. Jg. Leipzig 1939

Jaschke, Rudolf Theodor von. Ein Beitrag zu dem Thema: Unsere Aufgaben in der Bevölkerungspolitik. In: Zentralblatt für Gynäkologie 41 (1917), S. 65-81. 
Jaschke, Rudolf Theodor von. Kampf gegen die Fruchtabtreibung. In: Zentralblatt für Gynäkologie 57 (1924), S. 850-851.

Jaschke, Rudolf Theodor von. Betreuung des gesunden und kranken Neugeborenen in der geburtshilflichen Klinik. In: Bericht über die II. Tagung der Reichsarbeitsgemeinschaft für Mutter und Kind am 21. und 22. Mai 1937 in Bad Wildbad. Berlin 1937, S. 53-61.

Jaschke, Rudolf Theodor von. Eröffnungs-Ansprache zur 27. Tagung der Deutschen Gesellschaft für Gynäkologie, Karlsruhe, 20.-23. April 1949. In: Archiv für Gynäkologie 178 (1950), S. 1-8.

Jens, Walter. Eine deutsche Universität. 500 Jahre Tübinger Gelehrtenrepublik. 6. Aufl. München 1993.

Jonat, Walter/Andree, Christian/Schollmeyer, Thorwald (Hrsg.). Universitäts-Frauenklinik Kiel und Michaelis-Hebammenschule 1805-2005. Eine medizinhistorische Studie zum 200-jährigen Bestehen. Stuttgart 2005.

Jütte, Robert/Eckart, Wolfgang Uwe/Schmuhl, Hans-Walter/Süß, Winfried. Medizin und Nationalsozialismus. Bilanz und Perspektiven der Forschung. Göttingen 2011.

Kallmorgen, Wilhelm. Siebenhundert Jahre Heilkunde in Frankfurt am Main. Frankfurt am Main 1936.

Kaminsky, Uwe. Zwangssterilisation und „Euthanasie“ im Rheinland. Evangelische Erziehungsanstalten sowie Heil- und Pflegeanstalten 1933-1945. Köln 1995.

Karitzky, Holger. Eduard Kohlrausch - Kriminalpolitik in vier Systemen. Eine strafrechtshistorische Biographie. Berlin 2002.

Kästner, Ingrid. Der Frauenarzt Prof. Dr. med. Felix Otto Skutsch (18611951). In: Ärzteblatt Sachsen 24, 11 (2013), S. 486-489.

Kater, Michael H. Doctors under Hitler. Chapel Hill/London 1989.

Kaufmann, Carl. Echte Menstruation bei einer kastrierten Frau durch Zufuhr von Ovarialhormonen. In: Zentralblatt für Gynäkologie 57 (1933), S. $42-46$.

Kaufmann, Carl. Die Behandlung der Eierstocksinsuffizienz durch Keimdrüsenhormone. In: Archiv für Gynäkologie 166 (1938), S. 113-131.

Kaufmann, Doris. Geschichte der Kaiser-Wilhelm-Gesellschaft im Nationalsozialismus. Bestandsaufnahme und Perspektiven der Forschung. 2 Bde. Göttingen 2000.

Kentenich, Heribert/Rauchfuß, Martina/Diederichs, Peter (Hrsg.). Psychosomatische Gynäkologie und Geburtshilfe 1993/94. Berlin/Heidelberg 1994.

Kershaw, Ian. Hitler, Bd. 1: 1889-1936; Bd. 2: 1936-1945. Stuttgart 1998

Kinzelbach, Annemarie. Die Bayerische Gesellschaft für Geburtshilfe und Frauenheilkunde - eine Organisation von Fachärzten im historischen Kontext. In: Christoph Anthuber/Matthias W. Beckmann/Johannes Dietl/Fritz Dross/Wolfgang Frobenius (Hrsg.): Herausforderungen. 100 Jahre Bayerische Gesellschaft für Geburtshilfe und Frauenheilkunde. Stuttgart 2012, S. 7-35.

Kirchhoff, Heinz. 80. Geburtstag von Professor Dr. med. Dr. med. h. c. Heinrich Martius, Göttingen, am 2. Januar 1965. In: Die Naturwissenschaften 1 (1965), S. 1.

Kirschbaum, Michael/Herold, G. Die Baugeschichte der Gießener Frauenklinik von 1814 bis heute. In: Wolfgang Künzel/Jost Benedum (Hrsg.): Vom Accouchierhaus zur Frauenklinik. 175 Jahre Klinik für Geburtshilfe und Frauenheilkunde in Gießen. Gießen 1989, S. 267-306.

Klaesi, Jakob. Prof. Dr. med. Hans Guggisberg zum 70.Geburtstag am 5. Februar. In: Der Bund 59 (1950), S. 3.
Klee, Ernst. Das Personenlexikon zum Dritten Reich. Wer war was vor und nach 1945. Frankfurt am Main 2003.

Klee, Ernst. Auschwitz, die NS-Medizin und ihre Opfer. 2. Aufl. Frankfurt am Main 1997/4. Aufl., überarb. Neuausg. Frankfurt am Main 2008.

Kleinert, Ulrike. Radium-Jubel und Röntgen-Wertheim. Gynäkologische Radiologie an der Frankfurter Universitäts-Frauenklinik von den Anfängen bis 1938. Hildesheim 1988 .

Knaus, Hermann. Periodische Fruchtbarkeit und Unfruchtbarkeit des Weibes. Der Weg zur natürlichen Geburtenregelung. Wien 1934.

Knaus, Hermann. Über die periodische Fruchtbarkeit. In: Archiv für Gynäkologie 161 (1936), S. 122.

Köbsell, Swantje. Eingriffe. Zwangssterilisation geistig behinderter Frauen. München 1987.

Koch, Thomas. Zwangssterilisation im Dritten Reich. Das Beispiel der Universitätsklinik Göttingen. Frankfurt am Main 1994.

Köhler, Günter. Die Achse Berlin - Greifswald. Preußische Hochschulpolitik am Beispiel der Universitäts-Frauenklinik Greifswald. In: Matthias David/ Andreas D. Ebert (Hrsg.): Geschichte der Berliner Universitäts-Frauenkliniken. Strukturen, Personen und Ereignisse in und außerhalb der Charité. Berlin/New York 2010, S. 52-61.

Kohlrausch, Eduard. [Eingriffe aus eugenischer Indikation]. In: Archiv für Gynäkologie 156 (1934), S. 103-109.

Krischel, Matthis/Moll, Friedrich H./Fangerau, Heiner. Die 1907 gegründete „Deutsche Gesellschaft für Urologie“ und die „Gesellschaft Reichsdeutscher Urologen“ im Nationalsozialismus. In: Der Urologe 50, 9 (2011), S. $1154-1160$

Krischel, Matthis/Schmidt, Mathias/Groß, Dominik (Hrsg.). Medizinische Fachgesellschaften im Nationalsozialismus. Bestandsaufnahme und Perspektiven. Berlin 2016.

Kröner, Hans-Peter. Die Emigration deutschsprachiger Mediziner 19331945. Versuch einer Befundserhebung. In: Exilforschung 6 (1988), S. 83 97.

Krüger, Dorothea Irene Edith. Zwangssterilisation im Nationalsozialismus. Das „Gesetz zur Verhütung erbkranken Nachwuchses“ vom 14. Juli 1933 und seine Durchführung an der Universitäts-Frauenklinik Erlangen. Erlangen/Nürnberg 2007.

Krüger, Elisabeth/Küstner, Heinz. Frauenarbeit in der Textilindustrie. In: Archiv für Soziale Hygiene und Demographie 8 (1933/34), S. 249-251.

Kudlien, Fridolf. Ärzte im Nationalsozialismus. Köln 1985.

Kühl, Richard. Hertha Riese (1892-1981). In: Volker Sigusch/Günter Grau (Hrsg.): Personenlexikon der Sexualforschung. Frankfurt am Main/New York 2009, S. 591-593.

Kühl, Stefan. Die Internationale der Rassisten. Aufstieg und Niedergang der internationalen Bewegung für Eugenik und Rassenhygiene im 20. Jahrhundert. 2., aktual. Aufl. Frankfurt am Main 2014.

Kühn, Wolfgang/Gieseking, Friederike/Küppers, Volkmar/Lellé, Ralph J./Menton, Michael. Hans Hinselmann und die Kolposkopie im Nationalsozialismus. Der Frauenarzt 56 (2015), S. 300-302.

Kümmel, Werner F. Die Ausschaltung rassisch und politisch mißliebiger Ärzte. In: Fridolf Kudlien: Ärzte im Nationalsozialismus. Köln 1985, S. 64 66.

Künzel, Wolfgang/Oehmke, Frank. Die Präsidenten der Deutschen Gesellschaft für Gynäkologie und Geburtshilfe. Eine Synopsis von Wissenschaft und Forschung in der Gynäkologie und Geburtshilfe. Gießen 1996. 
Kürzel, Lotte. Aerztin und Nationalsozialismus. In: Ziel und Weg 4 (1934), S. 209-210.

Kwiet, Konrad/Eschwege, Helmut. Selbstbehauptung und Widerstand. Deutsche Juden im Kampf um Existenz und Menschenwürde, 1933-1945. Hamburg 1984

Labisch, Alfons/Tennstedt, Florian. Der Weg zum „Gesetz über die Vereinheitlichung des Gesundheitswesens“ vom 3. Juli 1934. Entwicklungslinien und -momente des staatlichen und kommunalen Gesundheitswesens in Deutschland, 2 Teile. Düsseldorf 1985.

Labisch, Alfons. Juristisches Urteilen - historisches Urteilen. Die Medizin im Nationalsozialismus und die Medizinische Akademie Düsseldorf nach 1945 - ein Versuch. In: Wolfgang Woelk/Frank Sparing/Karen Bayer/Michael G. Esch (Hrsg.): Nach der Diktatur. Die Medizinische Akademie Düsseldorf vom Ende des 2. Weltkriegs bis in die 1960er Jahre. Essen 2003, S. $425-453$.

Lang, Hans-Joachim. Die Frauen von Block 10. Medizinische Versuche in Auschwitz. 4. Aufl. Hamburg 2013, S. 144-166.

Lang, Hans-Joachim. Häftlingsärzte und Block 10 in Auschwitz. In: Matthis Krischel/Mathias Schmidt/Dominik Groß (Hrsg.): Medizinische Fachgesellschaften im Nationalsozialismus. Bestandsaufnahmen und Perspektiven. Berlin 2016, S. 321-331

Lang, Uwe. Rudolf Theodor Edler von Jaschke (1881-1963). In: Wolfgang Künzel/Jost Benedum (Hrsg.): Vom Accouchierhaus zur Frauenklinik. 175 Jahre Klinik für Geburtshilfe und Frauenheilkunde in Gießen. Gießen 1989, S. 219-235.

Langbein, Hermann. Menschen in Auschwitz. Wien 1972.

Lässig, Simone. Jüdische Wege ins Bürgertum. Kulturelles Kapital und sozialer Aufstieg im 19. Jahrhundert. Göttingen 2004.

Lehmann, Volker. Chronik der Frauenklinik Altona Bülowstraße. Hamburg [1995].

Lekebusch, Sigrid. Not und Verfolgung der Christen jüdischer Herkunft im Rheinland 1933-1945. Darstellung und Dokumentation. Köln 1995.

Leuthold, Gerhard. Veröffentlichungen des medizinischen Schrifttums in den Jahren 1933-1945 zum Thema „Gesetz zur Verhütung erbkranken Nachwuchses vom 14. Juli 1933“. Nürnberg 1975.

Leven, Karl-Heinz/Plöger, Andreas (Hrsg.). 200 Jahre Universitätsklinikum Erlangen. 1815-1915. Köln/Weimar/Wien 2016.

Ley, Astrid. Die Debatte um ein neues Sterilisationsgesetz in der Bundesrepublik. Zur Geschichte einer erfolglosen ärztlichen Forderung. In: Christoph Anthuber/Matthias W. Beckmann/Johannes Dietl/Fritz Dross/Wolfgang Frobenius (Hrsg.): Herausforderungen. 100 Jahre Bayerische Gesellschaft für Geburtshilfe und Frauenheilkunde, Stuttgart 2012, S. 197-205.

Lifton, Robert Jay. The Nazi Doctors. Medical Killing and the Psychology of Genocide. New York 1986.

Lisner, Wiebke. „Hüterinnen der Nation“. Hebammen im Nationalsozialismus. Frankfurt am Main/New York 2006.

Liste 1 des schädlichen und unerwünschten Schrifttums. Stand vom Okt. 1935, hrsg. von der Reichsschrifttumskammer. Berlin 1935.

Liste des schädlichen und unerwünschten Schrifttums. Stand vom 31. Dez. 1938, hrsg. von der Reichsschrifttumskammer. Leipzig 1938.

Longerich, Peter. „Davon haben wir nichts gewusst!“ Die Deutschen und die Judenverfolgung 1933-1945. München 2006.

Lönne, Friedrich. Früherfassung des weiblichen Genitalcarcinoms durch Aufklärungspropaganda und Vorsichtsuntersuchungen. In: Archiv für Gynäkologie 173 (1942), S. 67-80.
Lövset, Jörgen. Schulterentwicklung ohne Armlösung bei natürlicher und künstlicher Beckenendlage. In: Archiv für Gynäkologie 161 (1936), S. 397-398.

Ludwig, Fritz. Prof. Guggisberg zum 70. Geburtstag. In: Schweizerische Medizinische Wochenschrift 10 (1950), S. 265-266.

Ludwig, Hans. Zur Gründung der Deutschen Gesellschaft für Gynäkologie und Geburtshilfe. In: Lutwin Beck (Hrsg.): Zur Geschichte der Gynäkologie und Geburtshilfe. Aus Anlaß des 100jährigen Bestehens der Deutschen Gesellschaft für Gynäkologie und Geburtshilfe. Berlin/Heidelberg/New York u. a. 1986, S. $9-26$.

Ludwig, Hans (Hrsg.). Die Reden. Eröffnungsansprachen zu den Kongressen der Gesellschaft 1886-1998. Berlin 1998.

Ludwig, Hans (Hrsg.). Die Reden. Eröffnungsansprachen zu den Kongressen der Gesellschaft 1886-1998. 2., erw. Aufl. Heidelberg 1999.

Ludwig, Hans. Alfred Hegar (1830-1914). Ein Name wurde zum Begriff. In: Der Gynäkologe 37 (2004), S. 176-178.

Ludwig, Hans. Ludwig Fraenkel. „Das Corpus luteum ist eine Drüse innerer Sekretion“. In: Der Gynäkologe 6 (2004), S. 723-726.

Ludwig, Hans. Die Gründung der Deutschen Gesellschaft für Gynäkologie (1885). In: Der Frauenarzt 46, 10 (2005), S. 928-932.

Ludwig, Hans. Heinrich Martius (1885-1965). Als Forscher vielseitig, als Lehrer prägnant, als Arzt mitfühlend, als Chef leise und wirksam. In: Der Gynäkologe 39 (2006), S. 1003-1008.

Ludwig, Hans/Jonat, Walter (Hrsg.). Vom Programm zur Botschaft. A short history (1886-2008) of the German Society of Gynecology and Obstetrics reviewing its 57 congresses. 2. Aufl. Düsseldorf 2008.

Mack, Cécile. Die badische Ärzteschaft im Nationalsozialismus. Frankfurt am Main 2001

MacLean, James S. The Life of Hans Hinselmann. In: Obstetrical and Gynecological Survey 34, 11 (1979), S. 788-789.

Majewski, Olaf Edward. Medizin an der Reichsuniversität Posen (19411945) und der polnischen Untergrunduniversität der westlichen Gebiete U. Z. Z. (1942-1945). Heidelberg 2012.

Maria-Hix, Ilse. Zwangssterilisierungen. Eine spezielle Form der NS-Frauenpolitik. In: Annette Kuhn (Hrsg.): Frauenleben im NS-Alltag. Bonner Studien zur Frauengeschichte. Pfaffenweiler 1994, S. 232-245.

Martius, Goetz-Alexander. 1933-1945. Auch das geschah in Deutschland: Martius zum Beispiel. Neustadt/Aisch 2002/03.

Martius, Heinrich. [Diskussionsbeitrag]. In: Archiv für Gynäkologie 156 (1934), S. 292.

Martius, Heinrich. Otto von Franqué [Nachruf]. In: Zentralblatt für Gynäkologie 61 (1937), S. 1265-1276.

Martius, Heinrich. Eröffnung des 4. und letzten Kongreßtages. In: Archiv für Gynäkologie 180 (1951), S. 288.

Martius, Heinrich. Eröffnungs-Ansprache zur 28. Tagung der Deutschen Gesellschaft für Gynäkologie, Bad Pyrmont, 4.-8. April 1951. In: Archiv für Gynäkologie 180 (1951), S. 1-14.

Martius, Martius. Hans Hinselmann [Nachruf]. In: Deutsche Medizinische Wochenschrift 84 (1959), S. 1423-1425.

Martius, Heinrich. Hans C. Naujoks [Nachruf]. In: Geburtshilfe und Frauenheilkunde 20 (1960), S. 880-882.

Mayer, August. Eröffnungs-Ansprache zur 24. Tagung der Deutschen Gesellschaft für Gynäkologie (im 50. Gründungsjahr), München, 22.-26. Oktober 1935. In: Archiv für Gynäkologie 161 (1936), S. 1-10. 
Mayer, August. Deutsche Mutter und deutscher Aufstieg. Politische Biologie, Bd. 7. München/Berlin 1938.

Mayer, August. Konservatives Operieren unter Schonung der Fortpflanzungsfähigkeit. In: Archiv für Gynäkologie 166 (1938), S. 324-326.

Mayer, August. Oberarzt und Dozent Dr. med. habil. Moritz Tausch, gest. 13.3.1939. Dem verdienten Weggenossen und unvergesslichen Toten zum Gedenken [Nachruf]. Tübingen 1939.

Mayer, August. [Schlusswort]. In: Archiv für Gynäkologie 180 (1951), S. 349 .

Medvei, Victor C. The History of Clinical Endocrinology. Carnforth 1993.

Menge, Carl. Eröffnung der XVIII. Tagung der Deutschen Gesellschaft für Gynäkologie in Heidelberg. In: Archiv für Gynäkologie 120 (1924), XXXIV-XXXV.

Menge, Carl. [Diskussionsbeitrag]. In: Archiv für Gynäkologie 161 (1936), S. 471-472.

Metzler, Gabriele. Internationale Wissenschaft und nationale Kultur. Deutsche Physiker in der internationalen Community 1900-1960. Göttingen 2000.

Metzler, Gabriele. Deutschland in den internationalen Wissenschaftsbeziehungen, 1900-1930. In: Michael Grüttner/Rüdiger Hachtmann/Konrad H. Jarausch/Jürgen John/Matthias Middell (Hrsg.): Gebrochene Wissenschaftskulturen. Universität und Politik im 20. Jahrhundert. Göttingen 2010, S. 55-82.

Meyer, Paul. Die Penicillinbehandlung in Gynäkologie und Geburtshilfe. In: Archiv für Gynäkologie 178 (1950), S. 324-327.

Meyer, Robert/Novak, Emil. Autobiography of Dr. Robert Meyer (18641947). A Short Abstract of a Long Life. With a Memoir of Dr. Meyer by Emil Novak. New York 1949.

Mikulicz-Radecki, Felix von. Sammelstatistik über eugenische Sterilisierungen bei der Frau und daraus sich ergebende Richtlinien. In: Zentralblatt für Gynäkologie 59 (1935), S. 1759-1779.

Mikulicz-Radecki, Felix von. Der Eiauffangsmechanismus bei der Frau und die sich daraus ergebenden Schlußfolgerungen für die operative Behandlung der Sterilität. In: Archiv für Gynäkologie 161 (1936), S. 128-132.

Mikulicz-Radecki, Felix von. Die Bedeutung der Vorsichtsuntersuchungen zur Förderung der Krebsfrüherfassung. In: Archiv für Gynäkologie 173 (1942), S. 56-67.

Mildenberger, Florian. Tintenfische und Frauenkörper. Leben und Werk von Boris Belonoschkin (1906-1988). In: Fachprosaforschung - Grenzüberschreitungen I (2005-2007), S. 227-246.

Mitgliederversammlung. In: Archiv für Gynäkologie 166 (1938), S. 13-20.

Mitgliederversammlung. In: Archiv für Gynäkologie 173 (1942), S. 6-12.

Mitgliederversammlung. In: Verhandlungen der Deutschen Gesellschaft für Gynäkologie. Achtundzwanzigste Versammlung, abgehalten zu Bad Pyrmont vom 4. bis 8. April 1951, hrsg. von Heinrich Martius und Hans Naujoks. München 1951, XXXI-XLI.

Mitscherlich, Alexander/Mielke, Fred (Hrsg.). Das Diktat der Menschenverachtung. Eine Dokumentation. Heidelberg 1947.

Mitscherlich, Alexander/Mielke, Fred (Hrsg.). Medizin ohne Menschlichkeit. Dokumente des Nürnberger Ärzteprozesses. Frankfurt am Main 1960.

Moll, Friedrich H./Engel, Rainer M. Zur Emigration von Urologen während der Zeit des Nationalsozialismus. In: Matthis Krischel/Friedrich H. Moll/Julia Bellmann/Albrecht Scholz/Dirk Schultheiss (Hrsg.): Urologen im Nationalsozialismus. Zwischen Anpassung und Vertreibung. Berlin 2011, S. 219-226.
Möllers, Bernhard/Reiter, Hans (Hrsg.). Erb- und Rassenpflege. Sammlung Deutscher Gesundheitsgesetze, Bd. 1. Leipzig 1940.

Mönch, Gerhard. Über die Mikropathologie des Samens. In: Archiv für Gynäkologie 161 (1936), S. 64-76.

Moser, Gabriele. Deutsche Forschungsgemeinschaft und Krebsforschung 1920-1970. Stuttgart 2011.

Moser, Gabriele. „Röntgenkunde und Volksgesundheit“. Radiologie und Röntgenologie in der NS-Erbgesundheitspolitik. In: Fortschritte auf dem Gebiet der Röntgenstrahlen und der bildgebenden Verfahren 186, 3 (2014), S. 212-217.

Moser, Roland W. Hans Guggisberg (1880-1977). Tribut an einen Schweizer Gynäkologen. In: Der Gynäkologe 47 (2014), S. 219-222.

Müller, Joachim. Sterilisation und Gesetzgebung bis 1933. Husum 1985.

Müller-Hill, Benno. Der gute Dr. Samuel. In: Helgard Kramer (Hrsg.): NS-Täter aus interdisziplinärer Perspektive. München 2006, S. 231-242.

Nadav, Daniel. Ärzte in Zwangslagen. Dr. Maximilian Samuel (1880-1943). In: Medizin und Judentum 5 (2000), S. 135-139.

Nagel, Anne Christine. Die Philipps-Universität Marburg im Nationalsozialismus. Dokumente zu ihrer Geschichte. Stuttgart 2000.

Namal, Arin. Junge jüdische Emigranten aus Deutschland und Österreich an der Medizinischen Fakultät der Universität Istanbul. In: Ingrid Kästner/Jürgen Kiefer (Hrsg.): Von Maimonides bis Einstein. Jüdische Gelehrte und Wissenschaftler in Europa. Aachen 2015, S. 225-260.

Naujoks, Hans Christian. Fruchtschädigung durch Röntgenstrahlen. In: Monatsschrift für Geburtshilfe und Gynäkologie 68, 40 (1924), S. 40-43.

Naujoks, Hans Christian. Das Problem der temporären Sterilisierung der Frau. Stuttgart 1925

Naujoks, Hans Christian. Zur Legalisierung der Schwangerschaftsunterbrechung aus eugenischer Indikation. In: Deutsche Medizinische Wochenschrift 60, 15 (1934), S. 549-552.

Naujoks, Hans Christian. Die Wandlung der deutschen Frau. Stuttgart 1935.

Naujoks, Hans Christian. Die künstliche Schwangerschaftsunterbrechung. Indikationen und Methoden. 3., vollst. umgearb. Aufl. Stuttgart 1949.

Naujoks, Hans Christian. Schwangerschaftsunterbrechung und Sterilisierung. In: Archiv für Gynäkologie 180 (1951), S. 304-319.

Neumann-Redlin von Meding, Eberhard/Conrad, Hella. Ärzte unter dem Hakenkreuz. Die Berliner Medizinische Gesellschaft im Nationalsozialismus. Berlin 2013.

Niedermeyer, Albert. [Diskussionsbeitrag]. In: Archiv für Gynäkologie 156 (1934), S. 142-149.

Niedermeyer, Albert. Wahn, Wissenschaft und Wahrheit. Lebenserinnerungen eines Arztes. Innsbruck/Wien/München 1956.

Nitschke, Asmus. Die „Erbpolizei“ im Nationalsozialismus. Zur Alltagsgeschichte der Gesundheitsämter im Dritten Reich. Das Beispiel Bremen. Opladen/Wiesbaden 1999.

Notz, Gisela. Frauen in der Mannschaft. Sozialdemokratinnen im Parlamentarischen Rat und im Deutschen Bundestag 1948/49-1957. Bonn 2003.

NS-Presseanweisungen der Vorkriegszeit. Edition und Dokumentation. Bd. 7/I: 1939, Quellentexte Januar bis April, bearb. von Karen Peter. München 2001. 
O'Dowd, Michael J./Philipp, Elliot E. The History of Obstetrics and Gynaecology. Carnforth, England 1994.

Obermann-Jeschke, Dorothee. Eugenik im Wandel. Kontinuitäten, Brüche, Transformationen. Eine diskursgeschichtliche Analyse. Münster i. W. 2008.

Oehler-Klein, Sigrid. Die Gründung einer Akademie für medizinische Forschung und Fortbildung und die Entnazifizierung des ehemaligen Lehrkörpers. In: Sigrid Oehler-Klein (Hrsg.): Die Medizinische Fakultät der Universität Gießen im Nationalsozialismus und in der Nachkriegszeit. Personen und Institutionen, Umbrüche und Kontinuitäten. Stuttgart 2007, S. 467501.

Ohnhäuser, Tim. Verfolgung, Suizid und jüdische Ärzte. Annäherung an ein wenig erforschtes Thema. In: Thomas Beddies/Susanne Doetz/Christoph Kopke (Hrsg.): Jüdische Ärztinnen und Ärzte im Nationalsozialismus. Entrechtung, Vertreibung, Ermordung. Berlin 2014, S. 265-290.

Olbrich, Hubert. Zucker-Museum, 1904 bis 2004. Beiträge zum Jubiläumsjahr. Berlin 2004.

Ottow, Benno. Klinische Erfahrungen und Richtlinien bei der gesetzlichen Unfruchtbarmachung erbkranker Frauen. In: Archiv für Gynäkologie 161 (1936), S. 415-452.

Paletschek, Sylvia. Was heißt „Weltgeltung deutscher Wissenschaft“? Modernisierungsleistungen und -defizite der Universitäten im Kaiserreich. In: Michael Grüttner/Rüdiger Hachtmann/Konrad H. Jarausch/Jürgen John/Matthias Middell (Hrsg.): Gebrochene Wissenschaftskulturen. Universität und Politik im 20. Jahrhundert. Göttingen 2010, S. 29-54.

Pearle, Kathleen M. Preventive Medicine. The Refugee Physician and the New York Medical Community 1933-1945. Bremen 1991.

Peter, Jürgen. Der Einbruch der Rassenhygiene in die Medizin. Auswirkungen rassenhygienischen Denkens auf Denkkollektive und medizinische Fachgebiete von 1918 bis 1934. Frankfurt am Main 2004.

Peukert, Detlev. Volksgenossen und Gemeinschaftsfremde. Anpassung, Ausmerze und Aufbegehren unter dem Nationalsozialismus. Köln 1982.

Pfäfflin, Friedemann/Rüb, Herbert/Göpfert, Matthias/Komo, Günter/Thiele, Wilhelm/Bussche, Hendrik van den. Die Krankenversorgung. In: Hendrik van den Bussche/Angela Bottin (Hrsg.): Medizinische Wissenschaft im „Dritten Reich“. Kontinuität, Anpassung und Opposition an der Hamburger Medizinischen Fakultät. Berlin/Hamburg 1989, S. 267-380.

Pickel, Hellmuth. Emil Knauer (1867-1935). Ein früher Pionier der gynäkologischen Endokrinologie. In: Der Gynäkologe 29 (2016), S. 294-296.

Piechatzeck, Jana. Die Auswirkungen des Gesetzes zur Verhütung erbkranken Nachwuchses an der Unversitäts-Frauenklinik Kiel in der Zeit von 1932 bis 1940. Kiel 2009.

Powell, John L. Biographic Sketch (Powell's Pearls): Hans Peter Hinselmann, MD (1884-1959). In: Obstetrical and Gynecological Survey 59, 10 (2004), S. 693-695.

Prill, Hans-Joachim. Die Entwicklung der psychosomatischen Geburtshilfe und Gynäkologie. In: Lutwin Beck (Hrsg.): Zur Geschichte der Gynäkologie und Geburtshilfe. Aus Anlaß des 100jährigen Bestehens der Deutschen Gesellschaft für Gynäkologie und Geburtshilfe. Berlin/Heidelberg/New York u. a. 1986, S. $345-355$.

Pross, Christian. Das Krankenhaus Moabit 1920 - 1933 - 1945. In: Christian Pross/Rolf Winau (Hrsg.): nicht mißhandeln. Das Krankenhaus Moabit 1920-1933. Berlin 1984, S. 109-252.

Quellmann, Christina. Theodor Friedrich Ernst Heynemann (1878-1951). Ein Leben für die Universitätsklinik Hamburg-Eppendorf. Berlin/Münster i. W./Wien 2002.
Ratschko, Karl-Werner. Kieler Hochschulmediziner in der Zeit des Nationalsozialismus. Die Medizinische Fakultät der Christian-Albrechts-Universität im „Dritten Reich“. Essen 2014.

RBG = Reichsbürgergesetz vom 15. September 1935. In: Reichsgesetzblatt 1935 I, S. 1146.

Rech, Walter. Zum 80. Geburtstag von Dr. Adam Bauereisen. In: Münchener Medizinische Wochenschrift 48 (1955), S. 1629-1630.

Reichel, Peter/Schmid, Harald/Steinbach, Peter. Die „zweite Geschichte“ der Hitler-Diktatur. Zur Einführung. In: Peter Reichel/Harald Schmid/Peter Steinbach (Hrsg.): Der Nationalsozialismus - die zweite Geschichte. Überwindung, Deutung, Erinnerung. München 2009, S. 7-21.

Richter, Kurt. Beziehungen zwischen der Wiener und der Berliner operativen Gynäkologie. In: Lutwin Beck (Hrsg.): Zur Geschichte der Gynäkologie und Geburtshilfe. Aus Anlaß des 100jährigen Bestehens der Deutschen Gesellschaft für Gynäkologie und Geburtshilfe. Berlin/Heidelberg/New York u. a. 1986, S. $277-298$.

Rigg, Bryan Mark. Hitlers jüdische Soldaten. Paderborn/München/Wien/ Zürich 2003.

RMK = Reichs-Medizinal-Kalender für Deutschland: Leipzig [1902-1937].

Roelcke, Volker. Medizin im Nationalsozialismus - radikale Manifestation latenter Potentiale moderner Gesellschaften? Historische Kenntnisse, aktuelle Implikationen. In: Heiner Fangerau/Igor J. Polianski (Hrsg.): Medizin im Spiegel ihrer Geschichte, Theorie und Ethik. Schlüsselthemen für ein junges Querschnittsfach. Stuttgart 2012, S. 35-50.

Rohrbach, Jens Martin. Augenheilkunde im Nationalsozialismus. Stuttgart 2007.

Roos, Daniel. Julius Streicher und „Der Stürmer“ 1923-1945. Paderborn 2014.

Roth, Karl Heinz. Erbbiologische Bestandsaufnahme. Ein Aspekt „ausmerzender“ Erfassung vor der Entfesselung des Zweiten Weltkrieges. In: KarlHeinz Roth (Hrsg.): Erfassung zur Vernichtung. Von der Sozialhygiene zum „Gesetz über Sterbehilfe“. Berlin 1984, S. 57-100.

Rott, Fritz. [Diskussionsbeitrag]. In: Archiv für Gynäkologie 144 (1931), S. 401.

Rott, Fritz. Die Reichszentrale für Gesundheitsführung. In: NS-Gesundheitsdienst 1, 4 (1933), S. 6-8.

Rotzoll, Maike/Wiedemann, Klaus. Zur Erinnerung. Die „badische Judendeportation" und das Schicksal von Maximilian und Zilla Neu. In: Heidelberg. Jahrbuch zur Geschichte der Stadt 16 (2012), S. 249-254.

Rudloff, Udo/Ludwig, Hans. Jewish gynecologists in Germany in the first half of the twentieth century. In: Archives of Gynecology and Obstetrics 272 (2005), S. 245-260.

Runge, Hans. Gynäkologische Blutungen. Therapie. In: Archiv für Gynäkologie 156 (1934), S. 27-35.

Runge, Hans. [Diskussionsbeitrag]. In: Bericht über die II. Tagung der Reichsarbeitsgemeinschaft für Mutter und Kind am 21. und 22. Mai 1937 in Bad Wildbad. Berlin 1937, S. 24.

Runge, Hans. Zum Gedenken an Robert Schröder [Nachruf]. In: Geburtshilfe und Frauenheilkunde 52, 1 (1960), S.71-74.

Rupieper, Hermann-Josef. Beiträge zur Geschichte der Martin-Luther-Universität Halle-Wittenberg. Halle/Saale 2002.

Rüther, Martin. Ärztliches Standeswesen im Nationalsozialismus 1933 1945. In: Robert Jütte (Hrsg.): Geschichte der deutschen Ärzteschaft. Organisierte Berufs- und Gesundheitspolitik im 19. und 20. Jahrhundert. Köln 1997, S. 143-193. 
Sachs, Michael/Schmiedebach, Heinz-Peter/Schwoch, Rebecca/Steinau, HansUlrich/Bauer, Hartwig (Hrsg.). Deutsche Gesellschaft für Chirurgie 19331945. Die Präsidenten. Heidelberg 2011.

Saenger, Hans. Über die Zuverlässigkeit der Tubensterilisation nach Madlener. In: Archiv für Gynäkologie 156 (1934), S. 157-164.

Saretzki, Thomas. Reichsgesundheitsrat und Preußischer Landesgesundheitsrat in der Weimarer Republik. Berlin 2000.

Sasson, Horst. Überleben im Untergrund. Die Kinderärztin Dr. Erna Rüppel (1985-1970). In: Die Heimat 26 (2010/11), S. 4-37.

Sauer, Paul. Dokumente über die Verfolgung der jüdischen Bürger in Baden-Württemberg durch das Nationalsozialistische Regime 1933-1945. Stuttgart 1966.

Schabel, Elmer. Soziale Hygiene zwischen sozialer Reform und sozialer Biologie: Fritz Rott (1878-1959) und die Säuglingsfürsorge in Deutschland. Husum 1995.

Schäfer, Daniel/Mallmann, Peter. Gynäkologischer Alltag im „Dritten Reich“. Das Beispiel der Kölner Universitätsfrauenklinik. In: Geburtshilfe und Frauenheilkunde 65 (2005), S. 862-867.

Schäfer, Günther. Die Begrenzung des Fortpflanzungserfolgs der Vierzigjährigen. In: Zeitschrift der Gesundheitsführung für Mutterschaft, Kindheit, Jugend 1 (1934), S. 509-521.

Schäfer, Silke. Zum Selbstverständnis von Frauen im Konzentrationslager. Das Lager Ravensbrück. Berlin 2002.

Schagen, Udo. Die Forschung an menschlichen Organen nach „plötzlichem Tod“ und der Anatom Hermann Stieve (1886-1952). In: Rüdiger vom Bruch (Hrsg.): Die Berliner Universität in der NS-Zeit, Bd. 2: Fachbereiche und Fakultäten. Stuttgart 2005, S. 35-54.

Schagen, Udo. Die Vertreibungen aus der Berliner Medizinischen Fakultät 1933. In: Sabine Schleiermacher/Udo Schagen (Hrsg.): Die Charité im Dritten Reich. Zur Dienstbarkeit medizinischer Wissenschaft im Nationalsozialismus. Paderborn 2008, S. 51-66.

Schagen, Udo. Walter Stoeckel (1871-1961) als (un)politischer Lehrer Kaiser der deutschen Gynäkologen? In: Matthias David/Andreas D. Ebert (Hrsg.): Geschichte der Berliner Frauenkliniken. Berlin 2010, S. 73-88.

Schaller, Anton. Die Wertheim-Klinik. Eine Geschichte der II. Universitätsfrauenklinik in Wien. Wien 1992.

Scheiblechner, Petra. „... politisch ist er einwandfrei ...“. Kurzbiographien der an der Medizinischen Fakultät der Universität Graz in der Zeit von 1938 bis 1945 tätigen WissenschafterInnen. Graz 2002.

Schmid, Magnus. Döderlein, Albert Siegmund Gustav. In: Neue Deutsche Biographie 4 (1959), S. 14-15.

Schmidt, Eberhardt. Schwangerschaftsunterbrechung und Sterilisation nach geltendem und künftigem Recht. In: Archiv für Gynäkologie 180 (1951), S. 289-304.

Schmuhl, Hans-Walter. Rassenhygiene, Nationalsozialismus, Euthanasie. Von der Verhütung zur Vernichtung „lebensunwerten Lebens“ 18901945. 2., durchges. Aufl. Göttingen 1992.

Schmuhl, Hans-Walter. Grenzüberschreitungen. Das Kaiser-Wilhelm-Institut für Anthropologie, menschliche Erblehre und Eugenik 1927-1945. Göttingen 2005.

Schmuhl, Hans-Walter. Das „Dritte Reich“ als biopolitische Entwicklungsdiktatur. Zur inneren Logik der nationalsozialistischen Genozidpolitik. In: Margret Kampmeyer (Hrsg.): Tödliche Medizin. Rassenwahn im Nationalsozialismus. Berlin (Jüdisches Museum)/Göttingen 2009, S. 8-21.
Schmuhl, Hans-Walter. Zwangssterilisation. In: Robert Jütte/Wolfgang Uwe Eckart/Hans-Walter Schmuhl/Winfried Süß: Medizin und Nationalsozialismus. Bilanz und Perspektiven der Forschung. Göttingen 2011, S. 201213.

Schmuhl, Hans-Walter. Die Gesellschaft Deutscher Neurologen und Psychiater im Nationalsozialismus. Berlin/Heidelberg 2016.

Schnabel, Reimund. Macht ohne Moral. Eine Dokumentation über die SS. Frankfurt am Main 1957.

Scholz, Harry/Schroeder, Paul. Ärzte in Ost- und Westpreußen. Leben und Leistung seit dem 18. Jahrhundert. Würzburg 1970.

Schröder, Robert. Gynäkologische Blutungen. Pathogenese und Diagnose. In: Archiv für Gynäkologie 156 (1934), S. 1-27.

Schübelin, Jürgen. Expansionspolitik und Ärzteverbrechen. Das Beispiel Carl Clauberg. In: Martin Beutelspacher (Hrsg.): Volk und Gesundheit. Heilen und Vernichten im Nationalsozialismus. Begleitbuch zur gleichnamigen Ausstellung im Ludwig-Uhland-Institut für Empirische Kulturwissenschaft der Universität Tübingen. 3. Aufl. Frankfurt am Main 1988, S. 186204.

Schultze, Günter K. F. Die Bekämpfung der weiblichen Unfruchtbarkeit. In: Zeitschrift der Gesundheitsführung für Mutterschaft, Kindheit, Jugend 1 (1934), S. 445-462.

Schultze, Günter K. F. 800 sterile Ehen. Ursachen und Aussichten. In: Archiv für Gynäkologie 161 (1936), S. 122-128.

Schultze, Günter K. F. Gynäkologische Röntgendiagnostik. Hysterosalpingographie, Physiologie und Pathologie der gynäkologischen Kontrastdarstellung. Stuttgart 1939

Schulze, Winfried/Oexle, Otto Gerhard (Hrsg.). Deutsche Historiker im Nationalsozialismus. Frankfurt am Main 1999.

Schwartz, Michael. Sozialistische Eugenik. Eugenische Sozialtechnologien in Debatten und Politik der deutschen Sozialdemokratie 1890-1933. Bonn 1995.

Schwarze, Gisela. Kinder, die nicht zählten. Ostarbeiterinnen und ihre Kinder im Zweiten Weltkrieg. Essen 1997.

Schwedt, Ernst Walter. In Memoriam Adam Bauereisen [Nachruf]. In: Zentralblatt für Gynäkologie 83 (1961), S. 1441-1443.

Schwoch, Rebecca. Ärztliche Standespolitik im Nationalsozialismus. Julius Hadrich und Karl Haedenkamp als Beispiele. Husum 2001.

Schwoch, Rebecca (Hrsg.). Berliner jüdische Kassenärzte und ihr Schicksal im Nationalsozialismus. Ein Gedenkbuch. Berlin/Teetz 2009.

Schwoch, Rebecca. „Praktisch zum Verhungern verurteilt“. „Krankenbehandler" zwischen 1938 und 1945. In: Thomas Beddies/Susanne Doetz/ Christoph Kopke (Hrsg.): Jüdische Ärztinnen und Ärzte im Nationalsozialismus. Entrechtung, Vertreibung, Ermordung. Berlin 2014, S. 75-91.

Schwoch, Rebecca/Hahn, Judith. Planwirtschaftliche Aufgaben im Karteikasten. Das Reichsarztregister als Quellenbestand. In: Rainer Stommer (Hrsg.): Medizin im Dienste der Rassenideologie. Die „Führerschule der Deutschen Ärzteschaft“ in Alt Rehse. Berlin 2008, S. 94-101.

Sehn, Jan. Carl Claubergs verbrecherische Unfruchtbarmachungsversuche an Häftlings-Frauen in den Nazi-Konzentrationslagern. In: Hefte von Auschwitz 2 (1959), S. 3-32.

Seidler, Eduard/Scriba, Christoph J./Berg, Wieland (Hrsg.). Die Elite der Nation im Dritten Reich. Das Verhältnis von Akademien und ihrem wissenschaftlichen Umfeld zum Nationalsozialismus. Leipzig/Berlin/Heidelberg 1995. 
Seidler, Eduard. Die Medizinische Fakultät der Albert-Ludwigs-Universität Freiburg im Breisgau. Grundlagen und Entwicklungen. 1. korr. Nachdr. Berlin/Heidelberg 1993.

Seidler, Eduard. Kinderärzte 1933-1945. Entrechtet - geflohen - ermordet (= Pediatricians - victims of persecution 1933-1945). Bonn 2000.

Seidler, Eduard. Jüdische Kinderärzte 1933-1945. Entrechtet - geflohen ermordet. Erw. Neuaufl. Basel/Freiburg i. Br./Paris u. a. 2007.

Seitz, Ludwig. Innere Sekretion und Schwangerschaft. Leipzig 1913.

Seitz, Ludwig. [Eröffnung der wissenschaftlichen Sitzung]. In: Archiv für Gynäkologie 144 (1931), LVII.

Seitz, Ludwig. [Eröffnungsansprache]. In: Archiv für Gynäkologie 144 (1931), XLVI-XLVIII.

Seitz, Ludwig. Über die Verkoppelung der eugenischen Sterilisierung mit der eugenischen Schwangerschaftsunterbrechung bei besonders schweren Erbkrankheiten in einem einzigen Sondergesetz. In: Deutsche Medizinische Wochenschrift 59 (1933), S. 1084-1087.

Seitz, Ludwig. [Eingriffe aus eugenischer Indikation]. In: Archiv für Gynäkologie 156 (1934), S. 128-142.

Seitz, Ludwig. [Diskussionsbeitrag]. In: Archiv für Gynäkologie 161 (1936), S. 474.

Seitz, Ludwig. Die Betreuung der Schwangeren (Abort-Indikation). In: Bericht über die II. Tagung der Reichsarbeitsgemeinschaft für Mutter und Kind am 21. und 22. Mai 1937 in Bad Wildbad. Berlin 1937, S. 45-53.

Sellheim, Hugo. Die konstitutionelle Ertüchtigung der weiblichen Jugend. In: Zeitschrift der Gesundheitsführung für Mutterschaft, Kindheit, Jugend 1 (1934), S. 201-226.

Semm, Kurt. Der Einfluß der deutschen Gynäkologie auf die Diagnostik und Therapie der weiblichen und männlichen Sterilität. In: Lutwin Beck (Hrsg.): Zur Geschichte der Gynäkologie und Geburtshilfe. Aus Anlaß des 100jährigen Bestehens der Deutschen Gesellschaft für Gynäkologie und Geburtshilfe. Berlin/Heidelberg/New York u. a. 1986, S. 267-275.

Shelby, Karen D. Flemish Nationalism and the Great War. The Politics of Memory, Visual Culture and Commemoration. Basingstoke/New York 2014.

Siefert, Helmut. Knaus, Hermann. In: Neue Deutsche Biographie 12 (1979), S. 163-164.

Siegel, Sari J. Treating an Auschwitz Prisoner-Physician: The Case of Dr. Maximilian Samuel. In: Holocaust Genocide Studies 28, 3 (2014), S. 450481.

Sigusch, Volkmar. Geschichte der Sexualwissenschaft. Frankfurt am Main/ New York 2008.

Simmer, Hans H. Gynäkologische Endokrinologie in den Verhandlungen der Deutschen Gesellschaft für Gynäkologie von 1886 bis 1935. Beiträge deutschsprachiger Frauenärzte. In: Lutwin Beck (Hrsg.): Zur Geschichte der Gynäkologie und Geburtshilfe. Aus Anlaß des 100jährigen Bestehens der Deutschen Gesellschaft für Gynäkologie und Geburtshilfe. Berlin/Heidelberg/New York u. a. 1986, S. 202-207.

Simmer, Hans H. Zur Geschichte der Endokrinologie der Fortpflanzung. In: Otto Käser/Volker Friedberg u. a. (Hrsg.): Gynäkologie und Geburtshilfe. Grundlagen, Pathologie, Prophylaxe, Diagnostik, Therapie in 3 Bänden. Bd.1/1: Sexuelle Differenzierung, Genetik, Fortpflanzung, Kindheit und Pubertät. 2., neu bearb. Aufl. Stuttgart/New York 1987, 4.1-4.12.

Simmer, Hans H. Der Berliner Pathologe Ludwig Pick (1868-1944). Leben und Werk eines jüdischen Deutschen. Husum 2000.

Soden, Kristine von. Die Sexualberatungsstellen der Weimarer Republik 1919-1933. Berlin 1988.
Spring, Claudia Andrea. Zwischen Krieg und Euthanasie. Zwangssterilisationen in Wien 1940-1945. Wien/Köln/Weimar 2009.

Stamper, Gregory. For Christ and Country. The Vision and Ideals of William Pelley. Asheville 2007.

Stauber, Manfred. Gynäkologie und Nationalsozialismus. Konkrete Erinnerungen - Nachwirkungen - Schlußfolgerungen. In: Heribert Kentenich/ Martina Rauchfuß/Peter Diederichs (Hrsg.): Psychosomatische Gynäkologie und Geburtshilfe 1993/94. Berlin/Heidelberg 1994, S. 21-39.

Stauber, Manfred. Vergangenheitsbewältigung in der bayerischen Gynäkologie - Erfahrungen an der I. Universitätsfrauenklinik. In: Christoph Anthuber/Matthias W. Beckmann/Johannes Dietl/Fritz Dross/Wolfgang Frobenius (Hrsg.): Herausforderungen. 100 Jahre Bayerische Gesellschaft für $\mathrm{Ge}-$ burtshilfe und Frauenheilkunde. Stuttgart 2012, S. 237-256.

Stengel, Katharina. Hermann Langbein. Ein Auschwitz-Überlebender in den erinnerungspolitischen Konflikten der Nachkriegszeit. Frankfurt am Main/New York 2012.

Stoeckel, Walter. [Diskussionsbeitrag]. In: Archiv für Gynäkologie 144 (1931), S. 378.

Stoeckel, Walter. [Diskussionsbeitrag]. In: Archiv für Gynäkologie 156 (1934), S. 291-292.

Stoeckel, Walter. [Einführung zum Referat]. In: Archiv für Gynäkologie 156 (1934), S. 102-103.

Stoeckel, Walter. Eröffnungs-Ansprache zur 23. Tagung der Deutschen Gesellschaft für Gynäkologie. In: Archiv für Gynäkologie 156 (1934), XLIXLVII.

Stoeckel, Walter. [Dankesrede anlässlich der Verleihung der Ehrenmitgliedschaft der Gesellschaft für Geburtshülfe und Gynäkologie zu Berlin] In: Zeitschrift für Geburtshülfe und Gynäkologie 114 (1937), S. 99-100.

Stoeckel, Walter. Gotthard Schubert [Nachruf]. In: Zentralblatt für Gynäkologie 50 (1939), S. 2633-2634.

Stoeckel, Walter. Hans Fuchs [Nachruf]. In: Zentralblatt für Gynäkologie 66 (1942), S. 1906-1908.

Stoeckel, Walter. Hans Albrecht [Nachruf]. In: Zentralblatt für Gynäkologie 68 (1944), S. 2

Stoeckel, Walter. Ansprachen. Sammlung. Stuttgart 1952.

Stoeckel, Walter. Gelebtes Leben. o. O. 1954

Stoeckel, Walter. Erinnerungen eines Frauenarztes, hrsg. von Hans Borgelt München 1966.

Stoll, Willy. Von der Dorfhebamme zur Frauenklinik. Die Anfänge der klinischen Frauenheilkunde und die Entstehung der Frauenklinik Aarau. Baden 2010

Strassmann, Wolfgang Paul. Die Strassmanns. Schicksale einer deutsch-jüdischen Familie über zwei Jahrhunderte. Frankfurt am Main/New York 2006

Streck, Arnulf. [Grußwort]. In: Archiv für Gynäkologie 161 (1936), S. 11-13.

Stürzbecher, Manfred. Martius, Heinrich. In: Neue Deutsche Biographie 16 (1990), S. 313-314.

Stürzbecher, Manfred. Sigfrid Hammerschlag. Frauenarzt und Hebammenlehrer. In: Berlinische Monatsschrift beim Luisenstädtischen Bildungsverein 9 (1998), S. 67-73.

Süß, Winfried. Der „Volkskörper“ im Krieg. Gesundheitspolitik, Gesundheitsverhältnisse und Krankenmord im nationalsozialistischen Deutschland 1939-1945. München 2003. 
Szabó, Anikó. Vertreibung, Rückkehr, Wiedergutmachung. Göttinger Hochschullehrer im Schatten des Nationalsozialismus. Göttingen 2000.

Taubert, Hans-Dieter. Zwangssterilisierungen 1933-1945. Ein Versuch der Vergangenheitsbewältigung. In: Zentralblatt für Gynäkologie 120 (1998), S. 21-25.

Tiedemann, Kirsten. Hebammen im Dritten Reich. Über die Standesorganisation für Hebammen und ihre Berufspolitik. Frankfurt am Main 2001.

Tietze, Konrad Anton. Über periodische nicht menstruelle Blutungen. In: Archiv für Gynäkologie 156 (1934), S. 35-39.

Tilitzki, Christian. Die Albertus-Universität Königsberg. Ihre Geschichte von der Reichsgründung bis zum Untergang der Provinz Ostpreußen (1871-1945). Bd. 1: 1871-1918; Bd. 2: 1919-1945. Berlin 2012.

Tongeren, F. C. van. A. H. M. J. van Rooy [Nachruf]. In: Zentralblatt für Gynäkologie 2 (1938), S. 65-67.

Topp, Sascha. Geschichte als Argument in der Nachkriegsmedizin. Formen der Vergegenwärtigung der nationalsozialistischen Euthanasie zwischen Politisierung und Historiographie. Göttingen 2013.

Tümmers, Henning. Anerkennungskämpfe. Die Nachgeschichte der nationalsozialistischen Zwangssterilisation in der Bundesrepublik. Göttingen 2011.

Turunen, Aarno. Seth Edvin Wichmann [Nachruf]. In: Zentralblatt für Gynäkologie 43 (1938), S. 2330-2331.

Ueberschär, Gerd R. Emigrierte und vertriebene Hitlergegner im militärischen Kampf gegen Faschismus und Nationalsozialismus auf alliierter Seite. In: Gerd R. Ueberschär (Hrsg.): Handbuch zum Widerstand gegen Nationalsozialismus und Faschismus in Europa 1933/39 bis 1945. Berlin/ New York 2011, S. 349-355.

Ulrich, Uwe/Ebert, Andreas D./Pritze, Wolfgang. Vom Kaiserreich zur Teilung Deutschlands. Walter Stoeckel. In: Andreas D. Ebert/Hans Karl Weitzel (Hrsg.): Die Berliner Gesellschaft für Geburtshilfe und Gynäkologie 1844-1944. Berlin/New York 1994, S. 161-178.

Ulrich, Uwe/Ebert, Andreas D. G. A. Wagner. In schwerer Zeit. In: Andreas D. Ebert/Hans Karl Weitzel (Hrsg.): Die Berliner Gesellschaft für Geburtshilfe und Gynäkologie 1844-1944. Berlin/New York 1994, S. 193-205.

Usandizaga, Manuel. Victor Conill Montobbio (1886-1970) [Nachruf]. In: Anales de medicina y cirugía 50 (1970), S. 297-305.

Verhandlungen der Deutschen Gesellschaft für Gynäkologie: Achtundzwanzigste Versammlung, abgehalten zu Bad Pyrmont vom 4. bis 8. April 1951, hrsg. von Heinrich Martius und Hans Naujoks. Berlin/Heidelberg 1951.

Verhandlungen der Deutschen Gesellschaft für Gynäkologie: Erster Kongress, abgehalten zu München vom 17.-19. Juni 1886, hrsg. von Franz von Winckel und Richard Frommel. Leipzig 1886.

Verhandlungen der Deutschen Gesellschaft für Gynäkologie: Vierzehnte Versammlung, abgehalten zu München am 7.-10. Juni 1911, hrsg. von Albert Döderlein und Karl Baisch. Leipzig 1911.

Verhandlungen der Deutschen Gesellschaft für Gynäkologie: Neunzehnte Versammlung, abgehalten zu Wien vom 3. bis 6. Juni 1925, hrsg. von Heinrich von Peham und Eduard Martin. In: Archiv für Gynäkologie 125 (1925).

Villiez, Anna von. Mit aller Kraft verdrängt: Entrechtung und Verfolgung „,nicht arischer“ Ärzte in Hamburg 1933 bis 1945. München 2009.

Villiez, Anna von. Emigration jüdischer Ärzte im Nationalsozialismus. In: Thomas Beddies/Susanne Doetz/Christoph Kopke (Hrsg.): Jüdische Ärztinnen und Ärzte im Nationalsozialismus. Entrechtung, Vertreibung, Ermordung. Berlin 2014, S. 190-202.
VO GzVeN = Verordnung zur Ausführung des Gesetzes zur Verhütung erbkranken Nachwuchses. In: Reichsgesetzblatt 1933 I, S. 1021-1036.

Volkov, Shulamit. Antisemitismus als kultureller Code. Zehn Essays. München 2000.

Vossen, Johannes. Gesundheitsämter im Nationalsozialismus. Rassenhygiene und offene Gesundheitsfürsorge in Westfalen 1900-1950. Essen 2001.

Voswinckel, Peter. Erinnerungsort Krebsbaracke. Klarstellungen um das erste interdisziplinäre Krebsforschungsinstitut in Deutschland (Berlin, Charité), hrsg. von der Deutschen Gesellschaft für Hämatologie und Onkologie e.V. (DHO). Berlin 2014.

Wagner, G. A. Die Funktionen und die Funktionsstörungen des Ovarium und ihre Bedeutung für die Volksgesundheit. In: Archiv für Soziale Hygiene und Demographie 8 (1933/34), S. 394-396.

Wagner, G. A. Die Technik der Unfruchtbarmachung. In: Karl Bonhoeffer (Hrsg.): Die psychiatrischen Aufgaben bei der Ausführung des Gesetzes zur Verhütung erbkranken Nachwuchses; mit einem Anhang: Die Technik der Unfruchtbarmachung. Klinische Vorträge im erbbiologischen Kurs. Berlin 1934, S87-98.

Wagner, G. A. Grundlagen der Mutterschaftsfürsorge. In: 1.Tagung der Reichsarbeitsgemeinschaft für Mutter und Kind in Berlin am 26. April 1935. Bericht im Auftrage der Reichsarbeitsgemeinschaft für Mutter und Kind, hrsg. von Kurt Fenner, Stellvertreter des Leiters der Reichsarbeitsgemeinschaft für Mutter und Kind. Berlin 1935, S. 11-12.

Wagner, G. A. Eröffnungs-Ansprache zur 25. Tagung der Deutschen Gesellschaft für Gynäkologie, Berlin, 20.-23. Oktober 1937. In: Archiv für Gynäkologie 166 (1938), S. 1-13.

Wagner, G. A. Professor Hans Fuchs [Nachruf]. In: Archiv für Gynäkologie 174 (1942), S. 350-356.

Wecker, Regina/Braunschweig, Sabine/Imboden, Gabriele/Küchenhoff, Bernhard/Ritter, Hans Jakob (Hrsg.). Wie nationalsozialistisch ist die Eugenik? Internationale Debatten zur Geschichte der Eugenik im 20. Jahrhundert. Wien/Köln/Weimar 2009.

Weindling, Paul. Health, Race and German Politics between National Unification and Nazism 1870-1945. Cambridge 1989.

Weindling, Paul. The Impact of German Medical Scientists on British Medicine. A Case Study of Oxford 1933-45. In: Mitchell G. Ash/Alfons Söllner (Hrsg.): Forced Migration and Scientific Change. Emigré German-Speaking Scientists and Scholars after 1933. Cambridge/New York 1996, S. 86-114.

Weingart, Peter/Kroll, Jürgen/Bayertz, Kurt. Rasse, Blut und Gene. Geschichte der Eugenik und Rassenhygiene in Deutschland. 3. Aufl. Frankfurt am Main 2003.

Werner, Klaus. Juden in Offenbach am Main 1918-1945. Frankfurt am Main 1991.

Westermann, Stefanie. Verschwiegenes Leid. Der Umgang mit den NSZwangssterilisationen in der Bundesrepublik Deutschland. Köln 2010.

Wilking, Silvia. Eugenischer Rassismus. Die Fortpflanzungsbiologie Carl Claubergs. In: Wolfgang Voegeli (Hrsg.): Nationalsozialistische Familienpolitik zwischen Ideologie und Durchsetzung. Hamburg 2001, S. 247-269.

Winau, Rolf. Gynäkologie und Geburtshilfe 1933-1945. In: Heribert Kentenich/Martina Rauchfuß/Peter Diederichs (Hrsg.): Psychosomatische Gynäkologie und Geburtshilfe 1993/94. Berlin/Heidelberg 1994, S. 13-20.

Winkelmann, Andreas. The Anatomische Gesellschaft and National Socialism. A Preliminary Analysis Based on the Society Proceedings. In: Annals of Anatomy 194, 3 (2012), S. 251-266.

Winter, Georg. Die künstliche Schwangerschaftsunterbrechung. Indikationen und Methoden, hrsg. von Hans Naujoks. 3., vollst. umgearb. Aufl. Stuttgart 1949. 
Wittern-Sterzel, Renate (Hrsg.). Die Professoren und Dozenten der Friedrich-Alexander-Universität Erlangen 1743-1960, Teil 2: Medizinische Fakultät. Erlangen 1999.

Wittern-Sterzel, Renate. Frauenärztinnen in der ersten Hälfte des 20. Jahrhunderts. In: Christoph Anthuber/Matthias W. Beckmann/Johannes Dietl/ Fritz Dross/Wolfgang Frobenius (Hrsg.): Herausforderungen. 100 Jahre Bayerische Gesellschaft für Geburtshilfe und Frauenheilkunde. Stuttgart 2012, S. 47-59.

Wlaschek, Rudolf M. Biographia Judaica Bohemiae, Bd. 1. Dortmund 1995.

Woelk, Wolfgang. Jüdische Ärzte in der Stadt und an der Medizinischen Akademie Düsseldorf (1933-1938). In: Michael G. Esch/Herstin Griese/ Frank Sparing/Wolfgang Woelk (Hrsg.): Die Medizinische Akademie Düsseldorf im Nationalsozialismus. Essen 1997, S. 55-85.

Wolf, Maria. Eugenische Vernunft. Wien/Köln/Weimar 2008.

Wolf, Susanne. Carl Joseph Gauß. Leben und Werk. Würzburg 2008.

Zander, Josef/Goetz, Elisabeth. Hausgeburt und klinische Entbindung im Dritten Reich. In: Lutwin Beck (Hrsg.): Zur Geschichte der Gynäkologie und Geburtshilfe. Aus Anlaß des 100jährigen Bestehens der Deutschen Gesellschaft für Gynäkologie und Geburtshilfe. Berlin/Heidelberg/New York u. a. 1986, S. $143-157$

Zander, Josef/Zimmer Fritz. Die Bayerische Gesellschaft für Geburtshilfe und Frauenheilkunde. Eine Dokumentation anläßlich ihres 75jährigen Bestehens. München 1987.

Zander, Josef. Carl Kaufmann, 21. August 1900-18. August 1980 [Nachruf]. In: Geburtshilfe und Frauenheilkunde 41 (1981), S. 81-86.

Zeitschrift der Gesundheitsführung für Mutterschaft, Kindheit, Jugend, Organ der Reichsarbeitsgemeinschaft für Mutter und Kind. Berlin-Charlottenburg: Selbstverlag der Deutschen Vereinigung für Säuglings- und Kleinkinderschutz 1934-1936.

Ziegler, Béatrice. Frauen zwischen sozialer und eugenischer Indikation. Abtreibung und Sterilisation in Bern. In: Veronika Aegerter (Hrsg.): Geschlecht hat Methode. Ansätze und Perspektiven in der Frauen- und Geschlechtergeschichte. Zürich 1999, S. 293-301.

Zimmermann, Volker. Mikulicz-Radecki, Felix. In: Neue Deutsche Biographie 17 (1994), S. 499.

Zondek, Bernhard. Hypophysenvorderlappen. In: Archiv für Gynäkologie 144 (1931), S. 133-164.

Zweifel, Paul. [Schlusswort]. In: Verhandlungen der Deutschen Gesellschaft für Gynäkologie. Sechzehnte Versammlung, abgehalten zu Berlin am 26.-19. Mai 1920, hrsg. von Ernst Bumm, Eduard Martin und Walter Sigwart. 2. Teil: Sitzungsbericht. Leipzig 1921, S. 179-180.

\section{Internetquellen}

$\nabla$

BEG = Bundesentschädigungsgesetz. URL: http://www.gesetze-im-internet.de/beg/index.html (01.06.2016).

Catalogus Professorum Rostochiensium. URL: http://cpr.uni-rostock.de/ metadata/cpr_person_00002313 (01.06.2016).

CRT (= Claims Resolution Tribunal), Case No. CV96-4849. URL: http://www.crt-ii.org/_awards/_apdfs/Schwab_Vera.pdf (01.06.2016).

Freimüller, Tobias. Wie eine Flaschenpost. Alexander Mitscherlichs Dokumentation des Nürnberger Ärzteprozesses. In: Zeithistorische Forschungen/Studies in Contemporary History 7 (2010). URL: http://www. zeithistorische-forschungen.de/1-2010/id=4474 (01.06.2016).

Gedenkbuch des Bundesarchivs für die Opfer der nationalsozialistischen Judenverfolgung in Deutschland (1933-1945). URL: http://www.bundesarchiv.de/gedenkbuch/(01.06.2016).

Grau, Bernhard. Entschädigungs- und Rückerstattungsakten als neue Quelle der Zeitgeschichtsforschung am Beispiel Bayerns. In: zeitenblicke 3, 2 (2004). URL: http://www.zeitenblicke.historicum.net/2004/02/grau/ index.html (01.06.2016).

Gunst, Petra. Daels, Frans (1882-1974). In: UGentMemorie (2010). URL: www.ugentmemorie.be/personen/daels-frans-1882-1974 (01.06.2016).

Guntau, Martin. Schmid, Hans Hermann. In: Bundesstiftung Aufarbeitung, Biographische Datenbanken (2009). URL: http://bundesstiftung-aufarbeitung.de/wer-war-wer-in-der-ddr-\%2363\%3B-1424.html?ID=3068 (01.06.2016).

Holocaust.cz, Database of Victims. URL: http://www.holocaust.cz/en/ database-of-victims/.

Kailitz, Susanne. Das Experiment. In: ZEIT Online (12.01.2012). URL: http://www.zeit.de/2012/03/S-Geschlechtsumwandlung (01.06.2016).

$K u ß$, Erich. Heinrich Eymer. Die Vergangenheitsüber(be)wältigung und die Selbstkontrolle der Wissenschaft. München 2011. URL: http://epub.ub. uni-muenchen.de/12313/(01.06.2016).

NN: Unterm Wohnblock viel Geschichte. Erinnerung an eine verschwundene Klinik. URL: http://www.offenbach.de/kultur-und-tourismus/ stadtgeschichte/geschichte-offenbach/1900-1932/unterm-wohnblockviel-geschichte-greinsche-klinik.php (01.06.2016).

Piorr, Ralf. Vor 70 Jahren starb Gustav Wertheim. In: Westdeutsche Allgemeine Zeitung (2011). URL: http://www.derwesten.de/staedte/ nachrichten-aus-herne-und-wanne-eickel/vor-70-jahren-starb-gustavwertheim-id6087048.html (01.06.2016).

Reggiani, Andrés Horacio. Medicina y Kulturpolitik en la Era del Nacionalsocialismo. La Academia Médica Germano-Ibero-Americana (1936-1939). In: Sandra Carreras (Hrsg.): Der Nationalsozialismus und Lateinamerika. Institutionen - Repräsentationen - Wissenskonstrukte. In: Ibero-Online. de 3, I (2005), S. 57-74. URL: http://www.iai.spk-berlin.de/publikationen/ ibero-online.html (01.06.2016).

Villiez, Anna von. Verfolgte und vergessene Wegbereiter ihres Faches. Jüdische Kinderärzte und Kinderärztinnen 1933 bis 1945 in Hamburg. URL: http://www.beratungszentrum-alsterdorf.de/fileadmin/abz/data/ Menu/Fachdiskussion/Erinnern_an_die_Zukunft/Hamburger_juedische_Kinderaerzte_im_NS4.pdf (01.06.2016).

Yad Vashem, Zentrale Datenbank der Namen der Holocaustopfer. URL: http://www.yadvashem.org/yv/de/about/hall_of_names/ about_central_database.asp (01.06.2016). 


\section{Namenverzeichnis}

A

Adler, Karl 85

Adler, Ludwig $\quad 81,134$

Albrecht, Hans 9, 25, 45-48,

53, 109, 126

Alexander, Edgar $\quad 74,91$

Alfieri, Emilio 73

Alvensleben, Alkmar von 110

Amreich, Isidor Alfred 110

Anselmino, Karl Julius 84

Anthuber, Christoph 7

Arnstein, Eduard 87, 91

Aschheim, Selmar 15-16,

$37,52,76,81,87,97-98$, 120

Aschner, Bernhard 81

Ash, Mitchell 3

\section{B}

Baatz, Hans $13,16-17,111$

Bab, Hans $\quad 83,87,98$

Bach, Ernst 25, 45, 47, 58, $62-64,111,124$

Bakofen, Otto 98

Bartels, Friedrich 26-27, 31

Bauereisen, Johann

Adam 49, 111

Baumeister, Leonhard 140

Belonoschkin, Boris 18-19

Benda, Robert 87

Benthin, Walther 112

Berg, Dietrich 102

Berkeley, Comyns 73

Beruti, Josué 73

Bessau, Georg 30

Bickenbach, Werner 24,32, 112

Bigler, Walter 72

Björkenheim, Robert Edvard

Albert 113

Blumberg, Jacob Moritz 78

Bock, Gisela 4

Bokelmann, Otto 97

Boldt, Hermann J. 73

Borst, Max 53

Bracht, Erich 15

Brandt, Karl 131

Breipohl, Wilhelm 97, 113

Brinkschulte, Eva 7

Brühl, Robert 84

Bumke, Oswald 41-42

Bumm, Ernst 21, 135

Bürger, Max 16

\section{C}

Caffier, Paul Ottomar Johannes 97, 113-114

Chrobak, Rudolf 125

Clauberg, Carl 55, 66-67, 94,

$96,115,135,138$

Cohen, Walther 88,98

Cohn, Richard 91

Cònill i Montobbio, Victor 115

Conti, Leonardo $10,16,27$, $29-32,34,54,58,71$, $78-79,113,121,133$

Conti, Nanna $29-30,32-33$, 55

Čukor, Nikolaus 77

Czempin, Alex 90

\section{D}

Daels, Frans 72,115

Darwin, Charles 36

Dienst, Arthur 97

Diepgen, Paul 115

Dimpfl, Thomas 2,6-7

Döderlein, Albert $\quad 4,43,116$

Döderlein, Gustav 32 ,

$34-35,56,64,116,127$

Domagk, Gerhard 55-56, 112

Doneith, Thorsten 5

Dorpalen, Georg 91

Durand-Wever, Anne-Marie 83

\section{E}

Ehrhardt, Karl 5, 34-35, 65, 117, 135

Engel, Emil 90

Engle, Earl Theron 54

Esch, Peter $55,85,125$

Essen-Möller, Elis 73

Eymer, Heinrich $\quad 4,17,44,46$, $49,51,101-102,122,132$

\section{$\mathbf{F}$}

Feldweg, Paul 97

Fellenberg, K.G. Rudolf von 72

Fels, Erich 78, 88, 98, 117

Fischer, Eugen 26, 41-43

Fleischbein-Brinkschulte, Klaus von 7

Fleischmann, Carl 86
Fraenkel, Ludwig $\quad 10,19,27$, $37-38,52,76,83,96-98$, 117,125

Franken, Hermann 85

Frankenstein, Kurt 80

Frankl, Oskar 81,89

Franqué, Otto Friedrich

Wilhelm Paul von 14, 23,

$27,38,67,84,118$

Franz, Karl 15

Freund, Richard 90

Freund, Wilhelm Alexander 76, 96

Frick, Wilhelm 78

Frommolt, Günther 13 , $26-27,29,118$

Fuchs, Hans 10,17-21, 25, $32,34,55,57-58,71,97$, 116,119

Fürst, Walter 80

G

Gaifami, Ernst 73

Galton, Francis 36

Gauß, Carl Joseph 34,38 , $46-47,49,119,132$

Göbel, Paul 67

Goebbels, Joseph 13, 26, 34, 47, 73

Goebbels, Magda 13

Gottstein, Adolf 127

Göz, Hans 44, 49-50

Gräfenberg, Ernst $57,89,98$

Grawitz, Ernst 66,135

Grein, Ernst 97

Grote, Louis 54

Grunau, Martin 50

Guggisberg, Hans 37, 72, 120

Günther, Heinrich 16

Guthmann, Heinrich 11

Gütt, Arthur 43

H

Hahn, Viktor 87, $92-93$

Halban, Josef 96, 110, 112, $120,125,130$

Hammerschlag, Sigfrid $\quad 27$, 76, 78, 120, 130

Haselhorst, Gustav Heinrich Friedrich 32, 55-57, 113, 121

Haselwarter, Robert 101

Hegar, Alfred 15, 50

Hengge, Anton 121
Hepp, Hermann 102

Hess, Leo 87

Heusler-Edenhuizen,

Hermine 68-69

Heynemann, Theodor 51,122

Himmler, Heinrich $\quad$ 13, 66

Hindenburg, Paul von

$25,29,102$

Hinselmann, Hans 53, $67-68,96,98,101,118,122$

Hirsch, Max 37, 52-53, $55-56,76,86$

Hitler, Adolf $13-14,25,29$, 102,124

Hitschmann, Fritz 134

Hohlweg, Walter 52

Hubert, Rudolf 84

Hüssy, Paul 123

J

Jacoby, Irma 87, 92

Jaschke, Rudolf Theodor Edler von $2,9,20-21,30,73$, $95-97,115,123,132$

Jens, Walter 14

Joseph, Siegbert $\quad 92,98$

Jung, Martin 81

K

Kahr, Heinrich $\quad 81,97,110$

Kaufmann, Carl 16-17, 54-55, 123

Kayser, Marie Elise 68

Kehrer, Erwin Karl Adolf 22

Kehrer, Ferdinand Adolf 124

Kessler, Robert 134

Kindermann, Günther 3, 7, $101-103$

Kirstein, Friedrich 125

Klaften, Emanuel $\quad 81,110$

Klein, Gustav 47

Klein, Paul 15

Knauer, Emil 125

Knaus, Hermann Hubert $46-48,53,55,83,109$, $125-126$

Kohlrausch, Eduard 41

Köstlin, Rudolf 18

Krehl, Ludolf von 80

Krüger, Elisabeth 31

Kuppenheim, Rudolf 89-90

Kuß, Erich 101-102

Küstner, Heinz 31 
L

Laemmle, Isaak Kurt 78 Langbein, Hermann 96 Latzko, Wilhelm 81

Lehfeldt, Hans 37

Lehmann, Volker 7, 102-103

Lembcke, Hermann 120 Leunbach, Jonathan von 83 Leven, Karl-Heinz 7

Liepmann, Wilhelm Gustav 77-78, 88

Lippmann, Bernhard von 78

Littauer, Käthe 68

Loeffler, Lothar 38

Lönne, Friedrich Karl 32, 53,

$56-58,126$

Lövset, Jörgen 54

Ludwig, Hans $\quad 2,102$

M

Madlener, Max 77

Martin, Eduard August 21

Martin, Eduard Balduin Karl

Victor 9-10, 15, 21-23,

$44-45,64,73,127$

Martius, Heinrich Fedor

Emil 10, 23-24, 32, 34, 43,

51, 53, 74, 91, 96, 99, 115,

121,127

Mayer, August $\quad 4-5,9-10$,

$14-15,24-25,29,37-38$,

$44-53,57,62-64,69$,

$71-73,77-78,109,126$,

$128,137,140$

Menge, Carl 9, 46, 49, 70, 80, 85,132

Meyer, Paul 97

Meyer, Robert $12,26,81,86$, 96-98, 113, 138

Mikulicz-Radecki, Felix von $12,55-56,65-66$, 113,128

Moos, Samuel $\quad 81,88$

Müllerheim, Robert 90

Münch, Hans 94

$\mathbf{N}$

Naujoks, Hans Christian

22 - $23,32-33,44,99-101$, 112,129

Neu, Maximilian $\quad 80-81,90$

Niedermeyer, Albert $\quad 24$,

$42-43,72,84,86,129$

Nürnberger, Ludwig 129
0

Oehler-Klein, Sigrid 20

Offergeld, Heinrich 84

Ogino, Kyūsaku 53, 126

Ohnesorge, Victor 57

Olow, John 130

Opitz, Erich 20

Oppenheim, Hans 92

Ottow, Benno 13, 44, 48-50, 130

$\mathbf{P}$

Pankow, Otto 14, 85

Philipp, Ernst $\quad 12,29,34,131$

Pick, Ludwig 81,91

Pius XI., Papst 43

Priebatsch, Walter 91

\section{$\mathbf{R}$}

Raphael, Lutz 3

Rauh, Philipp 7

Read, Grantly Dick 132

Rech, Walter 49, 131

Redlich, Walter 83

Rehm, Margarete 22

Reiter, Hans 45-47

Richter, Johannes 54

Riedel, Else 59

Riediger, Kurt 97

Riese, Hertha $\quad 68,87$

Rindfleisch, Eduard von 118

Roederer, Johann Georg 96

Roelcke, Volker 4

Roemer, Hans 132

Rooy, Adrianus Henricus

Maria Josephus van 133

Rosenthal, Bernhard 89

Rossenbeck, Heinrich 97

Rosthorn, Alfons von 20

Rott, Fritz 30-31, 53

Röttgen, Hans 83

Rubinstein, Hermann

Rafael 125

Rüdin, Ernst $\quad 43-45,49,51$

Runge, Hans 31,53,

$133-134$

Rupprecht, Philipp 82

Ruttke, Falk 43

\section{S}

Samuel, Maximilian $\quad 87,89$, 93-94

Sänger, Hans 77,87

Sauerbruch, Ferdinand 13
Schäfer, Günther 31

Schagen, Udo 14

Schauta, Friedrich $\quad 12,17$

Schenk, Ferdinand 87

Schiffer, Georg 91

Schittenhelm, Alfred 45

Schlossmann, Hans 77,80

Schmid, Hans Hermann 78, 87

Schmidt, Eberhardt 99-100

Schmuhl, Hans-Walter 4

Schoenholz, Ludwig 88

Scholtz-Klink, Gertrud 54

Schröder, Robert 9, 53, 66, 133

Schubert, Gotthard 134

Schultze-Rhonhof, Friedrich 49

Schultze, Günter Karl Friedrich $12,31,54,66,97,134$

Schultze, Walter 45,47

Schwab, Max 83

Schweitzer, Bernhard 84-85

Schwoch, Rebecca 5

Seitz, Ludwig 4,9-11, 30, $37,41-42,44,49-50,65$, $70,100,110,112,120,130$, 135,140

Sellheim, Hugo 8, 31

Seuffert, Ernst Ritter von 82

Siegert, Friedrich $\quad 80,85$

Sigwart, Walter 136

Simon, Arthur 86

Skutsch, Felix Otto 92, 96-97

Slotta, Karl 117

Snoo, Klaas de 136

Stauber, Manfred 3-4, 7, $101-102$

Stauffenberg, Olga-Maria Gräfin von 14

Steinberg, Klara 90

Stieve, Hermann 19

Stoeckel, Walter $\quad 2,4,9-18$, $25-29,32,34,36,38$,

$40-47,53-54,57-58,62$,

$68,70-74,76-79,82$,

84-86, 96, 102, 113-114,

119-120, 130-131,

$135-136,138$

Straßmann, Erwin $\quad 78,88$

Straßmann, Paul 62, 79, 81, 86,89

Strauß, Kurt 126

Straus, Willi 81

Streck, Arnulf $\quad 45,47,63-64$, 71, 77-78, 136

Streicher, Julius 82

Stuckrad, Kurt-Otto von 32, $34,57,97,137$

Süssmann, Fritz 137
T

Tausch, Moritz 9, 45, 64, 109, 137

Tietze, Konrad 53

Tóth, Stephan von $\quad 69,72$, 138

Traugott, Marcel 77-78

Treite, Percival $\quad 12,138$

U

Unbehaun, Gerd 20

Unterberger, Franz 97

V

Voss, Hermann 19

W

Wagenseil, Ferdinand 21

Wagner, Georg August 9-10, $12-13,15-19,24,30-32$, $34-35,52,54,55,57$, $64-65,78,97,138$

Wagner, Gerhard 26, 45-47, $51,64,71,77,140$

Warnekros, Kurt 85

Weber, Franz Anton 83

Wechsberg, Julius 87,92

Weibel, Wilhelm 139

Werth, Richard 18

Wertheim, Ernst 11, 15, 139

Wichmann, Seth Edvin 139

Wiemer, Wernher 85

Wiener, Gustav 25, 91

Winau, Rolf 4

Winckel, Franz von 69

Winter, Georg 20, 22, 99,

112,127

Wintz, Hermann Ludwig 9 , $11,51,57,140$

Wirths, Eduard 67,93-94

Wirths, Helmut 67

Wirz, Franz 45-47

Wittern-Sterzel, Renate 7

\section{Z}

Zacherl, Hans 84

Zander, Josef 5, 10, 32

Zondek, Bernhard 15-16, $37,52,62,76,78,88,96,98$, 120 


\section{Abbildungsverzeichnis}

Umschlag: Bayerische Staatsbibliothek München, NL Josef Zander (Ana 691) (wie Abb. 31)

Abb. 1 (S.11): Universitätsarchiv Frankfurt am Main, Abt. 854 Nr. 1587

Abb. 2 (S. 11): Archiv des Instituts für Geschichte der Medizin und Ethik in der Medizin, Charité Universitätsmedizin Berlin

Abb. 3 (S. 12): Archiv des Instituts für Geschichte der Medizin und Ethik in der Medizin, Charité Universitätsmedizin Berlin

Abb. 4(S. 13): Archiv des Instituts für Geschichte der Medizin und Ethik in der Medizin, Charité Universitätsmedizin Berlin

Abb. 5 (S. 14): Foto: Arthur Gröger. Universitätsarchiv Tübingen, S 23/1, 894

Abb. 6 (S. 15): Archiv des Instituts für Geschichte der Medizin und Ethik in der Medizin, Charité Universitätsmedizin Berlin

Abb. 7 (S. 18): Aus: Archiv für Gynäkologie 174 (1942)

Abb. 8 (S. 20): Bildarchiv von Universitätsbibliothek und Universitätsarchiv Gießen, HR A 121 a

Abb. 9 (S. 23): Historisches Archiv der Universität zu Köln, Zugang 20/239

Abb. 10 (S.23): Staats- und Universitätsbibliothek Göttingen, Sammlung Voit

Abb. 11 (S. 24): Yad Vashem Photo Archive, Jerusalem, Nr. 34818

Abb. 12 (S. 31): Bundesarchiv Berlin, Bilddatenbank

Abb. 13 (S.33): Bayerische Staatsbibliothek München, NL Josef Zander (Ana 691)

Abb. 14 (S. 37): Institut für Stadtgeschichte Frankfurt am Main

Abb. 15a (S. 40): Archiv des Instituts für Geschichte der Medizin und Ethik in der Medizin, Charité Universitätsmedizin Berlin

Abb. 15b (S. 40): Archiv des Instituts für Geschichte der Medizin und Ethik in der Medizin, Charité Universitätsmedizin Berlin

Abb. 16 (S. 45): Haus der Geschichte Baden-Württemberg, Metzarchiv 7929 (Universitätsarchiv Tübingen, S 19/35-5 Nr. 30)

Abb. 17 (S. 46): Deutsches Dokumentationszentrum für Kunstgeschichte - Bildarchiv Foto Marburg

Abb. 18 (S.47): Universitätsarchiv Tübingen, NL August Mayer $(150 / 33,45)$

Abb. 19 (S. 48): Universitätsarchiv Tübingen, 150/33,41

Abb. 20 (S. 48): Universitätsbibliothek Erlangen

Abb. 21 (S. 55): Universitätsbibliothek Erlangen
Abb. 22 a (S. 56): Österreichische Nationalbibliothek Wien, S 208/ 16

Abb. 22b (S. 56): Österreichische Nationalbibliothek Wien, $105.289-\mathrm{E}$

Abb. 23 (S. 60): Andreas Thum

Abb. 24 (S. 61): Grafik: Andreas Thum, Karte: Ziegelbrenner, Wikimedia Commons, lizenziert unter GNU-Lizenz für freie Dokumentation

Abb. 25 (S. 64): Stadtarchiv Fürth, A 3349 b

Abb. 26 (S. 65): Archiv des Instituts für Geschichte der Medizin und Ethik in der Medizin, Charité Universitätsmedizin Berlin

Abb. 27 (S.67): United States Holocaust Memorial Museum, Washington, DC

Abb. 28 (S. 67): Privatbesitz Rudolf de Wall, Pinneberg

Abb. 29 (S. 68): Aus: Deutsches Ärzteblatt, 1969, Nr. 40, S. 2755

Abb. 30 (S. 70): Nationaal Archief, Den Haag

Abb. 31 (S. 74): Bayerische Staatsbibliothek München, NL Josef Zander (Ana 691) (wie Umschlag)

Abb. 32 (S. 75): Universitätsbibliothek Erlangen

Abb. 33a (S. 76): Ullstein Bild

Abb. 33 b (S. 76): Aus: Archiv für Gynäkologie 141 (1930)

Abb. 34 (S. 81): Ullstein Bild, Archiv Gerstenberg

Abb. 35 (S. 82): Foto: Abraham Pisarek. Bildarchiv Pisarek/akgimages

Abb. 36 (S. 83): Bayerische Staatsbibliothek München

Abb. 37 (S. 88): Aus: M. David/A. Ebert: Berühmte Frauenärzte in Berlin, Mabuse Frankfurt/Main 2007, mit freundlicher Genehmigung des Mabuse-Verlags und von Matthias David und Andreas Ebert, Berlin

Abb. 38 (S. 90): Privatbesitz Prof. Dr. med. Michael Goerig, Hamburg

Abb. 39 (S. 92): Privatbesitz Béatrice Steiner, Paris

Abb. 40 (S. 93): Jüdisches Museum Prag

Abb. 41 (S. 93): Privatbesitz Joe Bradley

Abb. 42 (S. 95): Foto: Rolf Kellner. Stadtarchiv Karlsruhe

Abb. 43 (S. 97): Universitätsarchiv Leipzig, FS N00688

Abb. 44 (S. 101): Thieme-Verlag (Herausforderungen 2012); Foto: Stephan Beißner, LMU-Frauenklinik München

Abb. 45 (S. 102): Frankfurter Allgemeine Zeitung vom 07.09.1994, Süddeutsche Zeitung vom 31.08.1994 
Geburtshilfe und Frauenheilkunde

76. Jahrgang

Eigentümer und Copyright:

(c) Georg Thieme Verlag KG 2016

\section{Leitende Herausgeber}

Prof. Dr. M. W. Beckmann

Frauenklinik

Universitätsklinikum Erlangen

Universitätsstraße 21-23

91054 Erlangen

Prof. Dr. D. Wallwiener

Department für Frauengesundheit Frauenklinik

Universitätsklinikum Tübingen

Calwerstraße 7

72076 Tübingen

\section{Co-Herausgeber}

PD Dr. C. R. Löhberg

Frauenklinik

St. Theresien-Krankenhaus Nürnberg

Mommsenstraße 24, 90491 Nürnberg

Aktuell referiert und Der Interessante Fall PD Dr. H. B. G. Franz

Frauenklinik

Städtisches Klinikum Braunschweig gGmbH

Celler Straße 38, 38114 Braunschweig

Prof. Dr. M. Friedrich

Klinik für Frauenheilkunde und Geburtshilfe

Helios Klinikum Krefeld

Lutherplatz 40, 47805 Krefeld

\section{Aktuell diskutiert}

Prof. Dr. B. Schauf

Frauenklinik Sozialstiftung Bamberg

Buger Straße 80, 96049 Bamberg

\section{Verlag}

Georg Thieme Verlag KG

Rüdigerstraße 14, 70469 Stuttgart oder

Postfach 301120, 70451 Stuttgart

Tel.: 07 11/8931-0, Fax: 0711/8931-298

http://www.thieme.de

http://www.gebfra.thieme.com

http://www.thieme-connect.de/ejournals

\section{Wichtiger Hinweis}

Wie jede Wissenschaft ist die Medizin ständigen Entwicklungen unterworfen. Forschung und klinische $\mathrm{Er}$ fahrung erweitern unsere Erkenntnisse, insbesondere was Behandlung und medikamentöse Therapie anbelangt. Soweit in diesem Heft eine Dosierung oder eine Applikation erwähnt wird, darf der Leser zwar darauf vertrauen, dass Autoren, Herausgeber und Verlag große Sorgfalt darauf verwandt haben, dass diese Angabe dem Wissensstand bei Fertigstellung der Zeitschrift entspricht. Für Angaben über Dosierungsanweisungen und Applikationsformen kann vom Verlag jedoch keine Gewähr übernommen werden. Jeder Benutzer ist angehalten, durch sorgfältige Prüfung der Beipackzettel der verwendeten Präparate und gegebenenfalls nach Konsultation eines Spezialisten festzustellen, ob die dort gegebene Empfehlung für Dosierungen oder die Beachtung von Kontraindikationen gegenüber der Angabe in dieser Zeitschrift abweicht. Eine solche Prüfung ist besonders wichtig bei selten verwendeten Präparaten oder solchen, die neu auf den Markt gebracht worden sind.

Jede Dosierung oder Applikation erfolgt auf eigene Gefahr des Benutzers. Autoren und Verlag appellieren an jeden Benutzer, ihm etwa auffallende Ungenauigkeiten dem Verlag mitzuteilen.

\begin{tabular}{|c|c|c|c|}
\hline jährliche Bezugspreise 2016* & Inland & Europa & weltweit \\
\hline Versandkosten & 39,80 & 61,90 & 99,90 \\
\hline $\begin{array}{l}\text { Normalpreis } \\
\text { (Gesamtpreis inkl. Versandkosten) }\end{array}$ & $320,00(359,80)$ & $320,00(381,90)$ & $320,00(419,90)$ \\
\hline $\begin{array}{l}\text { Institutionelles Abonnement } \\
\text { (Gesamtpreis inkl. Versandkosten)** }\end{array}$ & $582,00(621,80)$ & $582,00(643,90)$ & $582,00(681,90)$ \\
\hline $\begin{array}{l}\text { ermäßigter Preis für Ärzte in der Weiter- } \\
\text { bildung zum Gebietsarzt für maximal } 6 \text { Jahre } \\
\text { sowie für Hebammen und Studenten }\end{array}$ & $149,00(188,80)$ & $149,00(210,90)$ & $149,00(248,90)$ \\
\hline \multicolumn{4}{|c|}{ Printausgabe nur zusammen mit einem Online-Zugang erhältlich } \\
\hline \multicolumn{4}{|c|}{$\begin{array}{l}\text { Einzelheft } 48,00 \text { EUR (D) zuzüglich Versandkosten ab Verlagsort, unverbindlich empfohlener Preis; } \\
\text { inklusive der gesetzlichen Mehrwertsteuer }\end{array}$} \\
\hline \multicolumn{4}{|c|}{$\begin{array}{l}\text { in EUR (D); unverbindlich empfohlene Preise; inklusive der gesetzlichen Mehrwertsteuer. Das Abonnement wird zum Jahres- } \\
\text { wechsel im Voraus berechnet und zur Zahlung fällig. Das Abonnement kann jederzeit begonnen werden. Die Bezugsdauer } \\
\text { verlängert sich automatisch jeweils um ein Jahr, wenn bis zum } 30 \text {. September des Vorjahres keine Abbestellung vorliegt. } \\
\text { Weitere Informationen finden Sie unter http://www.thieme.de/connect/de/services/product-licensing.html. } \\
\text { Der institutionelle Jahresbezugspreis inkludiert Online-Zugriff für } 1 \text { Standort. }\end{array}$} \\
\hline
\end{tabular}

\section{Copyright}

Die Zeitschrift und alle in ihr enthaltenen einzelnen Beiträge und Abbildungen sind für die Dauer des Urheberrechts geschützt. Jede Verwertung außerhalb der engen Grenzen des Urheberrechtsgesetzes ist ohne Zustimmung des Verlages unzulässig und strafbar. Das gilt insbesondere für Vervielfältigungen, Übersetzungen, Mikroverfilmungen und die Einspeicherung und Verarbeitung in elektronischen Systemen.

\section{Redaktion}

Dr. Silvia Jung

Rüdigerstraße 14, 70469 Stuttgart

Tel.: 0711/8931-593, Fax: 0711/8931-392

E-Mail: Silvia.Jung@thieme.de

Verantwortlich für den Anzeigenteil

Thieme.media

Pharmedia Anzeigen- und Verlagsservice $\mathrm{GmbH}$

Ulrike Bradler

Rüdigerstraße 14, 70469 Stuttgart oder

Postfach 300880,70448 Stuttgart

Tel.: 0711/8931-466, Fax: 07 11/8931-624

E-Mail: Ulrike.Bradler@thieme.de

Zur Zeit gilt Anzeigenpreisliste Nr. 54 vom

1.10.2016.

Printed in Germany

Grafisches Centrum Cuno, Calbe/Saale

Satz

Ziegler + Müller, Kirchentellinsfurt

Herstellung

Tel.: 0711/8931-539, Fax: 0711/8931-393

E-Mail: Andrea.Hartmann@thieme.de

Abonnentenservice

Tel.: 0711/8931-321, Fax: 0711/8931-422

E-Mail: aboservice@thieme.de

Allgemeine Informationen

Geburtshilfe und Frauenheilkunde, ISSN 0016-5751, elSSN 1615-3367, erscheint 12-mal im Jahr.

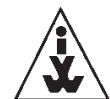

Mitglied der Informationsgemeinschaft zur Feststellung der Verbreitung von Werbeträgern e.V.

Informationen für unsere Leser

Wir bitten unsere Abonnenten, Adressänderungen dem Abonnentenservice mitzuteilen, um eine reibungslose Zustellung der Zeitschrift zu gewährleisten. Marken, geschäftliche Bezeichnungen oder Handelsnamen werden nicht in jedem Fall besonders kenntlich gemacht. Aus dem Fehlen eines solchen Hinweises kann nicht geschlossen werden, dass es sich um einen freien Handelsnamen handelt.
Informationen für unsere Autoren

Manuskriptrichtlinien und andere Informationen für Autoren entnehmen Sie bitte den Autorenhinweisen: gebfra.thieme.com/de/web/p/instructions-and-forms. Grundsätzlich werden nur solche Manuskripte angenommen, die vorher weder im Inland noch im Ausland (in vollem Umfang, in ähnlicher Form oder in jedweder anderen Medienform) veröffentlicht worden sind. Die Manuskripte dürfen auch nicht gleichzeitig anderen Publikationsorganen zur Publikation angeboten werden. Mit der Annahme des Manuskripts zur Veröffentlichung überträgt der Verfasser dem Verlag für die Dauer der gesetzlichen Schutzfrist ( $§ 64$ UrHG) das ausschließliche, räumliche und zeitlich unbeschränkte Recht für alle Auflagen/Updates zur auch auszugsweisen Verwertung in gedruckter Form sowie in elektronischen Medien (Datenbanken, Online-Netzsysteme, Internet, CD-ROM, DVD, PDA etc.) auch in geänderter Form oder in Form einer auszugsweisen Verknüpfung mit anderen Werken einschließlich der Übersetzung in andere Sprachen sowie durch Übertragung von Nutzungsrechten auf Dritte. Soweit Abbildungen aus anderen Veröffentlichungen entnommen sind, räumt der Verfasser dem Verlag lediglich das nicht ausschließliche Nutzungsrecht im Umfang des vorstehenden Absatzes ein. Der Verfasser ist für die vollständige Quellenangabe sowie die Einholung der schriftlichen Einwilligung des anderen Verlages zu den vorstehenden Rechtsräumungen verantwortlich und weist diese dem Verlag nach. Der korrespondierende Autor erhält eine pdf-Datei seines Artikels für private Zwecke.

Online

Die wissenschaftlichen Arbeiten stehen online in Thieme-connect zur Verfügung (www.thieme-connect. de/ejournals). Der Zugang ist für persönliche Abonnenten im Preis enthalten. Über kostenpflichtige Zugangsmöglichkeiten und Lizenzen für Institutionen (Bibliotheken, Kliniken, Firmen etc.) informiertSie gerne Carmen Krenz, E-Mail: sales@thieme-connect.de

For users in the USA

Authorization of photocopy items for internal or personal use, or the internal or personal use of specific clients, is granted by Georg Thieme Verlag Stuttgart . New York for libraries and other users registered with the Copyright Clearance Center (CCC) Transactional Reporting Service; www.copyright.com

For reprint information in the USA, please contact: International Reprint Corporation, 287 East "H" St., Benicia, CA 94510, USA; phone: + 1-7 07-746-8740, fax: +1-7 07-746-1643; e-mail: irc@intlreprints.com 
